\title{
PALEOBIOGEOGRAPHY OF EOCENE RADIOLARIANS IN THE SOUTHWEST PACIFIC
}

by

Kristina Michaela PASCHER

\author{
A thesis \\ submitted to Victoria University of Wellington \\ in fulfilment of the requirements for the degree of \\ Doctor of Philosophy
}

VICTORIA UNIVERSITY OF WELLINGTON 




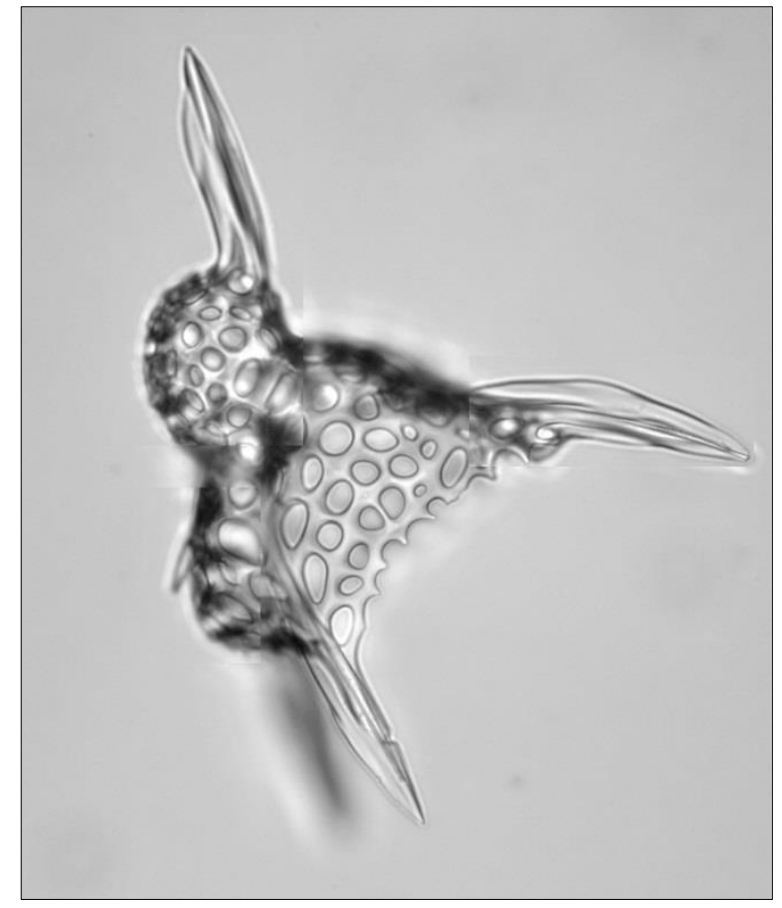

In all things of nature there is something of the marvellous - Aristotle 


\section{Abstract}

This thesis investigates the effect of climatic and oceanographic changes on the distribution of fossil radiolarian assemblages from the early Eocene to early Oligocene ( 56-30 Ma) in the Southwest Pacific. Radiolarian assemblages have been analysed from a series of archived cores collected by the Deep Sea Drilling Project (DSDP) and Ocean Drilling Program (ODP). The selected cores form a latitudinal transect designed to investigate the ecological change associated with the transition from the warm 'greenhouse' climate of the Eocene into the cooler Oligocene, when continental-scale glaciation is believed to have intiated in Antarctica. High-latitude sites were sampled on the Campbell Plateau (DSDP Site 277), Tasman Rise (DSDP sites 280 and 281) and the Tasman Sea (DSDP Site 283 and ODP Site 1172), while mid-latitude sites were sampled both to the west of New Zealand (DSDP sites 207, 206, 592) and east of New Zealand (ODP Site 1123). New foraminifer oxygen $\left(\delta^{18} \mathrm{O}\right)$ and carbon $\left(\delta^{13} \mathrm{C}\right)$ stable isotope data from DSDP sites 277, 207 and 592 are presented and provide additional age control and insights in the climatic and oceanographic changes in the Southwest Pacific during the early Eocene to early Oligocene.

This thesis contributes a comprehensive taxonomic review of Eocene radiolarian taxa with the intention of standardising nomenclature and to resolve synonymies. 213 out of 259 counting groups have been reviewed and assigned to species or subspecies level and 7 new species are yet to be described. All sites have been correlated to the Southern Hemisphere radiolarian zonation, from the upper Paleocene to upper Oligocene (RP6 $6_{\mathrm{SH}}$ to $\mathrm{RP} 17_{\mathrm{SH}}$ ). Alternative datums for the base of RP10 ${ }_{\mathrm{SH}}$ (LO of Artobotrys auriculaleporis) and the base of RP12 ${ }_{\mathrm{SH}}$ (LO of Lophocyrtis longiventer) are proposed.

The early Eocene climatic optimum (EECO, 53-49 Ma) can be identified by a negative excursion in foraminiferal $\delta^{18} \mathrm{O}$ values at Site 207. The radiolarian assemblages at sites 207 (paleolatitude $\sim 46^{\circ} \mathrm{S}$ ) and 277 (paleolatitude $\sim 55^{\circ} \mathrm{S}$ ) during the EECO are dominated by taxa with low-latitude affinities (Amphicraspedum spp. represents up to $89 \%$ of total fauna), but many typical low-latitude genera (e.g. Thyrsocyrtis, Podocyrtis, Phormocyrtis) are absent. Following the EECO, low-latitude taxa decrease at Site 207 and disappear at Site 277. Radiolarians are abundant and very diverse at mid-latitude sites 207 and 206 (paleolatitude $\sim 42^{\circ}$ S) during the middle Eocene, and low-latitude taxa are 


\section{Abstract}

common (up to $\sim 15 \%$ of the total fauna at Site 207 and $\sim 10 \%$ at Site 206). The middle Eocene climatic optimum (MECO, 40 Ma), although truncated by poor drilling recovery at Site 277, is identified by a negative shift in foraminiferal $\delta^{18} \mathrm{O}$ values at this site and is associated by a small increase in radiolarian taxa with low-latitude affinities (up to $~ 5 \%$ of total fauna).

Early in the late Eocene $(\sim 37 \mathrm{Ma})$, a positive shift in $\delta^{18} \mathrm{O}$ values at Site 277 is correlated with the Priabonian oxygen isotope maximum (PrOM). Within this cooling event, radiolarian abundance, diversity and preservation, as well as diatom abundance, increase abruptly at Site 277. A negative $\delta^{18} \mathrm{O}$ excursion above the PrOM is correlated to a late Eocene warming event ( $\sim 36 \mathrm{Ma})$ and is referred to as the late Eocene climatic optimum (LECO). The LECO is identified using stable isotopes at sites 277 and 592. Radiolarian abundance and diversity decline within this event at Site 277 although taxa with lowlatitude affinities increase (up to $\sim 10 \%$ of total fauna). At Site 592, radiolarian-bearing sediments are only present during this event with up to $\sim 6 \%$ low-latitude taxa. Apart from the LECO, late Eocene radiolarian assemblages at Site 277 are characterised by abundant high-latitude taxa. High-latitude taxa are also abundant during the late Eocene and Oligocene ( 38-27 Ma) at DSDP sites 280, 281, 283, and ODP sites 1172 and 1123 and are associated with very high diatom abundance.

Radiolarian assemblages are used for reconstructing the evolution of oceanic fronts. The composition of the assemblages suggests that the oscillation between warm subtropical and cool subtropical conditions can be explained by the varying influence of the warm proto-East Australian Current and cold proto-Ross Gyre. In contrast to temperature reconstructions based on geochemical proxies $\left(\mathrm{TEX}_{86}, \mathrm{U}^{\mathrm{K}}{ }_{37}\right.$ and $\mathrm{Mg} / \mathrm{Ca}$ ), which indicate tropical temperatures throughout most of the Eocene, radiolarians indicate warm subtropical conditions during the EECO. Warm surface water masses may have been transported by the proto-East Australian Current to $\sim 55^{\circ} \mathrm{S}$ during the EECO. During the middle to late Eocene, cool subtropical conditions prevailed in the Southwest Pacific. Localised occurrences of abundant diatoms indicate upwelling areas close to the Tasman Rise in the middle Eocene. The proliferation of radiolarian assemblages and expansion of high-latitude taxa onto the Campbell Plateau in the latest Eocene is explained by a northward expansion of proto-Ross Gyre. In the early Oligocene ( $32 \mathrm{Ma})$, there is an overall decrease in radiolarian abundance and diversity on the Campbell Plateau (Site 
277) and diatoms disappear. Major hiatuses in the region indicate intensified bottomwater currents associated with the establishment of the Antarctic Circumpolar Current. A frontal system similar to present day developed in the early Oligocene, with nutrientdepleted subantarctic waters bathing the southern Campbell Plateau, resulting in a more restricted radiolarian assemblage at Site 277. 


\section{Acknowledgements}

First of all, I want to thank my supervisors: Drs. Chris Hollis (GNS Science), Rob McKay (Victoria University Wellington) and Giuseppe Cortese (GNS Science). To Chris, for giving me the opportunity to carry out this $\mathrm{PhD}$ thesis and for taking me on-board although I did not have any background in radiolarian studies. Thank you for all your time, contributions of ideas and discussions to make this $\mathrm{PhD}$ a success. To Rob and Peppe, thank you so much for your time and discussions, reading through all manuscripts and providing support whenever needed. Thank you all for great times at several conferences!

Sincere thanks to Associate Professor Michael Hannah, Dr Christina Riesselman and Dr Shin-ichi Kamikuri for examining this thesis and providing valuable feedback.

Acknowledgement goes to the New Zealand Government for funding this project through the Marsden Fund (Contract GNS1201). Huge thanks to GNS Science and, in particular, the Department of Paleontology for providing a place to work, including a microscope and other logistical equipment. I am thankful to many scientists for their time and discussions, in particular, James Crampton, Hugh Morgans, Claire Shepherd, Percy Strong, Erica Crouch and Chris Clowes. Huge thanks to Sonja Peñiafiel-Bermudez who prepared countless samples for me, and to Hannu Seebeck, for providing all paleomaps. Thanks to many people at GNS who provided support and assistance every now and then. Thank you, Claire, Marianna and Sonja, for always having an open door, cheerful times and laughs!

Thanks go also to all staff and students I have met at the Antarctic Research Centre and the School of Geography, Environment and Earth Sciences, Victoria University, who made me always feel welcome, despite my very rare visits.

The Geological Society of New Zealand is thanked for the 'Young Researcher Travel Grant' that supported my travel to the CBEP conference in Italy.

Furthermore, the Antarctic Research Centre Endowment Development Fund is acknowledged, for its financial assistance to attend the CBEP conference and the Urbino Summerschool in Italy, and for supporting me financially for publishing parts of this thesis.

Many thanks to the radiolarian community, for a great meeting in Antalya, Turkey, which was very stimulating, joyful and motivational.

I am much obliged to many scientists for their support, in particular, Steven Bohaty, David Lazarus, Noritoshi Suzuki, Johan Renaudie, Shin-ichi Kamikuri and Annika Sanfilippo. Acknowledgements go to James Zachos and his laboratory for providing stable isotope measurements.

Special thanks to my friends in New Zealand who supported me during this journey and kept me sane, and to all friends overseas who stayed in touch despite the huge distance!

Last but not least, my deep gratitude goes towards my family in Germany, and especially my parents, Gudula and Karl, for their endless love, support and encouragement. 


\section{Table of Contents}

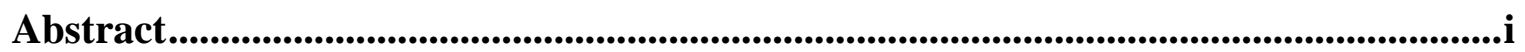

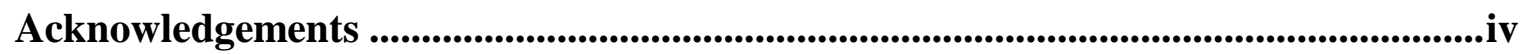

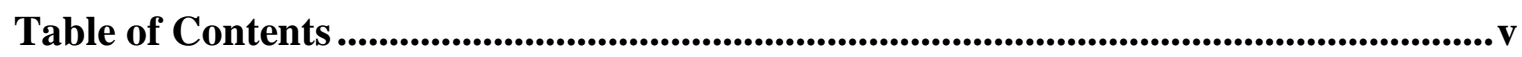

List of Figures.........................................................................................................................................

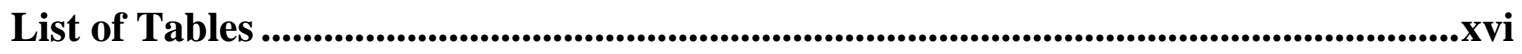

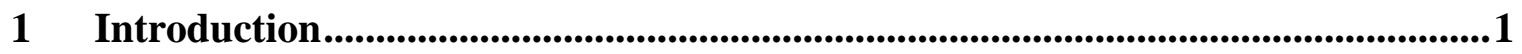

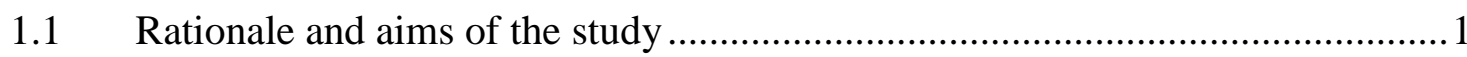

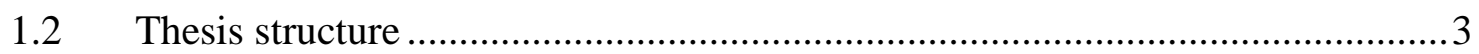

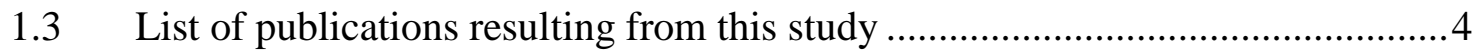

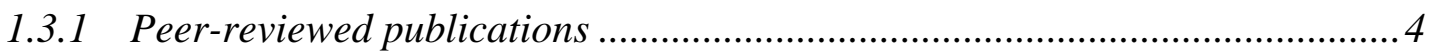

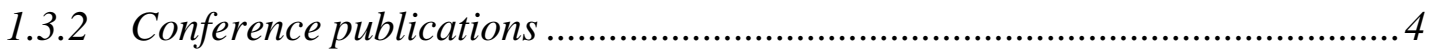

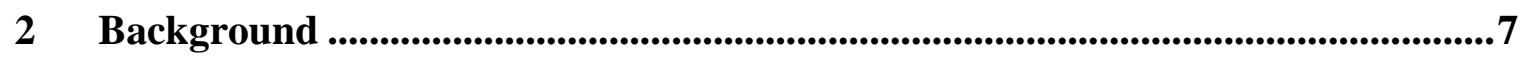

2.1 Oceanographic setting - Southern Ocean and Southwest Pacific Ocean ............7

2.1.1 The modern Southern Ocean circulation ...................................................... 7

2.1.2 Regional oceanography of the Southwest Pacific .......................................... 9

2.1.3 Paleogeographic reconstructions .............................................................. 10

2.1.4 Regional paleoceanography in the Southwest Pacific during the Paleogene 12

2.1.5 Southwest Pacific Paleogene unconformities .............................................. 16

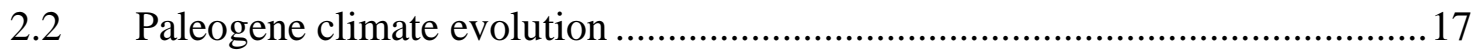

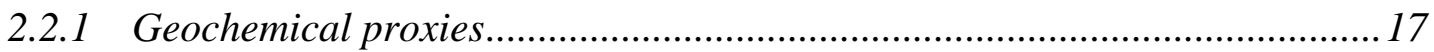

2.2.2 Climatic evolution throughout the Eocene ................................................... 19

2.2.3 What caused the global cooling during the Paleogene? ................................ 23

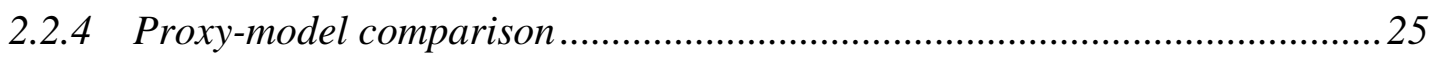

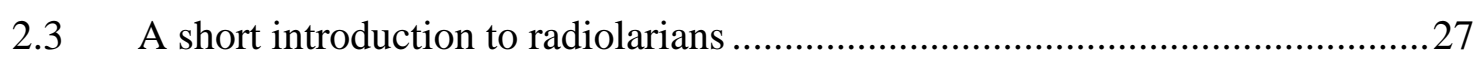

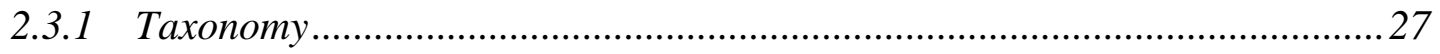

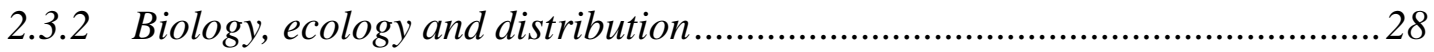

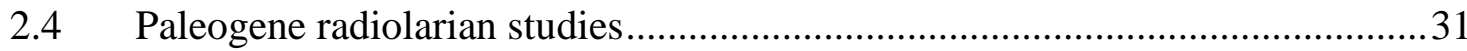


2.4.1 Radiolarian biostratigraphy - from low to high latitudes .............................31

2.4.2 Paleoenvironmental studies of Paleogene radiolarians ................................32

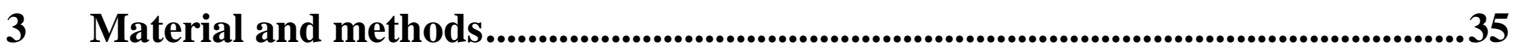

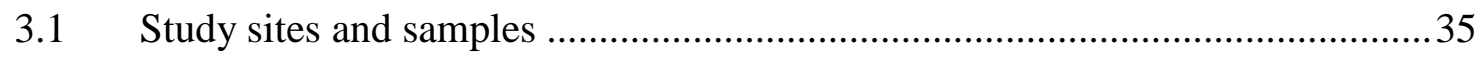

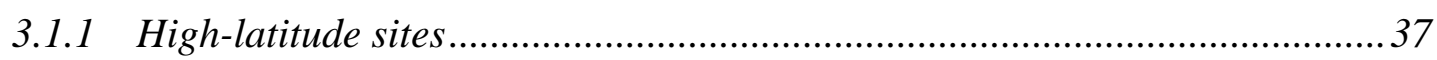

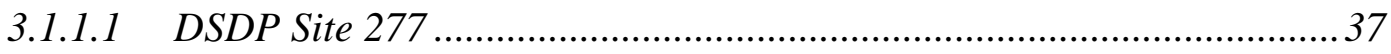

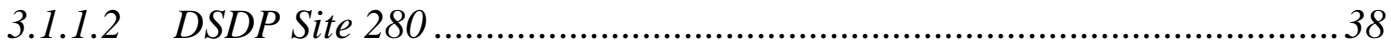

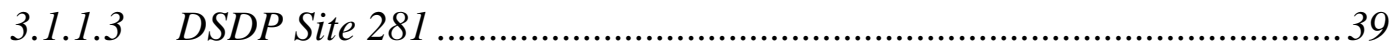

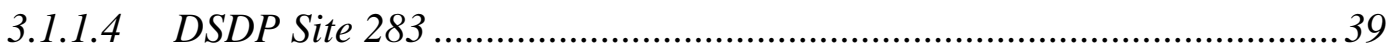

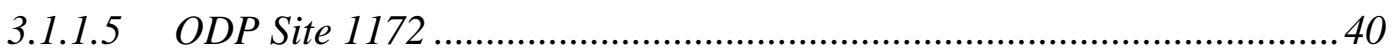

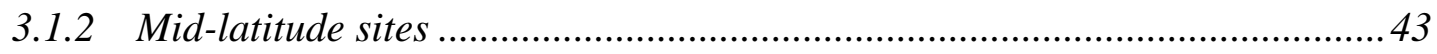

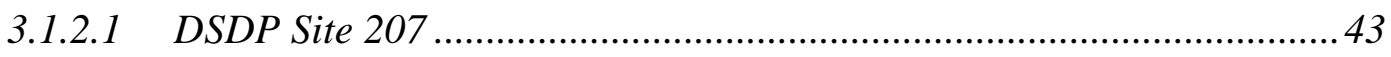

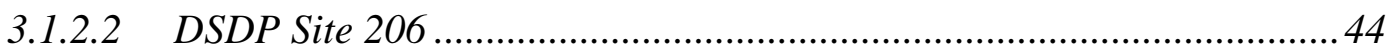

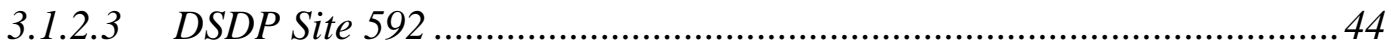

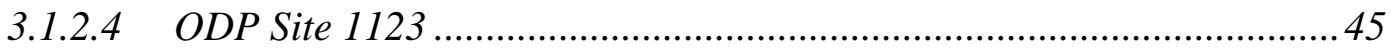

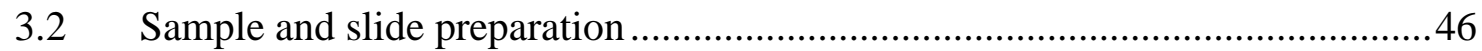

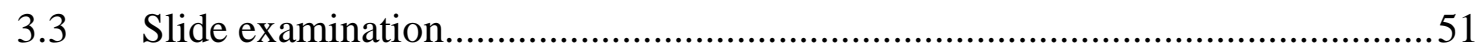

3.3.1 Radiolarian census data and relative abundance .........................................51

3.3.2 Radiolarian preservation and cumulative component analysis....................52

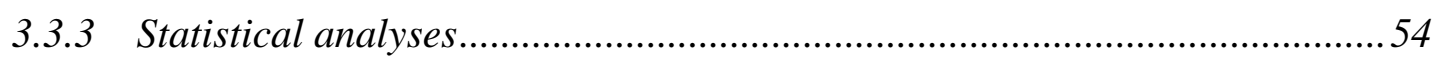

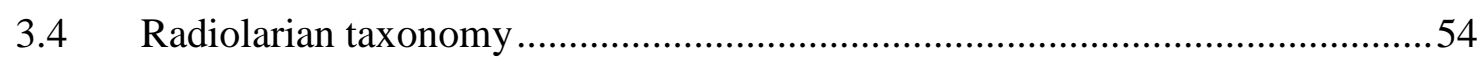

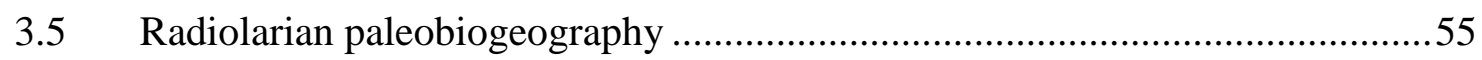

3.6 New Zealand Geological Timescale and radiolarian zonation ........................56

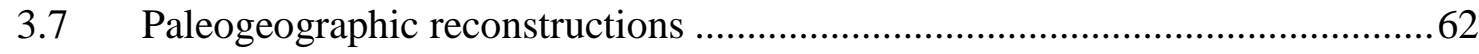

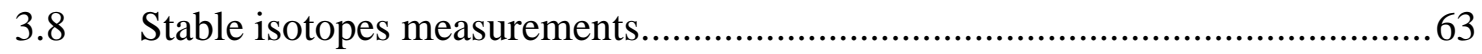

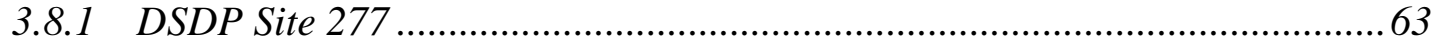

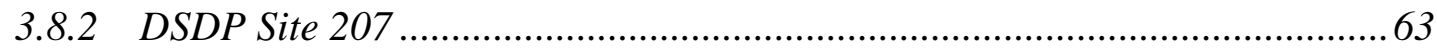

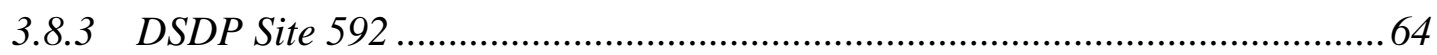

4 Radiolarian occurrence ...............................................................................................665

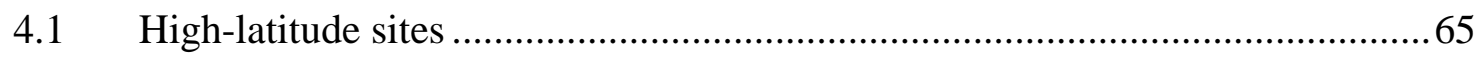




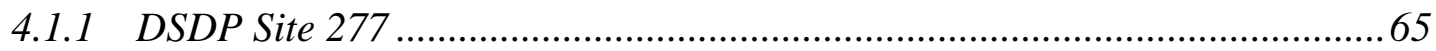

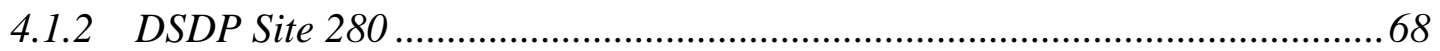

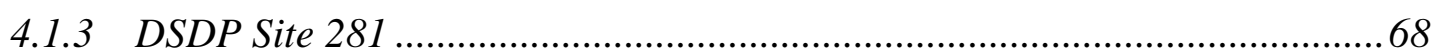

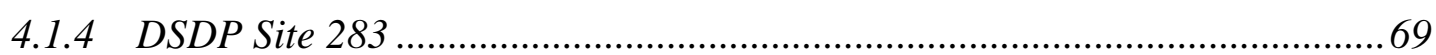

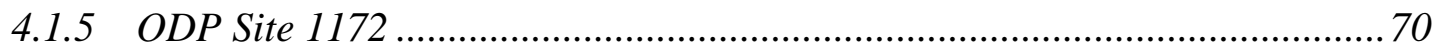

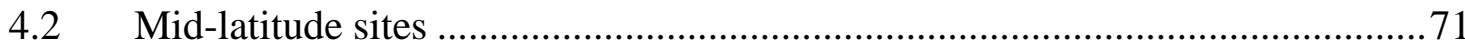

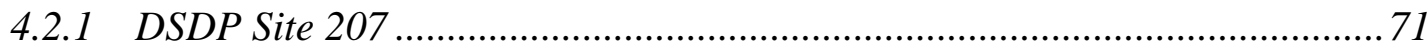

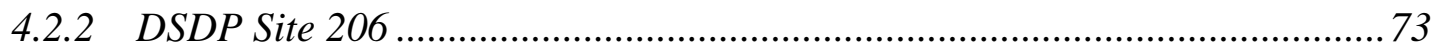

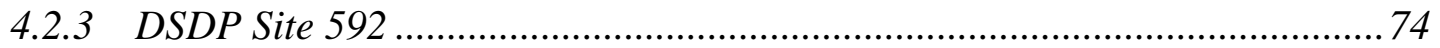

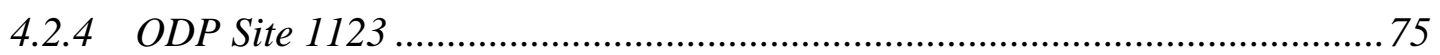

4.3 Comparison between sites...................................................................... 76

$5 \quad$ Radiolarian biostratigraphy and correlation ................................................8.

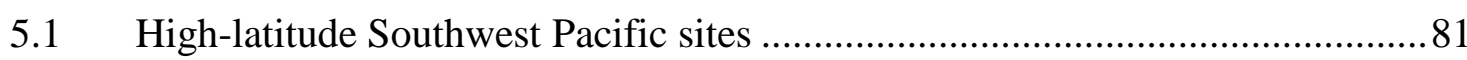

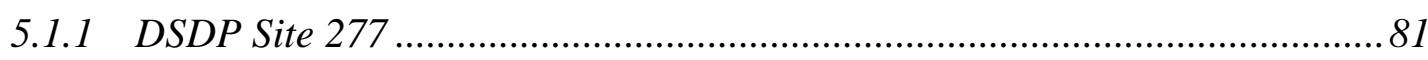

5.1.1.1 Intergrated chronostratigraphy ...................................................... 84

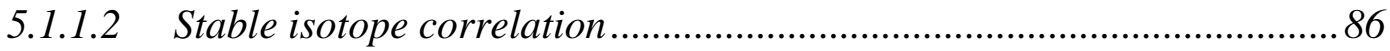

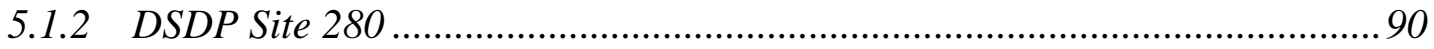

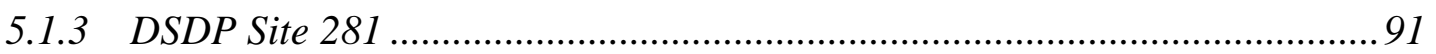

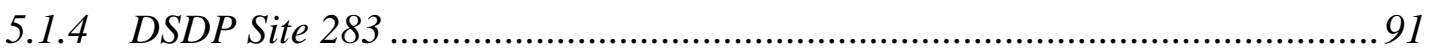

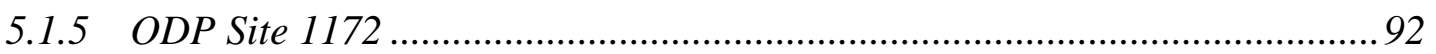

5.1.5.1 Integrated chronostratigraphy ...................................................... 93

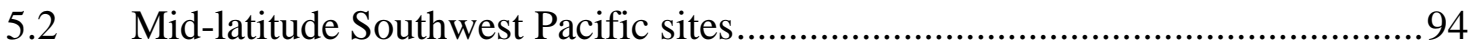

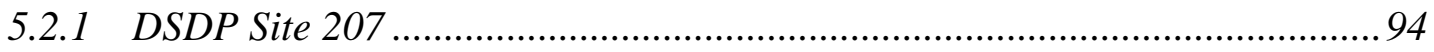

5.2.1.1 Intergrated chronostratigraphy ..................................................... 97

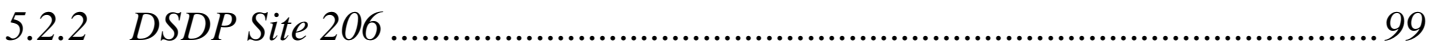

5.2.2.1 Integrated chronostratigraphy......................................................... 100

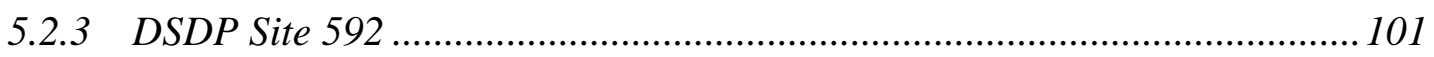

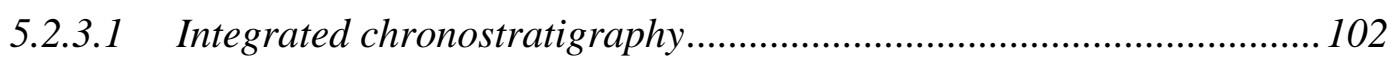

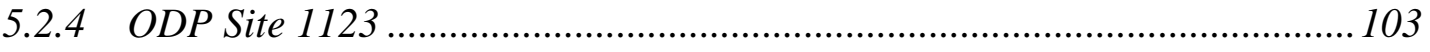

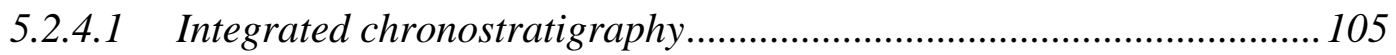

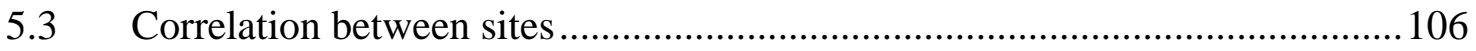


6 Radiolarian paleoecology and paleobiogeography .................................................109

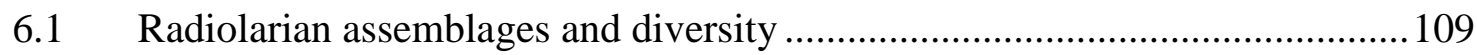

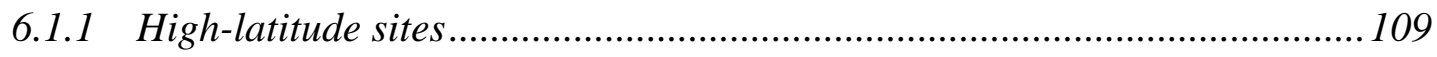

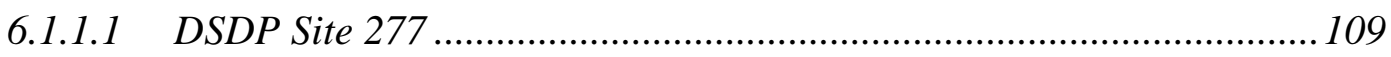

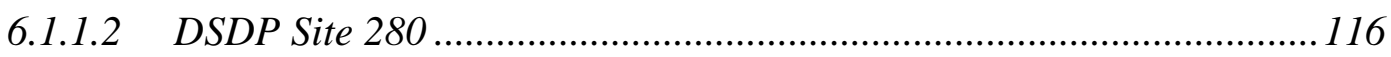

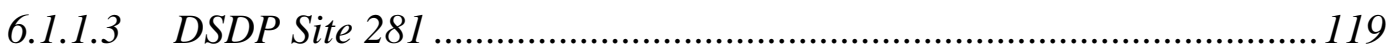

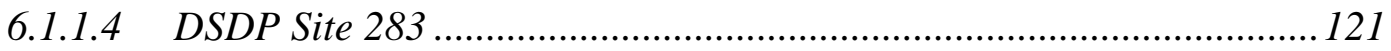

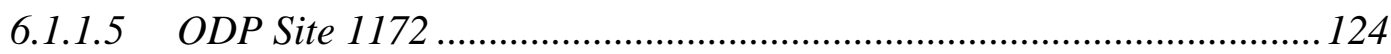

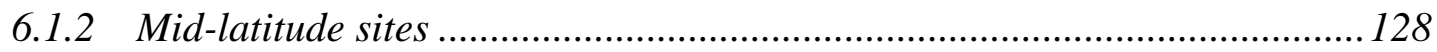

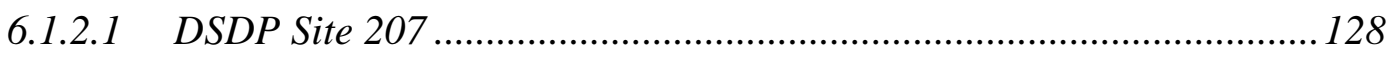

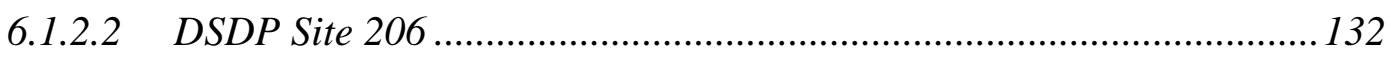

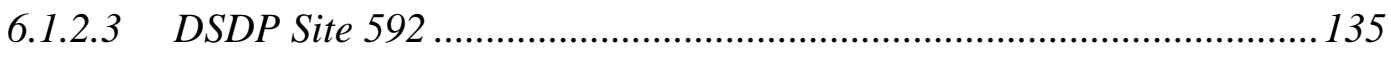

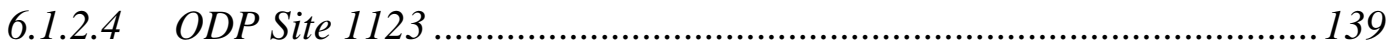

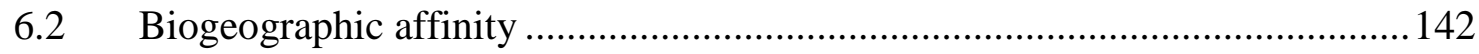

6.2.1 High-latitude sites................................................................................... 142

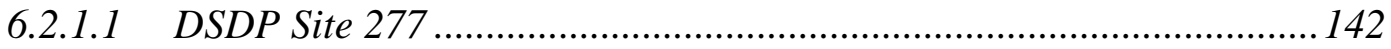

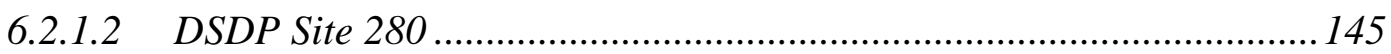

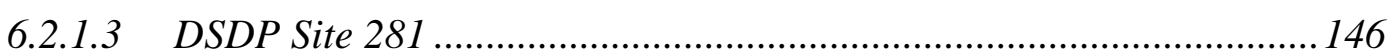

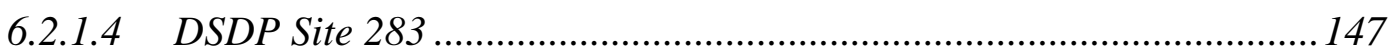

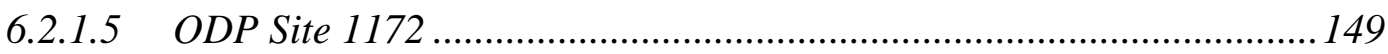

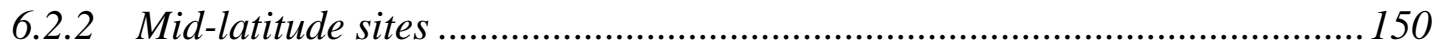

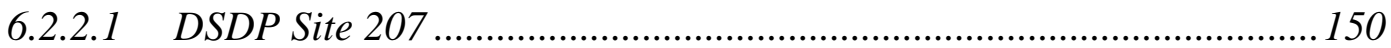

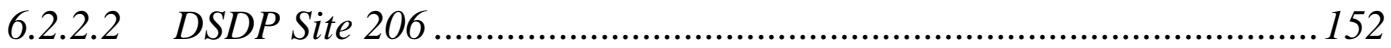

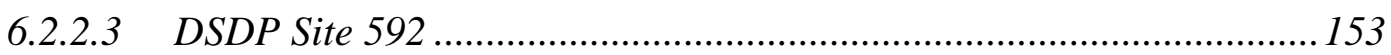

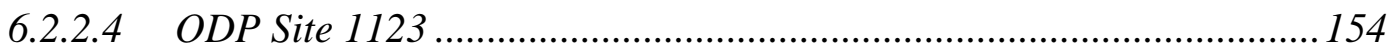

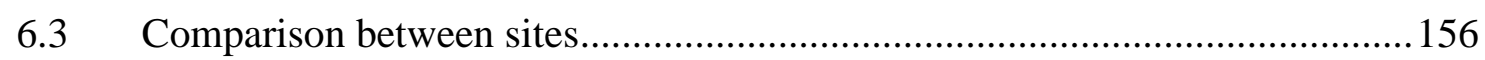

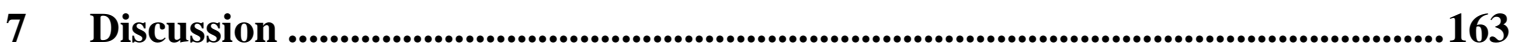

7.1 Biostratigraphy, age control and correlation between sites ...........................163

7.1.1 Correlation of sites and application of radiolarian zonations ....................163

7.1.2 Evaluation of radiolarian zonation........................................................... 163

7.2 General features of radiolarian assemblages and siliceous sediments.............171 
7.2.1 Where and when are siliceous sediments frequent and is there a difference between middle and high latitudes?...................................................................... 171

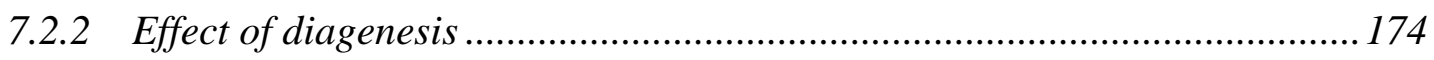

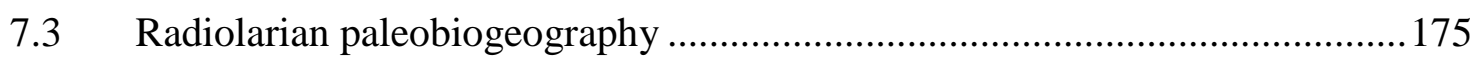

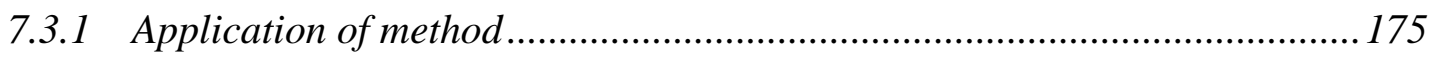

7.3.2 General trends through time and across the transect ................................ 176

7.3.3 Evolution of oceanic fronts: geochemical proxies vs. radiolarians ............ 180

7.3.4 Paleoceanographic reconstructions .......................................................... 183

7.3.4.1 Early Eocene climatic optimum ( 53-49 Ma).................................. 183

7.3.4.2 Middle Eocene ( 47-40 Ma) ............................................................. 185

7.3.4.3 Late middle to early late Eocene/PrOM event ( $38-37 \mathrm{Ma})$............... 186

7.3.4.4 Late Eocene climatic optimum $(\sim 36 \mathrm{Ma})$............................................ 187

7.3.4.5 Latest Eocene-earliest Oligocene ( 35-32 Ma) ................................ 188

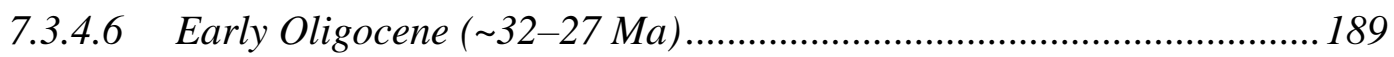

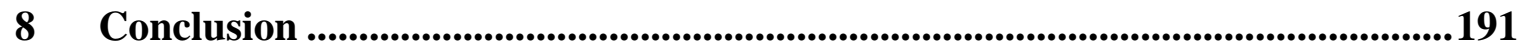

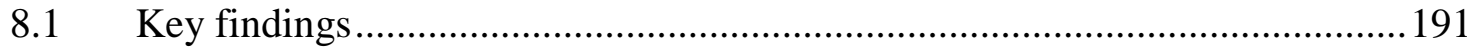

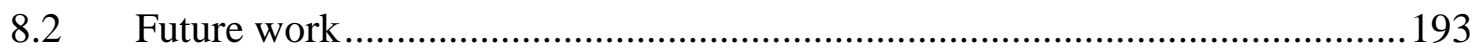

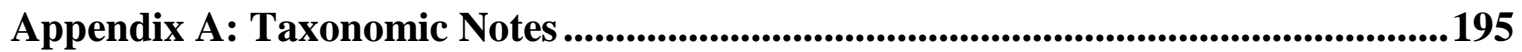

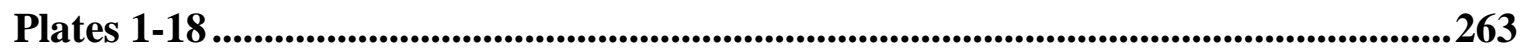

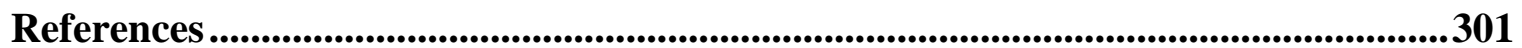

Appendix B: Radiolarian distribution charts (data on enclosed CD)

Appendix C: Biostratigraphic events (data on enclosed CD)

Appendix D: Stable isotopes (data on enclosed CD)

Appendix E: Paleobiogeographic indicators (data on enclosed CD) 


\section{List of Figures}

Figure 2.1 Map modified from Carter et al. (2008) showing the main oceanographic elements of the Southern Ocean: the Subtropical Front (STF), the clockwise Antarctic Circumpolar Current (ACC) which is constrained to the north by the Subantarctic Front (SAF) and to the south by the southern limit of Upper Circumpolar Deep Water or southern boundary (SB); the Ross, Weddell and unnamed subpolar gyres; and the main exit points of cold deep water towards the north, the deep western boundary currents (DWBC, blue arrows). Bathymetric elevations: R=ridge; K. Pl.=Kerguelen Plateau; F. Pl.=Falkland Plateau.

Figure 2.2 Modern oceanography in the Southwest Pacific from Cortese and Prebble (2015) with frontal locations after Orsi et al. (1995), Carter et al. (1998) and Orsi and Harris (2001). Abbreviations of oceanic fronts (bold): $\mathrm{TF}=$ Tasman Front; STF=Subtropical Front; $\mathrm{SF}=$ Southland Front; nSAF=northern Subantarctic Front; $\mathrm{SAF}=$ Subantarctic Front; $\mathrm{PF}=$ Polar Front; Currents (plain text): EAC=East Australian Current; EAuC=East Auckland Current; ECC=East Cape Current; Water-masses (italics): STW=Subtropical Water; SAW=Subantarctic Water; CSW=Circumpolar Water; ACC=Antarctic Circumpolar Current. ...................... 10

Figure 2.3 Schematic paleoceanographic and paleogeographic map from Nelson and Cooke (2001) for the Paleocene (65-55 Ma), based on the reconstructions of Lawver et al. (1992). No frontal systems were established yet and Antarctica was ice free. Numbers refer to DSDP sites; dark shaded grey areas represent the continental margin to the present day $2000 \mathrm{~m}$ isobath; orange shaded areas indicate cool subtropical water masses; yellow shaded areas indicate warm subtropical water masses; arrows indicate surface ocean currents. .. 13

Figure 2.4 Schematic paleoceanographic and paleogeographic map from Nelson and Cooke (2001) for the late middle to late Eocene (45-35 Ma), based on the reconstructions of Lawver et al. (1992). A proto-Subtropical Front (dashed line) and cool water flow around Antarctica were established in the late Eocene $(\sim 35 \mathrm{Ma})$. WAS=West Antarctic seaway. Numbers refer to DSDP sites; dark shaded grey areas represent the continental margin to the present day $2000 \mathrm{~m}$ isobath; orange shaded areas indicate cool subtropical water masses; yellow shaded areas indicate warm subtropical water masses; light blue shaded areas indicate subantarctic water masses; arrows indicate surface ocean currents.

Figure 2.5 modified from Bijl et al. (2011): Dinocyst distribution map for the middle to late Eocene (47-36 Ma) with ocean circulation based on model experiments (Huber et al., 2004); shaded areas represent submerged continental blocks. Abbreviations: TA-SW=Trans-Antarctic Seaway; TSA-SW=Trans-South American Seaway; EAC=East Australian Current; $\mathrm{p}$-LC=proto-Leeuwin Current; $\mathrm{p}-\mathrm{RG}=$ proto-Ross Gyre; TC=Tasman Current.

Figure 2.6 Compilation of a) left: atmospheric $\mathrm{CO}_{2}$ concentrations, right: representative concentration pathways (RCPs) for historic and future atmospheric $\mathrm{CO}_{2}$ emissions, b) composite deep ocean benthic $\delta^{18} \mathrm{O}$ record, c) long-term trend in deep-sea temperature from $\delta^{18} \mathrm{O}$ and $\mathrm{Mg} / \mathrm{Ca}$ estimates and d) reconstruction of sea-level lowstand and smoothed trend (black dashed line) throughout the Cenozoic; PETM: Paleocene-Eocene thermal maximum; EECO: early Eocene climatic optimum; MECO: middle Eocene climatic optimum; PrOM: Priabonian oxygen isotope maximum; modified after McKay et al. (2016).

Figure 2.7 Compilation of Southern Ocean stable oxygen isotope data and reconstructed ice-free temperature between 45 and $32 \mathrm{Ma}$ from various Ocean Drilling Program sites, showing warming (red) and cooling (blue) events in the middle and late Eocene. MECO=middle Eocene climatic optimum, LECO=late Eocene climatic optimum, PrOM=Priabonian oxygen isotope maximum, LE cooling=late Eocene cooling event after Vonhoff et al. (2000); for abbreviations of New Zealand stages see Figure 3.13; modified after Bohaty and Zachos (2003).

Figure 2.8 Comparison of sea surface temperature (SST) reconstructions derived from proxy records and the results of an Eocene climate model (4480 ppmv $\mathrm{CO}_{2}$ concentration), modified from Hollis et al. (2012).

Figure 2.9 from Hollis et al. (2012); comparison of SSTs derived from proxies for the EECO with modelled SSTs and ocean currents for Austral summer conditions under a high greenhouse gas scenario $\left(4480 \mathrm{ppm} \mathrm{CO}_{2}-\right.$ equivalent). A large clockwise subpolar gyre (Ross Gyre) in the Southwest Pacific blocks the East Australian Current reaching southward beyond $\sim 45^{\circ} \mathrm{S}$.

Figure 2.10 Molecular phylogenetic relationships of the Radiolaria, from Suzuki and Aita (2011).

Figure 2.11 Digital map of ocean floor sediments from Dutkiewicz et al. (2015).

Figure 3.1 Modern day map with location of studied DSDP and ODP sites as mentioned in the text. Dark grey=land masses, light grey $=2000 \mathrm{~m}$ continental boundary. Acronyms from north to south: EAC=East Australian Current, TF=Tropical Front, STW=Subtropical Water, STF=Subtropical Front, SAW=Subantarctic Water, $\mathrm{SAF}=$ Subantarctic Front, ACC=Antarctic Circumpolar Current, $\mathrm{PF}=$ Polar Front. Circulation simplified after Chiswell et al. (2015). 


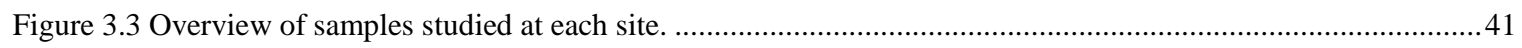

Figure 3.4 Samples with $\mathrm{HCl}$ added; note strong reaction in middle beaker..............................................................46

Figure 3.5 Breakdown of organic material and clay; hydrogen peroxide is causing a strong reaction in beaker to the right.

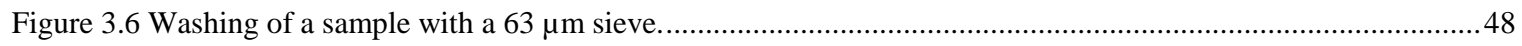

Figure 3.7 Washed residue gets transferred to a small plastic pot and then put in the oven for drying out....................48

Figure 3.8 Dried residue, which was divided in smaller portions for slide making. ...................................................50

Figure 3.9 Sprinkling of a known portion of dried residue onto three coverslips that were covered with gum tragacanth. .50

Figure 3.10 On the left: two coverslips with sprinkled residue, in the middle: two cover slides with Canada balsam, on the right: a coverslip was mounted onto a cover slide.............................................................................51

Figure 3.11 Final labelled slide, which was cleaned of excess Canada balsam with acetone. ......................................51

Figure 3.12 Examples of varying radiolarian preservation; PI: preservation index; scale bar $=100 \mu \mathrm{m}$. .....................53

Figure 3.13 Chart of Paleogene Geological Timescale after Raine et al. (2015) and biozones used in this study. Calcareous microfossil zones and low-latitude (LL) radiolarian zonation were calibrated to GTS 2012 by Norris et al. (2012); Southern Hemisphere (SH) radiolarian zonation is based on Hollis (pers. Comm. 2016). Abbreviations: For=planktonic foraminifer zonal scheme of Berggren and Pearson (2005) as modified by Wade et al. (2011) for the Paleogene; CP=Coccoliths Paleogene zones after Okado and Bukry (1980); NP=Paleogene nannoplankton zonation after Martini $(1970 ; 1971)$.

Figure 4.1 Overview of stratigraphy, NZ Stages, lithology and core recovery of DSDP Site 277; residue components, radiolarian abundance, diatom/radiolarian $(\mathrm{D} / \mathrm{R})$ ratio and radiolarian preservation. Preservation index: $0=$ barren, $1=$ =poor, $2=$ moderate, $3=$ good. Gaps in the components record are due to samples being picked and no assessment of the residue has been undertaken. For abbreviations of NZ Stages, please see Chapter 3.6. .67

Figure 4.2 Overview of stratigraphy, NZ Stage, RPSH Zone, lithology and core recovery of DSDP Site 280 Hole A. Residue components, radiolarian abundance and diatom/radiolarian (D/R) ratio. ......................................6 68

Figure 4.3 Overview of stratigraphy, NZ Stage, RPSH Zone, lithology and core recovery at DSDP Site 281. Residue components, radiolarian abundance and diatom/radiolarian $(\mathrm{D} / \mathrm{R})$ ratio.

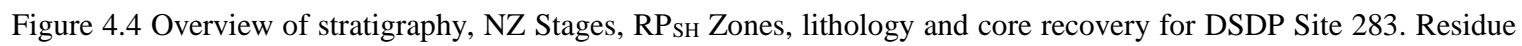
components, radiolarian abundance and diatom/radiolarian $(\mathrm{D} / \mathrm{R})$ ratio.

Figure 4.5 Results of smear-slide analyses of middle Eocene to lower Oligocene sediments of ODP Site 1172 Hole A (Cores 1172A-48X to -43X) and Hole D (Cores 1172D-3D to -1D); modified after Shipboard Scientific Party (2001).

. .71

Figure 4.6 Overview of stratigraphy, NZ Stages, lithology and core recovery of DSDP Site 207 Hole A; residue components, radiolarian abundance, diatom/radiolarian (D/R) ratio and radiolarian preservation. Preservation index: $0=$ barren, $1=$ poor, $2=$ moderate, $3=$ good. Gaps in the residues components plot signify complete dissolution of the sediment

Figure 4.7 Overview of stratigraphy, NZ Stages, lithology and core recovery for DSDP Site 206 Hole C; residue components and radiolarian preservation. Preservation index: $0=$ barren, $1=$ poor, $2=$ moderate, $3=$ good.........73

Figure 4.8 Overview of stratigraphy, NZ Stages, lithology and core recovery of DSDP Site 592; residue components and radiolarian abundance.

Figure 4.9. Overview of stratigraphy, NZ Stages, lithology and core recovery of ODP Site 1123 Hole C; residue components and diatom/radiolarian $(\mathrm{D} / \mathrm{R})$ ratio.

Figure 4.10 Comparison between investigated sites in terms of radiolarian abundance, preservation and main residue components.

Figure 5.1 Overview of stratigraphy, NZ Stages, nannofossil (NP) zones, radiolarian $\left(\mathrm{RP}_{\mathrm{SH}}\right)$ zones and core recovery of DSDP Site 277. Age-depth plot of Site 277 using nannofossil (blue squares), foraminifera (black squares) and radiolarian (green squares) events. Acronoyms: PETM=Paleocene-Eocene thermal maximum, LL=lowlatitude datum, $\mathrm{HL}=$ high-latitude datum, $\mathrm{SH}=$ Southern Hemisphere datum. Green bands indicate the agerange between LL and SH datum. For abbreviations of NZ Stages, please see Chapter 3.6, for species abbreviations see Appendix C (data on enclosed CD). . .85

Figure 5.2 DSDP Site 277 stratigraphy, NZ Stages (Raine et al., 2015), Southern Hemisphere radiolarian zones (RP), nannofossil zones (NP), lithology, core recovery, selected bioevents (ages calibrated to the 2012 geological timescale; Gradstein et al., 2012; Raine et al., 2015) and benthic $\delta^{18} \mathrm{O}$ and $\delta^{13} \mathrm{C}$ data of DSDP Site 277. The dashed lines correlate Site 277 based on the ages of the bioevents to Southern Ocean Cibicides data of ODP 
Site 689 (Maud Rise) (Diester-Haass and Zahn, 1996) calibrated to the GTS2012 timescale using the magnetostratigraphy data of Florindo and Roberts (2005) and Spiess (1990). LO=lowest occurrence, $\mathrm{LCO}=$ lowest common occurrence, $\mathrm{HO}=$ highest occurrence, $\mathrm{MECO}=$ middle Eocene climatic optimum, PrOM=Priabonian oxygen isotope maximum, LECO=late Eocene climatic optimum, EOT=Eocene-Oligocene transition; after Pascher et al. (2015).

Figure 5.3 DSDP Site $277 \delta^{18} \mathrm{O}$ and $\delta^{13} \mathrm{C}$ records and location of studied radiolarian samples within the MECO and LECO (red stars) and radiolarian-rich upper Eocene-lower Oligocene interval (blue stars); after Pascher et al. (2015). $\mathrm{MECO}=$ middle Eocene climatic optimum, PrOM=Priabonian oxygen isotope maximum, $\mathrm{LECO}=$ late Eocene climatic optimum, EOT=Eocene-Oligocene transition...

Figure 5.4 Age-depth plot of Site 1172, Hole A (Cores 1172A-48X to -43X) and Hole D (Cores 1172D-3D to -1D) using nannofossil (blue squares), radiolarian (green squares) and magnetostratigraphic (stars) events. Geomagnetic Polarity Timescale (Chrons) shown at the top; $b=b a s e, t=t o p . . . .$.

Figure 5.5 Age-depth plot of DSDP Site 207 Hole A using nannofossil (blue squares), foraminifera (black squares) and radiolarian (green squares) events. $\mathrm{LL}=$ low-latitude datum; $\mathrm{SH}=$ Southern Hemisphere datum. The green band for Phormocyrtis striata striata spans the range of its $\mathrm{HO}$ datum from high to low latitudes..

Figure 5.6 Age-depth plot of DSDP Site 206 Hole C using nannofossil (blue squares), foraminifera (black squares) and radiolarian (green squares) events. LL=low-latitude datum; $\mathrm{SH}=$ Southern Hemisphere datum. Green bands for Eusyringium fistuligerum and Zealithapium mitra indicate the age-range of the datum between low and high latitudes.

Figure 5.7 Age-depth plot of DSDP Site 592 using nannofossil (blue squares), foraminifera (black squares) and radiolarian (green squares) events. $\mathrm{HL}=$ high-latitude datum; LL=low-latitude datum. The green band indicates the age-range for the $\mathrm{HO}$ of $L$. amphitrite between low and high latitudes.

Figure 5.8 Age-depth plot of ODP Site 1123 Hole C using nannofossil (blue squares), foraminifera (black squares), radiolarian (green squares) events and magnetostratigraphic (stars) events. Geomagnetic Polarity Timescale (Chrons) shown at the top. Abbreviations: $\mathrm{b}=$ base; $\mathrm{LL}=\mathrm{low}-\mathrm{latitude}$ datum; $\mathrm{SH}=$ Southern Hemisphere datum. The green band indicates the age-range for the $\mathrm{HO}$ of L. amphitrite between low and high latitudes........... 105

Figure 5.9 Fence diagram showing the correlation of all sites; colours=NZ Stages.

Figure 6.1 General trends in radiolarian assemblages at DSDP Site 277 compared with the benthic foraminiferal $\delta^{18} \mathrm{O}$ record and climate events (Pascher et al., 2015), including radiolarian abundance (radiolarians/g), diatom/radiolarian (D/R) ratio, Fisher $\alpha$ Diversity Index, Simpson Evenness Index and relative abundance (\%) of spumellarians (grey) and nassellarians (white). Census size for all examined samples is colour-coded and shown to the right of the core $\log$. $\mathrm{MECO}=$ middle Eocene climatic optimum, PrOM=Priabonian oxygen isotope maximum, LECO=late Eocene climatic optimum, EOT=Eocene-Oligocene transition. For abbreviations of NZ Stages, please see Chapter 3.6.....

Figure 6.2 The relative abundance of the most abundant radiolarian families and counting groups at DSDP Site 277. Census size for all examined samples is colour-coded and shown to the right of the core log. $\mathrm{S}=$ spumellarians, $\mathrm{N}=$ nassellarians, $\mathrm{MECO}=$ middle Eocene climatic optimum, PrOM=Priabonian oxygen isotope maximum, LECO=late Eocene climatic optimum, EOT=Eocene-Oligocene transition.

Figure 6.3 The relative abundance of less common radiolarian families at DSDP Site 277. Census size for all examined samples is colour-coded and shown to the right of the core $\log$. S=spumellarians, $\mathrm{N}=$ nassellarians, $\mathrm{MECO}=$ middle Eocene climatic optimum, PrOM=Priabonian oxygen isotope maximum, $\mathrm{LECO}=$ late Eocene climatic optimum, EOT=Eocene-Oligocene transition.

Figure 6.4 Taxic richness (number of taxa) derived from individual rarefaction and range-through analyses for different census sizes for DSDP Site 277. Census size for all examined samples is color-coded and shown to the right of the core log. $\mathrm{MECO}=$ middle Eocene climatic optimum, PrOM=Priabonian oxygen isotope maximum, LECO=late Eocene climatic optimum, EOT=Eocene-Oligocene transition; modified from Pascher et al. (2015).

Figure 6.5 General features of radiolarian assemblages at DSDP Site 280 Hole A: taxic richness, Fisher $\alpha$ Diversity Index, Simpson Evenness Index, relative abundance (\%) of spumellarians (grey) and nassellarians (white). 117

Figure 6.6 The relative abundance of the most abundant radiolarian families and counting groups at DSDP Site 280 Hole A. $\mathrm{S}=$ spumellarians, $\mathrm{N}=$ nassellarians.

Figure 6.7 The relative abundance of less common radiolarian families and counting groups at DSDP Site 280 Hole A. $\mathrm{S}=$ spumellarians, $\mathrm{N}=$ nassellarians.

Figure 6.8 General features of radiolarian assemblages at DSDP Site 281: taxic richness, Fisher $\alpha$ Diversity Index, Simpson Evenness Index, relative abundance (\%) of spumellarians (grey) and nassellarians (white)........... 119

Figure 6.9 The relative abundance of the most abundant radiolarian families and counting groups at DSDP Site 281. $\mathrm{S}=$ spumellarians, $\mathrm{N}=$ nassellarians. 
Figure 6.10 The relative abundance of less common radiolarian families and counting groups at DSDP Site 281. $\mathrm{S}=$ spumellarians, $\mathrm{N}=$ nassellarians.

Figure 6.11 General features of radiolarian assemblages at DSDP Site 283: taxic richness, Fisher $\alpha$ Diversity Index, Simpson Evenness Index, relative abundance (\%) of spumellarians (grey) and nassellarians (white)........... 122

Figure 6.12 The relative abundance of the most abundant radiolarian families and counting groups at DSDP Site 283. $\mathrm{S}=$ spumellarians, $\mathrm{N}=$ nassellarians.

Figure 6.13 The relative abundance of less common radiolarian families and counting groups at DSDP Site 283. $\mathrm{S}=$ spumellarians, $\mathrm{N}=$ nassellarians.

Figure 6.14 General features of radiolarian assemblages at ODP Site 1172, Hole A (Cores 1172A-48X to -38X) and Hole D (Cores 1172D-3D to -1D): taxic richness, Fisher $\alpha$ Diversity Index, Simpson Evenness Index, relative abundance (\%) of spumellarians (grey) and nassellarians (white). The location of the MECO was adapted from Bijl et al. (2010)...

Figure 6.15 The relative abundance of the most abundant radiolarian families and counting groups at ODP Site 1172, Hole A (Cores 1172A-48X to -38X) and Hole D (Cores 1172D-3D to -1D). S=spumellarians..... 126

Figure 6.16 The relative abundance of less common radiolarian families at ODP Site 1172, Hole A (Cores 1172A-48X to $-38 \mathrm{X}$ ) and Hole D (Cores 1172D-3D to -1D). S=spumellarians, N=nassellarians.

Figure 6.17. General features of radiolarian assemblages at DSDP Site 207 Hole A, including taxic richness, Fisher $\alpha$ Diversity Index, Simpson Evenness Index, relative abundance (\%) of spumellarians (grey) and nassellarians (white), and $\delta^{18} \mathrm{O}$ and $\delta^{13} \mathrm{C}$ isotope values of two benthic foraminifer species (Cibicides praemundulus and Nuttalides truempyi). Two distinct horizons (dashed lines labelled \#1 and \#3) and one interval (blue shading labelled \#2) can be recognized where obvious assemblage and preservation changes occur. Census size for all examined samples is colour-coded and shown to the right of the core log. EECO=Early Eocene Climatic Optimum; "not det." marks a sample with Cretaceous radiolarians, which were not identified.

Figure 6.18 The relative abundance of the most abundant radiolarian families and counting groups at DSDP Site 207 Hole A. Census size for all examined samples is colour-coded and shown to the right of the core $\log$. $\mathrm{S}=$ spumellarians, $\mathrm{N}=$ nassellarians.

Figure 6.19 The relative abundance of less common radiolarian families and counting groups at DSDP Site 207 Hole A. Census size for all examined samples is colour-coded and shown to the right of the core log. $S=$ spumellarians, $\mathrm{N}=$ nassellarians. 132

Figure 6.20 General features of radiolarian assemblages at DSDP Site 206 Hole C: taxic richness, Fisher $\alpha$ Diversity Index, Simpson Evenness Index, relative abundance (\%) of spumellarians and nassellarians. Census size for all examined samples is colour-coded and shown to the right of the core log.

Figure 6.21 The relative abundance of the most abundant radiolarian families and counting groups at DSDP Site 206 Hole C. Only samples with a census size of $>300$ are plotted. Census size for all examined samples is colourcoded and shown to the right of the core $\log$. $\mathrm{S}=$ =spumellarians, $\mathrm{N}=$ nassellarians.

Figure 6.22 The relative abundance of less common radiolarian families and counting groups at DSDP Site 206 Hole C. Census size for all examined samples is colour-coded and shown to the right of the core log. Only samples with a census size of $>300$ are plotted. $\mathrm{S}=$ spumellarians, $\mathrm{N}=$ nassellarians. 135

Figure 6.23 General features of radiolarian assemblages at DSDP Site 592 (including taxic richness, Fisher $\alpha$ Diversity Index, Simpson Evenness Index and relative abundance (\%) of spumellarians (grey) and nassellarians (white) compared with the $\delta^{18} \mathrm{O}$ and $\delta^{13} \mathrm{C}$ record of benthic and planktic foraminifera (Murphy and Kennett, 1986) and of the fine fraction $(<63 \mu \mathrm{m})$. Census size for all examined samples is color-coded and shown to the right of the core log. EOT=Eocene-Oligocene transition, $\mathrm{LECO}=$ late Eocene climatic optimum, PrOM=Priabonian oxygen isotope maximum. The latter event may extend further downcore (see text for details). 136

Figure 6.24 The relative abundance of the most abundant radiolarian families and counting groups at DSDP Site 592. Census size for all examined samples is colour-coded and shown to the right of the core log. $\mathrm{S}=$ spumellarians, $\mathrm{N}=$ nassellarians. 137

Figure 6.25 The relative abundance of less common radiolarian families and counting groups at DSDP Site 592. Census size for all examined samples is colour-coded and shown to the right of the core log. S=spumellarians, $\mathrm{N}=$ nassellarians. 138

Figure 6.26 General features of radiolarian assemblages at ODP Site 1123 Hole C: taxic richness, Fisher $\alpha$ Diversity Index, Simpson Evenness Index, relative abundance (\%) of spumellarians (grey) and nassellarians (white).139

Figure 6.27 The relative abundance of the most abundant radiolarian families and counting groups at ODP Site 1123 Hole C. S=spumellarians, $\mathrm{N}=$ nassellarians. 140

Figure 6.28 The relative abundance of less common radiolarian families and counting groups at ODP Site 1123 Hole C. $\mathrm{S}=$ spumellarians, $\mathrm{N}=$ nassellarians ... 141 


\section{List of Figures}

Figure 6.29 Cumulative biogeographic affinity assignment for DSDP Site 277, showing all groups (left); and a more detailed breakdown of the high-latitude (middle) and low-latitude groups (right). EECO=early Eocene climatic optimum, $\mathrm{MECO}=$ middle Eocene climatic optimum, $\mathrm{PrOM}=$ Priabonian oxygen isotope maximum, $\mathrm{LECO}=$ late Eocene climatic optimum.

Figure 6.30 Cumulative biogeographic affinity assignment for DSDP Site 280 Hole A, showing all groups (left) and high-latitude groups (right). $\mathrm{T}_{\mathrm{LL}}=$ trace amount of low-latitude species A. prolixum gr. .............................. 146

Figure 6.31 Cumulative biogeographic affinity assignment for DSDP Site 281, showing all groups (left) and highlatitude groups (right).

Figure 6.32 Cumulative biogeographic affinity assignment for DSDP Site 283, showing all groups (left) and highlatitude groups (right). TLL=trace amount of low-latitude species $T$. pinguisicoides (lowermost) and $T$. tuberosa (all other).

Figure 6.33 Cumulative biogeographic affinity assignment for ODP Site 1172 Hole A (Cores 1172A-48X to $-38 X$ ) and Hole D (Cores 1172D-3D to -1D), showing all groups (left) and high-latitude groups (right). MECO=middle Eocene climatic optimum after Bijl et al. (2010).

Figure 6.34 Cumulative biogeographic affinity assignment for DSDP Site 207 Hole A, showing all groups (left); highlatitude groups (middle) and low-latitude groups (right). Two distinct horizons (\#1 and \#3) and one interval (\#2) can be recognized where obvious assemblage and preservation changes occur. EECO=Early Eocene Climatic Optimum. Two samples (*) are included which have less than 100 specimens in radiolarian census size.

Figure 6.35 Cumulative biogeographic affinity assignment for DSDP Site 206 Hole C, showing all groups (left); highlatitude groups (middle) and low-latitude groups (right).

Figure 6.36 Cumulative biogeographic affinity assignment for DSDP Site 592, showing all groups (left); high-latitude groups (middle) and low-latitude groups (right). LECO=late Eocene climatic optimum.

Figure 6.37 Cumulative biogeographic affinity assignment for ODP Site 1123 Hole C, showing all groups (left); highlatitude groups (middle) and low-latitude groups (right).

Figure 6.38 Summary of Taxic richness at all investigated sites across a transect from high-latitude to mid-latitude sites

Figure 6.39 Summary of relative abundance (\%) of high-latitude and low-latitude groups at all investigated sites across a transect from high-latitude to mid-latitude sites.

Figure 7.1 Fence diagram in time domain showing the correlation of radiolarian datums between investigated DSDP and ODP sites, Mead Stream and ages of datums in low latitudes. Low-latitude radiolarian zonation (RPLL) and Southern Hemisphere radiolarian zonation

Figure 7.2 Paleoceanographic reconstruction superimposed on modelled SSTs for the early Eocene (4480 $\mathrm{ppm} \mathrm{CO}_{2-}$ equivalent) (Huber and Caballero, 2011) showing the location of three reference sites: ODP Leg 113 Site 689, Mead Stream and IODP Leg 320/321 Site U1331; (C. Hollis, pers. comm. 2016).

Figure 7.3 Sedimentation rates for the studied intervals of DSDP sites 277, 280, 281, 283, 592, 207, 206, ODP sites 1172 and 1123 and three additional sites for comparison (Mead Stream, ODP Site 689 and IODP Site U1331). Superimposed on age-depth plots are radiolarian abundance, the presence of chert layers/nodules (red/orange bands) and diatom occurrence (D/R ratio, green asterisks). Four groups can be identified based on high $\mathrm{D} / \mathrm{R}$ ratio at high-latitude sites (Group 1), high radiolarian abundance and low D/R ratio at mid- to high latitude sites (Group 2), high radiolarian abundance and low D/R ratio at mid-latitude sites in the middle Eocene (Group 3) and high radiolarian abundance and low D/R ratio in the early Eocene (Group 4). Plots are arranged from top (low latitudes) to bottom (high latitudes) based on the location of the site at $\sim 40 \mathrm{Ma}$ (paleolatitude in brackets). EECO=early Eocene climatic optimum, $\mathrm{MECO}=$ middle Eocene climatic optimum, PrOM=Priabonian oxygen isotope maximum, LECO=late Eocene climatic optimum. .............................. 173

Figure 7.4 previous page, Biogeographic affinity of radiolarian assemblages along a transect from high to low latitudes. Results from this thesis as in Figure 6.38 plus three additional sites: High-latitude ODP Site 689 (Funakawa and Nishi, 2005), mid-latitude Mead Stream (C. Hollis, pers. comm. 2016) and low-latitude IODP Site U1331 (Kamikuri et al., 2013). The biogeographic affinities for the latter three sites were assigned to taxa as identified in this thesis plus additional low-latitude genera (Lamptonium, Thyrsocyrtis, Podocyrtis, Bekoma and Lithocyclia). For sites U1331 and 689, the biogeographic assignments of Kamikuri et al. (2013) and Funakawa and Nishi (2008), respectively, are indicated with a black dashed line.

Figure 7.5 The Paleogene evolution of Southwest Pacific Ocean fronts (after Nelson and Cooke, 2001) using TEX 86 and $\mathrm{Mg} / \mathrm{Ca}$ derived temperatures (Hollis et al., 2012; Hollis et al., 2015; Littler et al., 2016); Paleolatitudes for each site are calculated at $5 \mathrm{Ma}$ increments using www.paleolatitude.org (van Hinsbergen et al., 2015), except for Mead Stream and Mid-Waipara, for which the paleolatitudes were derived using the paleoceanographic reconstructions as outlined in chapter 3.7. Abbreviations: MW = Mid-Waipara, Mead = Mead Stream, 
TC=Tropical Convergence, TF=Tropical Front, STF=Subtropical Front, AAPF=Antarctic Polar Front. Modified from Hollis et al. (2016).

Figure 7.6 Reconstruction of oceanic fronts and water masses (after Nelson and Cooke, 2001) for the Southwest Pacific from the early Eocene to late Oligocene based on the relative abundance of high-latitude (HL), cosmopolitan and low-latitude (LL) taxa as shown in Figure 7.4. Paleolatitudes are calculated at $5 \mathrm{Ma}$ increments for each site using www.paleolatitude.org (van Hinsbergen et al., 2015), except for Mead Stream and Mid-Waipara, for which the paleolatitudes were derived using the paleoceanographic reconstructions as outlined in chapter 3.7. Abbreviations: MW = Mid-Waipara, Mead = Mead Stream, TF=Tropical Front, STF=Subtropical Front, $\mathrm{SAF}=$ Subantarctic Front, AAPF=Antarctic Polar Front. . .183

Figure 7.7 Biogeographic affinities and paleoceanographic reconstruction for the EECO ( 53-49 Ma). Biogeographic affinity pies show $\%$ only of the biogeographic constrained portions of the assemblage.

Figure 7.8 Biogeographic affinities and paleoceanographic reconstruction for the middle Eocene ( 47-40 Ma). Slightly different time slices apply for each site: Site 1172 ( 43-40 Ma), Site 277 (MECO, 40 Ma), Site 207 ( 47-42 Ma), Site 206 ( 42-41 Ma), U1331 ( 47-40 Ma), Mead Stream ( 46-43 Ma). Biogeographic affinity pies show $\%$ only of the biogeographic constrained portions of the assemblage. For key refer to Figure 7.7 .......185

Figure 7.9 Biogeographic affinities and paleoceanographic reconstruction for the late middle to early late Eocene/PrOM ( 38-37 Ma). Biogeographic affinity pies show \% only of the biogeographic constrained portions of the assemblage. For key refer to Figure 7.7; modified after Pascher et al. (2015). 186

Figure 7.10 Biogeographic affinities and paleoceanographic reconstruction for the late Eocene climatic optimum $(\sim 36$ Ma). Site 283 is tentatively included here although an older age was inferred ( $36.7 \mathrm{Ma})$. Biogeographic affinity pies show $\%$ only of the biogeographic constrained portions of the assemblage. For key refer to Figure 7.7; modified after Pascher et al. (2015).

Figure 7.11 Biogeographic affinities and paleoceanographic reconstruction for the latest Eocene to earliest Oligocene ( 35-32 Ma). Slightly different time slices apply for each site: Site $1172(\sim 35-34 \mathrm{Ma})$, Site 277 ( 35.3-32.4 Ma), Site 280 (34-32.5 Ma), Site 1123 (35.4-33.3 Ma). Biogeographic affinity pies show \% only of the biogeographic constrained portions of the assemblage. For key refer to Figure 7.7; modified after Pascher et al. (2015). 189

Figure 7.12 Biogeographic affinities and paleoceanographic reconstruction for the early Oligocene ( 32-27 Ma). Slightly different time slices apply for each site: Site $1172(\sim 28-26.6 \mathrm{Ma})$, Site $277(\sim 31.9 \mathrm{Ma})$. Biogeographic affinity pies show $\%$ only of the biogeographic constrained portions of the assemblage. For key refer to Figure 7.7; modified after Pascher et al. (2015). 


\section{List of Tables}

Table 3.1 Overview of samples at each site, which are arranged according to their paleolatitude at $\sim 40$ Ma. New samples were prepared in this study; existing samples from ${ }^{1}$ Hollis et al. (1997), ${ }^{2}$ DSDP/ODP Micropaleontological Reference Centre, ${ }^{3}$ slides provided by Y. Aita; ${ }^{4}$ assemblage data from N. Suzuki......

Table 6.1 Overview of relative abundance (\%) of the high-latitude (HL), cosmopolitan and low-latitude (LL) groups, averaged over specific time slices at high-latitude sites 280, 281, 1172, 283 and 277. Additionally, as shown in the graphs for each site in Chapter 6.2.1, the high- and low-latitude groups are separated into 6 and 5 subgroups, respectively. EECO=early Eocene climatic optimum; $\mathrm{MECO}=$ middle Eocene climatic optimum; PrOM=Priabonian oxygen isotope maximum; $\mathrm{LECO}=$ late Eocene climatic optimum. . .157

Table 6.2 Overview of relative abundance (\%) of the high-latitude (HL), cosmopolitan and low-latitude (LL) groups, averaged over specific time slices at mid-latitude sites 592, 1123, 207 and 206. Additionally, as shown in the graphs for each site in Chapter 6.2.2, the high- and low-latitude groups are separated into 6 and 5 subgroups, respectively. EECO=early Eocene climatic optimum; LECO=late Eocene climatic optimum.

Table A.1: List of encounteres species at high-latitude sites 280, 281, 283, 1172 and 277 and mid-latitude sites 1123, 592, 207 and 206. For Site 1172, a full species list of all encountered taxa can be found in Appendix B Table 6. Biogeographic affinity (BA) assignments to taxa: $\mathrm{H}=$ high latitude, $\mathrm{C}=$ cosmopolitan, $\mathrm{L}=$ low latitude. Location of images on plates for selected species. .258 


\section{Introduction}

\subsection{Rationale and aims of the study}

By the end of this century, atmospheric $\mathrm{CO}_{2}$ concentration is predicted to increase up to 1000 ppmv under the worst case RPC 8.5 scenario, with projections suggesting global mean surface temperatures may increase by up to $5^{\circ} \mathrm{C}$ (Meehl et al., 2007; Stocker et al., 2013; IPCC, 2014). The extra heat will be mostly stored in the oceans, especially in the Pacific Ocean, which accounts for over 50\% of global heat flow being channelized through its giant basin (Schmitz, 1995). The Southwest Pacific represents the main pathway for meridional flow between low and high latitudes. New Zealand is located in the transition between warm and cool circulation systems and the area spans major frontal systems. In order to predict how biological and physical systems will respond to extreme warming under high emission pathways, it is essential to study the Southwest Pacific during times of 'greenhouse climates'. During the Eocene epoch (56-34 Ma), atmospheric $\mathrm{CO}_{2}$ concentrations have likely exceeded 1000 ppmv (Beerling and Royer, 2011). The Southwest Pacific region is an ideal setting to test competing ideas on primary climate drivers: greenhouse gases vs. changes in ocean circulation. Oceanographic changes in the Southwest Pacific, related to the tectonic separation of Australia from Antarctica, have long been associated with the overall Cenozoic cooling trend and the onset of Antarctic glaciation at the Eocene-Oligocene transition (Kennett, 1977).

This thesis is part of a Marsden Fund Project 'Surviving in the Eocene ocean: the unbearable warmness of being.' The overall aim of the project is to investigate if trends in species turnover and geographic distribution of Paleogene marine plankton are consistent with geochemical evidence for extreme high-latitude warmth during the Eocene.

This doctoral thesis examines the distribution of Eocene and early Oligocene radiolarians in the Southwest Pacific, in order to improve our understanding of changing ocean circulation and thermal gradients through this time period. This thesis contributes to taxonomic knowledge and provides information on the distribution of Paleogene taxa in the Southwest Pacific. A key aspect of this thesis is the development of a consistent taxonomy between sites to allow the identification of locally significant biostratigraphic 
events. A large part of this thesis has been spent on creating an extensive taxonomic review based on occurrence data from various ocean drilling and onshore sites and to identify the biogeographic affinity of radiolarian taxa.

The following research questions are addressed in this thesis:

\section{Were there past episodes of global warmth in which tropical or subtropical water masses extended to polar latitudes in the Southwest Pacific?}

Radiolarian biotic turnover and trends in biogeographic affinities of species was documented across a transect from mid-latitude (DSDP sites 206, 207, 592 and ODP Site 1123) to high-latitude sites (DSDP sites 277, 280, 281, 283 and ODP Site 1172) in the Southwest Pacific. The abundance of low-latitude taxa at mid- and high-latitude sites was used to determine if tropical conditions reached as far south as New Zealand and other high-latitude Southwest Pacific sites during 'greenhouse' episodes, or at any other time in the Eocene. New stable oxygen and carbon isotope data from DSDP sites 277, 207 and 592 have been used to aid interpretation of the radiolarian results.

\section{What were the main mid-to high-latitude oceanographic changes in the Southwest} Pacific that occurred prior to, and during, the Eocene-Oligocene climate transition?

Radiolarian assemblages from five high-latitude and two mid-latitude Southwest Pacific sites were investigated. The high-latitude sites form a latitudinal transect from the southern Campbell Plateau (DSDP Site 277) to the Southwest Tasman Sea (DSDP Site 283, ODP Site 1172,) and South Tasman Rise (DSDP sites 281 and 280). Mid-latitude sites 592 and 1123 lie northwest and east of New Zealand, respectively. The study focussed on the late Eocene due to poor recovery of radiolarians in the early Eocene. Census counts of fossil radiolarian assemblages were obtained to identify when a distinct Southern Ocean fauna was established in the Southwest Pacific. These mid- and highlatitude sites were chosen to enable a reconstruction of the presence of oceanographic features (e.g. East Australian Current, a clockwise Tasman Gyre, Antarctic Circumpolar Current) that have been implicated in influencing climate in the Southwest Pacific at this climatic transition. 


\subsection{Thesis structure}

Chapter 1: Introduction. In this chapter, the aims, scope and rationale for the study are outlined.

Chapter 2: Background. This chapter begins with an overview of the present and past oceanographic and geological setting of the Southwest Pacific with a focus on the Paleogene. The second section of this chapter gives an overview about the evolution of the Paleogene climate, and a short outline of geochemical proxies and climate modelling results for the Southwest Pacific. The third section introduces radiolarians, their taxonomy and general features of this group. The last section of this chapter outlines Paleogene radiolarian studies, including radiolarian biostratigraphy and the application of radiolarians in paleoenvironmental studies.

Chapter 3: Material and methods. This chapter contains an overview of the different ocean drilling sites, the nature of their sedimentary archive and the intervals sampled. Sample and slide preparation methods and statistical analyses are described. This chapter also outlines the main resources that have been used for radiolarian identification. Furthermore, it introduces the New Zealand geological timescale and radiolarian zonations of the Southwest Pacific. The last sections of this chapter focuses on the methodology for paleogeographic reconstructions and stable isotope measurements.

Chapter 4: Radiolarian occurrence. This chapter provides an overview of the observed patterns in sedimentary components, radiolarian abundance and preservation at all studied sites.

Chapter 5: Radiolarian biostratigraphy and correlation. This chapter provides the biostratigraphic events of radiolarians, accompanied by foraminifer and nannofossil events, for all sites. Age-depth plots are presented for selected sites. Results of stable isotope measurements for DSDP Site 277 are included in this chapter.

Chapter 6: Radiolarian paleoecology and paleobiogeography. This chapter contains the results of the radiolarian census counts and assemblage analysis for all sites. Results of stable isotope measurements for sites 207 and 592 are provided in this chapter.

Chapter 7: Discussion. This chapter contains the discussion of this thesis' results, by integrating the main conclusions of all sites and discussing their significance in 
comparison to other Southern Ocean sites and studies to answer the objectives of this thesis. The first section discusses the biostratigraphy, age control and correlation between the studied sites, the second section discusses the general features of radiolarian assemblages and the third section discusses the findings based on radiolarian paleobiogeography.

Chapter 8: Conclusions and future work.

Appendix A: Taxonomic Notes. Brief descriptions of the radiolarian taxa encountered in this study with illustrations of selected taxa.

Appendix B: Radiolarian distribution charts of all investigated sites (data on enclosed $\mathrm{CD})$.

Appendix C: Biostratigraphic events. List of all biostratigraphic events of radiolarians, foraminifera and nannofossils (data on enclosed CD).

Appendix D: Stable isotopes of sites 277, 592 and 207 (data on enclosed CD).

Appendix E: Paleobiogeographic indicators. Review based on occurrence data from various ocean drilling and onshore sites and to identify the biogeographic affinity of radiolarian taxa (data on enclosed $\mathrm{CD}$ ).

\subsection{List of publications resulting from this study}

\subsubsection{Peer-reviewed publications}

Pascher, K.M., Hollis, C.J., Bohaty, S.M., Suzuki, N., Chiba, K., Seebeck, H., Cortese, G., McKay, R., 2015. Expansion and diversification of high-latitude radiolarian assemblages in the late Eocene linked to a cooling event in the Southwest Pacific. Climate of the Past, 11(12): 1599-1620; doi: 10.5194/cp-11-1599-2015.

\subsubsection{Conference publications}

Pascher, K.M., Bohaty, S.M., Hollis, C.J., Cortese, G., McKay, R.M. 2015 Have we discovered the late Eocene climatic optimum? In: McKay, R., Savage, M., Wilson, C. (Eds.), Geosciences 2015: Zealandia in Space and Time. Annual Conference of the Geoscience Society of New Zealand, Victoria University of Wellington. [oral]

Pascher, K.M., Bohaty, S.M., Hollis, C.J., Cortese, G., McKay, R.M. 2015 Expansion of Southern Ocean radiolarian fauna linked to a late Eocene cooling event. In: Radiolaria Newsletter Vol. 35, pp.154-155. The 14th Meeting of the International 
Association of Radiolarists, an International Conference on Fossil and Recent Radiolarians, Antalya, Turkey. [oral]

Pascher, K.M. Hollis, C.J.; McKay, R.; Cortese, G. 2014 Southern Ocean endemism evident in Late Eocene radiolarian assemblages, DSDP Site 277, Campbell Plateau (New Zealand). In: Rend. Online Soc. Geol. It., Vol. 31, pp. 167-168: Climatic and Biotic Events of the Paleogene 2014: Selected short notes and abstracts, Ferrara, Italy. [poster]

Pascher, K.M. Hollis, C.J.; McKay, R.; Cortese, G. 2014 Southern Ocean endemism evident in Late Eocene radiolarian assemblages, DSDP Site 277, Campbell Plateau (New Zealand). SCAR Open Science Conference, Auckland, New Zealand, Volume: SCAR OSC Abstracts, p. 453. [poster]

Hollis, C.J., Pascher, K.M., Hines, B.R., Littler, K., Kulhanek, D.K., Strong, C.P., Zachos, J.C., Eggins, S.M. \& Phillips, A. 2014 Was the Early Eocene ocean unbearably warm or are the proxies unbelievably wrong? In: Rend. Online Soc. Geol. It., Vol. 31 (2014), pp. 109-110: Climatic and Biotic Events of the Paleogene 2014: Selected short notes and abstracts, Ferrara, Italy.

Hollis, C.J., Pascher, K.M., Shepherd, C.L., Hines, B.R., Cortese, G., Morgans, H.E.G., Kulhanek, D.K., McKay, R. and Crampton, J.S. 2014 Reconciling proxies and fossils with Southern Ocean circulation models for the Paleogene, SCAR Open Science Conference, Auckland, New Zealand, Volume: SCAR OSC Abstracts, p. 445.

Pascher, K.M., Hollis, C.J., McKay, R. 2013 Paleobiogeography of Eocene radiolarians from the Southwest Pacific, In: Reid, C.M. \& A. Wandres, A. (Eds.): Geoscience Society of New Zealand miscellaneous publication 136A, abstracts, pp. 72-73: Geosciences 2013: Annual Conference of the Geoscience Society of New Zealand, Christchurch, New Zealand. [poster]

Hollis, C.J., Pascher, K.M., Shepherd, C.L., Hines, B., Morgans, H.E.G., Strong, C.P., Naafs, D. and Pancost, R.D. 2016 The tolerable warmness of the Eocene hyperthermal ocean, 12th International Conference on Paleoceanography (ICP12), Utrecht, The Netherlands.

The work described in this thesis was carried out while I was a full-time student at the Antarctic Research Centre, Victoria University of Wellington, based at GNS Science between $1^{\text {st }}$ April 2013 and $30^{\text {th }}$ September 2016. Except where mentioned in the text, the research described here is my own. No part of this thesis has been submitted to any other university or similar institution.

Wellington, New Zealand, February 2017

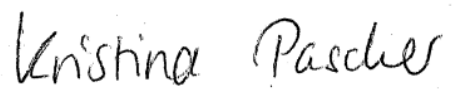




\section{Background}

\subsection{Oceanographic setting - Southern Ocean and Southwest Pacific Ocean}

\subsubsection{The modern Southern Ocean circulation}

The Southern Ocean is the most recent named ocean. The name was suggested by the International Hydrogeographic Organization (IHO) in 2000 and is defined as the body of water extending from the coast of Antarctica to $60^{\circ} \mathrm{S}$ latitude. However, not all countries have agreed on the proposed geographic boundary and the IHO has not ratified the definition of the Southern Ocean yet. Oceanographers often use oceanic fronts as the boundary, usually the Suptropical Front (STF), the boundary between subtropical and subantarctic waters (Orsi et al., 1995; Orsi and Harris, 2001; Orsi and Whitworth, 2005; Carter et al., 2008). The STF varies from latitudes $40^{\circ}$ to $45^{\circ}$, but can extend to $30^{\circ} \mathrm{S}$ (Orsi et al., 1995) (Figure 2.1). Other scientists use their own terminology and use for example the Antarctic Polar Front (APF) as the northernmost boundary of the Southern Ocean (Lazarus and Caulet, 1993). In this thesis, the STF will be used as the boundary of the Southern Ocean.

The Southern Ocean is one of the most important components of Earth's oceanicatmospheric climate system mainly due to its role in transferring heat meridionally between the low and high latitudes, and transferring heat, nutrients, and dissolved gases between the world's major ocean basin (Atlantic, Indian, and Pacific Oceans). It is estimated that about $60 \%$ of the ocean volume is cooled around Antarctica (Gordon, 1988). The heat transfer in surface waters is related to wind drift and eddies associated with oceanic fronts (Orsi et al., 1995; Orsi and Harris, 2001; Orsi and Whitworth, 2005; Carter et al., 2008).

The Southern Ocean is dominated by the Antarctic Circumpolar Current (ACC), which connects the major ocean basins and plays a fundamental role in the distribution of heat, salt and gases. The ACC is guided by submarine topography and extends from the ocean surface to the bottom. In some regions its flow is deflected and widens to the north and south (e.g. Kerguelen Plateau), whereas the Campbell Plateau in the Southwest Pacific 
restricts its flow to the north. The ACC gets narrower and shifts poleward between large gaps in the Indian and Pacific oceanic ridge system (Figure 2.1) (Carter et al., 2008). In the Southern Ocean, cold, deep waters flow northwards as deep western boundary currents (DWBC) which are a major component in the global overturning circulation (Schmitz, 1995). The DWBC are the main exit pathways for cold, dense bottom water flowing north towards the equator at water depths exceeding 3500-4000 m along the western boundaries of the various oceanic basins, represented by the continental margin off South America (Southwest Atlantic), South Africa (Southwest Indian) and east of the Campbell Plateau (Southwest Pacific) (Figure 2.1) (Schmitz, 1995; Carter et al., 2008).

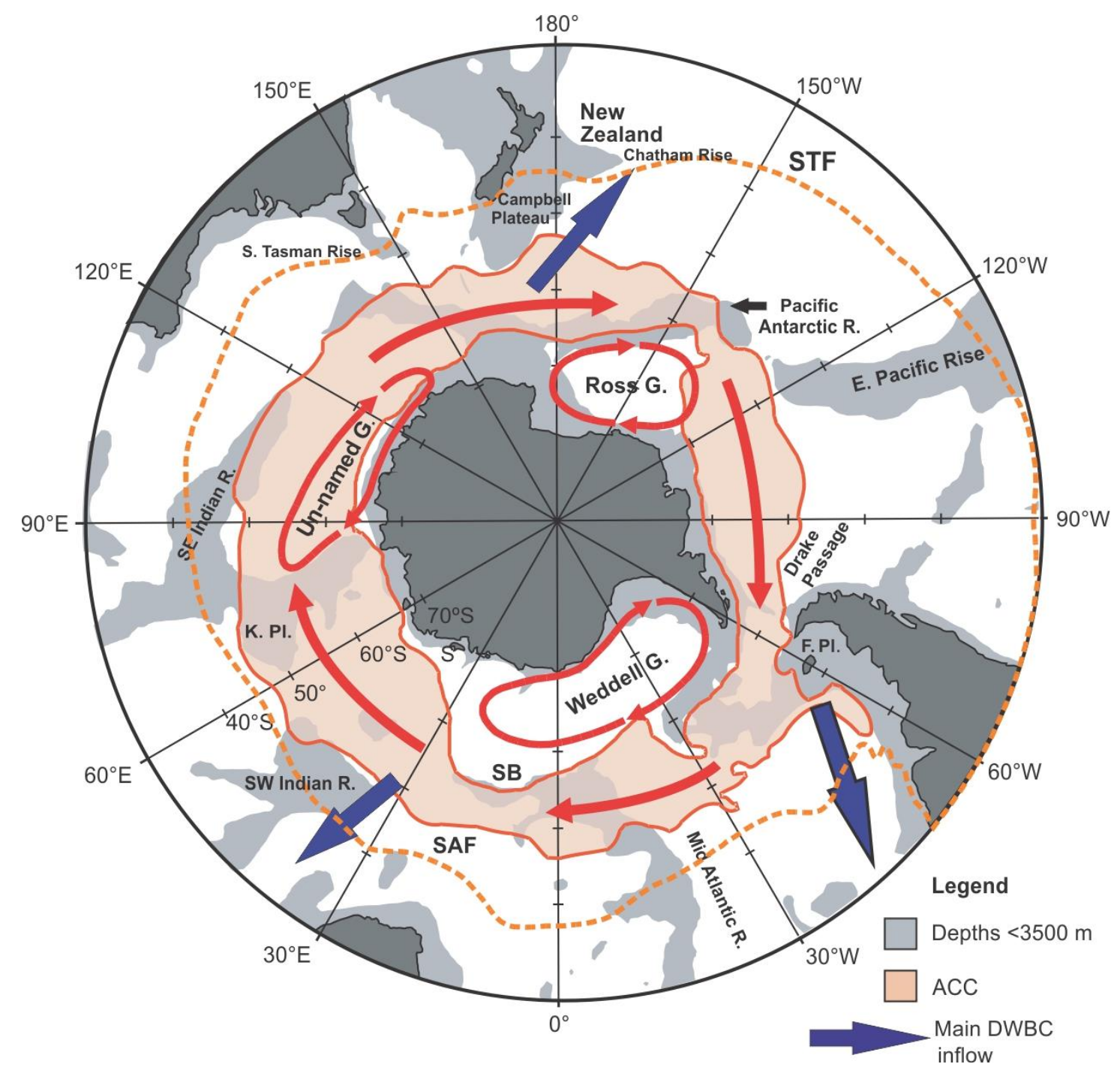

Figure 2.1 Map modified from Carter et al. (2008) showing the main oceanographic elements of the Southern Ocean: the Subtropical Front (STF), the clockwise Antarctic Circumpolar Current (ACC) which is constrained to the north by the Subantarctic Front (SAF) and to the south by the southern limit of Upper Circumpolar Deep Water or southern boundary (SB); the Ross, Weddell and unnamed subpolar gyres; and the main exit points of cold deep water towards the north, the deep western boundary currents (DWBC, blue arrows). Bathymetric elevations: R=ridge; K. Pl.=Kerguelen Plateau; F. Pl.=Falkland Plateau. 
Three large gyres connect the ACC and the Antarctic margin, with the Weddell Gyre being the largest (Figure 2.1). The Ross Gyre in the South Pacific is restricted to the $>4,000 \mathrm{~m}$ deep SE Pacific Basin (Carter et al., 2008).

\subsubsection{Regional oceanography of the Southwest Pacific}

The modern Southern Ocean is a complex arrangement of different bands of water masses, separated by ocean frontal systems, narrow zones where sudden changes in vertical structure, salinity, temperature and nutrients take place (Belkin and Gordon, 1996). The Southwest Pacific represents the main pathway for meridional flow between Antarctica and the tropics, with New Zealand being located at the transition between warm anticyclonic and cool cyclonic circulation systems. There are currently three main oceanic fronts between New Zealand and Antarctica (Figure 2.2), separating four main surface water masses. The Subtropical Front (STF) is the sharpest oceanic front in the Southwest Pacific as it separates warm Subtropical Surface Water (STW) (annual mean sea surface temperature $\left.(\mathrm{SST})>13^{\circ} \mathrm{C}\right)$ from cold Subantarctic Surface Water (SAW) $(6-$ $12^{\circ} \mathrm{C}$ ). These two water masses are not only different in temperatures, but also in nutrients, with the SAW being micronutrient-poor/macronutrient-rich, while STW is micronutrient-rich/macronutrient-poor (Heath, 1985; Carter et al., 2008). Currently, the STF lies near 43-45ㅇ (Figure 2.2) (Orsi et al., 1995; Carter et al., 1998; Orsi and Harris, 2001) and is bounded by the South Island of New Zealand.

The second important front in the New Zealand region is the Subantarctic Front (SAF) (Figure 2.2), separating SAW to the north from Circumpolar Surface Water (CSW) to the south, with the latter water mass having a lower salinity and cooler temperatures $\left(0-5^{\circ} \mathrm{C}\right)$ than the former (Carter et al., 2008). The third and southernmost front is the Antarctic Polar Front (PF), separating CSW from Antarctic Surface Water (ASW), which can be cooler than $0^{\circ} \mathrm{C}$ (Carter et al., 2008).

Two studies on recent radiolarian biogeographic distribution in the Southwest Pacific identified distinct sample groups that were interpreted to reflect different surface water masses, oceanographic fronts and regions (Hollis and Neil, 2005; Cortese and Prebble, 2015). In general, an increase in warm-water taxa to the north and increase in subantarctic taxa to the south was observed. A distinct sample group that was characterised by low 
radiolarian diversity and abundance was identified for the Campbell Plateau, which reflects the silica-poor SAW (Hollis and Neil, 2005; Cortese and Prebble, 2015).

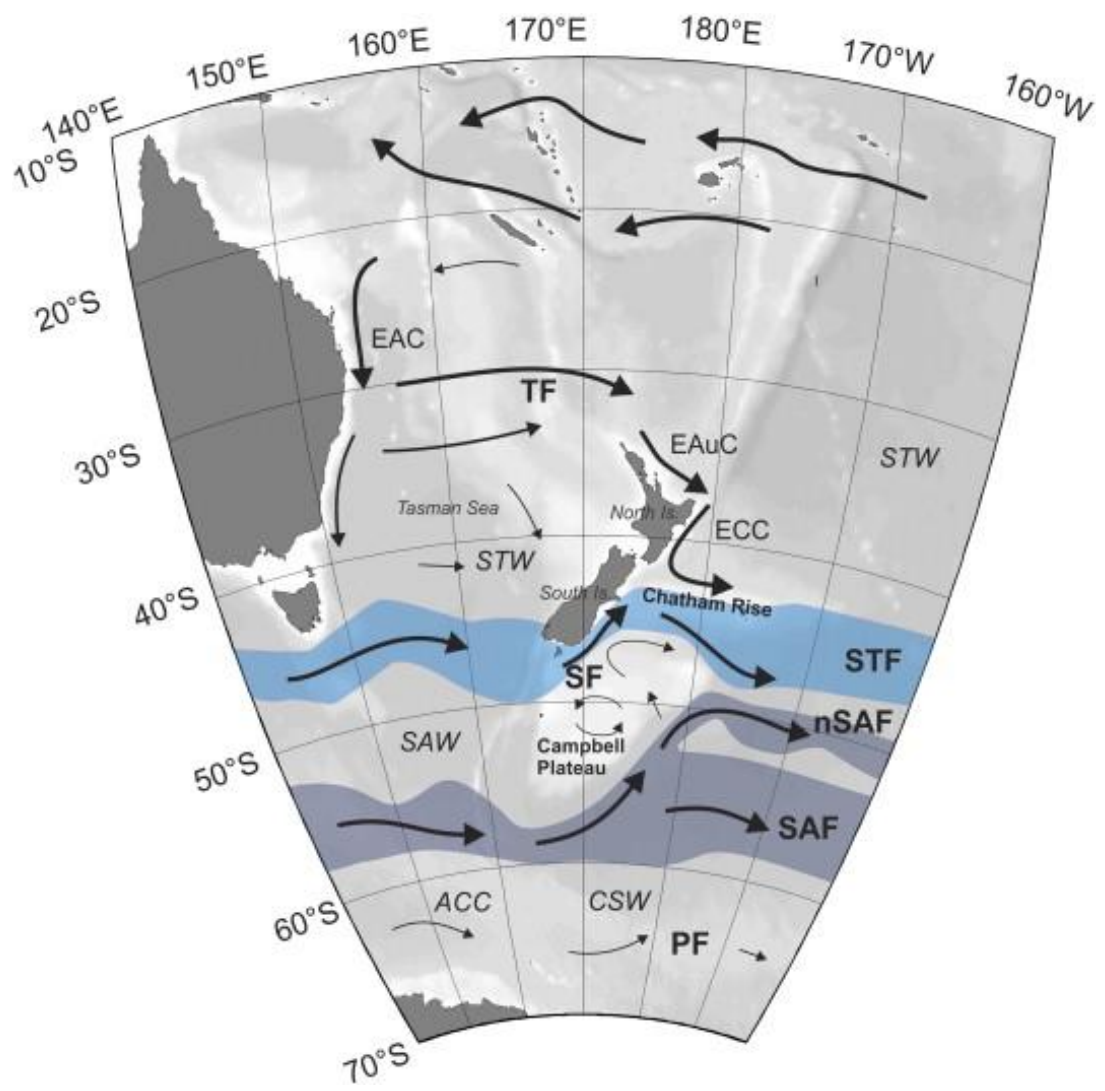

Figure 2.2 Modern oceanography in the Southwest Pacific from Cortese and Prebble (2015) with frontal locations after Orsi et al. (1995), Carter et al. (1998) and Orsi and Harris (2001). Abbreviations of oceanic fronts (bold): TF=Tasman Front; STF=Subtropical Front; SF=Southland Front; nSAF=northern Subantarctic Front; SAF=Subantarctic Front; $\mathrm{PF}=$ Polar Front; Currents (plain text): EAC=East Australian Current; EAuC=East Auckland Current; ECC=East Cape Current; Water-masses (italics): STW=Subtropical Water; SAW=Subantarctic Water; CSW=Circumpolar Water; ACC $=$ Antarctic Circumpolar Current.

\subsubsection{Paleogeographic reconstructions}

An essential aspect in the interpretation of paleoclimatic reconstructions based on various geological proxy records is the correct reconstruction of paleogeography, especially the continent-ocean configuration and paleolatitude. This is because the configuration of continental masses and oceanic basins plays an important role in the distribution of heat on the Earth's surface via atmospheric and oceanic circulation. Moreover, the correct identification of the position of a geological record at the moment of deposition is crucial, as its paleolatitude ultimately determines the incoming amount of solar energy at that location. A recent summary by van Hinsbergen et al. (2015) outlines the different approaches and techniques behind plate tectonic reconstructions and the use of different reference frames for specific questions. 
Relative plate motions have been reconstructed using marine magnetic anomalies and fracture zones along the ocean floors as reference frames (Hay et al., 1999; Scotese, 2001). However, these reconstructions are insufficient for the use in climatic studies as the position of a plate relative to the Earth's spin axis cannot be reconstructed. Two types of absolute reference frames have been developed for reconstructions that can be tied to Earth's spin axis or structures within the mantle.

A mantle reference frame allows for the study of the interactions of the Earth's mantle with the crust and to analyse the driving mechanisms of plate tectonics (van Hinsbergen et al., 2015). For this purpose, structures are needed that are relatively stationary in the mantle relative to their rock record on the Earth's surface. Hotspots are ideal for this purpose, and the first hotspot reference frames were developed by Cox and Hart (1986) and Müller et al. (1993). More recent hotspot reference frames were developed to correct for the plume motion factor (O'Neill et al., 2005; Doubrovine et al., 2012). Many paleoclimatic studies use a hotspot reference frame (Huber and Caballero, 2011; Hollis et al., 2012) for reconstructing paleolatitudes. The most common used software is GPlates, which includes a global plate reconstruction after Seton et al. (2012) and uses a mantle reference frame after O'Neill et al. (2005). Van Hinsbergen et al. (2015) pointed out that for paleoclimatic studies only a paleomagnetic reference frame based on global apparent polar wander path (GAPWaP) (Torsvik et al., 2012) should be used for reconstructing paleolatitudes because this method locates sites and regional geographies in relation to Earth's spin axis and thus its position relative to the sun. This is crucial because the Earth's relative position to the sun is an important determinant of climate conditions. In their view a mantle reference frame is appropriate for geodynamic studies but not for paleoclimatic ones. Doubrovine et al. (2012) indicated that a location in the Paleocene can be misplaced by up to $12^{\circ}(\sim 1200 \mathrm{~km})$ relative to the spin axis if a moving hotspot reference frame is used. Using the paleomagnetic reference frame brings the study sites of this thesis $\sim 5^{\circ}$ further north and thus closer to the possible influence of the East Australian Current. This current was modelled to not have extended further south than $45^{\circ}$ before turning east (Huber et al., 2004). Van Hinsbergen et al. (2015) developed an online freely available paleolatitude calculator for the last $200 \mathrm{Ma}$ based on the latest plate reconstructions after Seton et al. (2012) and the three choices of GAPWaP after Torsvik et al. (2012), Besse and Courtillot (2002) and Kent and Irving (2010). 


\subsubsection{Regional paleoceanography in the Southwest Pacific during the Paleogene}

The development of the Southern Ocean circulation and Antarctic Circumpolar Current (ACC) is linked to the continental break-up of Gondwanaland during the late Cretaceous ( 83 Ma), when Australia began to drift north, away from Antarctica (Cande and Mutter, 1982). The Australo-Antarctic Gulf formed between both continents, although Australia is inferred to have been connected at its Southeastern margin to Antarctica until about 64 Ma via the Tasmanian land bridge (Woodburne and Case, 1996). After 64 Ma, distinctly different mammal assemblages on Australia compared to Antarctica and South America suggests that a shallow seaway developed through the Tasmanian Gateway (Woodburne and Case, 1996). Kennett and Exon (2004) suggested, based on sedimentological evidence, that the South Tasman Rise and Tasmania formed a major oceanographic barrier until the latest Eocene. Prior to this time, sediments to the west of the barrier indicate poorly oxygenated, relatively warm shallow conditions within the Australo-Antarctic Gulf, whereas better oxygenated, relatively cool shallow-marine conditions prevailed in the Southwest Pacific (Exon et al., 2004). However, due to distinct dinoflagellate cyst assemblages east and west of the marine barrier, Bijl et al., 2013 argued that there was a restricted oceanographic connection between the AustraloAntarctic Gulf and the Southwest Pacific until 50 Ma, coinciding with the onset of the long-term cooling trend noted in the Cenozoic.

A comprehensive review of sedimentary facies, microfossil assemblages and geochemical proxies was undertaken by Nelson and Cooke (2001) who presented an updated synthesis on the oceanic front development in the Southwest Pacific during the Cenozoic. 


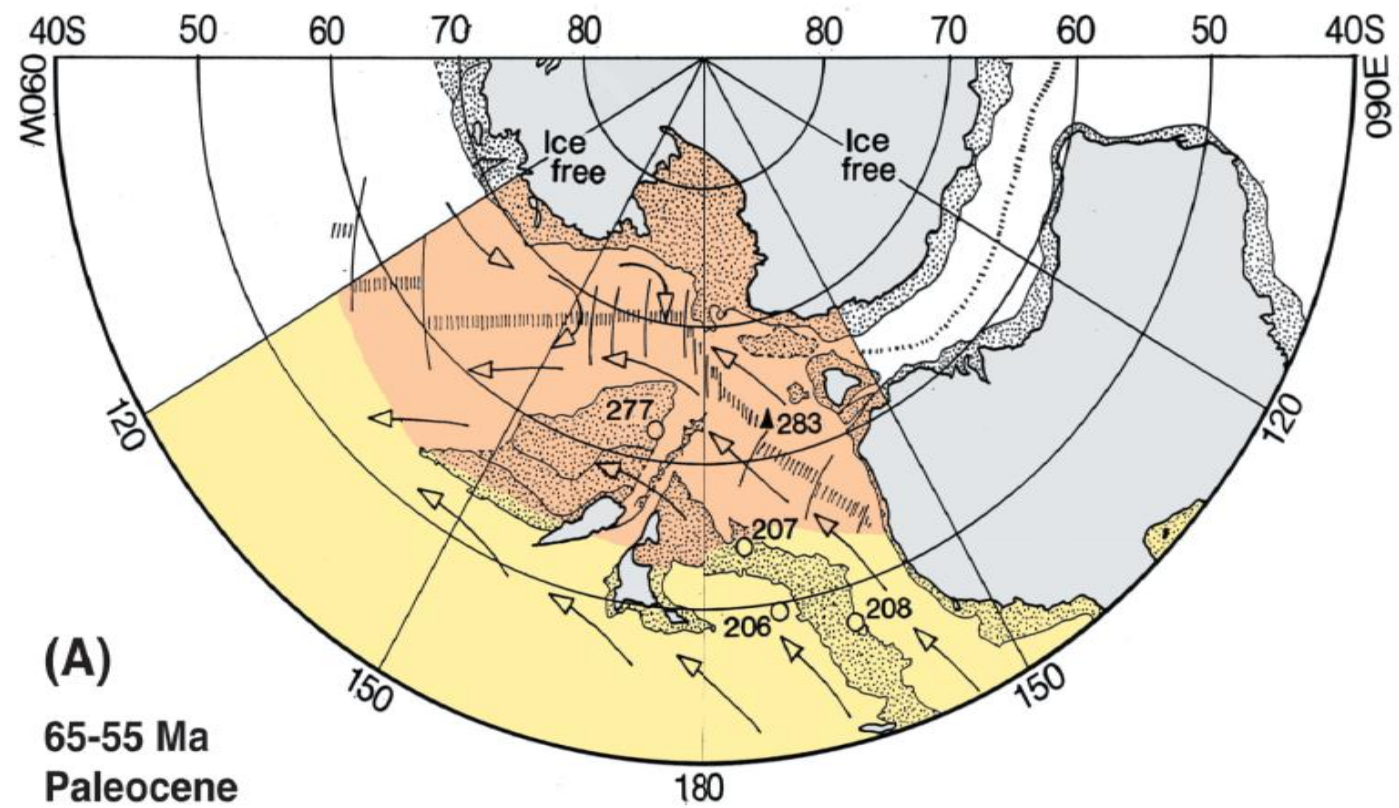

Figure 2.3 Schematic paleoceanographic and paleogeographic map from Nelson and Cooke (2001) for the Paleocene (65-55 Ma), based on the reconstructions of Lawver et al. (1992). No frontal systems were established yet and Antarctica was ice free. Numbers refer to DSDP sites; dark shaded grey areas represent the continental margin to the present day $2000 \mathrm{~m}$ isobath; orange shaded areas indicate cool subtropical water masses; yellow shaded areas indicate warm subtropical water masses; arrows indicate surface ocean currents.

According to Nelson and Cooke (2001) there are no indications for the presence of welldefined oceanic fronts during the Paleocene to late Eocene (Figure 2.3). However, Jenkins (1993) proposed the presence of a transition zone at around $50-55^{\circ} \mathrm{S}$ paleolatitude between warm and cool subtropical waters based on fossil evidence from New Zealand (Beu et al., 1990; Hornibrook, 1992). In the early Eocene, the presence of subtropical to marginally tropical marine biota, coastal mangroves and the genus Cocos (Arecaceae family, coconut palm trees) in New Zealand (Hornibrook 1992), suggests that the transition between cool and warm subtropical provinces lay further south $\left(\sim 60^{\circ} \mathrm{S}\right)$ (Nelson and Cooke, 2001). During the middle to late Eocene ( 45-35 Ma), the separation of Australia from Antarctica continued, with faster spreading rates starting from $\sim 50 \mathrm{Ma}$ (Close et al., 2009). According to Nelson and Cooke (2001) the earliest eastward cold water flow around Antarctica developed in the latest Eocene (Figure 2.4) ( $35 \mathrm{Ma}$ ) and an Antarctic Polar Front became established in the early Oligocene. 


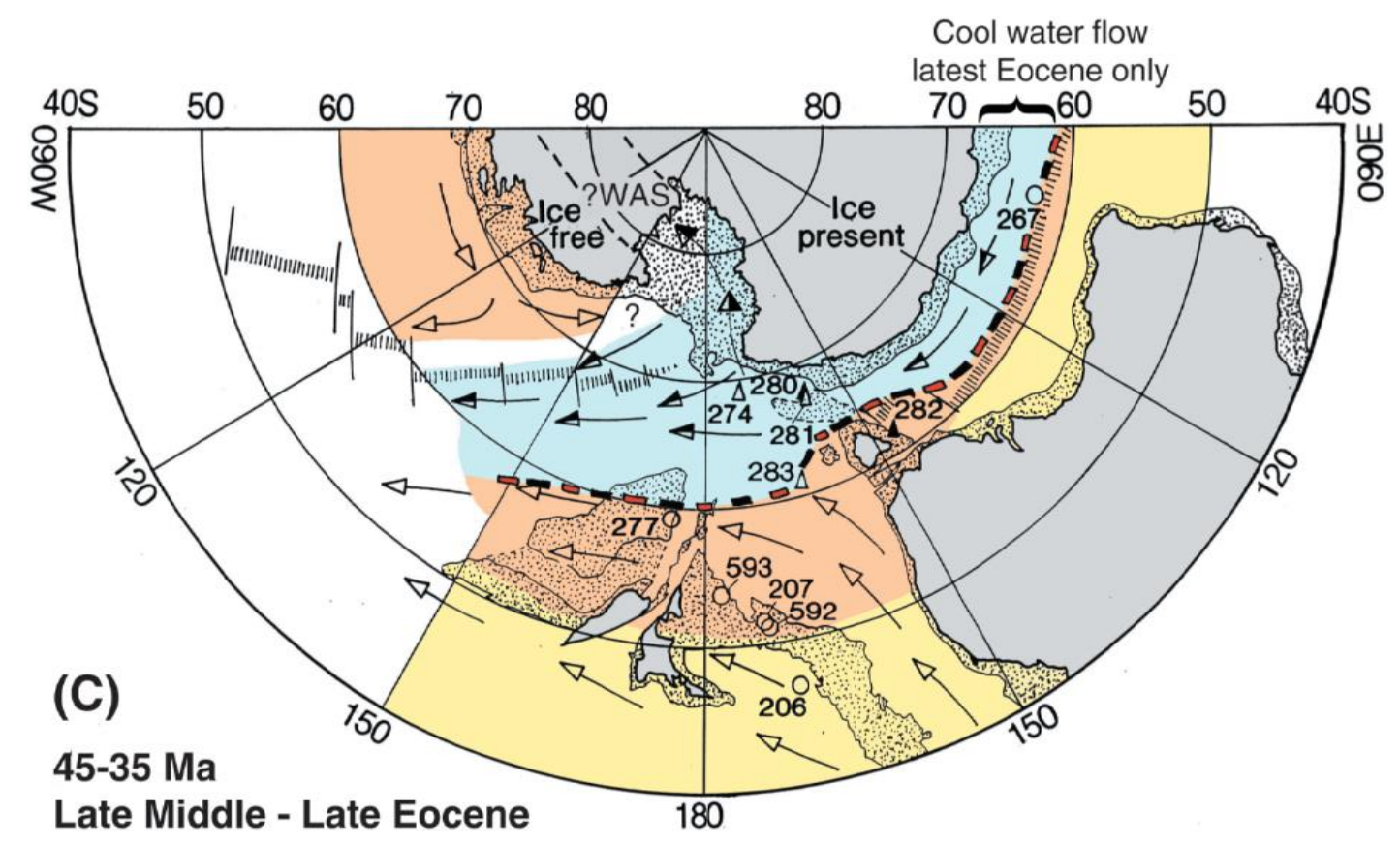

Figure 2.4 Schematic paleoceanographic and paleogeographic map from Nelson and Cooke (2001) for the late middle to late Eocene (45-35 Ma), based on the reconstructions of Lawver et al. (1992). A proto-Subtropical Front (dashed line) and cool water flow around Antarctica were established in the late Eocene ( $35 \mathrm{Ma})$. WAS=West Antarctic seaway. Numbers refer to DSDP sites; dark shaded grey areas represent the continental margin to the present day 2000 $\mathrm{m}$ isobath; orange shaded areas indicate cool subtropical water masses; yellow shaded areas indicate warm subtropical water masses; light blue shaded areas indicate subantarctic water masses; arrows indicate surface ocean currents.

More recent studies propose a completely different paleoceanographic setting for most of the Eocene. Based on dinoflagellate cyst assemblages and computer-based models, the Tasman Current, driven by the large proto-Ross Gyre, is inferred to have flowed north, supplying cold water to the Southwest Pacific (Figure 2.5) (Huber et al., 2004; Bijl et al., 2009). According to Bijl et al. (2013), the expansion of Antarctic endemic dinoflagellates in the Australo-Antarctic Gulf at $\sim 50 \mathrm{Ma}$ represents a key phase in the opening of the Tasman Gateway with the establishment of the westward flowing Antarctic Counter Current (Bijl et al. 2013). This westward flow is inferred to have been enhanced at this time due to the position of the Tasman Gateway at higher latitudes and thus in the pathway of the Polar Easterlies (Bijl et al., 2013; Scher et al., 2015). A synthesis of geophysical data with a chronology constrained by geological data from Ocean Drilling Leg 178 suggests that the first deep-water passage was established at $33.5 \mathrm{Ma}$ (Hill and Exon, 2004). However, Stickley et al. (2004a) suggested on the basis of diatom assemblage data that the Tasman Gateway opened at $\sim 36 \mathrm{Ma}$, which is $\sim 2 \mathrm{Ma}$ earlier than the climatic shift at the Eocene-Oligocene transition. 
Based on radiolarian assemblages from a suite of Southwest Pacific sites, Lazarus and Caulet (1993) concluded that no distinct Southern Ocean environment existed until the middle Eocene. However, by the late Eocene faunal endemism is noted in the Southern Ocean. Lazarus et al. (2008) argued that the major faunal change in radiolarian assemblages occurred $2 \mathrm{Ma}$ before the Eocene-Oligocene transition. This suggests that environmental changes started in the late Eocene and were probably initiated by the late Eocene deepening of the Tasman Gateway, as proposed by Stickley et al. (2004a), which affected faunal assemblages.

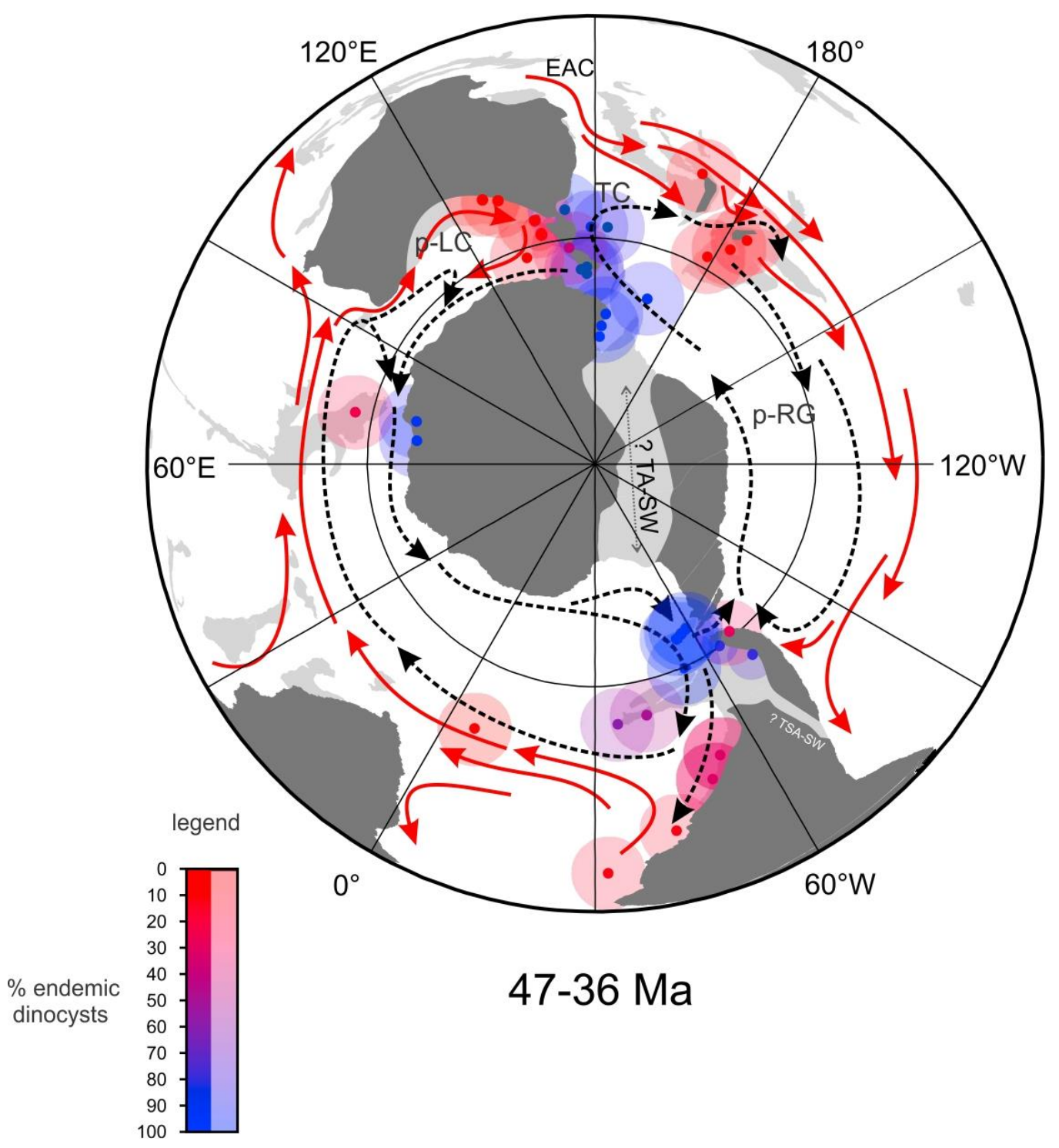

Figure 2.5 modified from Bijl et al. (2011): Dinocyst distribution map for the middle to late Eocene (47-36 Ma) with ocean circulation based on model experiments (Huber et al., 2004); shaded areas represent submerged continental blocks. Abbreviations: TA-SW=Trans-Antarctic Seaway; TSA-SW=Trans-South American Seaway; EAC=East Australian Current; p-LC=proto-Leeuwin Current; p-RG=proto-Ross Gyre; TC=Tasman Current. 
A recent study suggests that the ACC and the Antarctic Polar Front were not developed until $30 \mathrm{Ma}$ (Scher et al., 2015), when the Tasmanian Gateway aligned with the westerly wind flow (Hill et al., 2013). An additional consideration is that a fully developed ACC flow was not established until Drake Passage opened, but there is uncertainty about the timing of this event. According to Barker (2001) this passage was open at 22-17 Ma, whereas Lawver and Gahagan (2003) suggest an opening to deep water had occurred by $\sim 31 \pm 2 \mathrm{Ma}$, which matches well with the ACC being fully developed at $\sim 30 \mathrm{Ma}$ (Scher et al., 2015).

\subsubsection{Southwest Pacific Paleogene unconformities}

Unconformities in a sedimentary succession can be caused by erosion or non-deposition of sediments due to strong abyssal currents, by dissolution of carbonates (deepening of calcite compensation depth), by tectonic events or sediment starvation (e.g. Kennett et al., 1985). The presence of widespread unconformities in Southwest Pacific Paleogene deposits was first discussed at length by Edwards (1973). The oldest unconformities in this region occur between 58-39 Ma (Carter et al., 2004) and were recorded on Lord Howe Rise (Edwards, 1973), the Tasman Sea (Kennett et al., 1985), the Campbell Plateau (Hollis et al., 2015) and at sites north and south of New Zealand (Carter et al., 2004). During the early Oligocene, the Southwest Pacific experienced a widespread regional depositional hiatus (Kennett, 1977; Kennett and Von der Borch, 1985; Carter et al., 1999), which is referred to as the Marshall Unconformity (Carter and Landis, 1972; Carter, 1985). This hiatus, of variable duration, has been recorded in the Tasman Sea (Kennett, 1977; Exon et al., 2001; Exon et al., 2004), the Lord Howe Rise (Edwards, 1973; Kennett and Von der Borch, 1985; Kulhanek et al., 2013; Kulhanek and Morgans, 2013), eastern South Island New Zealand and adjacent continental margin (Carter and Landis, 1972; Fulthorpe et al., 1996) and at ODP Leg 181 sites (Carter et al., 1999; Carter et al., 2004). On the Lord Howe Rise (DSDP Leg 21, sites 206, 207, 208), the sediments underlying the unconformity are of middle Eocene age (Edwards, 1973; Kulhanek et al., 2013; Kulhanek and Morgans, 2013). Onshore sections from New Zealand reveal a narrower age for the unconformity of 32-29 Ma (Fulthorpe et al., 1996).

The development of erosive, abyssal currents in the Southwest Pacific is inferred to be the consequence of the opening of the Tasman Gateway (Kennett et al., 1975; Kennett and Von der Borch, 1985), which was later accompanied by the development of the ACC at 
$\sim 30 \mathrm{Ma}$ (Scher et al., 2015). A synthesis of the ODP Leg 181 results concluded that the sedimentary depositional system evolution offshore of eastern New Zealand was subject to widespread erosion as a consequence of an intensified Deep Western Boundary Current (DWBC) when New Zealand was positioned further south in the Paleogene (Carter et al. 2004).

The progressive separation and isolation of Antarctica and the establishment of the ACC is believed to have cooled Antarctica and decoupled any warm surface currents from the continent. This 'Tasmanian Gateway Hypothesis' implies that climate cooling at the Eocene-Oligocene transition was largely driven by tectonic processes (Kennett, 1977; Exon et al., 2004). This stands in contrast to other hypotheses that see changes in the global carbon cycle (atmospheric $\mathrm{CO}_{2}$ reduction) as the main driver for global cooling and built-up of Antarctic glaciation (DeConto and Pollard, 2003; Zachos and Kump, 2005; Pearson et al., 2009).

\subsection{Paleogene climate evolution}

\subsubsection{Geochemical proxies}

In order to understand and reconstruct Earth's climate history, a variety of proxies can be derived from marine and terrestrial sediment archives and cross-checked with paleontological data. Analysis of stable oxygen $\left(\delta^{18} \mathrm{O}\right)$ and carbon $\left(\delta^{13} \mathrm{C}\right)$ isotopes derived from planktic and benthic foraminifera calcite shells, originally developed by Emiliani (1955), is the most widely used proxy for temperature, ice volume and carbon cycle changes. A recent review of the history and use of paleotemperature proxies in marine calcite was done by Lea (2014). The $\delta^{18} \mathrm{O}$ values in the calcite shells of foraminifera are mainly influenced by water temperature and changes in $\delta^{18} \mathrm{O}$ of the surrounding seawater. The latter is influenced by salinity and ice volume changes. Deep-sea $\delta^{18} \mathrm{O}$ values can also be used as a record of high-latitude SST because bottom waters are derived primarily from cooling and sinking of polar water masses (Zachos et al., 2001). The first Cenozoic SST and sea floor temperature records were generated by Shackleton and Kennett (1975) from DSDP Leg 29 sites. This was followed by the first global compilation of records for the Cenozoic by Miller and Katz (1987). Since then, the deep-sea stable isotope record has been further updated and compiled into globally stacked records (Zachos et al., 2001; Miller et al., 2005; Zachos et al., 2008; Cramer et al., 2009). 
Another temperature-sensitive proxy is the $\mathrm{Mg} / \mathrm{Ca}$ ratio in planktic and benthic foraminiferal shells (Chave, 1954). During shell growth, $\mathrm{Mg}^{2+}$ substitutes for $\mathrm{Ca}^{2+}$, which is influenced by the temperature of the surrounding seawater. With increasing temperature, the $\mathrm{Mg} / \mathrm{Ca}$ ratio increases (Chave, 1954; Nürnberg, 1995; Nürnberg et al., 1996; Rosenthal et al., 1997; Elderfield and Ganssen, 2000; Lear et al., 2000; Lear et al., 2002; Rosenthal et al., 2006; Segev and Erez, 2006; Lear et al., 2010; summarized in Lea, 2014). This proxy was first calibrated on modern benthic species (Rosenthal et al., 1997), and later applied on Cenozoic benthic foraminiferal calcite (Lear et al., 2000; Segev and Erez, 2006; Cramer et al., 2011; Bohaty et al., 2012) to determine global ice-volume and deep-sea temperature during the Cenozoic (e.g. Lear et al., 2000; Lear et al., 2008; Lear et al., 2010). However, at depths below the calcite compensation depth, foraminiferal calcite is sensitive to dissolution and diagenetic overprinting, which will affect the $\mathrm{Mg} / \mathrm{Ca}$ ratio. Planktic foraminifera shells are particularly prone to dissolution throughout the water column and after deposition on the sea floor and the surface water signal of the calcite might be biased towards bottom waters (Schrag, 1999). Other difficulties arise from the species-specific uptake of $\mathrm{Mg}$ between planktic foraminifers, which requires speciesspecific temperature calibrations, and the possible influence of salinity and seawater $\mathrm{pH}$ (e.g., Lea et al., 1999). Nonetheless, this is not a universal phenomenon as well-preserved planktic foraminifer shells still yield reliable SST estimates (Pearson et al., 2001). However, biogenic carbonate is scarce at high-latitude settings close to the Antarctic continent, which hampers the use of the above described temperature proxies.

In order to circumvent the problems caused by the absence of carbonates and diagenetic alteration, lipid biomarker-based proxies for estimating past SSTs have been developed. The alkenone unsaturation index $\left(\mathrm{U}^{\mathrm{K}}{ }^{\prime}{ }_{37}\right)$ (Brassell et al., 1986) is derived from marine haptophyte algae (coccolithophores), which contain long-chain $\left(\mathrm{C}_{37}-\mathrm{C}_{39}\right)$ alkenones that show unsaturation changes with temperature. The tetraether index consisting of 86 carbon atoms $\left(\mathrm{TEX}_{86}\right)$ (Schouten et al., 2002) is derived from marine crenarchaeota which produce glycerol dialkyl glycerol tetraethers (GDGTs) in their membranes, whose distribution is dependent on temperature. To understand the relationship between the distribution of GDGTs and surrounding SST, calibration models are created, which are mathematical equations that show the best correlation between GDGTs and SSTs. Currently, there are three widely used equations. Kim et al. (2010) developed the TEX ${ }_{86}{ }^{\mathrm{H}}$ and $\mathrm{TEX}_{86}{ }^{\mathrm{L}}$ calibration. $\mathrm{TEX}_{86}{ }^{\mathrm{H}}$ is based on low- and mid-latitude core-top datasets and 
has a calibration error of $\pm 2.5^{\circ} \mathrm{C}$. It is recommended for SST records above $15^{\circ} \mathrm{C}$. $\mathrm{TEX}_{86} \mathrm{~L}$ is calibrated to a global dataset and has a calibration error of $\pm 4^{\circ} \mathrm{C}$. It is recommended for the application on SST records that extend above and below $15^{\circ} \mathrm{C}$ (Kim et al., 2010). The third equation (1/TEX 86 ) of Liu et al. (2009) (revised by Kim et al., 2010), uses the reciprocal approach of $\mathrm{TEX}_{86}{ }^{\mathrm{H}}$ and has a calibration error of $\pm 5.4^{\circ} \mathrm{C}$. Hollis et al. (2012) developed a paleo-calibration for $\mathrm{TEX}_{86}$ based on multiproxy Eocene records from the Southwest Pacific and showed that $\mathrm{TEX}_{86}{ }^{\mathrm{L}}$ yielded the best fit with the Eocene paleocalibrations.

Lipid biomarker-based proxies have been widely used on Paleogene sediments in the Southwest Pacific (Bijl et al., 2009; Hollis et al., 2009; Liu et al., 2009; Bijl et al., 2010; Hollis et al., 2012). Although organic biomarker proxies are independent from $\delta^{18} \mathrm{O}$ of the surrounding water masses, it has recently been suggested that reconstructed temperatures for the high-latitude Paleogene Southwest Pacific might be biased towards summer temperatures (Liu et al., 2009; Hollis et al., 2012).

\subsubsection{Climatic evolution throughout the Eocene}

During the Paleogene epoch (65-34 Ma), Earth's climate underwent major changes from a 'greenhouse climate' in the early Paleogene to an 'ice-house climate' towards the late Paleogene with the major shift in benthic $\delta^{18} \mathrm{O}$ values of $\sim+1.5 \%$ in the earliest Oligocene ( 33.9 Ma) (Shackleton and Kennett, 1975; Diester-Haass et al., 1996; Zachos et al., 2001) (Figure 2.6). Before the Eocene-Oligocene transition, Antarctica was free from large ice-sheets (Wise Jr et al., 1991; Zachos et al., 2001). However, a recent study indicated that small ice sheets might have existed in the late Paleocene based on geochemical analysis of an organic-rich marine mud stone which was deposited around New Zealand at $~ 59$ Ma (Hollis et al., 2014).

According to the temperature reconstructions based on DSDP Site 277 material (Shackleton and Kennett, 1975), the SST in the Southwest Pacific was about $19^{\circ} \mathrm{C}$ in the early Eocene, $13^{\circ} \mathrm{C}$ in the middle Eocene, $11^{\circ} \mathrm{C}$ in the late Eocene, and about $7^{\circ} \mathrm{C}$ in the Oligocene, respectively. The sea-floor temperatures were just $1{ }^{\circ} \mathrm{C}$ cooler than SSTs in the Paleocene and $2{ }^{\circ} \mathrm{C}$ colder in the Oligocene. TEX ${ }_{86}$ and $\mathrm{U}^{\mathrm{K}}{ }_{37}$ results on the same DSDP Site 277 record produced much higher SST estimates of $\sim 27^{\circ} \mathrm{C}$ directly prior to the Eocene-Oligocene transition (Liu et al., 2009). The authors argued that the cool SSTs 
derived from planktic $\delta^{18} \mathrm{O}$ were an artefact caused by seafloor diagenesis, and that the discrepancy between the cool sea-floor temperatures derived from benthic $\delta^{18} \mathrm{O}$ and near tropical SSTs derived from $\mathrm{TEX}_{86}$ and $\mathrm{U}^{\mathrm{K}^{\prime}}{ }_{37}$ are plausibly explained by seasonality biases. The benthic $\delta^{18} \mathrm{O}$ values may reflect enhanced deep-water formation during winter months, while organic biomarkers temperatures may have a warm-season bias as noted above.

During the early Paleogene, several extremely warm episodes, called hyperthermals, have been identified in sedimentary records based on their high negative $\delta^{13} \mathrm{C}$ signature. These excursions were interpreted as being the result of a rapid carbon release into the atmosphere which might have caused extremely high $\mathrm{pCO}_{2}$ exceeding $1000 \mathrm{ppmv}$ (Zachos et al., 2008) (Figure 2.6). The most extreme and best studied hyperthermal is the Paleocene-Eocene thermal maximum (PETM, 56 Ma ago), an event that lasted 170 000 years, when global temperatures increased by $5^{\circ} \mathrm{C}$ within just 10000 years (Zachos et al., 2008) and was associated with widespread carbonate dissolution in the deep sea (Zachos et al., 2005).

The early Eocene climatic optimum (EECO) was a longer-term extremely warm period (53-49 Ma ago, Figure 2.6), and according to proxy records $(\mathrm{Mg} / \mathrm{Ca}$ in planktic foraminifera, TEX $_{86}$ ), SSTs in the high-latitude Southwest Pacific reached $\sim 30^{\circ} \mathrm{C}$ (Bijl et al., 2009; Hollis et al., 2012). Palynological data from off the Wilkes Land margin suggest that the vegetation growing on Antarctica was similar to present-day forests from New Caledonia (Contreras et al., 2013). In the high Arctic, fossil remains from crocodiles and palm trees were found (Sluijs et al., 2009; Eberle and Greenwood, 2012). 


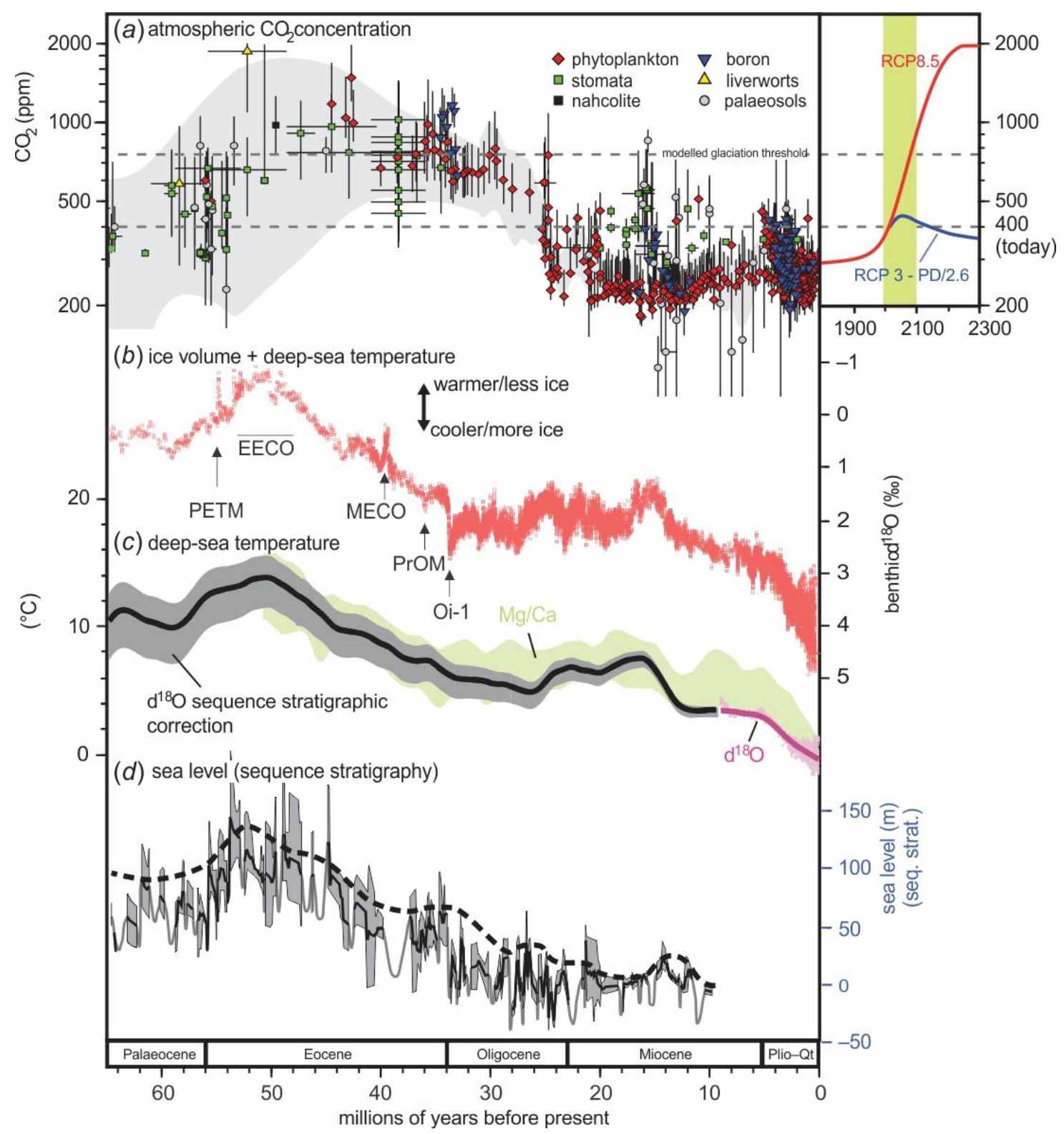

Figure 2.6 Compilation of a) left: atmospheric $\mathrm{CO}_{2}$ concentrations, right: representative concentration pathways (RCPs) for historic and future atmospheric $\mathrm{CO}_{2}$ emissions, b) composite deep ocean benthic $\delta^{18} \mathrm{O}$ record, c) long-term trend in deep-sea temperature from $\delta^{18} \mathrm{O}$ and $\mathrm{Mg} / \mathrm{Ca}$ estimates and d) reconstruction of sea-level lowstand and smoothed trend (black dashed line) throughout the Cenozoic; PETM: Paleocene-Eocene thermal maximum; EECO: early Eocene climatic optimum; MECO: middle Eocene climatic optimum; PrOM: Priabonian oxygen isotope maximum; modified after McKay et al. (2016).

The long-term cooling since the middle Eocene started at the termination of the EECO, and was interrupted by the middle Eocene climatic optimum (MECO) (Figure 2.7), a short warm period of $\sim 500000$ years peaking $\sim 40$ Ma that has been linked to an increase in atmospheric $\mathrm{pCO}_{2}$ (Bohaty and Zachos, 2003; Bohaty et al., 2009; Bijl et al., 2010). The MECO was characterized by a $\sim 4-6^{\circ} \mathrm{C}$ warming of surface and bottom water temperatures, and carbonate accumulation during this time was reduced worldwide due to a shoaling of the calcite compensation depth to about 3000 m (Bohaty et al., 2009). 
Organic biomarker-based climate proxies (Liu et al., 2009; Bijl et al., 2010) suggest the Southwest Pacific SSTs were tropical during the MECO $\left(28^{\circ} \mathrm{C}\right)$ and continued to be warm throughout the late Eocene $\left(24-27^{\circ} \mathrm{C}\right)$, cooling only slightly across the EoceneOligocene transition $\left(\sim 22^{\circ} \mathrm{C}\right)$.

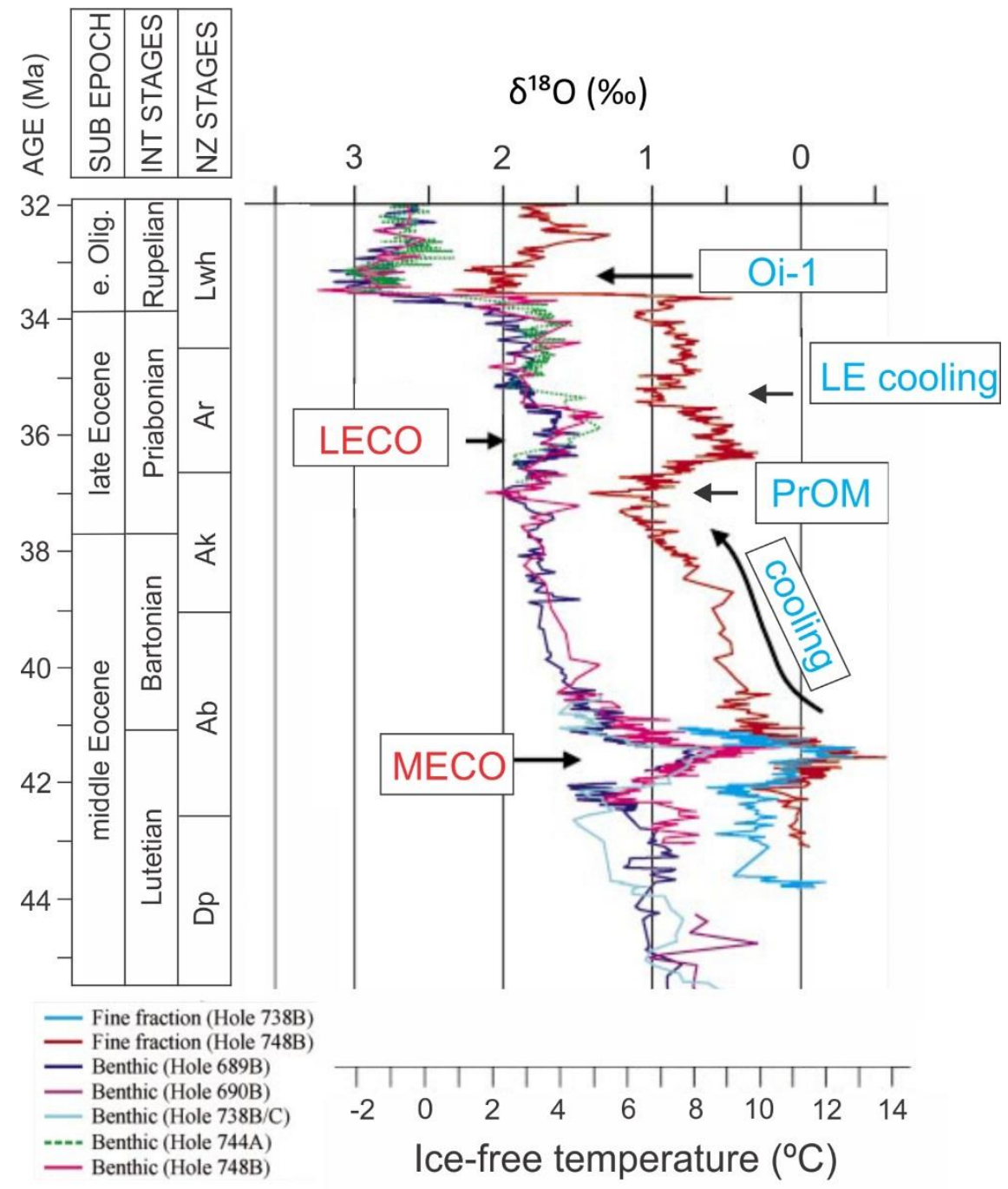

Figure 2.7 Compilation of Southern Ocean stable oxygen isotope data and reconstructed ice-free temperature between 45 and $32 \mathrm{Ma}$ from various Ocean Drilling Program sites, showing warming (red) and cooling (blue) events in the middle and late Eocene. MECO=middle Eocene climatic optimum, LECO=late Eocene climatic optimum, PrOM=Priabonian oxygen isotope maximum, LE cooling=late Eocene cooling event after Vonhoff et al. (2000); for abbreviations of New Zealand stages see Figure 3.13; modified after Bohaty and Zachos (2003).

Following the MECO event, benthic $\delta^{18} \mathrm{O}$ values increased to their maximum Eocene values of $\sim 2.3 \%$ at $\sim 37.3$ Ma during a short-lived cooling episode in the early late Eocene, designated as the Priabonian oxygen isotope maximum (PrOM) event (Scher et al., 2014) (Figure 2.7). This event was first discovered at Ocean Drilling Program (ODP) Site 738 at the Kerguelen Plateau, Southern Indian Ocean and was correlated to ODP Site 
689 (Maud Rise, South Atlantic). A change in the bottom water composition, derived from $\varepsilon N d$ signals from fossil fish teeth, and an abrupt change in terrigenous influx to Site 738 suggest a combination of cooling and ice growth in East Antarctica as the causal mechanisms for this oxygen isotope maximum (Scher et al., 2014).

Further climate oscillations are found in the late Eocene prior to the expansion of Antarctic ice that defines the Eocene-Oligocene transition (Figure 2.7). A short-lived warming event at $\sim 36 \mathrm{Ma}$ with associated changes in nannofossil assemblages has been reported in several Southern Ocean sites (Diester-Haass and Zahn, 1996; Bohaty and Zachos, 2003; Villa et al., 2008; Villa et al., 2014). However, the cause of this event is not known. In this thesis, this event is referred to as late Eocene climatic optimum (LECO) (Figure 2.7). A short cooling episode is reported by Vonhof et al. (2000) at 235 Ma, following two closely spaced extra-terrestrial impact events (Figure 2.7). Impactrelated cooling is thought to have been too short-lived to explain the estimated $\sim 100 \mathrm{ka}$ cooling, suggesting that a feedback mechanism sustained the cooling (Vonhof et al., 2000).

The Eocene-Oligocene climatic transition is characterized by at least two distinct increases in $\delta^{18} \mathrm{O}$ values in the late Eocene (Zachos et al., 1996; Coxall et al., 2005), labelled as EOT-1 and EOT-2 (Miller et al., 2008). The peak $\delta^{18} \mathrm{O}$ value in deep-sea foraminifera which occurred in the early Oligocene, also referred to as oxygen isotope event 1 (Oi-1) (Figure 2.7), is interpreted as representing an expansion of Antarctica`s ice sheets equivalent to $\sim 80 \mathrm{~m}$ of sea level, combined with a $4^{\circ} \mathrm{C}$ cooling of the deep ocean (Shackleton and Kennett, 1975; Zachos et al., 1992; Zachos et al., 2001; Coxall et al., 2005; DeConto et al., 2008; Liu et al., 2009; Wilson et al., 2013).

\subsubsection{What caused the global cooling during the Paleogene?}

While it is generally assumed that during the Paleocene and Eocene the poles were icefree (Zachos et al., 2001), more recent studies question that the pre-Oligocene truly was ice-free (Miller et al., 2005; Cramer et al., 2009; Cramer et al., 2011; Scher et al., 2014). Central to this debate is whether a fully functioning Antarctic Circumpolar Current (e.g. Kennett, 1977) is required before significant ice-sheets will form or if the glaciation is linked to some other processes that caused a drawdown of atmospheric $\mathrm{CO}_{2}$ (DeConto and Pollard, 2003). 
The proponents of the 'Tasmanian Gateway Hypothesis' argue that the global cooling during the Eocene-Oligocene transition was caused by the separation of Australia from Antarctica, culminating with the opening of the gateway at 33.9 Ma (Kennett, 1977; Exon et al., 2004). Huber et al. (2004) and Stickley et al. (2004a) argued against the 'Tasmanian Gateway hypothesis'. By examining the middle to late Eocene paleobiogeography of dinoflagellate cysts and diatom assemblages in the Southwest Pacific at ODP Leg 189, they found that assemblages in the Australo-Antarctic Gulf consist of warm, non-endemic species (cosmopolitan or Tethyan). However, on the Pacific side of the Tasmanian land bridge and along the Antarctic margin these assemblages consisted almost entirely of endemic species (Figure 2.5). General circulation models suggested that the proto- East Australian Current did not reach further south than $45^{\circ}$ and was therefore unable to sustain high-latitude warmth, due to the presence of a cold Tasman Current (Figure 2.5). They concluded that Antarctic glaciation must have been primarily caused by other factors than changes in ocean heat transport, and identified the long-term atmospheric $\mathrm{CO}_{2}$ decline as the main cause, perhaps driven by tectonically induced changes in the carbon cycle, as also suggested by DeConto and Pollard (2003). However, if the atmospheric $\mathrm{CO}_{2}$ drop was indeed the main reason behind the cooling that started in the middle Eocene, Bijl et al. (2013) argued that such a cooling should have been globally uniform, while in fact it appears to be absent in (sub) equatorial regions. By using organic biomarker and palynological data from the Wilkes' Land margin (IODP Exp. 318) and ODP Leg 189, Bijl et al. (2013) found that the cooling of Southern Ocean surface water and global deep ocean coincided with an early opening ( 49-50 Ma) of the Tasman Gateway, and that changes in oceanic heat transport related to opening of Southern Ocean gateways may indeed have played a primary role in Cenozoic cooling since the mid-Eocene.

Although temperature proxies indicated subtropical conditions during the early and middle Eocene at the East Tasman Plateau (Bijl et al., 2011, 2013), the authors suggested that surface water ocean fertility (and not temperature itself) at the onset of the postEECO cooling was the primary driver behind the rapid reorganization of high-latitude dinoflagellate assemblages. This scenario seemed to solve the problem of high-latitude warmth coexisting with endemic-transantarctic assemblages, with oceanographic changes induced by an early opening of the Tasman Gateway. 
However, in contrast, Houben et al. (2013) found a distinct shift in dinocyst assemblages around $\sim 33.6 \mathrm{Ma}$ in marine sediment cores off Wilkes Land, East Antarctica, and interpreted it as a direct effect of the Antarctic glaciation at the Eocene-Oligocene boundary. However, one of their sites has a large hiatus of 12 Ma separating the middle Eocene from the lower Oligocene, which hampers the determination of the exact timing of the faunal change.

\subsubsection{Proxy-model comparison}

Temperature reconstructions based on geochemical proxies and fossils indicate warm conditions at high-latitude sites in the Eocene (Kennett, 1977; Nelson and Cooke, 2001; Kennett and Exon, 2004; Houben et al., 2013), suggesting that subtropical waters warmed the Antarctic continent. According to Bijl et al. (2009) almost no SST gradient existed in the early Eocene between low and high latitudes based on lipid biomarker-derived temperature estimates. Pancost et al. (2013) provided evidence for a low temperature gradient in mean annual air temperature between New Zealand and Antarctica (Pross et al., 2012) during the EECO and early middle Eocene, and a weak $\sim 5^{\circ} \mathrm{C}$ gradient developing from the middle Eocene. Temperatures were reconstructed from leaf fossil and sporomorph assemblages as well as the MBT'-CBT proxy, based on the distribution of branched GDGTs derived from soil bacteria, using sediments from marine sections from Southern New Zealand (Pancost et al., 2013). Based on modelled SST results for a high $\mathrm{CO}_{2}$ world of $4480 \mathrm{ppm}$, the temperature gradient between tropics and $\sim 60^{\circ} \mathrm{S}$ was $>20^{\circ} \mathrm{C}$ (Figure 2.8) which is in contrast to the temperatures derived from geochemical proxies mentioned earlier. Attempts to reconcile these proxy data with ocean circulation models have proven to be difficult. Even under hypergreenhouse conditions (>2240ppm $\mathrm{CO}_{2}$ ), the models could not produce mean annual SSTs greater than $20^{\circ} \mathrm{C}$ for the $\mathrm{NZ}$ region, or mean summer SSTs $>25^{\circ} \mathrm{C}$ (Hollis et al., 2012). Model runs indicated the presence of a cyclonic gyre southeast of New Zealand which blocked subtropical water from penetrating southward beyond $45^{\circ} \mathrm{S}$ (Huber and Sloan, 2001; Huber et al., 2004), contrary to earlier conceptual models explaining high latitude Eocene warmth by the Tasmanian Gateway Hypothesis (Kennett, 1977; 1978; 1980).

More recent modelling experiments were able to reproduce SSTs and sea-floor temperatures consistent with the geochemical temperature proxies, but only if the following three assumptions were satisfied: proxies were considered biased towards 
seasonal maxima; the effect of a proto-East Australian Current was taken into account; and $\mathrm{pCO}_{2}$ was prescribed as extraordinarily high (4480 ppm) (Hollis et al., 2012) (Figure 2.9). Based on those inferences, Hollis et al. (2012) inferred a warm subtropical climate for the SW Pacific in the early Eocene. The proto-East Australian Current also might have had a longer-lived influence on the East Tasman Plateau than further east, explaining the absence of the pronounced SST temperature drop seen at New Zealand sites in the early middle Eocene (Hollis et al., 2012).

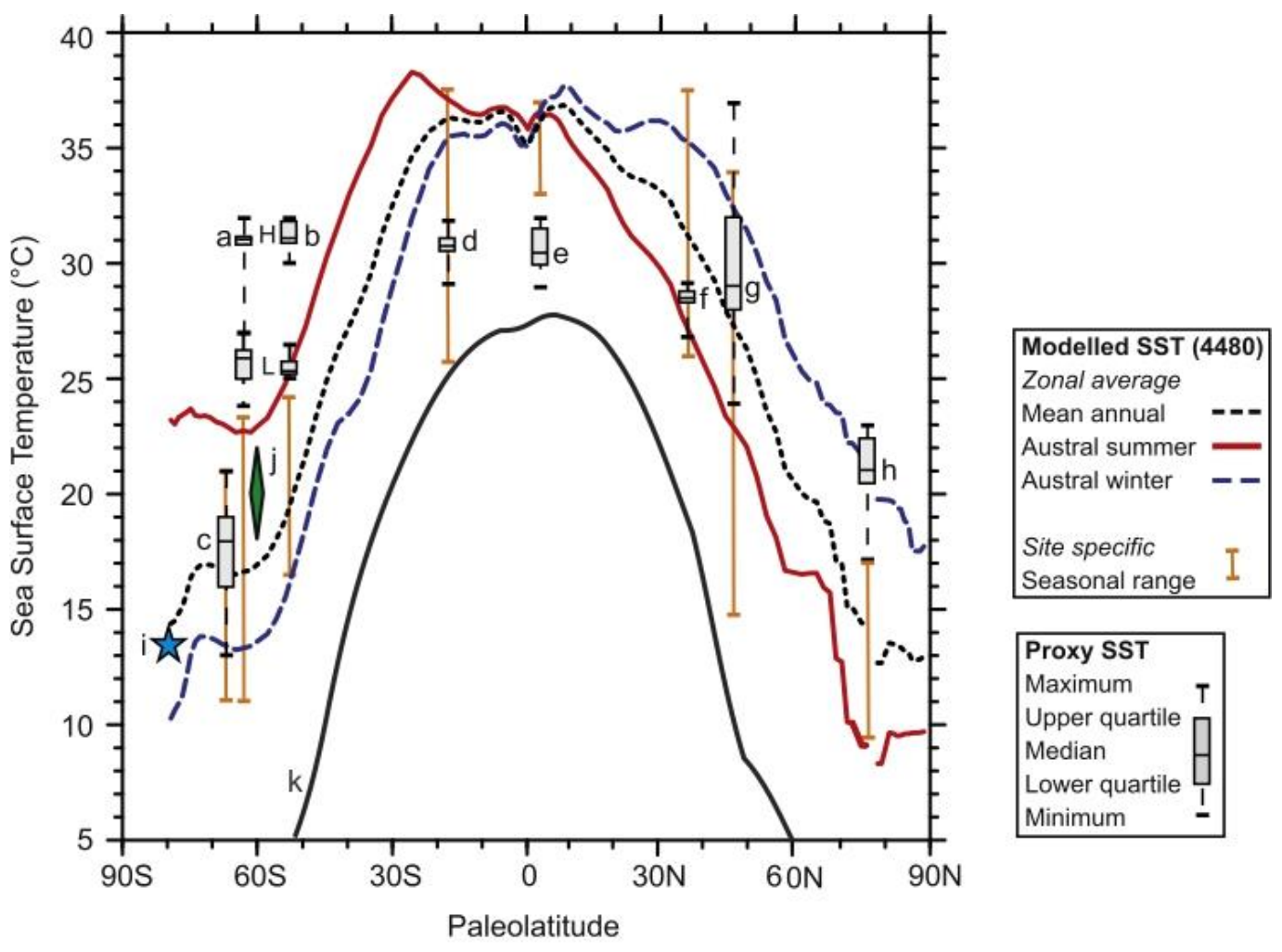
a) ODP Site 1172 (Bijl et al., 2009)
b) mid-Waipara River (Hollis et al., 2009)
c) Seymour Island (Ivany et al., 2008)
d) Tanzania (Pearson et al., 2007)
e) ODP Site 865 (Tripati et al., 2003; Kozdon et al., 2011)
f) eastern ISA (Keating-Bitoni et al., 2011)
g) Belgian Basin (Vanhove et al., 2011)
h) IODP Site 302-4A, Arctic Basin (Sluijs et al., 2006, 2009)
i) median bottom water temperature for the EECO (Cramer et al., 2009)
j) mean annual air temperature for southeast Australia (Greenwood et al., 2003, 2004)
k) present-day zonally averaged latitudinal temperature gradient (Shea et al., 1992)

Figure 2.8 Comparison of sea surface temperature (SST) reconstructions derived from proxy records and the results of an Eocene climate model (4480 ppmv $\mathrm{CO}_{2}$ concentration), modified from Hollis et al. (2012). 

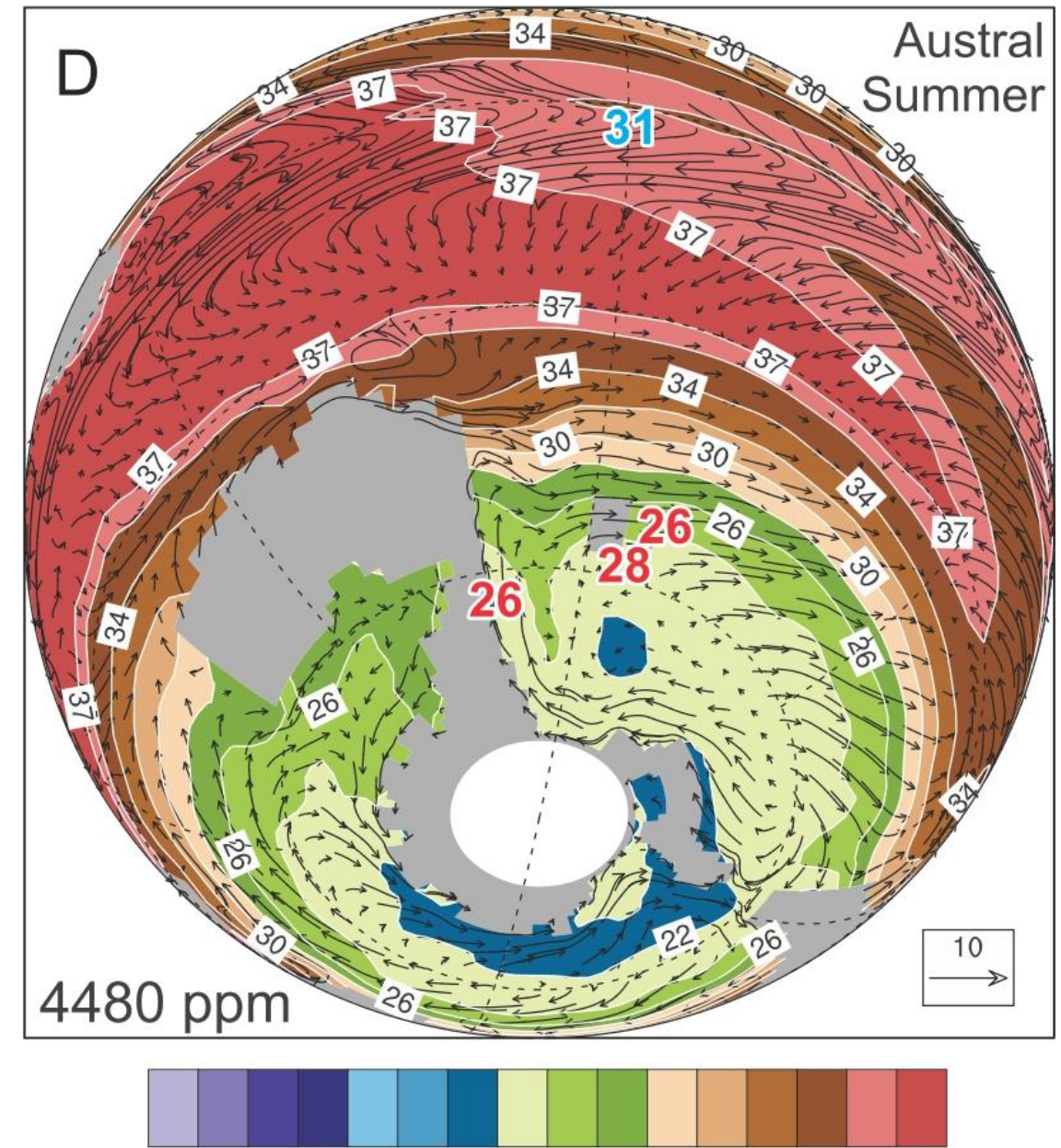

101214161820222426283032343638

Figure 2.9 from Hollis et al. (2012); comparison of SSTs derived from proxies for the EECO with modelled SSTs and ocean currents for Austral summer conditions under a high greenhouse gas scenario ( $4480 \mathrm{ppm} \mathrm{CO}_{2}$-equivalent). A large clockwise subpolar gyre (Ross Gyre) in the Southwest Pacific blocks the East Australian Current reaching southward beyond $\sim 45^{\circ} \mathrm{S}$.

\subsection{A short introduction to radiolarians}

\subsubsection{Taxonomy}

The term 'Radiolaria' was first introduced by Müller (1858) and since the first description of a radiolarian species by Meyen (1834) about 2500 genera/subgenera and 15000 species (living and fossil) have been described (Suzuki and Aita, 2011). Radiolarians have existed since the Cambrian (Won and Below, 1999). The oldest and most comprehensive classification by Haeckel $(1881,1887)$, is based on geometry and is rather artificial. Since then, two types of classifications have been developed: paleontological classifications based on for example the evolution of fossil lineages (Riedel, 1967a; Riedel and Sanfilippo, 1977), or inner skeletal structures (De Wever et al., 2001) and biological classifications based on the cytology (e.g., Suzuki and Aita, 2011). However, 
radiolarian taxonomy for the Cenozoic is not uniform and taxonomic names have been applied inconsistently (summarized in Lazarus et al., 2015). In the taxonomic classification as presented by Suzuki and Aita (2011), Radiolaria are grouped, together with the Cercozoa and Foraminifera, in the supergroup Rhizaria. Recent molecular analyses revealed five orders that belong to the Radiolaria (Figure 2.10): Acantharia, Spumellaria, Nassellaria, Collodaria (living in colonies) and Taxopodia. Phaeodaria are now considered to belong to the Cercozoa (Suzuki and Aita, 2011).

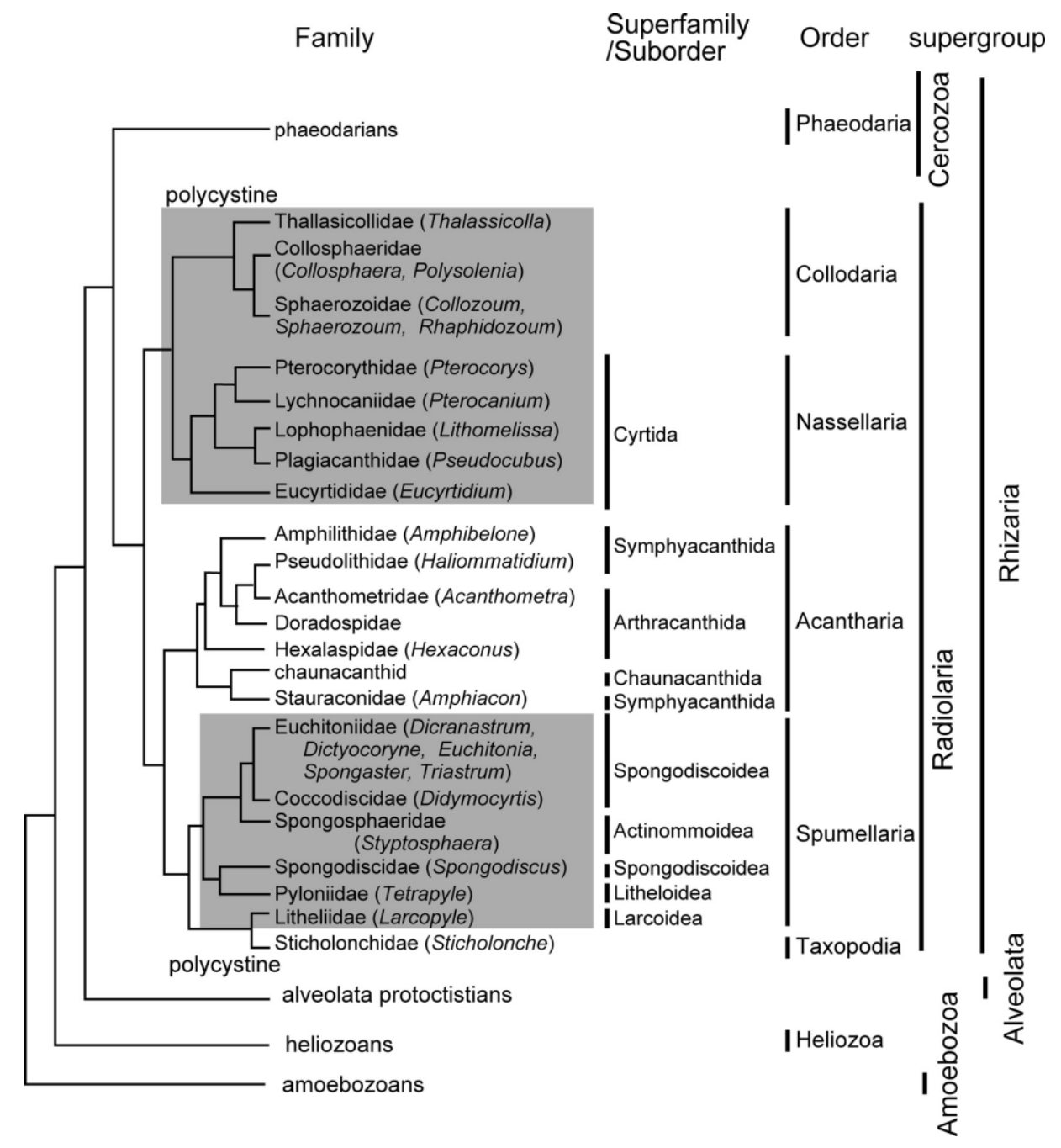

Figure 2.10 Molecular phylogenetic relationships of the Radiolaria, from Suzuki and Aita (2011).

\subsubsection{Biology, ecology and distribution}

Radiolarians are single-celled protozoa that exist since at least the middle Cambrian (Won and Below, 1999) and are found in all oceans throughout the world today (Sanfilippo et al., 1985). They are heterotrophic zooplankton, e.g. contrary to phytoplankton, that gains energy by photosynthesis, they have to feed themselves by other organic material or small 
algae like dinoflagellates. Some of them, mainly Collodaria, bear symbionts that help them with their energy requirements (e.g., Anderson, 1976). Radiolarians are usually between $0.04-0.4 \mathrm{~mm}$ in diameter and build a complex skeleton. Spumellarian, nassellarian and collodarian skeletons are composed of amorphous silica and after their decay their skeletal remains cover the ocean floor as siliceous ooze. These three orders are also referred to as polycystine radiolarians. Acantharia build their skeleton out of strontium sulphate which is not preserved in the fossil record. In the course of this thesis, Radiolaria or radiolarians refer to Spumellaria and Nassellaria only. Spumellarians consist in general of a concentric siliceous skeletal structure whereas nassellarians bear a conical test with segmentations referred to as 'cephalis', 'thorax', 'abdomen' and 'postabdominal' segments (e.g. De Wever et al., 2001).

Radiolarian diversity is highest in the tropics and most of the species live close to the thermocline in the upper few hundred meters of the ocean (Takahashi and Ling, 1980; Sanfilippo et al., 1985). However, deep-dwelling forms do exist at depths down to 4000 $\mathrm{m}$ (Suzuki and Aita, 2011). However, radiolarians are very sensitive to dissolution throughout the water column and on the ocean floor, because sea water is undersaturated with respect to silica at all depths, and particularly so in surface waters. Therefore, robust radiolarian tests are more common in assemblages that are accumulated on the sea floor (Takahashi and Honjo, 1981). In low-productivity environments, radiolarians are only preserved in the upper few centimetres of the ocean floor and are dissolved before they are buried due to the long exposure time to bottom water at the sediment-water interface (Sanfilippo et al., 1985). In modern ocean floor sediments, radiolarian ooze makes up the major part of the equatorial siliceous ooze, which reflects the high primary productivity in the water column. High-latitude silica belts also contain radiolarian skeletons, but these oozes are usually dominated by diatom remains (Figure 2.11). In summary, the ideal environment to find well preserved radiolarians in sediments is in highly productive localities and regions where other pelagic sediments like clay, volcanic ash or turbidites are contributed from ocean islands or continental rises (Sanfilippo et al. 1985). This results in the fast burial of radiolarians before they are subject to dissolution in the water column or on the sea floor. In settings below the carbonate compensation depth, the carbonate component is more easily dissolved, resulting in an indirect enrichment of radiolarians compared to other biogenic components in the sediment. 


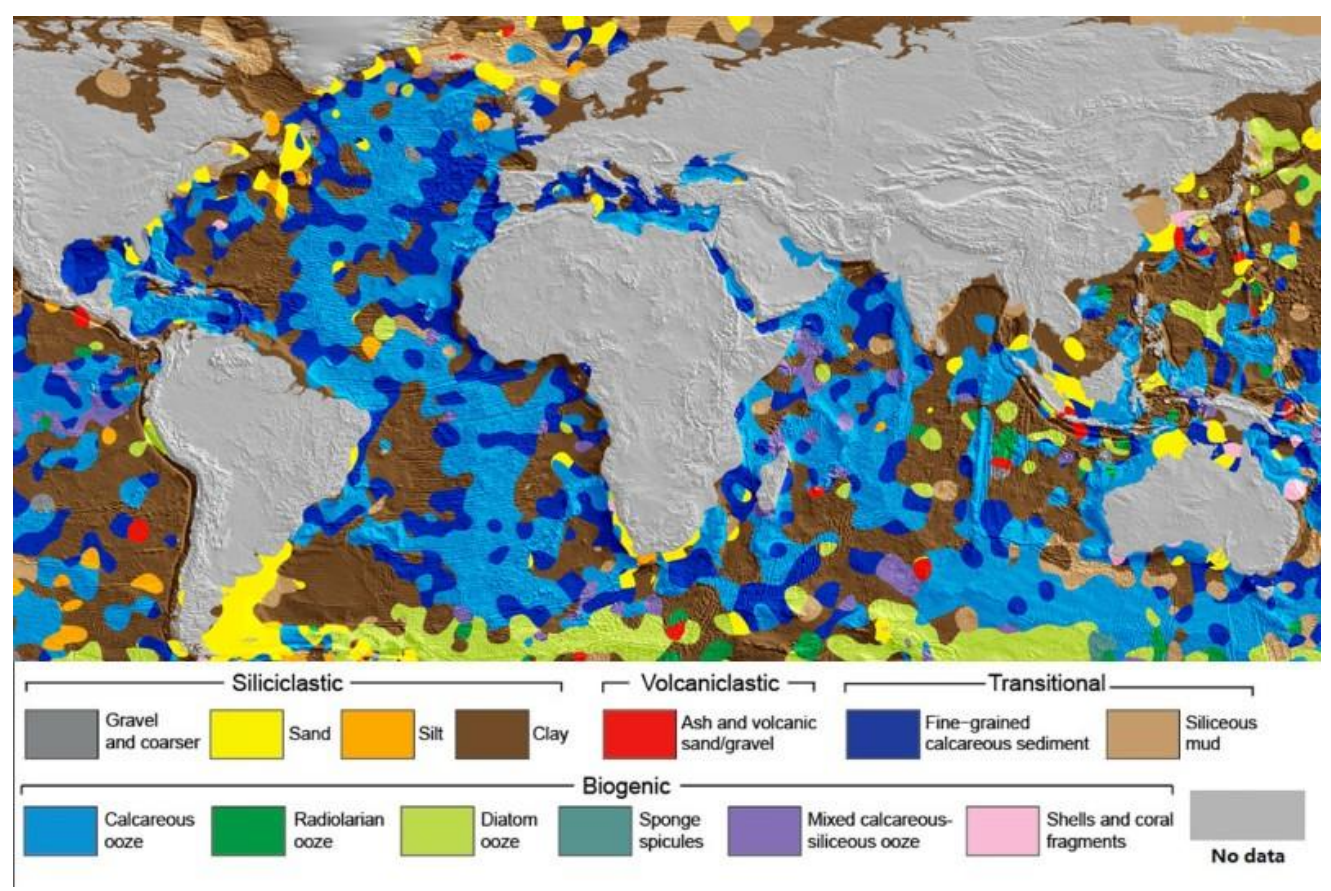

Figure 2.11 Digital map of ocean floor sediments from Dutkiewicz et al. (2015).

Although the radiolarian community is relatively small compared to the large community of researchers studying planktonic foraminifera or coccolithophores, radiolarians are extensively and successfully used in biostratigraphy, paleoceanography and paleobiology. However, there are problems that still need to be solved in radiolarian classification and taxonomy.

Environmental reconstructions based on radiolarian assemblages provide an advantage over other microfossil groups due to their greater overall diversity and widespread distribution, which extends to high latitudes. Because radiolarians have a planktonic life cycle, their distribution and abundance are mainly controlled by environmental conditions like nutrients and SST, and their abundances are usually well correlated to these environmental parameters. Some radiolarian species show a preference for a highlatitude, low-latitude or a cosmopolitan distribution (e.g. Lazarus and Caulet, 1993). Studies of modern radiolarian assemblages in the Southwest Pacific show that certain species and groups are strongly correlated to specific water masses (Hollis and Neil, 2005; Cortese and Prebble 2015). The radiolarian fauna is an important part of the Southern Ocean plankton community and its assemblage changes can be used for paleoenvironmental reconstructions in the modern ocean, as well as throughout the Cenozoic (Lazarus and Caulet, 1993; Funakawa and Nishi, 2005). 


\subsection{Paleogene radiolarian studies}

\subsubsection{Radiolarian biostratigraphy - from low to high latitudes}

The original low-latitude radiolarian zonation was developed by Riedel and Sanfilippo (1970, 1971; 1978) and Nigrini (1971). It was extended to the mid-latitudes of the North Atlantic by Nishimura $(1987,1992)$ and to the Southwest Pacific Paleocene by Hollis (1993). A key publication by Sanfilippo et al. (1985) summarized Cenozoic radiolarian studies targeting biostratigraphy and the biogeography of radiolarians for low and midlatitude sites. Later, the zonation was code numbered by Sanfilippo and Nigrini (1998a) as zones RP1-22 for the Paleogene, with six zones in the Paleocene (RP1-6), thirteen zones in the Eocene (RP7-19) and three zones in the Oligocene (RP20-22). The zonation was first applied to low-latitude Pacific material (Kamikuri et al., 2005; Funakawa et al., 2006a; Nigrini et al., 2006) and the latest update of the zonation was accomplished by Kamikuri et al. (2012a).

Due to absence of low and middle latitude marker species in high latitudes, the lowlatitude zonation cannot be applied at high-latitude sites. High-latitude radiolarian assemblages of the middle Eocene of DSDP Leg 28 (Naturaliste Plateau, South of Australia) were described by Chen (1975) as "similar to but less diverse than the late middle to late Eocene low-latitude assemblages". Takemura (1992) established a southern high-latitude zonation for the late Eocene to early Oligocene, which was later revised by Takemura and Ling (1997) and Funakawa and Nishi (2005).

The first Cenozoic radiolarian studies in the Southwest Pacific were undertaken during the course of the Deep Sea Drilling Program Leg 29 and resulted in the development of the Antarctic Cenozoic radiolarian compilation by Petrushevskaya (1975). During DSDP Leg 90, Site 592 was drilled on the Lord Howe Rise and contained radiolarians dating back to the late Eocene (Caulet, 1986). He described the fauna as "similar to tropical faunas but lacking some typical morphotypes, like the Lithocyclia group" and "somewhat different from the tropical forms". Caulet (1986) and Petrushevskaya (1975) found more similarities to the Eocene assemblages of California (Clark and Campbell, 1942) than to those from the Caribbean. However, no stratigraphic radiolarian zonation for highlatitudes was established at the time. 
Paleogene radiolarian assemblages in the Southwest Pacific differ from low-latitude or Northern hemisphere assemblages, as many key index species are absent, rare or have diachronous ranges in the New Zealand region (Hollis, 2002). Therefore, a South Pacific radiolarian zonation was established from Mead Stream and other sections from the Marlborough region, South Island, New Zealand (Hollis, 1993; Strong et al., 1995; Hollis, 1997; Hollis et al. 2005). This zonation scheme is integrated in this thesis with the Southern Ocean zonation of the late Eocene to early Oligocene (Takemura, 1992; Takemura and Ling, 1997; Funakawa and Nishi, 2005). The Southern Hemisphere radiolarian zonation now consists of RP1-18, with seven zones in the Paleocene (RP1-7), seven zones in the Eocene (RP8-14) and four zones in the Oligocene (RP15-18). Further key biostratigraphic and taxonomic studies in the Southwest Pacific were undertaken for the Cretaceous to Eocene (Hollis 1993, 1997, 2002) and Eocene to Oligocene and younger (O'Connor, 1994, 1997, 1999a, 1999b, 2000) on New Zealand outcrops.

The age calibration of the biostratigraphic zonation of the Southwest Pacific is based on the New Zealand Geological Timescale, which is based on foraminiferal events and was recently updated by Raine et al. (2015). The updated Paleogene timescale was calibrated to the Geomagnetic Polarity Timescale after Gradstein et al. (2012) and the Global Chronological Scale (Cohen et al., 2014). The first New Zealand divisions were defined by Finlay and Marwick (1947) for upper Cretaceous to Tertiary strata and have been revised and recalibrated several times since (e.g. Cooper 2004, Hollis et al., 2010, Raine et al. 2015).

\subsubsection{Paleoenvironmental studies of Paleogene radiolarians}

The first summary of the biogeographic development of planktic biota in the circumpolar Southern Ocean throughout the Cenozoic was provided by Kennett (1978). He inferred that the development of distinct polar plankton assemblages was related to the evolution of the ACC and the Antarctic Polar Front. Subsequent deep-sea drilling campaigns have provided additional data on regional changes in Southern Ocean plankton. These were integrated by Lazarus and Caulet (1993) into a set of circumpolar maps across specific time intervals. Moreover, these authors also carried out the first synthesis of radiolarian biogeography for the region and found a pattern of increasing endemism in the Southern Ocean across the Eocene-Oligocene transition. A more detailed study of radiolarian biogeographic patterns and trends in the Southwest Pacific (Lazarus et al., 2008) found 
increased endemism in the radiolarian fauna in the late Eocene $(\sim 35 \mathrm{Ma})$. Further radiolarian studies from the Atlantic sector of the Southern Ocean were performed by Funakawa and Nishi (2008), who recorded the first expansion of an Antarctic assemblage significantly earlier (38.5 Ma). They identified several faunal turnover events in the Antarctic assemblage from the late middle Eocene to late Oligocene and linked these events to migrations of the Antarctic Polar Front.

Radiolarian research from the Paleogene in the Southwest Pacific is relatively scarce (Petrushevskaya, 1975; Hollis et al., 1997; O'Connor, 1999; Hollis, 2002; Hollis et al., 2005; Hollis, 2007; Suzuki et al., 2009), but this region is particularly interesting for this time interval, as it underwent major changes during the transition from a global greenhouse to icehouse climate.

A section of an upper Paleocene-lower Eocene bathyal succession at Mead Stream, Marlborough, was dominated by assemblages found in cool, eutrophic water masses during the Paleocene, but during the PETM and EECO the siliceous biogenic sediment production and radiolarian diversity decreased significantly. Along with an abrupt appearance of low-latitude radiolarians characteristic of oligotrophic, stratified, warm water masses (e.g. Amphicraspedum prolixum s.s., Lychnocanium auxillum, Podocyrtis papalis, Phormocyrtis turgida, Theocorys? phyzella), the abundance of large, robust spumellarians increased relative to small actinommids during the PETM and EECO (Hollis et al., 2005; Hollis, 2006). With the onset of cooling in the middle Eocene, siliceous microfossils increased in abundance and species diversity in the Southern Ocean (Lazarus et al., 2008) following the biogeographic classification of taxa given by Lazarus and Caulet (1993). 


\section{Material and methods}

\subsection{Study sites and samples}

Sediment samples were obtained from archived ocean sediment cores from the mid- to high-latitude Southwest Pacific (Figure 3.1). The first part of the thesis investigates radiolarian assemblages in samples from five high-latitude Southwest Pacific sites. The studied sites form a transect from the southern Campbell Plateau (DSDP Site 277), across the Tasman Sea (ODP Site 1172, DSDP Site 283) and south of Tasmania on the Tasman Rise (DSDP sites 281 and 280). The second part of the thesis investigates radiolarian assemblages at four mid-latitude sites northwest (DSDP sites 207, 592 and 206) and east of New Zealand (ODP Site 1123).

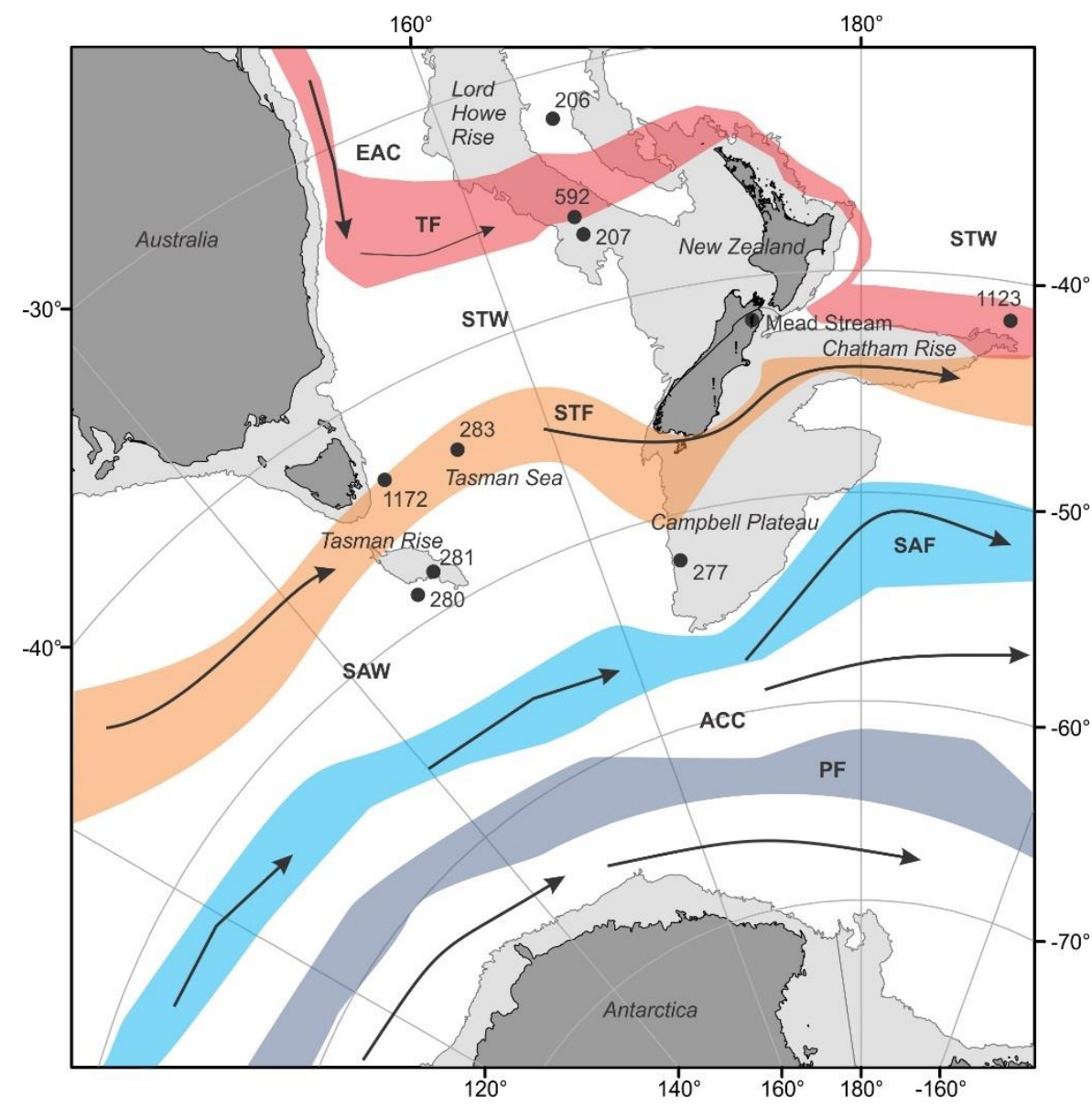

Figure 3.1 Modern day map with location of studied DSDP and ODP sites as mentioned in the text. Dark grey=land masses, light grey $=2000 \mathrm{~m}$ continental boundary. Acronyms from north to south: EAC=East Australian Current, TF=Tropical Front, STW=Subtropical Water, STF=Subtropical Front, SAW=Subantarctic Water, SAF=Subantarctic Front, $\mathrm{ACC}=$ Antarctic Circumpolar Current, $\mathrm{PF}=$ Polar Front. Circulation simplified after Chiswell et al. (2015). 
During the Eocene, the high-latitude sites were located between $\sim 55$ and $\sim 63^{\circ} \mathrm{S}$, the midlatitude sites between $\sim 40$ and $50^{\circ} \mathrm{S}$. A reconstruction of the Southwest Pacific at $\sim 40 \mathrm{Ma}$ shows the location of the studied sites at that time (Figure 3.2).

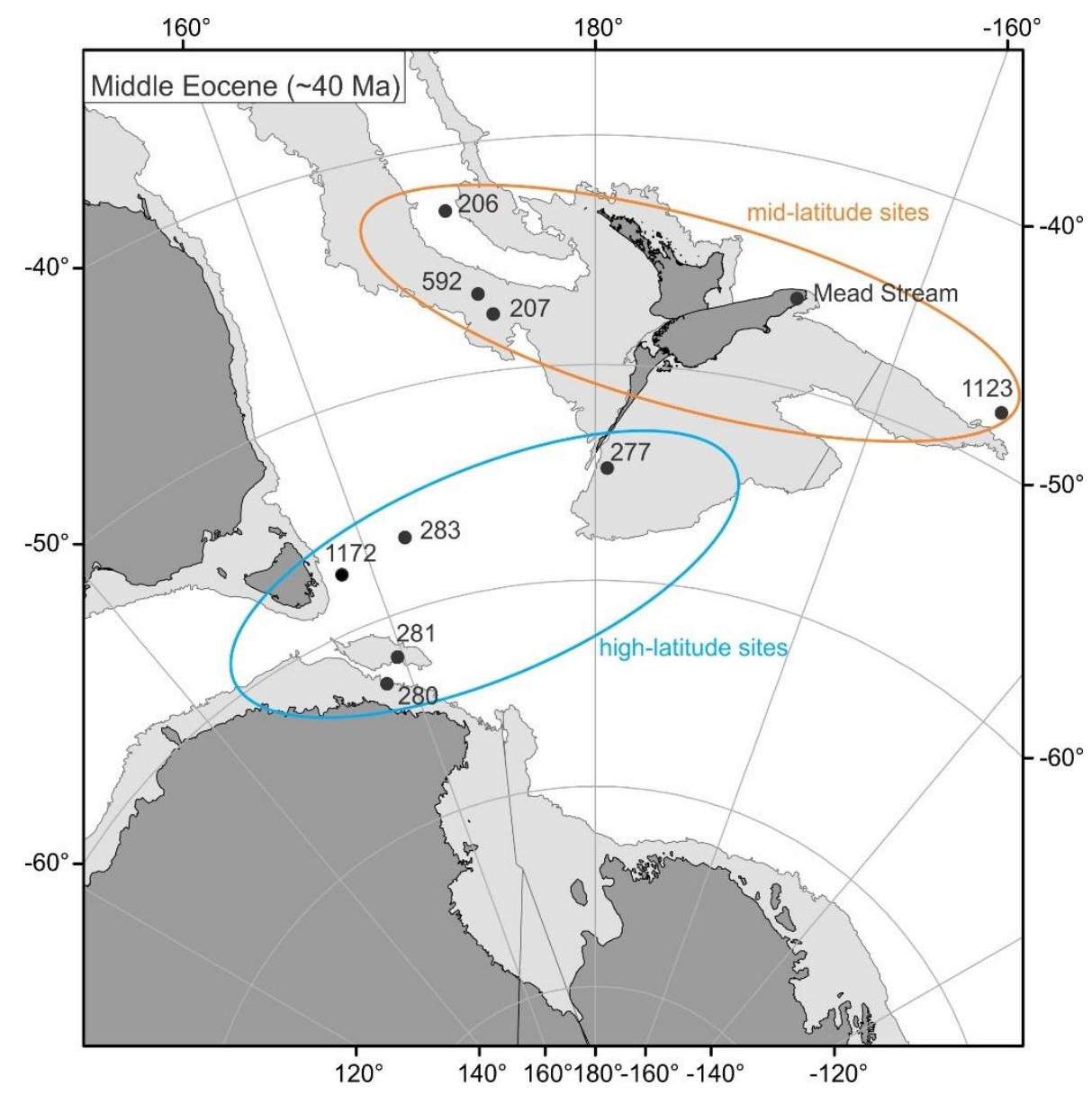

Figure 3.2 Reconstruction of the Southwest Pacific and the location of the studied sites at $40 \mathrm{Ma}$.

This study is based on the microscopic analysis of radiolarian assemblages from 9 sites and comprises 227 samples. I have counted radiolarian assemblages from 186 samples (DSDP sites 277, 280, 281, 206, 207, 592 and ODP site 1123), of which 125 new samples were processed and radiolarian strewn slides were prepared, and slides of 61 samples from existing collections at GNS Science were examined. Assemblage data from 41 samples from ODP Site 1172 were provided by Noritoshi Suzuki (Tohoku University, Japan). A summary of the samples investigated at each site is given in Table 3.1 and Figure 3.3. Radiolarian strewn slides for DSDP sites 277, 280 and 281 were prepared by me. The other new samples and radiolarian slides were prepared by laboratory technician Sonja Peñiafiel-Bermudez. 
Table 3.1 Overview of samples at each site, which are arranged according to their paleolatitude at 40 Ma (Figure 3.2). New samples were prepared in this study; existing samples from ${ }^{1}$ Hollis et al. (1997), 2 DSDP/ODP Micropaleontological Reference Centre, ${ }^{3}$ slides provided by Y. Aita $;{ }^{4}$ assemblage data from N. Suzuki.

\begin{tabular}{|l|cc|cc|c|cccc|}
\hline & \multicolumn{4}{|c|}{ High-latitude sites } & \multicolumn{3}{c|}{ Mid-latitude sites } \\
\hline Locality & \multicolumn{2}{|c|}{ Tasman Rise } & \multicolumn{2}{|c|}{ Tasman Sea } & $\begin{array}{c}\text { Campbell } \\
\text { Plateau }\end{array}$ & $\begin{array}{c}\text { East of } \\
\text { New } \\
\text { Zealand }\end{array}$ & \multicolumn{2}{|c|}{ Lord Howe Rise } \\
\hline Site & $\begin{array}{c}\text { Site } \\
\mathbf{2 8 0}\end{array}$ & $\begin{array}{c}\text { Site } \\
\mathbf{2 8 1}\end{array}$ & $\begin{array}{c}\text { Site } \\
\mathbf{1 1 7 2}\end{array}$ & $\begin{array}{c}\text { Site } \\
\mathbf{2 8 3}\end{array}$ & $\begin{array}{c}\text { Site } \\
\mathbf{2 7 7}\end{array}$ & $\begin{array}{c}\text { Site } \\
\mathbf{1 1 2 3}\end{array}$ & $\begin{array}{c}\text { Site } \\
\mathbf{2 0 7}\end{array}$ & $\begin{array}{c}\text { Site } \\
\mathbf{5 9 2}\end{array}$ & $\begin{array}{c}\text { Site } \\
\mathbf{2 0 6}\end{array}$ \\
\hline $\begin{array}{l}\text { New } \\
\text { samples }\end{array}$ & 4 & 4 & & & 46 & & 37 & 10 & 24 \\
\hline $\begin{array}{l}\text { Existing } \\
\text { samples }\end{array}$ & & $3^{2}$ & $41^{4}$ & $6^{2}$ & $31^{1}$ & $14^{3}$ & $7^{2}$ & & \\
\hline Total & 4 & 7 & 41 & 6 & 77 & 14 & 44 & 10 & 24 \\
\hline
\end{tabular}

Until 1981, DSDP sites were rotary drilled, so recovery of deep sediments is in general poor and the large core gaps are present at sites 206, 207, 277, 280, 281 and 283. A change in technology to hydraulic piston corer (HPC) and extended core barrel coring (XCB) has significantly improved the recovery of sediments (in particular the uppermost soft sediments) at sites 592, 1123 and 1172.

\subsubsection{High-latitude sites}

During Leg 29 of the Deep Sea Drilling Project (DSDP), sites 275 to 284 were drilled in the Southwest Pacific (Kennett et al., 1975). Site 277 on the Campbell Plateau was the primary high-latitude site in this study. However, to acquire a regional picture of radiolarian assemblage changes and paleobiogeography during the middle Eocene to early Oligocene in the high-latitude Southwest Pacific, three additional sites were also examined (sites 280, 281, 283). These were further supplemented by radiolarian assemblage data from Site 1172 provided by Noritoshi Suzuki (Tohoku University, Japan), who published the radiolarian taxonomy in Suzuki et al. (2009).

\subsubsection{DSDP Site 277}

DSDP Site 277 is located on the western margin of the Campbell Plateau (52 $13.43^{\prime} \mathrm{S}$; $166^{\circ} 11.48^{\prime} \mathrm{E}$ ) at a water depth of $1214 \mathrm{~m}$ (Figure 3.1). Forty-six cores were drilled with a maximum penetration of 472.5 meter below sea floor (mbsf), and a cored section of 434.5 $\mathrm{m}$. Total recovery was only $59.6 \%$ (or $258.5 \mathrm{~m}$ of sediments). The recovery was extremely poor between 368 and $301.5 \mathrm{mbsf}$, due to $9.5 \mathrm{~m}$ rotary coring runs being conducted every $19 \mathrm{~m}$. The upper $10 \mathrm{~m}$ consist of Plio-Pleistocene foraminifera-rich nannofossil ooze, separated by an unconformity from $462 \mathrm{~m}$ of nannofossil ooze of 
middle Paleocene to late Oligocene age (Kennett et al., 1975). The absence of most of the Neogene reflects the increase of bottom-water velocity throughout the region associated with the development of the Antarctic Circumpolar Current (Kennett et al., 1972; Kennett et al., 1975). As the sediment at this site is calcareous throughout the succession, a depositional depth at $1500 \mathrm{~m}$, well above the lysocline is suggested (Kennett et al., 1975; Hollis et al., 1997). The first part of this thesis was to re-assess existing slides from DSDP Site 277 and to process additional samples. In total, 77 samples of Site 277 were analysed, of which 31 were prepared and initially assessed by Hollis et al. (1997), in addition other 46 are prepared (Figure 3.3). The studied samples range from the upper Paleocene (Core 277-46R; $468.49 \mathrm{mbsf}$ ) to lower Oligocene (Core 277-15R; 134.50 mbsf). The mean paleolatitude throughout the early Eocene to early Oligocene ( $\sim 50-30$ Ma) was $\sim 55^{\circ} \mathrm{S}$ (van Hinsbergen et al., 2015).

\subsubsection{DSDP Site 280}

DSDP Site 280 comprising two holes (280 and 280A), is located $\sim 100 \mathrm{~km}$ south of the South Tasman Rise $\left(48^{\circ} 57.44^{\prime} \mathrm{S} ; 147^{\circ} 14.08^{\prime} \mathrm{E}\right)$ and was drilled at a water depth of $4176 \mathrm{~m}$ (Figure 3.1). Radiolarian assemblage data were collected from Hole 280A. In total, 23 cores were drilled at this hole, which consists of a $201 \mathrm{~m}$ cored section. However, the recovery was only $97.2 \mathrm{~m}$ (48.2 \%). Several unconformities characterise the sedimentary record. Manganese nodules occur in the top of the core, overlying a $1 \mathrm{~m}$ section of Pleistocene foraminiferal nannofossil ooze, which is separated by an unconformity from $5 \mathrm{~m}$ of lower Pliocene or upper Miocene siliceous nannofossil ooze and detrital clay. An unconformity separates this part from the underlying Oligocene and upper Eocene silty diatom ooze, of at least $100 \mathrm{~m}$ thickness. Underneath the latter unit, a lower to middle Eocene glauconitic clayey silt with chert and highly organic silty claystone with almost no biogenic material was recovered, which in turn rests on basaltic basement rocks (Kennett et al., 1975). The general paucity and poor preservation of calcareous microfossils suggest a paleodepth close to the calcite compensation depth. The studied interval (4 samples) spans Core 280A-7R (123.4 mbsf) to Core 280A-5R (92.54 mbsf) and is of early Oligocene age (Figure 3.3). During this time the site was located $\sim 60^{\circ} \mathrm{S}$ (van Hinsbergen et al., 2015). 


\subsubsection{DSDP Site 281}

DSDP Site 281 comprising two holes (281 and 281A), is located on the South Tasman Rise $\left(47^{\circ} 59.84^{\prime} \mathrm{S} ; 147^{\circ} 45.85^{\prime} \mathrm{E}\right)$ and drilled at a water depth of $1591 \mathrm{~m}$ (Figure 3.1). This study is based on the radiolarian assemblages in Hole 281. This hole was cored to 169 mbsf, but only $105.6 \mathrm{~m}(62.5 \%)$ was recovered. The upper part of the cored interval consists of $\sim 121 \mathrm{~m}$ of lower Miocene to recent nannofossil-foraminiferal ooze. The Oligocene and much of the upper Eocene record are disrupted by an unconformity, with a small horizon of greensand at the base of Core 281-13R. Beneath the unconformity, a $28.5 \mathrm{~m}$ interval of upper Eocene ( Kaiatan) biogenic-rich glauconitic sandy to silty clays was recovered, underlain by $19 \mathrm{~m}$ of upper Eocene glauconitic sandstone and mica schist breccia. The improved preservation of calcareous microfossils suggests a shallower depositional environment than Site 280. The upper Eocene section studied in Hole 281 (7 samples) spans Core 281-16R (149.04 mbsf) to Core 281-14R (122.5 mbsf) (Figure 3.3). The mean paleolatitude in the late Eocene ( $\sim 35 \mathrm{Ma}$ ) was $\sim 60.5^{\circ} \mathrm{S}$ (van Hinsbergen et al., 2015).

\subsubsection{DSDP Site 283}

DSDP Site 283 lies in the Central Tasman Sea (4354.6' S; $154^{\circ} 16.96^{\prime}$ E) in a water depth of $4729 \mathrm{~m}$ and also comprises two holes (283 and 283A) (Figure 3.1). Radiolarian data were collected from Hole 283. This hole was drilled to $592 \mathrm{mbsf}$ and recovered 19 cores. However, the length of the cored section was only $156 \mathrm{~m}$ and the total recovery of sediments was very poor with $61.6 \mathrm{~m}$ (39\%). The upper part of the cored section consists of $12.9 \mathrm{~m}$ fossiliferous zeolite clay of late Pliocene-Pleistocene age. It is abruptly underlain by $3 \mathrm{~m}$ of upper Miocene or Pliocene fossil-free zeolite clay that is separated by an unconformity from $164 \mathrm{~m}$ of upper Eocene diatom ooze containing nannofossils. Beneath that, $225 \mathrm{~m}$ of middle Eocene silty clay and $283 \mathrm{~m}$ of Paleocene fossil-poor silty clay and silty pyritic claystone, underlain by highly altered basalt, were recovered. Due to the poor preservation of calcareous material and the absence of planktonic foraminifera, the depositional depth is assumed to be close or below the calcium carbonate compensation depth (Kennett et al., 1975). Furthermore, the absence of the Oligocene and most of the Neogene is inferred to be due to erosion by bottom currents in the central Tasman Sea (Kennett et al., 1975). From this site, a section spanning Core 283-8R (192.25 mbsf) to 283-5R (87.75 mbsf) was studied (6 samples) containing upper Eocene 
sediments (Figure 3.3). The mean paleolatitude of this site in the late Eocene ( 35 Ma) was $\sim 55.5^{\circ} \mathrm{S}$ (van Hinsbergen et al., 2015).

\subsubsection{ODP Site 1172}

ODP Site 1172 is situated west of the East Tasman Plateau (43 $\left.57.58^{\prime} S ; 1^{\circ} 9^{\circ} 55.69^{\prime} \mathrm{E}\right)$ in a water depth of $2622 \mathrm{~m}$ and was drilled during ODP Leg 189 (Exon et al., 2001; Shipboard Scientific Party, 2001) (Figure 3.1). It comprises four holes (1172A, 1172B, 1172C and 1172D). Radiolarian data from Hole A and a short sequence of Hole D were provided by Noritoshi Suzuki (Tohoku University, Japan) who published the taxonomy in Suzuki et al. (2009). Hole 1172A was drilled by advanced piston corer/extended core barrel (APC/XCB) to 522.6 mbsf (92.6\% recovery), whereas Hole D was rotary cored between 344-373 mbsf and 497-766 mbsf. The uppermost unit at Site 1172 down to $355.8 \mathrm{mbsf}$ consists of foraminifera-bearing nannofossil ooze and chalk of early Miocene to Pleistocene age with some Oligocene in the lowest part. Unit 2 (361.12-355.8 mbsf) contains a short uppermost Eocene to Oligocene section with a sharp transition in the upper Oligocene between glauconite-bearing silty claystone and the overlying pelagic carbonate sequence consisting of nannofossil chalk (Exon et al., 2001). The glauconitic feature of the sequence indicates increased bottom-water current activity in the uppermost Eocene (Kennett and Exon, 2004; Stickley et al., 2004a). The underlying Unit 3 (503.4$361.12 \mathrm{mbsf}$ ) is characterized by claystone with diatoms in the lower part and nannofossils in the upper part, and is of middle to late Eocene age. Diatoms are more abundant and of inner neritic nature in the middle Eocene until $408 \mathrm{mbsf}$ ( 39 Ma), where they become more oceanic and may indicate a change to a more outer neritic regime. Above $\sim 376 \mathrm{mbsf}$ ( $\sim 38 \mathrm{Ma}$ ) the diatom assemblage indicates an inner to outer neritic regime (Röhl et al., 2004). The deepest unit (766.5-503.4 mbsf) consists of upper Cretaceous to lower Eocene claystones with some amounts of silt and nannofossils, however siliceous microfossils are absent. The radiolarian assemblage data are from Core 1172A-48X to $-39 \mathrm{X}$ (450.49-354.6 mbsf), spanning the middle Eocene to Oligocene interval, and from Core 1172D-2R (356.85-355.65 mbsf), covering an Oligocene interval (N. Suzuki, Figure 3.3). The paleolatitude of this site in the middle Eocene to early Oligocene ( 40-30 Ma) was $\sim 56^{\circ} \mathrm{S}$ (van Hinsbergen et al., 2015). 


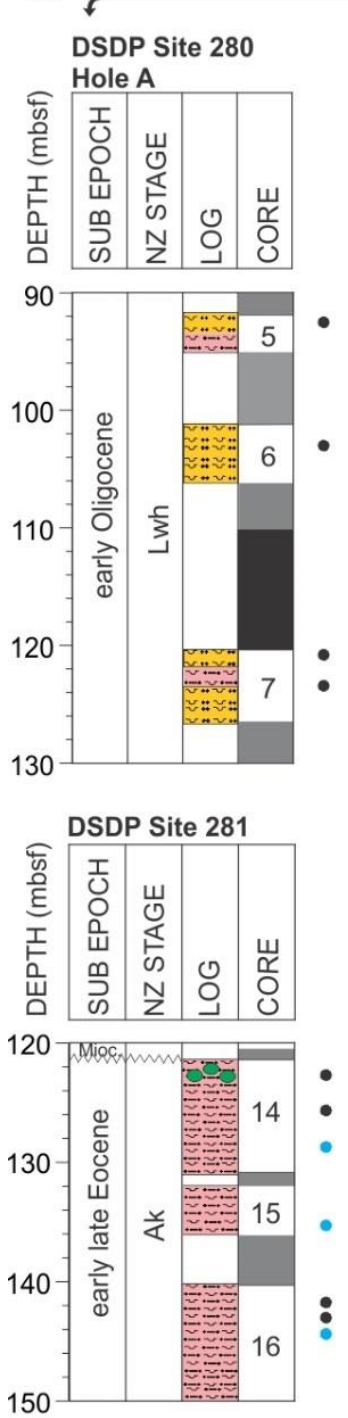

High latitudes
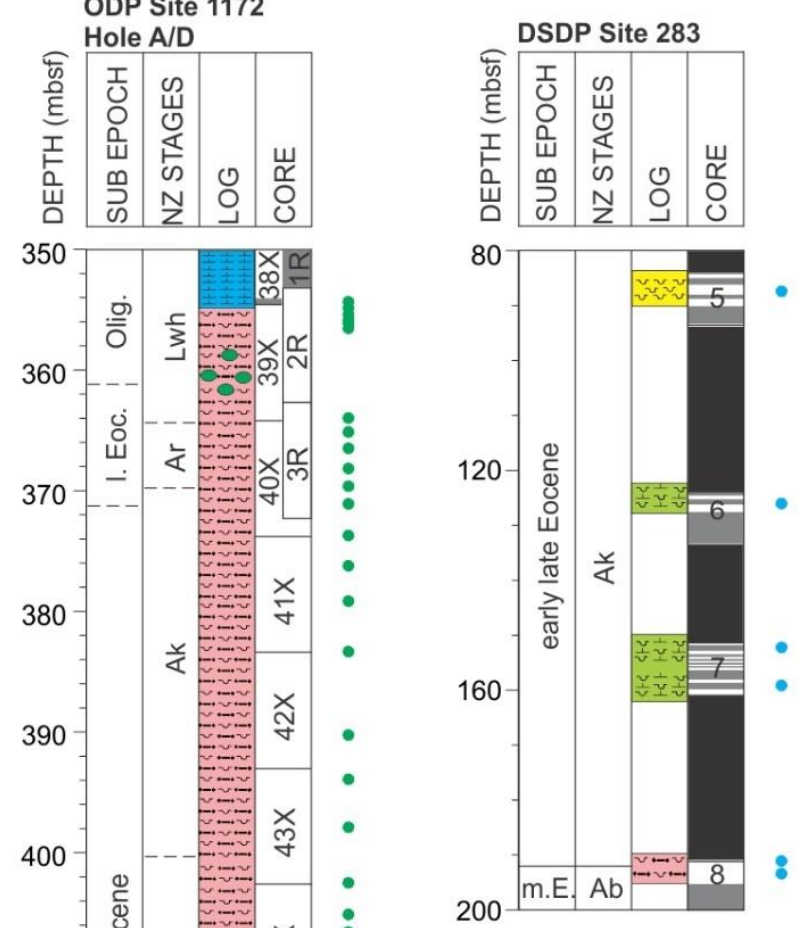

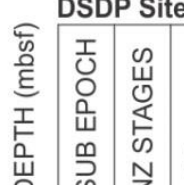

\begin{tabular}{|l|l|l|l|}
\hline & 15 \\
\hline
\end{tabular}

150

200

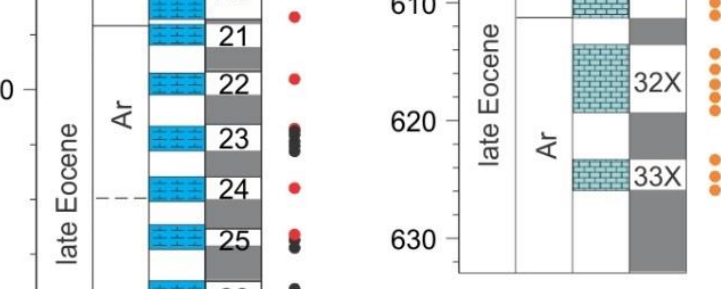

150
ODP Site 1123

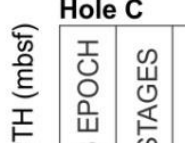

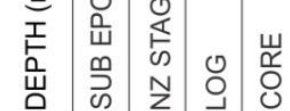

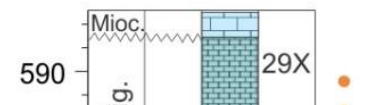

Sample key

政 Assemblage data provided by N. Suzuk $250-\begin{array}{r}27 \\ \hline 28 \\ \hline 2\end{array}$

$300-$

350

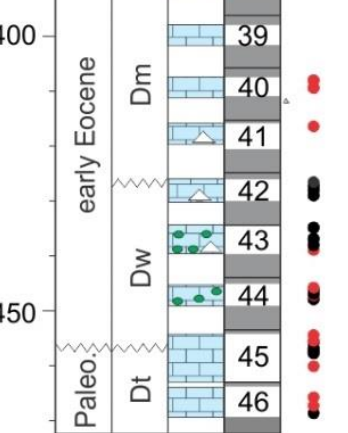

Mid latitudes

\section{DSDP Site 592}
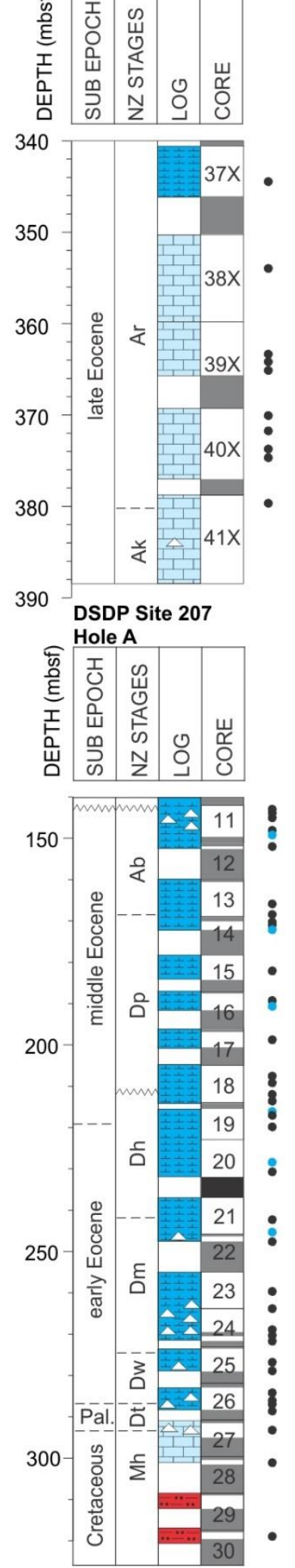

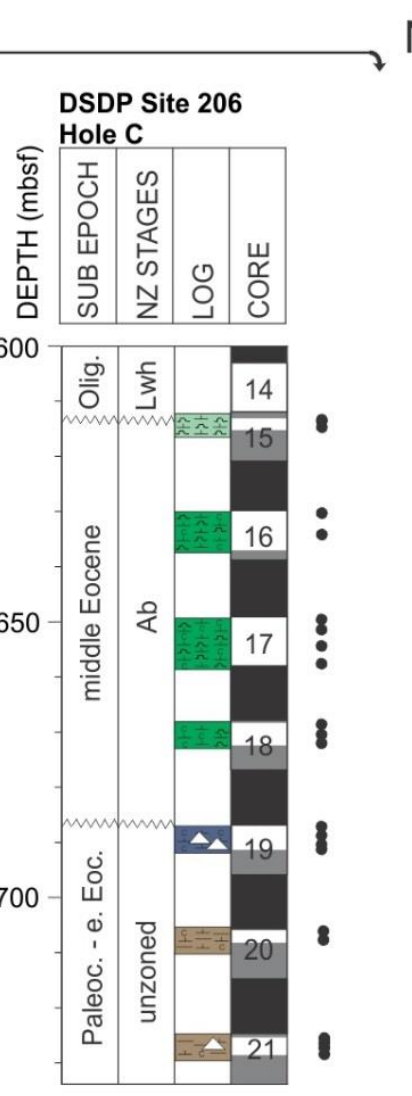

\begin{tabular}{|c|c|}
\hline holo & \\
\hline & \\
\hline & nanno ooze \\
\hline & nanno chalk \\
\hline & micritic limestone \\
\hline 분포권 & $\begin{array}{l}\text { siliceous fossil-rich } \\
\text { diatom-nanno ooze }\end{array}$ \\
\hline 슛쇼숏 & $\begin{array}{l}\text { fossil-rich rad- } \\
\text { nanno ooze }\end{array}$ \\
\hline & $\begin{array}{l}\text { fossil-rich rad- } \\
\text { nanno calcic ooze }\end{array}$ \\
\hline & nanno calcic claystone \\
\hline wa...... & silty diatom ooze \\
\hline 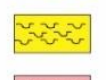 & $\begin{array}{l}\text { siliceous fossil-rich } \\
\text { diatom ooze }\end{array}$ \\
\hline$\because$ & diatom-sitty claystone \\
\hline & silty claystone \\
\hline & sandstone (upper 277R-27) \\
\hline$\because$ & glauconite \\
\hline 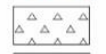 & chert nodules \\
\hline & no core recovery \\
\hline & core gaps \\
\hline
\end{tabular}




\subsubsection{Mid-latitude sites}

During DSDP Leg 21, sites 203-210 were drilled in the Tasman Sea and on or near the Lord Howe Rise from low to mid-latitudes (Burns et al., 1973). Site 207 on Lord Howe Rise was the primary mid-latitude site in this study. To acquire a regional picture of radiolarian assemblage changes at mid-latitude sites during the Paleogene, two additional sites on Lord Howe Rise (DSDP sites 206 and 592) and one site east of New Zealand (ODP Site 1123) were also examined.

\subsubsection{DSDP Site 207}

DSDP Site 207 is located in the southern part of the Lord Howe Rise (36 $57.75^{\prime} \mathrm{S}$; $165^{\circ} 26.06^{\prime} \mathrm{E}$ ) in a water depth of $1389 \mathrm{~m}$ and comprises two holes (207 and 207A) (Figure 3.1). In this study, Hole 207A was investigated, which was drilled to a depth of 513 mbsf (Burns et al., 1973). 50 cores were recovered but with only $47 \%$ recovery $(212.3 \mathrm{~m})$. The uppermost Unit 1 consists of $142 \mathrm{~m}$ of middle Miocene to Pleistocene carbonate ooze. Below, a Paleocene to middle Miocene unit (309-142 mbsf) was recovered, consisting of foraminiferal-nannofossil ooze and clay nannofossil ooze (or chalk) containing also siliceous fossils. Chert nodules are present in the lower part of this section (Cores 207A-27R to -24R). An unconformity separates middle Eocene from middle Miocene sediments (between Core 207A-11R-2, 20cm and -10R-CC), which can be detected by different microfossil components in the units above and below, consisting of up to $35 \%$ of siliceous fossils in the Eocene material of Unit 2. This major Southwest Pacific unconformity is also found in other Lord Howe Rise sites (206, 208, 209, 210). More recent research suggests that the Eocene-Oligocene hiatus developed as a result of uplift of the Lord Howe Rise due to tectonic processes associated with subduction (Sutherland et al., 2010). At Site 207, the hiatus spans the longest time period with $\sim 32$ Ma (Kennett et al., 1972). Kulhanek and Morgans (2013) determined the hiatus to be $\sim 25$ Ma in duration. The lower Units 3-5 (513-309 mbsf) are Cretaceous glauconitic silty claystone and sandstone rare in microfossils, underlain by rhyolitic rocks of various kinds. In this study, 44 samples from Core 207A-30R (318.96 mbsf) to Core 207A-11R (143.55 mbsf) were investigated, spanning a Paleocene (possibly upper Cretaceous) to middle Eocene interval (Figure 3.3). According to Kulhanek and Morgans (2013), the Eocene paleodepth at this site was between 2500-3000 m. The paleolatitude of Site 207 during the early to middle Eocene ( 50-40 Ma) was $\sim 47^{\circ} \mathrm{S}$ (van Hinsbergen et al., 2015). 


\subsubsection{DSDP Site 206}

DSDP Site 206 is situated in the New Caledonia Basin $\left(32^{\circ} 0.75^{\prime} \mathrm{S} ; 165^{\circ} 27.15^{\prime} \mathrm{E}\right)$ and was drilled in a water depth of $3196 \mathrm{~m}$ (Figure 3.1). Four holes were drilled at this site (206, 206A, 206B, 206C) but cores were only recovered from Holes 206 and 206C (Burns et al., 1973). Radiolarian assemblage data were obtained from Hole 206C. In this hole, 21 cores were recovered between 404 and 734 mbsf with a recovery of $47 \%(88.7 \mathrm{~m}$ of cored section). Unit 1 (389-0 mbsf) is a lower Miocene to possibly upper Pleistocene nannofossil-foraminiferal ooze containing minor volcanic ash. Unit 2 (614-389 mbsf) is a middle Oligocene to lower Miocene sequence, mainly consisting of semi-lithified nannofossil ooze with varying amounts of clay. Unit 3 (677-614 mbsf) is of middle Eocene to earliest late Eocene age and is composed of semi-lithified radiolarian-rich nannofossil ooze. This is underlain by Unit 4 (734-677 mbsf), of early Paleocene to middle Eocene age, whose lithology is semi-lithified nannofossil ooze and clay with minor chert. An unconformity between Units 2 and 3 was dated based on both planktic foraminifera and nannofossils to about 14 Ma (Kennett et al., 1972). More recent investigations suggest a hiatus of 6.65-9 Ma (Kulhanek and Morgans, 2013). 24 samples were investigated from Core 206C-21R (728 mbsf) to Core 206C-15R (613.70 mbsf), spanning a Paleocene to middle Eocene interval (Figure 3.3). The paleodepth during the Eocene is estimated to $2000 \mathrm{~m}$ (Kulhanek and Morgans, 2013). The paleolatitude of this site during the early to middle Eocene ( $50-40 \mathrm{Ma}$ ) was $\sim 42^{\circ} \mathrm{S}$ (van Hinsbergen et al., 2015).

\subsubsection{DSDP Site 592}

DSDP Site 592, recovered during DSDP Leg 90, is situated on the southern Lord Howe Rise $\left(36^{\circ} 28.40^{\prime} \mathrm{S} ; 164^{\circ} 26.92^{\prime} \mathrm{E}\right)$, close to Site 207 , and was drilled in a water depth of $1088 \mathrm{~m}$ (Figure 3.1) (Kennett et al., 1985). Forty-one cores were recovered at this site, penetrating to a depth of $388.5 \mathrm{mbsf}$. The total recovered section is $340.12 \mathrm{~m}$ long $(87.5 \%$ recovery) and was drilled using HPC until 234.9 mbsf, and XCB from 234.9-388.5 mbsf. The upper $305.8 \mathrm{~m}$ of the cored section covers a lower Miocene to Pleistocene interval with foraminifer-bearing nannofossil chalk and ooze. The lower part of the core consists of an $83.5 \mathrm{~m}$ long Paleogene sequence of nannofossil ooze and chalk of late Eocene to early Oligocene age. This site is the only site on the Lord Howe Rise that contains an intact Eocene-Oligocene boundary transition and, along with Site 277 and Site 1123, the only one in the Southwest Pacific to do so. An unconformity separates lower Oligocene 
from lower Miocene, and spans between 7 and $11 \mathrm{Ma}$ at this site (Kulhanek and Morgans, 2013). For this study, 10 samples from Core 592-41X (379.7 mbsf) to Core 592-37X (344.3 mbsf) were investigated. This interval is of late Eocene age and is the only radiolarian bearing interval at this site (Figure 3.3). The paleodepth of this site in the late Eocene is estimated to 1500-2000 m (Kulhanek and Morgans, 2013), the paleolatitude (at $\sim 35 \mathrm{Ma}$ ) to $\sim 46^{\circ} \mathrm{S}$ (van Hinsbergen et al., 2015).

\subsubsection{ODP Site 1123}

ODP Site 1123 was drilled during Leg 181 and is located east of New Zealand on the northeastern slopes of Chatham Rise, about $400 \mathrm{~km}$ northeast of the Chatham Islands (41ํ⒋4'S; 171 $\left.{ }^{\circ} 30^{\prime} \mathrm{E}\right)$ (Figure 3.1) (Carter et al., 1999; Shipboard Scientific Party, 1999). Site 1123 lies in a water depth of $3290 \mathrm{~m}$ and comprises three holes (1123A, 1123B and 1123C). Radiolarian assemblage data were collected from Hole 1123C. At this hole, 16 cores were recovered using an advanced hydraulic piston corer (APC), which resulted in excellent recovery of $101.45 \%(151.5 \mathrm{~m})$. A further 17 cores were drilled using XCB, which recovered $158.4 \mathrm{~m}$ (85.69\% recovery). The sedimentary succession that was recovered at Site 1123 is divided into four units. Unit 1 (uppermost $256.6 \mathrm{mbsf}$ ) consists of upper Miocene to Pleistocene nannofossil ooze with abundant to occasional tephra layers. Unit 2 spans 450.8-256.6 mbsf and consists of middle to upper Miocene nannofossil chalk with frequent tephra layers. Unit $3(587.2-450.8 \mathrm{mbsf})$ consists of lower to middle Miocene alternating nannofossil mudstone to nannofossil chalk. The lowermost unit, Unit 4 is upper Eocene to lower Oligocene micritic limestone (632.8$587.2 \mathrm{mbsf}$ ). An unconformity separates lower Oligocene from lower Miocene sediments at Site 1123. Radiolarian data were collected from 14 samples of Core 1123C-33X (625.68 mbsf) to Core 1123C-29X (590.9 mbsf), spanning an upper Eocene to lower Oligocene interval (Figure 3.3). These samples were prepared and provided by Yoshiaki Aita (Utsunomya University, Japan), shipboard radiolarian specialist on ODP Leg 181. The accumulation of calcareous sediments dominated by nannofossils indicates offshore conditions well above the lysocline. The paleolatitude of this site during the late Eocene to early Oligocene ( $\sim 35-30 \mathrm{Ma}$ ) was $\sim 50^{\circ} \mathrm{S}$ (van Hinsbergen et al., 2015). 


\subsection{Sample and slide preparation}

The following procedure for sample preparation is for chalk or limestone samples. Dependent on the available amount of material, between 1-10 grams of dried sample material was broken into $\sim 5 \mathrm{~mm}$-diameter chips and diluted with a little deionized water in a beaker.

The first step was to remove carbonate by gradually adding a solution of $10 \% \mathrm{HCl}$ to the sample and monitoring its reaction. This reaction usually lasted no more than an hour until the acid turned yellow indicating that the acidification process is complete (Figure $3.4)$.

After the acid reaction, the sample was washed and filtered through a $63 \mu \mathrm{m}$ sieve. To remove organic compounds and clay in the sample, the $>63 \mu \mathrm{m}$ residue (diluted with water in a beaker) was cleaned by gently heating and adding of a solution of $30 \%$ hydrogen peroxide $\left(\mathrm{H}_{2} \mathrm{O}_{2}\right)$ and $5 \%$ sodium hexametaphosphate (Calgon; $\left.\left(\mathrm{NaPO}_{3}\right)_{6}\right)$. The sample mixture was kept on a hotplate during this reaction, usually between 30 minutes and 2 hours, dependent on the amount of organic material and clay in the residue (Figure $3.5)$.

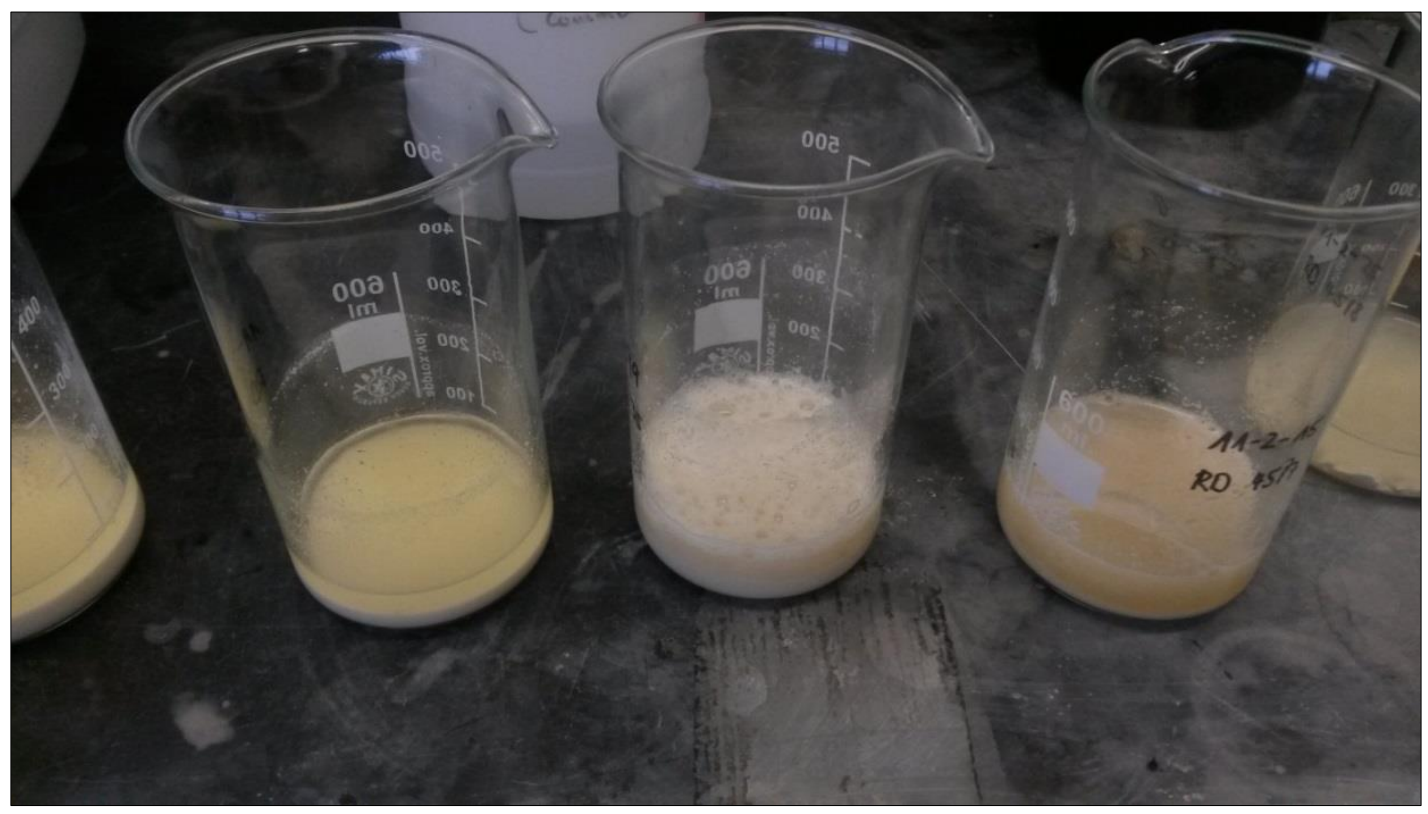

Figure 3.4 Samples with $\mathrm{HCl}$ added; note strong reaction in middle beaker. 


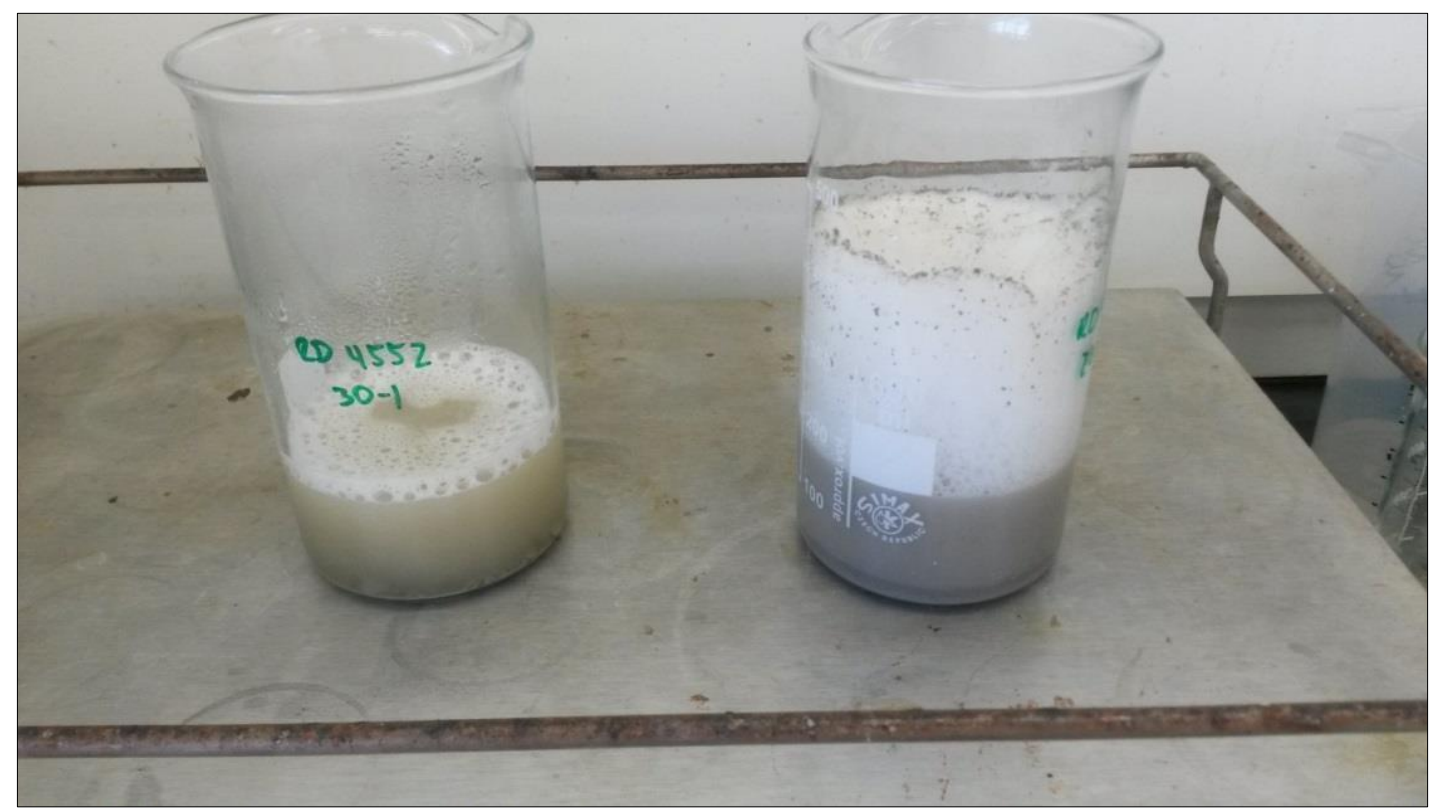

Figure 3.5 Breakdown of organic material and clay; hydrogen peroxide is causing a strong reaction in beaker to the right.

After the reaction had ceased, the residue was filtered through a $63 \mu \mathrm{m}$ sieve (Figure 3.6). The remaining material was observed under a stereo microscope to assess if the sample still needed further cleaning. In that case, a second $\mathrm{H}_{2} \mathrm{O}_{2}$ and Calgon wash was applied. The sample was then transferred to a plastic pot and dried (Figure 3.7). 


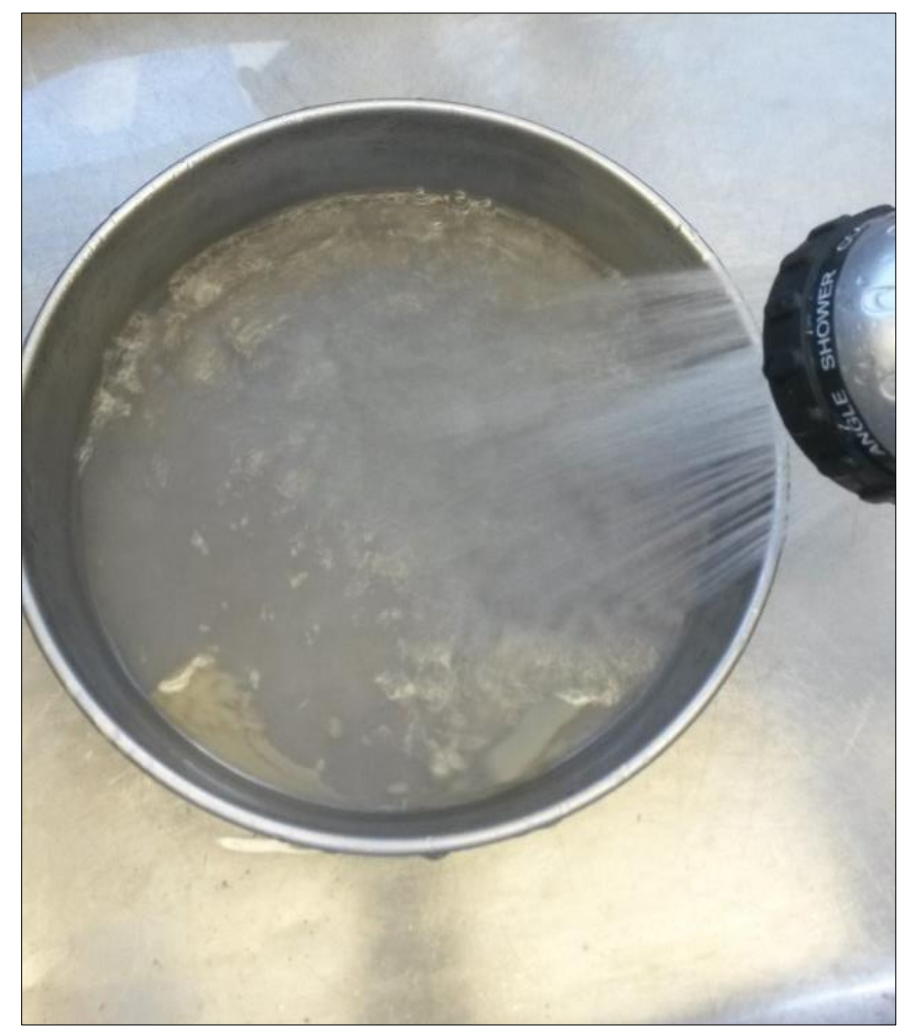

Figure 3.6 Washing of a sample with a $63 \mu \mathrm{m}$ sieve.

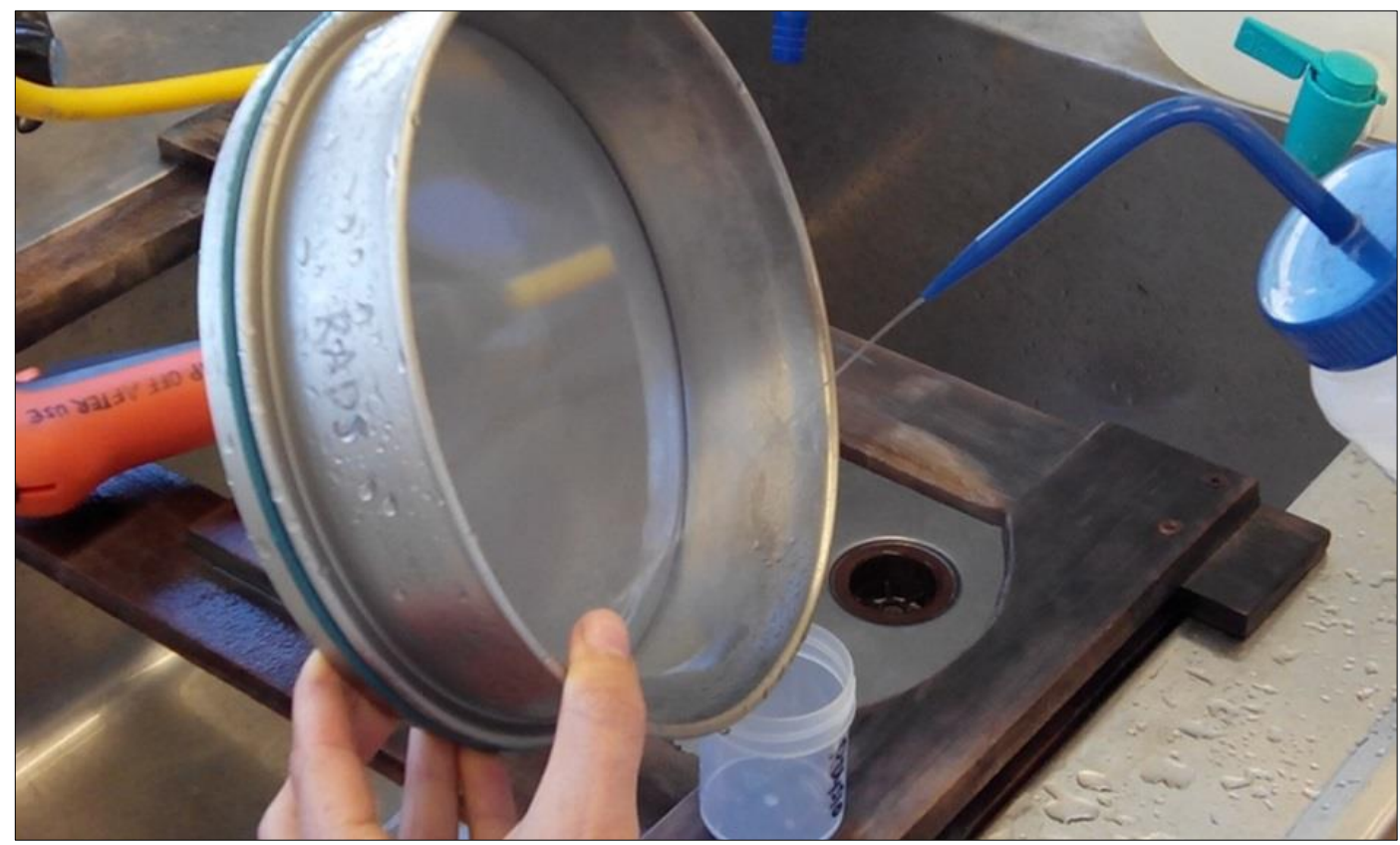

Figure 3.7 Washed residue gets transferred to a small plastic pot and then put in the oven for drying out.

Samples from DSDP Site 206 did not break down after $\mathrm{HCl} / \mathrm{H}_{2} \mathrm{O}_{2}$ treatment and received following hydrofluoric acid (HF) treatment. Only the fraction $>0.5 \mathrm{~mm}$ was used for this treatment and put into a polypropylene beaker. A 5\% HF solution was carefully added 
until all chips were covered. The time of exposure to HF was set to 2 hours. After 2 hours, the liquid was tipped off in another beaker and the remaining chips were washed with water three times in the same manner. The remaining chips were topped up with HF solution again for the next round. This step was repeated up to three times until there were no rock fragments remaining in the beaker. The solution that was tipped of was sieved through a $63 \mu \mathrm{m}$ sieve, washed with water and finally put into a glass beaker. In the final step, the residue received a Calgon ( $5 \%$ concentration) boil on the hotplate to which $\mathrm{H}_{2} \mathrm{O}_{2}$ (30\% concentration) was added to ensure a thorough cleaning of the radiolarians. Thereafter, the residue was rinsed though a $63 \mu \mathrm{m}$ sieve and dried.

Depending on the volume of the processed residue and the abundance of radiolarians, between 1-6 slides were prepared for each sample. For very sparse assemblages, radiolarians were individually picked under the stereo microscope. For slide preparation, a known portion of the dried material was gently sprinkled on a coverslip that was coated in dilute gum tragacanth (Figures 3.8 and 3.9). The coverslip was breathed on carefully to moisten it, so the radiolarians stick to the gum. Subsequently, the coverslip was inverted and the back of the coverslip tapped gently to remove any excess residue. The excess residue was collected and distributed onto areas on the coverslip that showed less dense radiolarian distribution. A few drops of Canada balsam were applied on the slide, which was placed on a hotplate. The coverslip with the residue was quickly inverted on the slide and remained on the hotplate for about 20 minutes until the mounting medium turned yellow (Figure 3.10). Any remaining air bubbles were removed by gently pressing the coverslip with a tooth pick. The slide was then removed from the hotplate allowed to dry and labelled (Figure 3.11). 


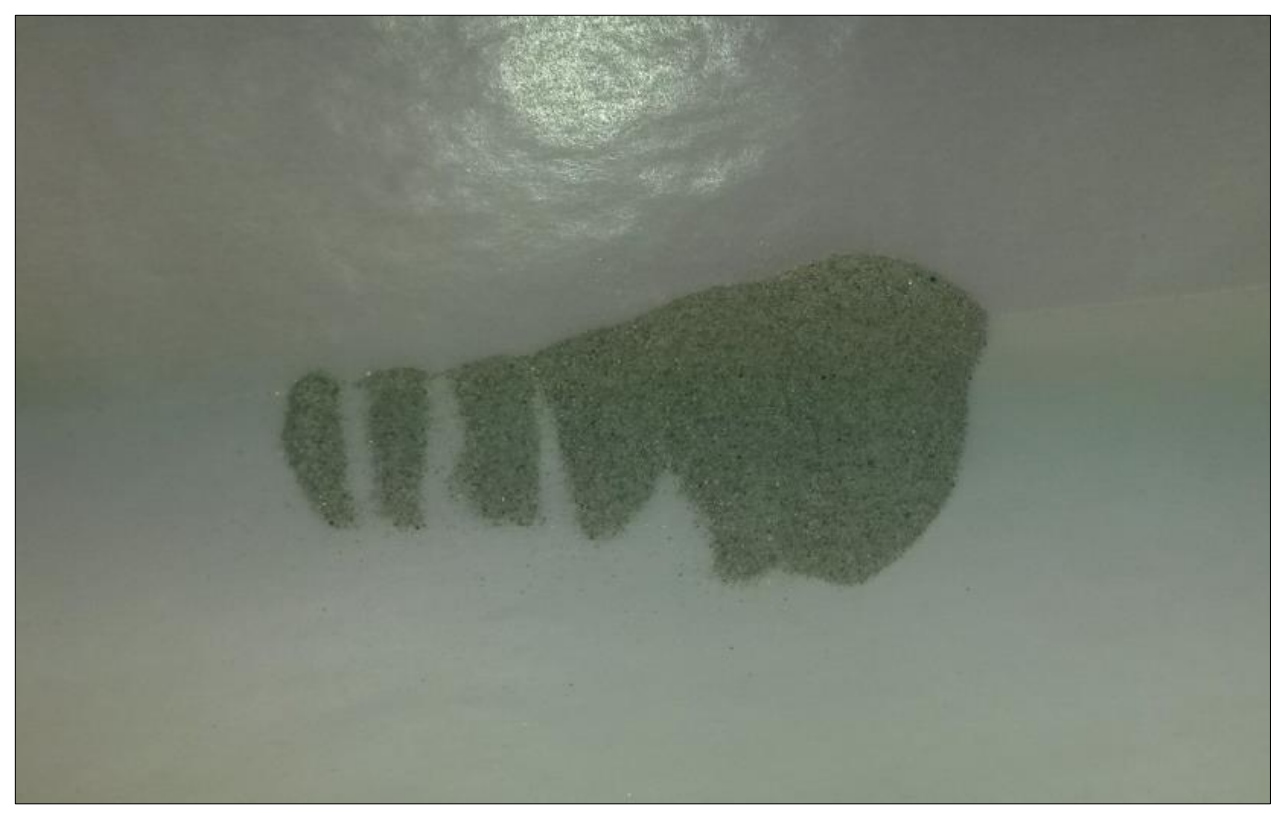

Figure 3.8 Dried residue, which was divided in smaller portions for slide making.

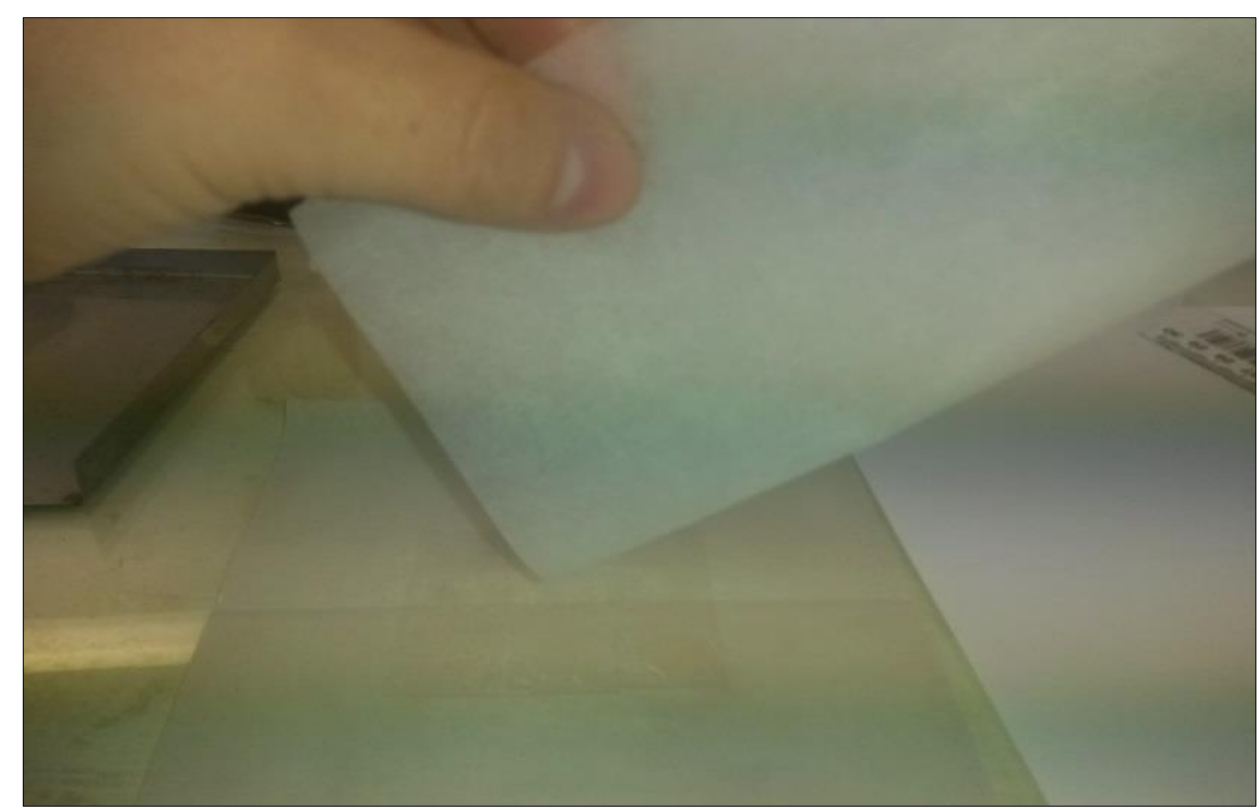

Figure 3.9 Sprinkling of a known portion of dried residue onto three coverslips that were covered with gum tragacanth. 


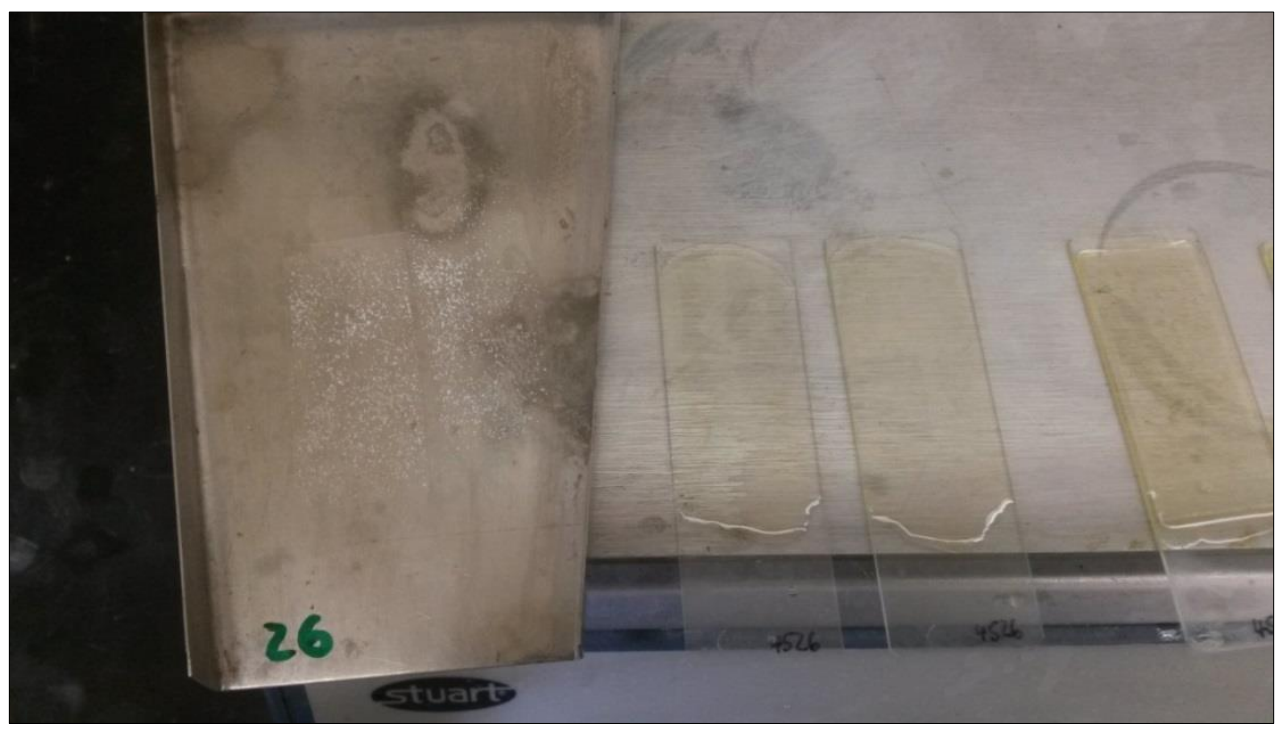

Figure 3.10 On the left: two coverslips with sprinkled residue, in the middle: two cover slides with Canada balsam, on the right: a coverslip was mounted onto a cover slide.

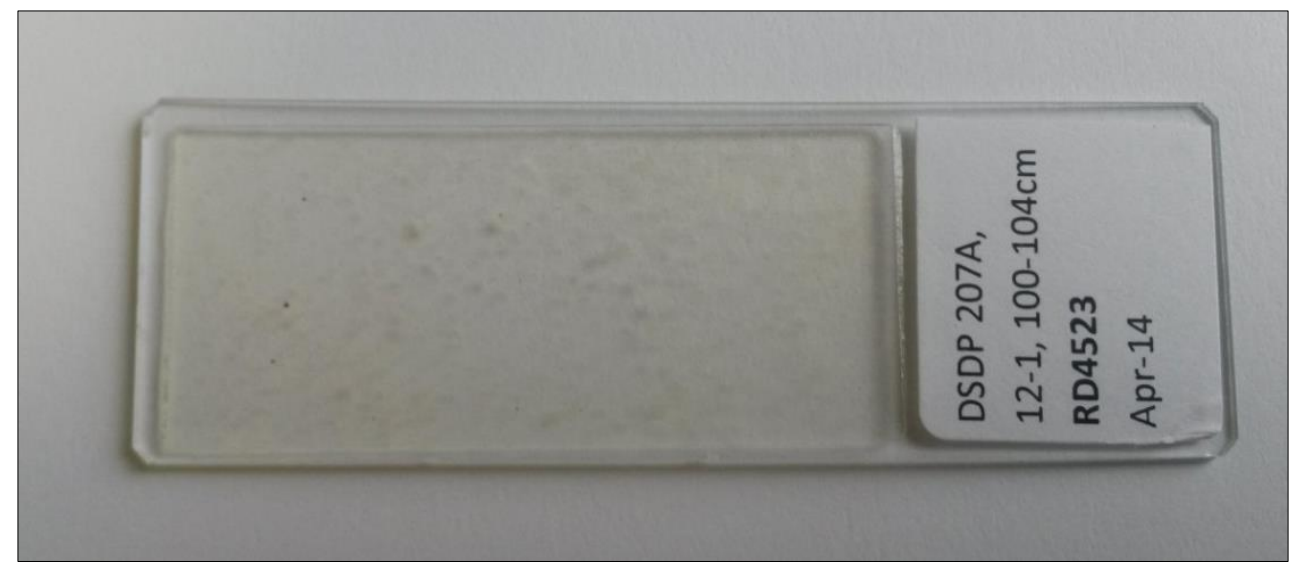

Figure 3.11 Final labelled slide, which was cleaned of excess Canada balsam with acetone.

\subsection{Slide examination}

\subsubsection{Radiolarian census data and relative abundance}

Strewn slides were examined using a Zeiss transmitted light microscope fitted with a Zeiss Axiocam ERc5s digital camera. For part one of the thesis, radiolarian census data were derived using the method of Hollis (2006). Radiolarians were counted on vertical slide traverses. For sparse samples ( $<300$ radiolarians per slide), all radiolarians on the prepared slide(s) were counted. For richer samples, all specimens were counted until a total number of 300 specimens was achieved. The proportion of the slide examined to this point was determined and the abundance of common taxa (>15 observed specimens) estimated for the rest of the slide. The remaining portion of the slide was then examined 
and rare taxa ( $<15$ observed specimens in initial count) recorded only. All intact tests or fragments that could confidently be assigned to a counting group were counted. Counting groups range from undifferentiated order (e.g. Nassellaria undet. or Spumellaria undet.) and family level (e.g. Plagiacanthidae undet.) to genus level (e.g. Lithomelissa spp.), species and subspecies. The advantage of this counting method is that it yields reliable abundances for rare taxa without spending too much time counting many hundreds of specimens. However, overall diversity was still underestimated as certain groups like the Trissocyclidae were not differentiated due to time constraints. Moreover, it was observed that large specimens (e.g. Lophocyrtids, Lychnocaniids) tend to distribute more at the edge of the slide, so estimating their abundance for the rest of the slide needs to be done carefully and checked randomly across the slide. Due to the latter reason and tight time constraints, the counting method was changed for part two of the thesis. For sites 206, 207, 592 and 1123, 400-500 specimens were counted along random vertical transects in the central area of the slide. The whole slide was scanned after the initial counting was completed and rare taxa that have not been encountered in the initial count were noted and marked with an ' $\mathrm{X}$ ' in the count sheets. This allowed the detection of very rare taxa that might be stratigraphically important and that might have been otherwise missed.

Radiolarian abundance was calculated using the following equation:

$(\mathrm{Xr} * \mathrm{Xs} * 1 / \mathrm{Xp}) / \mathrm{A}_{\mathrm{sed}}$

with $\mathrm{Xr}$ being the total number of radiolarians per slide, $\mathrm{Xs}$ the number of slides made of a known portion Xp of the dried material, $\mathrm{A}_{\mathrm{sed}}$ is the initial amount of dried sediment. The total number of radiolarians per slide $(\mathrm{Xr})$ was achieved counting specimens that are more than half complete along three vertical traverses. The average value of these three traverses was then used to extrapolate the abundance estimate for the whole slide. If radiolarians were very sparse (less than 300 specimens), Xs represents the total count of radiolarians.

\subsubsection{Radiolarian preservation and cumulative component analysis}

Radiolarian preservation was determined using the following criteria. Samples barren of radiolarians were assigned to a preservation index (PI) of 0 . Poorly preserved radiolarians (PI of 1) have a recrystallized test, poorly visible pores and external or internal features of the skeleton are hardly recognizable (Figure 3.12). Moderately preserved radiolarians (PI 
of 2) bear a rough surface but pores are visible. Very delicate features (e.g. spines) are often not preserved and test are often incomplete (Figure 3.12). Well preserved radiolarians (PI of 3) are characterized by a smooth surface, clear visible pore frames and the preservation of internal and external features (Figure 3.12).
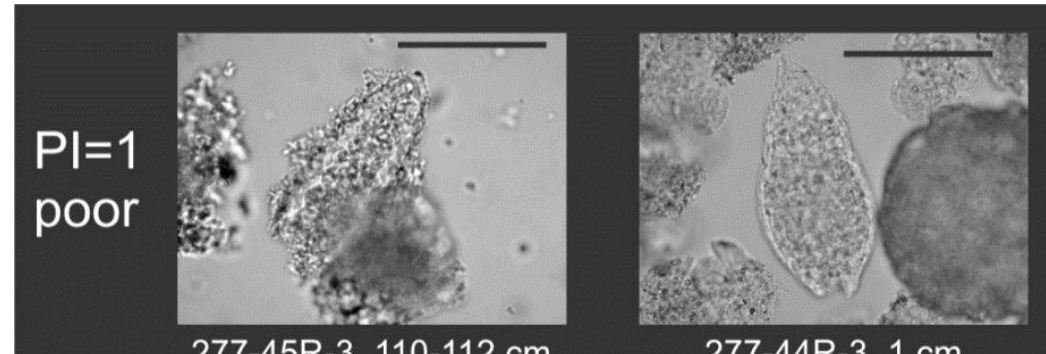

$277-44 \mathrm{R}-3,1 \mathrm{~cm}$

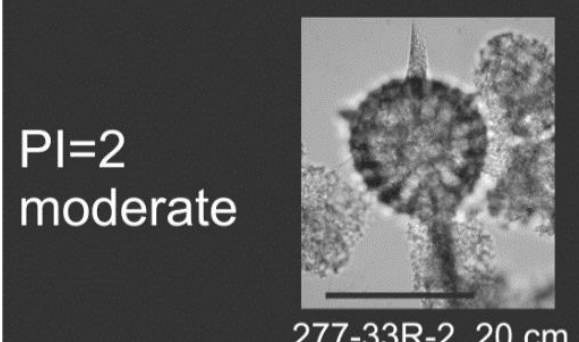

$277-33 R-2,20 \mathrm{~cm}$

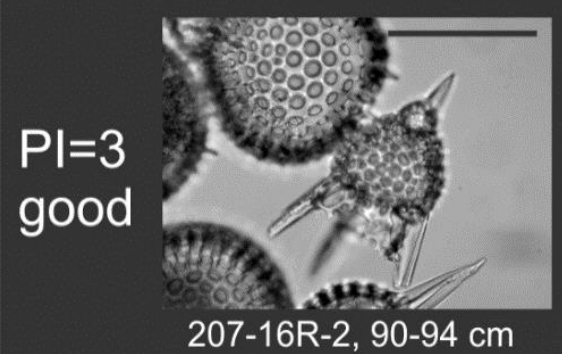

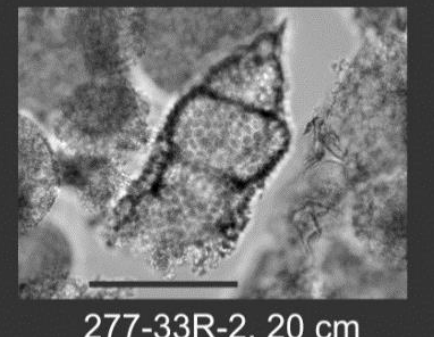

$277-33 R-2,20 \mathrm{~cm}$

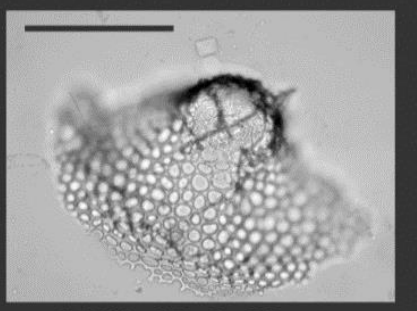

$280 \mathrm{~A}-6 \mathrm{R}-2,60 \mathrm{~cm}$

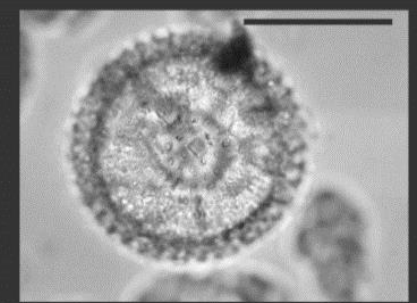

$277-44 \mathrm{R}-3,1 \mathrm{~cm}$

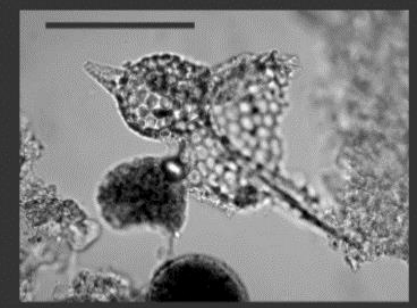

$277-26 \mathrm{R}-4,100 \mathrm{~cm}$

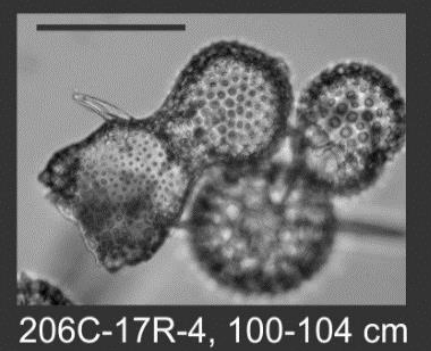

Figure 3.12 Examples of varying radiolarian preservation; PI: preservation index; scale bar $=100 \mu \mathrm{m}$.

Relative abundance of residue components in each sample was estimated by a count of 100 grains, where grains were assigned to one of the following categories: intact radiolarians, radiolarian fragments, diatoms, sand grains (including glauconite), sponge spicules, silicified foraminifera casts and dinoflagellates. The diatom/radiolarian ratio was calculated by using the counts of both groups from the $\sim 100$ grain counts. Although this method is not an accurate measure of the diatom abundance as most pelagic diatoms are smaller than $63 \mu \mathrm{m}$, it allowed to estimate the order of magnitude in changes of diatom abundance for identifying significant diatom event horizons. 


\subsubsection{Statistical analyses}

To evaluate the diversity and heterogeneity between samples and study sites, several statistical measures were obtained with the freely available statistical programme PAST Version 3.07 (Hammer et al., 2001). A simple measure for diversity is the species or taxic richness. However, this measure is largely dependent on the sample size and the larger the sample, the more species will be recorded. In case of uneven sampling size, rarefaction is a method that calculates the number of species for a sample size that is smaller than the collected sample (Harper, 1999). On the other hand, the taxic richness of different sample sizes can be calculated using subsampling techniques. Individual rarefaction is a method that calculates the number of species for different sample sizes. So for large sample sizes with for example 5000 individuals and 50 encountered species, the species richness can be calculated by rarefaction even if only 500 individuals were counted. Range-through diversity can be calculated to show if a drop in diversity in the middle of a series is a true diversity drop or just temporary absence due to preservation or ecologic conditions. The Fisher $\alpha$ index and the Simpson index of Evenness are both heterogeneity measures. The Fisher $\alpha$ Diversity Index is a general guide for diversity, calculated from the number of taxa and the total number of individuals. The Simpson Evenness Index takes the proportion of individuals assigned to species categories into account as well as the total number of species observed in a sample. It calculates the probability that two specimens picked at random belong to different species. It ranges from 0 (low diversity) to 1 . It is also called the evenness index, with low values indicating that a few species dominate the assemblage, while high values suggest that the identified species are equally abundant. This index is more sensitive to changes in the common species (Harper, 1999).

\subsection{Radiolarian taxonomy}

The taxonomy in this thesis is based on the supra-generic classification of Riedel (1967a, 1967b) and Petrushevskaya (1971a, 1971b) and is preferred to more recent alternatives (e.g. De Wever et al., 2001; Suzuki and Aita, 2011), which are based on cytology (e.g. endoplasm structure) and molecular phylogenetic analysis. This is not practical for the purpose of this study when aiming to assign specimens of variable preservation to counting group categories for statistical analysis.

For identifying radiolarians, key references on radiolarian taxonomy (Clark and Campbell, 1942, 1945; Riedel and Sanfilippo, 1970; Petrushevskaya and Kozlova, 1972; 54 
Sanfilippo, 1990; Sanfilippo and Riedel, 1992; Sanfilippo and Caulet, 1998), along with various Deep Sea Drilling Program (DSDP) reports from the Southwest Pacific (Chen, 1975; Petrushevskaya, 1975; Caulet, 1986; Hollis et al., 1997) and onshore New Zealand records (O'Connor, 1999a, 1999b, 2000; Hollis, 2002; Hollis et al., 2005) were used.

However, as Paleogene radiolarians from the Southwest Pacific are still sparsely studied, due to poor preservation and incomplete sedimentary records, species in open nomenclature are common. In order to standardise species assignments, familiarization with the taxonomy developed for other Southern Ocean records (e.g. Caulet, 1991; Takemura, 1992; Takemura and Ling, 1997; Funakawa and Nishi, 2005), northern latitude records (e.g. Nishimura, 1987, 1992) and low-latitude records (e.g. Foreman, 1973a; 1973b; Riedel and Sanfilippo, 1973; Sanfilippo and Riedel, 1973; Nigrini, 1977; Moore and Kamikuri, 2012; Kamikuri et al., 2013) was required. In Appendix A, all taxa that were encountered in this study are listed, along with synonyms relevant to this study.

\subsection{Radiolarian paleobiogeography}

An important focus of this study has been to use radiolarian paleobiogeography as a guide to paleo-watermass changes at a specific site and paleo-watermass differences between sites. In order to do this, I have endeavoured to categorise as many species as possible to one of three biogeographic regions: high latitude, low latitude and cosmopolitan.

Occurrence data were downloaded for all radiolarians encountered in this thesis from the Neptune Database Berlin (Lazarus, 1994; Spencer-Cervato, 1999), if available. Unfortunately, this database lacks many Paleogene radiolarians, and occurrence data are not always robust and still need to be cross-checked with the DSDP/ODP reports. In addition to this database, data on the geographic distribution of taxa were obtained from a few paleobiogeographic studies (Lazarus and Caulet, 1993; Sanfilippo and Caulet, 1998) and several regional studies (e.g. Petrushevskaya and Kozlova, 1972; Riedel and Sanfilippo, 1973; Petrushevskaya, 1975). However, it has not been possible to identify the biogeographic affinities of all the taxa in this study. This thesis represents the first attempt at assigning biogeographic affinities to Paleogene species based on their relative abundance (Appendix E, data on enclosed CD).

Sites were grouped in three categories based on their paleolatitude location: high-latitude $\left(>45^{\circ} \mathrm{S} / \mathrm{N}\right)$, mid-latitude $\left(25-45^{\circ} \mathrm{N} / \mathrm{S}\right)$ and low-latitude $\left(25^{\circ} \mathrm{S}-25^{\circ} \mathrm{N}\right)$. Taxa used in the 
paleobiogeographic analysis include all those species or genera with relatively wellresolved taxonomy and geographic distributions. Relative abundance and age range is recorded for all sites where the taxon is present. Radiolarian ranges and relative abundances were recorded for each species. Following relative abundance categories were established for species in this study: trace $(\mathrm{T},<1 \%)$, rare $(\mathrm{R}, 1-2 \%)$, few $(\mathrm{F}, 2-5 \%)$, common $(\mathrm{C},>5-10 \%)$ and abundant $(\mathrm{A},>10 \%)$. Only samples with a sample size $>100$ specimens were included when recording the relative abundance range over a certain time interval. For sample sizes <100 specimens, species were recorded as present. Biogeographic affinity is assigned based on the overall distribution of a taxon in high-, mid- and low-latitude sites. If the taxon is evenly distributed over all sites, it is considered to be cosmopolitan. If a taxon has a short-lived occurrence in high- or mid-latitudes, but is predominantly found in low latitudes, it is recorded as a low latitude indicator. No examples of high-latitude taxa making similar short-lived incursions into low-latitude sites are noted. However, it was observed that presence/absence data are not always a reliable guide to biogeographic affinity, mainly due to equatorial submergence, a distribution pattern frequently observed in planktonic organisms (Stepanjants et al., 2006). As an example of this, Lithomelissa ehrenbergi (Bütschli, 1882), which was originally described from Barbados, might be considered to have a tropical or cosmopolitan distribution. However, the species is far more abundant at high-latitude sites, and only rarely recorded at low-latitude sites. Moreover, Haeckel (1887) found recent $L$. ehrenbergi from deep-water samples at low latitudes. Therefore, this taxon is a cold-water indicator, commonly found in high-latitude samples and sometimes found in deep-water samples in low latitudes.

\subsection{New Zealand Geological Timescale and radiolarian zonation}

The geological timescale used in this thesis is GTS 2012 (Gradstein et al., 2012; Cohen et al., 2014). New Zealand stages have been recently calibrated to this timescale by Raine et al. (2015). Low latitude microfossil zones and key datums were calibrated to GTS 2012 by the shipboard micropaleontology team on IODP Expedition 342 (Norris et al., 2012). High-latitude and mid-latitude Southern Hemisphere radiolarian zonations have yet to be fully recalibrated to GTS 2012. In this study, a preliminary recalibration is presented (Figure 3.13) in which the South Pacific zonation for the Late Cretaceous to middle Eocene (Hollis, 1993; Strong et al., 1995; Hollis, 1997, 2002; Hollis et al., 2005) is 
integrated with the Southern Ocean zonation for the middle Eocene to early Oligocene (Takemura, 1992; Takemura and Ling, 1997; Funakawa and Nishi, 2005). Zones within this Southern Hemisphere zonation are referred to as $\mathrm{RPXX}_{\mathrm{SH}}$, herein, whereas low latitude zones are referred to as $\mathrm{RPXX}$ LL.

A brief description of the basis for recalibrating the Southern Hemisphere zones to the GTS 2012 is provided below (in blue) by C. Hollis (pers. comm. 2016). All zones are interval zones. The following abbreviations are used: $\mathrm{LO}=$ lowest occurrence, $\mathrm{LCO}=$ lowest consistent occurrence, $\mathrm{HO}=$ highest occurrence, $\mathrm{HCO}=$ highest consistent occurrence.

Zones RP1sh to RP5sh. These zones were established by Hollis (1993). Woodside Creek is the type section for RP1 $1_{\mathrm{SH}}$ to RP4 $4_{\mathrm{SH}}$ and DSDP Site 208 is the type section for RP5 ${ }_{\mathrm{SH}}$. Updated descriptions were provided in Hollis (2002). The base of RP1 $1_{\mathrm{SH}}$ coincides with the Cretaceous-Paleogene boundary $(\underline{66.04 \mathrm{Ma}})$. The base of $\mathrm{RP} 2_{\mathrm{SH}}$ is within the upper part of calcareous nannofossil zone NP1 ( $\underline{\sim 65.5 \mathrm{Ma}})$. The base of RP3 ${ }_{\mathrm{SH}}$ is poorly constrained but currently placed in upper NP2 ( 64.9 Ma). The base of RP4 $4_{\mathrm{SH}}$ is also poorly constrained but currently placed in mid-NP3 ( 64 Ma). The base of Zone RP5 $5_{\mathrm{SH}}$ is relatively well constrained at DSDP Site 208 and ODP Site 1121 (Hollis 2002) where the primary datum, the LO of Buryella tetradica, is in the middle of NP5 ( 62.3 Ma).

Zone RP6sh. This zone was established by Hollis (1997) and subsequently revised in Hollis (2002). Mead Stream is the type section but DSDP Site 208 and ODP Site 1121 are important reference sections. The base is defined by the LOs of Bekoma campechensis or Buryella pentadica. In low latitudes and the North Atlantic, these events are recorded within foraminiferal zone P1c (lower NP4 by Sanfilippo and Blome, 2001), at 63 Ma. The LOs of both species are much later in the Southwest Pacific, perhaps as much as 3 million years later. The LO of B. pentadica is within NP5 (Hollis, 2002) and the LO of $B$. campechensis is within an interval correlated with NP6-8 at Mead Stream (Hollis et al., 2005). The base of the zone is placed in upper NP5 at $\sim 60.5 \mathrm{Ma}$ based on age control for the LO of B. pentadica at ODP Site 1121 and DSDP Site 208 (Hollis, 2002). The LOs of Aspis velutochlamydosaurus and Lychnocanium babylonis also lie near the base of the zone. 


\section{Chapter 3: Material and methods}

Zone RP7sh. This zone was established by Hollis (1997) and subsequently revised in Hollis et al. (2005). Mead Stream is the type section. The base was originally placed at the $\mathrm{HO}$ of Bekoma campechensis but because this genus is very rare in the Southwest Pacific, the primary datum for the base of the zone was changed to the LO of Phormocyrtis striata exquisita. In low latitudes and the North Atlantic, this event occurs near the base of NP5 ( 61.5 Ma). However, the event does not occur until some 4 million years later in the Southwest Pacific ( $\sim 58 \mathrm{Ma}$, mid-NP8). For this reason, the base of this zone is dated at $\sim 58 \mathrm{Ma}$. The LOs of Phormocyrtis striata striata and Lamptonium pennatum are in the lower part of the zone, coincident with the base of zone NP9 ( 57 Ma) at Mead Stream (Hollis et al., 2005).

Zone RP8sh. Mead Stream is the type section. This zone was established by Hollis (1997) and revised in Hollis et al. (2005). The base was originally placed at the LO of Bekoma bidartensis but because this genus is very rare in the Southwest Pacific, the primary datum for the base of this zone was changed to the LO of Podocyrtis papalis. Hollis et al. (2005) also established that this event also coincides with the Paleocene-

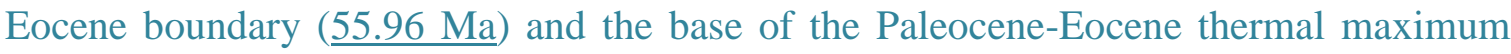
(PETM) at Mead Stream. Several low-latitude species have LOs at this horizon, including B. bidartensis, Amphicraspedum prolixum s.s. Lamptonium fabaeforme fabaeforme, Lychnocanium auxillum, Phormocyrtis cubensis, P. turgida, and Theocorys? phyzella. Most of these species, including P. papalis are present in the late Paleocene in low latitudes but appear to migrate into the mid-latitude southern Pacific as a consequence of ocean warming during the PETM. One of these species, however, appears to be a global marker for the base of the Eocene: Phormocyrtis turgida (Sanfilippo and Blome, 2001).

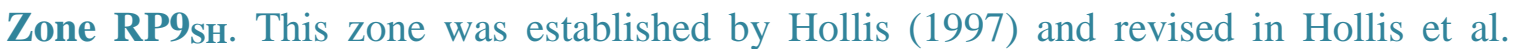
(2005). Mead Stream is the type section. The base was originally placed at the HO of Bekoma divaricata but because this genus is very rare in the Southwest Pacific, the primary datum for the base of the zone was changed to the $\mathrm{HO}$ of Lychnocanium auxillum. The age of this datum at Mead Stream is now well constrained by magnetostratigraphy and calcareous nannofossil biostratigraphy (Dallanave et al., 2015). It lies within magnetochron $\mathrm{C} 24 \mathrm{r}$ and close to the base of nannofossil zone NP11, indicating an age of $\sim 54 \mathrm{Ma}$ for the base of the zone. Several other events occur close to the base of RP9 $9_{\mathrm{SH}}$ the HOs of Phormocyrtis cubensis, P. turgida and Theocorys? 
phyzella and the $\mathrm{HCO}$ of Phormocyrtis striata exquisita. Other key events within the zone include the LOs of Lychnocanium bellum ( 53.2 Ma) and Theocampe urceolus ( 52 Ma) and the $\mathrm{HO}$ of Buryella tetradica near the top of the zone ( 51 Ma).

Zone RP10sh. This zone was established by Hollis (1997) based on the radiolarian succession at Mead Stream (Strong et al., 1995), which is the type section. The base is defined by the LO of Theocampe mongolfieri. This event is relatively well constrained to upper Chron C22r and directly above the base of nannofossil zone NP13 indicates an age of $\sim 49.7 \mathrm{Ma}$ (Strong et al., 1995; Dallanave et al., 2015). However, the species is very rare and sometimes difficult to identify and so a secondary datum at the same level, HO Podocyrtis aphorma, is a useful substitute in some records. The HO of Podocyrtis acalles occurs at $\sim 48.1 \mathrm{Ma}$ in low-latitudes. The $\mathrm{HO}$ of Buryella tetradica is also a useful alternative datum close to the top of the underlying zone. The HOs of Amphicraspedum prolixum s.s. and Phormocyrtis striata striata are in lower RP10 ${ }_{\mathrm{SH}}$ at Mead Stream ( 48.8 Ma).

Zone RP11sh. This zone was established by Hollis (1997) based on the radiolarian succession at Mead Stream (Strong et al., 1995), which is the type section. The base is defined by the LO of Eusyringium lagena, which occurs within Chron 21 but above the base of the Porangan Stage based on foraminifera (Dallanave et al., 2015). We estimate an age of $\sim 45.2 \mathrm{Ma}$ for the base of the zone. In low latitudes, the LO of E. lagena occurs earlier (46.21 Ma). The LO of Sethocyrtis chrysallis occurs in the upper part of the zone at Mead Stream ( 43.4 Ma).

Zone RP12sh. This zone was established by Hollis (1997) based on the radiolarian succession at Mead Stream (Strong et al., 1995), which is the type section. The base is defined by the LO of Eusyringium fistuligerum, which occurs within Chron 20n at Mead Stream and at the same level as the primary foraminiferal datum for the base of the Bortonian stage, the LO of Globigerinatheka index (Dallanave et al., 2015). For this reason, the base of the zone is placed at the base of the Bortonian (42.6 Ma). In low latitudes, E. fistuligerum has an earlier LO at $44.46 \mathrm{Ma}$ (Sanfilippo and Blome, 2001). The LO of Eucyrtidium nishimurae occurs within the zone; magnetostratigraphy at ODP Site 1172 provides a well-constrained age of $\sim 41.3 \mathrm{Ma}$ (mid-C19n) for this event (Suzuki et al., 2009). In lower latitudes, this interval includes the LOs of Zealithapium anoectum ( 42.5 Ma, mid-RP14LL), the HO of Eusyringium lagena ( 42.6 Ma, mid-RP14 $\left.{ }_{\mathrm{LL}}\right)$ and 


\section{Chapter 3: Material and methods}

Cryptocarpium ornatum (41.33 Ma, upper RP14 2 L). HO of Artobotrys biaurita occurs at $\sim 40.5 \mathrm{Ma}$ in low-latitudes, close to the base of RP15LL.

Zone RP13sh. This zone was established by Hollis (1997) based on the radiolarian succession at Mead Stream (Strong et al., 1995), which is the type section. The base is defined by the LO of Zealithapium mitra, which occurs within Chron C18n.1n (39.63 to $38.62 \mathrm{Ma}$ ) but still within the Bortonian stage (older than $39.1 \mathrm{Ma}$ ), based on foraminifera, at Mead Stream. This indicates an age for the base of the zone of $\sim 39.2 \mathrm{Ma}$. In low-latitudes, this taxon has an earlier occurrence at $\sim 42.3 \mathrm{Ma}$. Other events that occur within this time interval in lower latitudes include the LOs of Lithocyclia aristotelis and Theocampe pirum at 38.95 Ma.

Zone RP14sh (Eucyrtidium spinosum zone). This zone was established by Takemura (1992) and revised by Takemura and Ling (1997). The base is defined by the LO of Eucyrtidium spinosum. The best age control for this event is at ODP Site 748 (Takemura and Ling, 1997) where it is located within Chron C17n (38.33 to $36.97 \mathrm{Ma}$ ), close to the HO of Subbotina linaperta (37.96 Ma) and the LCO of Chiasmolithus oamaruensis (base of NP18, $37.32 \mathrm{Ma}$ ). We place the base of the zone at the middle/late Eocene boundary, 37.8 Ma, which is consistent with the DSDP Site 277 record, reported herein as well as the other Southern Ocean sites described by Takemura and Ling (1997). The HO of Eucyrtidium nishimurae occurs in mid-RP14 ${ }_{\mathrm{SH}}(\sim 36.7 \mathrm{Ma}$; Funakawa and Nishi, 2005). The HO of Lychnocanium amphitrite occurs near the top of the zone at $35.3 \mathrm{Ma}$ in high latitudes (Funakawa and Nishi, 2005) and $233.89 \mathrm{Ma}$ in low latitudes. Other events that occur within this time interval in lower latitudes include the HOs of Spongatractus pachystylus (37.75 Ma) and Cryptocarpium ornatum (33.89 Ma).

Zone RP15sh (Eucyrtidium antiquum zone). This zone was established by Funakawa and Nishi (2005) and is equivalent to the lower part of the Axoprunum irregularis zone of Takemura (1992; Takemura and Ling, 1997). The base is defined by the LO of Eucyrtidium antiquum, which approximately coincides with the Eocene-Oligocene boundary at 33.9 Ma (Funakawa and Nishi, 2005). A secondary datum within this zone, the LO of Axoprunum irregularis, occurs in lowermost Chron C13n with an estimated age of $\sim 33.7 \mathrm{Ma}$. 
Zone RP16sh (Lychnocanoma conica zone). This zone was established by Takemura (1992), revised by Takemura and Ling (1997) and further substantially revised by Funakawa and Nishi (2005). The base is defined by the LO of Lychnocanium aff. conicum (Lychnocanoma conica of the authors), which occurs within Chron C11n (29.97 to $29.183 \mathrm{Ma}$ ) and has an estimate age of $\simeq 29.6 \mathrm{Ma}$.

Zone RP17sh and RP18sh (Clinorhabdus robusta and Stylosphaera radiosa zones). These zones were described by Abelmann (1990) and emended by Funakawa and Nishi (2005). They are calibrated to GTS2012 using the magnetostratigraphic control outlined by Funakawa and Nishi (2005). The bases of the two zones are $\sim 28.5 \mathrm{Ma}$ and $\sim 26.25 \mathrm{Ma}$, respectively. The top of RP18 ${ }_{\text {SH }}$ has not been defined. 
Paleogene Geological Timescale and Biozones

\begin{tabular}{|c|c|c|c|c|c|c|c|c|c|c|c|c|}
\hline \multirow[b]{2}{*}{$\mathrm{Ma}$} & \multicolumn{4}{|c|}{ ICC 2014/10 } & \multicolumn{3}{|c|}{ NZGT 2015/1 } & \multicolumn{3}{|c|}{$\begin{array}{c}\text { Calcareous } \\
\text { microfossil zone }\end{array}$} & \multicolumn{2}{|c|}{$\begin{array}{l}\text { Radiolarian } \\
\text { zone }\end{array}$} \\
\hline & GPTS & Epoch & $\begin{array}{l}\text { Sub- } \\
\text { Epoch }\end{array}$ & Age & Series & Stage & Code & For & CP & NP & LL & $\mathrm{SH}$ \\
\hline $22=$ & $22.56 \mathrm{C} 6 \mathrm{~B}$ & $\frac{1}{5}$ & early & Aquitanian $_{23.03}$ & & & & M1a & $\mathrm{CN} 1$ & NN2 & ר2סקו & $\ln 7$ \\
\hline $23=$ & $\frac{3.96 \mathrm{C} 6 \mathrm{C}}{4.76 \mathrm{C} 7}$ & $\stackrel{\circlearrowright}{\stackrel{0}{\Sigma}}$ & & & & $\begin{array}{l}\text { Waitakian } \\
\qquad 25.2\end{array}$ & Lw & $\mathrm{O} 7$ & & NN1 & 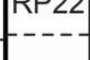 & Unzoned \\
\hline $26=$ & $\frac{25.10 \mathrm{C} 7 \mathrm{~A}}{26.42 \mathrm{C} 8}$ & & late & Chattian & & Duntroonian & Ld & O6 & СP19 & NP25 & RP21 & $\begin{array}{l}\text { RP18SH } \\
-----1 .\end{array}$ \\
\hline $27=$ & $86 \mathrm{C} 9$ & $\underset{\Phi}{\Phi}$ & 28.1 & 28.1 & 등 & $\begin{array}{r}27.3 \\
\end{array}$ & & O5 & & & & $\mathrm{RP} 17_{\mathrm{SH}}$ \\
\hline & $9.18 \mathrm{C} 10$ & Ü & & & సั & upper & & 04 & & NP24 & & $\mathrm{RP} 16_{\mathrm{SH}}$ \\
\hline $30=$ & ${ }_{30.59} \mathrm{C} 11$ & 을 & & & & & & O3 & $=-\mathrm{CP} 18$ & & & \\
\hline $31=$ & C12 & 0 & early & Rupelian & & Whaingaroan & Lwh & $\mathrm{O} 2$ & CP17 & NP23 & RP20 & RP15sh \\
\hline $33=$ & 3.16 & & 33.9 & 33.9 & & lower & & O1 & CP16 & \begin{tabular}{|l|} 
NP22 \\
NP21 \\
\end{tabular} & & \\
\hline $\begin{array}{l}34= \\
35-\end{array}$ & $35 .{ }^{\mathrm{C} 13}$ & & & & & 34.6 & & E16 & & & RP19 & \\
\hline $36=$ & & & late & Priabonian & & $\begin{array}{r}\text { Runangan }_{36.7} \\
\end{array}$ & Ar & E15 & CP15 & $\left|\begin{array}{c}N P 19 \\
/ 20\end{array}\right|$ & RP18 & $\mathrm{RP} 14_{\mathrm{SH}}$ \\
\hline $\begin{array}{l}37= \\
38=\end{array}$ & $\mathrm{C} 17$ & & 37.8 & 37.8 & 는 & Kaiatan & Ak & E14 & & FP18 & $=\overline{R P} 17$ & \\
\hline $39=$ & & & & Bartonian & 은 & 39.1 & & E13 & & NP17 & RP16 & RP13SH \\
\hline $\begin{array}{l}40= \\
41=\end{array}$ & $\begin{array}{l}\text { C18 } \\
1.15\end{array}$ & & & 41.2 & & Bortonian & $A b$ & $=E 12=$ & CP14 & & $=\overline{R P} \overline{15}$ & RP12 \\
\hline $42=$ & ${ }_{42.3} \mathrm{C} 19$ & & & & & & & & & NP16 & RP14 & 1. I $2 \mathrm{SH}$ \\
\hline $43-$ & & & middle & & & & & E10 & & & & \\
\hline $\begin{array}{l}44- \\
45-\end{array}$ & $\mathrm{C} 20$ & $\overline{0}$ & & Lutetian & & Porangan & Dp & $\mathrm{F} 8$ & CP13 & NP15 & R-13 & RP11sh \\
\hline $46=$ & 172 & 요 & & & & & & & & NP15a & RP12 & \\
\hline $47=$ & C21 & & 47.8 & 47.8 & & Heretaungan & Dh & $E 7 b$ & |CP12 & INP14 & RP11 & $\mathrm{RP} 10_{\mathrm{SH}}$ \\
\hline $49=$ & & & & & & & & 570 & & & $F-\bar{R} P 10$ & \\
\hline $50=$ & ${ }_{50.63}^{C 22}$ & & & & & Mangaorapan & $\mathrm{Dm}$ & Ela & CP11 & NP13 & RP9 & \\
\hline $\begin{array}{l}51= \\
52=\end{array}$ & $\mathrm{C}_{62}$ & & early & Ypresian & 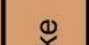 & 52.0 & & E5 & |CP10 & INP12 & RP8 & $\mathrm{RP}_{\mathrm{SH}}$ \\
\hline $\begin{array}{l}53- \\
54=\end{array}$ & & & & & (1) & Waipawan & Dw & E4 & CPO & NP11 & & \\
\hline $55=$ & C24 & & 56.0 & 56.0 & $\frac{\mathrm{C}}{\mathrm{N}}$ & & & $\frac{E 3}{E 1}=2$ & Cry & NP10 & PP7 & $\mathrm{RP}_{\mathrm{SH}}$ \\
\hline $\begin{array}{l}56= \\
57=\end{array}$ & 57.1 & & & Thanatin & & & & P5 & СР8 & NP9 & RाP & RP7sh \\
\hline $58=$ & $\mathrm{C} 25$ & $\stackrel{\oplus}{\complement}$ & late & Thanetian & & unner & & & CP6 & NP8 & & \\
\hline & & $\overline{0}$ & & & & & & P4b & CP5 & $=\mathrm{NPP}$ & $R P G$ & $\mathrm{RP}_{\mathrm{SH}}$ \\
\hline $\begin{array}{l}60= \\
61=\end{array}$ & C26 & రั & middle & Selandian & & Teurian & Dt & $\mathrm{P}_{\mathrm{P}}^{\mathrm{Pa}}$ & CP4 & NP5 & $\mathrm{RP}$ & - \\
\hline $62=$ & 2.22 & $\overline{0}$ & & & & & & $2 \stackrel{p a}{3}+2$ & CP3 & NP4 & 0 & 5SH \\
\hline $63=$ & 63.49 & & & $\operatorname{lon}$ & & Jaw & & $\mathrm{P} 1 \mathrm{c}$ & & 1014 & (1) & $\mathrm{RP}_{\mathrm{SH}}$ \\
\hline 64 & ${ }_{64.96}^{\mathrm{C} 28}$ & & early & Danian & & lower & & $P$ & CP2 & NP3 & N & $\bar{R} \bar{P} 3$ \\
\hline & $\mathrm{C} 29$ & & 66.0 & 66.0 & & 66.0 & & & CP1 & $-\mathrm{NP} 1=$ & ร & $\mathrm{RP} 1^{-}-\mathrm{RP} 2$ \\
\hline $67=$ & $\begin{array}{l}\mathrm{C} \\
68.37\end{array}$ & 远 & Maastr. & Maastrichtian & Mata & Haumurian $_{83.6}$ & Mh & & & & A.tyl. & RK9 \\
\hline
\end{tabular}

Figure 3.13 Chart of Paleogene Geological Timescale after Raine et al. (2015) and biozones used in this study. Calcareous microfossil zones and low-latitude (LL) radiolarian zonation were calibrated to GTS 2012 by Norris et al. (2012); Southern Hemisphere ( $\mathrm{SH})$ radiolarian zonation is based on Hollis (pers. Comm. 2016). Abbreviations: For=planktonic foraminifer zonal scheme of Berggren and Pearson (2005) as modified by Wade et al. (2011) for the Paleogene; $\mathrm{CP}=$ Coccoliths Paleogene zones after Okado and Bukry (1980); NP=Paleogene nannoplankton zonation after Martini $(1970 ; 1971)$.

\subsection{Paleogeographic reconstructions}

Tectonic reconstructions of the Australia-Antarctica-Pacific plate circuit were undertaken in GPlates (Boyden et al., 2011) using finite poles of rotation for the relative motions between Australia and East Antarctica from Cande and Stock (2004) (0-38.13 Ma) and Whittaker et al. (2013) (43.79-79.08 Ma), East Antarctica and West Antarctica from Granot et al. (2013) (30.94-40.13 Ma) and West Antarctica and Pacific from Croon et al. 
(2008) (0-42.54 Ma) and Wobbe et al. (2012) (42-83 Ma). Relative motions of the Australia-Antarctica-Pacific plate circuit were tied to the Australian paleomagnetic apparent polar wander path of Torsvik et al. (2012) to provide an estimate of paleolatitude appropriate for paleoclimate studies (van Hinsbergen et al., 2015). The $2000 \mathrm{~m}$ isobath from the GEBCO bathymetric grid was used to approximate continental boundaries. DSDP and ODP sites have been assigned to the appropriate plate for reconstruction. The paleolatitudes of all sites included in this study (except of Mead Stream and MidWaipara) were determined using the online calculator at www.paleolatitude.org (van Hinsbergen et al., 2015).

\subsection{Stable isotopes measurements}

\subsubsection{DSDP Site 277}

At the University of California Santa Cruz (UCSC) and the University of Southampton (UoS), stable oxygen $\left(\delta^{18} \mathrm{O}\right)$ and carbon $\left(\delta^{13} \mathrm{C}\right)$ isotope ratios were determined for bulk carbonate, Cibicides spp., Subbotina spp. (Core 277-34R (332.62 mbsf) to -18R (159.88 mbsf)) and Globigerinatheka index (Core 277-34R (332.62 mbsf) up to its last occurrence in Core 277-21R (188.58 mbsf)). In total, 157 samples spanning the middle Eocene to lower Oligocene interval of DSDP Site 277 were measured and all measurements were published in Pascher et al. (2015). Stable isotope analyses at UCSC were performed on a VG Prism dual-inlet mass spectrometer coupled to a carousel preparation device with common acid bath maintained at $90^{\circ} \mathrm{C}$. Analyses at the UoS were performed on a Europa GEO 20-20 dual-inlet mass spectrometer with Cassini Plasma Spectrometer preparation oven maintained at $70^{\circ} \mathrm{C}$. All values are reported relative to the Vienna Pee Dee Belemnite (VPDB) standard. In both labs, analytical precision based on replicate analyses of in-house marble standards and NBS-19 averaged $\sim 0.05 \%$ o $(1 \sigma)$ for $\delta^{13} \mathrm{C}$ and $\sim 0.08 \%$ o $(1 \sigma)$ for $\delta^{18} \mathrm{O}$. All planktic foraminifera in this record appeared to have a "frosty" preservation, which reflects some degree of dissolution after sedimentation and alteration of its shell chemistry.

\subsubsection{DSDP Site 207}

At the University of California Santa Cruz (USCS), stable oxygen $\left(\delta^{18} \mathrm{O}\right)$ and carbon $\left(\delta^{13} \mathrm{C}\right)$ isotope ratios were determined for two benthic foraminifera species, Cibicides 
praemundulus and Nuttalides truempyi (Core 207A-21R (242.48 mbsf) to -11R (143.58 mbsf)). In total, a set of 15 samples spanning the lower to middle Eocene of DSDP Site 207 were measured. Stable isotope analyses at UCSC were performed on a ThermoScientific Kiel IV carbonate device interfaced to ThermoScientific MAT-253 dual-inlet isotope ratio mass spectrometer. All values are reported relative to the VPDB standard. Analytical precision based on calibration to in-house Carrera Marble and NBS18 limestone standards is $\sim 0.05 \%$ o $(1 \sigma)$ for $\delta^{13} \mathrm{C}$ and $\sim 0.08 \%$ o $(1 \sigma)$ for $\delta^{18} \mathrm{O}$.

\subsubsection{DSDP Site 592}

Stable oxygen $\left(\delta^{18} \mathrm{O}\right)$ and carbon $\left(\delta^{13} \mathrm{C}\right)$ isotope ratios were determined for the fine fraction $(<63 \mu \mathrm{m})$ from Core $592-41 \mathrm{X}$ to $-38 \mathrm{X}(387.20-350.90 \mathrm{mbsf})$ at the National Isotope Centre (NIC), GNS Science, Lower Hutt. Twenty-three samples from the upper Eocene were analysed on a GVI IsoPrime Carbonate Preparation System at a reaction temperature of $50^{\circ} \mathrm{C}$ for 24 hours and run via dual inlet on the IsoPrime mass spectrometer. All values are reported relative to the VPDB standard. Analytical precision, based on calibration the in-house GNS Marble with reported values of $2.04 \%$ for $\delta^{13} \mathrm{C}$ and $-6.20 \%$ for $\delta^{18} \mathrm{O}$, are better than $0.1 \%$ for $\delta^{13} \mathrm{C}$ and $0.2 \%$ for $\delta^{18} \mathrm{O}$. 


\section{Radiolarian occurrence}

This chapter provides an overview of the observed patterns in sedimentary components, radiolarian abundance and preservation at all studied sites. The first part comprises the high-latitudes sites. Radiolarians from the main high-latitude site, DSDP Site 277 were first studied by Hollis et al. (1997). However, only presence-absence was recorded for the late Eocene to Oligocene interval. In this study a more detailed quantitative study of the site was undertaken with a focus on the middle Eocene to early Oligocene interval because radiolarians are relatively rare and poorly preserved in the Paleocene and lower Eocene interval. For the sake of completeness, Appendix B (data on enclosed CD) contains all radiolarian and sample data for this site and the biostratigraphic section, the age-depth plot and the paleobiogeographic affinity comprise the whole record. However, for the discussion on diversity and radiolarian assemblage analysis in Chapter 6, only the middle Eocene to lower Oligocene interval will be discussed. In addition to Site 277, four other high-latitude sites covering the same time interval were studied. The second part of this chapter examines the mid-latitude sites. The main mid-latitude site is DSDP Site 207, which comprises a lower to middle Eocene interval of well-preserved radiolarians. In addition to this site, three other mid-latitude sites covering an upper middle Eocene to lower Oligocene interval were studied. A summary at the end of this chapter compares the main findings from each site.

\subsection{High-latitude sites}

\subsubsection{DSDP Site 277}

Radiolarians are very rare to few ( $<50$ radiolarians $/ g$ ), and poorly to moderately preserved in the upper Paleocene to lower Eocene (Cores 277-46R to -42R; 468.49-426.34 mbsf) (Figure 4.1). Two isolated peaks in abundances (150 radiolarians/g and 1600 radiolarians/g) are recorded in the lower Eocene at 455.30 and $447 \mathrm{mbsf}, \sim 2 \mathrm{~m}$ and $\sim 10 \mathrm{~m}$ above the Paleocene-Eocene boundary, respectively. Overall, the acid-leached residues through this interval are dominated by sand grains, with relatively common silicified casts of foraminifera. The upper lower Eocene and the middle Eocene (Cores 277-41R to -29R; 416.20-264.50 mbsf) are characterised by slightly more abundant radiolarians (20-100 radiolarians/g) (Figure 4.1) of poor to moderate preservation. The residue is still 
dominated by sand grains. Isolated occurrences of abundant sponge spicules (380.8 mbsf) and silicified casts of foraminifera (312.70 mbsf) are noted. A short interval at 313.5-296 mbsf contains better preserved radiolarians. The lower upper Eocene interval (Cores 277$28 \mathrm{R}$ to $-25 \mathrm{R} ; 254.50-227.2 \mathrm{mbsf}$ ) is characterised by very rare to common radiolarians ( $<100$ radiolarians/gram), but the preservation is only moderate and the residue is dominated by sand grains (Figure 4.1). In the upper Eocene (Cores 277-25R to -22R; 226.1-197.82 mbsf), radiolarians are abundant to very abundant (>1500 specimens/g), well preserved and accompanied by abundant spicules (5-35\%). A short-lived drop in radiolarian abundance ( $<500$ radiolarians/g) is observed at 210.5-207.5 mbsf. The lower Oligocene samples also have abundant to very abundant (1500-6400 radiolarians/g), well-preserved radiolarians (Cores 277-20R to 15R; 186.50-134.50 mbsf). Sponge spicules increase to $\sim 80 \%$ of the residue in the uppermost sample (134.50 mbsf). Radiolarian abundance decreases progressively through the E-O transition from a peak of 9600 radiolarians/g in the latest Eocene to $\sim 750$ radiolarians $/ g$ in the uppermost Oligocene sample (Figure 4.1). 


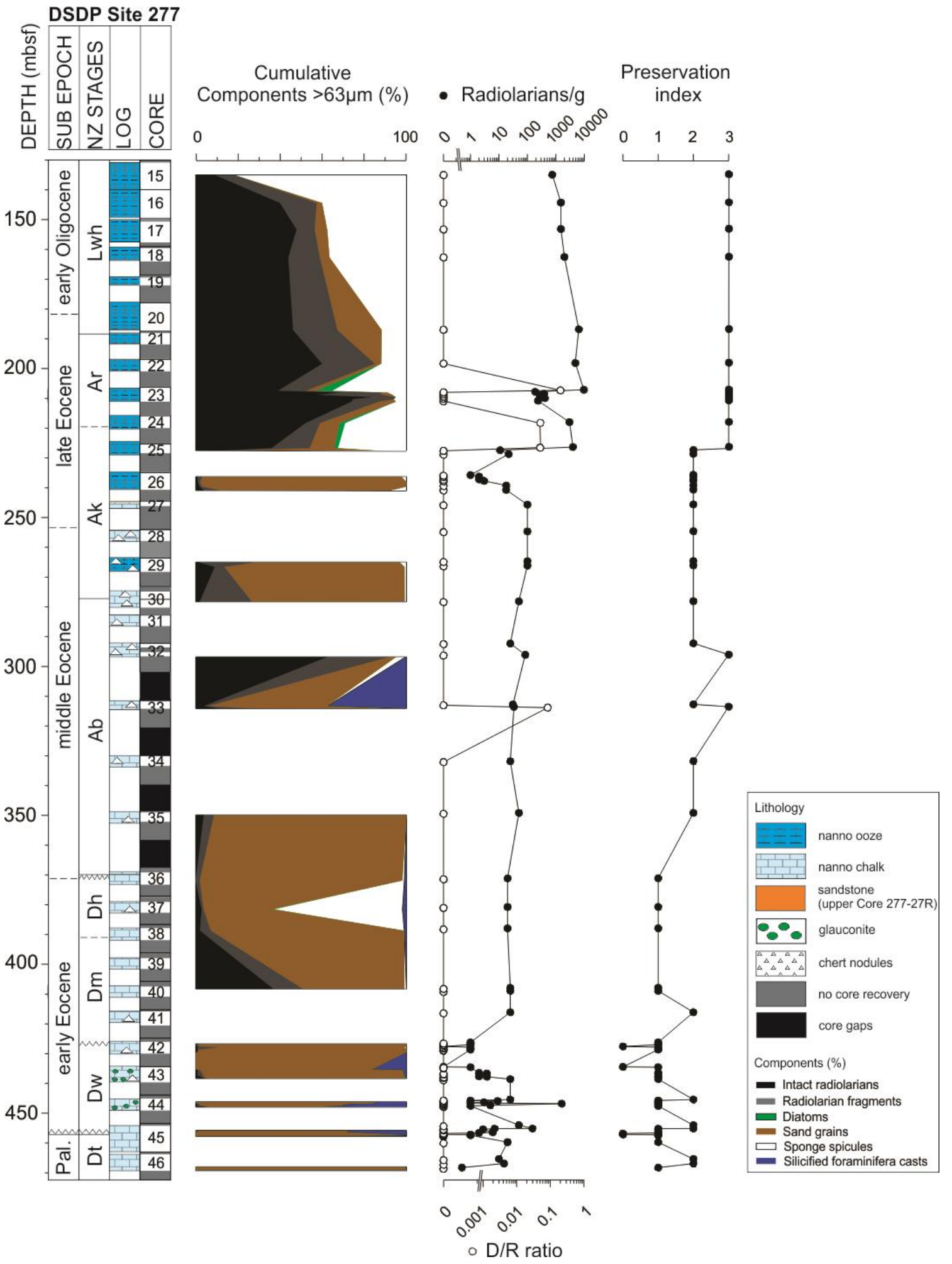

Figure 4.1 Overview of stratigraphy, NZ Stages, lithology and core recovery of DSDP Site 277; residue components, radiolarian abundance, diatom/radiolarian $(\mathrm{D} / \mathrm{R})$ ratio and radiolarian preservation. Preservation index: $0=$ barren, $1=$ poor, $2=$ moderate, $3=$ good. Gaps in the components record are due to samples being picked and no assessment of the residue has been undertaken. For abbreviations of NZ Stages, please see Chapter 3.6.

Diatoms are very rare at Site 277 and are restricted to three intervals. At $313.50 \mathrm{mbsf}$, the diatom/radiolarian (D/R) ratio is $\sim 0.08$, with $\sim 1 \%$ diatoms in the component analysis. At 
$\sim 226.10-217.70 \mathrm{mbsf}$, the $\mathrm{D} / \mathrm{R}$ ratio increases to $\sim 0.05$ ( $\sim 2-3 \%$ diatoms). The highest $\mathrm{D} / \mathrm{R}$ ratio of 0.2 is observed at $206.83 \mathrm{mbsf}$, with a $\sim 8 \%$ diatom component.

\subsubsection{DSDP Site 280}

Radiolarians are abundant (1000-2500 specimens/gram) (Figure 4.2) and well preserved (preservation index of 3) throughout the lower Oligocene. Diatoms are far more abundant than radiolarians $(\mathrm{D} / \mathrm{R} \sim 4-11)$, which is also shown by the compositional estimates as derived from examination of the residue ( $\sim 83 \%$ diatoms, $\sim 15 \%$ radiolarians). Rare sponge spicules occur in the uppermost sample (Core 280A-5R; 92.54 mbsf) (Figure 4.2).

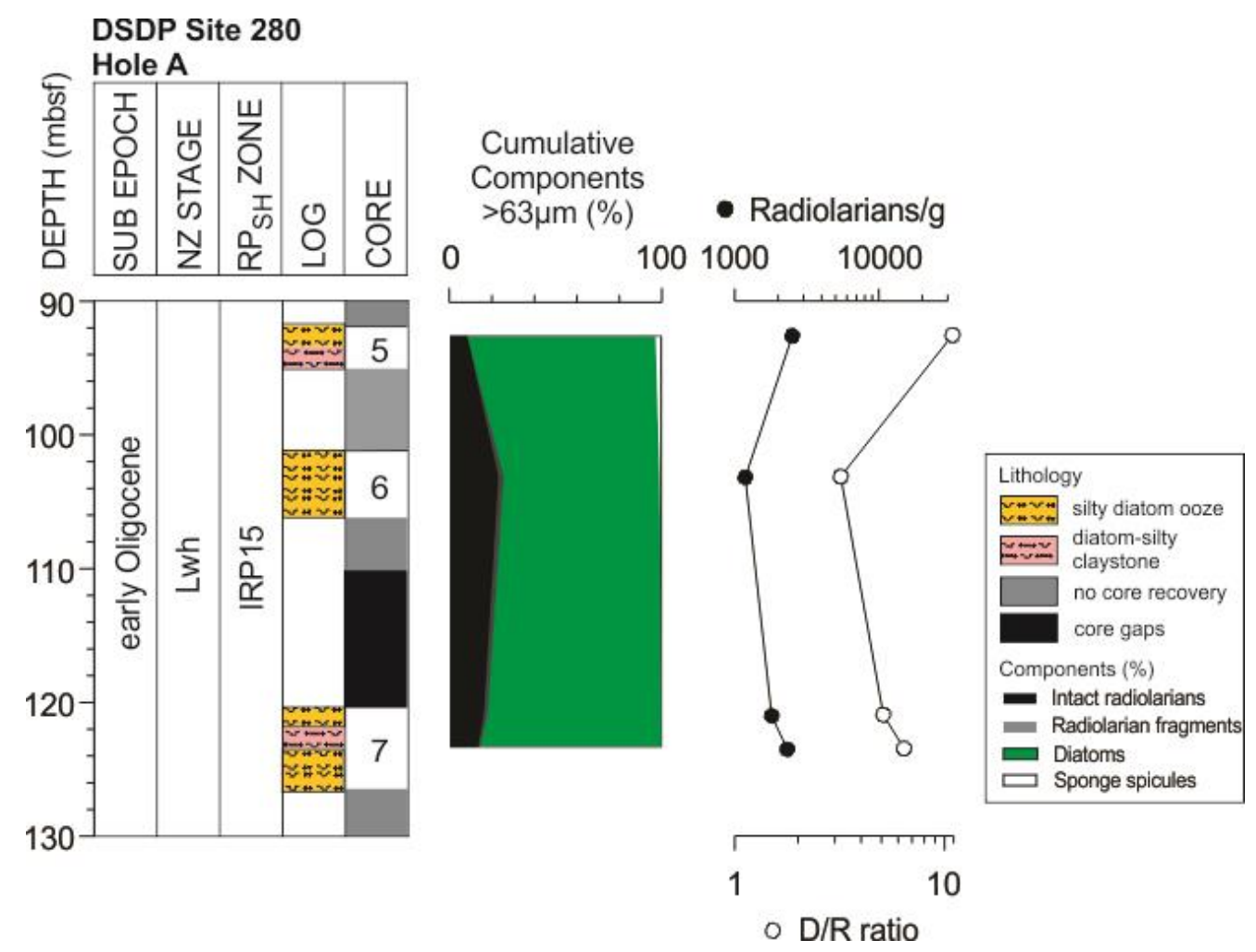

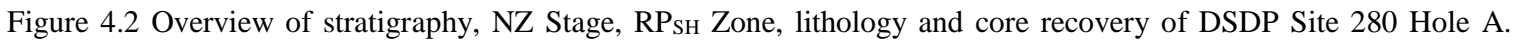
Residue components, radiolarian abundance and diatom/radiolarian (D/R) ratio.

\subsubsection{DSDP Site 281}

Results from three of the DSDP Site 281 samples discussed below were previously reported in Crouch and Hollis (1996) but have been re-examined for this study. Radiolarians are abundant ( 2300-3700 radiolarians/g) (Figure 4.3) and well preserved (preservation index of 3 ) in the lower upper Eocene ( Kaiatan) from Cores 281-16R to 14R (149-122.5 mbsf). Except for the uppermost two samples in Core 281-14R, diatoms are more abundant than radiolarians (D/R $\sim 3-5$ ) (Figure 4.3). The residue component 
analysis reveals a very different result compared to nearby Site 280 , as the residue is dominated by spicules ( $32 \%$ average) and diatoms ( 25\% average) (Figure 4.3$)$. Radiolarians have a constant abundance of $\sim 8 \%$. The lowermost and the uppermost samples are dominated by sand grains (62-66\%), which are mainly of glauconitic nature in the upper part of Core 281-14R. The higher content of sponge spicules at Site 281 compared to Site 280 indicates a shallower setting, which is also suggested by Crouch and Hollis (1996).

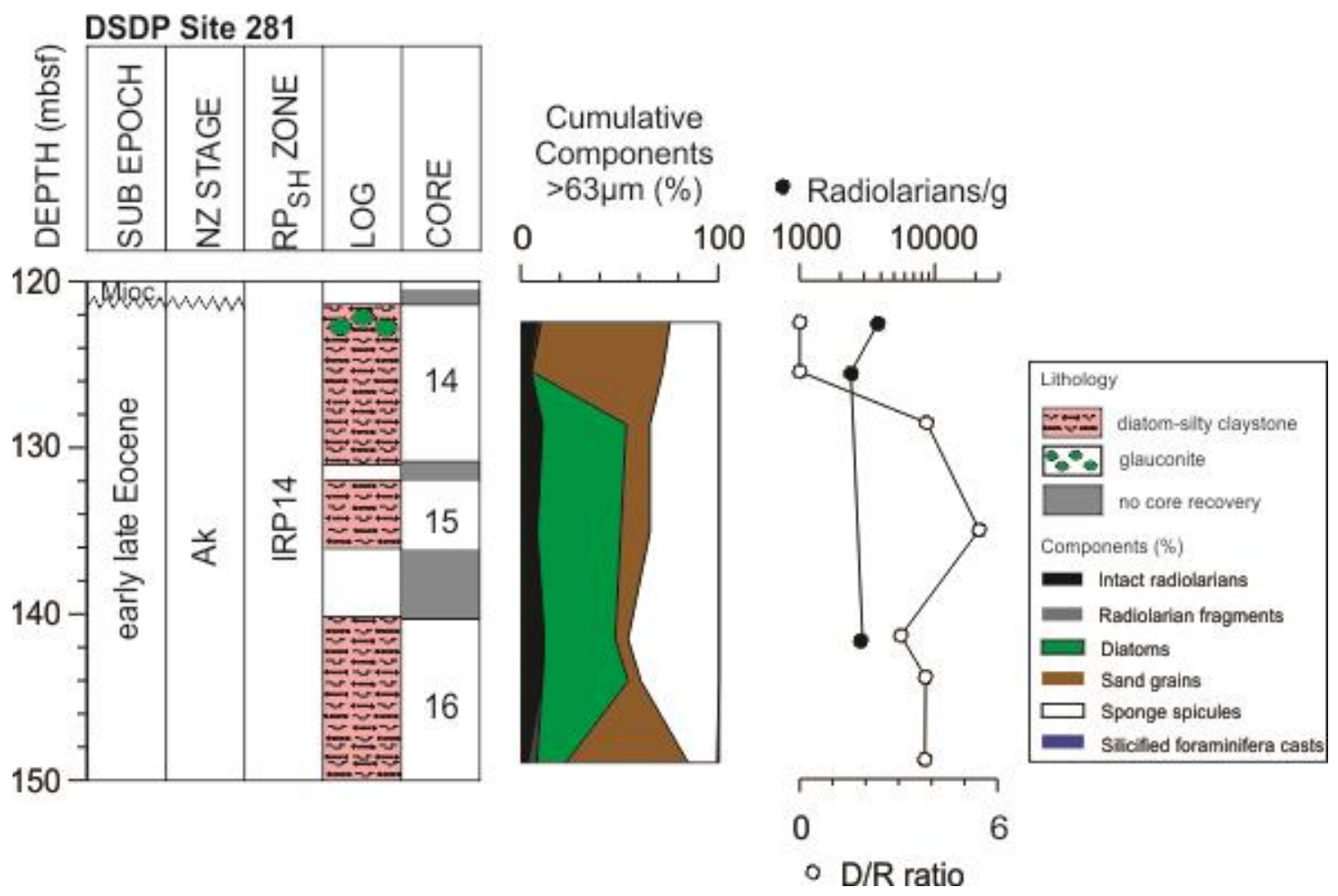

Figure 4.3 Overview of stratigraphy, NZ Stage, RP $\mathrm{SH}_{\mathrm{SH}}$ Zone, lithology and core recovery at DSDP Site 281. Residue components, radiolarian abundance and diatom/radiolarian (D/R) ratio.

\subsubsection{DSDP Site 283}

Radiolarians are very abundant (4700-21000 radiolarians/g) (Figure 4.4) and well preserved (preservation index of 3 ) in the investigated interval (Cores 283-8R to $-5 \mathrm{R}$; 192.25-87.75 mbsf). Diatoms are present in low to very high abundance with $\mathrm{D} / \mathrm{R}$ ratios of $0.1-1.1$. The highest $\mathrm{D} / \mathrm{R}$ ratio occurs in Core 283-6R (125.90 mbsf). Residues are made up of sponge spicules $(\sim 40 \%)$, radiolarians ( $27 \%$ on average), sand grains $(\sim 15 \%)$ and diatoms $(\sim 10 \%)$. The presence of siliceous ooze in the upper middle to upper Eocene and the absence (or very rare occurrence) of foraminifera at this deep-water site indicates a setting close or below the Calcite Compensation Depth (CCD). 


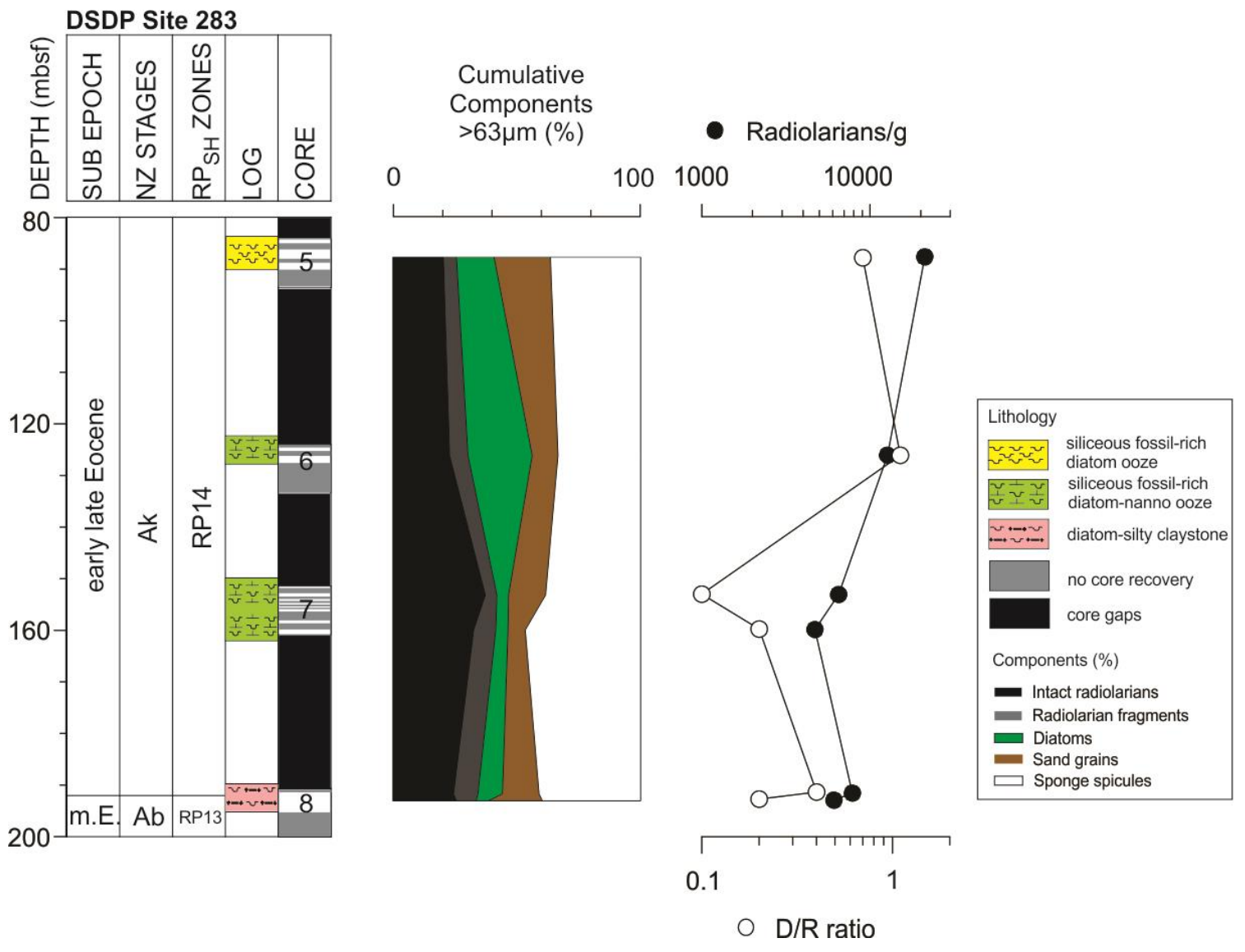

Figure 4.4 Overview of stratigraphy, NZ Stages, RPsh Zones, lithology and core recovery for DSDP Site 283. Residue components, radiolarian abundance and diatom/radiolarian $(\mathrm{D} / \mathrm{R})$ ratio.

\subsubsection{ODP Site 1172}

The initial radiolarian study of this site was carried out by Suzuki et al. (2009). No information on radiolarian or diatom abundance was provided. However, shipboard smear slide analysis (Shipboard Scientific Party, 2001) indicates that diatoms are more abundant than radiolarians $(\mathrm{D} / \mathrm{R}$ ratio $>1)$ (Figure 4.5). Furthermore, radiolarians are common to abundant throughout the Eocene and few in the Oligocene succession (Shipboard Scientific Party, 2001). Eocene silty claystone is overlain by a transitional unit in the uppermost Eocene consisting of glauconitic siltstone, which is interpreted to indicate increased bottom-water current activity in the uppermost Eocene (Kennett and Exon, 2004; Stickley et al., 2004a). There is a sharp transition to a pelagic carbonate unit consisting of nannofossil chalk in the lowermost Oligocene (Exon et al., 2004). Diatoms are more abundant and indicate a shallow neritic setting in the middle Eocene until 408 mbsf ( $39 \mathrm{Ma})$, where an increase in oceanic elements indicate a deeper outer neritic setting. Above $\sim 376 \mathrm{mbsf}$ ( $\sim 38 \mathrm{Ma}$ ), the diatom assemblage indicates an inner to outer 
neritic setting until the top of the investigated interval at $\sim 364$ mbsf ( $\sim 36 \mathrm{Ma})$ (Röhl et al., 2004).

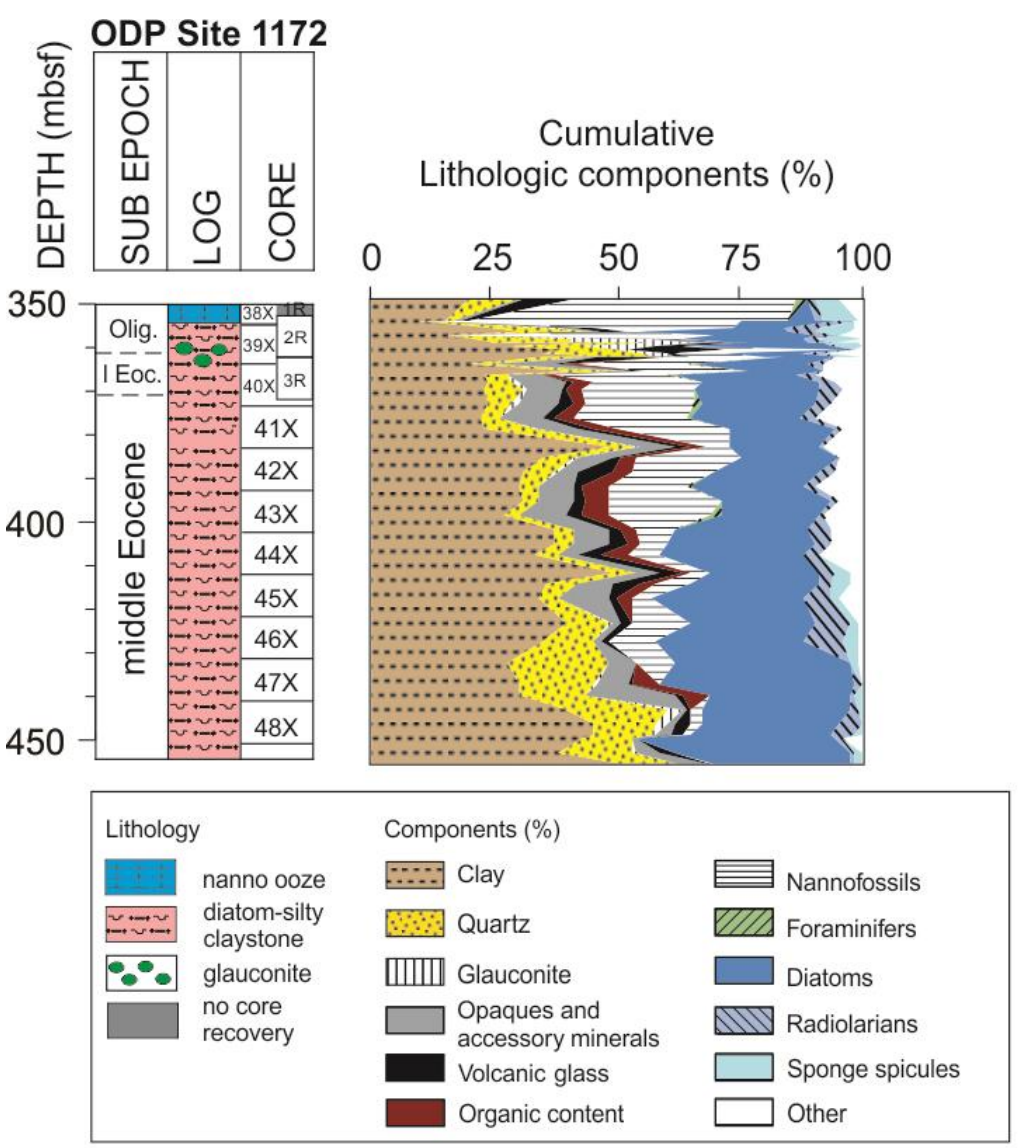

Figure 4.5 Results of smear-slide analyses of middle Eocene to lower Oligocene sediments of ODP Site 1172 Hole A (Cores 1172A-48X to -43X) and Hole D (Cores 1172D-3D to -1D); modified after Shipboard Scientific Party (2001).

\subsection{Mid-latitude sites}

\subsubsection{DSDP Site 207}

Radiolarians are generally very rare to rare ( $<20$ radiolarians/g) and poorly to moderately preserved (preservation index of 0 to 2 ) in the Cretaceous, Paleocene and lower Eocene (Cores 207A-30R to -21R; 319-245.38 mbsf) (Figure 4.6). Abundant radiolarians are present in a single sample (207A-28R-1, 100cm; $301 \mathrm{mbsf} ; 1000$ radiolarians/g) and very rare well-preserved radiolarians occur in Sample 207A-26R-2, $70 \mathrm{~cm}$ (284.20 mbsf). The residue of this interval has a high percentage of sand grains and silicified foraminifera casts. Dinoflagellate cysts are noted in Sample 207A-28-1, 100cm (301 mbsf). Radiolarian preservation improves and abundance increases abruptly (7000-66000 radiolarians/g) in Core 207A-21R (from Sample 207A-21R-4, 96cm; $242.46 \mathrm{mbsf}$ ) and 
abundance remains very high towards the top of this interval (Core 207A-12R; $152 \mathrm{mbsf}$ ) (Figure 4.6). Radiolarians show a small decrease in preservation and sand grains increase relative to radiolarians in Sample 207A-18R-3, 46cm (208.46 mbsf). However, radiolarian abundance could not be determined as this slide was from the MRC and no information on sample weight is available. Diatoms are very rare throughout the studied interval (D/R <0.01) and occur only from Core 207A-21R to -14R (242.46-171.82 mbsf). The highest diatom concentration (3-7\%) is recorded in the interval from 228.20-219.47 mbsf (Core 207A-20R to $-19 \mathrm{R}$ ) with a D/R ratio of 0.04-0.08. Radiolarians are absent or very rare in Core 207A-11R whereas sand grains and silicified foraminifera casts are abundant.

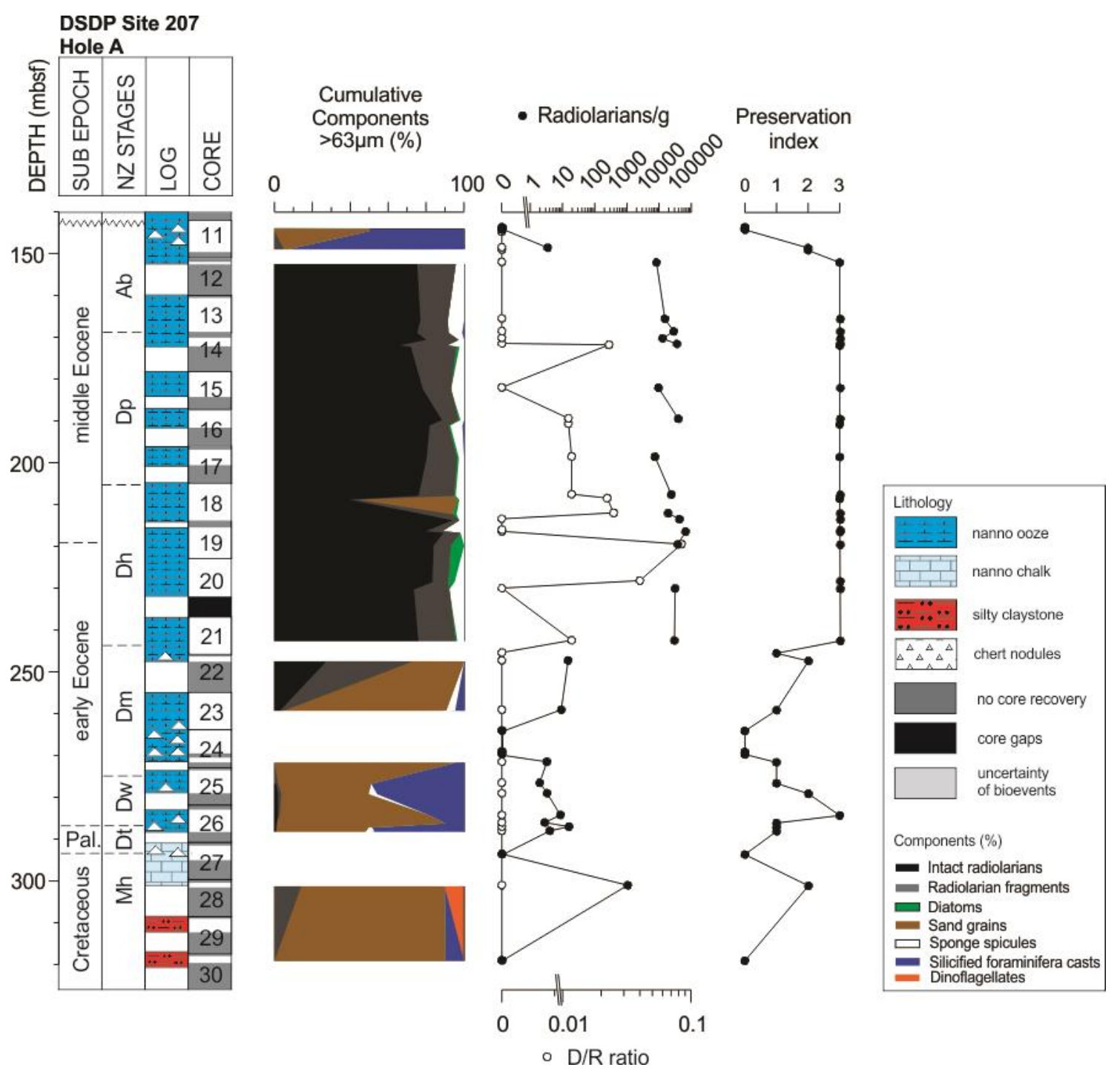

Figure 4.6 Overview of stratigraphy, NZ Stages, lithology and core recovery of DSDP Site 207 Hole A; residue components, radiolarian abundance, diatom/radiolarian $(\mathrm{D} / \mathrm{R})$ ratio and radiolarian preservation. Preservation index: $0=$ barren, $1=$ poor, $2=$ moderate, $3=$ good. Gaps in the residues components plot signify complete dissolution of the sediment. 


\subsubsection{DSDP Site 206}

Radiolarians are very rare and poorly to moderately preserved (preservation index of 0 to 2) from Core $206 \mathrm{C}-21 \mathrm{R}$ to $-19 \mathrm{R}$ (728-687.51 mbsf), an interval inferred to be Paleoceneearly Eocene in age (Figure 4.7). The residue is dominated by sand grains and silicified foraminifer casts in two samples (206C-20R-1, $39 \mathrm{~cm}$; 206C-19R-CC) (Figure 4.7). Radiolarian abundance was not determined due to difficulties in breaking down the sediment. The samples required multiple treatments with both $\mathrm{HCl}$ and $\mathrm{HF}$ using varying size fractions. A sudden improvement in radiolarian abundance and preservation (preservation index of 3) is observed in Core 206C-18R (672 mbsf) (Figure 4.7). Abundance remains high and preservation remains good to the top of the interval (Core 206C-15R; 613.75 mbsf), which spans a middle to late middle Eocene interval (Bortonian stage). The residue is dominated by radiolarians although diatoms are also abundant in the upper part ( 21\% at $634 \mathrm{mbsf}, \sim 36 \%$ at $613.75 \mathrm{mbsf}$ ). However, diatoms were generally clumped together on the slide, so the residue count tends to result in an underestimate of their abundance.

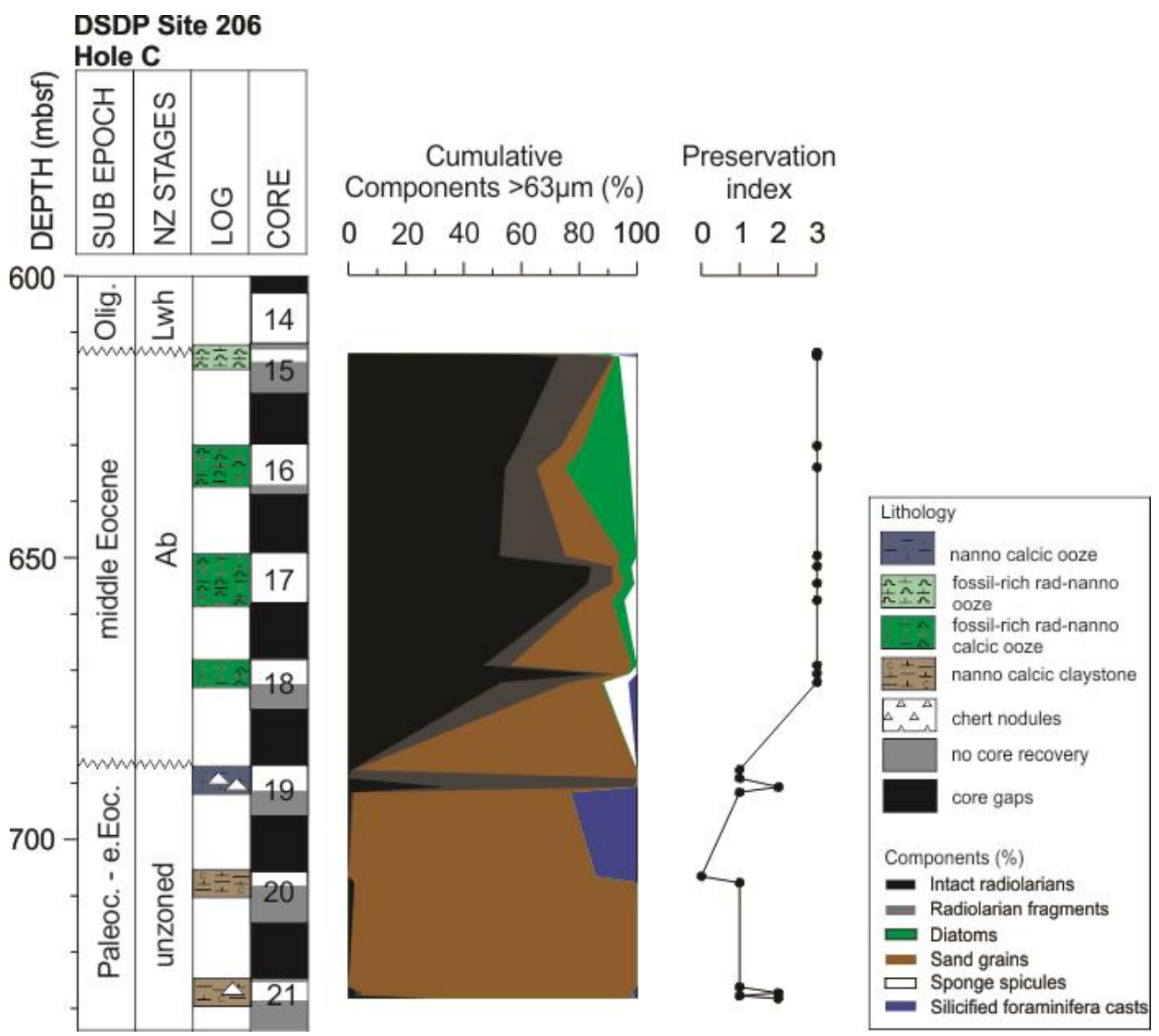

Figure 4.7 Overview of stratigraphy, NZ Stages, lithology and core recovery for DSDP Site 206 Hole C; residue components and radiolarian preservation. Preservation index: $0=$ barren, $1=$ poor, $2=$ moderate, $3=$ good. 


\subsubsection{DSDP Site 592}

Radiolarians are very rare to few ( $<100$ radiolarians/gram) in the lowest Sample 592$41 \mathrm{X}-1,80 \mathrm{~cm}$ (379.70 mbsf) and in the upper three samples 592-39X-3, $80 \mathrm{~cm}, 592-38 \mathrm{X}-$ $3,80 \mathrm{~cm}$ and 592-37X-3, $80 \mathrm{~cm}$ (363.50-344.30 mbsf) (Figure 4.8). An increase in radiolarian abundance (100-1889 radiolarians/gram) is recorded in the interval between 374.60-364.07 mbsf. In this interval and in the uppermost sample (344.30 mbsf), the residue is dominated by radiolarians $(\sim 35 \%)$ and sponge spicules $(\sim 40 \%)$ (Figure 4.8$)$. Diatoms are very abundant in Core 592-39X (365 mbsf). However, they are clumped together, so the residue count shows a too small percentage for this group. Radiolarians are well preserved (preservation index of 3 ) in all studied samples.

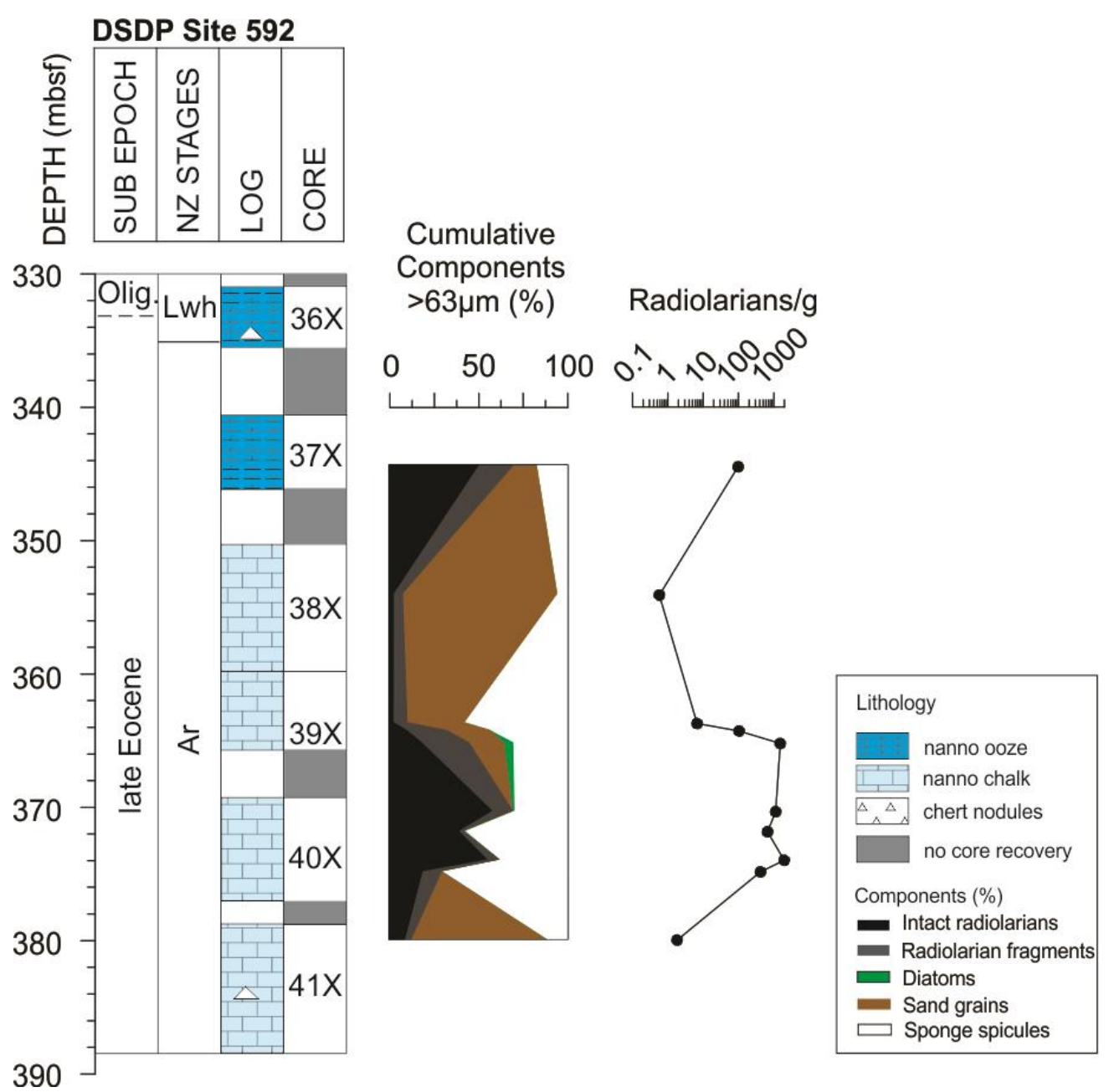

Figure 4.8 Overview of stratigraphy, NZ Stages, lithology and core recovery of DSDP Site 592; residue components and radiolarian abundance. 


\subsubsection{ODP Site 1123}

Radiolarian preservation is good (preservation index of 3) in all samples from the upper Eocene to lower Oligocene (Cores 1123C-33X to $-29 \mathrm{X}$; 625.86-590.90 mbsf). Radiolarian abundance could not be determined because sample weights are not available. Radiolarians are abundant in residues in the lower part of the interval (625.86-616.99 mbsf) (Figure 4.9). The D/R ratio ranges between 0.01-1.5. Four samples are barren of diatoms. A short interval (618.15-610.1 mbsf) has abundant diatoms of ( 13\%, D/R ratio of 0.4). The upper interval (599.74-590.9 mbsf), covering the lower Oligocene, shows an increase in sand grain content and a decrease in absolute radiolarian abundance.

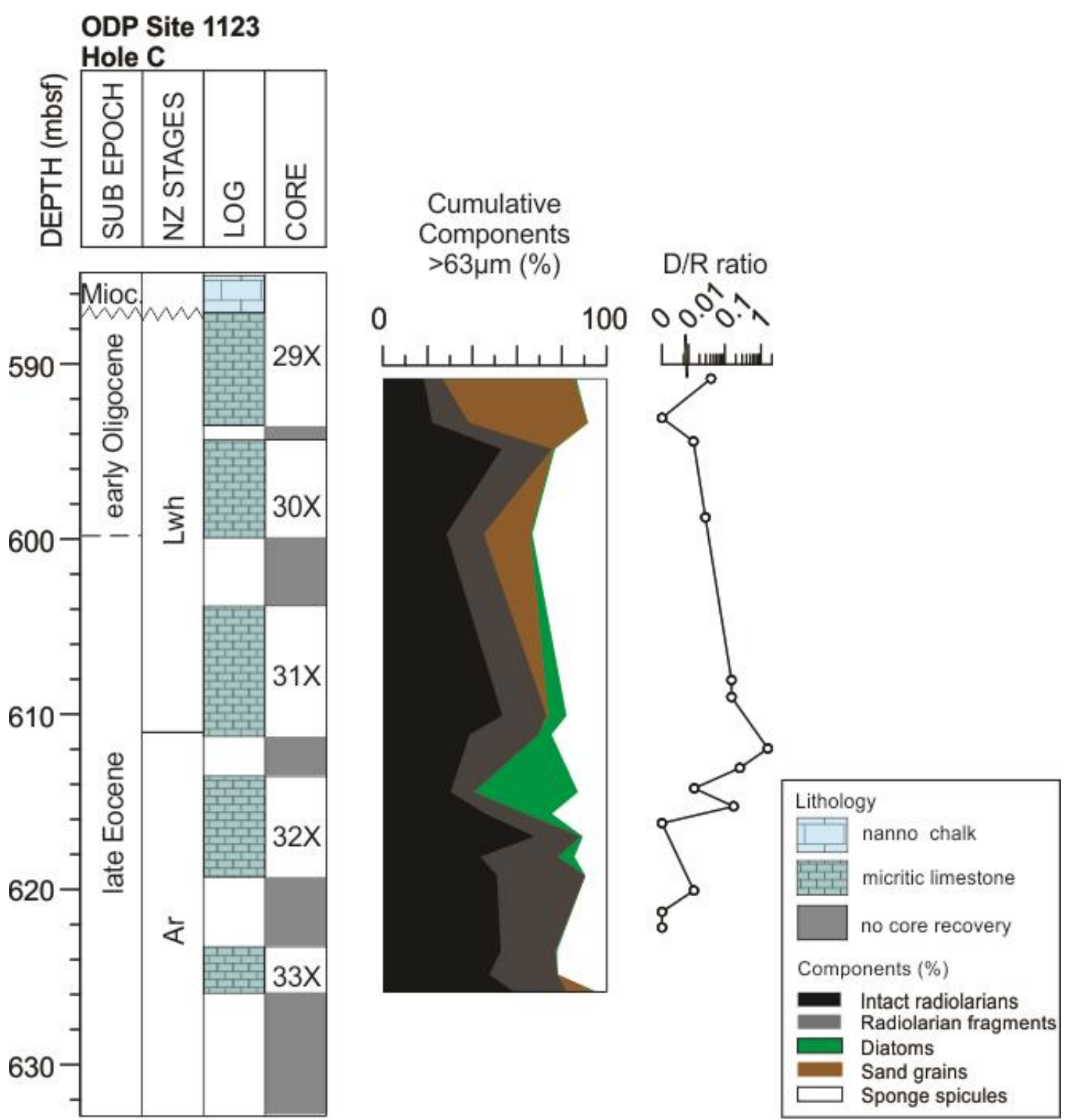

Figure 4.9. Overview of stratigraphy, NZ Stages, lithology and core recovery of ODP Site 1123 Hole C; residue components and diatom/radiolarian $(\mathrm{D} / \mathrm{R})$ ratio. 


\subsection{Comparison between sites}

Radiolarian preservation is linked to radiolarian abundance and in general, well-preserved radiolarians are common to abundant. Additionally, radiolarians are less common and poorly preserved in older sediments at the sites examined.

- Early Eocene (Waipawan to Heretaungan) radiolarians are present only at sites 277 (Campbell Plateau) and 207 (Lord Howe Rise). Radiolarians are rare and poorly preserved at Site 277, but better preserved and abundant at Site 207.

- Middle Eocene (Heretaungan to Bortonian) radiolarian abundance is higher in the mid-latitudes on the Lord Howe Rise (sites 207 and 206) than at Site 277. However, middle Eocene radiolarians are also common to abundant at sites 1172 and 283 (Tasman Rise and Tasman Sea).

- Radiolarian abundance increases abruptly in the late Eocene (Runangan) at Site 277, as well as at sites 592 and 1123. Radiolarians are also common to abundant at sites 1172, 283 and 281 in the late Eocene.

- Throughout the early Oligocene (Whaingaroan), radiolarian abundance decreases at sites 277, 1172 and 1123 and radiolarians are absent from the Oligocene at Site 592. However, radiolarians are abundant and well preserved at Site 280 during the early Oligocene.

Diatom abundance increases with increasing latitude, and is highest in the southernmost sites. This is similar to today's high-latitude environment where siliceous microfossils are dominated by diatoms near the poles. In comparison, diatoms have isolated peaks in abundance at mid-latitude sites in the early to late Eocene.

- At high-latitude sites 280, 1172 and 281, diatoms are abundant and persistent throughout the studied intervals. The $\mathrm{D} / \mathrm{R}$ ratio is $>1$.

- At high-latitudes sites 283 and 277, the $\mathrm{D} / \mathrm{R}$ ratio is $<1$. The occurrence of diatoms at site 283 is continuous and the $\mathrm{D} / \mathrm{R}$ ratio ranges between $0.1-1.1$, whereas the ratio at Site 277 in the late Eocene is smaller (0.05-0.2) and diatom occurrences are sporadic.

- Diatoms occur sporadically at mid-latitude sites 207 and 206 in the early and middle Eocene. The D/R ratio is always $<0.1$ at Site 207 although there is a peak in diatom abundance in the latest early to early middle Eocene (Heretaungan). 


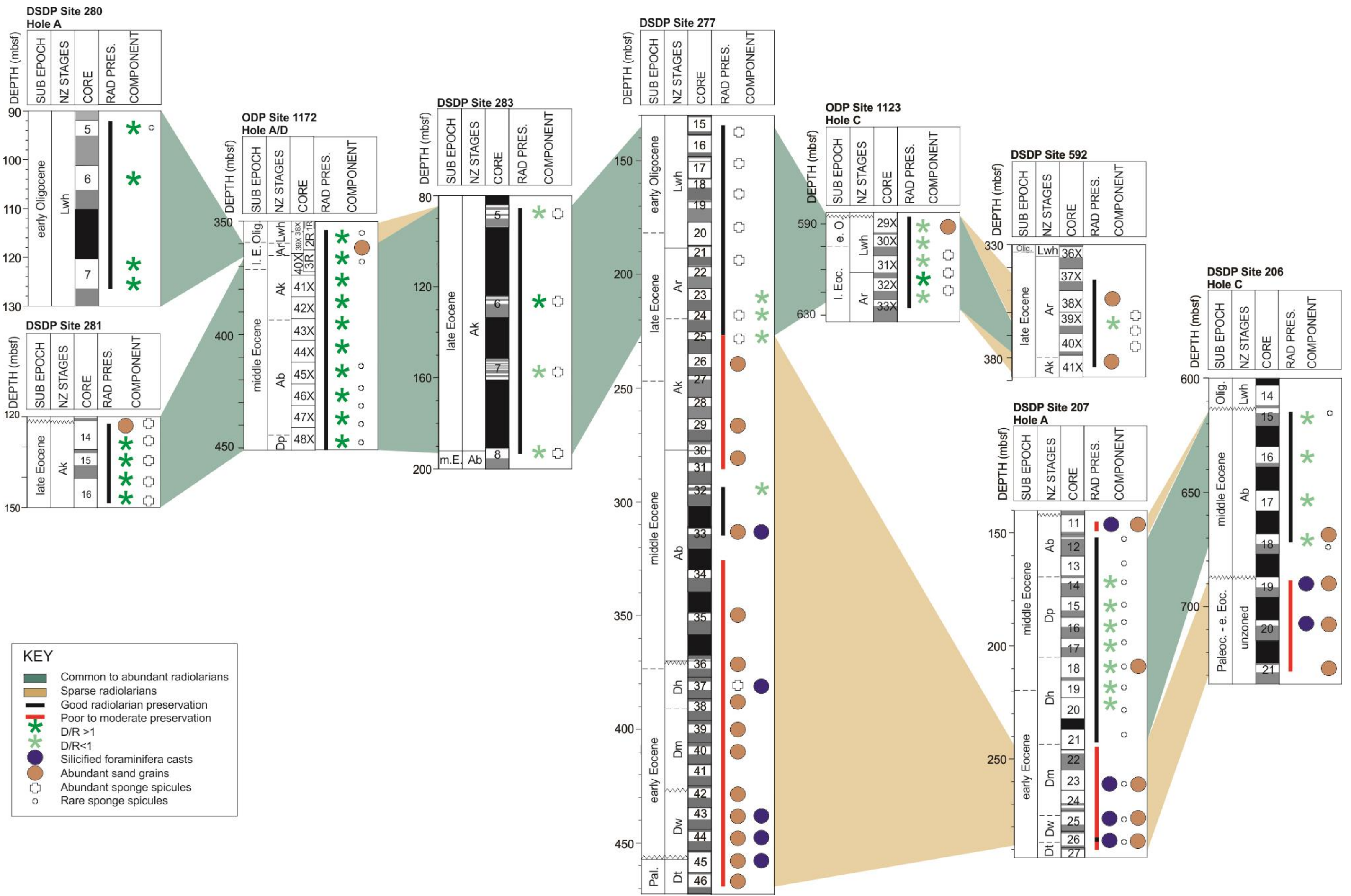


- Diatoms also occur sporadically in the late Eocene at sites 592 and 1123, where the average $D / R$ ratio is $<0.25$. However, there is a peak in the $D / R$ ratio of $>1$ at both sites in the latest Eocene (Runangan).

Other components in the residues vary through the cores in the following manner:

- Sponge spicule content is highest in the late Eocene at sites 277, 281, 283, 592 and 1123 when radiolarians and diatoms are also abundant. It is lowest at Site 280 (early Oligocene), at Site 1172 (middle Eocene to Oligocene), and at sites 207 and 206 (early to middle Eocene).

- Silicified foraminifera casts occur only at sites 277, 207 and 206, during the early and middle Eocene, and are generally associated with the presence of chert nodules. At the same time radiolarians are very rare or absent.

- Sand grains are present at all sites and are in general more abundant when radiolarians are very rare and poorly preserved. 


\section{Radiolarian biostratigraphy and correlation}

\subsection{High-latitude Southwest Pacific sites}

\subsubsection{DSDP Site 277}

At this site, the interval from 468.49 to 134.20 mbsf has been correlated to radiolarian zones RP6sh to RP15 $5_{\mathrm{SH}}$. The following succession of radiolarian biostratigraphic events are identified (from oldest to youngest, Figure 5.1, Appendix C, data on enclosed CD) and compared to Hollis et al. (1997):

1. The base of the studied interval (465.66 mbsf) lies within $\mathrm{RP} 6 \mathrm{SH}$ or RP7 $\mathrm{SH}$ based on the presence of Lychnocanium babylonis. Primary markers for the base of Zones RP6 ${ }_{\mathrm{SH}}$ and RP7 $\mathrm{SH}$ are absent. The LO of Phormocyrtis striata striata, a secondary datum for the base of Zone $\mathrm{RP} 7_{\mathrm{SH}}$ occurs higher at $454.25-447.01$ mbsf. Although two samples within that range were processed (447.71 and 447.51 mbsf), the residue contained only a trace amount of radiolarians and was poorly preserved. This zone is in agreement with Hollis et al. (1997).

2. The base of Zone RP8SH is placed at $454.25-447.51 \mathrm{mbsf}$ based on the LO of Podocyrtis papalis. The LO of Amphicraspedum prolixum s.s. is also found at this level. The base of this zone is slightly lower than that recorded in Hollis et al. (1997).

3. The base of Zone RP9 ${ }_{\mathrm{SH}}$ is placed at $438.71-416.20 \mathrm{mbsf}$ based on the isolated $\mathrm{HO}$ of Lychnocanium auxillum. Although several samples were processed within that range, the residue contained only a trace amount of radiolarians and was poorly preserved. Hollis et al. (1997) did not define the base of RP9 $9_{\mathrm{SH}}$.

4. The $\mathrm{HO}$ of Buryella tetradica, an upper-RP9 ${ }_{\mathrm{SH}}$ datum, occurs at $437.75-436.78$ mbsf.

5. The base of Zone RP10 ${ }_{\mathrm{SH}}$ is identified by a secondary marker, LO of Artobotrys auriculaleporis, at 438.71-416.2 mbsf. The primary datum for this zone (LO of Theocampe mongolfieri) has not been identified at this site. The placement of this zone is in agreement with Hollis et al. (1997). 
6. The $\mathrm{HO}$ of Amphicraspedum prolixum s.s. is found at $409.33-407.83 \mathrm{mbsf}$ and the HO of Phormocyrtis striata striata at $387.98-380.75$ mbsf, both datums fall within lower RP10 ${ }_{\mathrm{SH}}$.

7. In the absence of Eusyringium lagena, the base of zone RP11 $1_{\mathrm{SH}}$ cannot be located.

8. The base of Zone RP12sH is placed at $371.25-349.25 \mathrm{mbsf}$ based on the LO of Lophocyrtis longiventer, which is a secondary marker for the base of this zone. The LO of Eusyringium fistuligerum, which is the primary marker for RP12 ${ }_{\mathrm{SH}}$, is found higher up at 313.5-312.7 mbsf and coincides with the primary datum for RP13 ${ }_{\mathrm{SH}}$ (Zealithapium mitra). The base of the zone is slightly lower than that recorded in Hollis et al. (1997).

9. The base of RP13 $3_{\mathrm{SH}}$ is revised to $313.50-312.70 \mathrm{mbsf}$ based on the LO of $Z$. mitra. The base of this zone was not identified by Hollis et al. (1997). The LO of Cryptocarpium ornatum ( $\mathrm{LO}$ at $\sim 41.33 \mathrm{Ma}$ at low-latitudes) is found at 312.70 296 mbsf.

10. The base of Zone RP14 1 SH is identified by the LO of Eucyrtidium spinosum at 264.57-254.5 mbsf and agrees with Hollis et al. (1997).

11. The HOs of Lychnocanium amphitrite and Cryptocarpium ornatum are datums in upper RP14 ${ }_{\mathrm{SH}}$ that are found at 206.83-197.82 mbsf.

12. The base of RP15 $15_{\mathrm{SH}}$ is identified by the $\mathrm{LO}$ of Eucyrtidium antiquum at 197.82186.5 mbsf and agrees with that recorded in Hollis et al. (1997). The LO of Axoprunum? irregularis is a datum within Zone RP15 ${ }_{\mathrm{SH}}$ and is found at $152.83-$ 143.90 mbsf. It was used to separate lower and upper RP15 ${ }_{\mathrm{SH}}$ in Hollis et al. (1997). The zone is slightly lower than that recorded in Hollis et al. (1997).

Foraminiferal and calcareous nannofossil biostratigraphy help to refine the age control for Site 277. The interval spanning the Paleocene-Eocene boundary (Cores 277-46R to -36R) was investigated by Hollis et al. (2015) and the following datums were identified:

1. The base of NP9 is placed at $465.12-462.43$ mbsf based on the LO of Discoaster multiradiatus

2. The base of the Paleocene-Eocene Thermal Maximum (PETM) is placed at 457.3456.96 mbsf. The hiatus at the top of the PETM is inferred from the HO of Subbotina velascoensis at $456.94-456.92 \mathrm{mbsf}$, which is the primary marker for 
the base of E3. The base of NP10 cannot be determined, as it falls within the hiatus.

3. The HO of Discoaster multiradiatus is a datum within zone NP11 is identified at 445.15-438.90 mbsf.

4. The base of NP12 is located at $434.57-429.40$ mbsf based on the LO of Discoaster lodoensis.

Subsequent study of nannofossil biostratigraphy (C. Shepherd, pers. comm. 2016) determined further datums:

1. The base of NP11 is tentatively placed at $446.92-446.50 \mathrm{mbsf}$ based on the LO of Sphenolithus radians, that has the same age as the base of the zone.

2. The base of NP13 is placed at 426.53-419.60 mbsf based on the HO of Tribrachiatus orthostylus.

3. The base of NP14 is located at 391-389.50 mbsf based on the LO of Discoaster sublodoensis.

4. The LO of Nannotetrina cristata is a datum within NP14 and is recorded at 372.08-370.58 mbsf.

5. The base of NP16 is placed at 370.58-369 mbsf based on the LO of Reticulofenestra umbilicus $(>14 \mu \mathrm{m})$

Subsequent study of foraminiferal biostratigraphy (C.P. Strong, pers. comm. 2016) determined further datums:

1. The base of the Mangaorapan Stage (bDm, early Eocene, $52 \mathrm{Ma}$ ) is placed at 427.12-426.90 mbsf based on the LO of Morozovella crater

2. The base of the Porangan Stage (bDp, middle Eocene, $45.7 \mathrm{Ma}$ ) is placed at 380.75-372.08 mbsf based on the HO of Morozovella crater.

3. The base of the Bortonian (bAb, middle Eocene, $42.6 \mathrm{Ma}$ ) Stage is placed at 388370.40 mbsf based on the LO of Globigerinatheka index.

Further refinement of the age control for Site 277 Core 277-33R to $-21 \mathrm{R}$ is possible through application of additional foraminiferal (Jenkins 1975) and nannofossil (Edwards $\&$ Perch-Nielsen 1975) bioevents, which help to correlate the discontinuous stable isotope record of this site to those from other Southern Ocean sites (Figure 5.2): 
1. The base of the Kaiatan Stage (bAk, late middle Eocene, 39.1 Ma) is placed at 280-273 mbsf based on the HO of Acarinina primitiva (Morgans, 2009). The base of the Kaiatan was set at 276.5 mbsf to allow for the correlation between isotope records.

2. The base of the Whaingaroan Stage (bLwh, latest Eocene, 34.61 Ma; Raine et al., 2015 ) is identified by the HO of Globigerinatheka index; this event was identified at 189.6 mbsf by Jenkins (1975), but has been determined to occur slightly higher at 188.58-187.5 mbsf in Pascher et al. (2015).

3. The base of NP17 is placed at 312.5-301.5 mbsf based on the HO of Chiasmolithus solitus.

4. The base of NP18 is placed at 244.5-240.6 mbsf based on the LCO of Chiasmolithus oamaruensis.

5. The base of NP19-20 is placed at 226.58-225.5 mbsf based on the LO of Isthmolithus recurvus.

6. Within NP19-20, the HO of Cribrocentrum reticulatum is found at 206.5-201.1 mbsf (Edwards and Perch-Nielsen, 1975). This datum was placed at 36.44 Ma by (Raine et al., 2015) who noted that the datum occurs within Chron C16n.2n at multiple Southern Ocean sites according to Berggren et al. (1995). This age was adopted by Pascher et al. (2015). However, Gradstein et al. (2012) reported 35.92 $\mathrm{Ma}$ as being the age of the datum in high latitudes. This age determination is in better agreement with the age-depth plot (Figure 5.1).

7. The base of NP21-22 is placed at 191.6-190.1 mbsf based on the HO of Discoaster saipanensis. As D. saipanensis is a warm-water taxon, its disappearance is likely to have occurred earlier at high latitudes. Marker taxa for the base of NP22 are absent.

8. The acme of Clausicoccus subdistichus is a datum within NP21 (33.43 Ma, Gradstein et al., 2012) and is found at 186.50-152.83 mbsf (A. Costa, pers. com. 2015). This taxon has an isolated occurrence at Site 277.

\subsubsection{Intergrated chronostratigraphy}

The bioevents described above and other event horizons have been used to develop an age model for Site 277 (Figure 5.1). The sedimentation rate in uppermost Paleocene and basal Eocene is very low $(0.5 \mathrm{~cm} / \mathrm{ka})$, although this is constrained by only one bioevent. Above the hiatus, which is inferred to have lasted from $\sim 55.8-55.1$ Ma during early Waipawan 
(early Eocene) (Hollis et al., 2015), the sedimentation rate is $\sim 1.8-2.3 \mathrm{~cm} / \mathrm{ka}$. A second hiatus appears to separate upper Waipawan ( 53.3 Ma) from middle Mangaorapan ( 50.5 Ma) sediments based on the close association of the LO of D. lodoensis (53.7 Ma), the LO of M. crater (52 Ma) and the $\mathrm{HO}$ of $T$. ortostylus (50.5 Ma). It is inferred to have lasted for $\sim 2.8$ Ma. Thereafter, the sedimentation rate stays constant between 1.4-2.6 $\mathrm{cm} / \mathrm{ka}$. The base of the Heretaungan (48.9 Ma, late early Eocene) cannot be constrained by foraminifera events, but the LO of $D$. sublodoensis $(49.11 \mathrm{Ma})$ can be used as a secondary datum (Raine et al., 2015).

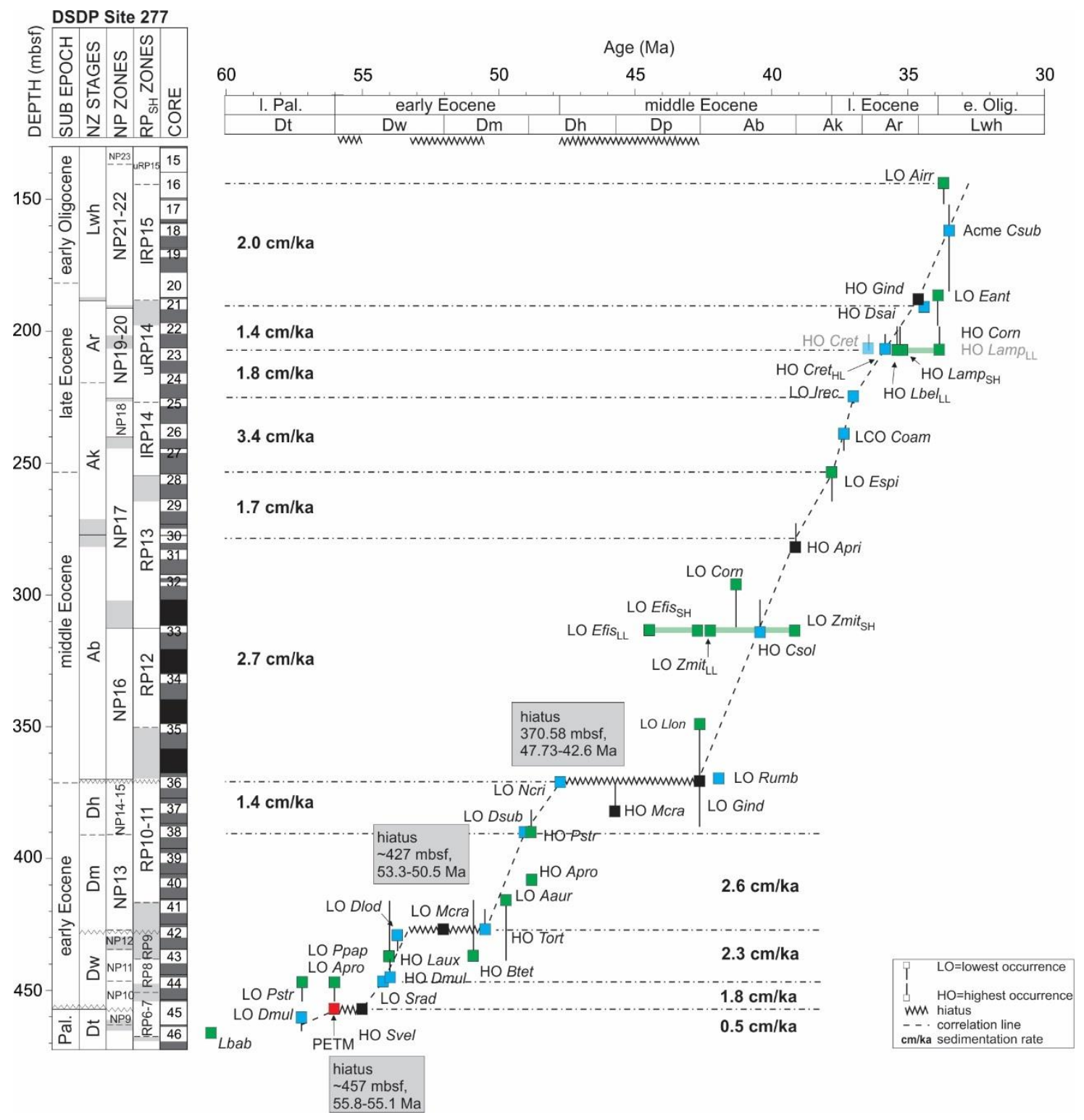

Figure 5.1 Overview of stratigraphy, NZ Stages, nannofossil (NP) zones, radiolarian ( $\left.\mathrm{RP}_{\mathrm{SH}}\right)$ zones and core recovery of DSDP Site 277. Age-depth plot of Site 277 using nannofossil (blue squares), foraminifera (black squares) and radiolarian (green squares) events. Acronoyms: PETM=Paleocene-Eocene thermal maximum, LL=low-latitude datum, $\mathrm{HL}=$ high-latitude datum, $\mathrm{SH}=$ Southern Hemisphere datum. Green bands indicate the age-range between LL and SH datum. For abbreviations of NZ Stages, please see Chapter 3.6, for species abbreviations see Appendix C (data on enclosed CD). 
A third hiatus within Core 277-36R (370.58 mbsf) based on the close association of the LO of $N$. cristata, the HO of $M$. crater and the LO of $G$. index spans most of the Heretaungan and all of the Porangan and appears to have lasted for $~ 5.1 \mathrm{Ma}$. Above this hiatus, the sedimentation rate is $1.7-2.7 \mathrm{~cm} / \mathrm{ka}$ during the remaining middle Eocene. During the early late Eocene (37.8-36.97 Ma), sedimentation rate increases to $3.4 \mathrm{~cm} / \mathrm{ka}$. It drops for the remaining late Eocene to $1.4-1.8 \mathrm{~cm} / \mathrm{ka}$. As mentioned above, the highlatitude (HL) HO datum of $C$. reticulatum (35.92 Ma) fits the age-depth plot better than the age inferred by Raine et al. (2015) and, in particular, agrees with the estimated age for the the $\mathrm{HO}$ of L. bellum. The southern hemisphere $(\mathrm{SH})$ datum of L. amphitrite fits this correlation better than the low-latitude (LL) datum. The sedimentation rate increases in the early Oligocene to $2 \mathrm{~cm} / \mathrm{ka}$, which is based on the correlation between the $\mathrm{HO}$ of $G$. index and the acme of $C$. subdistichus. The acme comprises only one sample (162.20 mbsf) where the taxon is present. The LO of A.? irregularis seems to occurs later at Site 277 than at other sites in the Southern Hemisphere (Funakawa and Nishi, 2005).

\subsubsection{Stable isotope correlation}

As reported by Pascher et al. (2015), stable isotope data have been used to improve correlation in the middle Eocene to lower Oligocene at Site 277 (Figure 5.2). Although gaps in recovery in the Site 277 stable isotope record preclude detailed correlation, the broad trends and major events such as the MECO ( 40 Ma), PrOM event ( 37.3 Ma) and the Eocene-Oligocene transition $(\sim 34 \mathrm{Ma})$ are identified in the benthic $\delta^{18} \mathrm{O}$ and $\delta^{13} \mathrm{C}$ isotope profiles and have been compared to the middle Eocene-to-early Oligocene benthic isotope stratigraphy from ODP Site 689 (Maud Rise; Diester-Haass \& Zahn, 1996) (Figure 5.2). 


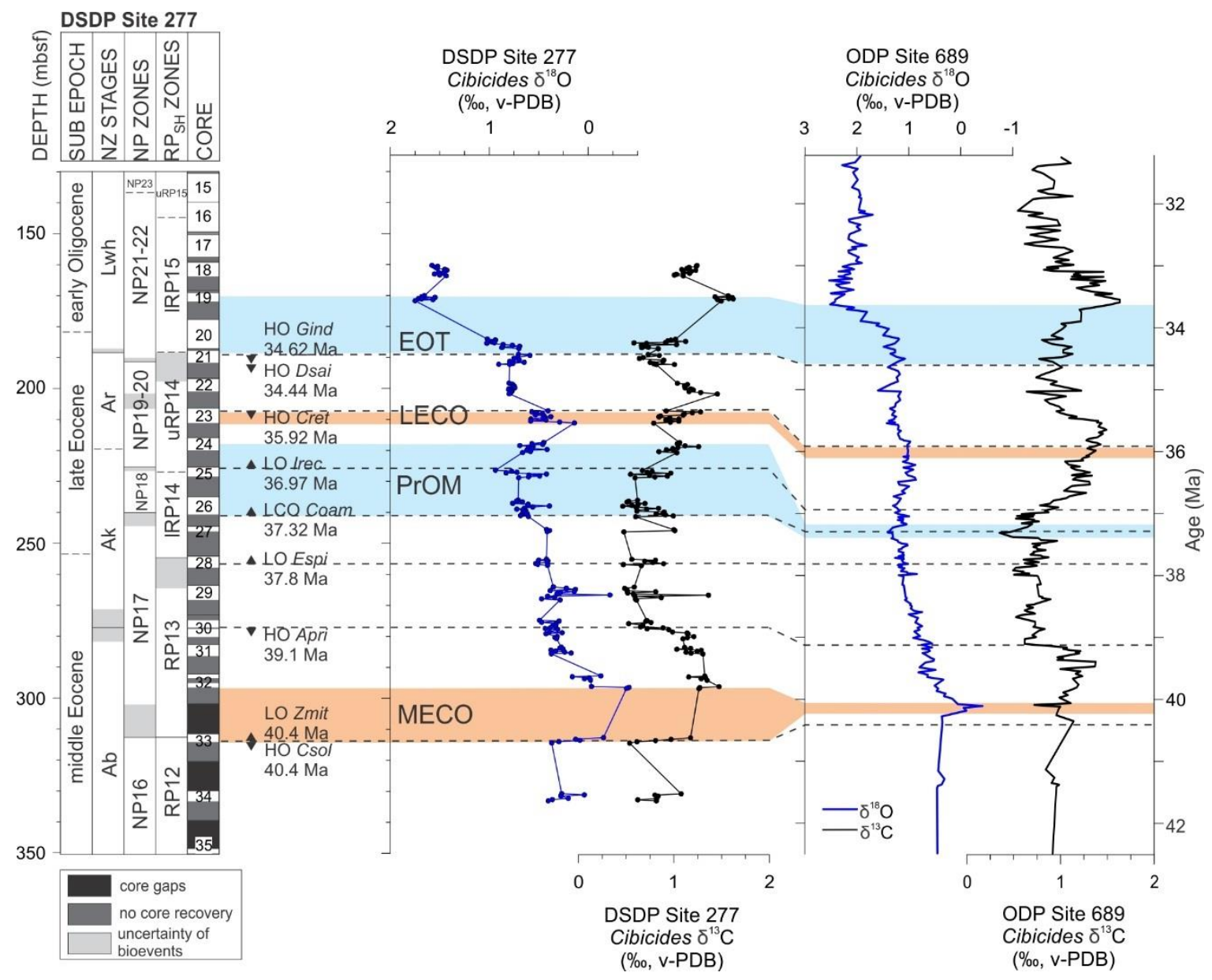

Figure 5.2 DSDP Site 277 stratigraphy, NZ Stages (Raine et al., 2015), Southern Hemisphere radiolarian zones (RP), nannofossil zones (NP), lithology, core recovery, selected bioevents (ages calibrated to the 2012 geological timescale; Gradstein et al., 2012; Raine et al., 2015) and benthic $\delta^{18} \mathrm{O}$ and $\delta^{13} \mathrm{C}$ data of DSDP Site 277. The dashed lines correlate Site 277 based on the ages of the bioevents to Southern Ocean Cibicides data of ODP Site 689 (Maud Rise) (DiesterHaass and Zahn, 1996) calibrated to the GTS2012 timescale using the magnetostratigraphy data of Florindo and Roberts (2005) and Spiess (1990). LO=lowest occurrence, LCO=lowest common occurrence, $\mathrm{HO}=$ highest occurrence, $\mathrm{MECO}=$ middle Eocene climatic optimum, $\mathrm{PrOM}=$ Priabonian oxygen isotope maximum, $\mathrm{LECO}=$ late Eocene climatic optimum, EOT=Eocene-Oligocene transition; after Pascher et al. (2015). 


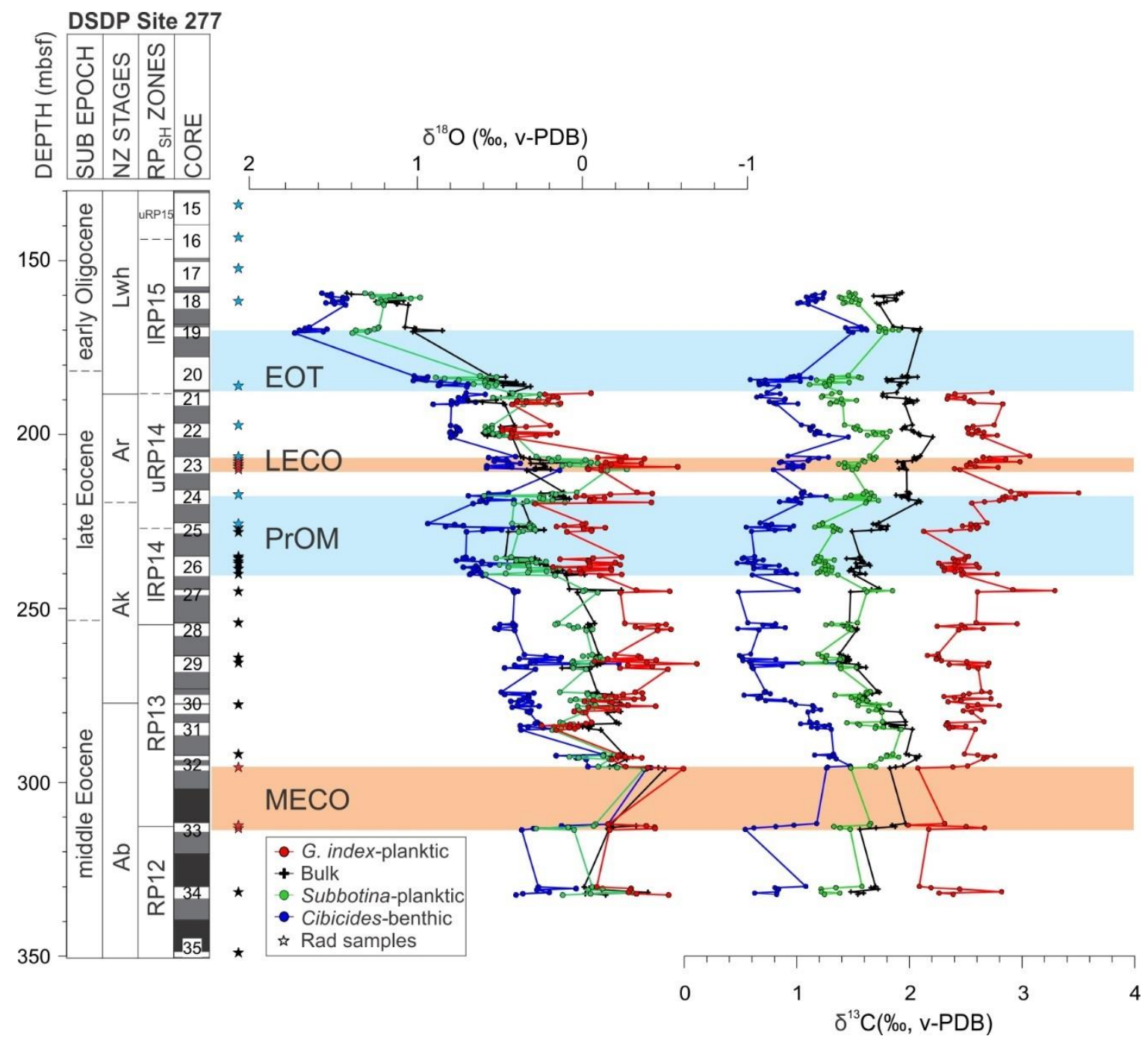

Figure 5.3 DSDP Site $277 \delta^{18} \mathrm{O}$ and $\delta^{13} \mathrm{C}$ records and location of studied radiolarian samples within the MECO and LECO (red stars) and radiolarian-rich upper Eocene-lower Oligocene interval (blue stars); after Pascher et al. (2015). $\mathrm{MECO}=$ middle Eocene climatic optimum, $\mathrm{PrOM}=$ Priabonian oxygen isotope maximum, $\mathrm{LECO}=$ late Eocene climatic optimum, EOT=Eocene-Oligocene transition.

Foraminiferal $\delta^{18} \mathrm{O}$ values show a normal planktic-benthic gradient with more positive values in the benthic foraminifers compared to bulk and planktic foraminifera with some crossover in the latter two (Figure 5.3). Foraminiferal $\delta^{13} \mathrm{C}$ values also show a typical positive benthic-planktic gradient. Therefore, relatively robust stable isotope signals can be interpreted as representative of deep (intermediate, Cibicides spp.), upper (thermocline, Subbotina spp.) and uppermost (mixed/surface, G. index) waters, although it is likely that the $\delta^{18} \mathrm{O}$ gradients are attenuated by diagenetic effects on planktic foraminifera (Sexton et al., 2006) as they have a "frosty" preservation.

Several short-lived climatic events are identified in the benthic stable isotope records at Site 277. The body of the MECO ( 40 Ma) was not recovered (due to a 16m sampling 
gap between the top of Core 277-33R and the base of Core 277-32R), but its onset and recovery is well constrained by a $0.5 \%$ negative excursion in benthic ${ }^{18} \mathrm{O}$ values at $\sim 313$ mbsf (between Samples 277-33R-2, 106-108cm and -33R-1, 129-130.5 cm) and a $\sim 0.4 \%$ o positive excursion in $\delta^{18} \mathrm{O}$ values at $\sim 296 \mathrm{mbsf}$ (between samples 277-32R-3, $107-109 \mathrm{~cm}$ and $-32 \mathrm{R}-3,77-79 \mathrm{~cm}$ ), indicating that the MECO spans $\sim 17 \mathrm{~m}$ (Figure 5.3). The MECO is more strongly expressed in the benthic $\delta^{18} \mathrm{O}$ than in the planktic record but this may relate to the poor recovery of the body of the event at this site or diagenetic impacts on planktic $\delta^{18} \mathrm{O}$ values (Pearson et al., 2001; Sexton et al., 2006). In agreement with other records (Bohaty and Zachos, 2003; Bohaty et al., 2009), a positive $\delta^{13} \mathrm{C}$ excursion is observed at the onset of the MECO in the benthic and bulk carbonate records, although the $\delta^{13} \mathrm{C}$ record is also compromised by the missing core of the event.

The PrOM event (Scher et al., 2014) is well-defined in the $\delta^{18} \mathrm{O}$ record from DSDP Site 277 but also spans two significant recovery gaps between the base of Cores 277-26R, 25R and $-24 \mathrm{R}$ ( $\sim 244.5$ to $225.5 \mathrm{mbsf}$ ). The $\sim 0.4 \%$ positive shift in $\delta^{18} \mathrm{O}$ that marks the onset of the PrOM, spans upper Core 277-26R and lower Core 277-25R ( 240-230 mbsf), and is followed by an interval of relatively low $\delta^{18} \mathrm{O}$ values in upper Core $277-25 \mathrm{R}$ ( 228-227 mbsf), prior to reaching maximum values in uppermost Core 277-25R ( 226 m) (Figure 5.3). A gradual decrease in $\delta^{18} \mathrm{O}$ occurs through Core $277-24 \mathrm{R}(\sim 220-217$ mbsf). The PrOM at DSDP Site 277 is defined as the interval within these three cores in which benthic $\delta^{18} \mathrm{O}$ exceeds $1.25 \%$, with the exception of the interval noted above in upper Core 277-25R.

These benthic $\delta^{18} \mathrm{O}$ values are lower than those reported by Scher et al. (2014), but it is likely that peak $\delta^{18} \mathrm{O}$ values are not captured at Site 277. Consequently, the PrOM is placed between 240.62 and 219.57 mbsf (spanning a $\sim 21 \mathrm{~m}$ section) (Figure 5.3). The planktic $\delta^{18} \mathrm{O}$ record is similar to the benthic record, but lacks the maximum excursion in uppermost Core 277-25R. At the onset of the event, short-lived negative $\delta^{13} \mathrm{C}$ excursions are evident in the benthic, bulk and planktic records. However, a longer-term positive trend for planktic and benthic $\delta^{13} \mathrm{C}$ values becomes apparent simultaneously to the benthic $\delta^{18} \mathrm{O}$ maximum. Directly above the PrOM event, $\delta^{18} \mathrm{O}$ values decrease by $\sim 0.5 \%$ in upper Core 277-24R and -23R (217.37 to $207.41 \mathrm{mbsf}$ ), evident in benthic and planktic foraminifera as well as bulk carbonate. This interval can be correlated to the late Eocene warming interval interpreted at ODP Sites 689 (Maud Rise), 738, 744, and 748 
(Kerguelen Plateau) (Diester-Haass and Zahn, 1996; Bohaty and Zachos, 2003; Villa et al., 2008; Villa et al., 2014). The Eocene-Oligocene transition is characterized by a large $(\sim 0.75 \%)$ positive shift in benthic oxygen and carbon isotopes between Cores $277-20 \mathrm{R}$ and -19R (183.64-171.28 mbsf) (Shackleton and Kennett, 1975; Keigwin, 1980), which is slightly lower than the full magnitude of the benthic $\delta^{18} \mathrm{O}$ shift seen at other Southern Ocean sites on the Kerguelen Plateau and Maud Rise (Diester-Haass and Zahn, 1996; Zachos et al., 1996; Bohaty et al., 2012). The most positive values in benthic and planktic $\delta^{18} \mathrm{O}$ and $\delta^{13} \mathrm{C}$ occur in Core 277-19R (171.28-169.65 mbsf), within the earliest Oligocene. The Eocene-Oligocene boundary is approximated between Core 277-20R and $-19 \mathrm{R}$. More precise location is complicated by incomplete recovery and the highly disturbed nature of Cores 277-21R, -20R, and -19R.

\subsubsection{DSDP Site 280}

In previous work, the E-O boundary at Site 280 was placed at the base of Core 280A-6R (110.5 mbsf) based on the presence of Larcopyle frakesi (Crouch and Hollis, 1996), which according to Caulet (1991) has a LO in the early Oligocene. O'Connor (2000) revised the base of the E-O boundary to lie between Core 280A-8R-1, 70cm and Core 280A-7R-3, 40cm (139-123.4 mbsf) as he found L. frakesi further downcore. Furthermore, he identified Axoprunum? irregularis at $123.4 \mathrm{mbsf}$ upcore and assigned the interval from Core $280 \mathrm{~A}-7 \mathrm{R}$ to $-2 \mathrm{R}$ to upper $\mathrm{RP} 15_{\mathrm{SH}}$. L. frakesi is now inferred to have its LO in the late Eocene ( $35 \mathrm{Ma}$; Funakawa and Nishi, 2005) and I could not confirm the presence of A.? irregularis in samples from Cores 280A-7R to $-5 \mathrm{R}$.

However, due to the presence of Eucyrtidium antiquum (33.9-28.1 Ma; Funakawa and Nishi 2005), the studied interval (123.4-92.54 mbsf) can be placed in the early Oligocene (Whaingaroan) (Figure 4.2 and Appendix C). The absence of A.? irregularis further infers an age of the interval of 33.9-33.7 Ma. This would result in a sedimentation rate of $\sim 15$ $\mathrm{cm} / \mathrm{ka}$, which is unrealistic. At Site 277 this species has a later LO at $\sim 32.4 \mathrm{Ma}$ suggesting a diachronous LO between the Southwest Pacific and the South Atlantic. If 32.5 $\mathrm{Ma}$ is used as the upper age boundary of the studied section, the sedimentation rate would yield $2.2 \mathrm{~cm} / \mathrm{ka}$.

Eucyrtidium spinosum, which according to Funakawa and Nishi (2005) has its HO in the early Oligocene in the South Atlantic, is absent in the Site 280 study interval. The HO of 
this species is also recorded within the upper Eocene interval at Site 277, suggesting also a diachronous HO between the two ocean basins.

\subsubsection{DSDP Site 281}

Due to the presence of Eucyrtidium spinosum and Eucyrtidium nishimurae, the latter with its HO at 125.5-122.5 mbsf, the studied interval (149.04-122.5 mbsf) at Site 281 can be correlated with lower RP14 ${ }_{\mathrm{SH}}$ (late Eocene, Kaiatan local stage, Figure 4.3, Appendix C). A hiatus spanning the latest Eocene and Oligocene is inferred from the presence of abundant glauconite in the upper part of Core 281-14R as well as from common Cyrtocapsella tetrapera in Core 281-13R, which indicates a Miocene age (Crouch and Hollis, 1996). Assuming an age of at least $37.8 \mathrm{Ma}$ for the deepest sample (149.04 mbsf) and 36.7 Ma for the sample at $125.5 \mathrm{mbsf}$, results in a sedimentation rate of $2.1 \mathrm{~cm} / \mathrm{ka}$ for the studied interval. Although this studied interval spans the interval during which the PrOM event occurs, it cannot be located at this site. Eucyrtidium nishimurae is absent at Site 277 , which is likely a preservation artefact, as the corresponding interval contains only very rare to few radiolarians, which are poorly to moderately preserved.

\subsubsection{DSDP Site 283}

The lowermost sample at $192.25 \mathrm{mbsf}$ is correlated to RP13 ${ }_{\mathrm{SH}}$ (middle Eocene, Bortonian) based on the absence of Eucyrtidium spinosum (Figure 4.4). The uppermost five samples are correlated to Zone RP14 ${ }_{\mathrm{SH}}$ (early late Eocene, Kaiatan) based on the LO of E. spinosum at 192.25-190.9 mbsf (Appendix C). Eucyrtidium nishimurae is present in all samples (192.25-87.75 mbsf). Cores 283-6R and -5R (162-124 mbsf) can be correlated to NP18 based on the presence of Chiasmolithus oamaruensis (Edwards and Perch-Nielsen, 1975). Planktic foraminifera are absent at this site and there are no other useful datums to develop a full age model for this site. Taking the LO datum of $E$. spinosum and assuming $\sim 36.7 \mathrm{Ma}$ for the uppermost sample due to the presence of $E$. nishimurae, the sedimentation rate yields $9.3 \mathrm{~cm} / \mathrm{ka}$. This is too high for an environmental setting assumed to be offshore and very deep. It is possible that E. nishimurae is an unreliable datum and its $\mathrm{HO}$ might be later. At Site 1172 it has a slightly later $\mathrm{HO}$ at 36.2 Ma. Although Site 283 spans the interval in which the PrOM event occurs, it cannot be located. 


\subsubsection{ODP Site 1172}

The faunal assemblages of ODP Site 1172 were described by Suzuki et al. (2009), who did not correlate them to RP Zones. At this site, the interval from $450.49 \mathrm{mbsf}$ to 356.60 mbsf has been correlated to radiolarian zones RP12 ${ }_{\mathrm{SH}}$ to $\mathrm{RP} 17_{\mathrm{SH}}$. Many taxa used to define Southern Hemisphere RP zones at Site 277 are absent at Site 1172 or have diachronous ranges, so only a few radiolarian datums can be applied (Figure 5.4, Appendix C).

1. The interval from 450.49-373.74 mbsf can be correlated to combined Zone RP12$13_{\mathrm{SH}}$ due to the presence of Lophocyrtis longiventer and the absence of Zealithapium mitra, which defines the base of RP13 $3_{\mathrm{SH}}$. Eusyringium fistuligerum has only a trace occurrence in at 417.7 mbsf. Further radiolarian datums in this zone are the LO of Eucyrtidium nishimurae at 436.9-431.3 mbsf and the LO of Artobotrys biaurita at 417.7-416.2 mbsf.

2. The base of $\mathrm{RP} 14_{\mathrm{SH}}$ is placed at $373.74-371.2 \mathrm{mbsf}$ based on the LO of Eucyrtidium spinosum. Further datums in this zone are the HO of Eucyrtidium nishimurae at 363.9-356.85 mbsf and the $\mathrm{HO}$ of Lychnocanium amphitrite at 366.7-365.2 mbsf.

3. The base of $\mathrm{RP} 15_{\mathrm{SH}}$ cannot be located as Eucyrtidium antiquum has a single occurrence at $365.2 \mathrm{mbsf}$, which is in the upper Eocene, but is absent in the Oligocene interval.

4. Clinorhabdus robusta (LO at 28.5 Ma) and Axoprunum? irregularis (33.7-26.6 $\mathrm{Ma})$ are found in the Oligocene interval at this site (356.85-354.6 mbsf) which can be assigned to $\mathrm{RP} 17_{\mathrm{SH}}$.

Additional age information of samples from Site 1172 (base and top of magnetic reversals and one nannofossil event) were obtained from Stickley et al. (2004b) and calibrated to the GTS2012 timescale (Gradstein et al., 2012):

1. The top of $\mathrm{C} 20 \mathrm{n}$ is found at $441 \mathrm{mbsf}(42.3 \mathrm{Ma})$.

2. The base of C19n is found at $432 \mathrm{mbsf}(41.39 \mathrm{Ma})$.

3. The base of C18n. $2 \mathrm{n}$ is found at $415 \mathrm{mbsf}(40.15 \mathrm{Ma})$.

4. The top of $\mathrm{C} 18 \mathrm{n} .1 \mathrm{n}$ is found at $382.10 \mathrm{mbsf}(38.62 \mathrm{Ma})$.

5. The base of C17n.3n is found at $373.90 \mathrm{mbsf}$ (38.33 Ma).

6. The base of C16n.2n is found at $365 \mathrm{mbsf}$ ( $36.7 \mathrm{Ma}$ ). 
7. The base of C16n. $1 \mathrm{n}$ is found at $361.30 \mathrm{mbsf}(35.89 \mathrm{Ma})$.

8. The top of C16n. $1 \mathrm{n}$ is found at $360.10 \mathrm{mbsf}$ (35.71 Ma).

9. The base of $\mathrm{C} 15 \mathrm{n}$ is found at $359.80 \mathrm{mbsf}$ (35.29 Ma).

10. The HO of Reticulofenestra umbilicus $>14 \mu \mathrm{m}$ is found at $361.235-357.535 \mathrm{mbsf}$.

Additionally, two nannofossil datums have been reported for this site (Shipboard Scientific Party, 2001):

1. The LO of Cribocentrium reticulatum is found at $412.47-402.83 \mathrm{mbsf}$.

2. The LO of Chiasmolithus solitus is found at 402.83-393.18 mbsf.

\subsubsection{Integrated chronostratigraphy}

The above listed bio- and magnetostratigraphic events have been used to develop an age model for Site 1172 (Figure 5.4). In the lower part of the middle Eocene (450-415 mbsf), the sedimentation rate is $\sim 1.2 \mathrm{~cm} / \mathrm{ka}$. In the upper part of the middle Eocene the sedimentation rate increases to $\sim 2.25 \mathrm{~cm} / \mathrm{ka}$. From the uppermost middle Eocene to upper Eocene ( $374-360 \mathrm{mbsf})$, the sedimentation rate drops to $0.5 \mathrm{~cm} / \mathrm{ka}$ and further decreases to $0.04 \mathrm{~cm} / \mathrm{ka}$ in the lowermost Oligocene. In the uppermost Eocene and lowermost Oligocene, glauconitic rich sediment at $\sim 362-359$ mbsf indicates a very condensed interval. RP15 $5_{\mathrm{SH}}$ and RP16 ${ }_{\mathrm{SH}}$ cannot be located at this site and the sediments have either been eroded or have not been deposited due to the very low sedimentation rate. The presence of one specimen of Eucyrtidium antiquum (primary marker for RP15) at 365.2 mbsf might be due to downworking. The $\mathrm{HO}$ datum of L. amphitrite does not fit the agedepth plot and indicates an earlier $\mathrm{HO}$ at $\sim 36.8$ Ma. The presence of Clinorhabdus robusta (primary marker of $\mathrm{RP} 17_{\mathrm{SH}}$ ) from 356.85-364.6 mbsf suggests that the condensed interval in the Oligocene spans almost $7 \mathrm{Ma}$. The nannofossil datums more or less agree with the age-depth plot and the slight disagreement might be due to badly preserved specimens in a highly siliceous sediment. 


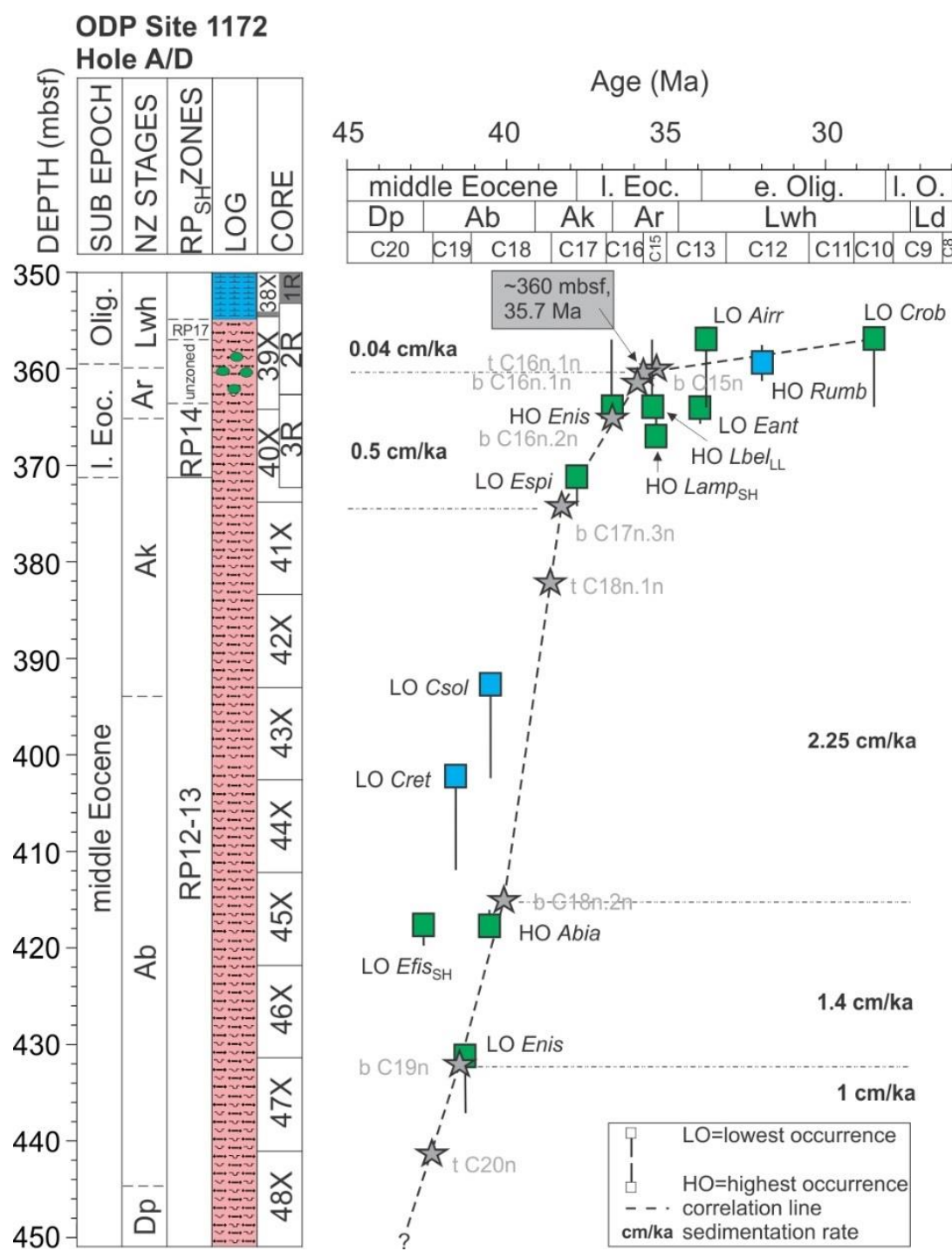

Figure 5.4 Age-depth plot of Site 1172, Hole A (Cores 1172A-48X to $-43 \mathrm{X}$ ) and Hole D (Cores 1172D-3D to -1D) using nannofossil (blue squares), radiolarian (green squares) and magnetostratigraphic (stars) events. Geomagnetic Polarity Timescale (Chrons) shown at the top; $b=b a s e, t=t o p$.

\subsection{Mid-latitude Southwest Pacific sites}

\subsubsection{DSDP Site 207}

Due to absence or scarcity of primary markers for the low-latitude zonation of Sanfilippo and Nigrini (1998a) (emended by Kamikuri et al., 2012a), the Southern Hemisphere zonation has been applied at this site. The interval from 242.46 to $143.55 \mathrm{mbsf}$ has been correlated to radiolarian zones $\mathrm{RP} 10_{\mathrm{SH}}$ to $\mathrm{RP} 12_{\mathrm{SH}}$. Due to the scarcity of radiolarians from 318.96-245.38 mbsf, this interval can only be tentatively correlated to radiolarian zones. The following succession of radiolarian biostratigraphic events are identified (from oldest to youngest, Figure 5.5, Appendix C): 
1. The base of $\mathrm{RP} 9_{\mathrm{SH}}$ cannot be located as primary marker taxa are absent. Other key events close to the base of the zone are the LO of Lychnocanium bellum at 286284.20 mbsf and Theocampe urceolus at 284.20-279 mbsf. The latter taxon has only an isolated lowest occurrence and is very rare at this site.

2. The LO of Amphicraspedum prolixum s.s. is found at 286-284.20 mbsf.

3. The top of $\mathrm{RP}_{\mathrm{SH}}$ is placed at $279-276.51 \mathrm{mbsf}$ based on the $\mathrm{HO}$ of Buryella tetradica, which is an event close to the top of the zone.

4. The interval between $276-245$ mbsf cannot be assigned to a zone because of very rare and poorly preserved radiolarians.

5. The base of RP10 $\mathrm{SH}$ is placed at 245.38-242.46 mbsf based on the LO of Artobotrys auriculaleporis, which is proposed as a secondary datum for this zone. The primary marker for the base of $\mathrm{RP} 10_{\mathrm{SH}}$, Theocampe mongolfieri, has an isolated occurrence at $216.01 \mathrm{mbsf}$. The HO of Podocyrtis aphorma occurs at 219.47-216.40 mbsf and cannot be used as a secondary marker for the base of the zone as it seems to have a later $\mathrm{HO}$, within $\mathrm{RP} 10_{\mathrm{SH}}$ at this site.

6. The HO of Podocyrtis acalles is found at 228.20-219.47 mbsf, a datum within RP10 ${ }_{\text {SH. }}$.

7. The HO of Amphicraspedum prolixum s.s. is found at 198.51-190.66 mbsf, in upper RP10 ${ }_{\mathrm{SH}}$.

8. The base of RP11 $1_{\mathrm{SH}}$ is placed at $189.4-182 \mathrm{mbsf}$ based on the LO of Eusyringium lagena.

9. The base of RP12 $\mathrm{SH}$ is placed at $170.19-168.50$ mbsf based on the LOs of Eusyringium fistuligerum and Lophocyrtis longiventer. Both these species are very rare at this site.

10. The LO of Zealithapium anoectum close to the base of $\mathrm{RP} 12_{\mathrm{SH}}$ is found at 168.50-165.50 mbsf.

11. The base of $\mathrm{RP} 13_{\mathrm{SH}}$ cannot be located at this site as the primary marker, Zealithapium mitra, has an isolated occurrence at 170.19 mbsf, within upper $\mathrm{RP} 11_{\mathrm{SH}}$. This earlier occurrence is consistent with the earlier LO of this taxon in low-latitudes $(\sim 42.3 \mathrm{Ma})$.

12. The HOs of Eusyringium lagena and Artobotrys biaurita are found at 152-149.06 mbsf. 
Foraminiferal biostratigraphy has been used to correlate the studied interval to New Zealand stages (H.E.G. Morgans, pers. comm. 2016).

1. A Haumurian (Mh, Late Cretaceous) fauna was observed in one sample at 301 mbsf (Core 207A-28R-1, $100 \mathrm{~cm}$ ).

2. A Teurian (Dt, Paleocene) assemblage is present in the succeeding sample at 293.55 mbsf (Core 207A-27R-2, $105 \mathrm{~cm}$ ).

3. The base of the Waipawan (bDw, early Eocene) is placed at 288-287 mbsf based on the LO of Morozovella aequa aequa.

4. The base of the Mangaorapan (bDm, early Eocene) is placed at 276.51-269 mbsf based on the LO of Morozovella crater. The large sample gap is due to the occurrence of early forms of this taxon at $276.51 \mathrm{mbsf}$, whereas typical forms do not occur until 269 mbsf.

5. The base of the Heretaungan (bDh, latest early to middle Eocene) is placed at 230.01-219.47 mbsf based on LO of Elphidium hampdenense.

6. The base of the Porangan (bDp, middle Eocene) is placed at 213.4-212 mbsf based on the $\mathrm{HO}$ of Morozovella crater, a secondary datum to define the base of the Porangan.

7. The base of the Bortonian (bAb, middle Eocene) is placed at $170.19-168.50 \mathrm{mbsf}$ based on the LO of Globigerinatheka index. The base correlates well with the base of RP12 $\mathrm{SH}$. Two specimens of that taxon were found at $182 \mathrm{mbsf}$, however, none in the two samples thereafter.

Nannofossil biostratigraphy has been used to correlate the studied interval with zones NP10 to NP16 (1.-9.: C. Shepherd, pers. comm. 2016) and Kulhanek \& Morgans (2013).

1. The base of NP10 is placed at 286-284.20 mbsf, based on the HO of Fasciculithus spp.

2. The base of NP11 is tentatively placed at $286-284.20 \mathrm{mbsf}$, based on the LO of Sphenolithus radians, which has the same age as the base of NP11.

3. The base of NP12 is placed at 279-276.51 mbsf, based on the LO of Discoaster lodoensis.

4. The base of NP13 is placed at 271.5-269.6 mbsf based on the HO of Tribrachiatus orthostylus. 
5. The base of NP14 is placed at 247.26-242.46 mbsf based on the LO of Discoaster sublodoensis.

6. The LO of Nannotetrina cristata is found at $230.01-219.47 \mathrm{mbsf}$, an event within upper NP14.

7. The base of NP15b (45.49 Ma; Gradstein et al., 2012) is placed at 207.52198.51 mbsf based on the LO of $C$. gigas. Indicator taxa for the base of NP15a are absent.

8. The base of NP15c is placed at $182-171.51 \mathrm{mbsf}$ based on the $\mathrm{HO}$ of $C$. gigas.

9. The base of NP16 cannot be identified by the HO of Nannotetrina fulgens, the primary marker. The LO of Reticulofenestra umbilicus $>14 \mu \mathrm{m}$ occurs near the base of NP16 and can be found at 182-171.51 mbsf.

10. The sequence is truncated by the Marshall Unconformity between 143.55-139 mbsf; the sediments directly below (143.55 mbsf) have an age of 41.66-40.4 Ma based on the presence of Cribrocentrum reticulatum and Chiasmolithus solitus. The sediments directly above (139 mbsf) are of latest early to earliest middle Miocene age (Clifdenian-Lillburnian).

\subsubsection{Intergrated chronostratigraphy}

An age-depth plot has been constructed using the bioevents outlined above (Figure 5.5). The sedimentation rate in the lowermost Eocene (earliest Waipawan) is very low, $\sim 0.15$ $\mathrm{cm} / \mathrm{ka}$. During the Waipawan, the sedimentation rate increases to $\sim 1.6 \mathrm{~cm} / \mathrm{ka}$ based on nannofossil datums. In the uppermost Waipawan, the sedimentation rate decreases to 0.2 $\mathrm{cm} / \mathrm{ka}$. Alternatively, there could be two hiatuses instead of the very low sedimentation rates, but there is a lack of glauconite or other lithologic evidence for a hiatus. The presence of chert nodules from Cores 207A-26R to $-22 \mathrm{R}$ indicates the possibility of diagenetic compaction of biogenic silica, resulting in the very low sedimentation rates in this interval. The sedimentation rate increases in the Mangaorapan to mid-Heretaungan to $1.8 \mathrm{~cm} / \mathrm{ka}$. The base of the Heretaungan is approximated by the age-depth plot and corresponds well with the LO of $D$. sublodoensis, a secondary marker for this event. The primary datum for the base of this zone (LO of E. hampdenense) occurs $~ 1.2$ Ma later. From mid-Heretaungan to upper Porangan, the sedimentation rate decreases to $1 \mathrm{~cm} / \mathrm{ka}$, based on nannofossil datums. The base of the Porangan is also based on the age-depth plot. The secondary marker for the base of this zone (HO of M. crater) is $\sim 1.6 \mathrm{Myr}$ earlier. The base of NP15a cannot be located due to absence of marker species 
Nannotetrina fulgens. The first persistent occurrence of G. index was used as the marker for the base of NZ Bortonian stage (42.6 Ma), which coincides with the LO of $L$. longiventer and fits well with other radiolarian datums. The LO of $R$. umbilicus was not used as a correlation point as it is likely that this species has a diachronous lowest occurrence in the Southwest Pacific, appearing earlier in the Southwest Pacific than in other parts of the world (Kulhanek and Morgans 2013). The sedimentation rate increases in the Bortonian to $\sim 2.5 \mathrm{~cm} / \mathrm{ka}$. The upper Bortonian from $\sim 40.4 \mathrm{Ma}$ is missing. This hiatus recorded at the top of Core 207A-11R (143.55-139 mbsf) has been correlated to the Marshall Unconformity by Kulhanek and Morgans (2013).

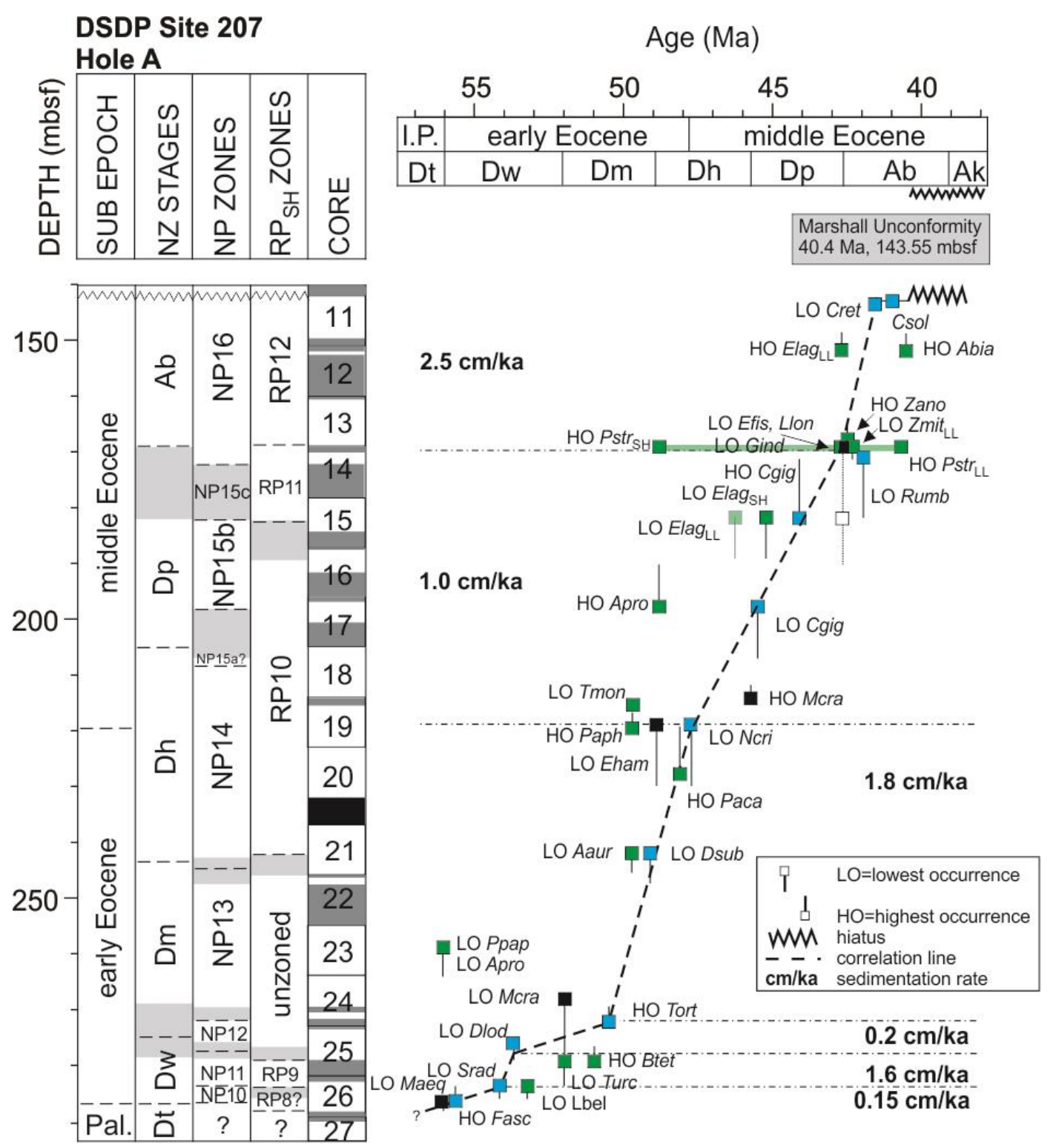

Figure 5.5 Age-depth plot of DSDP Site 207 Hole A using nannofossil (blue squares), foraminifera (black squares) and radiolarian (green squares) events. LL=low-latitude datum; SH=Southern Hemisphere datum. The green band for Phormocyrtis striata striata spans the range of its $\mathrm{HO}$ datum from high to low latitudes. 


\subsubsection{DSDP Site 206}

Although this is the most northern site studied, low-latitude markers are absent or very rare. For this reason, the Southern Hemisphere zonation is applied to the interval from 687.51-613.70 mbsf, spanning zones RP12-13 sh. In this study, the following succession of radiolarian events is identified (from oldest to youngest, Figure 5.6, Appendix C):

1. The lowermost interval from 728-687.51 mbsf (Cores 206C-21R to $-19 \mathrm{R}$ ) contains only very rare and poorly preserved radiolarians. Several taxa are present that have their LOs in the Paleocene or early Eocene such as Buryella granulata $\left(\mathrm{RP} 3_{\mathrm{SH}}\right)$, B. foremanae $\left(\mathrm{RP} 4_{\mathrm{SH}}\right)$, B. tetradica $\left(\mathrm{RP} 5_{\mathrm{SH}}\right)$, Phormocyrtis striata striata $\left(\mathrm{RP}_{\mathrm{SH}}\right)$, as well as Podocyrtis papalis $\left(\mathrm{RP} 8_{\mathrm{SH}}\right)$. However, no age can be determined as Paleocene restricted species B. foremanae co-occurs with Eocene restricted species $P$. papalis and A. prolixum s.s. in Core 206C-21R, which indicates core disturbance.

2. The radiolarian-rich interval from $672-613.70 \mathrm{mbsf}$ (Cores $206 \mathrm{C}-18 \mathrm{R}$ to $-15 \mathrm{R}$ ) is placed in Zone RP12 ${ }_{\mathrm{SH}}$ based on the LO of Eusyringium fistuligerum at 678.51672 mbsf. The LO of Lophocyrtis longiventer is found at 672-670.5 mbsf. However, the sudden increase in abundance and diversity in Core 206C-18R may be an artefact of preservation. It is possible that zone RP12 $2_{\mathrm{SH}}$ may extend lower in the sequence.

3. The HO of Eusyringium lagena, a datum in lower RP12 $\mathrm{SH}$, is recorded at 657.5$654.5 \mathrm{mbsf}$.

4. The base of RP13sh is placed at 654.5-651.5 mbsf based on the LO of Zealithapium mitra.

5. The HO of Spongatractus pachystylus at $649.6-634$ mbsf is earlier at this site compared to its low-latitude HO of 37.75 Ma (GTS2012; Kamikuri et al. 2012a).

6. Eucyrtidium nishimurae has its LO at $669-657.5 \mathrm{mbsf}$, a datum within RP12 $\mathrm{SH}$.

7. The LO of Cryptocarpium ornatum is found at $649.60-634 \mathrm{mbsf}$ (41.3 Ma; Gradstein et al., 2012).

8. The LO occurrence of Lithocyclia aristotelis and Theocampe pirum at 630.15614.28 mbsf, both with a LO datum of $38.95 \mathrm{Ma}$ (Gradstein et al., 2012) suggest correlation to NZ Kaiatan stage.

9. The HO of Phormocyrtis striata striata is recorded at $614.28-614.02 \mathrm{mbsf}$ (40.65 Ma, Gradstein et al., 2012). 
Foraminiferal biostratigraphy has been used to correlate the interval to New Zealand Stages (Burns et al. 1973).

1. Bortonian sediments are present from $687.55-613.70 \mathrm{mbsf}$ based on the presence of Globigerinatheka index and Acarinina primitiva. The LO of G. index is found at $688.16-687.55$ mbsf.

Three samples from 649.6-613.7 mbsf were analysed for planktic foraminifer and nannofossil datums (Kulhanek and Morgans, 2013) and the assemblage is correlated to the Bortonian Stage of 42.6-39.1Ma. Nannofossil age control suggests an age of 41.8541.66 Ma (NP16) for Sample Core 206A-17R-1, 15cm, based on the absence of Nannotetrina spp. (HO 41.85 Ma) and C. reticulatum (LO 41.66 Ma) which agrees with other age control (Figure 5.6). Based on nannofossils, an age of 38.25-37.98 Ma is inferred for Sample 206A-16R-1, 13cm. This is much younger compared to foraminifer age control (>40.49 Ma based on the presence of Acarinina bullbroki). Furthermore, nannofossil biostratigraphy suggests the unconformity is located between 613.75 and 613.70 mbsf, with an early Oligocene assemblage of $\sim 31.35-30 \mathrm{Ma}$ in Sample 206A15R-2, 20cm (613.70 mbsf). The foraminifer assemblage at $613.70 \mathrm{mbsf}$ lack species restricted to the early Oligocene but middle Eocene species are present (Acarinina primitiva, $\mathrm{HO}$ datum of $39.1 \mathrm{Ma}$ ).

\subsubsection{Integrated chronostratigraphy}

The age-depth plot suggests two scenarios. The preferred (black) correlation line is drawn using the LO datum of $G$. index, nannofossil age control and radiolarian datum of $C$. ornatum. However, given the mid-latitude position of the site, the LOLL datums of $E$. fistuligerum and Z. mitra is plotted as well. It shows that the correlation line agrees the high-latitude age for the LO of E. fistuligerum but, conversely, is a better fit with lowlatitude age for the LO of Z. mitra. A hiatus is present between Paleocene-lower Eocene and middle Eocene sediments, but it cannot be determined how long exactly it lasted, as radiolarians are rare and poorly preserved in Paleocene-lower Eocene sediments. The black correlation line places the Marshall Unconformity at the top of the interval in Core 206A-15R, which would suggest $3.7 \mathrm{~cm} / \mathrm{ka}$ sedimentation rate throughout the interval. The fact that $T$. pirum and L. aristotelis were found in this Core, might be due to core disturbance or reworking. The hiatus started from $\sim 40.6 \mathrm{Ma}$ and is located in Core 206A15R-2 at 613.70 mbsf (Burns et al. 1973; Kulhanek \& Morgans 2013) (Figure 5.6). 


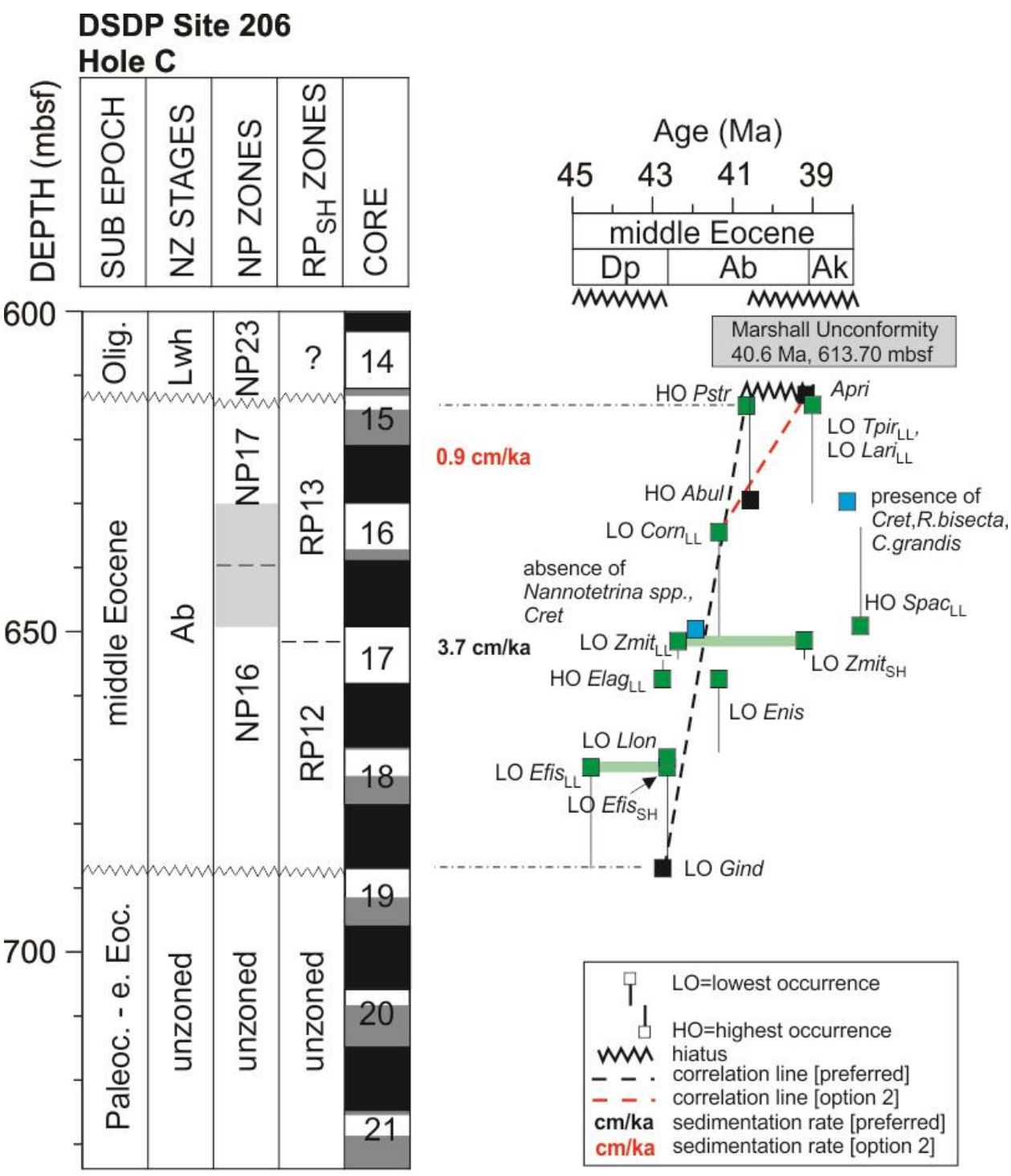

Figure 5.6 Age-depth plot of DSDP Site 206 Hole C using nannofossil (blue squares), foraminifera (black squares) and radiolarian (green squares) events. LL=low-latitude datum; SH=Southern Hemisphere datum. Green bands for Eusyringium fistuligerum and Zealithapium mitra indicate the age-range of the datum between low and high latitudes.

\subsubsection{DSDP Site 592}

Because calcareous microfossil (nannofossil and foraminifer) biostratigraphy provide a better resolved age control for this site (Kulhanek and Morgans, 2013) than radiolarian biostratigraphy, it is presented here first (Figure 5.7, Appendix C):

1. The combined presence of Globigerinatheka index ( $\mathrm{HO}$ at $34.61 \mathrm{Ma}$ ) and Chiasmolithus oamaruensis (LCO at 37.32 Ma, Gradstein et al., 2012) in Sample $592-41 X-6,100 \mathrm{~cm}$ (387.40 mbsf) places this sample in the latest Kaiatan stage (late Eocene), younger than 37.32 Ma.

2. The base of NP19-20 is placed at 387.40-382.80 mbsf based on the LO of Isthmolithus recurvus (36.97 Ma, Raine et al. 2015). 
3. The $\mathrm{HO}$ of Cribocentrium reticulatum (35.92 Ma) is at $363.70-354.10 \mathrm{mbsf}$.

4. The LO of Reticulofenestra oamaruensis (35.54 Ma, Gradstein et al. 2012) is at 354.10-344.50 mbsf.

5. The base of the Whaingaroan Stage (age) is placed at 335.15-334.65 mbsf based on the HO of Globigerinatheka index.

6. The base of NP21 is placed at 335.15-334.90 mbsf based on the HO of Discoaster saipanensis.

7. The HO of Reticulofenestra oamaruensis (33.97 Ma, Gradstein et al., 2012), a datum within NP21, is observed at 333.40-328.30 mbsf.

Based on nannofossil and foraminifer biostratigraphy, the studied succession lies within NP19-20, which corresponds to RP14 $4_{\mathrm{SH}}$ or RP18-19LL. However, important radiolarian marker species for this interval are absent.

1. The primary marker for $\mathrm{RP} 14_{\mathrm{SH}}$, Eucyrtidium spinosum, has only an isolated occurrence at $365 \mathrm{mbsf}$. Based on nannofossil and foraminifer stratigraphy, the studied radiolarian samples lie within NP19-20 which equals RP14 ${ }_{\mathrm{SH}}$.

2. Cryptocarpium ornatum is present in low numbers from $374.60-365$ mbsf, which can be assigned to late Eocene low-latitude zones RP18-19. Other typical lowlatitude marker species for these zones like Lithocyclia spp., Calocyclas bandyca or Thyrsocyrtis bromia are absent.

3. The HO of Lychnocanium amphitrite is identified at $363.50-353.90 \mathrm{mbsf}$ and an isolated occurrence of Lychnocanium bellum at 344.30 mbsf. Both datums occur within the late Eocene.

\subsubsection{Integrated chronostratigraphy}

Two age models are considered for this site (Figure 5.7). The preferred (black) correlation line indicates a sedimentation rate of $2 \mathrm{~cm} / \mathrm{ka}$ for the upper Eocene followed by a decrease in the uppermost Eocene and lower Oligocene $(0.6 \mathrm{~cm} / \mathrm{ka})$. As noted for Site 277 , there are two age estimates for the $\mathrm{HO}$ of $C$. reticulatum in high latitudes. As at that site, the younger age estimate (Gradstein et al., 2012) is in best agreement with the age model at Site 592. The estimated paleodepth of this site in the late Eocene is around 1500-2000 m (Kulhanek and Morgans, 2013), which is a relatively deep setting in which $2 \mathrm{~cm} / \mathrm{ka}$ would seem to be realistic. The high-latitude datum for $L$. amphitrite also fits the age model better than the low-latitude datum. 


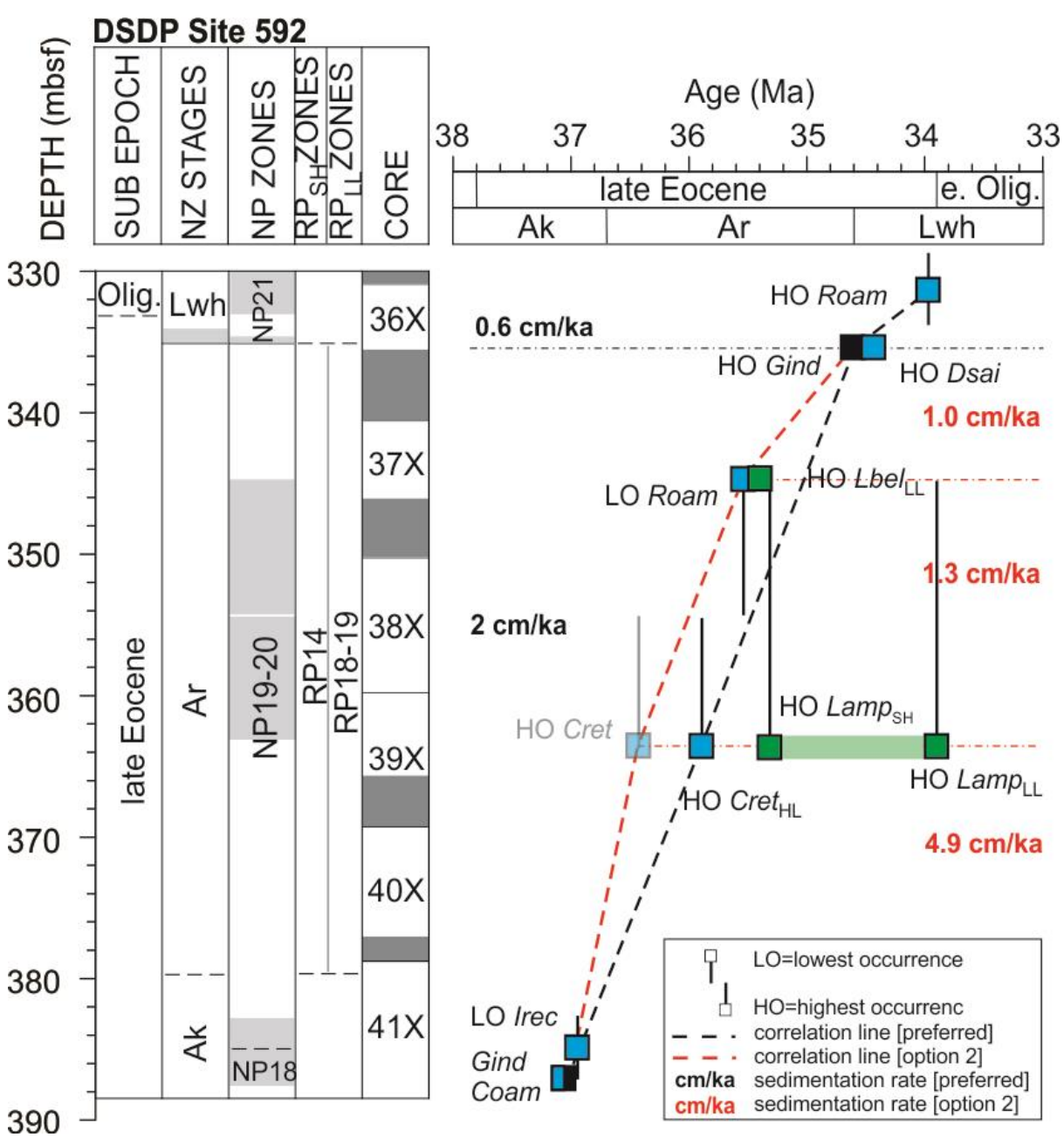

Figure 5.7 Age-depth plot of DSDP Site 592 using nannofossil (blue squares), foraminifera (black squares) and radiolarian (green squares) events. HL=high-latitude datum; $\mathrm{LL}=$ low-latitude datum. The green band indicates the agerange for the $\mathrm{HO}$ of $L$. amphitrite between low and high latitudes.

\subsubsection{ODP Site 1123}

The site has been correlated with $\mathrm{RP}_{\mathrm{SH}}$ Zones using the following datums (Figure 5.8, Appendix C):

1. The base of RP14 ${ }_{\mathrm{SH}}$ is placed at $624.86-623.51 \mathrm{mbsf}$ based on the LO of Eucyrtidium spinosum.

2. The base of $\mathrm{RP} 15_{\mathrm{SH}}$ is placed at $614.46-611.18 \mathrm{mbsf}$ based on the LO of Eucyrtidium antiquum. However, this taxon is present with only trace occurrences.

3. The LO of Axoprunum? irregularis, a datum in RP15 $5_{\mathrm{SH}}$, is found at 599.74594.90 mbsf. 
Additionally, the following events have been used to correlate the succession with $\mathrm{RP}_{\mathrm{LL}}$ Zones:

1. The top of RR19LL is placed at 599.74-594.9 mbsf based on the HO of Cryptocarpium ornatum, the primary marker for this zone. The same interval records the HOs of Lychnocanium amphitrite and Theocampe mongolfieri.

2. The HO of Cryptocarpium azyx is recorded at $619.21-618.15$ mbsf, a datum within RP19 $\mathrm{LL}$. However, it is only an isolated single occurrence of this taxon. HO $\sim 34.97 \mathrm{Ma}$

3. The HO of Theocampe pirum is recorded at 593-590.90 mbsf, a datum within RP19LL.

4. The base of RP20 $\mathrm{LL}$ is placed at 599.74-594.9 mbsf based on the LO of Thyrsocyrtis tuberosa, the primary marker for this zone. However, this taxon has a trace to rare occurrence.

Additional planktic foraminifer, nannofossil and magnetostratigraphic datums are taken from the Site Report for ODP Site 1123 (Shipboard Scientific Party, 1999). Ages have been recalibrated to Gradstein et al. (2012) (Figure 5.8).

1. The age of the bottom of Core 1123C-33X (625.86 mbsf) is $~ 36.7-34.6$ Ma based on the presence of Globigerinatheka semiinvoluta, (LO 38.62 Ma, HO $36.18 \mathrm{Ma}$ ), which is restricted to the upper Runangan ( 36-34.6 Ma) in New Zealand (Jenkins, 1971). As Site 1123 is the site closest to mainland New Zealand in terms of latitude, the New Zealand range of this species was used to assign an age to the bottom of the hole (Shipboard Scientific Party, 1999).

2. The base of $\mathrm{C} 13 \mathrm{r}$ is found at $616.03 \mathrm{mbsf}(34.99 \mathrm{Ma})$.

3. The base of $\mathrm{C} 13 \mathrm{n}$ is found at $599.68 \mathrm{mbsf}(33.7 \mathrm{Ma})$.

4. The base of the Whaingaroan Stage is placed at 611.08-599.64 mbsf based on the HO of Globigerinatheka index (34.61 Ma).

5. The base of NP21 is placed at 611.08-599.64 mbsf based on the HO of Discoaster saipanensis (34.44 Ma).

6. The acme of Clausicoccus subdistichus is a datum within NP21 (33.43 Ma, Gradstein et al. 2012) and is found at 599.64-587.39 mbsf.

7. The base of $\mathrm{C} 12 \mathrm{r}$ is found at $591.08 \mathrm{mbsf}(33.15 \mathrm{Ma})$. 
8. The HO of Isthmolithus recurvus is located at $587.39-587.19 \mathrm{mbsf}$ and is dated at 32.49 Ma, within Zone NP22.

9. The Marshall Unconformity is located at the top of Core 1123C-29X (587.20 mbsf), separating early Oligocene from Miocene sediments and dated at $\sim 33 \mathrm{Ma}$ (Shipboard Scientific Party, 1999).

\subsubsection{Integrated chronostratigraphy}

Using the age control outlined above (Figure 5.8), the sedimentation rate for the interval spanning Cores $1123 \mathrm{C}-33 \mathrm{X}$ to $-31 \mathrm{X}$ (625.86 to $610.10 \mathrm{mbsf})$ is $1.7 \mathrm{~cm} / \mathrm{ka}$. In the lower Oligocene, the sedimentation rate drops to $1.4 \mathrm{~cm} / \mathrm{ka}$ for the interval from Core $1123 \mathrm{C}$ $31 \mathrm{X}$ to $-29 \mathrm{X}$ (610.10 to $587.20 \mathrm{mbsf})$. This may be the due to increased bottom water currents winnowing the sediments prior to the episode of erosion or non-deposition that is associated with the Marshall Unconformity at 33 Ma (Shipboard Scientific Party, 1999).

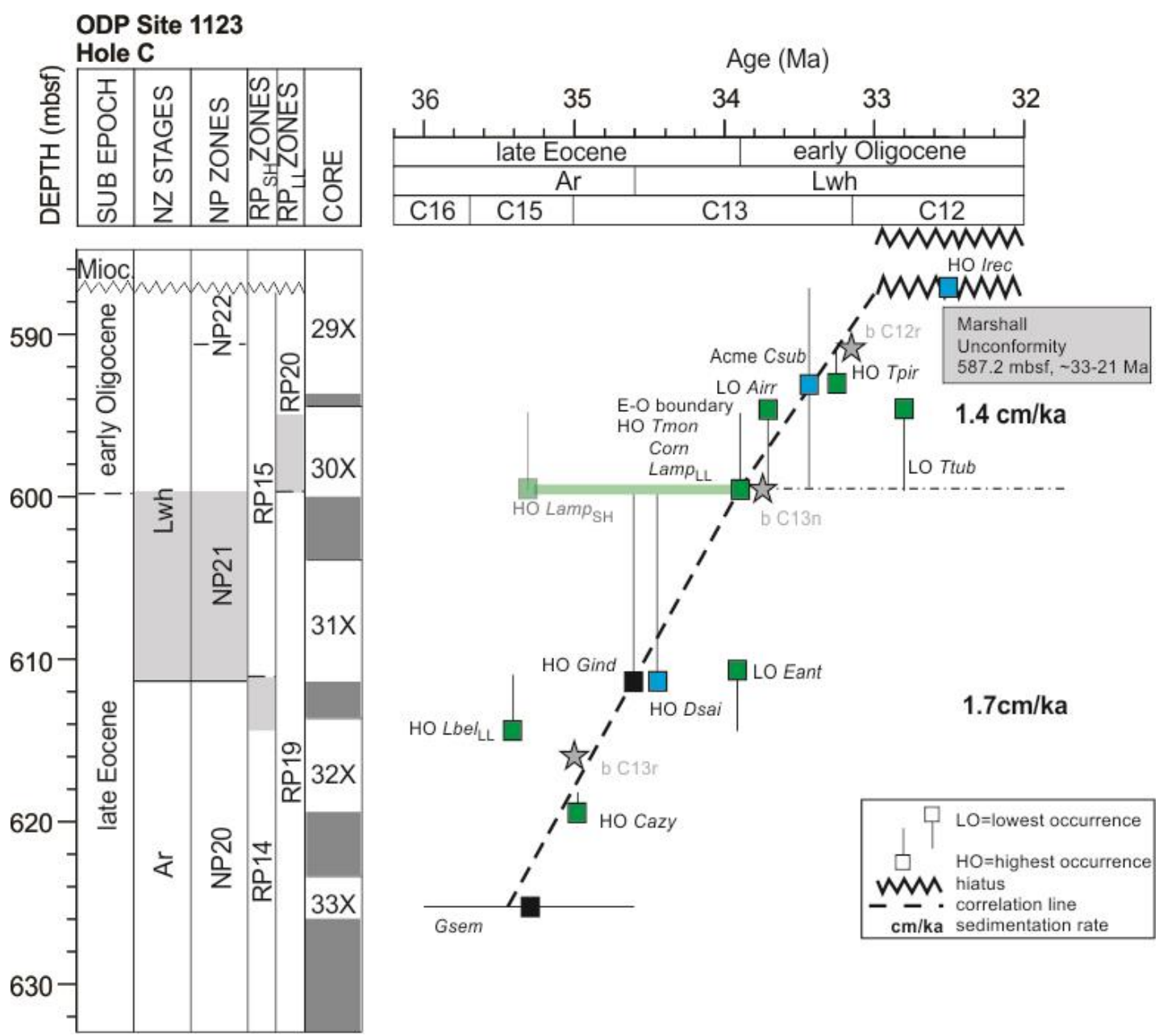

Figure 5.8 Age-depth plot of ODP Site 1123 Hole C using nannofossil (blue squares), foraminifera (black squares), radiolarian (green squares) events and magnetostratigraphic (stars) events. Geomagnetic Polarity Timescale (Chrons) shown at the top. Abbreviations: $\mathrm{b}=$ base; $\mathrm{LL}=\mathrm{low}$-latitude datum; $\mathrm{SH}=\mathrm{Southern}$ Hemisphere datum. The green band indicates the age-range for the $\mathrm{HO}$ of L. amphitrite between low and high latitudes. 
As at DSDP Site 592, the sedimentation rate decreases in the late Eocene and across the E-O transition. The low-latitude $\mathrm{HO}$ datum of $L$. amphitrite fits the age-depth plot better than the Southern Hemisphere datum of 35.3 Ma. Based on the age-depth plot, an age of $\sim 35.5 \mathrm{Ma}$ can be inferred for the bottom of the hole.

\subsection{Correlation between sites}

Based on Figure 5.9, the following key points can be made:

- Sites 277 and 207 have the most continuous records of radiolarian-bearing sediments, extending from upper Paleocene to middle Eocene at Site 207 and to lower Oligocene at Site 277, with all New Zealand stages present from Teurian to Whaingaroan.

- Other sites have partial records but relatively complete composite sections. The middle Eocene to upper Oligocene (Bortonian to Whaingaroan) can be constructed from the southern sites $(280,281,283$ and 1172) and northern sites (206, 592 and 1123).

- Condensed intervals or hiatuses are identified in the earliest Eocene (early Waipawan, Site 277), middle Eocene (Porangan; sites 277 and 206), late Eocene (Site 1172) and early Oligocene (sites 206, 1123 and 1172).

- Conversely, expanded intervals are identified in the middle Eocene at sites 277 (Bortonian), 207 (Porangan-Bortonian) and 206 (Bortonian) and late Eocene at sites 277 and 283.

- The Southern Hemisphere radiolarian zonation has been successfully applied to all high- and mid-latitude sites and facilitates correlation, especially from late early Eocene to Oligocene (RP10 $0_{\mathrm{SH}}$ to RP15 $\left.5_{\mathrm{SH}}\right)$. 


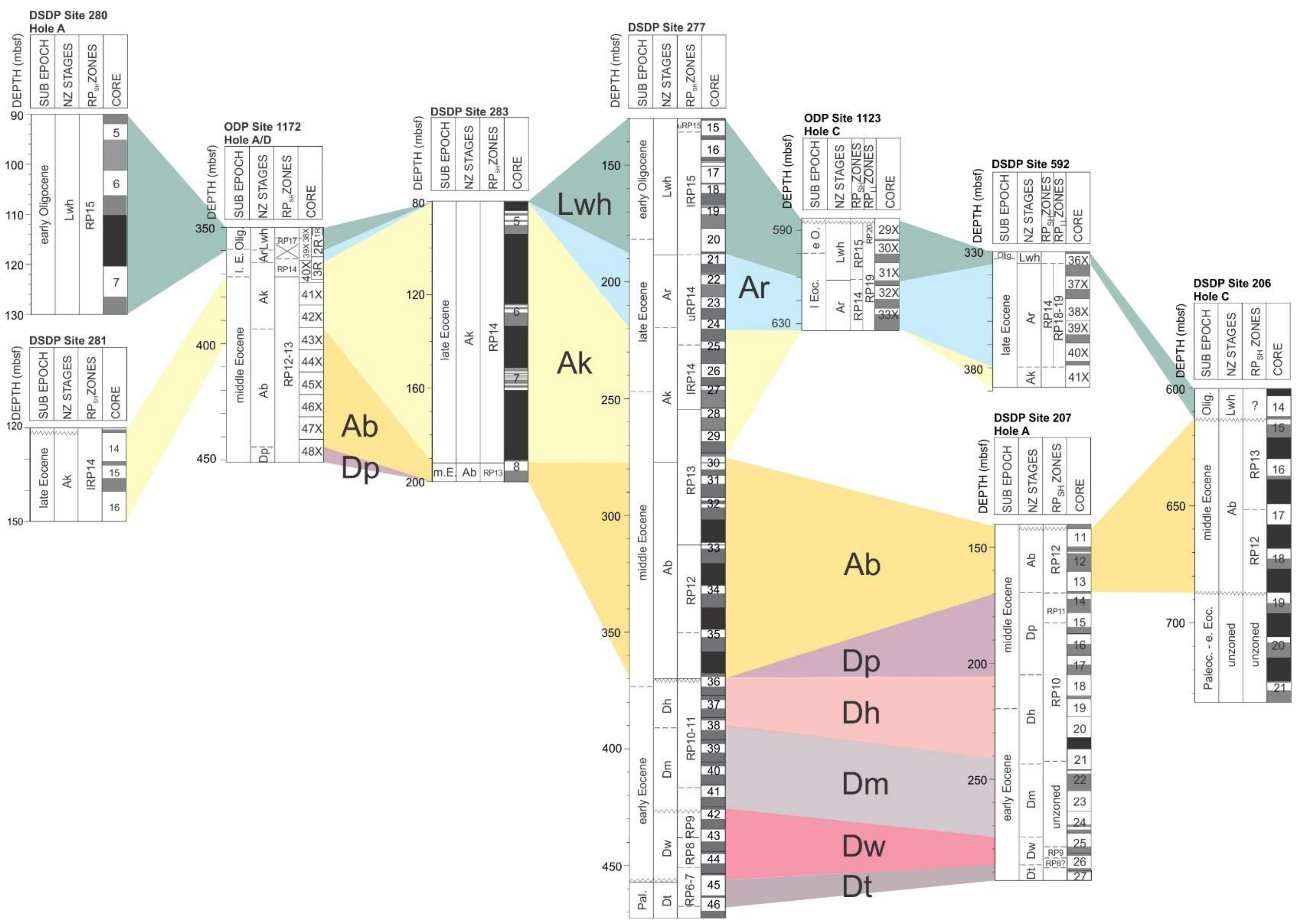




\section{Radiolarian paleoecology and paleobiogeography}

In the first part of this chapter, the radiolarian assemblages at high- and mid-latitude sites are analysed, including diversity measures and relative abundances of radiolarian families for all sites. Results from stable oxygen and carbon isotope analysis are included for sites 277, 207 and 592 (Appendix D, data on enclosed CD). In the second half of the chapter, the radiolarian assemblages are grouped according to their biogeographic affinity (highlatitude, cosmopolitan and low-latitude) and the results are presented in cumulative affinity plots for each site. All radiolarian distribution data, abundances and diversity measures can be found in Appendix B (data on enclosed CD).

\subsection{Radiolarian assemblages and diversity}

\subsubsection{High-latitude sites}

\subsubsection{DSDP Site 277}

The radiolarian assemblages examined from this site comprise 139 counting groups, which include 67 genera and 16 families. A total of 108 taxa were identified to species level (Appendix A, Appendix B Table 1). Diversity increases within the MECO (313.5$296 \mathrm{mbsf})$ and in the upper Eocene (226.10-186.5 mbsf) and decreases in the lower Oligocene (162.2-134.5 mbsf) (Figure 6.1). Diversity closely parallels trends in abundance and preservation.

Simpson Evenness also tracks the diversity curve, but exhibits greater troughs where samples are sparse and dominated by undetermined spumellarians. Spumellarians are dominant in most samples, with their relative abundance ranging between $\sim 44$ and $96 \%$ ( $71 \%$ average) (Figure 6.1$)$. 


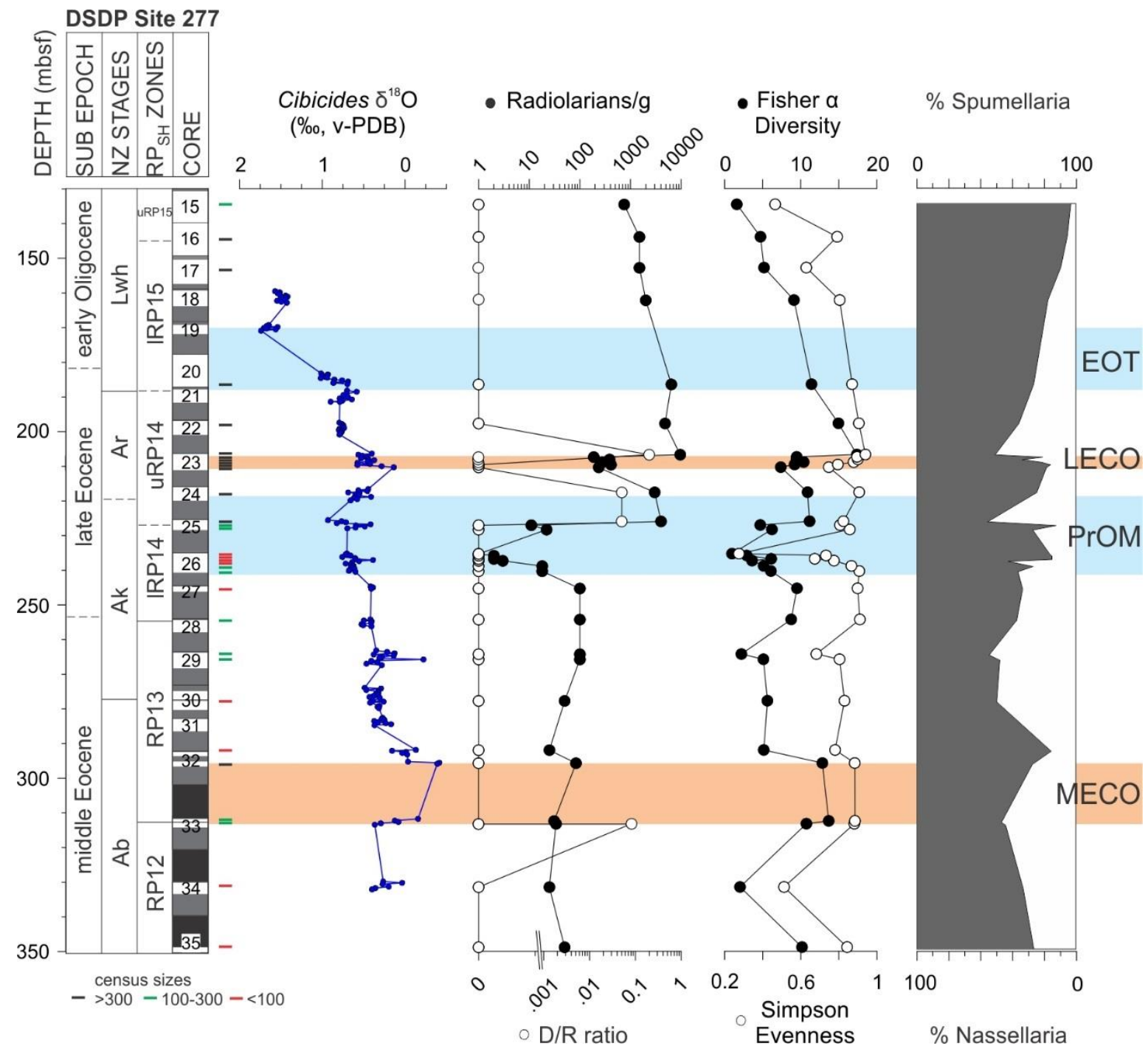

Figure 6.1 General trends in radiolarian assemblages at DSDP Site 277 compared with the benthic foraminiferal $\delta^{18} \mathrm{O}$ record and climate events (Pascher et al., 2015), including radiolarian abundance (radiolarians/g), diatom/radiolarian $(\mathrm{D} / \mathrm{R})$ ratio, Fisher $\alpha$ Diversity Index, Simpson Evenness Index and relative abundance (\%) of spumellarians (grey) and nassellarians (white). Census size for all examined samples is colour-coded and shown to the right of the core log. $\mathrm{MECO}=$ middle Eocene climatic optimum, $\mathrm{PrOM}=$ Priabonian oxygen isotope maximum, LECO=late Eocene climatic optimum, EOT=Eocene-Oligocene transition. For abbreviations of NZ Stages, please see Chapter 3.6. 
The main families are the undetermined spumellarians ( $25 \%$ average), Actinommidae ( 22\%), Litheliidae ( 14\%), Spongodiscidae ( 7\%), Artostrobiidae ( 7\%), Lychnocaniidae $(\sim 6 \%)$, Lophocyrtiidae $(\sim 6 \%)$, undetermined nassellarians $(\sim 3 \%)$ and Trissocyclidae ( $3 \%$ ) (Figure 6.2, Appendix B Table 1). The remaining radiolarian families account for $\sim 7 \%$ of the total assemblage: Phacodiscidae, Eucyrtidiidae, Plagiacanthidae, Sponguridae and Acropyramididae each with $\sim 1 \%$, and rare $(<1 \%)$ Cannobotryidae, Pterocorythidae, Amphipyndacidae and Sethophormididae (the latter two are not shown in Figure 6.3).

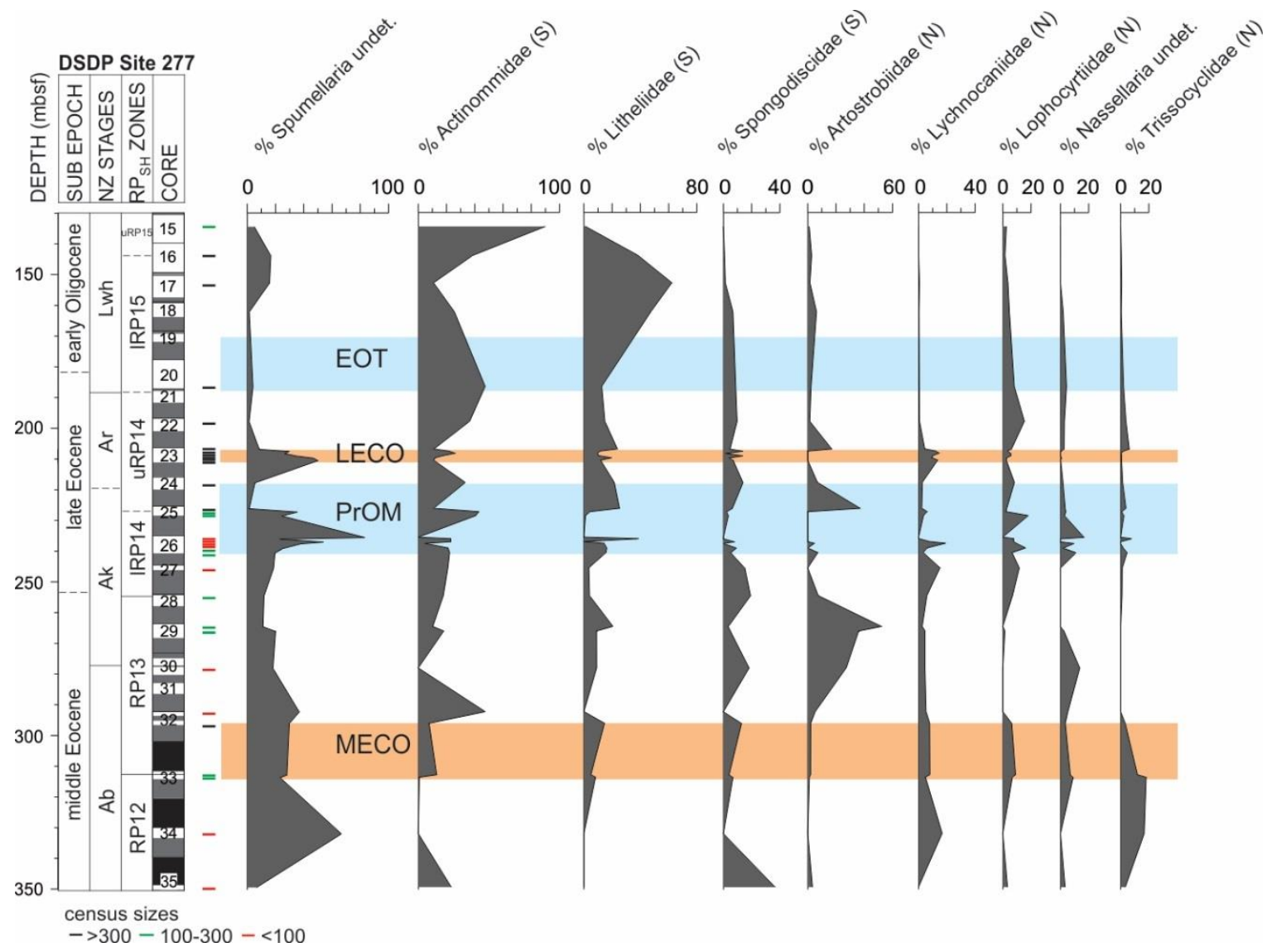

Figure 6.2 The relative abundance of the most abundant radiolarian families and counting groups at DSDP Site 277. Census size for all examined samples is colour-coded and shown to the right of the core log. $\mathrm{S}=$ spumellarians, $\mathrm{N}=$ nassellarians, $\mathrm{MECO}=$ middle Eocene climatic optimum, $\mathrm{PrOM}=$ Priabonian oxygen isotope maximum, $\mathrm{LECO}=\mathrm{late}$ Eocene climatic optimum, EOT=Eocene-Oligocene transition. 


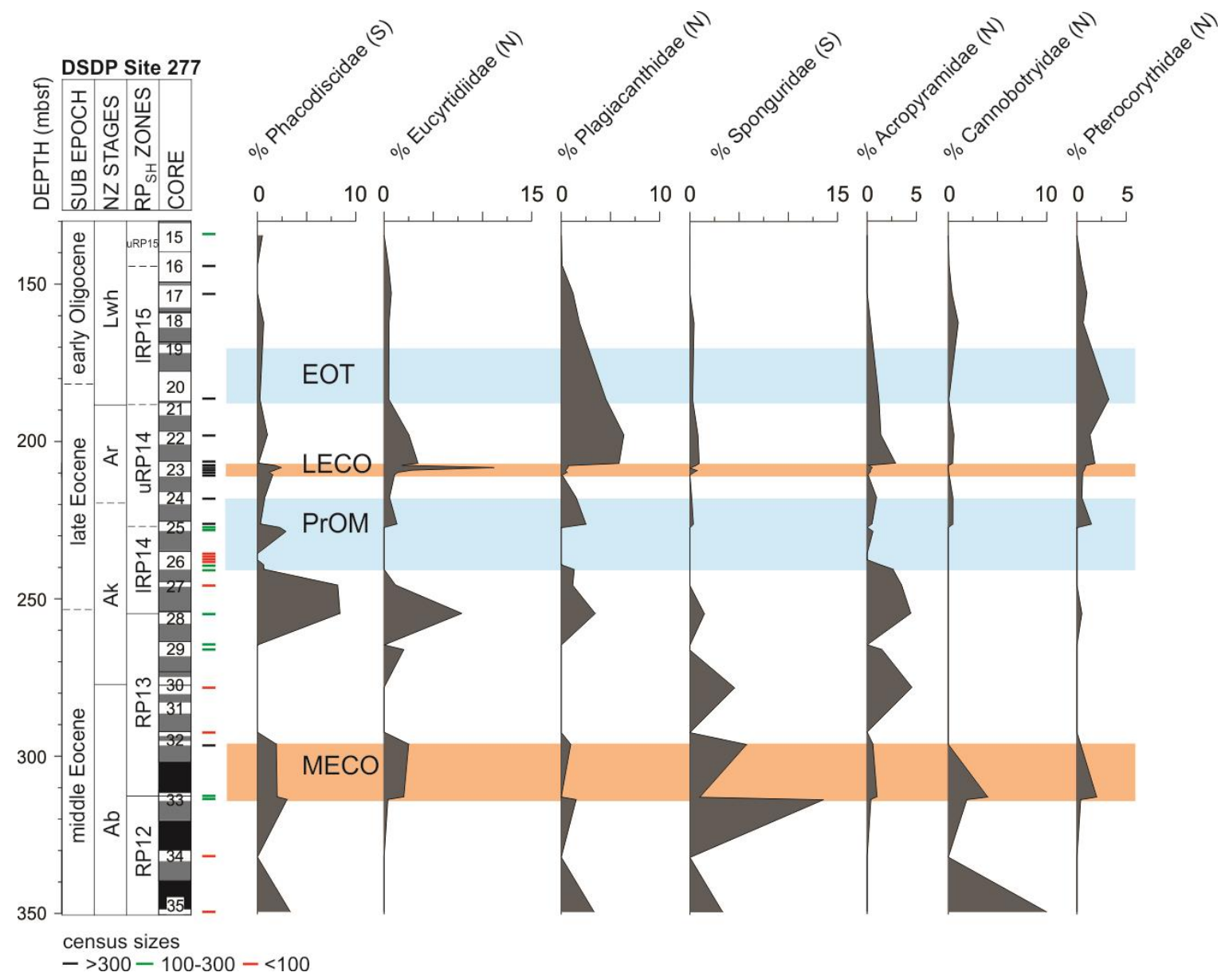

Figure 6.3 The relative abundance of less common radiolarian families at DSDP Site 277. Census size for all examined samples is colour-coded and shown to the right of the core $\log$. $\mathrm{S}=$ spumellarians, $\mathrm{N}=$ nassellarians, MECO=middle Eocene climatic optimum, PrOM=Priabonian oxygen isotope maximum, LECO=late Eocene climatic optimum, EOT=Eocene-Oligocene transition.

Rarefaction analysis of Site 277 radiolarian data (Figure 6.4, Appendix B Table 2) indicates that counts of at least 300 specimens are required to achieve a reliable measure of diversity and taxic richness (Pascher et al. 2015). Poor radiolarian preservation in the middle Eocene and lower upper Eocene intervals ( 350 to 227 mbsf, Figure 4.1) has resulted in 19 samples containing <300 specimens of which 9 samples contain $<100$ specimens. Because these samples span an interval in which significant changes in diversity and assemblage composition occur, metrics for all samples were included in Figures 6.1 to 6.4 (samples with census sizes of $<100$ specimens, 100-300 specimens and $>300$ specimens are indicated). To investigate whether the interval of low taxic richness between $\sim 292$ to $\sim 227$ mbsf is a preservation artefact or a real feature of the assemblage, range-through taxic richness was also determined (Figure 6.4, Appendix B Table 2). Samples with census sizes of 100 and 300 (both with a subsampling of 1000), respectively, were chosen as they show the same trend but a much more muted signal in 
the individual rarefaction analysis. The decrease in range-through taxic richness at the top and bottom of the record is due to edge effects. The analysis shows range-through taxic richness for samples with census sizes of 100 and 300 is higher than the observed richness of the original census sizes from $\sim 292$ to $\sim 227$ mbsf. Chert nodules are present down-core from $\sim 246$ mbsf, so the scarcity of taxa in the interval between $\sim 350$ and 246 mbsf is likely to be an artefact of diagenesis. The increase in taxic richness in the MECO is supported by this analysis, but only in the highest sample (296 mbsf) for a census size of 300. The analysis also indicates that the increase in diversity related to the PrOM event at 226 mbsf is more muted than the raw data suggest. It is notable that the decrease in diversity evident in the raw data during the LECO is not shown in the range-through data. In fact, the analysis shows a further increase in taxic richness within this interval. This analysis of range-through taxic richness has been a helpful tool in determining if diversity changes are a preservational artefact or a response to changing environmental conditions, especially when coupled with consideration of the lithologic changes (e.g. chertification). 


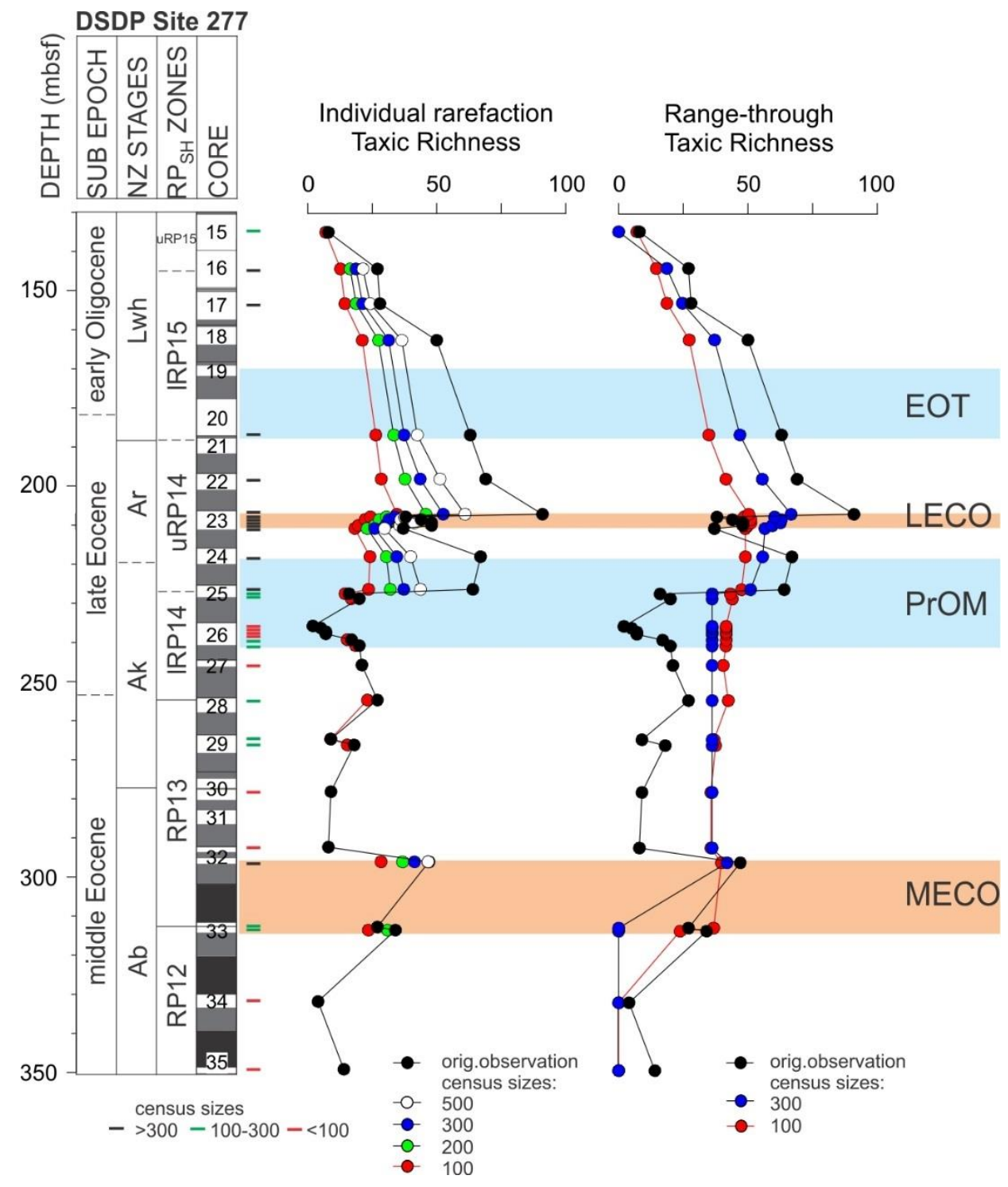

Figure 6.4 Taxic richness (number of taxa) derived from individual rarefaction and range-through analyses for different census sizes for DSDP Site 277. Census size for all examined samples is color-coded and shown to the right of the core $\log$. $\mathrm{MECO}=$ middle Eocene climatic optimum, PrOM=Priabonian oxygen isotope maximum, LECO=late Eocene climatic optimum, EOT=Eocene-Oligocene transition; modified from Pascher et al. (2015).

There is considerable variation in the relative abundance of radiolarian families and undetermined Spumellaria/Nassellaria, which is partly a consequence of variable preservation, but it can also be related to the climatic/oceanic events and trends identified in the section. Four of these events are discussed in more detail below: the MECO, the PrOM, the LECO and the EOT.

Three samples from the middle Eocene interval at Site 277 (313.5 mbsf, 312.7 mbsf, 296 mbsf; Cores 277-32R and 33R) that lie within the onset and recovery of the MECO, show improved preservation, a peak in diversity, and mark the first significant occurrence of diatoms (Figure 6.1). Amphicraspedum murrayanum and A. prolixum gr. have isolated 
occurrences in this interval, although $A$. prolixum gr. also has trace occurrences in five samples in the uppermost Eocene to lowermost Oligocene (Cores 277-24R to $-20 \mathrm{R}$ at 217.70 mbsf, 209 mbsf, $207.5 \mathrm{mbsf}, 197.82 \mathrm{mbsf}$ and $186.50 \mathrm{mbsf}$ ). Several species are restricted to the MECO, including Artobotrys titanothericeraos, Sethocyrtis chrysallis, Eusyringium fistuligerum and Stichopilium cf. bicorne. Lophocyrtis jacchia hapsis, which is a high-latitude variant of L. jacchia jacchia (Sanfilippo and Caulet, 1998) and endemic to the Southern Ocean, is also common during the MECO and uppermost Eocene (217.7206.83 mbsf) but is absent from the remaining middle and lower upper Eocene. Furthermore, the LOs of several (albeit rare) species are recorded at this site during the MECO interval (Axoprunum pierinae, Zealithapium mitra, Periphaena spp., Larcopyle hayesi, L. polyacantha, Zygocircus buetschli, Siphocampe? amygdala, Eucyrtidium montiparum, Lychnocanium amphitrite, Clinorhabdus anantomus, Lophocyrtis keraspera, Lophocyrtis dumitricai, Cryptocarpium ornatum and Lamprocyclas particollis) (Appendix B Table 1).

A major change in siliceous assemblages is associated with maximum values in benthic $\delta^{18} \mathrm{O}$ within the PrOM (226.10 mbsf; Core 277-25R) (Figure 6.1). The lower part of the PrOM (240.50-227.20 mbsf) is characterized by very rare radiolarians (Figure 6.1) and moderate preservation (Figure 4.1). A pronounced increase in radiolarian abundance (from $<50$ to $\sim 4000$ specimens/gram), preservation and diversity occurs at $226.10 \mathrm{mbsf}$ (Sample 277-25R-1, $60 \mathrm{~cm}$ ), and coincides with an increase in diatom abundance (Figure 6.1). Undetermined spumellarians $(\sim 31 \%)$, Actinommidae ( 22\%), Litheliidae $(\sim 13.7 \%)$ and Spongodiscidae $(\sim 4.8 \%)$ are the most abundant spumellarian families during the PrOM interval (Figure 6.2). The most abundant nassellarian families within this interval are the Lophocyrtiidae $(\sim 7.9 \%)$, Artostrobiidae ( 5.6\%), and Lychnocaniidae $(\sim 5.1 \%)$ (Figure 6.2). Plagiacanthidae account for $\sim 0.5 \%$ of the total assemblage (Figure 6.3 ). The following taxa have their LO within the PrOM at Site 277: Ceratocyrtis spp., Lithomelissa ehrenbergi, L. gelasinus, L. sphaerocephalis, Siphocampe nodosaria, Artostrobus annulatus, Artostrobus cf. pretabulatus, Clathrocyclas universa, Dictyophimus? aff. archipilium, Lychnocanium waiareka, Aphetocyrtis rossi and Theocyrtis tuberosa (Appendix B Table 1).

Above the PrOM event, the LECO is identified in the stable isotope record, with five samples (210.5-207.5 mbsf) at Site 277 within this event. Radiolarian abundance and 
diversity, and diatom abundance decrease significantly in this interval (Figure 6.1). The radiolarian assemblages in these five samples differ from the other upper Eocene samples in that Lychnocaniidae are more abundant $(\sim 12 \%)$ and Artostrobiidae are absent. Furthermore, Lophocyrtiidae decrease $(\sim 4 \%)$ and Plagiacanthidae, Lithomelissa spp. and Larcopyle spp. are very rare $(\sim 0.5 \%, \sim 0.1 \%$ and $\sim 0.9 \%$, respectively; Appendix B Table 1). Thyrsocyrtis pinguisicoides and Lophocyrtis jacchia hapsis have abundance peaks in this interval, and a possible new species Lophocyrtis? sp. B is restricted to this interval.

Immediately after the LECO, a second pronounced increase in radiolarian abundance (from <200 to 9600 specimens/gram) and diversity is observed at $206.83 \mathrm{mbsf}$, together with an increase in diatom abundance (Figure 6.1). In the uppermost-Eocene-tolowermost-Oligocene interval (206.83-186.5 mbsf), Plagiacanthidae ( 5\%), Artostrobiidae $(\sim 7 \%)$ and Lophocyrtiidae $(\sim 10 \%)$ increase, whereas Lychnocaniidae decrease ( 2\%; Figures 6.2 and 6.3), relative to underlying intervals. Theocyrtis tuberosa is present but very rare from the upper Eocene to lower Oligocene ( 226-143.9 mbsf; Core 277-25R to -16R). This species is also known to have had isolated occurrences in the southern Atlantic and southern Indian oceans in the late Eocene (Takemura, 1992; Takemura and Ling, 1997) and is common in latest Eocene to early late Oligocene assemblages from low to middle latitudes of all ocean basins (Sanfilippo et al., 1985).

A significant decline in radiolarian abundance (6400 to 750 radiolarians/g) and diversity is observed through the lower Oligocene (186.5 to $134.5 \mathrm{mbsf}$; Cores $277-20 \mathrm{R}$ to $-15 \mathrm{R}$ ) (Figure 6.1). Many nassellarian taxa decline or disappear, especially within the Lophocyrtiidae and Plagiacanthidae. Spumellarians increase from $\sim 73 \%$ to $\sim 97 \%$ of the total fauna, with Litheliidae and Actinommidae being the most abundant families (Figure $6.2)$.

\subsubsection{DSDP Site 280}

The radiolarian assemblages examined from this site comprise 71 counting groups, which include 15 families and 40 genera. A total of 51 taxa were identified to species level (Appendix A, Appendix B Table 3). Fisher $\alpha$ Diversity and Simpson Evenness are stable and high in all samples (Figure 6.5). Spumellarians are slightly more abundant than nassellarians (52-66\% of the assemblage, Figure 6.5). 
The most abundant families and counting groups belong to the Litheliidae ( $30 \%$ average, $20-37 \%)$, Plagiacanthidae $(\sim 17 \%, 14-22 \%)$, undetermined spumellarians ( 14\%, 7-23\%), Actinommidae ( 8\%, 4-12 \%), Spongodiscidae ( 6\%, 5-9\%), Lophocyrtiidae ( 5.8\%, 3-8\%), Eucyrtidiidae ( 5.6\%, 4-8\%) and Cannobotryidae ( 2\%, 1-3\%) (Figure 6.6). More species of the genera Lithomelissa (7) and Larcopyle (5) are present compared to Site 277 , which account for $6-13.5 \%$ and $7-11 \%$ of the total radiolarian fauna, respectively. Compared to DSDP Site 277, this site has a higher diatom abundance and better overall preservation, and potentially explains the higher diversity. Lophocyrtiidae are also more abundant, whereas lychnocaniids are very rare at this site $(<$ $1 \%$ ) (Figure 6.7). Less common families and counting groups are the Nassellaria undet. $(\sim 1.7 \%)$, Trissocyclidae ( 1.6\%), Pterocorythidae ( 1.5\%), Acropyramididae $(\sim 1.4 \%)$, Phacodiscidae $(\sim 0.8 \%)$, Sponguridae $(\sim 0.7 \%)$, Lychnocaniidae $(\sim 0.5 \%)$, Artostrobiidae $(\sim 0.5 \%)$ and Sethophormididae ( 0.3\%) (Figure 6.7). Amphipyndacidae are absent.

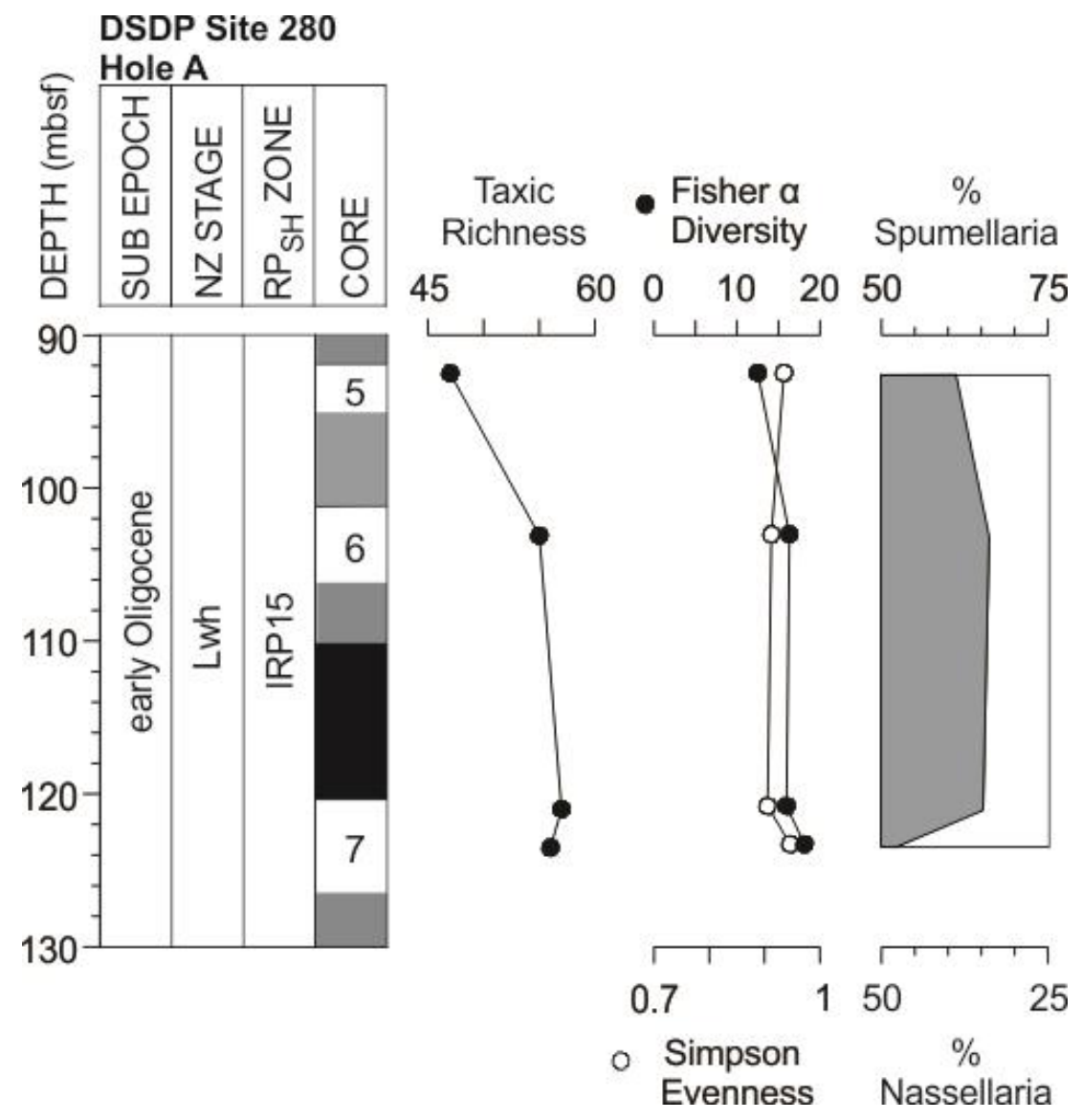

Figure 6.5 General features of radiolarian assemblages at DSDP Site 280 Hole A: taxic richness, Fisher $\alpha$ Diversity Index, Simpson Evenness Index, relative abundance (\%) of spumellarians (grey) and nassellarians (white). 


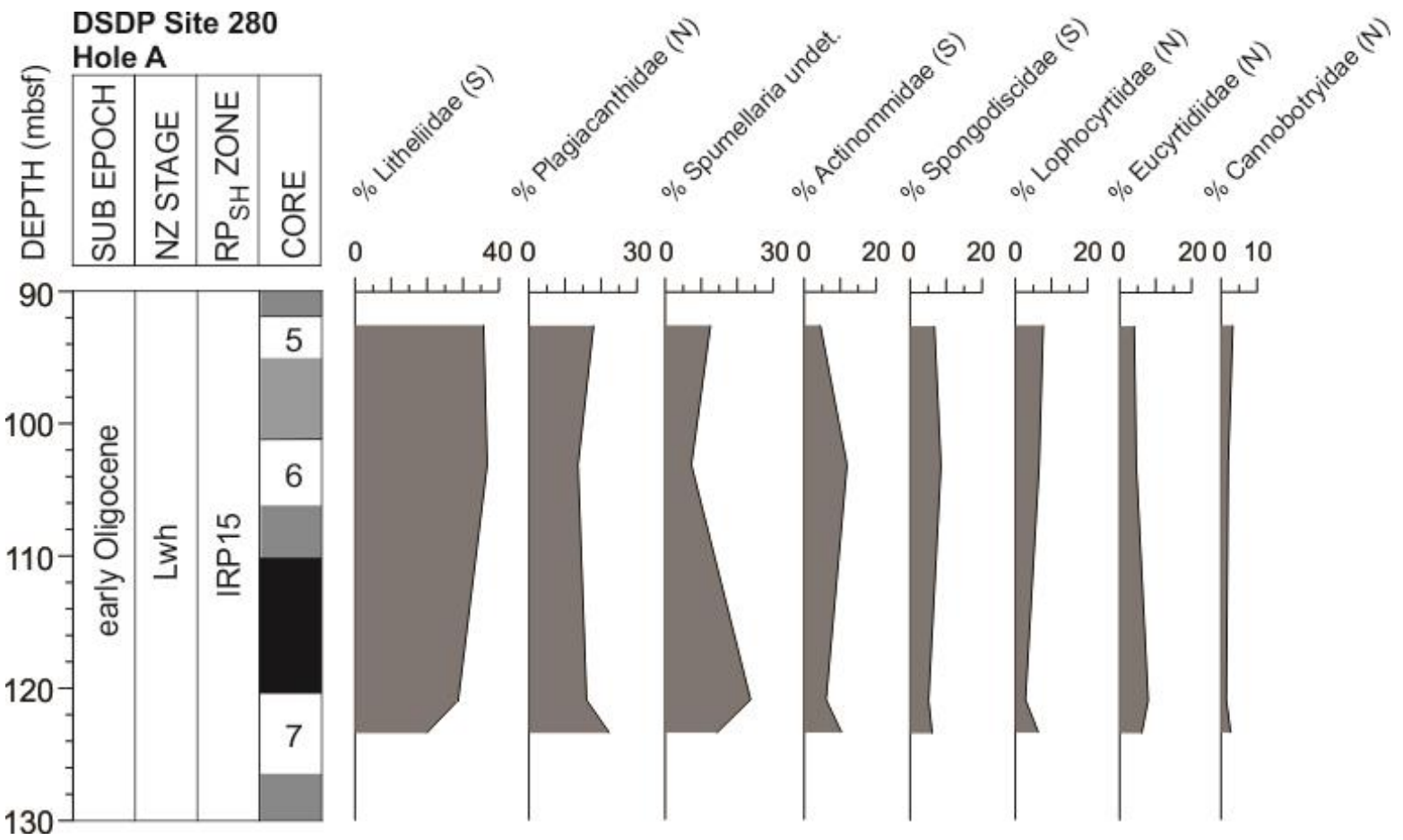

Figure 6.6 The relative abundance of the most abundant radiolarian families and counting groups at DSDP Site 280 Hole A. S=spumellarians, $\mathrm{N}=$ nassellarians.

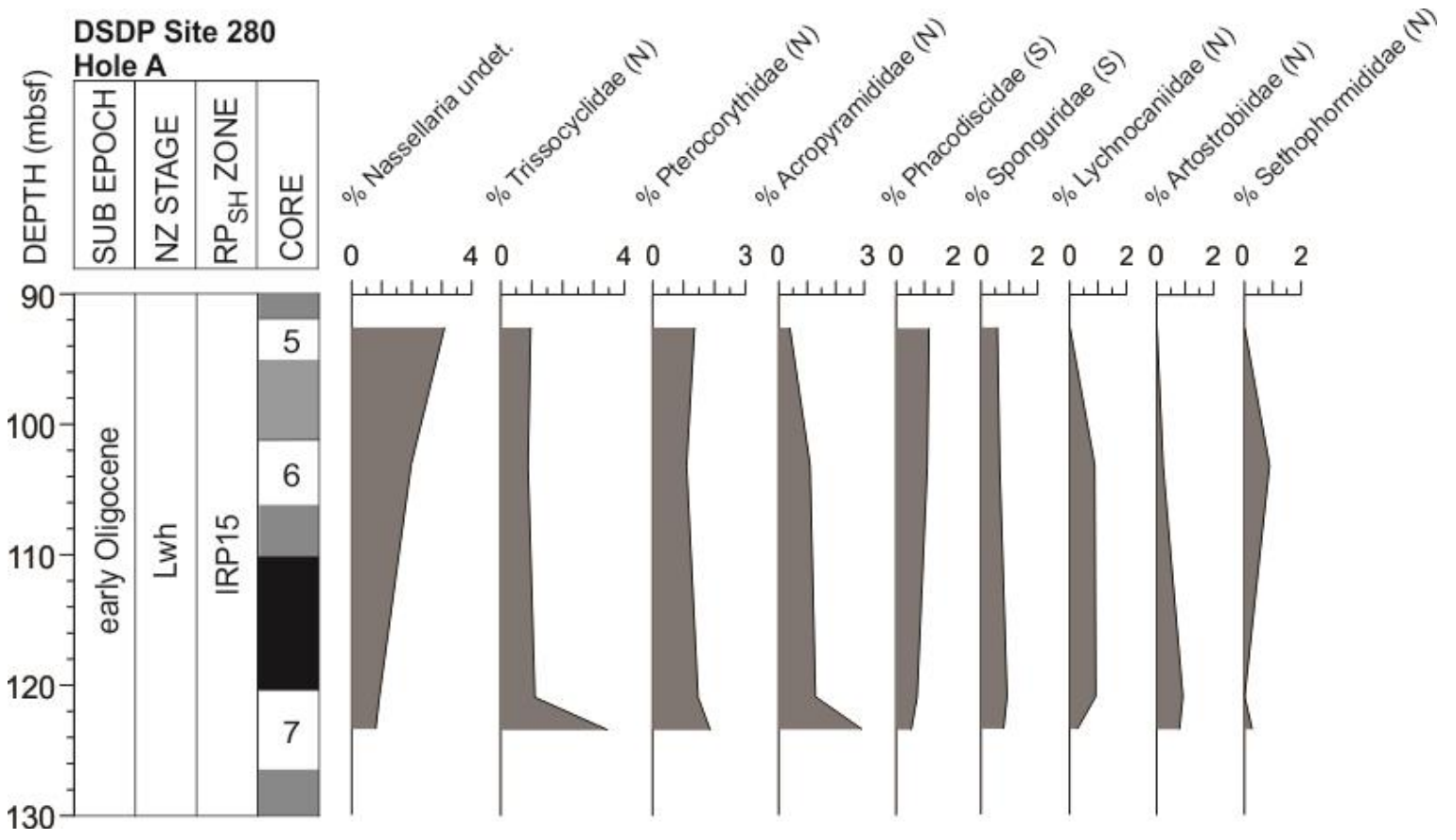

Figure 6.7 The relative abundance of less common radiolarian families and counting groups at DSDP Site 280 Hole A. $\mathrm{S}=$ spumellarians, $\mathrm{N}=$ nassellarians. 


\subsubsection{DSDP Site 281}

The radiolarian assemblages examined from this site comprise 59 counting groups, which include 14 families and 36 genera. A total of 46 taxa were identified to species level (Appendix A Table 1, Appendix B Table 4). Fisher $\alpha$ Diversity Index is lower than at Site 280, but Simpson Evenness still very high and similar to the other sites (Figure 6.8). The radiolarian assemblages are dominated by spumellarians (55-93\%) (Figure 6.8).

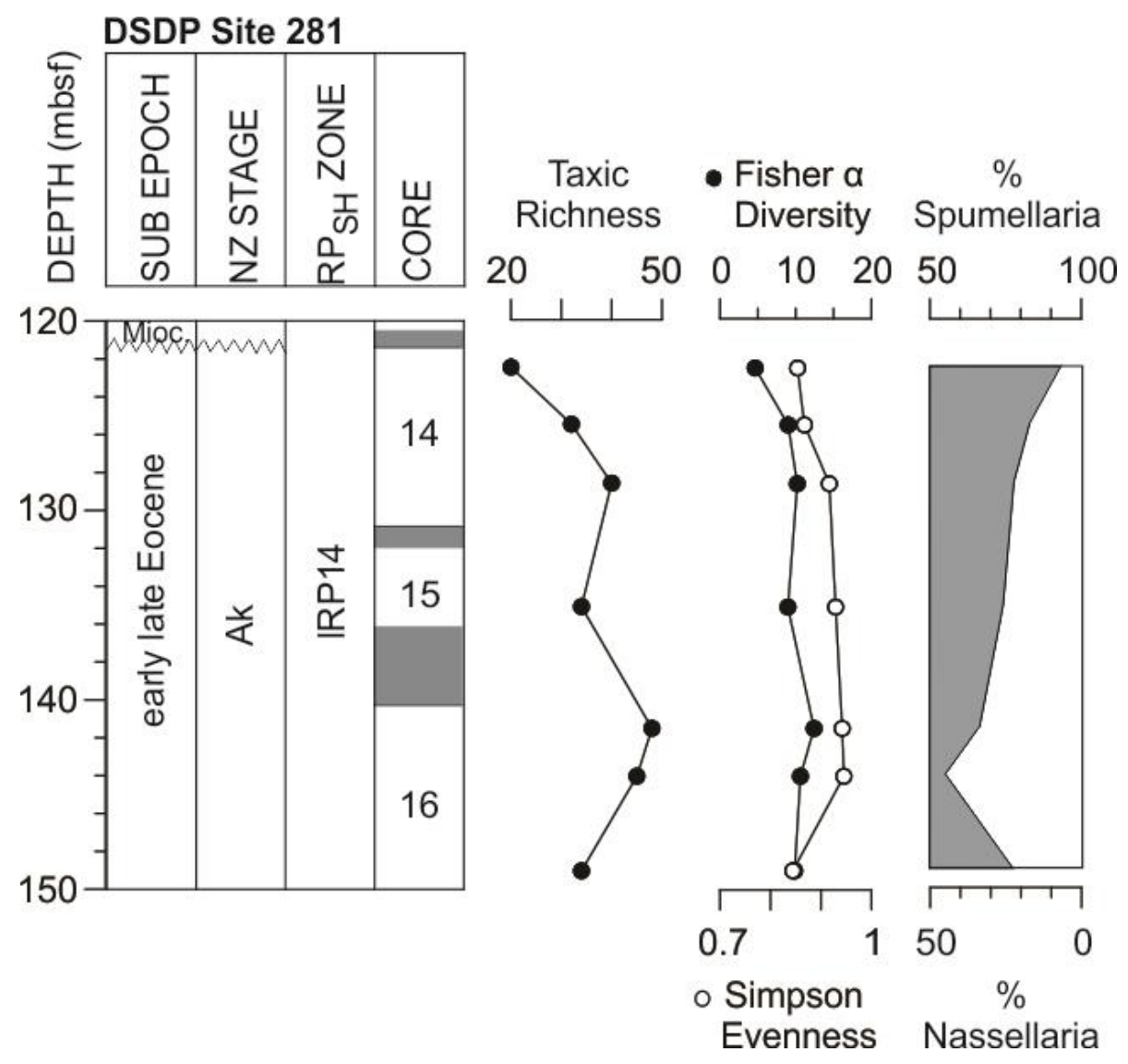

Figure 6.8 General features of radiolarian assemblages at DSDP Site 281: taxic richness, Fisher $\alpha$ Diversity Index, Simpson Evenness Index, relative abundance (\%) of spumellarians (grey) and nassellarians (white).

The five most abundant families or counting groups are Litheliidae ( 24\% average, $17-$ 42\%), Spongodiscidae ( 20\%, 12-30\%), undetermined spumellarians ( 15\%, 6-30\%), Actinommidae $(\sim 12 \%, 10-20 \%)$ and Plagiacanthidae ( 6\%, 1-15\%) (Figure 6.9). Less common radiolarian families and counting groups belong to the Lophocyrtiidae ( 5\%, $3-$ $7 \%)$, Acropyramididae ( 2\%, 0.2-6\%), Eucyrtidiidae ( 2\%, 1-7\%), Trissocyclidae $(\sim 3.6 \%, 0-6.2 \%)$, Cannobotryidae $(\sim 2 \%, 0-4.9 \%)$ and Phacodiscidae $(\sim 2 \%, 0.5-4.8 \%)$ (Figure 6.10). Artostrobiidae $(\sim 0.4 \%)$, undetermined nassellarians $(\sim 0.3 \%)$, Pterocorythidae $(\sim 0.2 \%)$, Sponguridae $(\sim 0.2 \%)$ and Lychnocaniidae $(\sim 0.05 \%)$ are all very rare (Appendix B Table 4). 

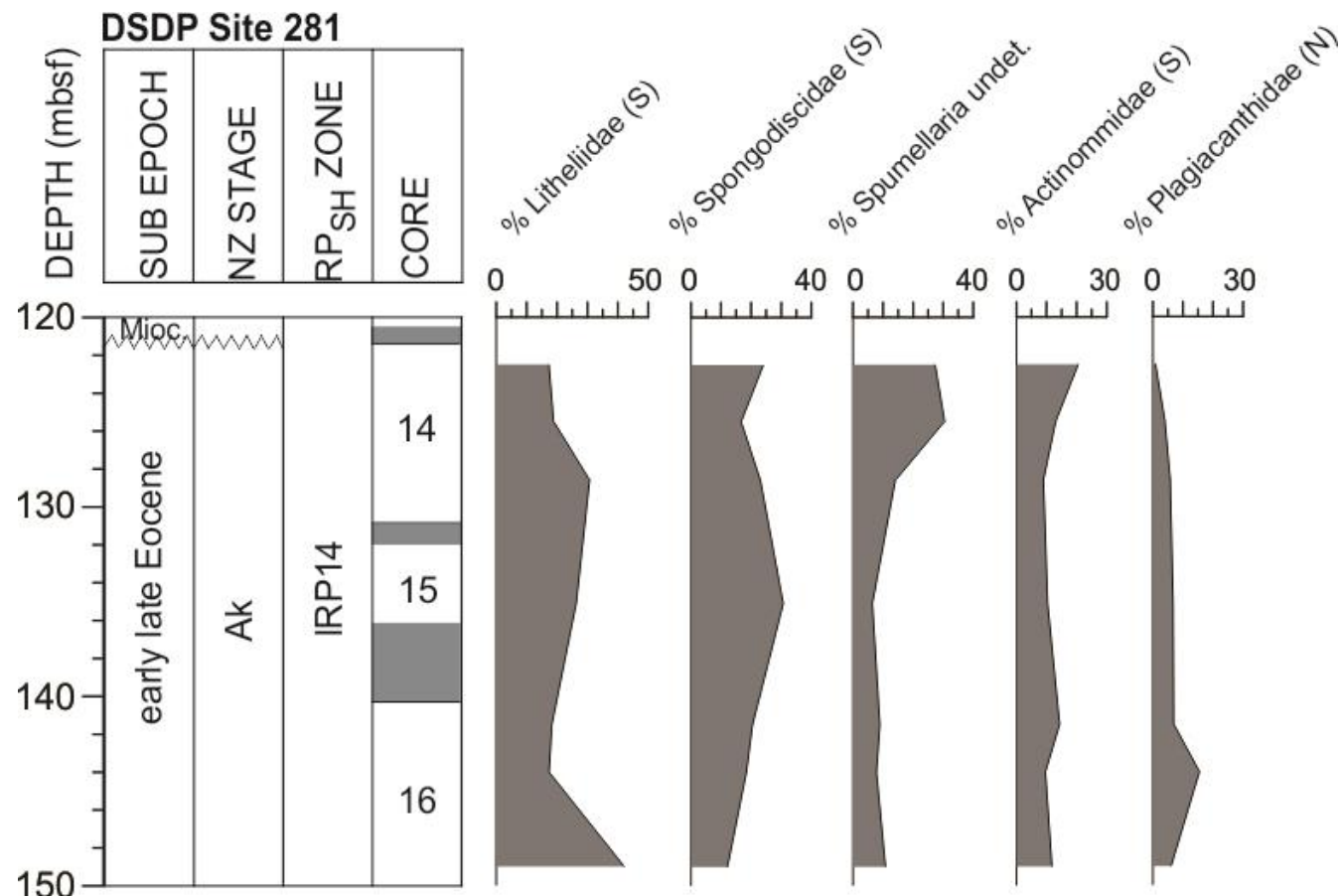

$\begin{array}{lll}0 & 40 & 0\end{array}$

400

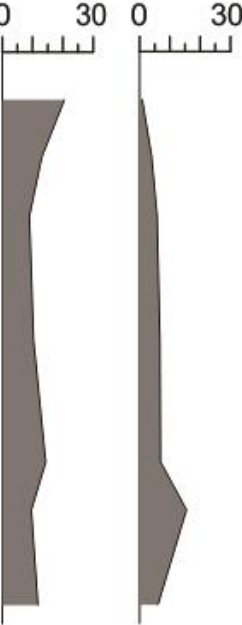

Figure 6.9 The relative abundance of the most abundant radiolarian families and counting groups at DSDP Site 281. $\mathrm{S}=$ spumellarians, $\mathrm{N}=$ nassellarians.
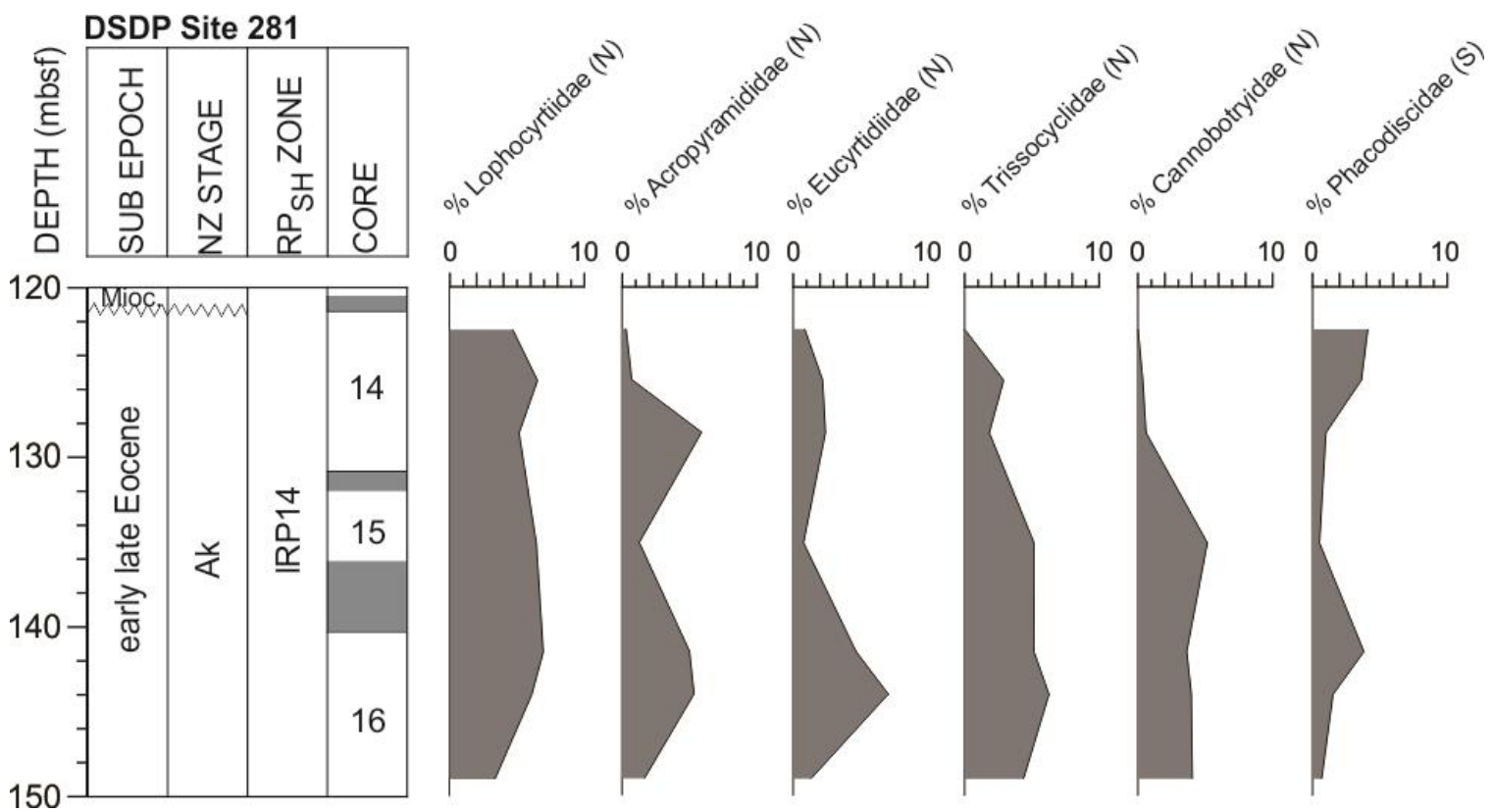

Figure 6.10 The relative abundance of less common radiolarian families and counting groups at DSDP Site 281. $\mathrm{S}=$ spumellarians, $\mathrm{N}=$ nassellarians. 
Although sites 280 and 281 are relatively close to each other (Figure 3.1) the radiolarian assemblages are distinctly different, possibly indicating different oceanographic conditions. Crouch and Hollis (1996) concluded that the depositional setting of Site 281 in the early late Eocene was shallower and closer to terrigenous influx than the setting of Site 280 in the early Oligocene, which is interpreted as pelagic. Support for a shallower setting at Site 281 comes from its large spicule and detrital clast content, and the high abundance of Spongodiscidae (Casey, 1993). Compared to the early late Eocene assemblage of Site 277, where radiolarian abundance and diversity are very low, with several samples containing less than $\sim 100$ specimens, Site 281 contains more spongodiscids ( $\sim 20 \%$ vs. $\sim 7 \%$ on average), plagiacanthids ( $\sim 6 \%$ vs. $\sim 1 \%$ on average), and litheliids ( $25 \%$ vs. $\sim 8 \%$ on average). Site 277 contains more undetermined nassellarians and spumellarians than Site 281, which is linked to preservation, but also more lophocyrtids ( $10 \%$ vs. $5 \%$ on average) and lychnocaniids ( $5 \%$ vs. $0.05 \%)$ than Site 281. The genus Lychnocanium is completely absent at Site 281.

\subsubsection{DSDP Site 283}

The radiolarian assemblages examined from this site comprise 100 counting groups, which include 16 families and 52 genera. A total of 82 taxa were identified to species level (Appendix A, Appendix B Table 5). Radiolarian assemblages are very diverse and taxic richness ranges between 59 and 81 taxa per sample. Fisher $\alpha$ Diversity Index is high with 10-13, as well as Simpson Evenness Index ranging between 0.75-0.89. Spumellarians account for $59-87 \%$ of the assemblage (Figure 6.11). 


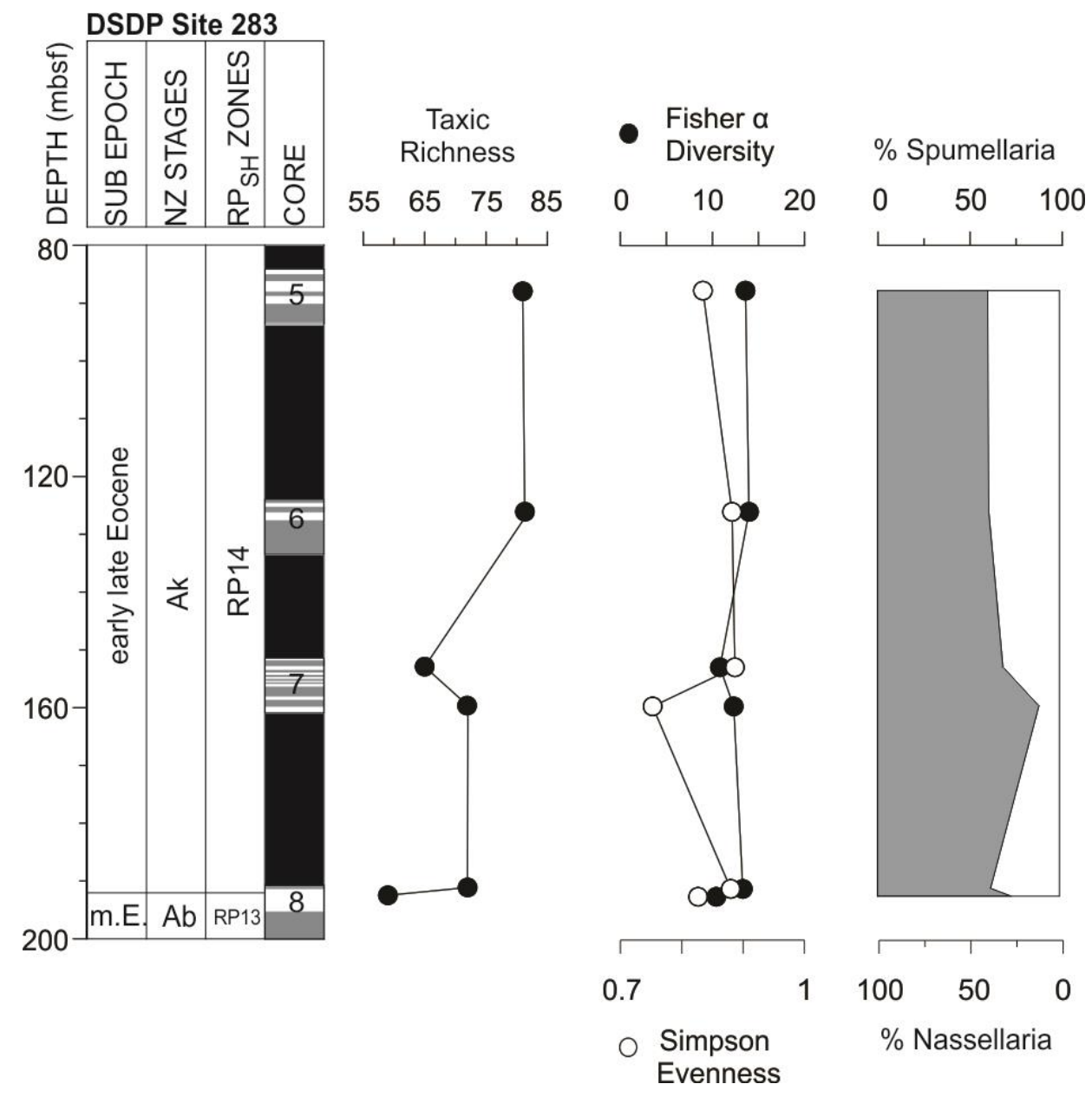

Figure 6.11 General features of radiolarian assemblages at DSDP Site 283: taxic richness, Fisher $\alpha$ Diversity Index, Simpson Evenness Index, relative abundance (\%) of spumellarians (grey) and nassellarians (white).

The most common families and counting groups are the Litheliidae ( $33 \%$ average, $23-$ $38 \%)$, undetermined spumellarians ( 17\%, 10-26\%), Actinommidae ( 10\%, 5-19\%), Eucyrtidiidae ( 6\%, 2-11\%) and Trissocyclidae ( 6\%, 2-11\%) (Figure 6.12). 


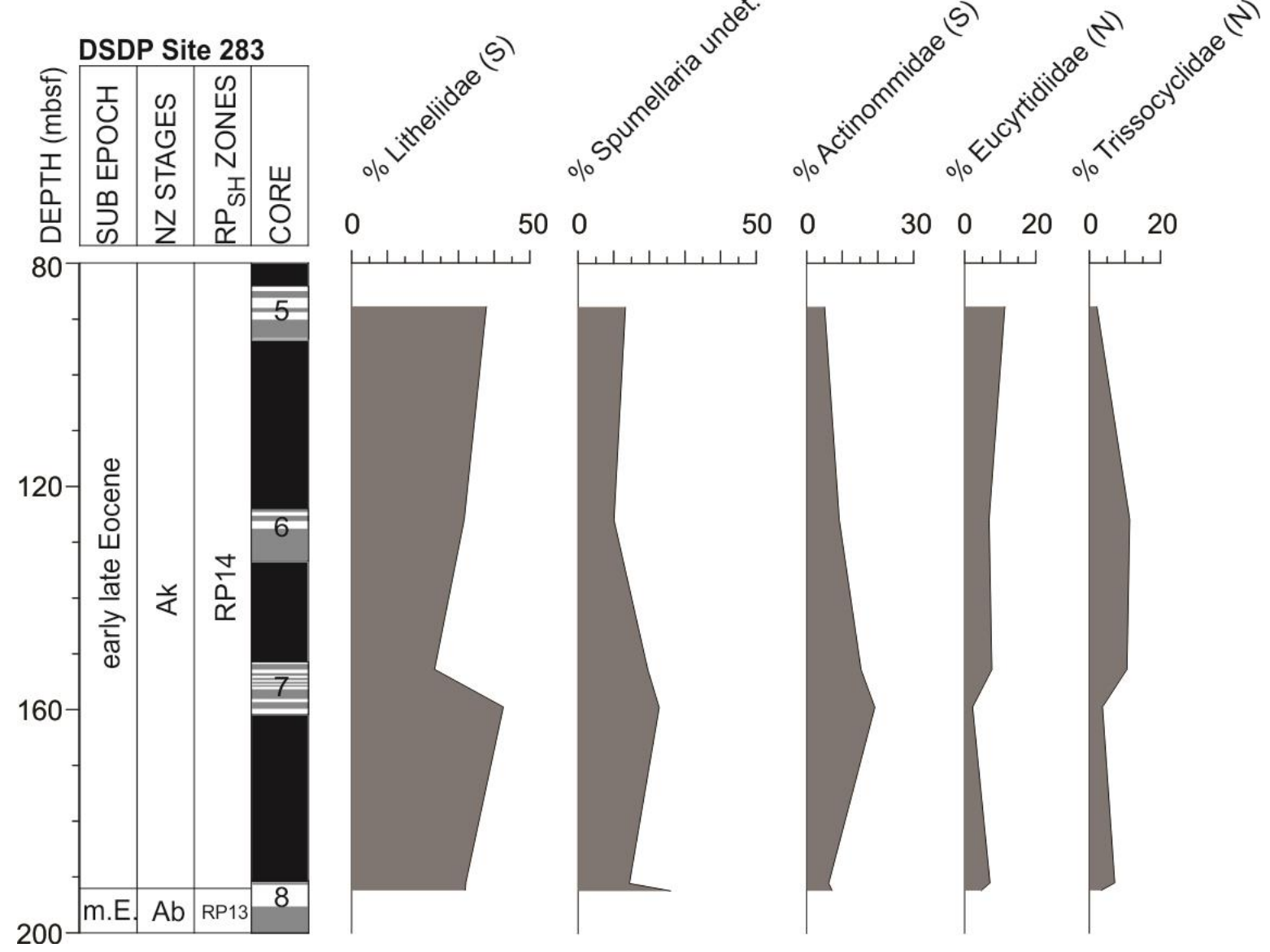

Figure 6.12 The relative abundance of the most abundant radiolarian families and counting groups at DSDP Site 283. $\mathrm{S}=$ spumellarians, $\mathrm{N}=$ nassellarians.

Less common families and counting groups are the Lophocyrtiidae ( $\sim 5 \%$ average, $3-8 \%)$, Spongodiscidae $(\sim 5 \%, 2-8 \%)$, Plagiacanthidae ( 4\%, 2-8\%), undetermined nassellarians ( 3.8\%, 0.2-7.6\%), Pterocorythidae ( 2\%, 0.2-8.37\%), Sponguridae ( 1.3\%, 0.5-2.4\%), Acropyramididae ( 1.3\%, 0.5-2.2\%) and Lychnocaniidae ( 1\%, 0.2-3.3\%) (Figure 6.13). Artostrobiidae ( 0.5\%, 0.5-2.2\%), Cannobotryidae ( 0.5\%, 0.1-1.2\%) and Phacodiscidae ( 0.5, 0.2-1.1\%) Amphipyndacidae ( 0.02\%, 0-0.04\%) and Sethophormididae $(0.02 \%$, $0-0.07 \%$ ) are all very rare (Appendix B Table 5).

Theocyrtis tuberosa is very abundant in the youngest sample (Appendix B Table 5). The acme of this species might be correlated to the LECO at Site 277. Several taxa appear earlier at Site 283 (late middle to early late Eocene) than at Site 277 (middle late Eocene). These include the following taxa that occur in the upper middle Eocene (e.g. Axoprunum bispiculum, Amphicentria sp. 1 sensu Suzuki, Ceratocyrtis spp., Lithomelissa ehrenbergi, L. cf. haeckeli, L. sphaerocephalis, L. tricornis, Pseudodictyophimus gracilipes gr., Tripodiscinus clavipes, Siphocampe nodosaria, Spirocyrtis joides, Aspis sp. A sensu 
Hollis, Clathrocyclas universa, Eurystomoskevos petrushevskaae, Lychnocanium waiareka, Aphetocyrtis gnomabax) or lower upper Eocene (Spirocyrtis greeni, Eurystomoskevos cauleti, Lophocyrtis jacchia hapsis, Lamprocyclas particollis) at Site 283.

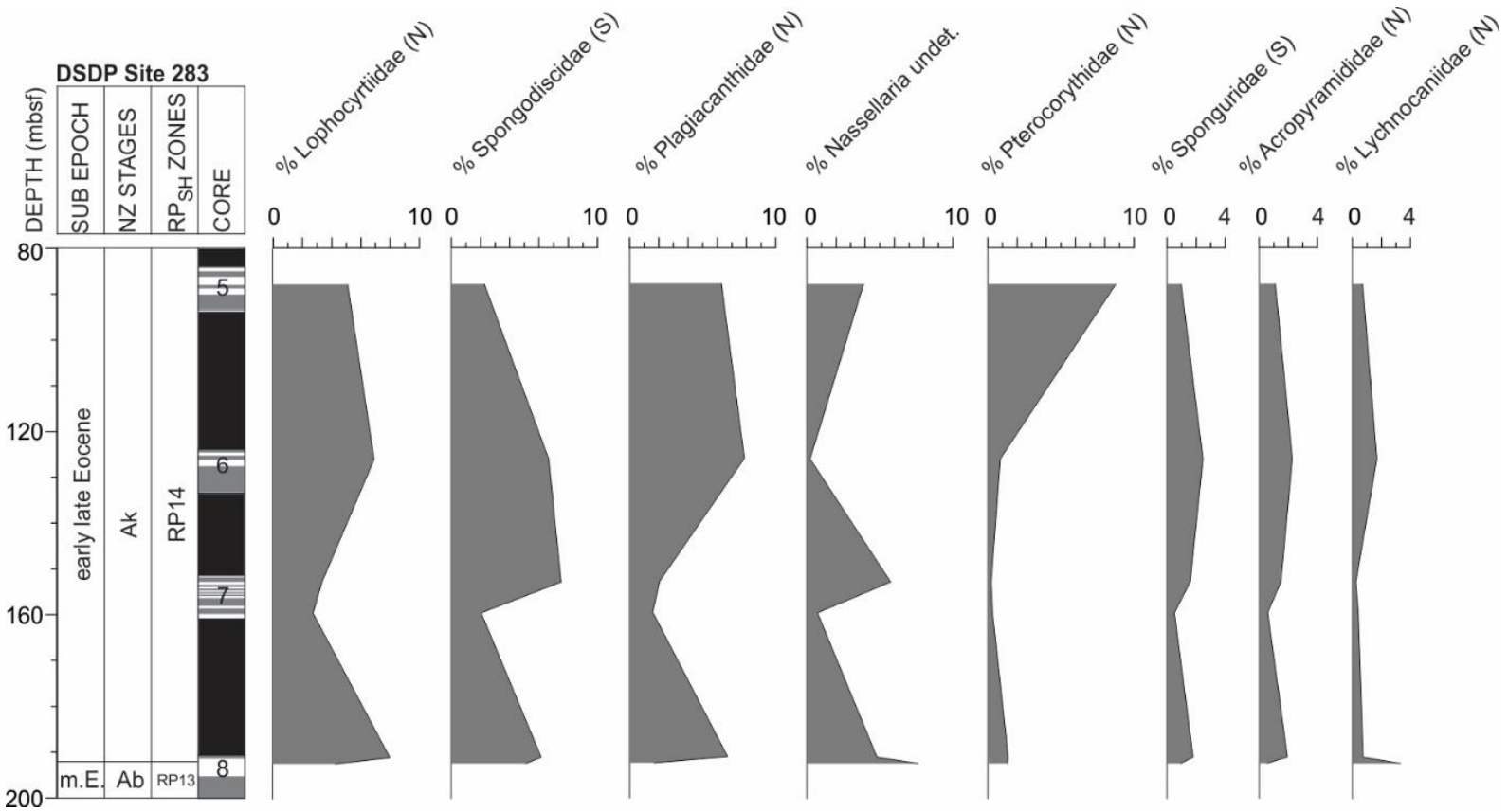

Figure 6.13 The relative abundance of less common radiolarian families and counting groups at DSDP Site 283. $\mathrm{S}=$ spumellarians, $\mathrm{N}=$ nassellarians.

\subsubsection{ODP Site 1172}

The radiolarian assemblages examined at this site comprise 147 counting groups after updating the taxonomic list of Suzuki et al. (2009) to bring them in line with a broader taxonomic approach used in this thesis (Appendix A, Appendix B Table 6). These groups include 14 families, 71 genera and 140 species. Taxic richness ranges between 39 and 61 taxa per sample. Spumellarians dominate Site 1172 assemblages throughout the middle Eocene to lower Oligocene $(\sim 82 \%)$. Fisher $\alpha$ Diversity and Simpson Evenness indexes are very high throughout the succession, ranging between $\sim 10-20$ and 0.82-0.96, respectively. Similar to Site 277, Fisher $\alpha$ Diversity and Simpson Evenness decrease in the lower Oligocene (Figure 6.14, Appendix B Table 6). 


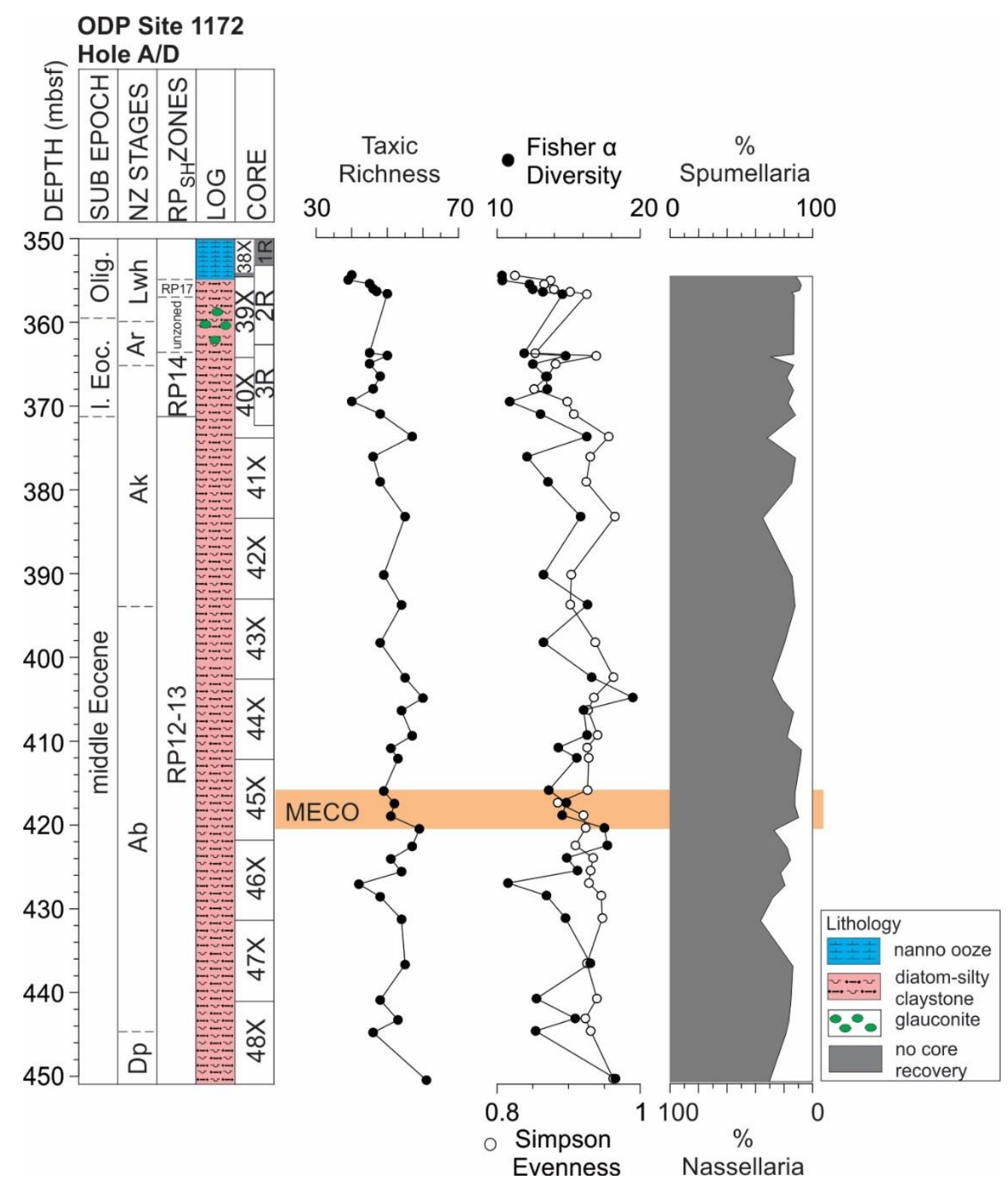

Figure 6.14 General features of radiolarian assemblages at ODP Site 1172, Hole A (Cores 1172A-48X to -38X) and Hole D (Cores 1172D-3D to -1D): taxic richness, Fisher $\alpha$ Diversity Index, Simpson Evenness Index, relative abundance (\%) of spumellarians (grey) and nassellarians (white). The location of the MECO was adapted from Bijl et al. (2010).

The Litheliidae is the most abundant family ranging between $8-43 \%$ and comprising about $20 \%$ of the total radiolarian fauna on average in the middle Eocene, $35 \%$ in the upper Eocene, and 25\% in the lower Oligocene (Figure 6.15). Unclassified Spumellaria and Actinommidae, each with $\sim 18 \%$ on average, range between $8-51 \%$ and $8-38 \%$, respectively. Spongodiscidae are the fourth most abundant group with on average $17 \%$ (ranging between 5-30\%) (Figure 6.15). Less common families and counting groups are the Lophocyrtiidae ( $3.7 \%$ average, $0.6-14 \%)$, undetermined nassellarians $(\sim 3.6 \%, 0.5-$ $10 \%)$, Phacodiscidae $(\sim 3.6 \%, 0-11.5 \%)$, Eucyrtidiidae $(\sim 2.5 \%, 0.6-14 \%)$ and 
Lychnocaniidae $(\sim 2.2 \%, 0-12 \%)$ (Figure 6.16). Cannobotryidae have their abundance peak in the lower interval $(\sim 1.7 \%, 0-14 \%)$, similarly to the Trissocyclidae $(\sim 1.4 \%$ average, 0-8\%) (Figure 6.16). Plagiacanthidae and Acropyramididae are more frequent in the upper part of the interval with $\sim 1 \%(0-4.7 \%)$ and $0.6 \%$ average $(0-3.6 \%)$, respectively. Sponguridae are rare throughout the interval with $\sim 1.4 \%(0.2-3 \%)$. Pterocorythidae are basically absent in most of the Eocene ( 0.3\% average, $0-4.7 \%)$ and Artostrobiidae are present with $\sim 0.3 \%$ on average, ranging between 0 and $2 \%$ throughout the record (Figure 6.16).

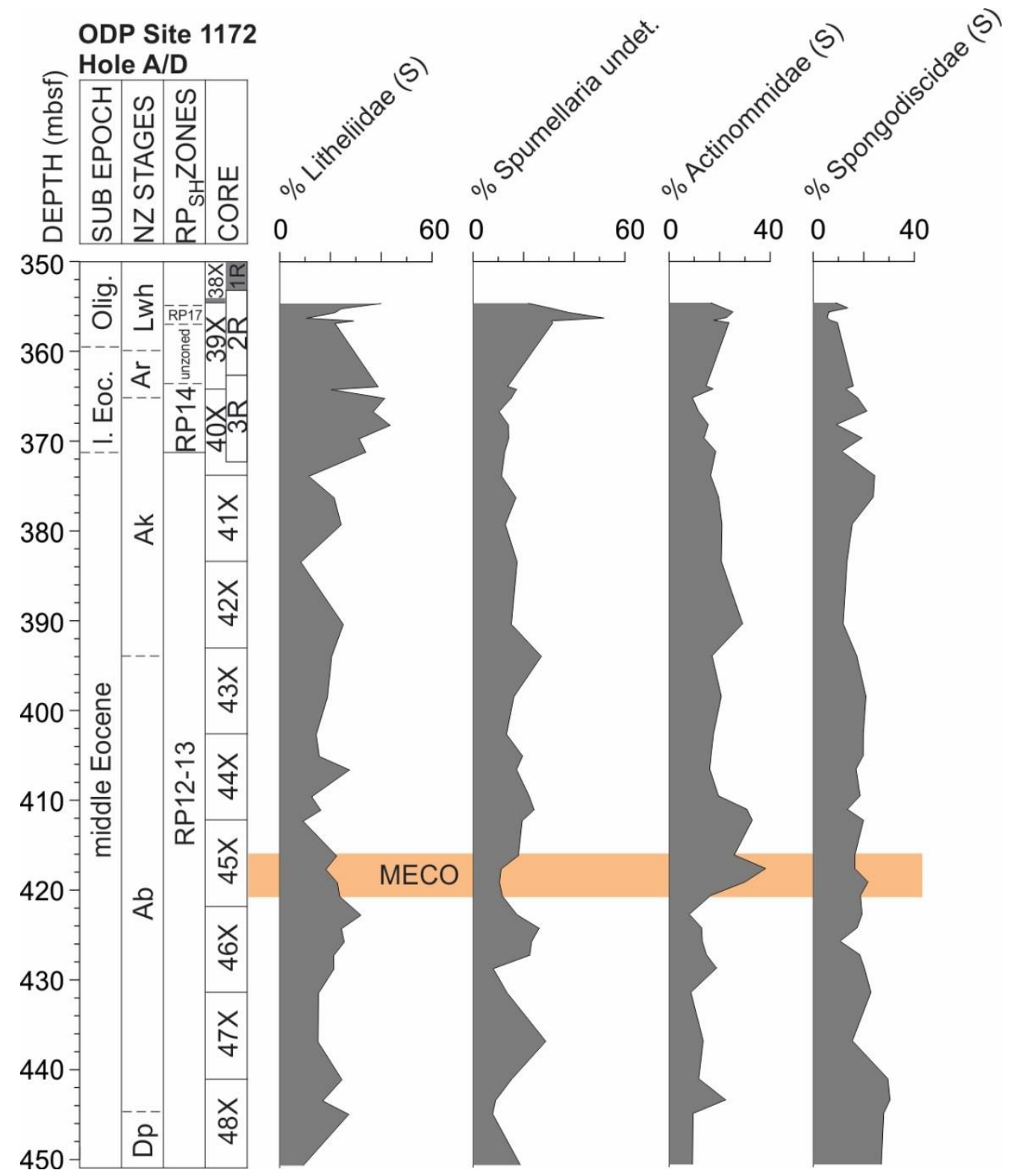

Figure 6.15 The relative abundance of the most abundant radiolarian families and counting groups at ODP Site 1172, Hole A (Cores 1172A-48X to -38X) and Hole D (Cores 1172D-3D to -1D). S=spumellarians. 


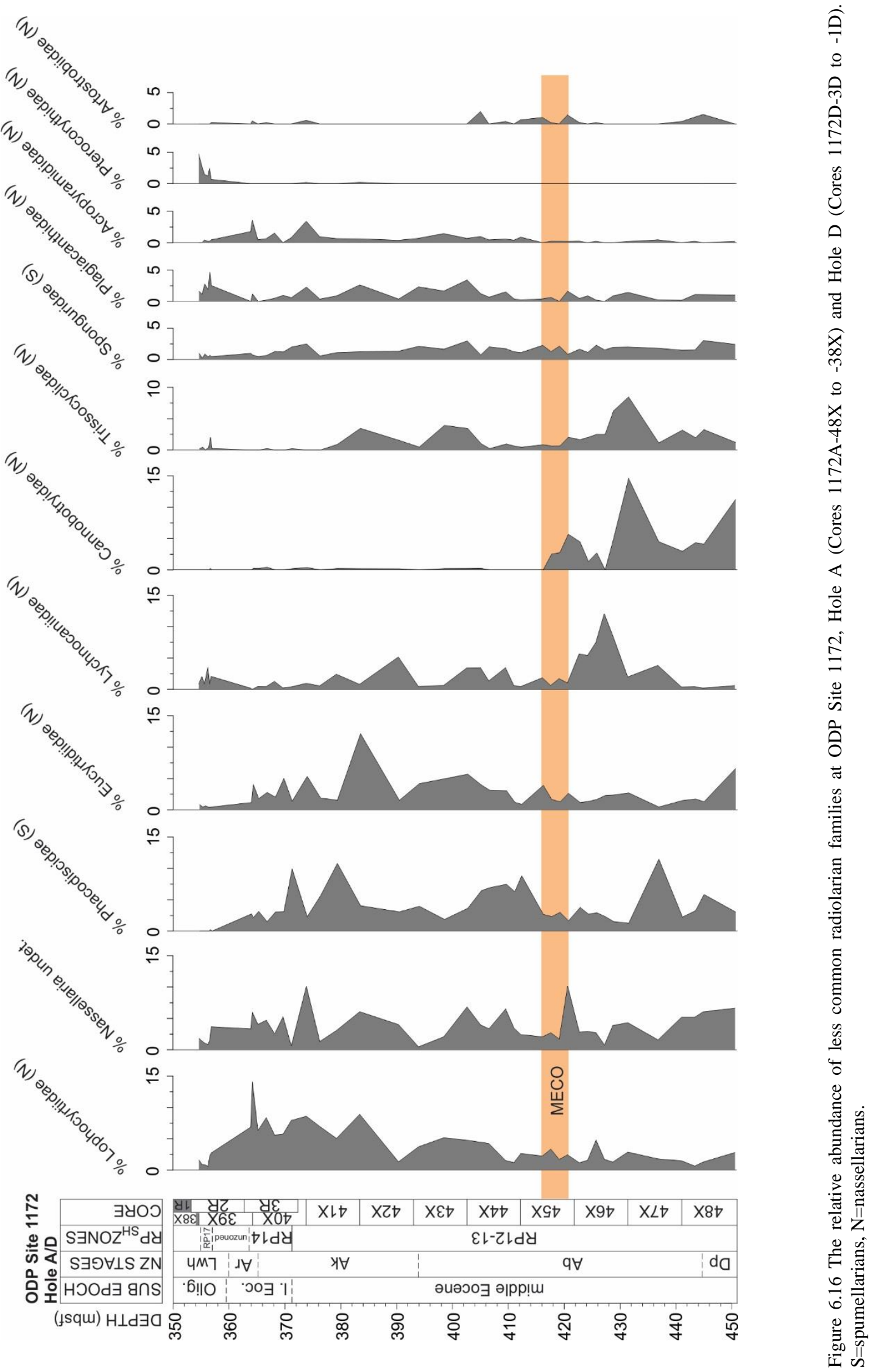




\subsubsection{Mid-latitude sites}

\subsubsection{DSDP Site 207}

The radiolarian assemblages examined from this site comprise 151 counting groups, which include 16 families and 67 genera. A total of 120 taxa were identified to species level (Appendix A, Appendix B Table 7). Taxic richness and diversity are low in the lower part of the section (319-245.38 mbsf). Taxic richness ranges between 2-20 taxa per sample and Fisher $\alpha$ Diversity Index between 1.6-8, respectively (Figure 6.17). Simpson Evenness largely mirrors the low diversity with values between 0.5 and 0.8. Except for two samples (259.04-247.26 mbsf), radiolarian counts were below 100 specimens in this interval, which contains Cretaceous to lower Eocene sediments. The Cretaceous radiolarians were not identified; however, at least 20 different morphotypes could be identified. Five samples did not contain any radiolarians (318.96 mbsf; 293.55 mbsf; 269.60-264 mbsf). The presence of chert nodules may explain the generally low abundance and poor preservation of radiolarians, as well as the presence of silicified foraminifera casts.

An abrupt improvement in preservation, diversity and radiolarian abundance is recorded within Core 207A-21R, at 242.46 mbsf (horizon \#1, Figure 6.17). Except for a short interval in the upper Heretaungan (216.40-208.46 mbsf, Core 207A-19R to $-18 \mathrm{R}$ ) (interval \#2), where there is a decline in diversity and taxic richness, good preservation persists and diversity and abundance remain high until Core 207A-12R (152 mbsf, horizon 3\#). Between horizon \#1 and \#3, taxic richness ranges between 34 and 69. Fisher $\alpha$ Diversity Index and Simpson Evenness are high and range between 13-23 and 0.860.93 , respectively.

In Core 207A-12R (horizon \#3), radiolarian abundance and diversity drop rapidly and radiolarians disappear. Chert nodules are present in Core 207A-11R just before the unconformity. The presence of Hantkenina spp. (H. E. G. Morgans, pers. comm. 2016) in Core 207A-11R indicates warm conditions right before the unconformity.

Oxygen $\left(\delta^{18} \mathrm{O}\right)$ and carbon $\left(\delta^{13} \mathrm{C}\right)$ stable isotope data for two benthic foraminifer species (Cibicides praemundulus and Nuttalides truempyi) are shown in Figure 6.17 (Appendix C). The $\delta^{18} \mathrm{O}$ values for both species show a trend towards more positive values throughout the studied interval and correlate well with each other (correlation coefficient 
$\mathrm{R}=0.66$ ). The interval between $276.51-247.26 \mathrm{mbsf}$ (Core 207A-25R to $-22 \mathrm{R}$ ) has the lowest $\delta^{18} \mathrm{O}$ value of $\sim-0.86$ to $-0.63 \%$ for $C$. praemundulus and $\sim-0.97$ to $-0.73 \%$ for $N$. truempyi, respectively. According to the age model this interval covers 53.48-49.08 Ma and is identified as the early Eocene climatic optimum (EECO) (Figure 6.17). The lowest $\delta^{18} \mathrm{O}$ value of $-1.05 \%$ for $N$. truempyi is measured at 279 mbsf, which is not included in the EECO interval here. The long-term cooling trend culminates in the highest $\delta^{18} \mathrm{O}$ values in Core 207A-11R (143.65 mbsf) with $\sim 0.8 \%$ or $C$. praemundulus and $\sim 0.6 \%$ for N. truempyi, respectively. This cooling trend is steeper in the upper Heretaungan (interval \#2), and coincides with a decrease in radiolarian diversity (Figure 6.17).

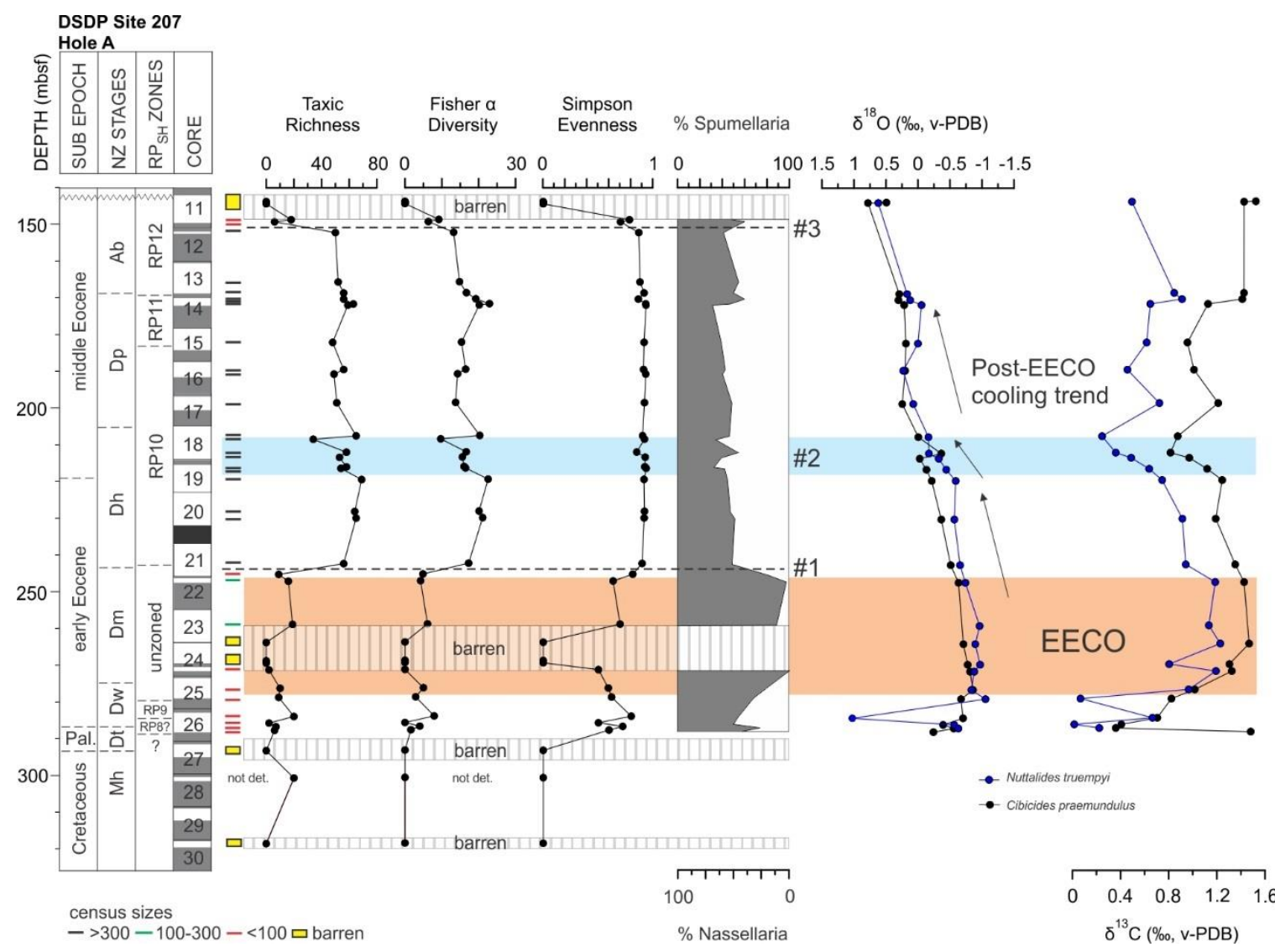

Figure 6.17. General features of radiolarian assemblages at DSDP Site 207 Hole A, including taxic richness, Fisher $\alpha$ Diversity Index, Simpson Evenness Index, relative abundance (\%) of spumellarians (grey) and nassellarians (white), and $\delta^{18} \mathrm{O}$ and $\delta^{13} \mathrm{C}$ isotope values of two benthic foraminifer species (Cibicides praemundulus and Nuttalides truempyi). Two distinct horizons (dashed lines labelled \#1 and \#3) and one interval (blue shading labelled \#2) can be recognized where obvious assemblage and preservation changes occur. Census size for all examined samples is colour-coded and shown to the right of the core log. EECO=Early Eocene Climatic Optimum; "not det." marks a sample with Cretaceous radiolarians, which were not identified.

The $\delta^{13} \mathrm{C}$ values show an offset between the two species ranging between 0.04 and $0.93 \%$ (Figure 6.17) but both datasets correlate well with each other $(\mathrm{R}=0.78)$. The offset increases towards the top of the section. The reason for the offset is not known at this 
stage. From 287-264 mbsf, the general trend of $\delta^{13} \mathrm{C}$ is towards higher values, with maxima of $1.46 \%$ for $C$. praemundulus and $1.22 \%$ for $N$. truempyi. Thereafter, the values decrease. Within 219.47-207.52 mbsf (interval \#2), the decreasing trend is steeper and the lowermost $\delta^{13} \mathrm{C}$ values of $\sim 0.25 \%$ for $N$. truempyi and $0.82 \%$ for $C$. praemundulus are found at $207.52 \mathrm{mbsf}$ and $212 \mathrm{mbsf}$, respectively. From the minima, the $\delta^{13} \mathrm{C}$ values increase again towards the top of the section, however, they exhibit another interval of lower values in Cores 207A-16R and -15R (189.4-171.51 mbsf).

The radiolarian-rich interval from the middle lower Eocene to middle Eocene (242.46152 mbsf; Heretaungan to Bortonian) has slightly more abundant nassellarians than spumellarians and range from $\sim 40-68 \%$ (average $~ 54 \%$ ) (Figure 6.17). The most abundant families and counting groups are the undetermined spumellarians ( $21 \%$ average, range 14-35\%), the Lychnocaniidae ( 13.8\%, 6-37\%), the Trissocyclidae ( 8\%, $\sim 3-16 \%)$, the Eucyrtidiidae ( 8\%, 3-16\%), the Spongodiscidae ( 8\%, $\sim 2-18 \%)$, the Artostrobiidae $(\sim 7 \%, \sim 0.2-23 \%)$, the Cannobotryidae (7\%, $\sim 2-12 \%)$, the Actinommidae $(\sim 6 \%, \sim 0.6-24 \%)$ (Figure 6.18) and the Lophocyrtiidae ( 4\%, $\sim 0.8-9 \%$ ) (Figure 6.19).

The remaining $\sim 15 \%$ of the radiolarian assemblages are represented by the Sponguridae ( 3.7\% average, $\sim 0.3-9.6 \%)$, Litheliidae $(\sim 2.7 \%, \sim 0.4-6.8 \%)$ (Figure 6.18) undetermined Nassellaria $(\sim 2 \%, 0-3 \%)$, Plagiacanthidae $(\sim 1.7 \%, 0-1.7 \%)$, Phacodiscidae $(\sim 1.4 \%, 0$ $4.1 \%$ ) and Pterocorythidae $(\sim 1.3 \%, 0-8.8 \%)$ (Figure 6.19$)$. Sponguridae are very abundant from 259.04-247.26 mbsf ( 27-68\%) (Figure 6.19). Very rarely present are Sethophormididae $(\sim 0.2 \%$ average), Acropyramididae $(\sim 0.2 \%)$ and Amphipyndacidae ( 0.08\%) (Appendix B Table 7).

Several early to middle Eocene species that are absent from Site 277 are present at this site: Podocyrtis? pupa, P.? aphorma, P. acalles, Lophocyrtis semipolita, L. jacchia jacchia, L. sp. A, L. cf. dumitricai, L. nomas, Dictyopodium oxylophus, Rhopalocanium spp., Pterocanium spp., Lychnocanium aff. grande, L. sp. A, L. turgidum, L. trichopus, L. satelles, Lithochyrtis spp., Dictyophimus pocillum, D. craticula, Thyrsocyrtis rhizodon, Theocotyle spp., Theocorys spp., Phormocyrtis ligulata, Lamptonium cf. pennatum, Ewingella? sp., Eusyringium lagena, Calocycloma cf. L. pennatum, Theocampe mongolfieri, T. amphora, Tripilidium sp. A, Giraffospyris didiceros, Dorcadospyris 
argisca, Histiastrum quadribrachiatus quadribrachiatus, Tripodictya sp., Lithocyclia ocellus, Flustrella spp., Zealithapium anoectum.

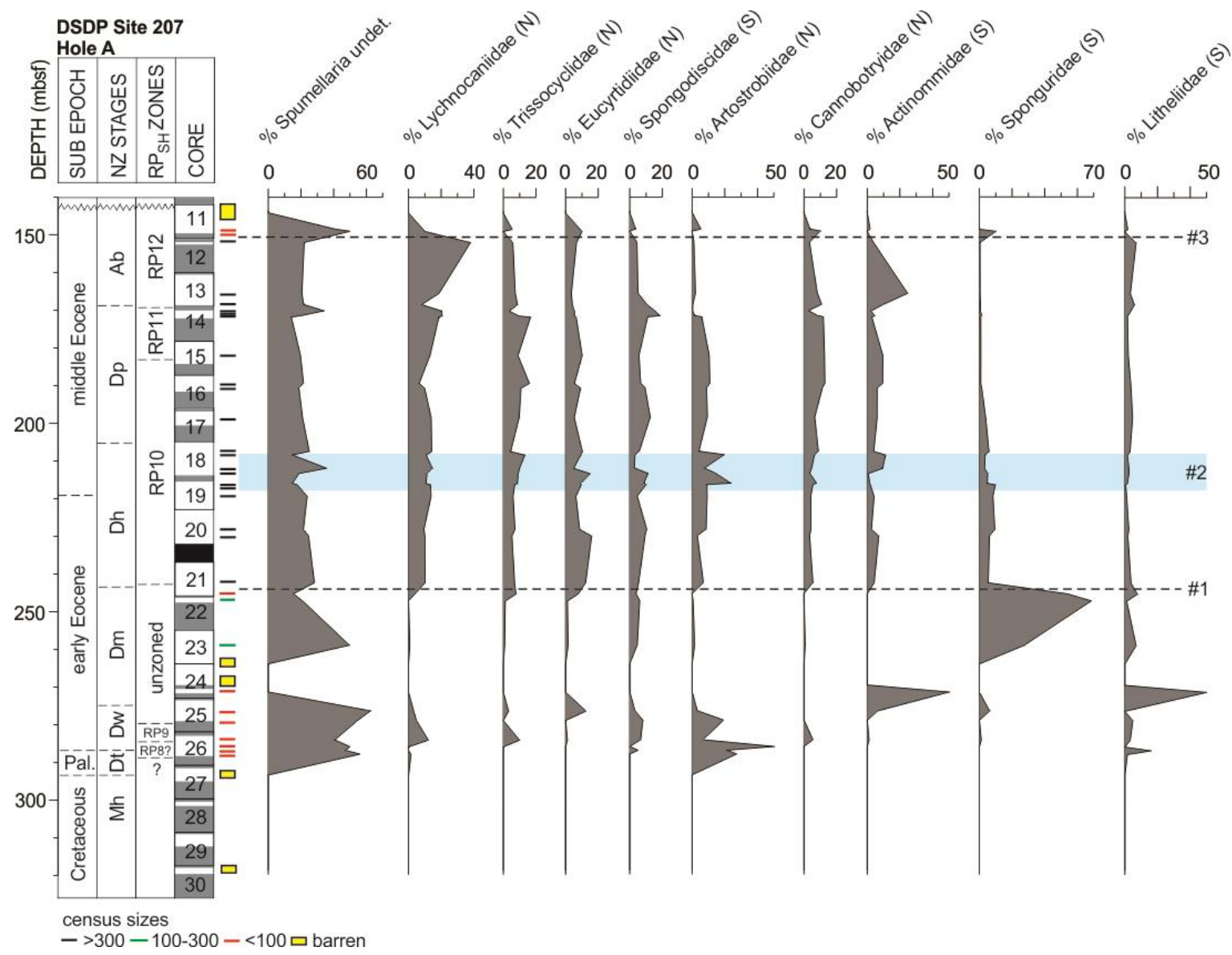

Figure 6.18 The relative abundance of the most abundant radiolarian families and counting groups at DSDP Site 207 Hole A. Census size for all examined samples is colour-coded and shown to the right of the core log. S=spumellarians, $\mathrm{N}=$ nassellarians. 


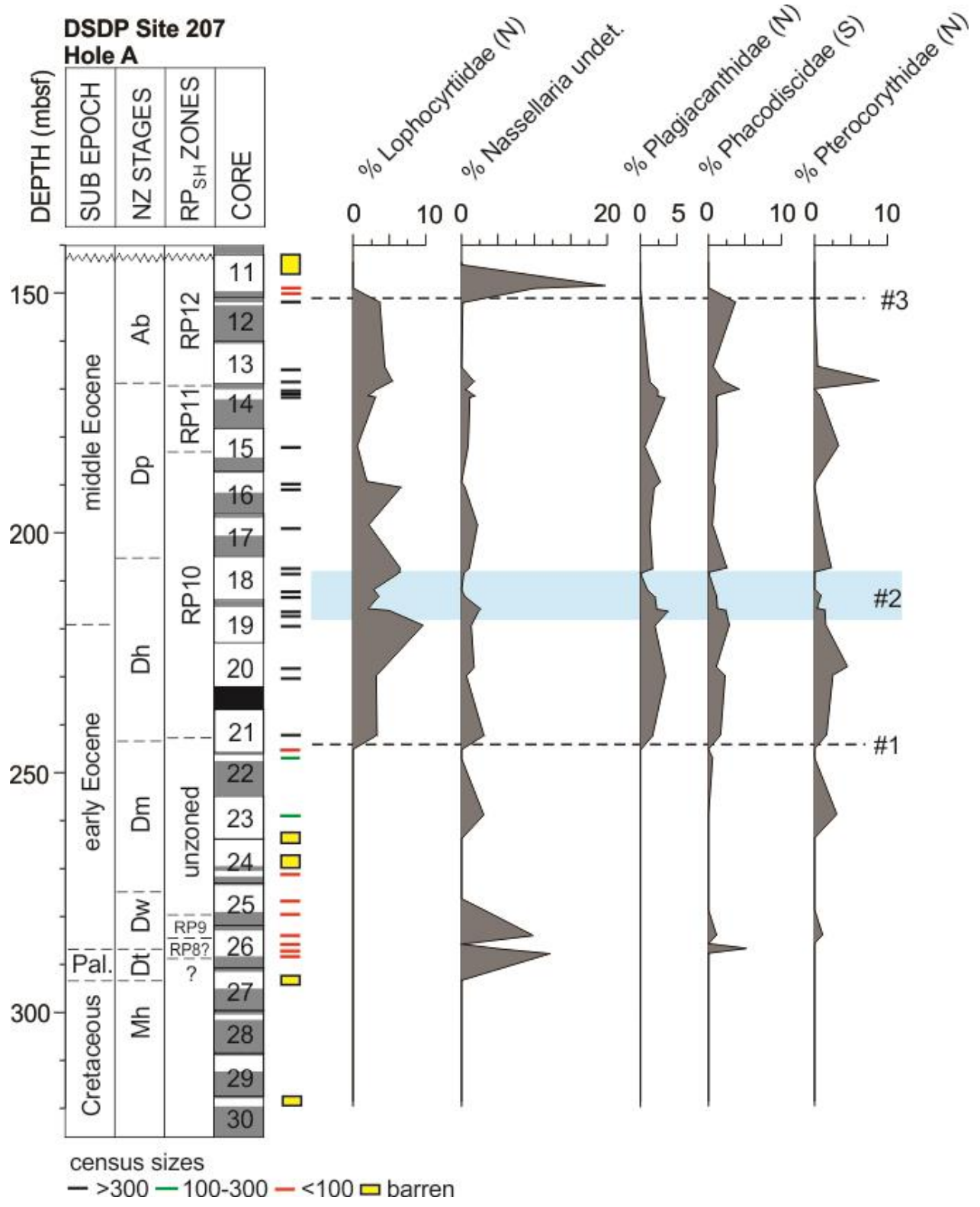

Figure 6.19 The relative abundance of less common radiolarian families and counting groups at DSDP Site 207 Hole A. Census size for all examined samples is colour-coded and shown to the right of the core log. $\mathrm{S}=$ spumellarians, $\mathrm{N}=$ nassellarians.

\subsubsection{DSDP Site 206}

The radiolarian assemblages examined from this site comprise 143 counting groups, which include 16 families and 66 genera. A total of 121 taxa were identified to species level (Appendix A, Appendix B Table 8). In the Paleocene to lower Eocene section (728687.51 mbsf, Core 206C-21R to -19R), abundance, preservation and diversity is low. One sample (706.39 mbsf) was barren of radiolarians, the other samples yielded between 1 and 24 taxa. The Fisher $\alpha$ Diversity Index ranges between 0.4-6 and Simpson Evenness between 0.1-0.76 (Figure 6.20). From 672 to $613.75 \mathrm{mbsf}$ (Core 206C-18R to -15R), 
radiolarians are diverse, well preserved and abundant. Taxic richness ranges between 49 and 76 taxa (average 61), Fisher $\alpha$ Diversity Index ranges between 15 and 27 (average 21) and Simpson Evenness is high between 0.88 and 0.96 (average 0.91) (Figure 6.20). A sudden drop in diversity and abundance occurs at the top of the section in Sample 206C15R-2, $20 \mathrm{~cm}$ (613.70 mbsf) directly below the unconformity (Kulhanek and Morgans, 2013). The middle Eocene section at Site 206 is thinner than at Site 207, and seems to cover only parts of the Bortonian stage.

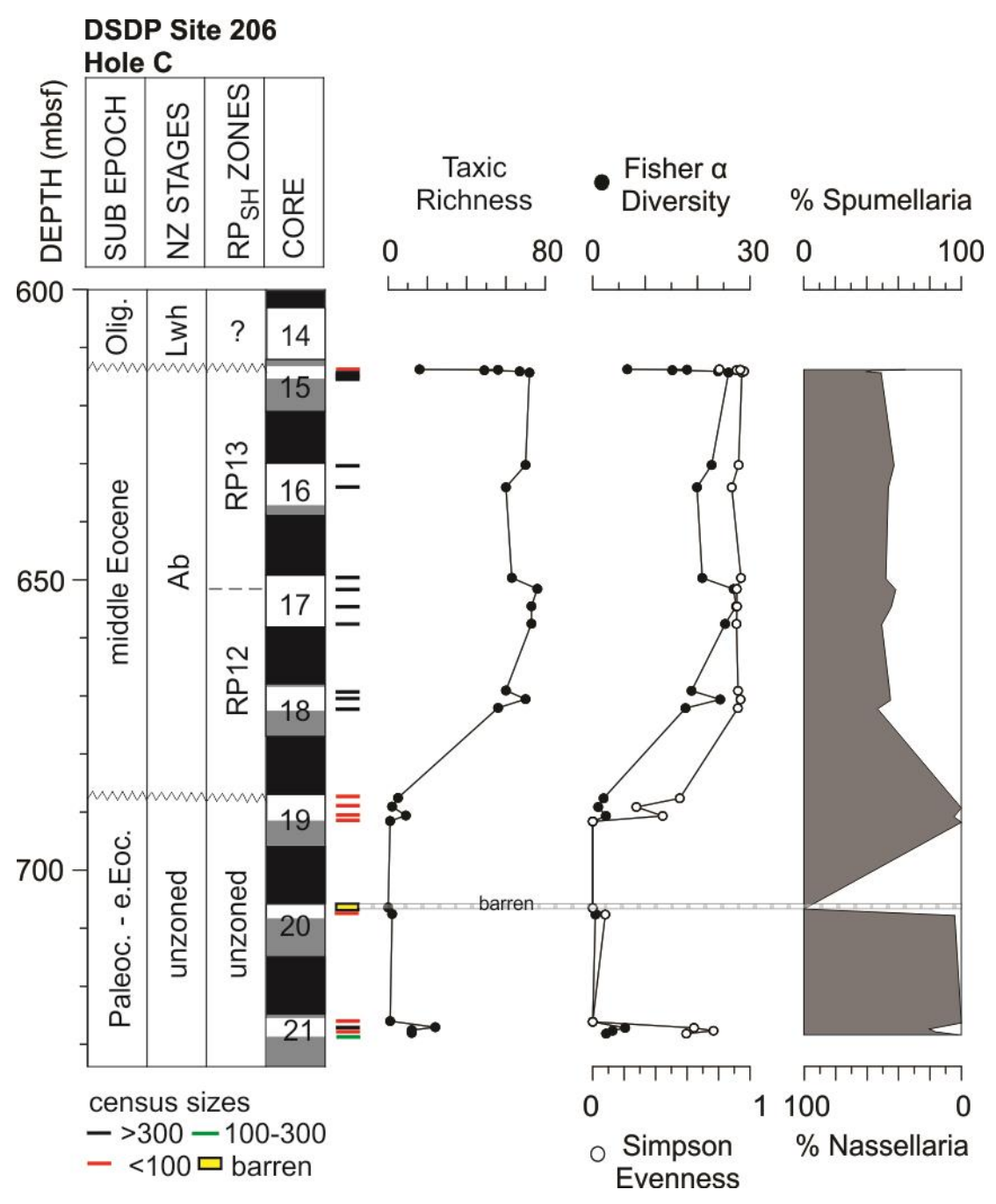

Figure 6.20 General features of radiolarian assemblages at DSDP Site 206 Hole C: taxic richness, Fisher $\alpha$ Diversity Index, Simpson Evenness Index, relative abundance (\%) of spumellarians and nassellarians. Census size for all examined samples is colour-coded and shown to the right of the core log.

In the radiolarian-rich interval of the middle Eocene (Bortonian) spumellarians ( 52\% average, 39-58\%) and nassellarians ( 48\%, 41-60\%) occur in similar abundances (Figure 6.20). The most abundant counting groups are the undetermined spumellarians $(\sim 21 \%$ average, 11-31\%), the Spongodiscidae ( 14\%, 7-20\%), the Lychnocaniidae ( 11\%, 4- 
$25 \%)$, the Eucyrtidiidae ( 10\%, 4-16\%), the Litheliidae ( 7\%, 3-11\%), Trissocyclidae $(\sim 6 \%, 3-11 \%)$ and Lophocyrtiidae ( 5\%, 1-10\%) (Figure 6.21). Represented with $\sim 3 \%$ on average are the Actinommidae (1-6\%), the Pterocorythidae (0-12\%), the Phacodiscidae (1-9\%), the Cannobotryidae (0-9\%), the Plagiacanthidae (0.2-9\%) and the Artostrobiidae $(0.2-5 \%)$. Sponguridae $(0.7-4 \%)$ and undetermined Nassellaria $(0-4 \%)$ account for $\sim 2 \%$ of the assemblages (Figure 6.22). Acropyramididae are present with $\sim 0.5 \%$ average (0-1.3\%) (Figure 6.22), Sethophormididae and Amphipyndacidae are very rare (Appendix B Table 8).

Several middle Eocene taxa are only found at Site 206: Lithocyclia aristotelis, Artophormis aff. dominasinensis, Phormocyrtis proxima, Theocorys anapographa, $T$. anapographa Var. A, Theocotylissa ficus, Thyrsocyrtis cf. triacantha, Thyrsocyrtis sp. A and D, Sethochytris triconiscus and Pterocorythidae? indet. sp. A (Appendix B Table 8).

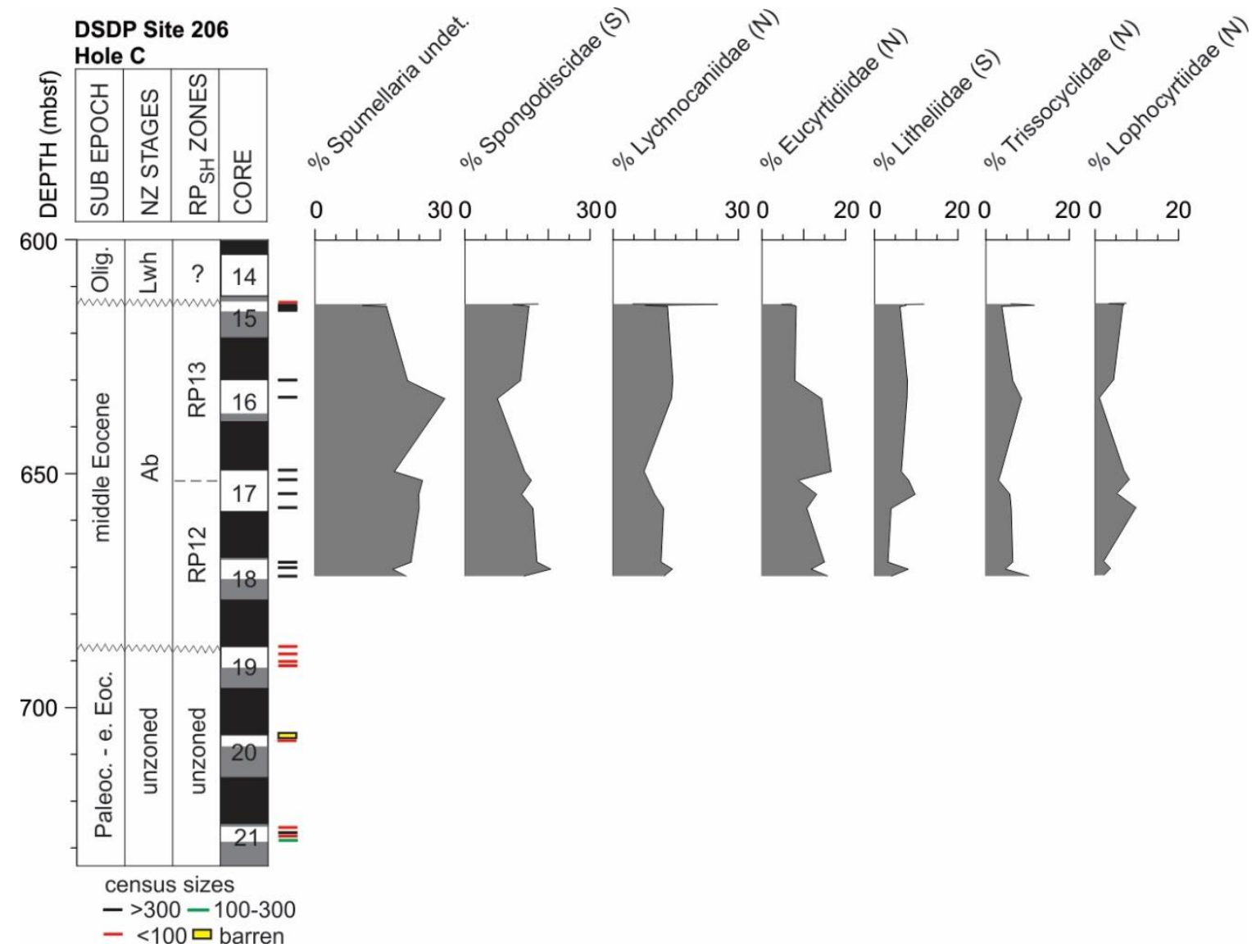

Figure 6.21 The relative abundance of the most abundant radiolarian families and counting groups at DSDP Site 206 Hole C. Only samples with a census size of $>300$ are plotted. Census size for all examined samples is colour-coded and shown to the right of the core $\log$. $\mathrm{S}=$ spumellarians, $\mathrm{N}=$ nassellarians. 


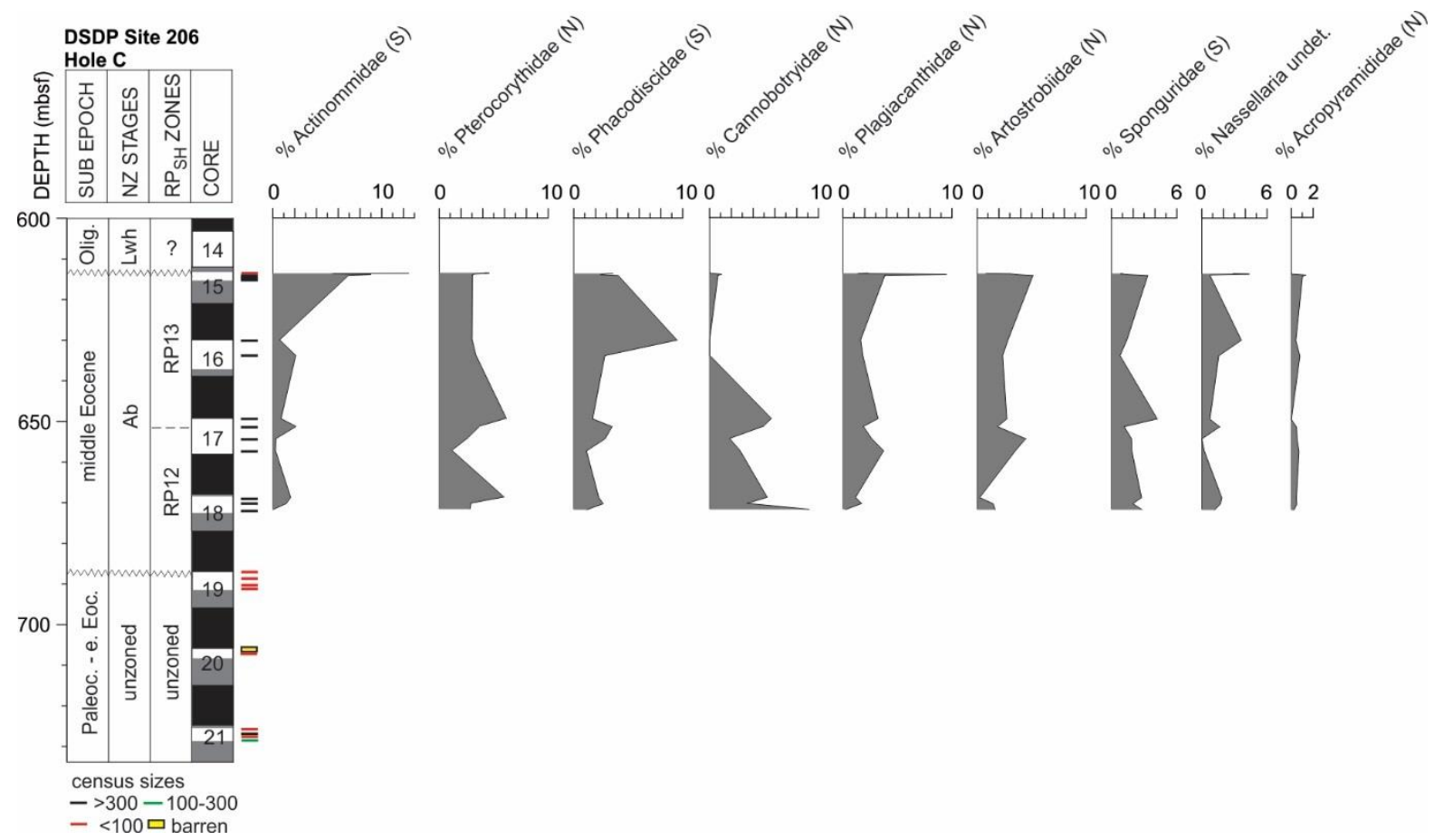

Figure 6.22 The relative abundance of less common radiolarian families and counting groups at DSDP Site 206 Hole C. Census size for all examined samples is colour-coded and shown to the right of the core log. Only samples with a census size of $>300$ are plotted. $\mathrm{S}=$ =spumellarians, $\mathrm{N}=$ nassellarians.

\subsubsection{DSDP Site 592}

The radiolarian assemblages examined from this site comprise 64 counting groups, which include 14 families and 33 genera. A total of 50 taxa were identified to species level (Appendix A, Appendix B Table 9). Three samples (379.70 mbsf, $363.50 \mathrm{mbsf}$ and $353.90 \mathrm{mbsf})$ contain scarce radiolarians (8, 34 and 3 specimens, respectively). A short, radiolarian-rich interval is observed at 374.60-364.07 mbsf and in one sample at 344.30 mbsf, with taxic richness ranging between 23-45 taxa per sample (Figure 6.23). Fisher $\alpha$ Diversity and Simpson Evenness closely resemble the trend in taxic richness, ranging between 5.4-13.85 and 0.59-0.89, respectively. The fauna in the rich interval has slightly more abundant nassellarians ( $\sim 55 \%$ average, $16-75 \%)$ than spumellarians $(\sim 45 \%, 24-$ 83\%) (Figure 6.23). 


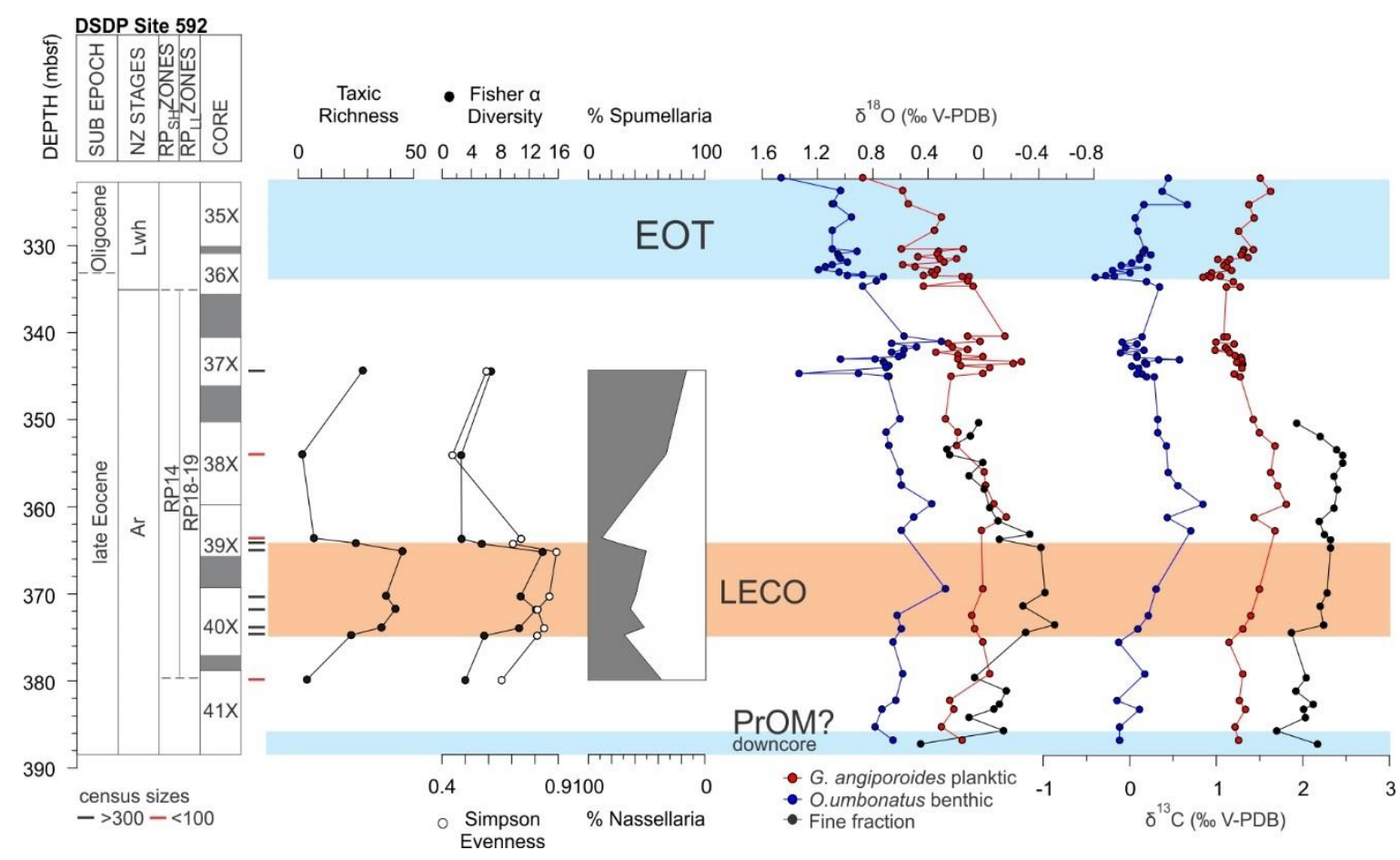

Figure 6.23 General features of radiolarian assemblages at DSDP Site 592 (including taxic richness, Fisher $\alpha$ Diversity Index, Simpson Evenness Index and relative abundance (\%) of spumellarians (grey) and nassellarians (white) compared with the $\delta^{18} \mathrm{O}$ and $\delta^{13} \mathrm{C}$ record of benthic and planktic foraminifera (Murphy and Kennett, 1986) and of the fine fraction $(<63 \mu \mathrm{m})$. Census size for all examined samples is color-coded and shown to the right of the core log. EOT=EoceneOligocene transition, LECO=late Eocene climatic optimum, PrOM=Priabonian oxygen isotope maximum. The latter event may extend further downcore (see text for details).

Stable oxygen and carbon isotopes for the bulk fine fraction and the two foraminifer species Globigerina angiporoides (planktic) and Oridorsalis umbonatus (benthic), the latter two derived from Murphy and Kennett (1986) are plotted in Figure 6.23 (Appendix C). In the bottom Core 592-41X (387.20-385.70 mbsf), bulk $\delta^{18} \mathrm{O}$ values decrease from 0.45 to $-0.15 \%$. This part of the core is $\sim 37 \mathrm{Ma}$ old and it might suggest the presence of the PrOM event immediately below the base of the cored section (Core 592-41X was the lowermost core collected at this site). A second decrease in $\delta^{18} \mathrm{O}$ values is present between Core 592-41X (379.71 mbsf) and Core 592-40X (374.61 mbsf). Within Core $592-40 X$ and the bottom of Core 592-39X (374.61-365.01 mbsf), the bulk $\delta^{18} \mathrm{O}$ values range between -0.29 and $-0.52 \%$. This interval yielded high radiolarian abundance and diversity. The foraminifer $\delta^{18} \mathrm{O}$ values do not show this pronounced decrease, and the values in this interval are lighter than deeper in the section. The age model for this site suggests an age of 36.4-35.9 Ma for this interval, which corresponds to the LECO present at Site 277. After the LECO, both planktic and benthic $\delta^{18} \mathrm{O}$ increase from $\sim 364 \mathrm{mbsf}$ towards the top of Core 592-38X with the highest value of $0.26 \%$ at $353.91 \mathrm{mbsf}$. The Eocene-Oligocene transition is evident in the $\delta^{18} \mathrm{O}$ values of Core 592-36X as a rapid 136 
increase in the isotopic ratio. The $\delta^{13} \mathrm{C}$ values of all three measurements show a positive trend from Core 592-41X towards the middle of Core 592-38X, before decreasing up core towards the Eocene-Oligocene transition (Core 592-36X), and then increasing again during the Oligocene. The initial increase in the late Eocene seems to be steeper for the benthic and planktic values than for the values of the fine fraction throughout the LECO. After a baseline shift at $374.60-373.73 \mathrm{mbsf}$, the $\delta^{13} \mathrm{C}$ values of the fine fraction are stable throughout this interval.

The most abundant family is the Lychnocaniidae, a group dominated by L. amphitrite, with on average $\sim 32 \%$ (Figure 6.24). The second and third most abundant groups are undetermined spumellarians ( 27\% average, 15-62\%) and Actinommidae ( $~ 8 \%, 5-14 \%)$. Trissocyclidae are also abundant $(\sim 7 \%, 1-32 \%)$, followed by Lophocyrtiidae $(\sim 7 \%, 1-$ $12 \%)$ and Eucyrtidiidae ( $\sim 5 \%$ average, $0.6-9 \%)$ (Figure 6.24).

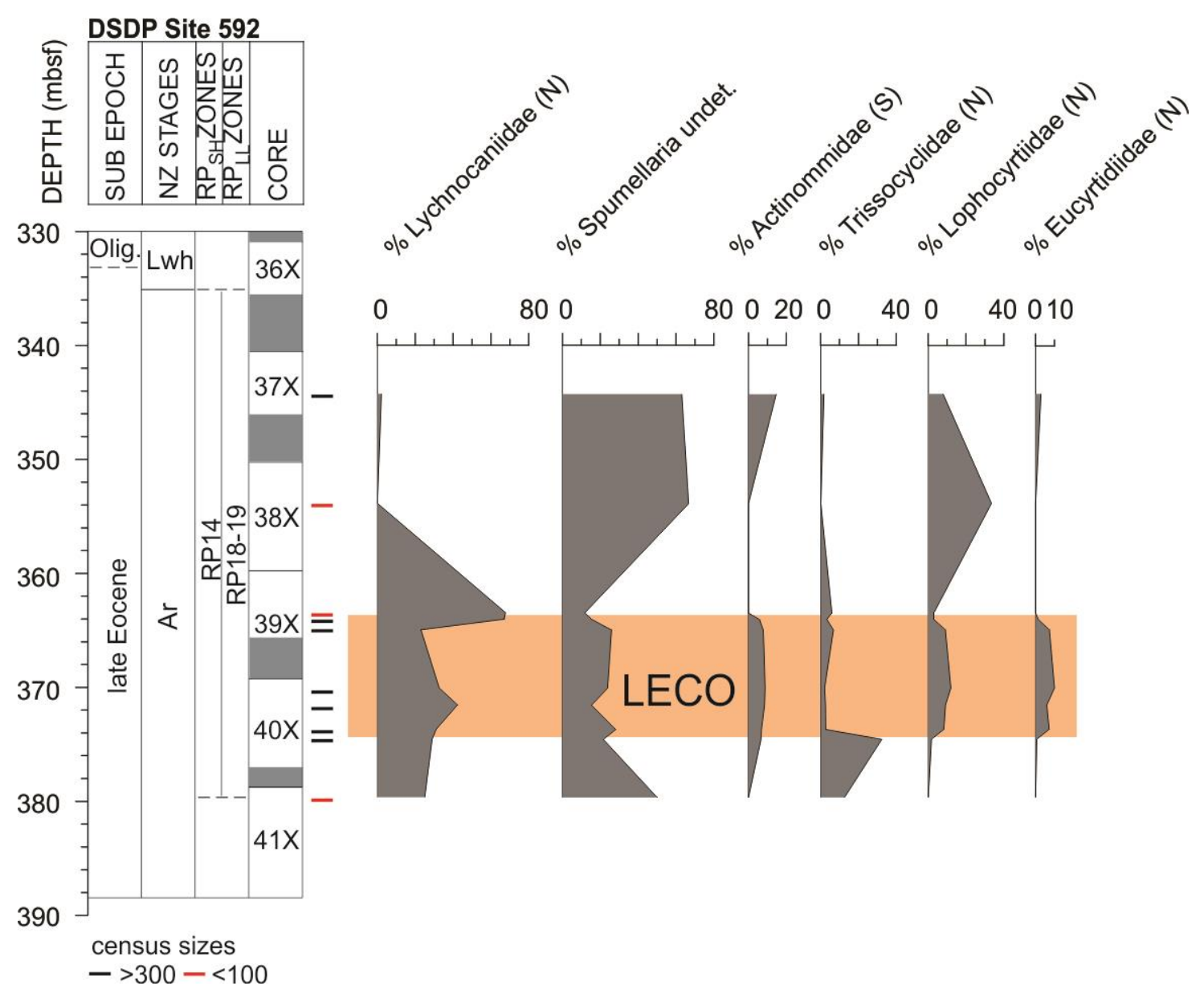

Figure 6.24 The relative abundance of the most abundant radiolarian families and counting groups at DSDP Site 592. Census size for all examined samples is colour-coded and shown to the right of the core log. S=spumellarians, $\mathrm{N}=$ nassellarians. 
Litheliidae ( $\sim 3.5 \%$ average), Spongodiscidae $(\sim 3 \%)$ and Phacodiscidae $(\sim 2 \%)$ are less abundant than at other sites. Undefined nassellarians $(\sim 2.8 \%)$, Pterocorythidae $(\sim 1.1 \%)$, Artostrobiidae $(\sim 1 \%)$, are rare (Figure 6.25$)$. Acropyramididae $(\sim 0.6 \%)$, Plagiacanthidae $(\sim 0.5 \%)$ (Figure 6.25$)$, Sponguridae and Cannobotryidae are very rare. Amphipyndacidae and Sethophormididae are absent.

The assemblage in the radiolarian-rich interval resembles the one observed at Site 277 during the LECO. L. amphitrite is abundant and the Plagiacanthidae and Larcopyle spp. are very rare in this interval at both sites. Compared to Site 277, Site 592 has more abundant Lophocyrtis? sp. B and Thyrsocyrtis cf. norrisi. The latter species is absent at Site 277, where instead T. pinguisicoides is present, which looks similar, however lacks feet. Therefore, it seems that the LECO identified at Site 277 can be traced to Site 592. At both sites, the nannofossil species $C$. reticulatum has its $\mathrm{HO}$ directly above the event at $35.92 \mathrm{Ma}$

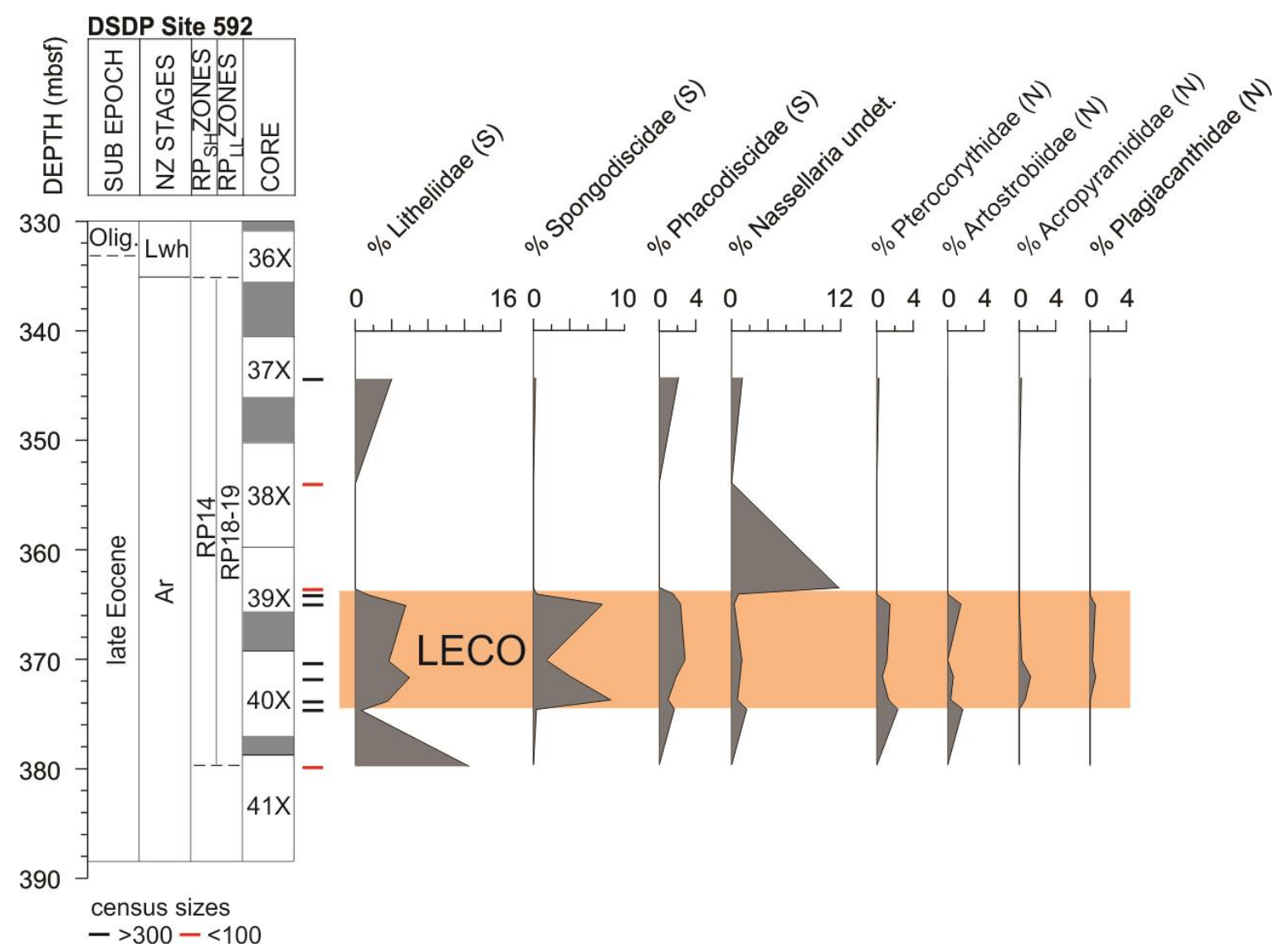

Figure 6.25 The relative abundance of less common radiolarian families and counting groups at DSDP Site 592. Census size for all examined samples is colour-coded and shown to the right of the core log. $\mathrm{S}=$ spumellarians, $\mathrm{N}=$ nassellarians. 


\subsubsection{ODP Site 1123}

The radiolarian assemblages examined from this site comprise 124 counting groups, which include 16 families and 64 genera. A total of 103 taxa were identified to species level (Appendix A, Appendix B Table 10). Taxic richness is very high with 41-73 taxa per sample (Figure 6.26). Diversity and evenness of the assemblages are high. Fisher $\alpha$ Diversity Index ranges between 11-24 and Simpson Evenness between 0.52-0.95. The lower values for taxic richness and diversity indices occur in the uppermost four samples. The radiolarian faunal assemblage is dominated by spumellarians ( 56\% average, $39-$ 89\%) (Figure 6.26).

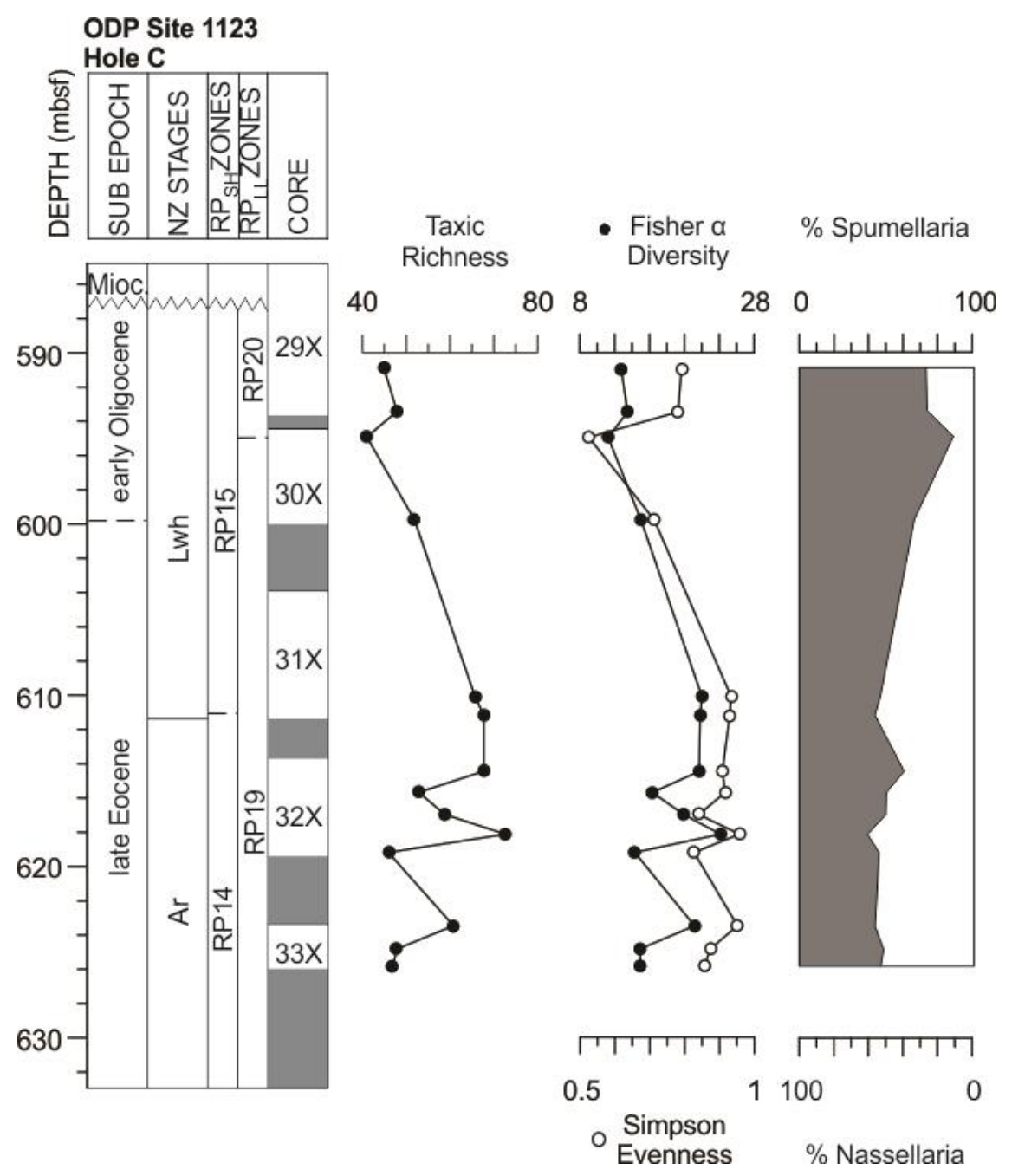

Figure 6.26 General features of radiolarian assemblages at ODP Site 1123 Hole C: taxic richness, Fisher $\alpha$ Diversity Index, Simpson Evenness Index, relative abundance (\%) of spumellarians (grey) and nassellarians (white).

The most abundant counting groups are the undetermined spumellarians ( $\sim 32 \%$ average, $11-68 \%)$ and the Actinommidae ( 11\%, 2-19\%) (Figure 6.27). The most abundant nassellarians are the Lophocyrtiidae $(\sim 10 \%, 2-19 \%)$, followed by the Trissocyclidae 
$(\sim 9 \%, 3-16 \%)$ and the Lychnocaniidae ( 6\%, 0.2-25\%) (Figure 6.27). Eucyrtidiidae and Litheliidae are $\sim 5 \%$ in average and range between $0.2-9 \%$ and $0.8-9 \%$, respectively. Spongodiscidae account for $\sim 4 \%(0.5-8 \%)$, Pterocorythidae for $\sim 3 \% \quad(0.9-16 \%)$, Artostrobiidae for $\sim 3 \%(0.5-7 \%)$ and Plagiacanthidae for $\sim 2 \%(0.2-6 \%)$. Undetermined Nassellaria (0-9\%), Acropyramididae $(0.2-3 \%)$ and Sponguridae $(0-3 \%)$ account for $\sim 1 \%$ on average (Figure 6.28). The remaining Phacodiscidae, Cannobotryidae, Sethophormididae and Amphipyndacidae are very rare ( $<1 \%$ on average) (Appendix B).

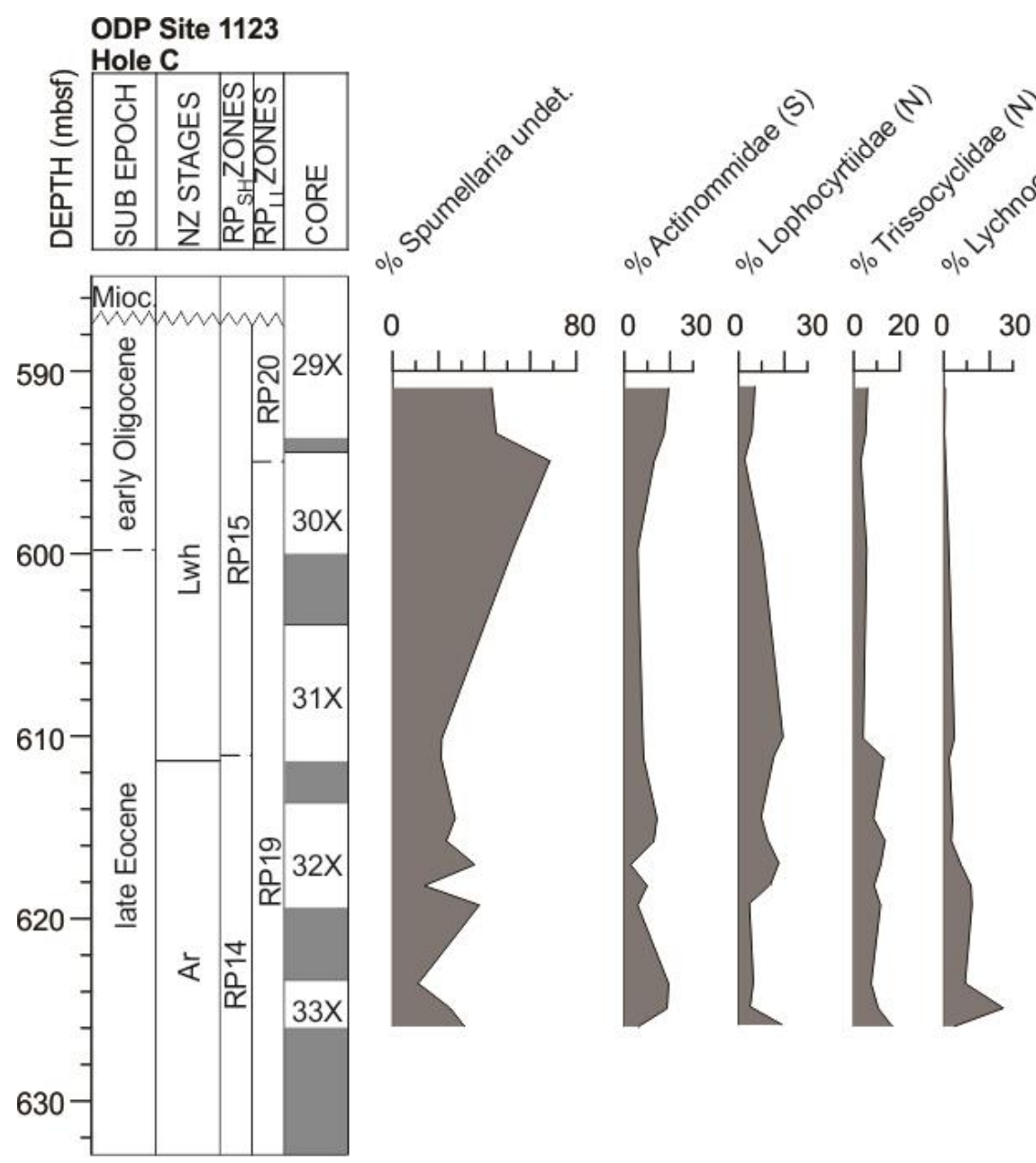

Figure 6.27 The relative abundance of the most abundant radiolarian families and counting groups at ODP Site 1123 Hole C. $\mathrm{S}=$ spumellarians, $\mathrm{N}=$ nassellarians.

The radiolarian assemblage resembles the late Eocene to early Oligocene assemblages of Site 277. However, several taxa are present that are absent at Site 277: Saturnalis circularis, Zealithapium oamaru, Lithocyclia sp., Rhopalodictyum californicum, Tristylospyris triceros, Theocampe mongolfieri, T. pirum, Thyrsocyrtis cf. norrisi, Verutotholus edwardsi, Lychnocanium alma, L. waitaki, L. turgidum, Lophocyrtis aspera Form B, L. hadra, L. millowi, Pterosyringium hamata and Cryptocarpium azyx. Site 1123 140 
shows the same trend in the early Oligocene as Site 277: a decrease in diversity and an increase in the abundance of spumellarians and actinommids.

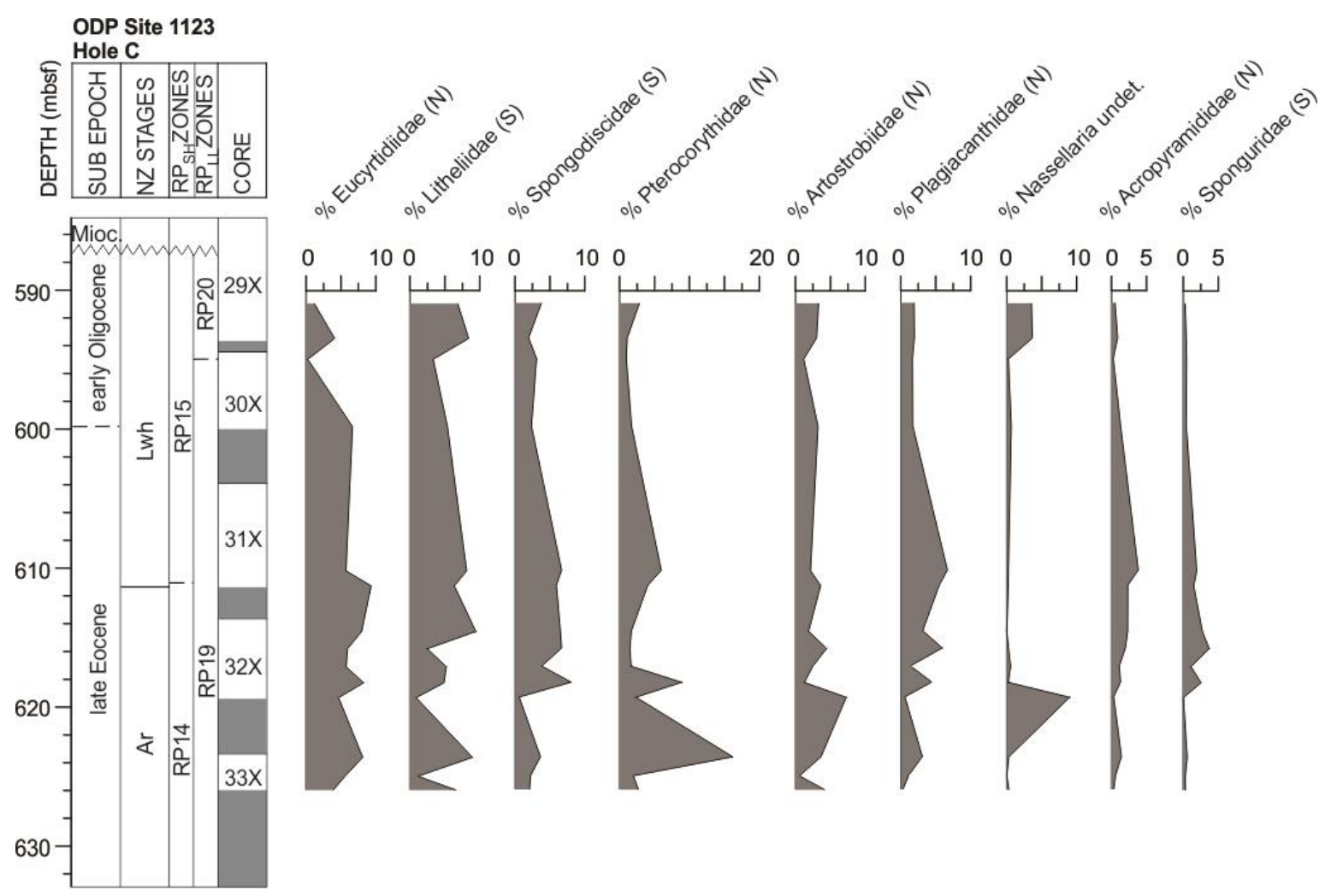

Figure 6.28 The relative abundance of less common radiolarian families and counting groups at ODP Site 1123 Hole C. $\mathrm{S}=$ spumellarians, $\mathrm{N}=$ nassellarians.

Site 1123 has a more diverse assemblage than Site 592 with many taxa not present in the late Eocene (Runangan) interval at Site 592: Amphisphaera spinulosa, Saturnalis circularis, Zealithapium oamaru, Flustrella sp. H, Spongopyle osculosa, Amphymenium splendiarmatum, Rhopalodictyum californicum, Spongurus bilobatus, Larcopyle labyrinthusa, L. polyacantha gr., Archipilium macropus, Ceratocyrtis spp., Lithomelissa gelasinus, Lophophaena spp., Pseudodictyophimus gracilipes gr., Tripodiscinus clavipes, Siphocampe amygdala, S. nodosaria, S. quadrata, Spirocyrtis joides, Theocampe mongolfieri, Eurystomoskevos petrushevskaae, Eusyringium fistuligerum, Verutotholus edwardsi, Dictyophimus spp., Lychnocanium waitaki, Pteropilium aff. contiguum, Aphetocyrtis gnomabax, A. rossi, Lophocyrtis aspera Form B, Cryptocarpium azyx, Cryptocarpium spp., Lamprocyclas particollis, Velicucullus spp. and Amphipternis clava.

Several taxa might be reworked at Site 1123, as they usually occur earlier at other sites: Amphipternis clava, Podocyrtis sp., Phormocyrtis ligulata, Buryella granulata, B. 
tetradica, Dictyomitra multicostata and Mita regina. Stichocorys delmontensis is a Miocene species and occurs in very rare numbers in the three uppermost samples (594.90-590.90 mbsf). It might have been downworked by drilling contamination as the Marshall Unconformity is located at $\sim 587.20$ mbsf.

\subsection{Biogeographic affinity}

The radiolarian assemblages at all nine sites include 134 species, species groups or genera that can be assigned to one of three biogeographic categories: high-latitude (48), cosmopolitan (49), and low-latitude (37) (Appendix A, Table A.1). Biogeographic affinities remain poorly known for the remaining 108 taxa assigned to species or genus level. Not included in this number are taxa that are assigned to family or order level only (17). Biogeographic affinities remain also unknown for $\sim 100$ taxa at ODP Site 1172 reported by Suzuki et al. (2009). Within the high-latitude group, six taxa are bipolar (Artostrobus annulatus, Axoprunum bispiculum, Ceratocyrtis spp., Cycladophora cosma cosma, Pseudodictyophimus gracilipes gr. and Spongopyle osculosa), whereas 42 taxa are inferred to be endemic to the Southern Ocean.

In the following section, a cumulative biogeographic affinity plot will be presented for each site for samples with a radiolarian census of $>100$ specimens. Along with that diagram, the cumulative relative abundance of high-latitude groups (Larcopyle spp., Lithomelissa spp., Lophocyrtiidae, Eucyrtidiidae, other high-latitude Nassellaria and other high-latitude Spumellaria) and low-latitude groups (Spumellaria, Eucyrtidiidae, Pterocorythidae, Lophocyrtiidae and other low-latitude Nassellaria), if present, is shown.

\subsubsection{High-latitude sites}

\subsubsection{DSDP Site 277}

At Site 277, taxa with high-latitude affinities are present with $\sim 10 \%$ relative abundance in the lower Eocene (Waipawan stage) (Figure 6.29), but consist of only one species (Buryella granulata). Both cosmopolitan and low-latitude taxa make up $\sim 15 \%$ of the assemblage each. During the Mangaorapan stage ( 50 Ma), the low-latitude group is dominant with up to $89 \%$. This interval can be assigned to the early Eocene climatic optimum (EECO); high-latitude taxa are absent. Spumellarians (Amphicraspedum prolixum gr., Amphicraspedum prolixum s.s., Middourium regulare and Monobrachium 
irregulare) are the main components of the low-latitude group in the lower Eocene. The only low-latitude nassellarian species is Phormocyrtis striata striata (Figure 6.29).

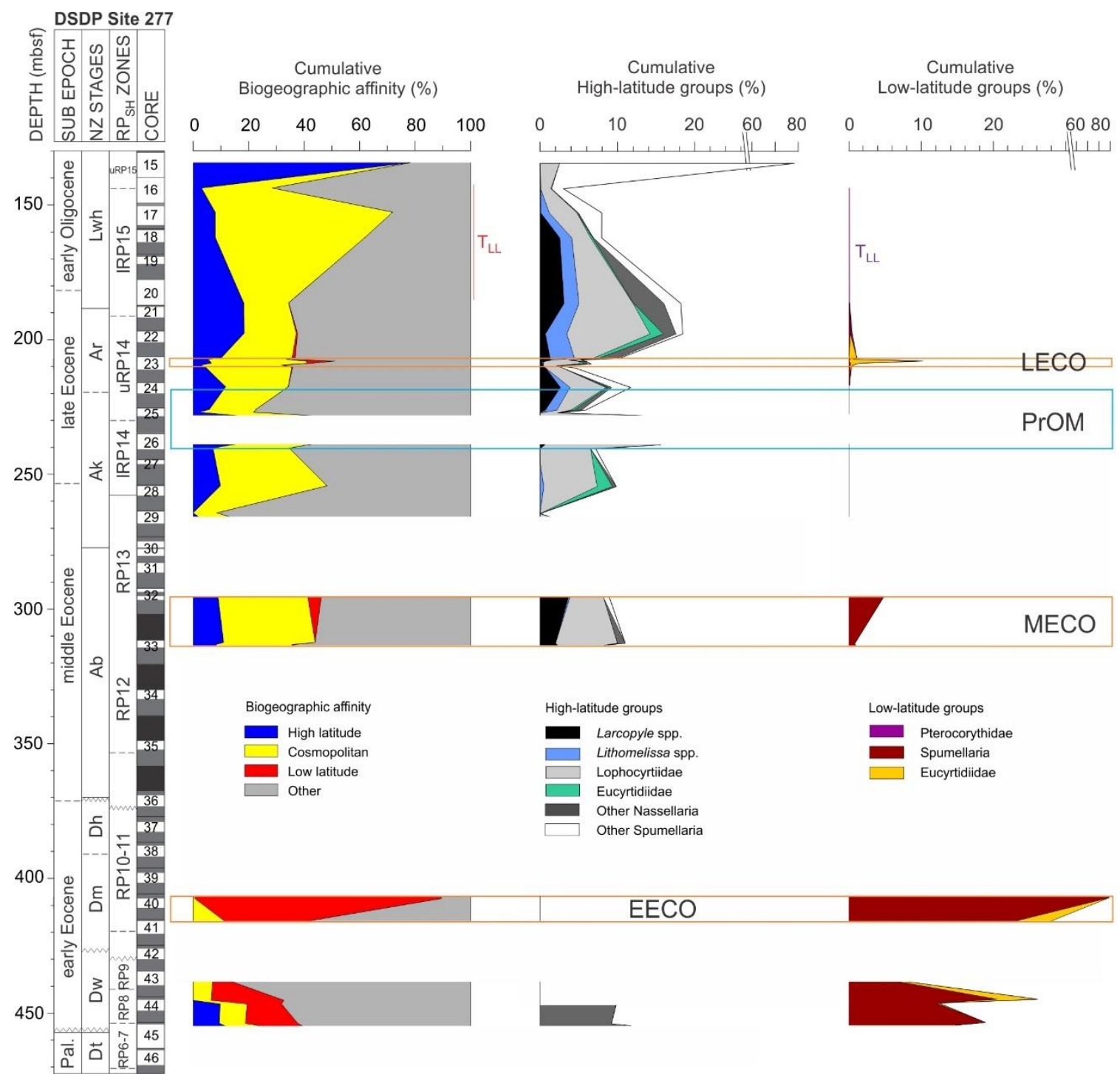

Figure 6.29 Cumulative biogeographic affinity assignment for DSDP Site 277, showing all groups (left); and a more detailed breakdown of the high-latitude (middle) and low-latitude groups (right). EECO=early Eocene climatic optimum, $\mathrm{MECO}=$ middle Eocene climatic optimum, $\mathrm{PrOM}=$ Priabonian oxygen isotope maximum, $\mathrm{LECO}=$ late Eocene climatic optimum.

The MECO is characterized by the presence of high-latitude taxa $(\sim 10 \%$ of the assemblage, mainly Larcopyle spp., Lophocyrtis jacchia hapsis, L. longiventer), but also the appearance of low-latitude species Amphicraspedum murrayanum and A. prolixum gr. (up to $\sim 5 \%$ ) (Figure 6.29). Cosmopolitan taxa increase in abundance to $\sim 30 \%$. Lophocyrtis jacchia hapsis is considered to be a high-latitude variant of L. jacchia jacchia and has a short stratigraphic range in the middle to late Eocene in the Southern Ocean (Sanfilippo and Caulet, 1998). In this study, this taxon has a common appearance only 
during the MECO and in the upper Eocene at Site 277. At the start of the upper Eocene (254.50-239 mbsf), high-latitude taxa comprise between $\sim 7-16 \%$ of the assemblage (dominated by L. longiventer, and trace amounts of Lithomelissa tricornis, Aphetocyrtis gnomabax, L. aspera, Eucyrtidium spinosum, Larcopyle hayesi, Pseudodictyophimus gracilipes gr. and Spongopyle osculosa). Cosmopolitan taxa account for on average $\sim 30 \%$. During the lower half of the PrOM event (237.50-235.50 mbsf), radiolarian assemblages are badly preserved and radiolarians are scarce. From $228.50-217.70 \mathrm{mbsf}$, high-latitude taxa comprise between $2-17 \%$ (Figure 6.29). The Lophocyrtiidae ( $L$. longiventer, L. aspera Form A, L. jacchia hapsis, Aphetocyrtis gnomabax, A. rossi) are the most abundant component ranging between $1.8-17 \%$. In the middle of the PrOM event ( 226.1 mbsf), radiolarian abundance and diversity suddenly increases. At this point, Larcopyle spp. and Lithomelissa spp. increase in abundance to $\sim 0.7-2.6 \%$ and $1.3-$ $1.5 \%$, respectively. High-latitude Eucyrtidiidae and other high-latitude Nassellaria are only present in trace abundances, while high-latitude Spumellaria range between 0.5 $2.5 \%$.

During the LECO, high-latitude taxa decrease to $\sim 5 \%$ at Site 277 and only trace occurrences of Lithomelissa spp., Larcopyle spp. and high-latitude Eucyrtidium spp. are noted (Figure 6.29). High-latitude lophocyrtids are mainly L. longiventer and L. aspera Form A. The LECO however coincides with the abundant occurrence of the low-latitude taxon Thyrsocyrtis pinguisicoides (up to 10\%) and the trace occurrence of A. prolixum gr. Cosmopolitan taxa are dominated by Lychnocanium spp., but general diversity also decreases within the LECO (Appendix B Table 1). After this event, high-latitude taxa increase to up to $\sim 18 \%$ in the upper Eocene Core $277-22 \mathrm{R}$ (197.82 mbsf) with the reappearance of all high-latitude taxa and an overall diversification (Figure 6.29). The high-latitude Lophocyrtiidae (Aphetocyrtis gnomabax, A. rossi, Clinorhabdus anantomus, Lophocyrtis aspera Form A, L. jacchia hapsis, L. longiventer) make up the major component of the high-latitude group (2.5-10.8\%). Larcopyle spp. (L. hayesi, L. polyacantha) are present with $0.7-3.1 \%$, Lithomelissa spp. (L. ehrenbergi, L. gelasinus, L.? sakaii, L. sphaerocephalis, L. tricornis) account for $1.9-3.1 \%$ and high-latitude Eucyrtidiidae (Aspis sp. A, Cycladophora spp., Eucyrtidium antiquum, E. mariae, E. spinosum, Eurystomoskevos cauleti, E. petrushevskaae) for 0.1-1.7\%. Other high-latitude nassellarians (Amphicentria sp. 1, Ceratocyrtis spp., Pseudodictyophimus gracilipes gr., Artostrobus annulatus, A. cf. pretabulatus, Dictyophimus? archipilium, D. aff. 
archipilium, Lamprocyclas particollis) comprise 1.6-3.9\% and Spumellaria (Spongopyle osculosa) 0.3-2.2\%. During the lower Oligocene (162.2-134.50 mbsf), diversity declines and all high-latitude groups decrease in abundance (Figure 6.29). The cosmopolitan group increases in abundance to up to $64 \%$ until $~ 144$ mbsf, with Lithelius minor gr. the dominant species. Above 144 mbsf, Lithelius minor gr. decreases in abundance and highlatitude actinommids (Axoprunum bispiculum and A.? irregularis) dominate the assemblage with $78 \%$ and make up $~ 97 \%$ of the high-latitude assemblage (the remaining $\sim 3 \%$ is L. longiventer).

\subsubsection{DSDP Site 280}

DSDP Site 280 contains the highest constant portion of high-latitude taxa of all investigated sites, ranging between 31 and 35\% in the lower Oligocene (Figure 6.30). Cosmopolitan taxa are present with on average $\sim 21 \%$. Only a trace occurrence of the lowlatitude species Amphicraspedum prolixum gr. is present. The high-latitude assemblage of this site contains together with Site 281 the highest abundances of Larcopyle spp. ( $L$. hayesi, L. frakesi, L. polyacantha, L. labyrinthusa, L. cf. pylomaticus) and Lithomelissa spp. (L. challengerae, L. ehrenbergi, L. gelasinus, L. robusta, L.? sakaii, L. sphaerocephalis, L. tricornis), ranging between $\sim 5-13 \%$ and $\sim 7-11 \%$, respectively (Figure 6.30). High-latitude Lophocyrtiidae (Aphetocyrtis gnomabax, A. rossi, Lophocyrtis longiventer) are present with $\sim 2.7-7.5 \%$ and Eucyrtidiidae (Aspis sp. A, Cycladophora humerus, C. cosma cosma, Eucyrtidium antiquum, Eurystomoskevos cauleti, E. petrushevskaae) with $\sim 2-7.2 \%$ (Figure 6.30). Other high-latitude Nassellaria (Antarctissa cylindrica, A. robusta, Ceratocyrtis spp., Pseudodictyophimus galeatus, P. gracilipes gr., Dictyophimus? archipilium, Lamprocyclas particollis) comprise on average $\sim 3 \%$ and other Spumellaria (Spongopyle osculosa) $\sim 0.1-1.5 \%$. Several highlatitude taxa that are present in the lower Oligocene at SIte 280 are absent at Site 277, including Cycladophora cosma cosma, C. humerus, Lithomelissa challengerae, Larcopyle frakesi, L. labyrinthusa, L. cf. pylomaticus, Lithomelissa sakaii, L. robusta, Pseudodictyophimus galeatus and Antarctissa spp. 


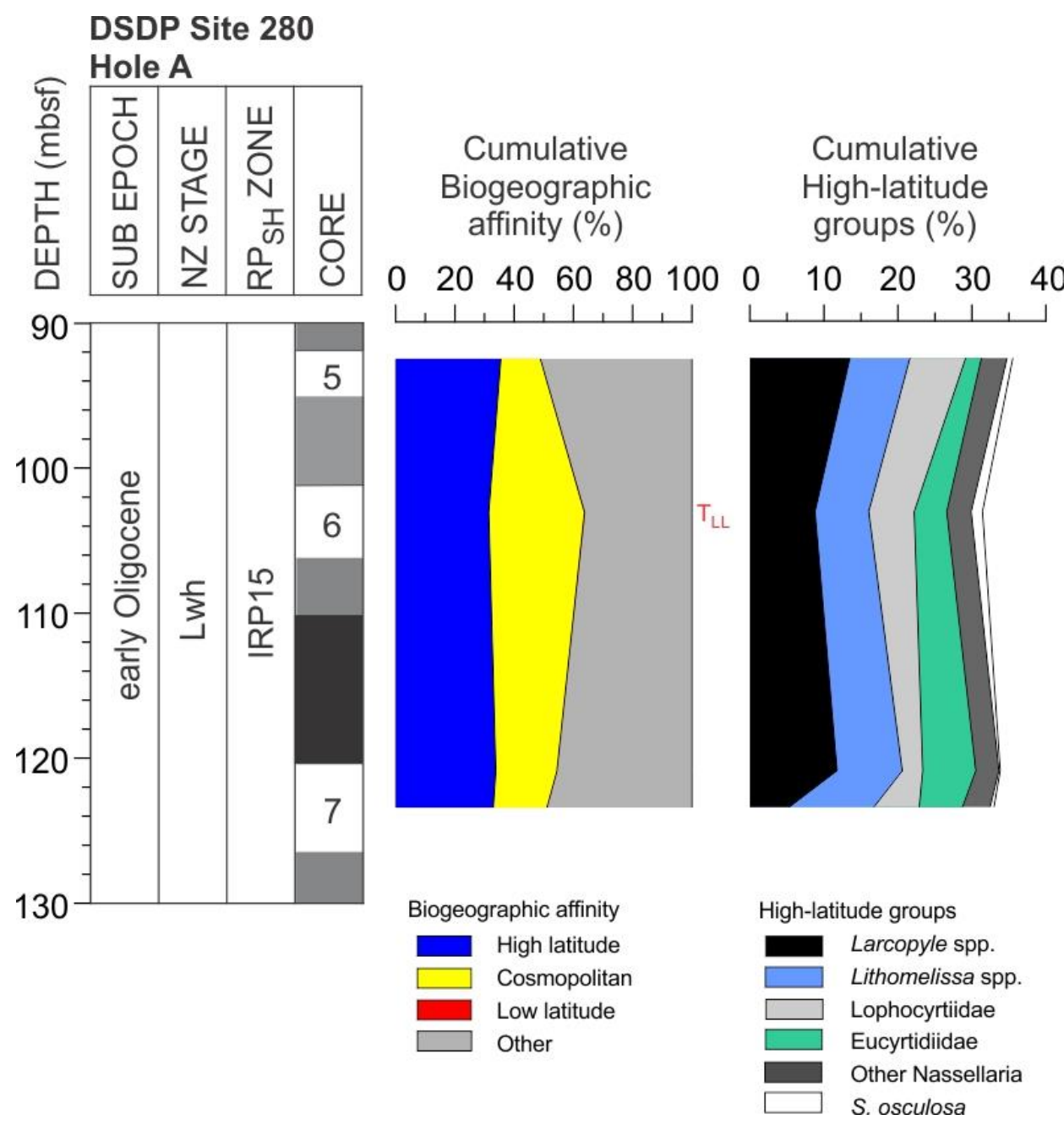

Figure 6.30 Cumulative biogeographic affinity assignment for DSDP Site 280 Hole A, showing all groups (left) and high-latitude groups (right). $\mathrm{T}_{\mathrm{LL}}=$ trace amount of low-latitude species $A$. prolixum $\mathrm{gr}$.

\subsubsection{DSDP Site 281}

The assemblage at this site contains the most abundant high-latitude assemblage from the late Eocene of all investigated sites. The high-latitude group ranges between 13-34\%; the cosmopolitan group is less abundant with 11-19\%. Low-latitude taxa are absent (Figure 6.31). Several high-latitude taxa that are present in the upper Eocene at this site are absent at Site 277, including Larcopyle cf. pylomaticus, Cycladophora humerus, and Eucyrtidium nishimurae. Larcopyle spp. (L. hayesi, L. polyacantha, L. cf. pylomaticus) and Lithomelissa spp. (L. ehrenbergi, L. gelasinus, L. sphaerocephalis, L. tricornis) are the most abundant groups ranging between $\sim 3.3-12 \%$ and $\sim 0.5-12.8 \%$ (Figure 6.31 ), respectively. High-latitude Lophocyrtiidae (Aphetocyrtis gnomabax, Clinorhabdus anantomus, Lophocyrtis aspera Form A, L. longiventer) account for 3.3-6.9\% and Eucyrtidiidae (Cycladophora spp., Eucyrtidium nishimurae, E. spinosum, Eurystomoskevos cauleti, E. petrushevskaae) are present with $\sim 0.7-7 \%$. Other high146 
latitude Nassellaria (Amphicentria sp. 1, Pseudodictyophimus gracilipes gr., Dictyophimus aff. archipilium, Lamprocyclas particollis), and Spumellaria (Spongopyle osculosa) are present in trace to rare abundances (Figure 6.31).

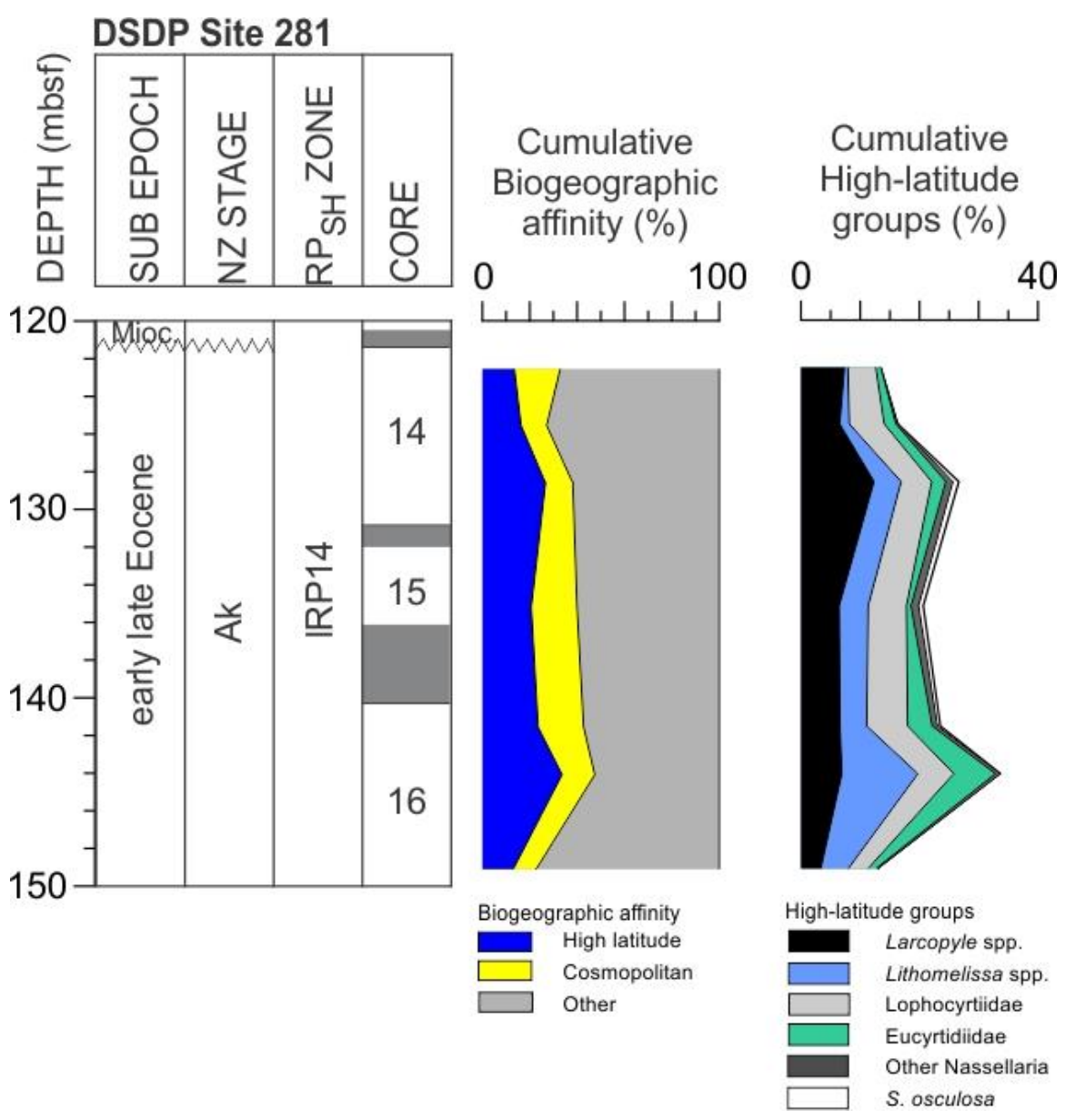

Figure 6.31 Cumulative biogeographic affinity assignment for DSDP Site 281, showing all groups (left) and highlatitude groups (right).

\subsubsection{DSDP Site 283}

At Site 283, high-latitude taxa are present from the uppermost middle Eocene and range between $\sim 6$ and $23 \%$ (Figure 6.32). Larcopyle spp. (L. hayesi, L. polyacantha) are present with $\sim 0.6-3 \%$, Lithomelissa spp. (L. ehrenbergi, L. gelasinus, L. robusta, L. sphaerocephalis, L. tricornis) with $\sim 0.9-5 \%$, high-latitude Lophocyrtiidae (Aphetocyrtis gnomabax, A. rossi, Clinorhabdus anantomus, Lophocyrtis aspera Form A, L. jacchia hapsis, L. longiventer) with $\sim 2-7.5 \%$ and high-latitude Eucyrtidiidae (Aspis sp. A, Cycladophora spp., Eucyrtidium nishimurae, E. spinosum, Eurystomoskevos petrushevskaae, E. cauleti) with $\sim 0.8-6.7 \%$. Other high-latitude Nassellaria (Amphicentria sp. 1, Ceratocyrtis spp., Pseudodictyophimus gracilipes gr., Artostrobus 
annulatus, Dictyophimus? archipilium, Dictyophimus? aff. archipilium and Lamprocyclas particollis) and Spumellaria (Axoprunum bispiculum, Spongopyle osculosa) account for $\sim 0.5-2.4 \%$ and $\sim 0.3-2 \%$, respectively. The cosmopolitan group is more abundant than the high-latitude group ranging between 32 and $48 \%$ (Figure 6.32) and dominated by Lithelius minor gr. (21-41\%). Low-latitude taxa (Thyrsocyrtis pinguisicoides and Theocyrtis tuberosa) are present in trace amounts in the lower part of the record. However, the uppermost sample contains $\sim 7 \%$ T. tuberosa (Figure 6.32). Tentatively, this relatively high abundance of the low-latitude species can be correlated to the LECO at Site 277 , but it is at odds with the existing age models ( $\sim 36.7$ Ma for site 283 vs. $\sim 36 \mathrm{Ma}$ for Site 277).

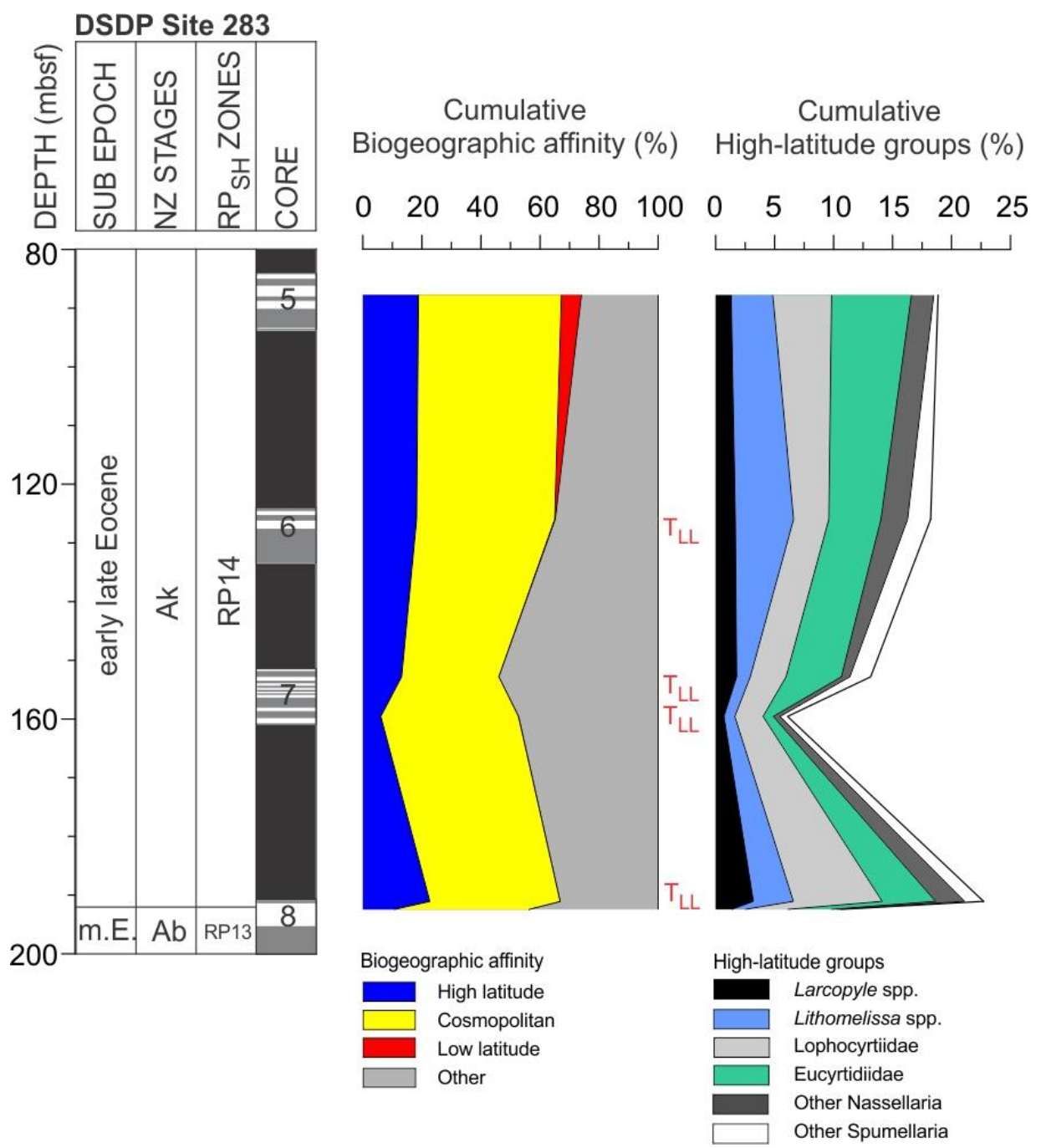

Figure 6.32 Cumulative biogeographic affinity assignment for DSDP Site 283, showing all groups (left) and highlatitude groups (right). TLL=trace amount of low-latitude species T. pinguisicoides (lowermost) and T. tuberosa (all other). 


\subsubsection{ODP Site 1172}

At Site 1172, high-latitude taxa are present in the middle and upper Eocene, although in varying abundance between $\sim 0.6$ and $9 \%$ of the assemblage (Figure 6.33), while the highest abundance of high-latitude taxa at Site 1172 is recorded in the Oligocene ( 1117\%). In the Eocene, cosmopolitan taxa are far more abundant ranging between 16 and 52\%. The MECO interval at this site (Core 1172A-45X; Bijl et al., 2010) corresponds to a relative minimum in high-latitude taxa, which is part of an interval of decreased abundance of high-latitude taxa from 430 to $410 \mathrm{mbsf}$ (Figure 6.33). High-latitude Larcopyle spp. is only present in the Oligocene at this site. Eucyrtidium nishimurae, E. spinosum, E. antiquum and Eurystomoskevos petrushevskaae comprise the high-latitude Eucyrtidiidae. The high-latitude Lophocyrtiidae contain Lophocyrtis longiventer and Aphetocyrtis rossi in the middle to upper Eocene and only Clinorhabdus robusta is the Oligocene interval. The only high-latitude spumellarian species in the middle and upper Eocene is Spongopyle osculosa, which is absent in the Oligocene interval. The most abundant high-latitude component of the Oligocene is A.? irregularis, similarly to Site 277. Except for very rare Theocampe mongolfieri in the middle Eocene (Figure 6.33), none of the low-latitude taxa found at the other sites are present at Site 1172. 


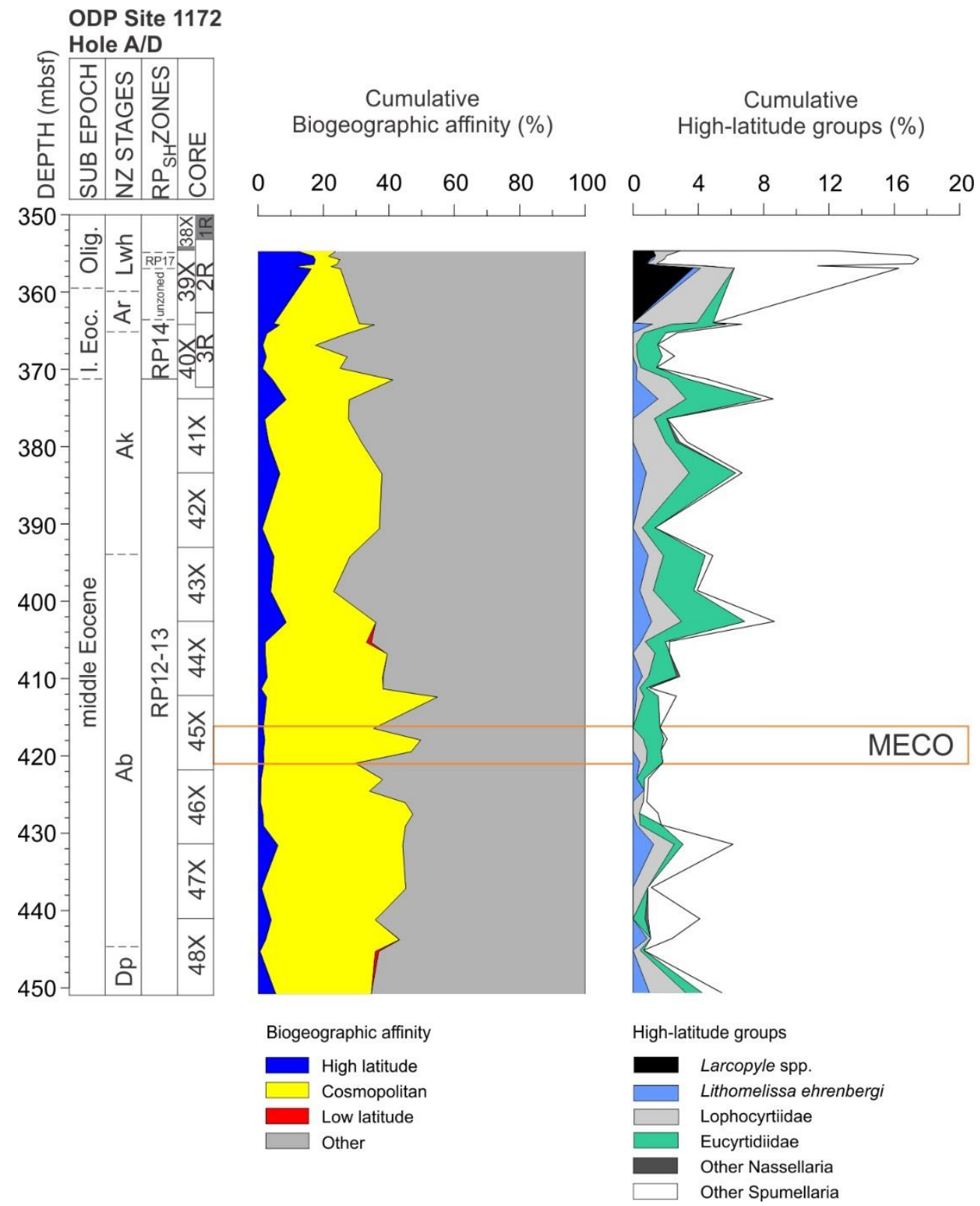

Figure 6.33 Cumulative biogeographic affinity assignment for ODP Site 1172 Hole A (Cores 1172A-48X to -38X) and Hole D (Cores 1172D-3D to -1D), showing all groups (left) and high-latitude groups (right). MECO=middle Eocene climatic optimum after Bijl et al. (2010).

\subsubsection{Mid-latitude sites}

\subsubsection{DSDP Site 207}

High-latitude taxa are rare at this site in the lower to middle Eocene $(<2 \%)$ (Figure 6.34). The high-latitude groups are Larcopyle spp. (Larcopyle hayesi, L. polyacantha), ranging between $0-0.5 \%$, Lithomelissa spp. (L. ehrenbergi, L. sphaerocephalis, L. tricornis), ranging between 0-0.6\%, Lophocyrtiidae (Aphetocyrtis gnomabax, Lophocyrtis aspera Form A, L. longiventer and L. jacchia hapsis), ranging between $0-0.9 \%$ and 
Eurystomoskevos cauleti and Ceratocyrtis spp., ranging between $0-0.2 \%$ and $0-1.1 \%$, respectively.

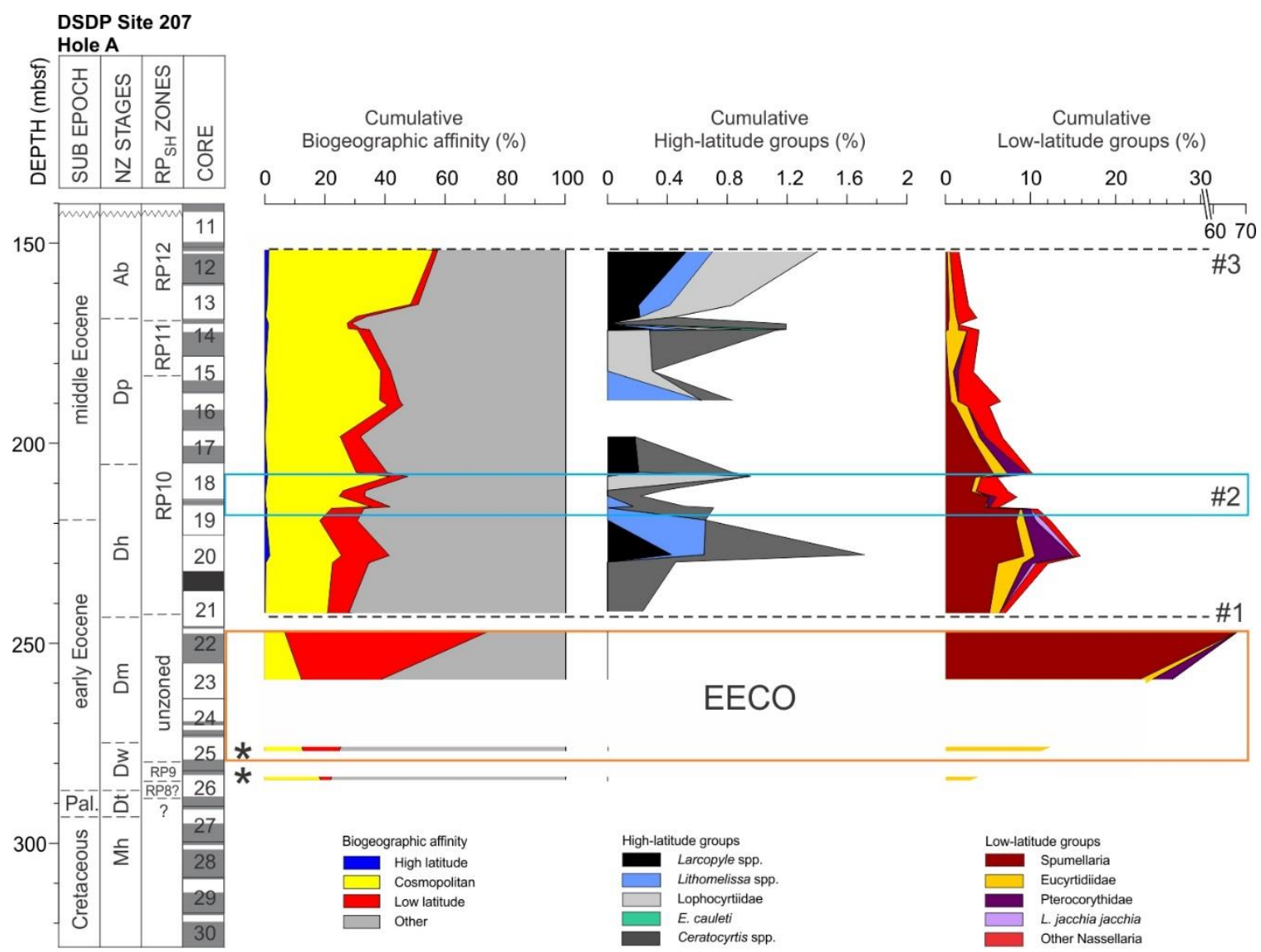

Figure 6.34 Cumulative biogeographic affinity assignment for DSDP Site 207 Hole A, showing all groups (left); highlatitude groups (middle) and low-latitude groups (right). Two distinct horizons (\#1 and \#3) and one interval (\#2) can be recognized where obvious assemblage and preservation changes occur. EECO=Early Eocene Climatic Optimum. Two samples (*) are included which have less than 100 specimens in radiolarian census size.

Low-latitude taxa are very abundant $(\sim 26-67 \%)$ in the EECO (upper Mangaorapan stage, 259.04-247.26 mbsf) (Figure 6.34). The dominant group in the EECO, similar to what was observed at Site 277, are the spumellarians with Amphicraspedum murrayanum, A. prolixum gr. and A. prolixum s.s. ranging between $\sim 23-67 \%$. A few other species also occur, with very rare abundances: Podocyrtis papalis, Phormocyrtis striata striata and Theocorys spp. During the lower Eocene and middle Eocene, low-latitude taxa occur in lower abundances and make up 1.5-15\% of the assemblage (Figure 6.34). The main lowlatitude taxa are spumellarians (Amphicraspedum spp., Middourium regulare, Monobrachium irregulare, Histiastrum quadribrachiatus quadribrachiatus, Lithocyclia ocellus) with a maximum of $\sim 9 \%$, Eucyrtiidae (Dictyopodium aff. oxylophus, Phormocyrtis striata striata, Theocorys spp., Theocotyle nigriniae and Thyrsocyrtis 
rhizodon) with up to $\sim 3 \%$, Pterocorythidae (Podocyrtis spp.) with a maximum of $4.5 \%$, other Nassellaria (Theocampe mongolfieri, Lithochytris vespertilio, Giraffospyris didiceros and Dorcadospyris argisca) with up to 5\%, and trace amounts of Lophocyrtis jacchia jacchia (Figure 6.34). During the middle Eocene (upper Heretaungan, 219.47208.46 mbsf), a short interval (horizon \#2) with a pronounced decrease in radiolarian diversity is accompanied also by a decrease in low-latitude taxa to $~ 6 \%$ (Figure 6.34). Thereafter, low-latitude taxa show a short increase again at the top of Core 207A-18R (207.52 mbsf). However, the overall trend for the remaining middle Eocene is a steady decrease in abundance to $\sim 1.5 \%$ at 152 mbsf (Core 207A-12R). The cosmopolitan taxa increase in abundance throughout the studied interval from a minimum of $6 \%$ in the EECO to $\sim 54 \%$ in the upper middle Eocene.

\subsubsection{DSDP Site 206}

High-latitude taxa are present in the middle Eocene (Bortonian stage) interval at Site 206, ranging between $\sim 2$ and $9 \%$ (Figure 6.35). Within the topmost $\sim 50 \mathrm{~cm}$ of the interval (at $\sim 614 \mathrm{mbsf}$ ), there is a strong fluctuation of the abundances between 3 and $9 \%$, probably due to a small sampling distance $(\sim 10-30 \mathrm{~cm})$ and proximity to an unconformity at $\sim 613.70$ mbsf. The main high-latitude taxa are Larcopyle spp. (Larcopyle hayesi and L. polyacantha) ranging between $0.2-3.8 \%$, Lophocyrtiidae (Aphetocyrtis gnomabax, Lophocyrtis aspera, L. jacchia hapsis and L. longiventer), ranging between 0.5-2.8\% and Eucyrtidiidae (Eucyrtidium nishimurae, Eurystomoskevos petrushevskaae and Aspis sp. A), ranging between 0-2.7\%. Lithomelissa spp. (Lithomelissa ehrenbergi, L. sphaerocephalis), Ceratocyrtis spp., and Spongopyle osculosa occur only in trace amounts $(<1 \%)$.

Low-latitude taxa are about as abundant as high-latitude taxa at this site, ranging between 4-9\% (Figure 6.35). The main low-latitude taxa are Spumellaria (Amphicraspedum prolixum gr. and Lithocyclia spp.), ranging between $0.5-5.6 \%$, and other Nassellaria (Sethochytris triconiscus, Lithochytris vespertilio, Theocampe mongolfieri, Theocampe pirum, Giraffospyris didiceros and Dorcadospyris argisca) ranging between 0.7-4.7\%. Eucyrtidiidae (Phormocyrtis striata striata, Dictyopodium aff. oxylophus, Theocorys spp. and Thyrsocyrtis spp.) are rare with $0-1.4 \%$. Cosmopolitan taxa are present throughout the interval, with abundances ranging between 26-43\% (Figure 6.35). 


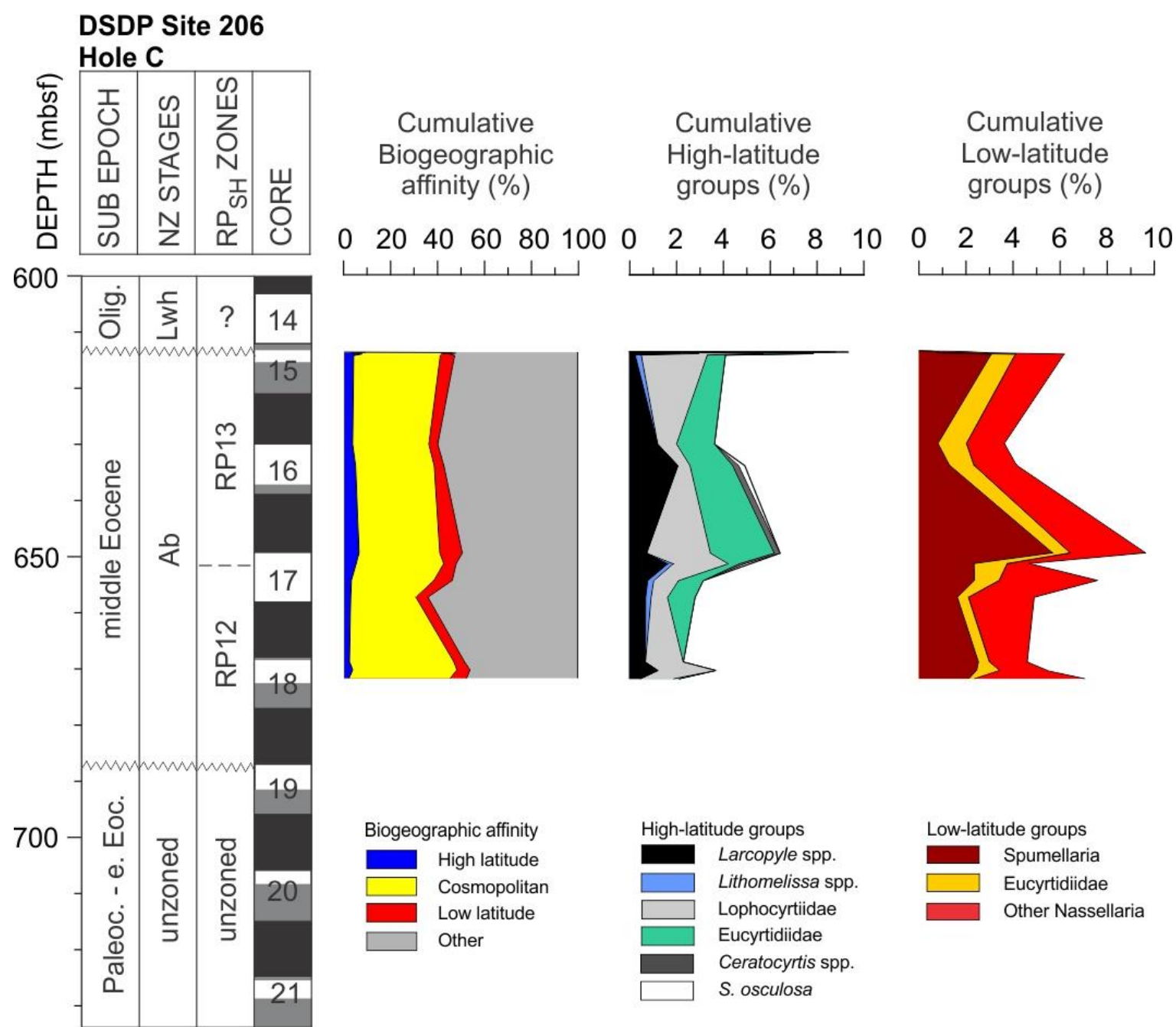

Figure 6.35 Cumulative biogeographic affinity assignment for DSDP Site 206 Hole C, showing all groups (left); highlatitude groups (middle) and low-latitude groups (right).

\subsubsection{DSDP Site 592}

The LECO at this site contains a mix of taxa having both high- and low-latitude affinity, with their abundances ranging between $\sim 1-6 \%$ and $\sim 3-5.5 \%$, respectively (Figure 6.36). The high-latitude group is dominated by lophocyrtids, (L. longiventer, L. aspera Form A and L. jacchia hapsis) ranging between $0-5.1 \%$. The high-latitude group contains also trace amounts of Larcopyle hayesi, Lithomelissa spp. (Lithomelissa ehrenbergi, L. sphaerocephalis) and Eucyrtidium spinosum. The low-latitude group is dominated by eucyrtiids (Thyrsocyrtis cf. norrisi and T. pinguisicoides) ranging between 0-4.2\% and other nassellaria (Theocampe pirum, Dorcadospyris argisca and Tristylospyris triceros), ranging between 0.6-3.3\%. Amphicraspedum prolixum gr. is present in trace amounts. The cosmopolitan group varies between $28-58 \%$ (Figure 6.36). The sample from Core 
592-37X (344.30 mbsf) contains 3\% high-latitude, $\sim 18 \%$ cosmopolitan and is barren of low-latitude taxa.

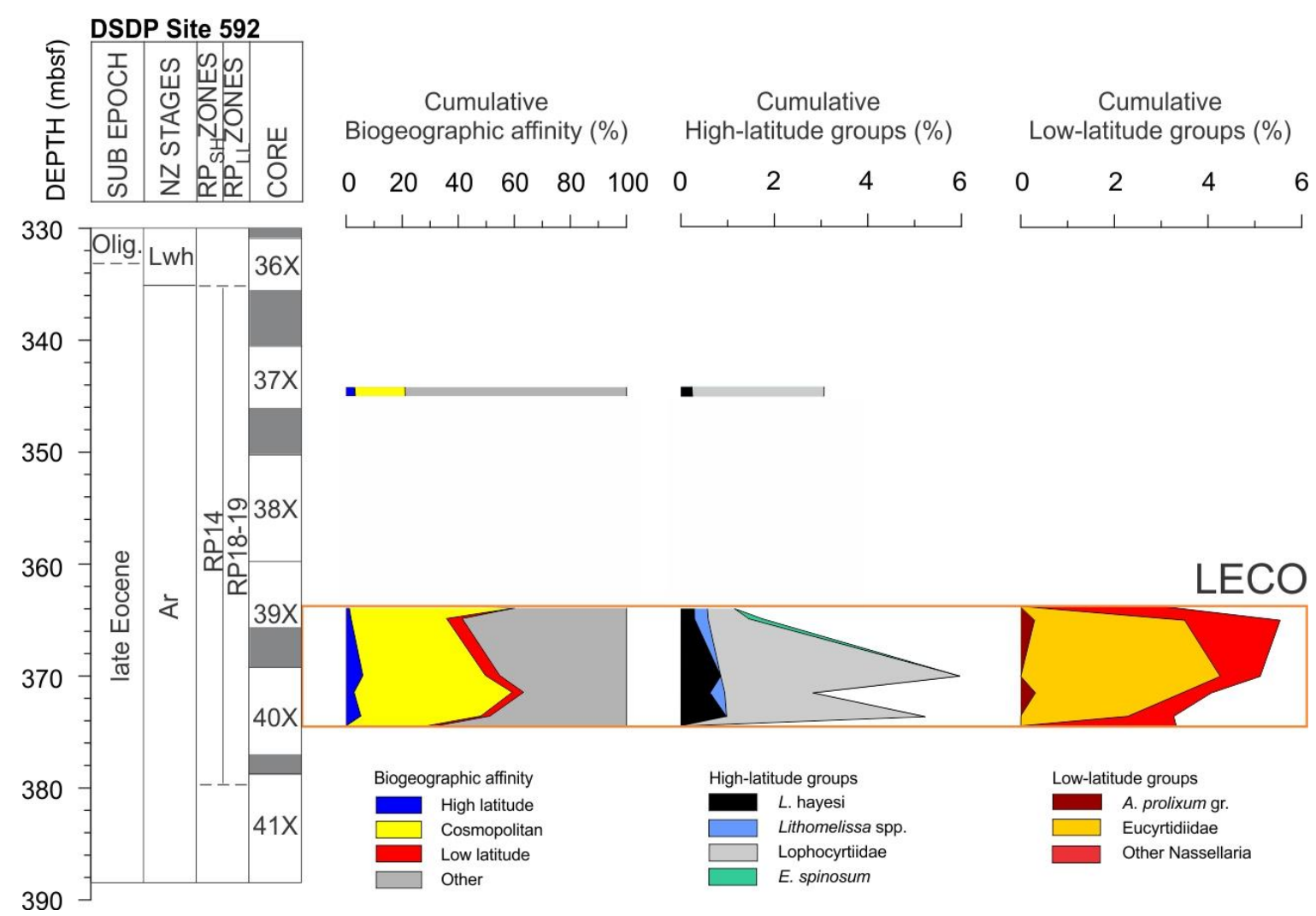

Figure 6.36 Cumulative biogeographic affinity assignment for DSDP Site 592, showing all groups (left); high-latitude groups (middle) and low-latitude groups (right). LECO=late Eocene climatic optimum.

\subsubsection{ODP Site 1123}

ODP Site 1123 contains more abundant high-latitude than low-latitude taxa in the late Eocene to early Oligocene (Figure 6.37) with high-latitude taxa increasing in abundance between 625.86 and $610.10 \mathrm{mbsf}(\sim 3$ to $23 \%$ ), and decreasing throughout the lower Oligocene to $\sim 6-15 \% \quad(599.74-590.90 \mathrm{mbsf})$. The main high-latitude taxa are lophocyrtids (Aphetocyrtis gnomabax, A. rossi, Lophocyrtis aspera Form A, L. jacchia hapsis and L. longiventer) which make up $\sim 1.3-6.6 \%$ of the assemblage, Eucyrtidiidae (Aspis sp. A, Eucyrtidium antiquum, E. mariae, E. spinosum and Eurystomoskevos petrushevskaae; 0-7.3\% of the assemblage), and other nassellarians (Amphicentria sp. A, Ceratocyrtis spp., Pseudodictyophimus gracilipes gr., Artostrobus cf. pretabulatus, Dictyophimus? archipilium and Lamprocyclas particollis; 0-6\% of the assemblage) (Figure 6.37). Larcopyle spp. (L. hayesi, L. labyrinthusa, L. polyacantha) and Lithomelissa spp. (L. ehrenbergi, L. gelasinus, L. sphaerocephalis) are only small components of the high-latitude group comprising $\sim 0-2.3 \%$ and $\sim 0-4.2 \%$ of the high- 
latitude assemblage, respectively. Other high-latitude spumellarians (Axoprunum bispiculum, A.? irregularis, Sphaeropyle tetrapila and Spongopyle osculosa) are also a minor component $(\sim 0-2.3 \%)$.

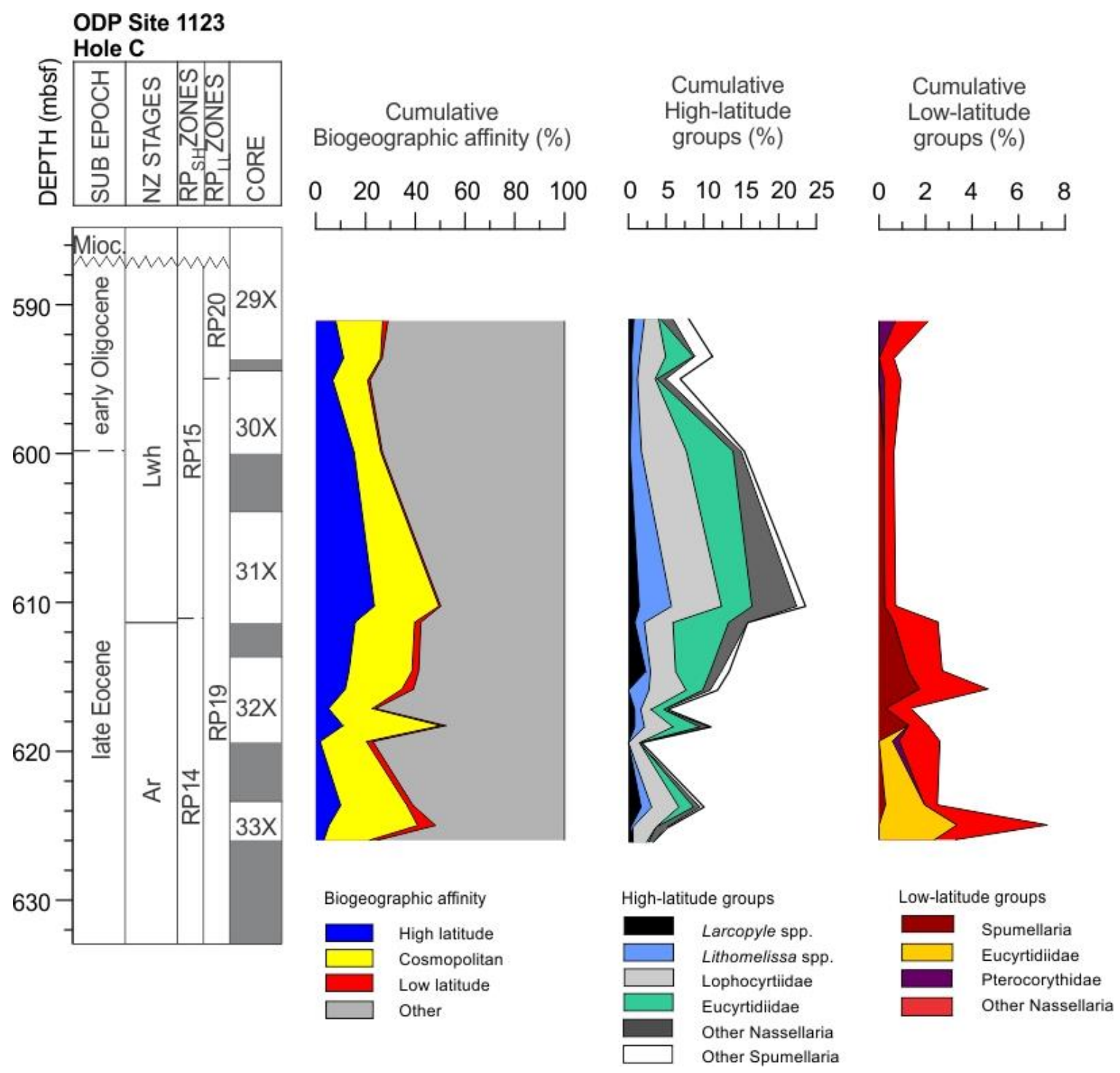

Figure 6.37 Cumulative biogeographic affinity assignment for ODP Site 1123 Hole C, showing all groups (left); highlatitude groups (middle) and low-latitude groups (right).

Low-latitude taxa are more abundant in the late Eocene until 610.10 mbsf, ranging between $\sim 1.3-7 \%$ with a maximum at 624.86 mbsf (Figure 6.37). From 610.10 to 590.90 mbsf, the abundance varies between $\sim 0.6-2 \%$ in the early Oligocene. Low-latitude Nassellaria comprise $0.4-3.9 \%$ and include Theocampe mongolfieri, T. pirum and Tristylospyris triceros. Low-latitude Eucyrtidiidae (Thyrsocyrtis cf. norrisi and $T$. pinguisicoides) are only present in the late Eocene with an abundance of $0.58-3.3 \%$. Low-latitude spumellarians $(0-1.7 \%)$ are represented dominantly by Amphicraspedum 
prolixum gr. and a trace amount of Lithocyclia sp. Pterocorythids (Cryptocarpium azyx and Theocyrtis tuberosa) are very rare (0.2-0.7\%). Cosmopolitan taxa are present with abundances ranging between $\sim 18-40 \%$ (Figure 6.37).

\subsection{Comparison between sites}

As outlined in the summary of Chapter 4, radiolarian abundance is strongly correlated to preservation. In this context, radiolarian diversity is also linked to preservation and abundance. In total, radiolarians were categorized into 259 counting groups. Of those, 213 taxa were assigned to species or subspecies level (Appendix A). Twenty-nine are undifferentiated genera, 17 are undifferentiated families, or undifferentiated Spumellaria or Nassellaria.

In the early Eocene, radiolarians are poorly preserved at Site 277 and radiolarian abundance (Figure 4.1) and taxic richness (Figure 6.38) are very low, respectively. During the middle Eocene, preservation is moderate and taxic richness is low. Only during the MECO (middle Eocene climatic optimum, 40 Ma), taxic richness is moderate to high (Figure 6.38). At Site 1172, the radiolarian record is well preserved and diverse in the middle Eocene ( 43-38 Ma) (Figures 6.14 and 6.38). At Site 283, a latest middle Eocene record $(\sim 38 \mathrm{Ma})$ is present with a high diversity, but taxic richness is slightly higher at this site in the late Eocene ( 38-37 Ma) (Figure 6.38). Site 277 has the highest taxic richness in the late Eocene ( $37-34 \mathrm{Ma})$, but during the LECO (late Eocene climatic optimum, $\sim 36 \mathrm{Ma}$ ), diversity decreases (Figure 6.38). The late Eocene assemblages of Site 281 ( 38-36.5 Ma) and Site 1172 ( 38-36 Ma, Figure 6.38) exhibit lower taxic richness compared to Site 277. In the early Oligocene of Site 277 ( 33-32 Ma), taxic richness decreases steadily (Figure 6.38). The Oligocene assemblages of sites 280 $(\sim 33.9-32.5 \mathrm{Ma})$ and $1172(\sim 28-26.6 \mathrm{Ma})$ are more diverse compared to Site 277, but they also show a decreases in diversity throughout the Oligocene (Figure 6.38).

At mid-latitude Site 207, radiolarians are poorly preserved in the older part of the early Eocene ( 56-49 Ma, Figure 6.17) and taxic richness is very low (Figure 6.38), similar to Site 277. In contrast to Site 277, the late early to middle Eocene record ( 49-42 Ma) of Site 207 and the middle Eocene record of Site 206 ( 42-40.6 Ma) comprise very diverse radiolarian assemblages (Figure 6.38). The late Eocene assemblage at Site 592 is only diverse during the LECO ( $36 \mathrm{Ma}$, Figure 6.38). Site 1123 contains a well preserved and 
diverse assemblage in the latest Eocene ( 35-34 Ma) and a slightly less diverse one in the earliest Oligocene ( $33 \mathrm{Ma}$, Figure 6.38).

As expected, high-latitude taxa are more abundant at high-latitude sites than at midlatitude sites (Figure 6.39 and Table 6.1). The highest amount of this group (dominated by Axoprunum? irregularis) is present at Site 277 in the early Oligocene ( 32 Ma, Figure 5.29). A constant abundance of high-latitude taxa is only present at sites 280, 281 and 283 during the late Eocene and early Oligocene (Figure 6.39). The southernmost sites 280 and 281 are also the only sites where high-latitude taxa are more abundant than cosmopolitan ones (Table 6.1). At sites 277 and 1172, high-latitude taxa increase from the middle Eocene towards the late Eocene and early Oligocene (Figure 6.39 and Table 6.1).

Table 6.1 Overview of relative abundance (\%) of the high-latitude (HL), cosmopolitan and low-latitude (LL) groups, averaged over specific time slices at high-latitude sites 280, 281, 1172, 283 and 277. Additionally, as shown in the graphs for each site in Chapter 6.2.1, the high- and low-latitude groups are separated into 6 and 5 subgroups, respectively. $\mathrm{EECO}=$ early Eocene climatic optimum; $\mathrm{MECO}=$ middle Eocene climatic optimum; PrOM=Priabonian oxygen isotope maximum; LECO=late Eocene climatic optimum.

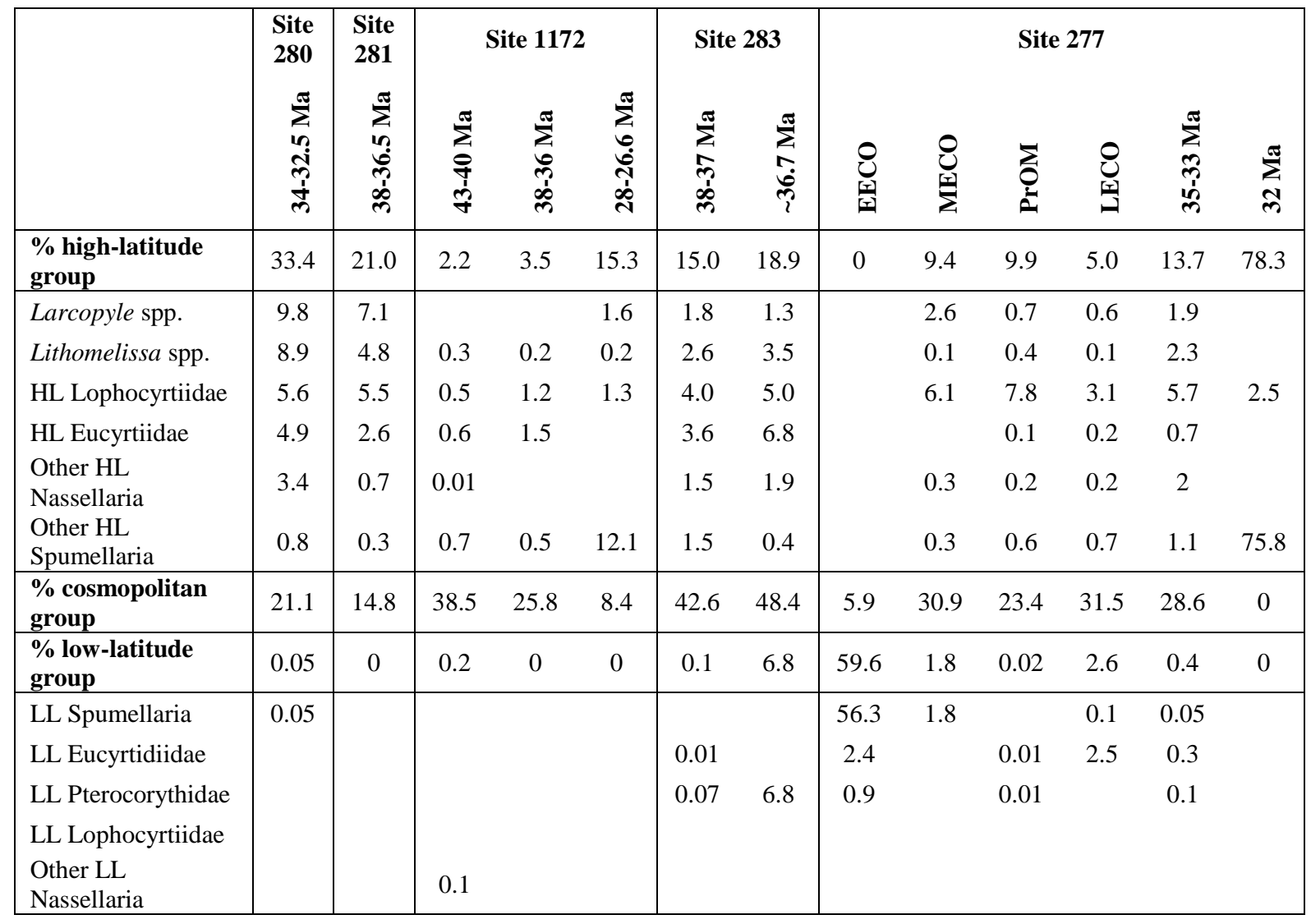




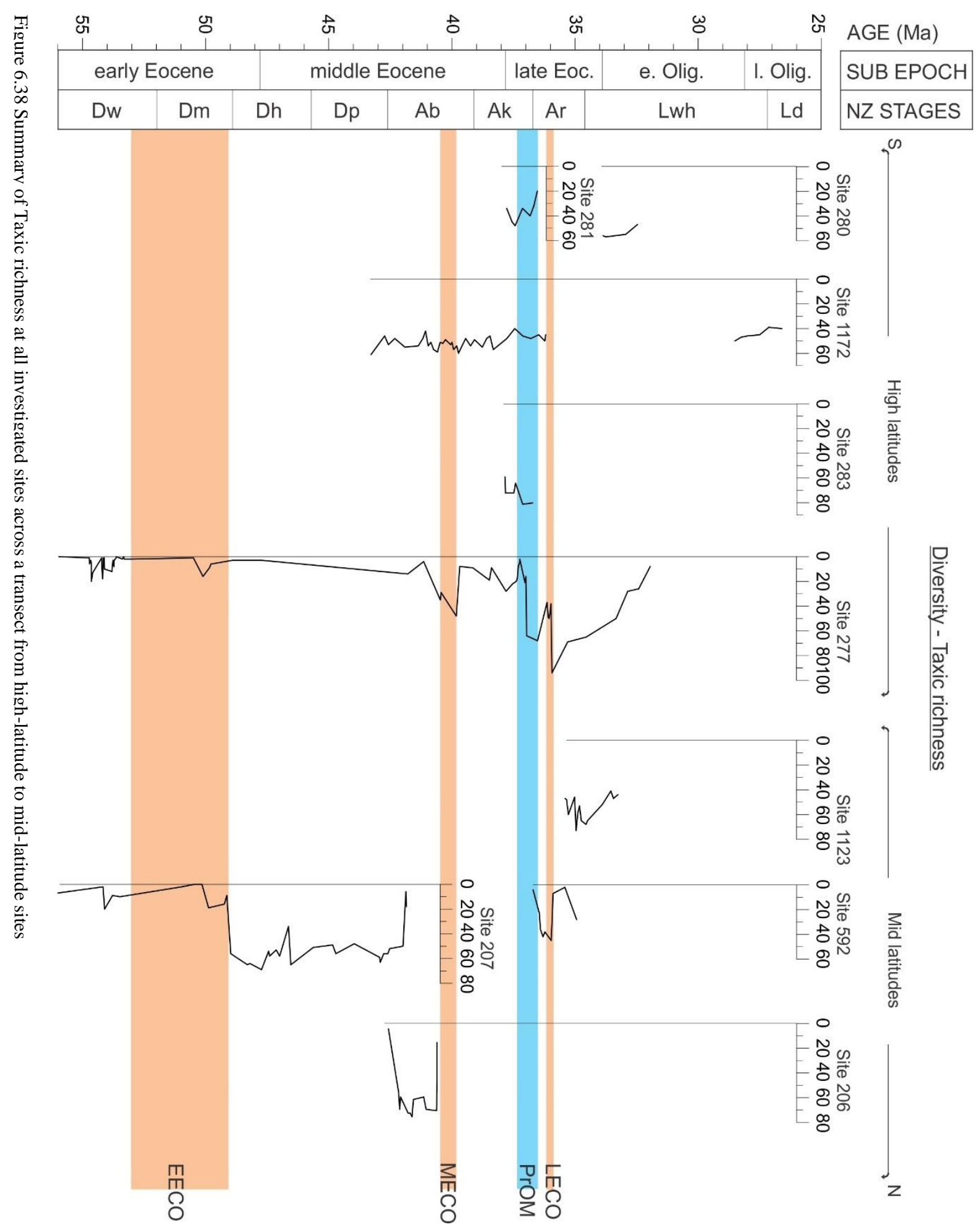




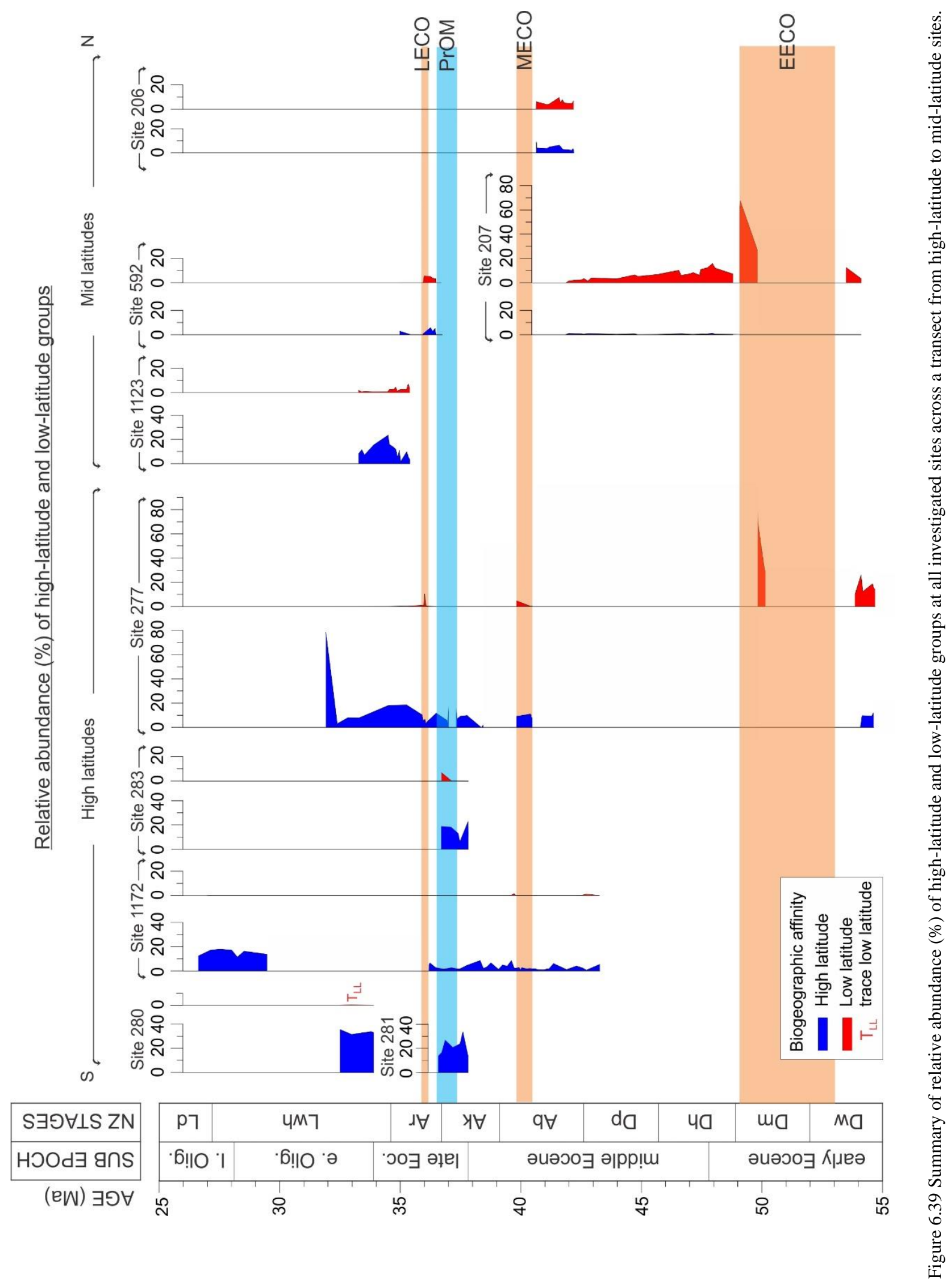


Low-latitude taxa are present at Site 277 during the EECO, MECO (dominated by Amphicraspedum spp.) and the LECO (mainly Thyrsocyrtis pinguisicoides) (Table 6.1 and Figure 6.39). In the remaining late Eocene and earliest Oligocene, low-latitude taxa are only very rare. Low-latitude taxa are absent at Site 281 and only very rare at Site 280 (Figure 6.39). At Site 283, the low-latitude species Theocyrtis tuberosa is common at 36.7 Ma. At Site 1172, low-latitude species Theocampe mongolfieri has sporadic very rare occurrences in the middle Eocene.

High-latitude species are less abundant at mid-latitude sites (Table 6.2 and Figure 6.39). They are very rare at Site 207 during the late early to middle Eocene. Few high-latitude taxa are present in the late middle Eocene at Site 206 and during the LECO at Site 592 (Table 6.2 and Figure 6.39). High-latitude species are more abundant than low-latitude species at Site 1123 during the late Eocene to early Oligocene (Table 6.2 and Figure 6.39). Low-latitude species (dominated by Amphicraspedum spp.) are abundant in the EECO at Site 207, and common in the remaining early to middle Eocene at that site (Table 6.2 and Figure 6.39). Low-latitude species are slightly more abundant than highlatitude species at sites 206 and 592 during the late middle Eocene and the LECO, respectively. They are absent at Site 592 in the latest Eocene ( 35 Ma, Table 6.2 and Figure 6.39). 
Table 6.2 Overview of relative abundance (\%) of the high-latitude (HL), cosmopolitan and low-latitude (LL) groups, averaged over specific time slices at mid-latitude sites 1123, 592, 207 and 206. Additionally, as shown in the graphs for each site in Chapter 6.2.2, the high- and low-latitude groups are separated into 6 and 5 subgroups, respectively. $\mathrm{EECO}=$ early Eocene climatic optimum; LECO=late Eocene climatic optimum.

\begin{tabular}{|c|c|c|c|c|c|c|c|}
\hline & \multicolumn{2}{|c|}{ Site 1123} & \multicolumn{2}{|c|}{ Site 207} & \multicolumn{2}{|c|}{ Site 592} & \multirow{2}{*}{$\begin{array}{c}\text { Site } 206 \\
42-40.6 \mathrm{Ma}\end{array}$} \\
\hline & 35-34 Ma & $\sim 33 \mathrm{Ma}$ & EECO & 49-42 Ma & LECO & $35 \mathrm{Ma}$ & \\
\hline $\begin{array}{l}\text { \% high-latitude } \\
\text { group }\end{array}$ & 10.6 & 8.7 & 0 & 0.7 & 3.15 & 3.1 & 4.5 \\
\hline Larcopyle spp. & 0.8 & 0.5 & & 0.1 & 0.55 & 0.2 & 1.2 \\
\hline Lithomelissa spp. & 1.3 & 1.1 & & 0.1 & 0.1 & & 0.2 \\
\hline HL Lophocyrtiidae & 3.6 & 2.6 & & 0.2 & 2.4 & 2.8 & 1.9 \\
\hline HL Eucyrtiidae & 2.9 & 1.4 & & 0.01 & 0.06 & & 1.1 \\
\hline Other HL Nassellaria & 1.5 & 1.0 & & 0.3 & & & 0.08 \\
\hline Other HL Spumellaria & 0.5 & 2.1 & & & & & 0.08 \\
\hline $\begin{array}{l}\text { \% cosmopolitan } \\
\text { group }\end{array}$ & 24.0 & 15.9 & 9.4 & 30.9 & 41.2 & 17.9 & 36.4 \\
\hline $\begin{array}{l}\text { \% low-latitude } \\
\text { group }\end{array}$ & 2.8 & 1.2 & 47.1 & 6.75 & 4.3 & 0 & 5.1 \\
\hline LL Spumellaria & 0.5 & & 45.15 & 3.3 & 0.1 & & 2.0 \\
\hline LL Eucyrtidiidae & 0.7 & & 0.8 & 1.0 & 2.6 & & 0.7 \\
\hline LL Pterocorythidae & 0.03 & 0.3 & 1.15 & 0.6 & 1.6 & & \\
\hline LL Lophocyrtiidae & & & & 0.08 & & & \\
\hline Other LL Nassellaria & 1.5 & 0.9 & & 1.7 & & & 2.2 \\
\hline
\end{tabular}




\section{Discussion}

\subsection{Biostratigraphy, age control and correlation between sites}

\subsubsection{Correlation of sites and application of radiolarian zonations}

High-latitude DSDP sites 277, 280, 281 and 283 and ODP Site 1172 have been correlated using the southern high-latitude radiolarian zonation. The low-latitude zonation of Kamikuri et al. (2012a) could not be used at any of these sites (see Chapter 5.1). Even for DSDP sites 206 and 207, which are the most northerly sites studied, low-latitude marker species are absent or too rare and sporadic in occurrence to be useful for biostratigraphy (see Chapter 5.2).

Due to a condensed upper Eocene section and the absence or scarcity of marker species at DSDP Site 592, it was not possible to correlate assemblages with confidence to either the low-latitude or the high-latitude zonation. Tentative assignment to RP14 $4_{\mathrm{SH}}$ and RP1819 $\mathrm{LL}_{\mathrm{L}}$ is based on nannofossil and foraminifer stratigraphy. In contrast, stratigraphic markers present at ODP Site 1123 allow correlation to both low- and high-latitude zones (RP14-15 $\mathrm{SH}, \mathrm{RP} 19_{\mathrm{LL}}$ to RP20 $\mathrm{LL}$ ).

\subsubsection{Evaluation of radiolarian zonation}

This study has refined knowledge of the age ranges of radiolarian species in the Southwest Pacific, which allows improvements to be made to the existing radiolarian zonation (Figures 3.11, 5.9). The merits of specific datums are discussed below and new datums are proposed. Diachrony between sites and intervals with poor radiolarian recovery were the main issues and often caused large age uncertainties (Figure 7.1).

The identification of the bases of zones $\mathrm{RP} 6_{\mathrm{SH}}$ to $\mathrm{RP} 9_{\mathrm{SH}}$ was difficult in this study because radiolarian abundance was very low and preservation was poor in sections studied. Furthermore, marker species were very rare and sporadic in occurrence.

Zone RP6sh and RP7sh. The respective datums for the bases of these zones (LOs of Buryella pentadica and Phormocyrtis striata exquisita) are not present in the Paleocene interval studied at DSDP sites 277 and 207. 
Zone RP8sh. The base of this zone coincides with the P-E boundary ( $56 \mathrm{Ma})$. The datum for the base of the zone (LO of Podocyrtis papalis) is recorded at Site 277, but is delayed at this site ( 54.2 Ma) and Site 207 ( 49.9 Ma) because lower Eocene assemblages are sparse or very poorly preserved at both sites. The only other species that has an LO at the base of RP8 $8_{\mathrm{SH}}$ at these sites is Amphicraspedum prolixum s.s.; this event is at the same level as the LO of P. papalis at both sites (Figure 7.1).

Zone RP9 ${ }_{\mathrm{SH}}$. The marker for the base of RP9 ${ }_{\mathrm{SH}}(\sim 54 \mathrm{Ma})$, the HO of Lychnocanium auxillum, is only identified at Site $277(\sim 53.8 \mathrm{Ma})$, but the age uncertainty is large due to a hiatus from 53.3-50.5 Ma (Figure 7.1). At Site 207, the LOs of L. bellum and Theocampe urceolus are used as secondary datums for the base and middle of this zone. Other marker species that are used to define the base of the zone at Mead Stream (Hollis et al. 2005) are not present at Site 207. The HO of Buryella tetradica is used to approximate the top of RP9 $9_{\mathrm{SH}}$ at Site 207, but cannot be used at Site 277 because the HO is below a hiatus.

Zone RP10sh. The marker for the base of RP10 ${ }_{\mathrm{SH}}(\sim 49.7 \mathrm{Ma}, 47.98 \mathrm{Ma}$ in low latitudes), the LO of Theocampe mongolfieri, is absent from Site 277 and the species is restricted to an isolated occurrence $(\sim 47.4 \mathrm{Ma})$ at Site 207 . The secondary marker for the base of this zone, the HO of Podocyrtis aphorma, occurs at Site 207 at 47.7 Ma. T. mongolfieri is very rare in the studied sections and hard to identify when not well preserved. P. aphorma is predominantly a low-latitude species with a restricted range in higher latitudes, so not a suitable marker here. In contrast, Artobotrys auriculaleporis is common at sites 277 and 207 and easy to identify. It occurs at $\sim 50.1 \mathrm{Ma}$ at Site 277 and at $\sim 49 \mathrm{Ma}$ at Site 207, but earlier, in mid-RP9 ${ }_{\mathrm{SH}}(\sim 52.5 \mathrm{Ma})$, at Mead Stream (C. Hollis, pers. comm. 2016) (Figure 7.1). This species may be a useful mid-RP9 $9_{\mathrm{SH}}$ datum, but poor sediment recovery, very sparse radiolarians in underlying samples at sites 277 and 207 and a hiatus at Site 277 ( 53.3-50.5 Ma), makes it impossible to constrain the age of the datum (Figure 7.1). The $\mathrm{HO}$ of Amphicraspedum prolixum s.s. and Phormocyrtis striata striata are in lower RP10 ${ }_{\mathrm{SH}}(\sim 48.8 \mathrm{Ma})$ at Mead Stream. The $\mathrm{HO}$ of A. prolixum s.s is earlier at Site 277 $(\sim 49.8 \mathrm{Ma})$ and later at $\sim 45.6 \mathrm{Ma}$ at Site 207 (Figure 7.1). As this is a low-latitude species, it might have disappeared at high-latitude sites earlier than at mid-latitude sites. However, its $\mathrm{HO}$ at Site 277 might be also biased by the presence of a hiatus from $\sim 47.7$ to $42.6 \mathrm{Ma}$ and very poor preservation in the interval spanning $\sim 2 \mathrm{Ma}$ before the hiatus. 
The $\mathrm{HO}$ of $P$. striata striata is at $\sim 48.9 \mathrm{Ma}$ at Site 277 and at the top of RP11 $\mathrm{SH}$ at Site 207 ( $42.8 \mathrm{Ma})$. At Site 206 its $\mathrm{HO}$ is at $\sim 40.6 \mathrm{Ma}$, close to its $\mathrm{HO}$ in low latitudes ( 40.65 Ma) (Figure 7.1). As this is also interpreted to be a warm water species, it is likely it disappeared earlier at high latitudes.

Zone RP11sh. The marker of the base of RP11 $1_{\mathrm{SH}}(\sim 45.2 \mathrm{Ma})$, the LO of Eusyringium lagena, is used at Site 207, the only site where RP11 $1_{\text {SH }}$ was identified. Sites 207 and 1172 are the only sites where Porangan sediments were recovered, but E. lagena was absent from Site 1172. It is a useful datum that appears to have a delayed LO in the Southwest Pacific (Mead Stream, $45.2 \mathrm{Ma}$; Site 207, 44 Ma) compared to low latitudes ( 46.2 Ma) (Figure 7.1). The LOs of Artobotrys titanothericeraos, Dictyophimus craticula and possibly Podocyrtis? pupa are at the base of RP11 $1_{\mathrm{SH}}$ at this site.

Zone RP12sh. The marker for the base of RP12 ${ }_{\mathrm{SH}}$, the LO of Eusyringium fistuligerum, has also a diachronous LO between low ( 44.46 Ma) and mid-latitudes (Mead Stream, 42.6 Ma). At sites 207 and 206, the younger age is in good agreement with the age model (Figure 7.1). At high-latitude sites 277 and 1172, the species has a later first appearance ( 40.4 Ma and 40.1 Ma, respectively). However, this species has a sporadic distribution at these sites, being restricted to two samples at Site 277 and one sample at Site 1172. Nevertheless, a pattern similar to E. lagena is observed with a later LO in higher latitudes (Figure 7.1). Lophocyrtis longiventer appears to be a better marker species with its LO consistently at the base of RP12 ${ }_{\text {SH }}$ at Site 277 and Mead Stream, while also present at mid-latitude sites 206 and 207 (Figure 7.1). Its LO is at $\sim 42.8 \mathrm{Ma}$ at Mead Stream (C. Hollis, pers. comm. 2016) and at $41.8 \mathrm{Ma}$ at Site 277. The LO at the latter site is likely due to very sparse radiolarian occurrence and a hiatus from 47.73-42.6 Ma. Although the species is recorded earlier at Site 1172 (Suzuki et al., 2009), it is possible that these earlier records are in fact L. dumitricai, a very similar species. In low latitudes, the $\mathrm{HO}$ of E. lagena is at $\sim 42.6 \mathrm{Ma}$ (mid-RP14 $4_{\mathrm{LL}}$ ), at sites 206 and 207 it is at $\sim 41.8 \mathrm{Ma}$ and $\sim 42 \mathrm{Ma}$, respectively, which is a good match (Figure 7.1). At Site 207 the $\mathrm{HO}$ of this species is directly below an interval of low radiolarian abundance prior to the Marshall Unconformity. The low-latitude age estimate for the HO of Zealithapium anoectum ( 42.5 Ma) is in agreement with the timing of the event at mid-latitude Site 207 $(\sim 42.6 \mathrm{Ma})$, but it is not a useful marker species as it only had a patchy occurrence at this site. The LO of Eucyrtidium nishimurae is at $\sim 41.3 \mathrm{Ma}$ (mid-RP12 $2_{\mathrm{SH}}$ ) at Site 1172 and 
slightly earlier at $\sim 41.8 \mathrm{Ma}$ at Site 206 (Figure 7.1). This species is absent from Site 277, but this might be due to a scarcity of radiolarians and poor preservation through the interval corresponding to the range of this species. The LO of Cryptocarpium ornatum at Site $206(\sim 41.2 \mathrm{Ma})$ is close to its low-latitude LO at $\sim 41.3 \mathrm{Ma}$. At Site 277 it appears later at $\sim 39.8 \mathrm{Ma}$, because radiolarians are rare and poorly preserved in this interval. The species does not occur at Site 1172. The HO of Artobotrys biaurita ( 40.5 Ma) is not a useful datum in this study. It has a $\mathrm{HO}$ at $40.7 \mathrm{Ma}$ at Site 206, which immediately precedes the Marshall Unconformity, and at $\sim 42 \mathrm{Ma}$ at Site 207 where it is directly below an interval of low radiolarian abundance prior to the Marshall Unconformity. It ranges slightly longer at Site 1172 ( 40.1 Ma) (Figure 7.1), but it is the only high-latitude site where it is documented. It has an isolated occurrence at Site 592 (late Eocene), which might be due to reworking, and at Site 1123. Reworking of several species has been documented for the latter site in this study as well as by the Shipboard Scientific Party (1999).

Zone RP13 ${ }_{\text {SH. The marker of the base of RP13 }}$ SH, the LO of Zealithapium mitra, is used to define the zone at sites 206, 207 and 277. The species is absent from Site 1172. However, the event is diachronous between low ( 42.3 Ma) and mid-latitudes $(\sim 39.2$ Ma). At Site 206, it is dated to $\sim 41.6 \mathrm{Ma}$. The species has an isolated occurrence at $\sim 42.8$ Ma at Site 207 (Figure 7.1). This interval is truncated by the Marshall Unconformity at sites 206 and 207. The LO is later at Site 277 ( 40.4 Ma), which is similar to the LO at Mead Stream ( 39.2 Ma). Sediments at Site 277 contain only rare radiolarians within this zone.

Zone RP14sh. The marker for the base of RP14 ${ }_{S H}$, the LO of Eucyrtidium spinosum, is present at sites 277, 281, 283, 1172, and 1123. The species only has an isolated occurrence at Site 592 and therefore the high-latitude zonation cannot be applied at this site. At Site 1123 , the LO of E. spinosum is at $\sim 35.3 \mathrm{Ma}$ and thus substantially later than at other sites, which may reflect the influence of a warmer water mass at this site (see below). The $\mathrm{HO}$ of E. nishimurae is a mid-RP14 $4_{\mathrm{SH}}$ event $(\sim 36.7 \mathrm{Ma})$, which is in general agreement with Site $1172(\sim 36.2 \mathrm{Ma})$. However, the species is absent from Site 277. The event is used for developing the age-models for sites 281 and 283. Another event within $\mathrm{RP} 14_{\mathrm{SH}}$, the HO of Lychnocanium amphitrite, is known to be diachronous between low and high latitudes. It is dated at $\sim 35.9 \mathrm{Ma}$ at Site 277 as well as Site 592. It disappears 
earlier ( $36.8 \mathrm{Ma})$ at Site 1172 (Figure 7.1). The estimated age of the event at Site 1123 is equivalent to the low-latitude age ( $33.9 \mathrm{Ma})$ (Figure 7.1$)$. This supports the idea that Site 1123 was influenced by low-latitude currents. It is notable that this species is very abundant in the LECO at sites 277 and 592, which is consistent with a warm-water affinity. In general, it is far less common at high-latitude sites 283 and 1172. It is a similar case for the $\mathrm{HO}$ of Cryptocarpium ornatum, which is earlier at high-latitude sites $(\sim 35.9$ Ma at Site 277; $\sim 36 \mathrm{Ma}$ at Site 592; absent at Site 1172) than at low-latitude sites ( 33.9 Ma) (Figure 7.1). This event is dated at 33.9 Ma at Site 1123 and is used together with the $\mathrm{HO}$ of Theocampe mongolfieri and L. amphitrite to define the top of RP19 $\mathrm{LL}_{\mathrm{L}}$ at this site (Figure 7.1). The only reliable occurrence of Spongatractus pachystylus is at Site 206, where its $\mathrm{HO}$ is at $\sim 41.6 \mathrm{Ma}$, considerably earlier than in low latitudes (37.75 Ma) (Figure 7.1). The $\mathrm{HO}$ of L. bellum ( $35.4 \mathrm{Ma}$ in low latitudes) is at $\sim 35.9 \mathrm{Ma}$ at Site 277 at the same time as the $\mathrm{HO}$ of $L$. amphitrite. L. bellum has an isolated occurrence at $\sim 35 \mathrm{Ma}$ at Site 592 after the HO of L. amphitrite and at $\sim 34.7 \mathrm{Ma}$ at Site 1123 before the HO of $L$. amphitrite. $\mathrm{HO}$ of L. bellum is at $\sim 36.2 \mathrm{Ma}$ at Site 1172 after the $\mathrm{HO}$ of L. amphitrite (Figure 7.1) directly below an interval of condensed sedimentation. The LO of L. bellum is a relatively reliable datum across all latitudes. The crossover of $L$. amphitrite and $L$. bellum might be due to misidentification.

Zone RP15sh. The marker for the base of RP15 ${ }_{\mathrm{SH}}$, the LO of Eucyrtidium antiquum, is used at sites 277, 280 and 1123. It is present at Site 1172 with an isolated occurrence at $\sim 36.5 \mathrm{Ma}$, which may be due to downworking. The LO is earlier at sites 277 ( $\sim 34.5 \mathrm{Ma}$ ) and 1123 ( $\sim 34.6 \mathrm{Ma}$ ), close to the Runangan-Whaingaroan boundary (Figure 7.1). This is very similar to the age estimate for the South Atlantic (33.9 Ma; Funakawa and Nishi, 2005). A secondary datum, the LO of Axoprunum? irregularis proves to be unreliable at the investigated sites. It is only applicable at Site 1123, where it occurs at $\sim 33.5 \mathrm{Ma}$. At Site 277 , the LO is later at $\sim 32.4 \mathrm{Ma}$ and this species is absent in the early Oligocene of Site 280. The equivalent zone to RP15 $5_{\mathrm{SH}}$ in low latitudes is RP20 $\mathrm{LL}$. The LO of Theocyrtis tuberosa occurs in lower RP20 $\mathrm{LL}(\sim 32.8 \mathrm{Ma})$, but it is found earlier at Site $1123(\sim 33.5$ Ma). The concentration of events at Site 1123 at the top of the interval might be due to the overlying Marshall Unconformity at $\sim 33$ Ma (Figure 7.1). T. tuberosa is very rare in the late Eocene and early Oligocene at Site 277 ( 37 to $32.4 \mathrm{Ma}$ ) and is common in the late Eocene at Site 283 ( 37.5 to $36.70 \mathrm{Ma}$ ). This species is known to have had isolated 
Chapter 7: Discussion

occurrences in the southern Atlantic and southern Indian oceans in the late Eocene (Takemura 1992; Takemura and Ling 1997).

Except for a short section of Zone RP17sh at Site 1172, none of zones RP16sh to Zone RP18sh were recovered at the studied sites. 


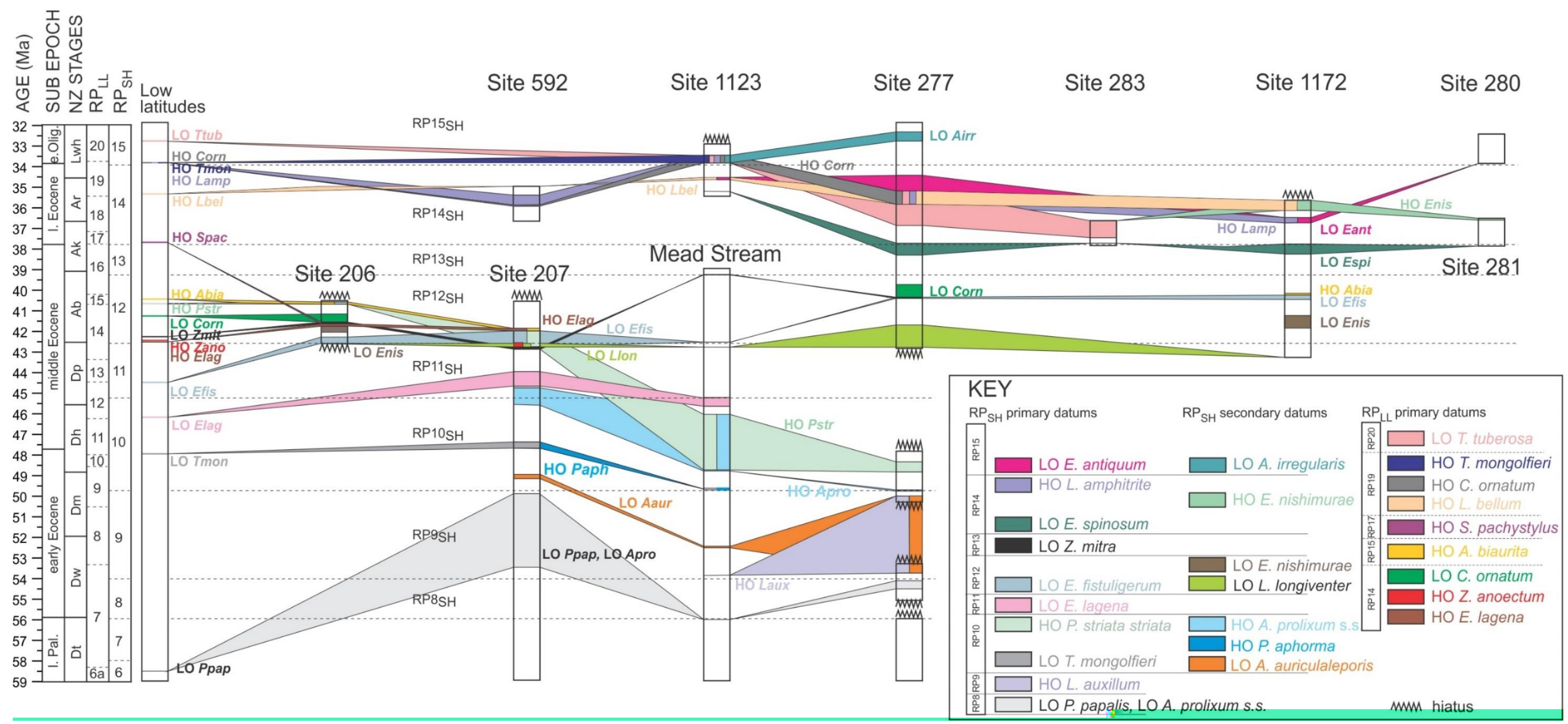

Figure 7.1 Fence diagram in time domain showing the correlation of radiolarian datums between investigated DSDP and ODP sites, Mead Stream and ages of datums in low latitudes. Low-latitude radiolarian zonation (RPLL) and Southern Hemisphere radiolarian zonation RPsH) on the left. Key: radiolarian events used for correlation as described in Chapter 3.6. 


\subsection{General features of radiolarian assemblages and siliceous sediments}

The nature of radiolarian occurrence and preservation varies greatly between the different sites from mid to high latitudes. In Chapter 4, it was shown that radiolarian preservation is linked to radiolarian abundance. However, several other questions linking the occurrence/preservation of radiolarians to the nature of the sediment at different sites and latitudes will be discussed in this section.

\subsubsection{Where and when are siliceous sediments frequent and is there a difference between middle and high latitudes?}

In addition to the sites studied in this thesis, the age-depth plots and radiolarian abundances of Mead Stream (Hollis et al., 2005), ODP Leg 113 Site 689 (South Atlantic, pers. comm. S. Bohaty, 2014) and IODP Leg 320 Site U1331 (Expedition 320/321 Scientists, 2010) (Figure 7.2) are used for comparison. In Figure 7.3, all sites and their age-depth plots and resulting sedimentation rates are plotted and arranged according to their paleolatitude at $40 \mathrm{Ma}$, with radiolarian abundance, diatom and chert presence also shown.

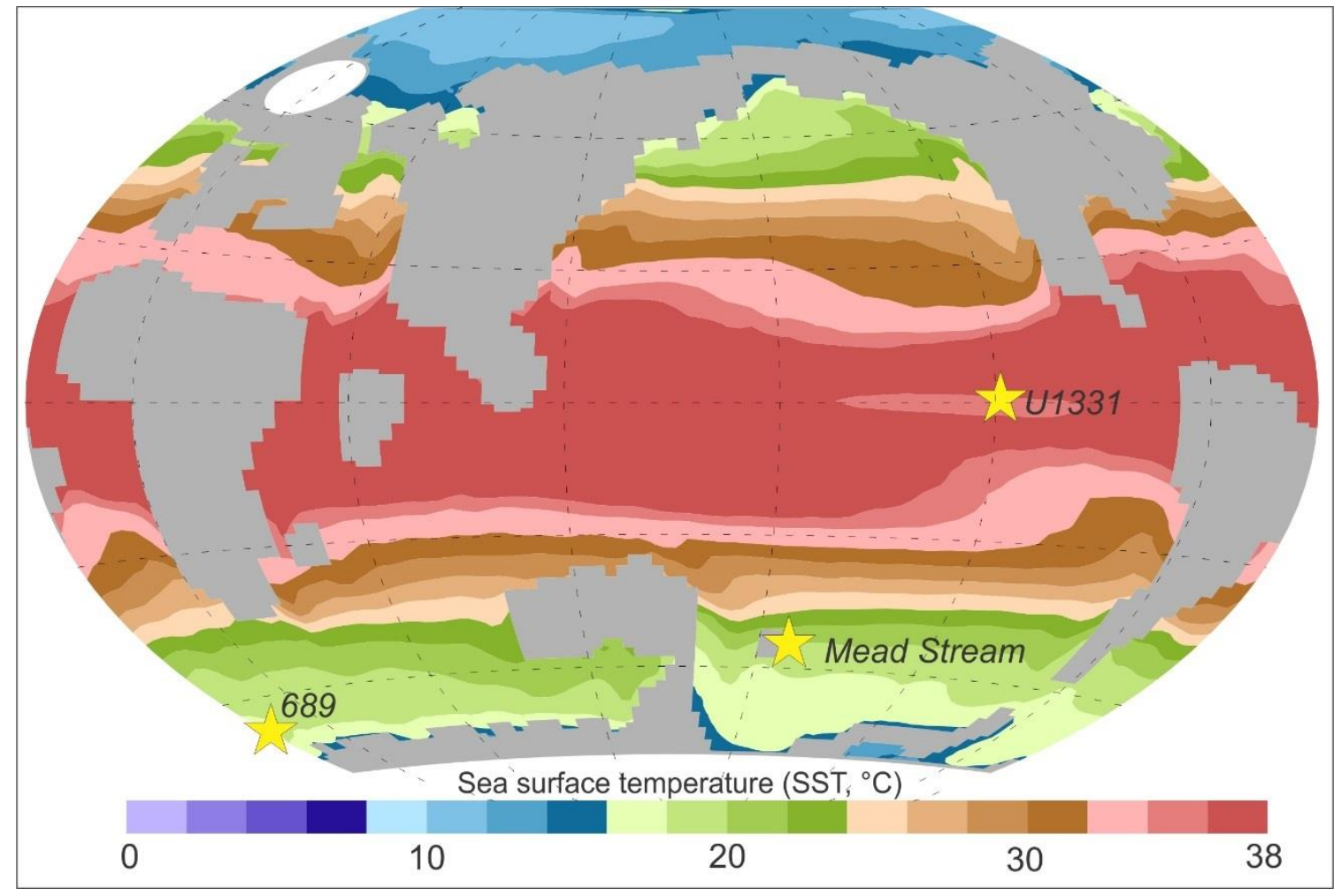

Figure 7.2 Paleoceanographic reconstruction superimposed on modelled SSTs for the early Eocene (4480 $\mathrm{ppm} \mathrm{CO}_{2-}$ equivalent) (Huber and Caballero, 2011) showing the location of three reference sites: ODP Leg 113 Site 689, Mead Stream and IODP Leg 320/321 Site U1331; (C. Hollis, pers. comm. 2016). 
Four groups based on radiolarian abundance and D/R ratio can be distinguished. Group 1 has common to high radiolarian abundance from the middle Eocene to the early Oligocene at high-latitude sites 1172, 689, 280 and 281. Diatoms are more abundant than radiolarians through this interval at all four locations. Group 2 is also characterized by high radiolarian abundance from late Eocene to early Oligocene, but diatoms are only a small component of the siliceous assemblage. Only two samples, one at Site 283 and one at Site 1123 have a $D / R$ ratio of $>1$. In the previous section (Chapter 7.1), Site 1123 is inferred to have been influenced by a warm water mass as indicated by the occurrence low-latitude species. However, here this site is grouped with two high-latitude sites. Therefore, it seems that Site 1123 was in a transitional zone during the late Eocene and Oligocene, influences by both a low-latitude water mass from the north and cooler water mass from the south. The short radiolarian-rich, diatom-poor interval of Site 592 is also included in Group 2.

The high siliceous content of Groups 1 and 2 is in agreement to other studies, that showed biosiliceous sedimentation began to be widespread at or near the base of the late Eocene in the Southern Ocean (Lazarus and Caulet, 1993; Lazarus et al., 2008). The dominance of diatoms at Site 1172 in the middle Eocene (Shipboard Scientific Party, 2001) may be related to local upwelling in this coastal setting. 


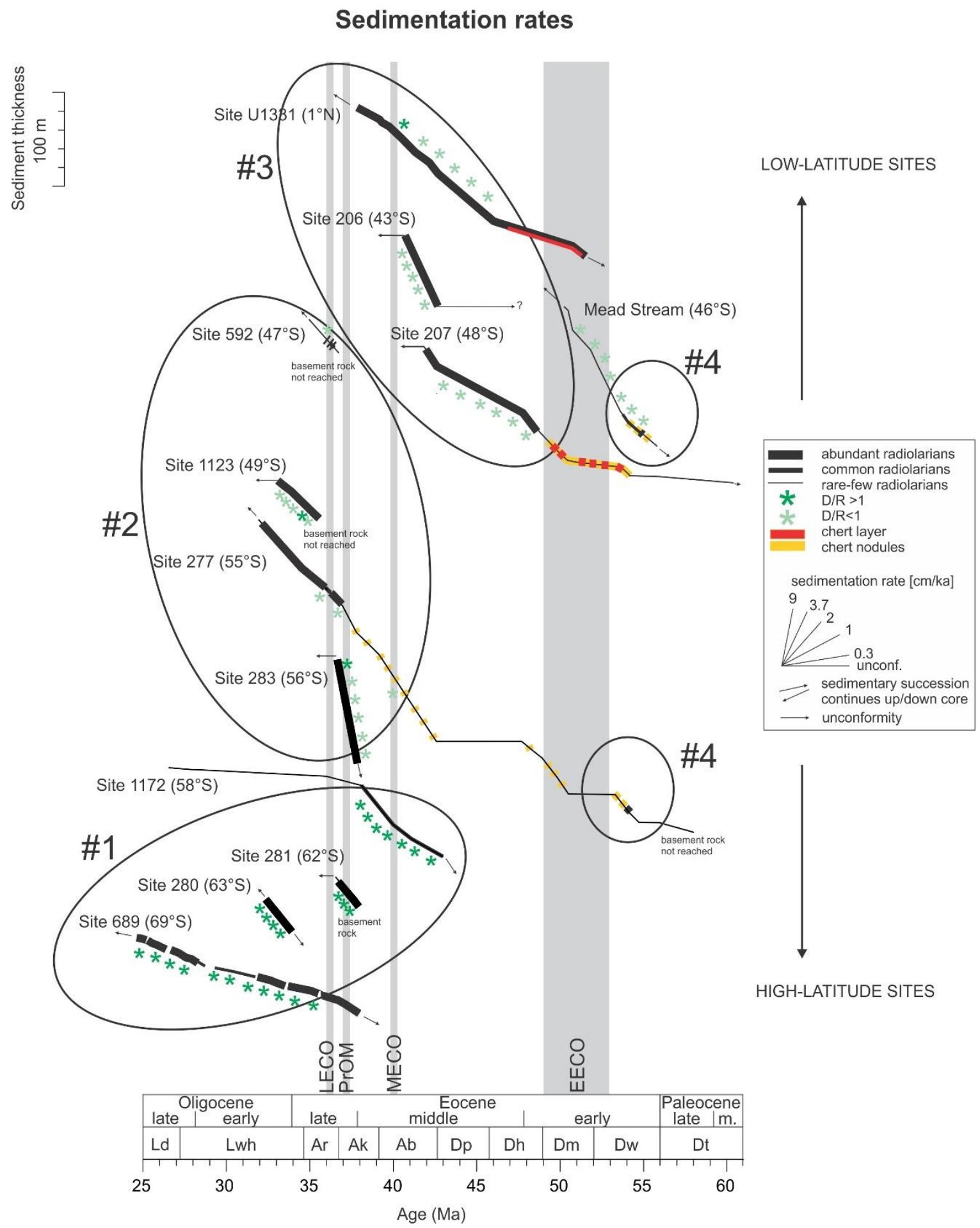

Figure 7.3 Sedimentation rates for the studied intervals of DSDP sites 277, 280, 281, 283, 592, 207, 206, ODP sites 1172 and 1123 and three additional sites for comparison (Mead Stream, ODP Site 689 and IODP Site U1331). Superimposed on age-depth plots are radiolarian abundance, the presence of chert layers/nodules (red/orange bands) and diatom occurrence (D/R ratio, green asterisks). Four groups can be identified based on high D/R ratio at highlatitude sites (Group 1), high radiolarian abundance and low D/R ratio at mid- to high latitude sites (Group 2), high radiolarian abundance and low D/R ratio at mid-latitude sites in the middle Eocene (Group 3) and high radiolarian abundance and low D/R ratio in the early Eocene (Group 4). Plots are arranged from top (low latitudes) to bottom (high latitudes) based on the location of the site at $\sim 40 \mathrm{Ma}$ (paleolatitude in brackets). EECO=early Eocene climatic optimum, $\mathrm{MECO}=$ middle Eocene climatic optimum, PrOM=Priabonian oxygen isotope maximum, LECO=late Eocene climatic optimum. 
The distinguishing feature of Group 3 is the abundance of radiolarians in early to middle Eocene sediments of equatorial Pacific Site U1331 and mid-latitude sites 207 and 206. In general, radiolarians are abundant and dominate the siliceous assemblage in the early and middle Eocene, whereas diatoms are only a minor component. A peak in diatom abundance towards the end of the middle Eocene at Site U1331 was interpreted to be related to a cooling event and associated with a carbonate accumulation event (Kamikuri et al., 2013). The increase in radiolarian abundance in the middle Eocene was interpreted to be related to cooling of tropical surface water masses (Kamikuri et al., 2013). The high radiolarian abundance at mid-latitude sites 206 and 207 might also be related to postEECO cooling. An alternative explanation may be that southward flow of northern warm water masses during the early and middle Eocene enhanced radiolarian and diatom productivity in the otherwise oligotrophic waters on Lord Howe Rise. The latter explanation is also reconcilable with the short appearance of radiolarian-rich sediments at Site 592 that occurs only during the LECO. Group 4 is characterised by high radiolarian abundance and low D/R ratio of lowermost Eocene sediments at Mead Stream and Site 277. This increase in radiolarian abundance was related to cooling conditions after the Paleocene-Eocene thermal maximum and before the early Eocene climatic optimum, which resulted in a decrease of radiolarian diversity and abundance (Hollis, 2006).

The findings from this study are in agreement with general global trends in marine biosiliceous sediment deposition throughout the Cenozoic: radiolarian-dominated siliceous sediments prior to the Eocene-Oligocene boundary and diatom-dominated sediments from the Oligocene (Renaudie, 2016). However, the study also shows that diatoms dominate high-latitude Southwest Pacific siliceous assemblages from the earliest late Eocene. Earlier peaks in diatom abundance, as in the middle Eocene at Site 1172, may be due to localised upwelling.

\subsubsection{Effect of diagenesis}

The occurrence of chert nodules and chert layers at the studied sites and comparison sites are shown in Figure 7.3. Chert nodules occur throughout the upper Palaeocene-middle Eocene at Site 277 (Figure 7.3), with a transition between chert-bearing nannofossil chalk and overlying nannofossil ooze at 246 mbsf (lower upper Eocene, Figure 4.1) (Kennett et al., 1975). As discussed in Pascher et al. (2015), one explanation for the sudden increase in radiolarian abundance and diversity in the upper Eocene at Site 277 could be that these 
trends are an artefact of biogenic opal diagenesis. The presence of chert in combination with the generally poorer preservation of radiolarians in the lower Paleogene interval indicates some degree of diagenesis, which is also reflected in the range-through taxic richness analysis (Figure 6.4). However, the first major radiolarian turnover event occurs $20 \mathrm{~m}$ above the lithological transition from chert-bearing nannofossil chalk to nannofossil oozes, which implies that the event represents a real increase in radiolarian and diatom abundance and not an artefact of diagenesis. Furthermore, the observed diversity and abundance decrease during the LECO, and the increase in diversity and abundance thereafter are not related to lithological changes. This indicates that these changes are real features of the assemblage and related to environmental changes.

Chert nodules and layers are also present in the lower Eocene at Site 207. The transition from chert-bearing foram-rich nanno ooze to siliceous fossil-rich foram-bearing nanno ooze, occurs in Core 207A-21R at 246 mbsf. The abrupt increase in radiolarian abundance and diversity and the occurrence of diatoms is observed $\sim 3 \mathrm{~m}$ above the transition and coincides with an improvement in radiolarian preservation. It is likely that this abrupt improvement in preservation and appearance of siliceous microfossils is an artefact of diagenesis. Chert layers occur also at tropical Site U1331 during the EECO and $\sim 2$ Ma later, but radiolarian abundance is high throughout the record (Figure 7.3) (Expedition 320/321 Scientists, 2010). A sudden increase in radiolarian mass accumulation rate at $\sim 46 \mathrm{Ma}$ was not considered to be an artefact of diagenesis, but instead a response to a cooling event (Kamikuri et al., 2013). At Mead Stream, chertbearing limestone is present in the earliest Eocene and radiolarians have an abundance peak in that interval, which was related to cooler oceanographic conditions following the PETM (Hollis et al., 2005). During the EECO, radiolarian abundance is low and chert is absent (Hollis et al., 2005), which is in contrast to sites 207, 277 and U1331, where chert seems to be a feature of warm intervals.

\subsection{Radiolarian paleobiogeography}

\subsubsection{Application of method}

In this thesis, radiolarian paleobiogeography has been used as a guide for paleo-water mass changes in the Eocene to early Oligocene throughout the Southwest Pacific. In total, 134 of 259 radiolarian counting groups have been assigned to either high-latitude, 
cosmopolitan or low-latitude affinity (Appendix A and E, data on enclosed CD). Paleobiogeographic affinities have been assigned to species in previous studies in order to reconstruct frontal systems in the Southern Ocean (Lazarus and Caulet, 1993), track the movement of the Antarctic Polar Front (AAPF) (Funakawa and Nishi, 2008) or identify warming and cooling events and paleoceanographic changes in the equatorial Pacific (Funakawa et al., 2006a; Kamikuri et al., 2013). Some of the paleobiogeographic assignments made by Lazarus and Caulet (1993) have been amended based on new evidence collected during the present study. The present study also improves on the approach of Funakawa et al. (2006a), Funakawa and Nishi (2008) and Kamikuri et al. (2013) as these authors used only 10-12 species in their interpretations of environmental change and only used presence/absence data, rather than relative abundance, when assigning biogeographic affinities.

This study thus provides the first comprehensive assignment of biogeographic affinities based on relative abundance data of species from multiple ocean drilling sites and onshore sections. Due to time constraints, not all species could be assigned to a biogeographic group.

\subsubsection{General trends through time and across the transect}

Based on the relative abundance of low- and high-latitude taxa, radiolarian assemblages were categorized into four groups considered to be representative of the following water masses: warm subtropical, cool subtropical (warm temperate), cool subtropical (cool temperate), and subantarctic (Figure 7.4). Radiolarian assemblages were grouped according to the relative abundance of high-latitude (HL) and low-latitude (LL) taxa. A warm subtropical assemblage is characterised by the dominance of LL and cosmopolitan taxa and $<0.5 \%$ HL taxa; a cool subtropical (warm temperate) assemblage consists of more abundant LL than HL taxa; a cool subtropical (cool temperate) assemblage consists of more abundant HL than LL taxa; a subantarctic assemblage is characterised by the dominance of HL taxa over cosmopolitan taxa and the absence of LL taxa.

During the EECO, the radiolarian assemblages recovered from sites 277 and 207 have the highest percentage of low-latitude taxa found in this study (Figure 7.4). However, the assemblage composition is very distinct and dominated by Amphicraspedum spp., which is likely an artefact of poor radiolarian recovery and preservation. Radiolarian 
assemblages from Mead Stream (C. Hollis, pers. comm. 2016) have a slightly higher diversity and include low-latitude genera such as Bekoma, Lamptonium, Theocorys, Theocotyle and Podocyrtis, while not being as diverse as the tropical assemblage at eastern central Pacific Site U1331 (Kamikuri et al., 2013). For this reason, the assemblages of Mead Stream, Site 207 and Site 277 are referred to as warm subtropical. In contrast to the assemblage interpretation of Kamikuri et al. (2013) (Figure 7.4), the low-latitude group at Site U1331 is less abundant during the EECO than thereafter. Kamikuri et al. (2013) assigned Stylosphaera coronata coronata (=Amphisphaera coronata in this study) to the low-latitude group, whereas in this thesis (and Pascher et al., 2015) this species was assigned to the cosmopolitan group. Furthermore, the EECO interval at this site also suffered from poor preservation due to silica dissolution and the overall diversity was relatively low compared to the middle Eocene (Kamikuri et al., 2013).

In the early and middle Eocene, high-latitude taxa (e.g. Larcopyle polyacantha, L. hayesi, Ceratocyrtis spp., Lithomelissa spp., Lophocyrtis longiventer) are very rare at sites 277 and 207, and also very rare at Mead Stream and low-latitude Site U1331 (Figure 7.4). At Site 207 and Mead Stream, low-latitude taxa (e.g. Amphicraspedum spp., Histiastrum quadribrachiatus quadribrachiatus, Theocorys spp., Lophocyrtis jacchia jacchia, Podocyrtis spp.) show a decrease throughout the middle Eocene, but high-latitude taxa do not increase and remain very rare (Figure 7.4). Only sites 206 and 592 have a noticeable high-latitude component, but low-latitude taxa remain more abundant. This assemblage is referred to as cool subtropical (warm temperate) and is only present at mid-latitude sites. The long-term cooling trend that started after the EECO is not observed at Site U1331 as the low-latitude group shows an overall consistent abundance through the middle Eocene (Figure 7.4). 


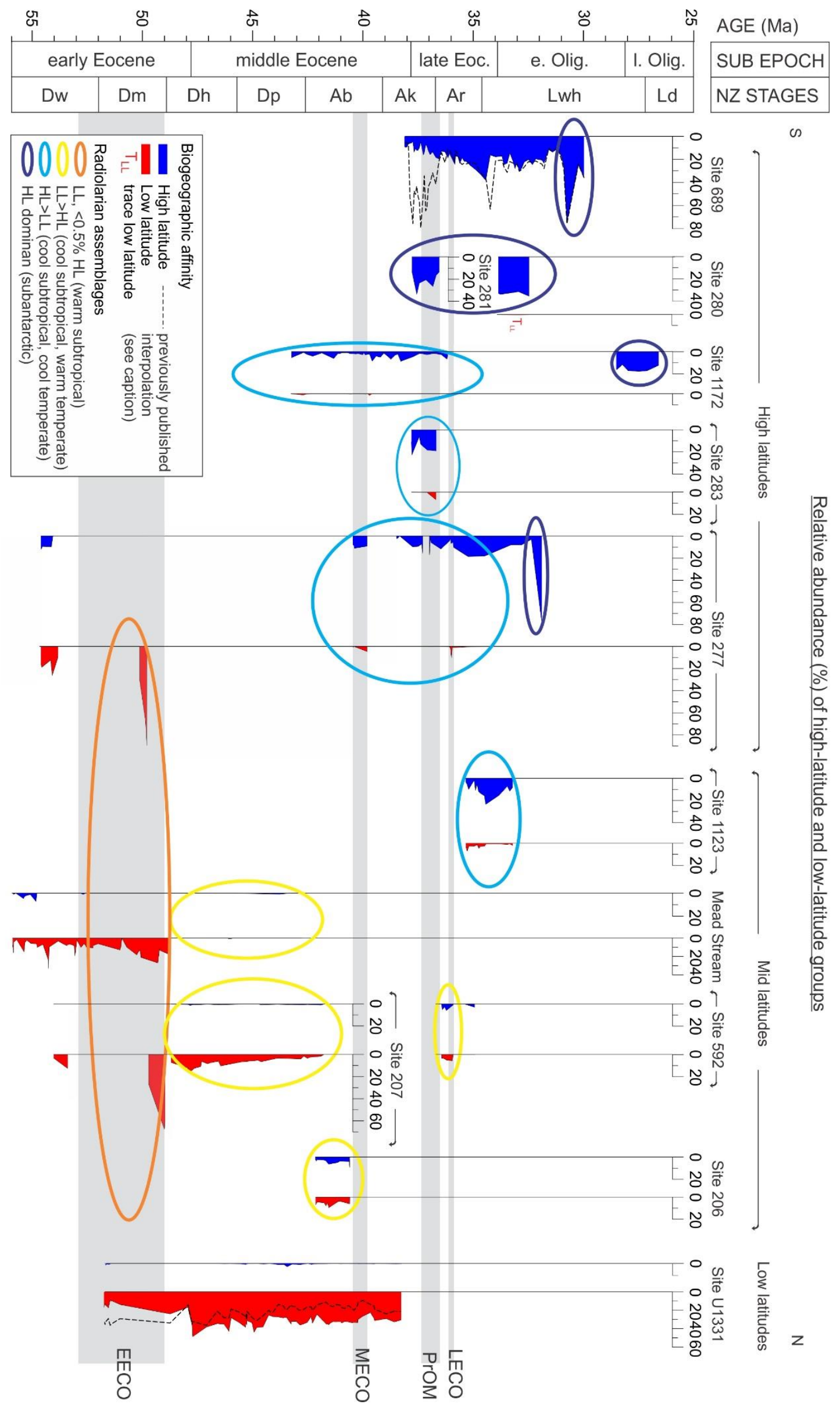


Figure 7.4 previous page, Biogeographic affinity of radiolarian assemblages along a transect from high to low latitudes. Results from this thesis as in Figure 6.38 plus three additional sites: High-latitude ODP Site 689 (Funakawa and Nishi, 2005), mid-latitude Mead Stream (C. Hollis, pers. comm. 2016) and low-latitude IODP Site U1331 (Kamikuri et al., 2013). The biogeographic affinities for the latter three sites were assigned to taxa as identified in this thesis plus additional low-latitude genera (Lamptonium, Thyrsocyrtis, Podocyrtis, Bekoma and Lithocyclia). For sites U1331 and 689, the biogeographic assignments of Kamikuri et al. (2013) and Funakawa and Nishi (2008), respectively, are indicated with a black dashed line.

High-latitude taxa are more abundant at high-latitude sites than at mid- and low-latitude sites, except at Site 1123 where there are more abundant high-latitude than low-latitude taxa. They were present from at least the middle Eocene ( $43 \mathrm{Ma})$ at high-latitude sites 277, 283, 1172, but also at mid-latitude Site 206 and from at least $~ 38 \mathrm{Ma}$ at the southernmost sites 281 and 689. The assemblage with more abundant high-latitude than low-latitude taxa is referred to as cool subtropical (cool temperate) and is mainly found at high-latitude sites during the middle to late Eocene and early Oligocene. Although the interval of peak warmth of the MECO may not be preserved at Site 277, the radiolarian assemblages at sites 277 and 1172 lack typical low-latitude species and genera. Taxa with low-latitude affinities account for only $5 \%$ of the total assemblage at Site 277 and consist of Amphicraspedum murrayanum and A. prolixum gr.

From the earliest late Eocene ( $\sim 38 \mathrm{Ma})$ many high-latitude taxa that are present at sites 281 and 283 appear later at Site 277 in the middle of the PrOM event ( $37 \mathrm{Ma}$, Figure 6.29) where the appearance is accompanied by a sudden increase in abundance, diversity and preservation. This is interpreted as the expansion of high-latitude water masses across the Campbell Plateau during this short-lived cooling event rather than the response to gradual, long-term cooling (Pascher et al., 2015). Funakawa and Nishi (2008) reported a marked increase in radiolarian taxa with Antarctic faunal affinities at ODP Site 689 (Maud Rise, southern Atlantic) in the earliest late Eocene ( 38.6-36.9 Ma; Chron C17) (Figure 7.4), which they interpreted to signify the northward expansion of the Antarctic Polar Front. New calibration to GTS2012 (S. Bohaty, pers. comm. 2014) and the assignment of species to the high-latitude group revealed no increase in high-latitude taxa at that time (Figure 7.4). The large discrepancy is due to Amphisphaera aff. spinulosa, which was treated as a high-latitude species by Funakawa and Nishi (2008), whereas Amphisphaera spinulosa is assigned to the cosmopolitan group here (Appendix E).

During the LECO ( 36 Ma), a decrease in high-latitude taxa and general diversity and abundance was observed at Site 277 (Figures 6.29, 6.38 and 7.4). Low-latitude species Thyrsocyrtis pinguisicoides has an abundance peak of $\sim 10 \%$ (Figure 6.29). The LECO 
was also recovered at Site 592, and at that site, low-latitude taxa are on average slightly more abundant than high-latitude taxa (Figure 7.4). After the LECO, the radiolarian assemblage at Site 277 shows an increase in high-latitude taxa diversity and abundance towards the Eocene-Oligocene boundary (Figure 6.29), which is also observed at sites 1123 and 689 (Figures 6.37 and 7.4).

During the early Oligocene radiolarian assemblages recovered at sites 277, 1123 and 689 (Funakawa and Nishi, 2008) show a decrease in high-latitude taxa, whereas Site 280 does not (Figure 7.4). At $\sim 32 \mathrm{Ma}$, high-latitude taxa increase in abundance at Site 277 and at $\sim 31 \mathrm{Ma}$ at Site 689, with both assemblages being dominated by Axoprunum? Irregularis (Figure 6.29). At Site 689, the interval from $\sim 31-29 \mathrm{Ma}$ is characterised by poor preservation and a decrease in diversity (Funakawa and Nishi, 2008). A subantarctic radiolarian assemblages is inferred from the dominance of high-latitude taxa over cosmopolitan taxa and the absence of low-latitude taxa and was established in the late Eocene at the southernmost Site 281 and in the early Oligocene at sites 277, 280, 1172 and 689 (Figure 7.4).

\subsubsection{Evolution of oceanic fronts: geochemical proxies vs. radiolarians}

All oceanographic features described in this and the following section are 'proto' features, that are understood to be analogous to but not necessarily identical to the modern features of the same name.

The evolution of oceanic fronts in the Southwest Pacific has been reconstructed for the Paleogene, updating the earlier reconstructions provided by Nelson and Cooke (2001), based on temperature reconstructions from an integration of geochemical proxies for sea surface temperature (SST) (Figure 7.5) and radiolarian assemblages (Figure 7.6). Based on geochemical proxies TEX $_{86}, \mathrm{Mg} / \mathrm{Ca}$ ratios, Hollis et al., 2012; 2015; Littler et al., 2016), the Tropical Convergence (TC) may have reached as far south as $\sim 55^{\circ}$ during the PETM and EECO explaining the fully tropical surface water conditions $\left(\sim 28-35^{\circ} \mathrm{C}\right)$ in the southern Southwest Pacific (sites 1172 and 277). Warm subtropical conditions ( 23$27^{\circ} \mathrm{C}$ ) prevailed in the Southwest Pacific for most of the Eocene suggesting that the TC moved further north and instead an associated Tasman Front (TF) may have been at as far as $\sim 57^{\circ} \mathrm{S}$. Cool subtropical conditions $\left(\sim 15-22^{\circ} \mathrm{C}\right)$ were present in the late Paleocene and late Eocene, indicating that the TF retracted to the north and instead a proto-Subtropical 
Front was established (STF) (Figure 7.5). Overall, the reconstructed oceanic fronts, if present, may have been much more contracted compared to today (Figure 7.5). An Antarctic Polar Front (AAPF) was suggested to have existed since 30 Ma (Scher et al., 2015).

In contrast to the geochemical proxy-based reconstruction, radiolarian assemblages indicate that the Southwest Pacific did not experience tropical conditions during the Eocene. Warm subtropical water masses may have reached to $\sim 55^{\circ} \mathrm{S}$ during the EECO (Figure 7.6). During middle Eocene, cool subtropical conditions prevailed in the region with warm temperate assemblages at the northern sites and cool temperate assemblages at the southern sites. This is in agreement with the reconstructions of cool-subtropical surface water masses $\left(15-20^{\circ} \mathrm{C}\right)$ for the mid- to high-latitude Southwest Pacific by Nelson and Cooke (2001). From the late Eocene, a STF may have developed and separated cool subtropical water masses in the north from cold subantarctic water masses in the south. Subantarctic radiolarian assemblages existed since the late Eocene at the southernmost sites 280 and 281 (paleolatitude $\sim 61^{\circ} \mathrm{S}$ ). The STF subsequently shifted northwards in the late Eocene and early Oligocene and a Subantarctic Front (SAF) may have developed in the early Oligocene. The presence of an AAPF from 30 Ma onwards (Scher et al., 2015) cannot be confirmed with radiolarians. 


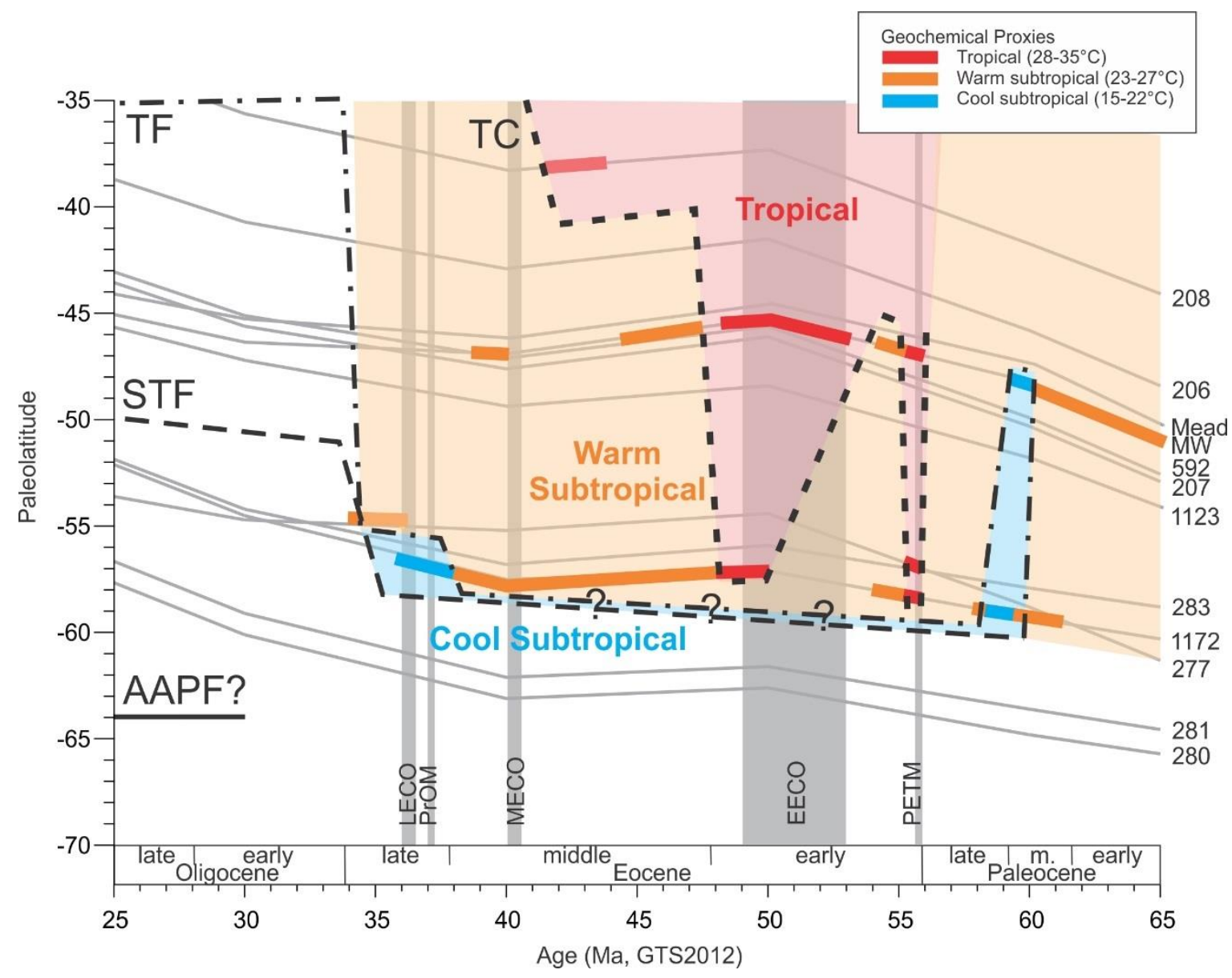

Figure 7.5 The Paleogene evolution of Southwest Pacific Ocean fronts (after Nelson and Cooke, 2001) using TEX 86 and $\mathrm{Mg} / \mathrm{Ca}$ derived temperatures (Hollis et al., 2012; Hollis et al., 2015; Littler et al., 2016); Paleolatitudes for each site are calculated at $5 \mathrm{Ma}$ increments using www.paleolatitude.org (van Hinsbergen et al., 2015), except for Mead Stream and Mid-Waipara, for which the paleolatitudes were derived using the paleoceanographic reconstructions as outlined in chapter 3.7. Abbreviations: MW = Mid-Waipara, Mead = Mead Stream, TC=Tropical Convergence, TF=Tropical Front, $\mathrm{STF}=$ Subtropical Front, AAPF=Antarctic Polar Front. Modified from Hollis et al. (2016).

The differences in oceanic features using geochemical proxies and radiolarian assemblages may be due to the seasonal bias of geochemical proxies towards warm summer temperatures, problems in the paleo-calibration of TEX 86 values or the alteration of $\mathrm{Mg} / \mathrm{Ca}$ during diagenesis (Hollis et al., 2012). Radiolarians in turn may represent average annual sea surface temperature conditions. In support of the radiolarian assemblage reconstructions, nannofossil assemblages also indicate warm to cool subtropical conditions in the Eocene Southwest Pacific (C. Shepherd, pers. comm. 2016). 


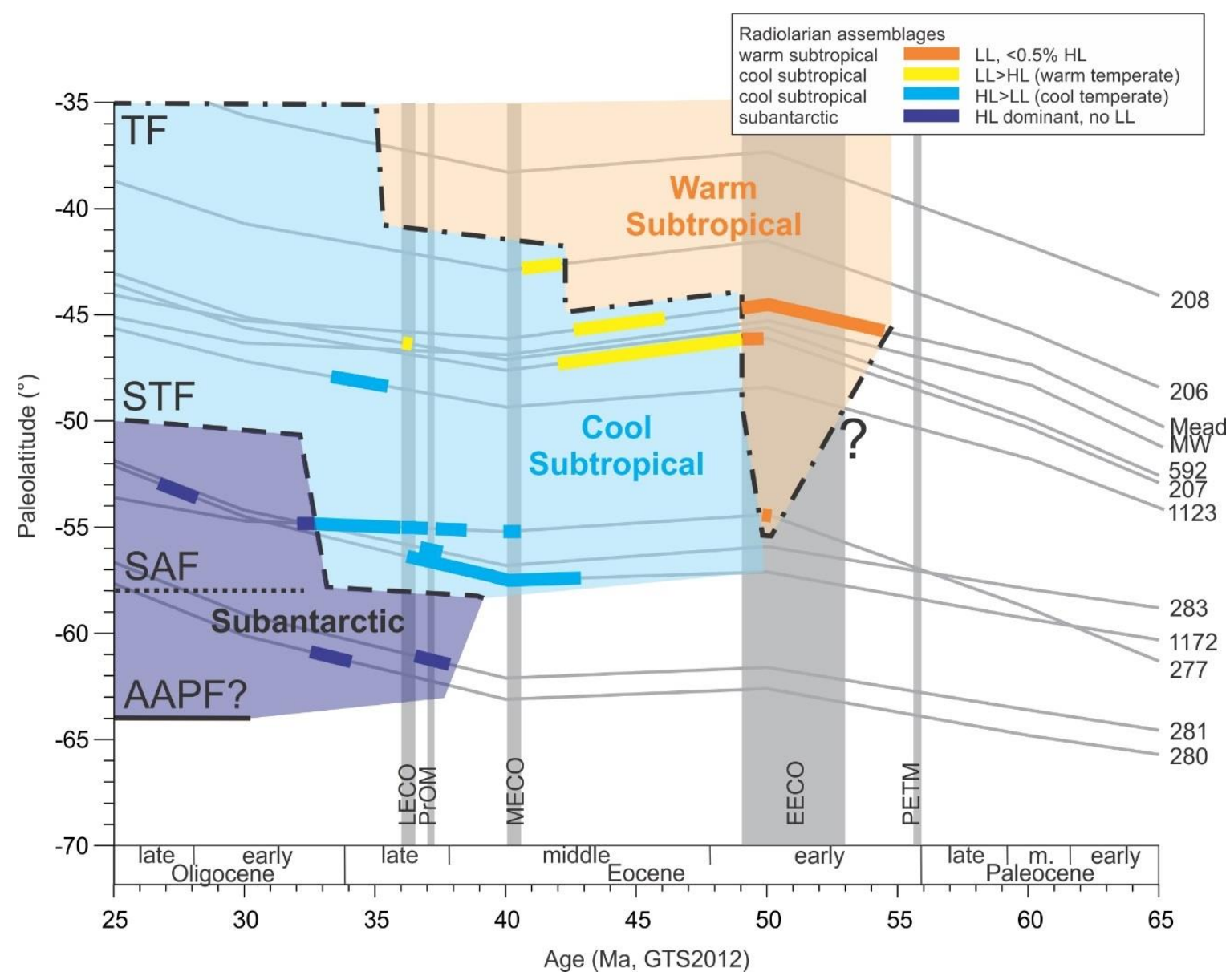

Figure 7.6 Reconstruction of oceanic fronts and water masses (after Nelson and Cooke, 2001) for the Southwest Pacific from the early Eocene to late Oligocene based on the relative abundance of high-latitude (HL), cosmopolitan and lowlatitude (LL) taxa as shown in Figure 7.4. Paleolatitudes are calculated at $5 \mathrm{Ma}$ increments for each site using www.paleolatitude.org (van Hinsbergen et al., 2015), except for Mead Stream and Mid-Waipara, for which the paleolatitudes were derived using the paleoceanographic reconstructions as outlined in chapter 3.7. Abbreviations: MW = Mid-Waipara, Mead = Mead Stream, TF=Tropical Front, STF=Subtropical Front, SAF=Subantarctic Front, $\mathrm{AAPF}=$ Antarctic Polar Front.

\subsubsection{Paleoceanographic reconstructions}

In this section the reconstructions presented in Figures 7.4 and 7.6 are used to infer paleoceanographic conditions in six time slices.

\subsubsection{Early Eocene climatic optimum ( 53-49 Ma)}

The Southwest Pacific was under the influence of warm subtropical water masses delivered from the East Australian Current (EAC) (Figure 7.7). Radiolarian assemblages are very distinct at sites 277 and 207 from those at Mead Stream and low-latitude Site U1331. Although the relative abundance of low-latitude taxa at sites 277 and 207 is greater (high abundance of Amphicraspedum spp.) than at Mead Stream and Site U1331, the diversity of low-latitude species is significantly lower. Thus, it cannot be inferred that temperatures were higher in the Southwest Pacific compared to low-latitudes. Radiolarian 
abundance is in general low during the EECO in the Southwest Pacific compared to low latitudes (Kamikuri et al., 2013). The Tasman Front (TF) may have extended as far south as $\sim 55^{\circ} \mathrm{S}$, concomitant with contraction of the Ross Gyre.
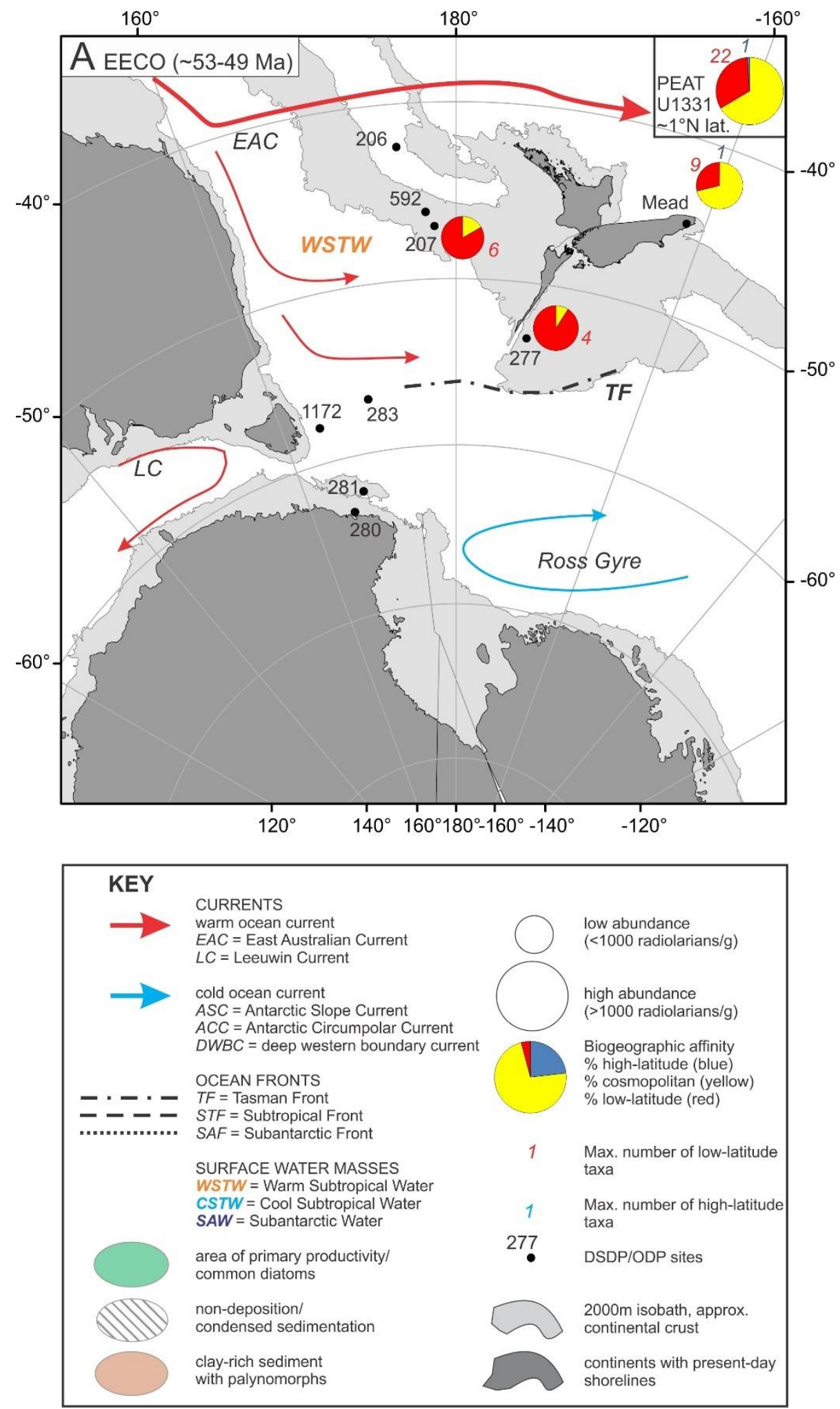

Figure 7.7 Biogeographic affinities and paleoceanographic reconstruction for the EECO ( 53-49 Ma). Biogeographic affinity pies show \% only of the biogeographic constrained portions of the assemblage. 


\subsubsection{Middle Eocene ( 47-40 Ma)}

During the middle Eocene, high-latitude taxa increase in abundance and diversity in the Southwest Pacific, indicating cooler conditions and a greater influence of Ross Gyre (Figure 7.8). The TF moved towards the north and the influence of the EAC weakened. Low-latitude taxa are more abundant at mid-latitude sites 206 and 207, indicating warm temperate conditions on Lord Howe Rise, compared to cool temperate conditions in the southern Southwest Pacific. Radiolarians are abundance at Lord Howe Rise sites 206 and 207 and at Site 1172. Diatoms are also common at these sites at this time, indicating areas of local upwelling along continental margins.

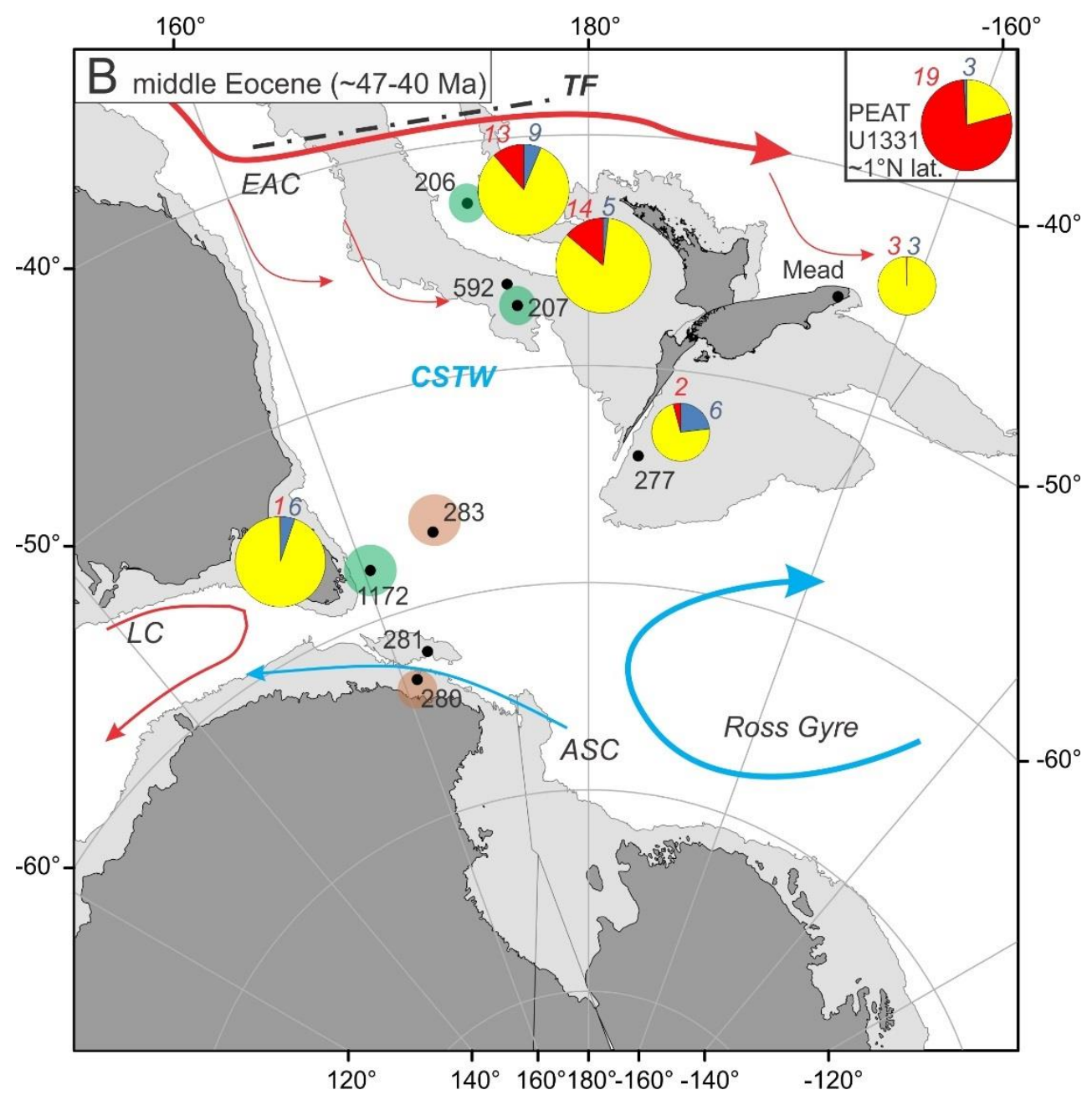

Figure 7.8 Biogeographic affinities and paleoceanographic reconstruction for the middle Eocene ( 47-40 Ma). Slightly different time slices apply for each site: Site 1172 ( 43-40 Ma), Site 277 (MECO, 40 Ma), Site 207 ( 47-42 Ma), Site 206 ( 42-41 Ma), U1331 ( 47-40 Ma), Mead Stream ( 46-43 Ma). Biogeographic affinity pies show \% only of the biogeographic constrained portions of the assemblage. For key refer to Figure 7.7. 


\subsubsection{Late middle to early late Eocene/PrOM event ( 38-37 Ma)}

During the PrOM event, the abundance of high-latitude taxa increased in the Southwest Pacific (Figure 7.9). This increase is seen at the onset of the event at Site 1172 and in the middle of the event $(\sim 37 \mathrm{Ma})$ at Site 277 , where an increase in overall radiolarian diversity and abundance is observed. During this time, radiolarians were also abundant at sites 283 and 281 with the largest component of high-latitude taxa at Site 281. The region might have experienced an intensification of the Ross Gyre that delivered nutrient-rich water masses from the south, extending the area of high productivity onto the Campbell Plateau and initiating the Subtropical Front.

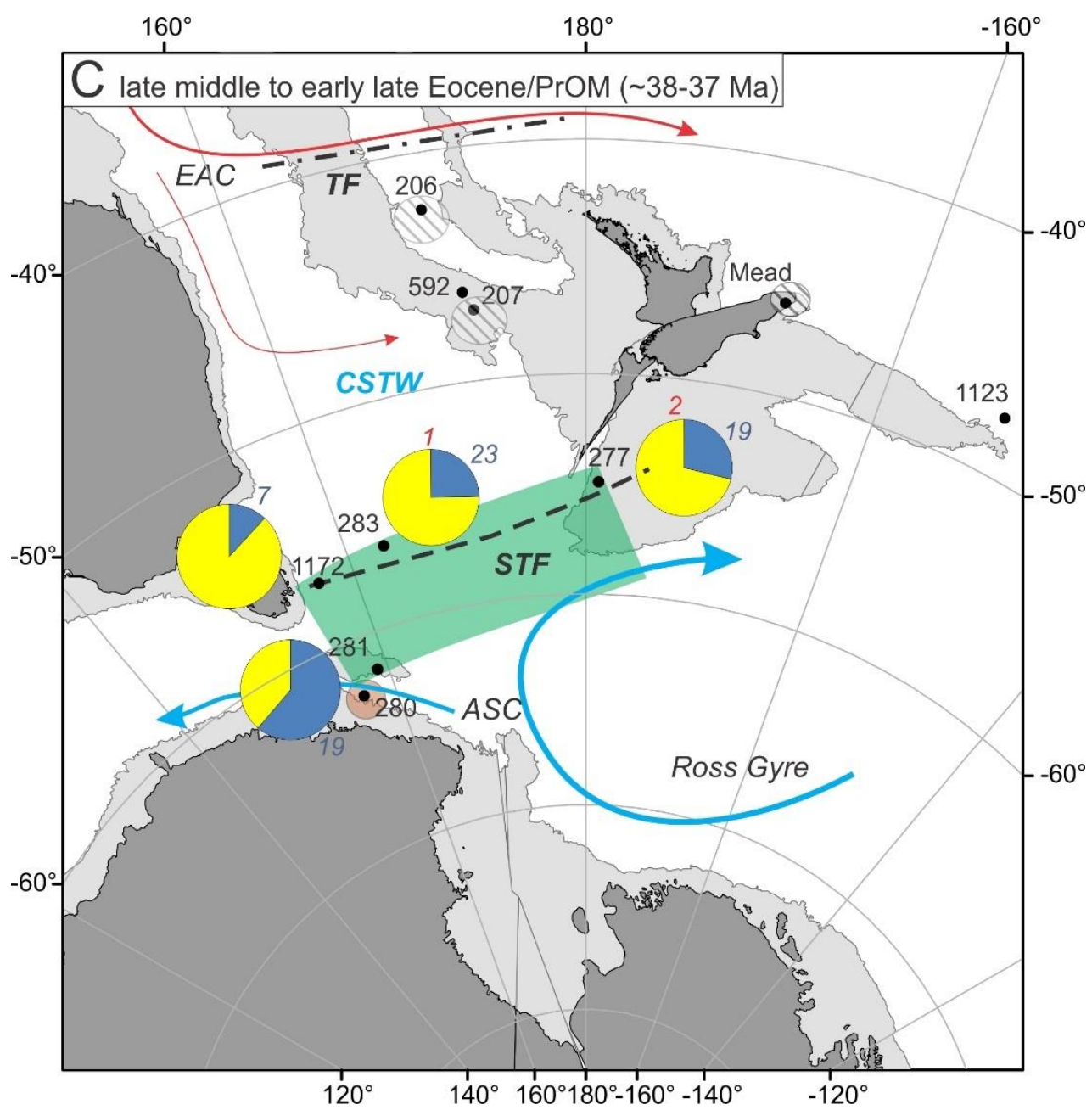

Figure 7.9 Biogeographic affinities and paleoceanographic reconstruction for the late middle to early late Eocene/PrOM ( 38-37 Ma). Biogeographic affinity pies show \% only of the biogeographic constrained portions of the assemblage. For key refer to Figure 7.7; modified after Pascher et al. (2015).

Whether this event was caused by a drop in atmospheric $\mathrm{CO}_{2}$ concentrations or was related to the opening of the Tasmanian Gateway, which may have been open to shallow surface circulation as early as $\sim 50 \mathrm{Ma}$ (Bijl et al., 2013), has yet to be determined. 


\subsubsection{Late Eocene climatic optimum ( 36 Ma)}

Radiolarian diversity decreased abruptly within the LECO at Site 277, and was accompanied by a decrease in high-latitude taxa and diatoms. Low-latitude taxa appeared at sites 277 and 283, and to a slightly greater extent at mid-latitude Site 592 (Figure 7.10). A late Eocene hiatus at Site 281 implies an increase in the strength of the Antarctic Slope Current (ASC) across the Tasmanian Gateway. The changes might have been associated with an increase in the strength of the EAC and a decrease in the strength of the Ross Gyre, explaining the drop in diversity and abundance at Site 277. Surface water masses were cool subtropical, with a warm temperate northern region across Site 592 and a cool temperate region in the south.

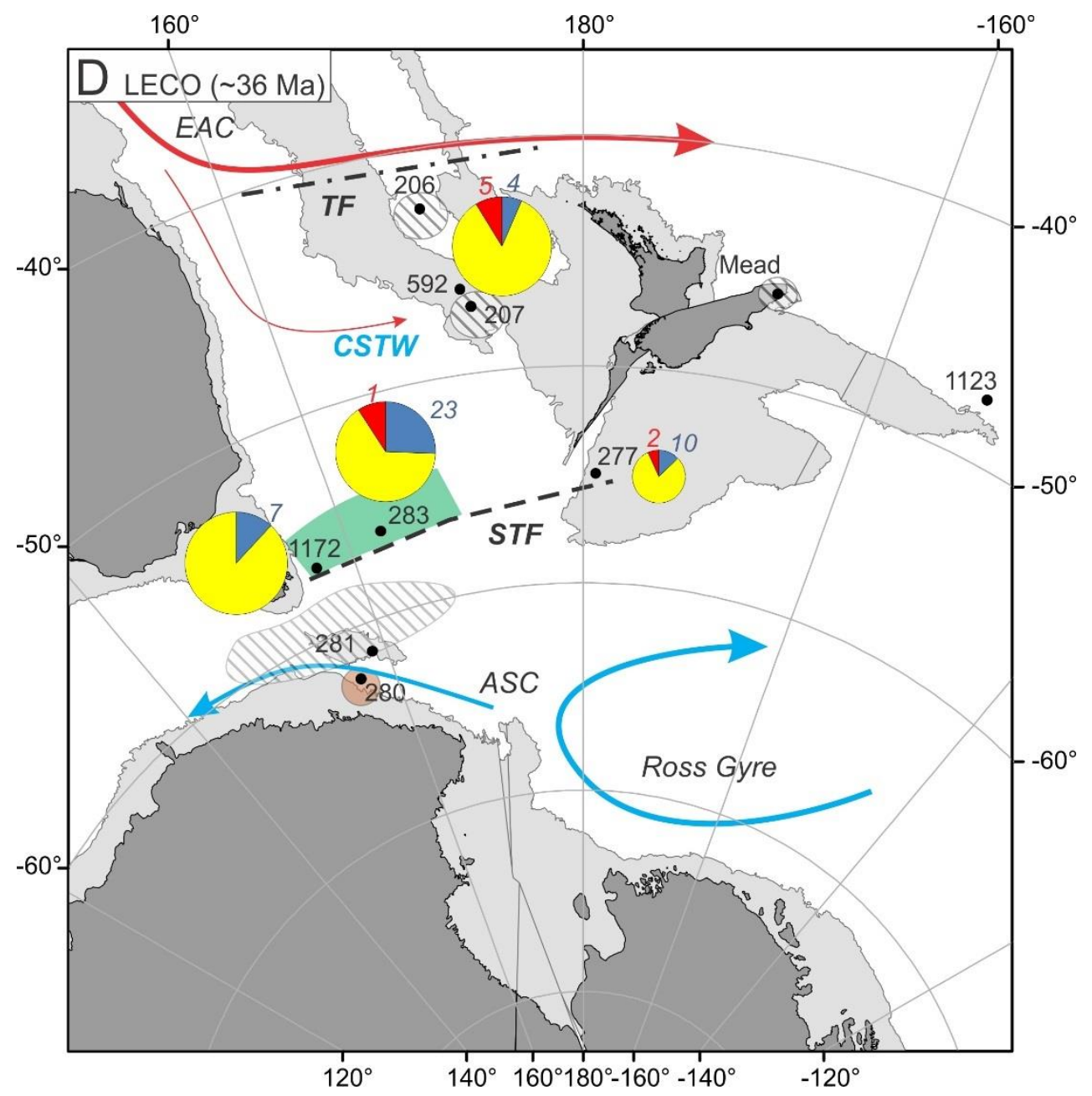

Figure 7.10 Biogeographic affinities and paleoceanographic reconstruction for the late Eocene climatic optimum $(\sim 36$ Ma). Site 283 is tentatively included here although an older age was inferred ( 36.7 Ma). Biogeographic affinity pies show \% only of the biogeographic constrained portions of the assemblage. For key refer to Figure 7.7; modified after Pascher et al. (2015). 
No evidence is found to support the presence of a large cyclonic gyre (Tasman Current) as proposed by Huber et al. (2004) and Bijl et al. (2010). This current was inferred to have delivered southern sourced surface water to the wider Southwest Pacific in the Eocene. Instead, the data suggest that Site 277 was positioned at the northernmost limit of the Ross Gyre and that sites 277 and 283 were the southernmost sites of influence of warm water delivered by the EAC (Pascher et al., 2015).

\subsubsection{Latest Eocene-earliest Oligocene ( 35-32 Ma)}

During this interval, the region experienced a second cooling interval associated with an increase in siliceous plankton abundance and the reappearance of many high-latitude radiolarian taxa (Figure 7.11). The cooling in the latest Eocene led to the expansion of Ross Gyre to encroach on Campbell Plateau and on Site 1123 east of New Zealand. At the same time, Site 1123 was under the influence of warm waters originating from the EAC. The area of non-deposition widened across the Tasmanian Gateway over sites 281, 283 and 1172, perhaps reflecting strengthening of northward- and westward-flowing bottom currents. The abundance of radiolarians and diatoms at Site 280 during the earliest Oligocene suggests a region of high primary productivity. Intensified upwelling may have been caused by the ASC in conjunction with deepening in this sub-basin. 


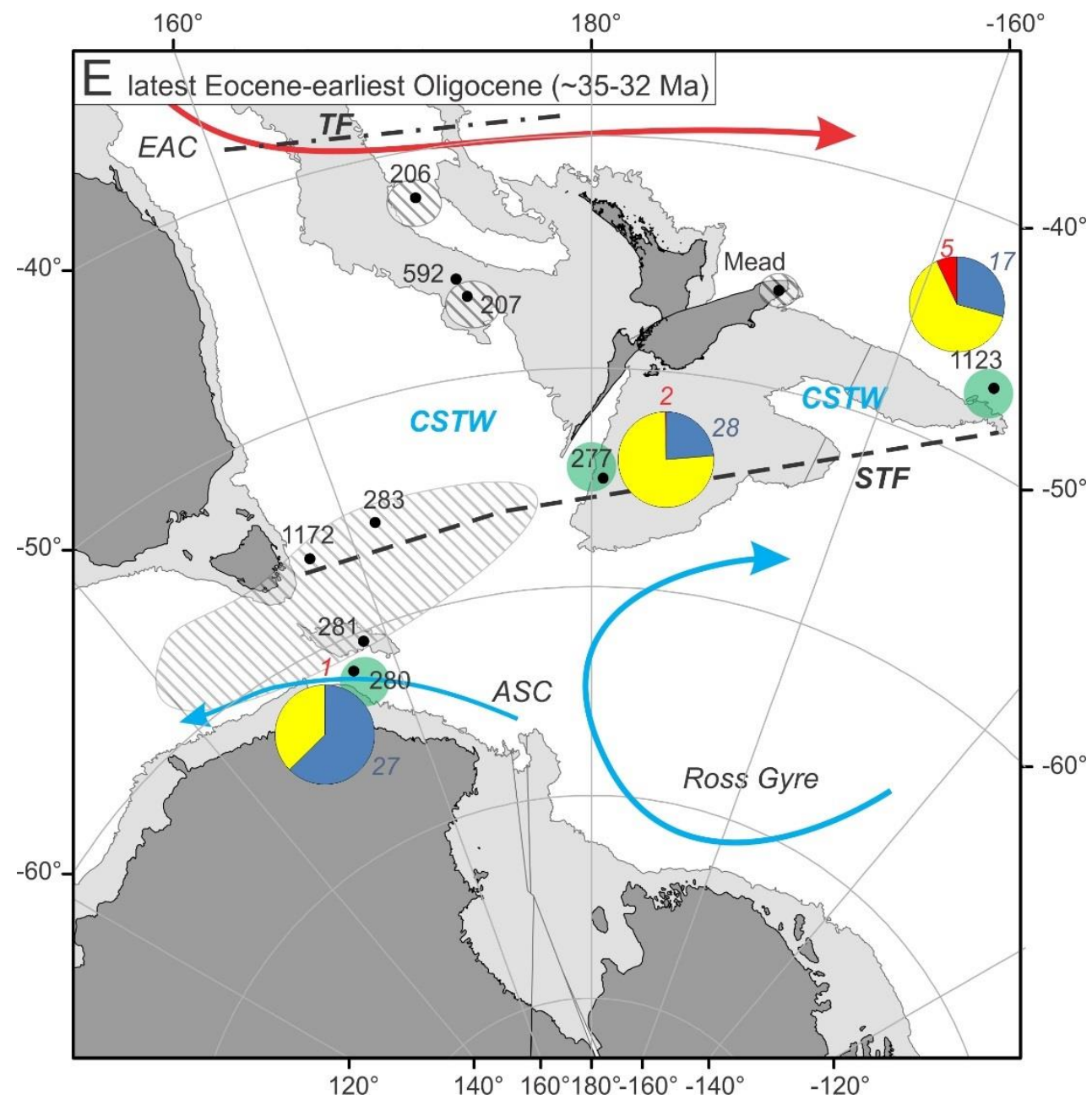

Figure 7.11 Biogeographic affinities and paleoceanographic reconstruction for the latest Eocene to earliest Oligocene ( 35-32 Ma). Slightly different time slices apply for each site: Site $1172(\sim 35-34 \mathrm{Ma})$, Site $277(\sim 35.3-32.4 \mathrm{Ma})$, Site 280 (34-32.5 Ma), Site 1123 (35.4-33.3 Ma). Biogeographic affinity pies show \% only of the biogeographic constrained portions of the assemblage. For key refer to Figure 7.7; modified after Pascher et al. (2015).

\subsubsection{Early Oligocene ( 32-27 Ma)}

In the early Oligocene, radiolarian abundance and diversity declined and diatoms became scarce in the region (Figure 7.12). The Tasmanian Gateway became fully open at $\sim 30 \mathrm{Ma}$ (Carter et al., 2004) and its northward tectonic migration brought it in line with the westerly wind belt (Scher et al., 2015). As a result the ACC developed and the zone of non-deposition extended over Site 280 in the late Oligocene when this site moved into the direct pathway of the ACC. The radiolarian assemblages at sites 1172 and 277 became very distinct and typical for cold conditions. The general low diversity and scarcity of diatoms suggests the establishment of a cold-water, nutrient depleted environment, similar to the modern subantarctic setting (Hollis and Neil, 2005). The development of the ACC restricted the northward extent of the Ross Gyre and helped to establish the Subantarctic Front on the southern margin of the Campbell Plateau. The non-deposition at 
Site 1123 is attributed to the development of the Deep Western Boundary Current to the east of the Campbell Plateau and Chatman Rise, and is inferred to have intiated alongside the establishment of the ACC (Carter et al. 2004).

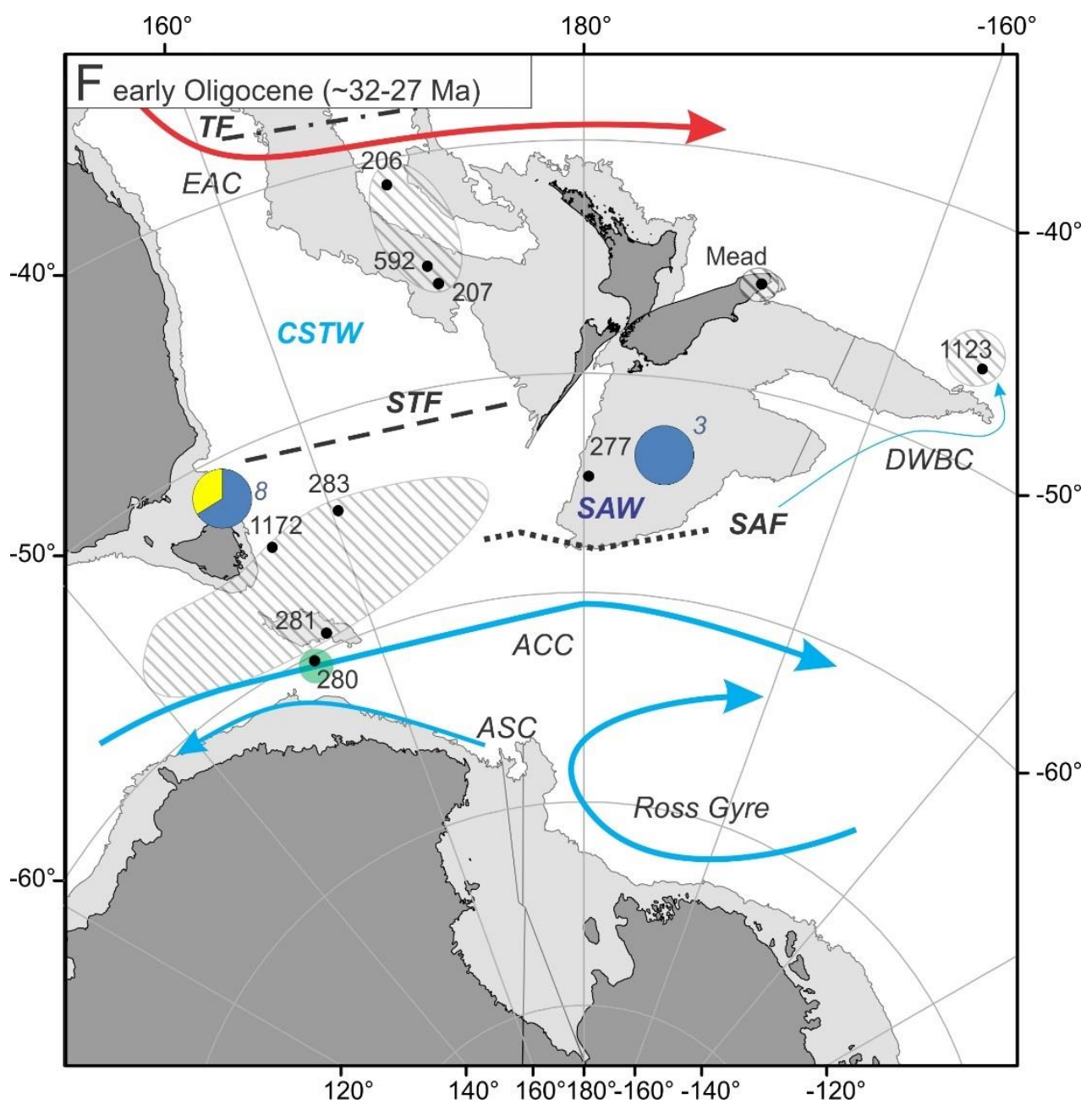

Figure 7.12 Biogeographic affinities and paleoceanographic reconstruction for the early Oligocene ( 32-27 Ma). Slightly different time slices apply for each site: Site 1172 ( 28-26.6 Ma), Site 277 ( 31.9 Ma). Biogeographic affinity pies show $\%$ only of the biogeographic constrained portions of the assemblage. For key refer to Figure 7.7; modified after Pascher et al. (2015). 


\section{Conclusion}

\subsection{Key findings}

The long-term cooling trend from the 'greenhouse' early Eocene to late Eocene was punctuated by several large-scale climatic perturbations that culminated in a shift to an 'icehouse' climate at the Eocene-Oligocene transition. Radiolarian assemblages from high-latitude sites (DSDP sites 277, 280, 281, 283, ODP Site 1172) to mid-latitude sites (DSDP sites 206, 207, 592, ODP Site 1123) were examined to investigate the relative influence of low- and high-latitude water masses in the Southwest Pacific during the Eocene.

The key findings of this study are:

- Radiolarian-bearing sediments have been recovered from all sites, extending from the upper Paleocene to Oligocene (Teurian to Whaingaroan).

- All sites have been successfully correlated to the Southern Hemisphere radiolarian zonation, from the late Paleocene to Oligocene (RP6 $6_{\mathrm{SH}}$ to $\left.\mathrm{RP} 17_{\mathrm{SH}}\right)$.

- Two alternative datums are proposed for zone boundaries: LO of Artobotrys auriculaleporis for the base of RP10 ${ }_{\mathrm{sH}}$; LO of Lophocyrtis longiventer for the base of RP12 1 SH.

- Radiolarian occurrence, preservation and diatom occurrence varies greatly with latitude and through time. In general, high-latitude sites have abundant diatoms while radiolarian-rich sediments are mainly recovered from the late Eocene to early Oligocene. Mid-latitude sites have rare diatoms, and radiolarian-rich sediments are recovered mainly from the middle Eocene. The localised abundance of diatoms in the middle Eocene at Site 1172 (paleolatitude $\sim 56^{\circ} \mathrm{S}$ ) suggests coastal upwelling around the South Tasman Rise at this time maybe driven by strong polar easterlies.

- Stable oxygen and carbon isotope measurement of foraminifer tests from DSDP sites 277, 207 and 592 have been used to identify the following events: The EECO optimum and post-EECO cooling (Site 207), MECO (Site 277), PrOM event (Site 277), LECO (sites 277 and 592) and the Eocene-Oligocene transition (Site 277). 
- Radiolarian paleobiogeography has been successfully used as a guide for paleowater mass changes from the early Eocene to early Oligocene. In total, 134 of 259 radiolarian counting groups have been assigned to either high-latitude, cosmopolitan or low-latitude affinity. Mid-latitude sites 206 and 207 exhibit the largest number of low-latitude genera of all studied sites. However, many species of typically low-latitude genera such as Podocyrtis, Thyrsocyrtis, Lamptonium, Theocorys and Theocotyle are absent in the Southwest Pacific.

- The aim of this thesis, to investigate if trends in species turnover and geographic distribution of Paleogene radiolarians are consistent with geochemical evidence for extreme high-latitude warmth during the Eocene, has been achieved. In contrast to geochemical proxies $\left(\mathrm{TEX}_{86}, \mathrm{U}^{\mathrm{K}^{\prime}} 37\right.$ and $\left.\mathrm{Mg} / \mathrm{Ca}\right)$, that indicate tropical conditions at high-latitude sites during the warmest intervals within the Eocene, radiolarian assemblages do not indicate tropical conditions at any time during the Eocene. Instead, radiolarian assemblages indicate that warm subtropical water masses may have extended to $\sim 55^{\circ} \mathrm{S}$ during the EECO. It is likely that the protoTasman Front expanded southward to the high-latitude sites at this time, which would bring warm but not fully tropical surface waters into the region. Cool subtropical conditions prevailed at other times during the Eocene.

- The evolution of oceanic fronts was reconstructed for six different time slices from early Eocene to early Oligocene. The oscillation between cool and warm subtropical conditions is interpreted to have resulted from variations in the strength of the warm proto-East Australian Current and cool proto-Ross Gyre.

- During the late middle to early late Eocene/PrOM event ( $38-37 \mathrm{Ma})$, an expansion of proto-Ross Gyre led to proliferation of radiolarian assemblages, increase in diversity and abundance of high-latitude taxa offshore of Wilkes Land (sites 281, 283), Tasman Rise (Site 1172) and the Campbell Plateau (Site 277). During the LECO ( $36 \mathrm{Ma})$, radiolarian diversity and abundance of high-latitude taxa decrease on the Campbell Plateau (Site 277) and few low-latitude taxa appear in in the mid- to high-latitude sites of the Tasman Sea and Campbell Plateau (sites 277, 283 and 592).

- A second cooling interval from the latest Eocene to earliest Oligocene ( $35-32$ $\mathrm{Ma}$ ) resulted in the reappearance of many high-latitude taxa, diversification and increase in radiolarian abundance. At that time, Site 1123 (paleolatitude $\sim 48^{\circ} \mathrm{S}$ ) 
was the southernmost site with few low-latitude taxa, suggesting that the protoEast Australian Current had reduced influence in the region relative to the early and middle Eocene.

- A consequence of the development of the ACC in the early Oligocene ( 33 Ma) was wide-spread non-deposition in the Southwest Pacific. Furthermore, the ACC restricted the northward flow of proto-Ross Gyre over the Campbell Plateau. This resulted in a nutrient-depleted environment over Campbell Plateau, and an overall reduction in diversity, similar to the modern subantarctic setting.

Finally, this thesis provides valuable contributions to the fields of Paleogene radiolarian micropaleontology, biostratigraphy and paleoceanography.

\subsection{Future work}

Despite an incomplete core recovery of early drilling campaigns largely limiting the ability to resolve orbital-scale changes in the early to middle Eocene sediments in the Southwest Pacific, this study has identified that this region contains a critical archive for resolving Paleogene climatic and oceanography changes. For 2017/2018, the International Ocean Discovery Program (IODP) has scheduled several drilling campaigns in the Southwest Pacific and the Ross Sea. Specifically, IODP Expedition 371 'Tasman Frontier Subduction Initiation and Paleogene Climate' will recover Eocene sediments from the Lord Howe Rise and Tasman Sea. This thesis provides the base for assessing paleo-water mass changes in the Southwest Pacific during the Eocene and may turn out to be a valuable reference for this upcoming expedition, and for helping to identify locations for additional geological drilling. Furthermore, this thesis contributes a comprehensive taxonomic review of Eocene radiolarian taxa and is intended to be a useful reference for future radiolarian studies. With the additional of future drilling in this region, there remains considerable scope in the future regarding categorizing radiolarian species into biogeographic affinity groups based on their relative abundance at low-, mid- and highlatitude sites.

Following publications (to be submitted to peer-reviewed journals) will likely result from this thesis:

- Paleobiogeography of Southwest Pacific radiolarians, including the full taxonomic notes 
Chapter 8: Conclusion

- Integrated biostratigraphy (radiolarians, nannofossils, foraminifers) of Lord Howe Rise DSDP Site 207 and Site 277 on the Campbell Plateau

- Late Eocene climatic optimum at DSDP sites 277 and 592 
Appendix A: Taxonomic Notes 


\section{Subclass RADIOLARIA Müller 1858 \\ Suborder POLYCYSTINA Ehrenberg 1838, emend. Riedel 1967a}

\section{Order SPUMELLARIA Ehrenberg 1875}

\section{Family ACTINOMMIDAE Haeckel 1887, emend. Riedel 1967a}

Actinommidae n.sp. A sensu Hollis [Plate 1, fig. 1]

Actinommidae n.sp. A, Hollis et al. 1997, p. 45, pl. 1, fig. 18-19.

Medium-sized actinommid with slightly irregular spheroidal cortical shell. Pores numerous, closely spaced, circular in regular hexagonal frames. Eight evenly spaced, slender, bladed radial spines. One or two medullary shells.

\section{Genus AMPHISPHAERA Haeckel, emend. Petrushevskaya 1975}

The genus name is applied in the sense of Petrusheskaya (1975). See Hollis (1997) for further discussion.

Amphisphaera coronata group (Ehrenberg), New Group [Plate 1, fig. 2]

Stylosphaera coronata Ehrenberg 1873, p. 258; 1875, pl. 25, fig. 4; Ogane et al. 2009, pl.

12, fig. 1a-d; Suzuki et al. 2009, p. 244, pl. 1, fig. 13a-b.

Stylosphaera radiosa Ehrenberg 1875, pl. 24, fig. 5.

Ellipsostylus anisoxyphos Clark and Campbell 1942, p. 32, pl. 5, fig. 7, 11.

Lithatractus hederae Clark and Campbell 1942, p. 33, pl. 5, fig. 3.

Lithatractus pterosphaerus Clark and Campbell 1942, p. 33, pl. 5, fig. 33.

Stylosphaera coronata coronata (Ehrenberg), Sanfilippo and Riedel 1973, p. 520, pl. 1,

fig. 13-17, pl. 25, fig. 4; Nishimura 1992, p. 329, pl. 1, fig. 2, pl. 11, fig. 9; Sanfilippo

and Blome 2001, p. 217.

Stylosphaera coronata laevis (Ehrenberg), Sanfilippo and Riedel 1973, p. 520, pl. 1, fig.

19, pl. 25, fig. 5-6.

Stylosphaera coronata sabaca (Ehrenberg), Sanfilippo and Riedel 1973, p. 521, pl. 1, fig. 18, pl. 25, fig. 57-8.

Amphisphaera spp. gr. D. Hollis 1991, p. 71, pl. 3, fig. 20; 1993, p. 319.

Amphisphaera coronata Ehrenberg s.1., Hollis 1997, p. 35, pl. 2, fig. 14-17; Hollis et al. 1997, p. 42.

Stylosphaera gigantea (Haeckel), Suzuki et al. 2009, p. 244, pl. 1, fig. 9.

Stylosphaera ex. gr. radiosa Ehrenberg, Suzuki et al. 2009, p. 244, pl. 1, fig. 8.

This species group includes all members of the genus with a subspherical to ellipsoidal outer shell and opposing polar spines of unequal length. Sanfilippo and Riedel (1973) distinguished $A$. coronata s.s. by the shorter polar spine having an arrow-shaped termination. Reillustration of the type specimen (Ogane et al., 2009) indicates that the species may be even more narrowly defined: the shorter polar spine has distinct ridges and increases in width prior to the arrow-like termination. The morphotype Sanfilippo 
and Riedel (1973) consider typical S. coronata compares well with Lithatractus hederae Clark and Campbell. Many of the other bipolar spumellarians described by Clark and Campbell (1942) are included in A. coronata group here. However, these narrow definitions do not reflect how the name has been applied in the past (e.g. Nishimura 1992; Suzuki et al., 2009) and so a broad definition of the species group that accommodates a wide range of variation was used. A. macrosphaera is distinguished by a spherical outer shell and the shorter spine being no longer than the width of the outer shell. A. spinulosa is distinguished by having at least one additional spine outside the polar plane. Suzuki et al.'s (2009) Stylosphaera gigantea and Stylosphaera ex. gr. radiosa are included in the concept of A. coronata group here.

BIOGEOGRAPHIC AFFINITY: Cosmopolitan.

\section{Amphisphaera macrosphaera (Nishimura)}

Druppatractus sp., Dumitrica 1973, p. 787, pl. 12, fig. 3.

Stylosphaera coronata (Ehrenberg), Nishimura 1987, p. 729, pl.1, fig. 1-2.

Amphisphaera radiosa (Ehrenberg), Hollis 1991, p. 71, pl. 3, fig. 16-19; 1993, p. 319, pl.

1, fig. 6; Strong et al. 1995, p. 208; Crouch and Hollis 1996, p. 26; (non Ehrenberg, 1854b).

Stylosphaera coronata macrosphaera Nishimura 1992, p. 325, pl. 1, fig. 3, 4; pl. 11, fig. 1.

Amphisphaera macrosphaera (Nishimura), Hollis 1997, p. 34, pl. 2, fig. 1-2; Hollis et al. 1997, p. 43.

Distinguished by its spherical outer shell and very short polar spines.

Amphisphaera radiosa (Ehrenberg) [Plate 1, fig. 3a, b]

Stylosphaera radiosa Ehrenberg, 1854a, p. 246; 1875, pl. 24, fig. 5; Ogane et al. 2009, pl. 12, fig. 3a-4e (non Abelmann 1990).

Ellipsoxiphus? sp., Hollis et al. 1997, pl. 1, fig. 3-4.

This distinctive species is characterised by a strongly ellipsoidal outline, thickened outer shell and two polar spines of unequal length, the shorter spine being as long as the thickness of the outer shell.

\section{Amphisphaera aff. radiosa (Ehrenberg) = Stylosphaera radiosa sensu Abelmann \\ [Plate 1, fig. 4a, b] \\ Stylosphaera radiosa Ehrenberg, Abelmann 1990, p. 692, pl. 2, fig. 4a, b, c, 7; (?) Caulet 1991, p. 539 (non Ehrenberg 1854). \\ Amphisphaera radiosa (Ehrenberg), Hollis et al., 1997, p. 43, pl. 1, fig. 5-6 (non Crouch and Hollis 1996, p. 26, = A. macrosphaera). \\ ? Amphisphaera radiosa (Ehrenberg), Petrushevskaya 1975, p. 570, pl. 2, fig. 18-20.}

The species ascribed to $S$. radiosa by Abelmann (1990) bears little resemblance to the type specimen reillustrated by Ogane et al. (2009). Abelmann (1990) suggests that $A$. radiosa has a more spherical shell than $A$. coronata but this is clearly not the case. $A$. radiosa s.s. has a more ellipsoidal shell than $A$. coronata and is further distinguished by a thicker outer shell and more smoothly tapering polar spines, the shorter one of which is no longer than the thickness of the outer shell. The species referred to A. aff radiosa here has a relatively small but thickened outer shell, which is subspheroidal, and one very short polar spine. Additional short spines or thorns may be present. This species compares 
well with the species reported by Petrushevskaya (1975) but is only tentatively synomised with the species described by Abelmann (1990) in which the shorter spine varies in length. The Late Oligocene FAD of this species at ODP Sites 689 and 690 is used to define the base of Abelmann's (1990) Stylophaera radiosa zone. The wider utility of this zone is questionable as A. aff. radiosa first appears in the late Eocene at DSDP Site 277.

Amphisphaera spinulosa (Ehrenberg) = A. goruna (Sanfilippo and Riedel) $[$ Plate 1, fig. 5]

Stylosphaera spinulosa Ehrenberg 1873, p. 259; 1875, pl. 25, fig. 8; Caulet 1991, p. 539;

Ogane et al. 2009, pl. 12, 6a-f (erroneously recorded as Stylosphaera liostylus).

Druppatractus cf. coronatus (Squinabol), Dumitrica 1973, p. 787, pl. 6, fig. 4,6; pl. 12, fig. 11.

Stylosphaera goruna Sanfilippo and Riedel 1973, p. 521, pl. 1, fig. 20-22; pl. 25, fig. 9, 10 (? fig. 11); Nishimura 1987, p. 729, pl. 1, fig. 3; Nishimura 1992, p. 329, pl. 1, fig. 1; pl. 11, fig. 8; Sanfilippo and Blome 2001, p. 219.

Amphisphaera spinulosa (Ehrenberg), Petrushevskaya 1975, p. 570, pl. 15, fig. 8; Hollis 1991, p. 69, pl. 3, fig. 11-15; 1993, p. 318, pl. 1, fig. 5.

Amphisphaera goruna (Sanfilippo and Riedel). Strong et al. 1995, p. 208, fig. 8G, 9A;

Hollis 1997, p. 34, pl. 2, fig. 10, 11; Hollis et al. 1997, p. 42.

With the reillustration of Ehrenberg's type specimen of this species (Ogane et al. 2009) there can be little doubt the A. goruna is a junior synonym of A. spinulosa. The discontinuous range observed at Mead Stream (Strong et al. 1995; Hollis 1997) and possibly other regions may be a response to climatic changes, with the species appearing to show a preference for the cooler conditions of the Paleocene and the late Middle Eocene to Oligocene. BIOGEOGRAPHIC AFFINITY: Cosmopolitan.

Amphisphaera? megapora (Ehrenberg) [Plate 1, fig. 6]

Cenosphaera megapora Ehrenberg 1873, p. 218, 1875, pl. 3, fig. 1; Ogane et al. 2009, pl. 3 , fig. 1a-c.

Amphisphaera aff. spinulosa (Ehrenberg), Crouch and Hollis 1996, p. 26; Hollis et al. 1997, p. 43, pl. 1, fig. 1,2.

? Amphisphaera spinulosa (Ehrenberg) group. Petrushevskaya 1975 (in part), p. 570.

Distinguished from A. spinulosa by a spherical cortical shell and the absence of distinct polar spines. All radial spines are of similar length. As A. spinulosa was not encountered in Site 281 material (Crouch and Hollis 1996) it seems likely that the form recorded from the Eocene of DSDP Site 280 by Petrushevskaya (1975) is A. megapora.

\section{Genus ANOMALACANTHA Loeblich \& Tappan 1961}

Anomalacantha dentata (Mast) [Plate 1, fig. 7]

Heteracantha dentata Mast 1910 p. 159, pl. 37, fig. 47,

Anomalacantha dentata (Mast), Benson 1966, p. 170, pl. 5, fig. 10-11.

Anomalocantha dentata [sic] (Mast), Petrushevskaya and Kozlova 1979, fig. 219, 427.

Cladococcus eocenica (Petrushevskaya and Kozlova 1979), Suzuki et al. 2009, p. 244, pl. 2, fig. 9 .

Genus STYLOSPHAERA Ehrenberg, emend. Petrushevskaya 1975 
Stylosphaera minor Clark and Campbell group [Plate 1, fig. 8]

Stylosphaera minor Clark and Campbell 1942, p. 27, pl. 5, fig. 1, 2, 2a, 12; Petrushevskaya 1975, p. 569; Caulet 1986, p. 853; 1991, p. 539; Strong et al. 1995, p. 209; Shilov 1995, p. 124, pl. 3, fig. 2.

Amphisphaera minor (Clark and Campbell), Sanfilippo and Riedel 1973, p. 486, pl. 1, fig. 1-5; pl. 22, fig. 4; Chen 1975, p. 452, pl. 3, fig. 1; Westberg-Smith and Riedel 1984, p. 486.

Axoprunum minor (Clark and Cambell), Suzuki et al. 2009, p. 241, pl. 4, fig. 5a-6c.

Included in this complex are forms with a moderately large spherical, outer shell with numerous small circular pores, slender conical (rarely bladed) polar spines. Suzuki et al. (2009) observe the presence of equatorial beams and on this basis transfer the species to Axoprunum. These structures are not evident in the specimens referred to $S$. minor here. Similar specimens that have equatorial beams characteristic of Axoprunum are placed in A. pierinae gr. here.

BIOGEOGRAPHIC AFFINITY: Cosmopolitan.

\section{Genus ZEALITHAPIUM O’Connor 1999a}

Zealithapium anoectum (Riedel and Sanfilippo) [Plate 1, fig. 9]

Lithapium anoectum Riedel and Sanfilippo 1970, p. 520, pl. 4, fig. 4-5; Riedel and Sanfilippo 1973, p. 739; Palmer 1987, p. 356; Takemura 1992, p. 742, pl. 7, fig. 1. Zealithapium anoectum (Riedel and Sanfilippo), Nigrini et al. 2006, p. 56.

This species evolved from Z. plegmacantha and is the ancestor of Z. mitra (Sanfilippo and Riedel 1973).

BIOGEOGRAPHIC AFFINITY: Cosmopolitan

Zealithapium mitra (Ehrenberg) [Plate 1, fig. 10]

Cornutella mitra Ehrenberg, 1873, p. 221; 1875, pl. 2, fig. 8.

Lithapium mitra (Ehrenberg), Riedel and Sanfilippo 1970, p. 520, pl. 4, fig. 6, 7; Sanfilippo and Riedel 1973, p. 516; Palmer 1987, p. 356; Takemura 1992 (cf.), p. 742, pl. 7, fig. 2.; Hollis et al. 1997, p. 45, pl. 1, fig. 20.

Zealithapium mitra (Ehrenberg), O’Connor 1999a, p. 5-6, pl. 9, fig. 47; Moore and Kamikuri 2012, p. 13, pl. 10, fig. 5.

non Zealithapium mitra (Ehrenberg), Funakawa et al. 2006b, p. 44, pl. 17, fig. 5.

Distinguished by its single cortical shell in the shape of an inflated cone, narrowing slightly at the open end. Meshwork is coarse with thorns arising from junctions of pore frames. Only specimens with a simple horn are included. The specimens figured by Funakawa et al. (2006b) have the characteristic 'cockscomb-like' apical horn of Aspis sp. A of Hollis (2002). However, it is likely that true Z. mitra is present at both ODP Leg 199and at nearby IODP Site U1331 (Moore and Kamikuri 2012), being reported as abundant at both sites.

BIOGEOGRAPHIC AFFINITY: Cosmopolitan.

Zealithapium oamaru O'Connor [Plate 1, fig. 11]

Zealithapium oamaru O’Connor 1999a, p. 5, pl. 2, fig. 6-11, pl. 5, fig. 29-32. 


\section{Subfamily SATURNALINAE Deflandre 1953}

\section{Genus AXOPRUNUM Haeckel}

Axoprunum bispiculum (Popofsky) [Plate 1, fig. 12]

Stylacontarium bispiculum Popofsky 1912, p. 91, pl. 2, fig. 2; Chen 1975, p. 454, pl. 21, fig. 1-2.

Axoprunum bispiculum (Popofsky), Takemura 1992, p. 741, pl. 1, fig. 1-2; Hollis et al. 1997, p. 43. pl. 1, fig. 14; Takemura and Ling 1997, p. 111; Kamikuri et al. 2006, p. 7; (non Suzuki et al. 2009).

Distinguished from A. pierinae by a larger, almost spherical cortical shell and shorter polar spines, which often diverge slightly from main axis. Intermediate forms occur in the early Oligocene.

BIOGEOGRAPHIC AFFINITY: High latitude.

Axoprunum pierinae (Clark and Campbell) group, New Group [Plate 1, fig. 13, 14]

Lithatractus pierinae Clark and Campbell 1942, p. 34, pl. 5, fig. 25.

Sylatractus pictus Mamedov 1969, p. 99, pl. 2, fig. 4-4a.

Axoprunum pierinae (Clark and Campbell), Sanfilippo and Riedel 1973, p. 488, pl. 1, fig. 6-12, pl. 23, fig. 3; Petrushevskaya 1975, p. 571; Caulet 1991, p. 537; Takemura. 1992, p. 742, pl. 6, fig. 3-6; Nishimura 1992, p. 329; Strong et al. 1995, p. 208, fig. 10c; Crouch and Hollis 1996, p. 26; Hollis et al. 1997, p. 44, pl. 1, fig. 7-13; Takemura and Ling, 1997, pl. 1, fig. 1.

Axoprunum liostylum (Ehrenberg), Petrushevskaya and Kozlova 1972, p. 521, pl. 10, fig.

3; Petrushevskaya 1975, p. 571, pl. 2, fig. 22; Crouch and Hollis 1996, p. 26.

Axoprunum bispiculum (Popofsky), Suzuki et al. 2009, p. 241, pl. 1, fig. 3a-b.

Axoprunum venustum (Borisenko), Suzuki et al. 2009, p. 241, pl. 1, fig. 1, 2.

? Axoprunum euterpe (Haeckel), Caulet 1986, p. 852.

non Stylosphaera liostylus Ehrenberg 1875, pl. 25, fig. 2; Ogane et al. 2009, pl. 12, fig. 6a-f.

Ellipsoidal cortical shell with 2 conical polar spines, usually of unequal length; typically slender but may be thickened throughout or medially. One or two medullary shells supported by 2 strong polar beams and 4 evenly spaced equatorial beams. It is uncertain if this species group comprises a single polymorphic species or several distinct species. Variations in cortical shell thickness and size, polar spine thickness and shape, and shape of outer medullary shell may have some ecological significance. Morphotypes with thicker polar spines appear to be restricted to southern high latitude locations (e.g. Takemura 1992, pl. 6, fig. 3-4; Hollis et al., pl. 1, fig. 7; Takemura and Ling 1997, pl. 1, fig. 1; Suzuki et al., 2009, pl. 1, fig. 1), whereas morphotypes with medially inflated polar spines appear to have a bipolar distribution (e.g. Mamedov 1969, pl. 2, fig. 4-4a; Kozlova 1999, pl. 33, fig. 10, pl. 38, fig. 2; Suzuki et al. 2009, pl. 1, fig. 2). At Site 277, however, there appears to be a gradation between these specimens with thickened spines, specimens that conform with the type species and specimens with near-spherical cortical shells (Hollis et al. 1997, pl. 1, fig. 9). For this reason, this range of morphotypes is combined into a single species group here. This group accommodates the forms ascribed to A. liostylum by Petrushevskaya (1975) and probably several of the species ascribed to 
Axoprunum by Petrushevskaya and Kozlova (1972). Ehrenberg's species bears little resemblance to the genus and instead may well be a synonym for Amphisphaera spinulosa. No figure is available for A. euterpe but Haeckel's (1887, p. 135) description conforms with A. pierinae. A. venustum and A. aff. venustum of Suzuki et al. (2009) are included in the concept of $A$. pierinae.

BIOGEOGRAPHIC AFFINITY: Cosmopolitan.

Axoprunum? irregularis Takemura [Plate 1, fig. 15]

Actinomma medusa (Ehrenberg) gr., Petrushevskaya 1975 (in part), p. 568, pl. 2, fig. 6-8.

? Amphisphaera sp. Chen 1975, pl. 6, fig. 1.

Axoprunum? irregularis Takemura 1992, p. 742, pl. 3, fig. 8-11; Hollis et al. 1997, p. 44, pl. 1, fig. 15; Takemura and Ling, 1997, pl. 1, fig. 2.

Axoprunum irregularis Takemura, Apel et al. 2002, p. 17, pl. 1, fig. 15-16.

Irregular-shaped, almost polygonal cortical shell with two slender, conical polar spines, usually set askew to main axis. Two medullary shells are supported by more than 6 radial bars. Lacks diagnostic features of the genus (ellipsoidal cortical shell, 6 symmetrically arranged internal beams) but provisionally retained in Axoprunum because of a possible phylogenetic link with A. bispiculum (see Takemura 1992).

BIOGEOGRAPHIC AFFINITY: High latitude.

\section{Genus SATURNALIS Haeckel 1881, emend. Nigrini 1967}

Saturnalis circularis Haeckel [Plate 1, fig. 16]

Saturnalis circularis Haeckel 1887, p. 131; Nigrini 1967, p. 24, pl. 1, fig. 9; Chen 1975, p. 454 , pl. 24, fig. 2.

\section{Genus SPONGATRACTUS (Ehrenberg)}

Spongatractus pachystylus (Ehrenberg) [Plate 1, fig. 17] Spongosphaera pachystyla Ehrenberg, 1873, p. 256; 1875, pl. 26, fig.3.

Spongatractus pachystylus (Ehrenberg), Sanfilippo and Riedel, 1973, p. 519, pl. 2, figs.46; pl. 25, fig. 3, Kamikuri et al. 2012b, p. 4.

Thick-walled ellipsoidal shell covered with spongy meshwork, with two robust, bladed polar spines.

BIOGEOGRAPHIC AFFINITY: Low latitude (Note: One specimen in a picked sample for DSDP Site 277 (29-277-25, CC) was not included in the faunal affinity calculation).

\section{Family PHACODISCIDAE Haeckel 1881}

Genus HELIODISCUS Haeckel emend. O'Connor 1999b

= Astrophacus Haeckel (see O'Connor, 1999b)

Heliodiscus inca Clark and Campbell [Plate 2, fig. 1] 
Heliodiscus inca Clark and Campbell 1942, p. 38, pl. 3, fig. 17; Hollis et al. 1997, p. 45, pl. 1, fig. 25, 26.

Heliodiscus hexasteriscus Clark and Campbell 1942 (in part), pl. 3, fig. 15.

Astrophacus inca (Clark and Campbell), Caulet 1986, p. 851; 1991, p. 537.

Lenticular cortical shell with 6-10 moderately long, bladed marginal spines. Surface of cortical shell roughened by raised sepaloid points or thorns at junctions between welldeveloped hexagonal pore frames. Distinguished from $H$. linckiaformis and $H$. hexasteriscus s.s. by much longer spines.

\section{Genus HELIOSTYLUS Haeckel 1881}

Heliostylus spp. [Plate 2, fig. 2]

Heliostylus spp. Sanfilippo and Riedel 1973, p. 522, pl. 8, fig. 1-7, pl. 26, fig. 10-12, pl. 27, fig. 1.

This generic name was applied following Sanfilippo and Riedel (1973) to all phacodiscids with two opposite bars connecting the cortical and outer medullary shells. In general, the specimens are very large.

\section{Genus PERIPHAENA Ehrenberg 1873}

Periphaena decora Ehrenberg [Plate 2, fig. 3]

Periphaena decora Ehrenberg, 1873, p. 246; 1875, pl. 28, fig. 6; Sanfilippo and Riedel 1973, p. 523, pl. 8, fig. 8-10; pl. 27, fig. 2-5; Caulet 1986, p. 853; Palmer 1987, p. 356; Caulet 1991, p. 538; Takemura 1992, p. 743, pl. 6, fig. 8; Strong et al. 1995, p. 209, fig. 10j; Crouch and Hollis 1996, p. 26; Hollis et al. 1997, p. 46, pl. 1, fig. 2124; Scient.Party ODP 171B, 1998; Funakawa et al. 2006b, p. 42, pl. 15, fig. 5-6; Kamikuri et al. 2012b, p. 4.

Heliodiscus pertsus [sic] Haeckel, Suzuki et al. 2009, p. 246, pl. 3, fig. 10.

Lenticular cortical shell with a marginal girdle of varying width, with or without marginal spines. Surface of cortical shell smooth, with numerous small pores. Heliodiscus pertsus of Suzuki et al. (2009) conforms to this concept of P. decora.

BIOGEOGRAPHIC AFFINITY: Cosmopolitan.

Periphaena heliastericus (Clark and Campbell) [Plate 2, fig. 4]

Heliodiscus heliastericus Clark and Campbell, p. 39, pl. 3, fig. 10, 11.

Periphaena heliasteriscus [sic] (Clark and Campbell), Sanfilippo and Riedel 1973, p. 523, pl. 9, fig. 1-6; pl. 27, fig. 8, 9; Caulet 1986, p. 853; 1991, p. 538; Caulet 1991, p. 538; Takemura 1992, p. 743, pl. 4, fig. 13; Strong et al. 1995, p. 209, fig. 10h; Crouch and Hollis 1996, p. 26.

Periphaena heliastericus (Clark and Campbell), Hollis et al. 1997, p. 46.

Heliodiscus perplexus Clark and Campbell, Suzuki et al. 2009, pl. 3, fig. 11.

Distinguished from $P$. decora by absence of marginal girdle. Usually has marginal spines. Heliodiscus perplexus of Suzuki et al. (2009) conforms to this concept of P. heliastericus. BIOGEOGRAPHIC AFFINITY: Cosmopolitan. 
Periphaena? duplus (Kozlova) [Plate 2, fig. 5]

Phacodiscus duplus Kozlova and Gorbovetz 1966, p. 69, pl. 11, fig. 2; Hollis et al. 1997, p. 46 , pl. 2, fig. 1-5.

Inflated lenticular test with rounded margin. Surface smooth with closely-spaced irregular rounded pores. Internal meshwork usually dense. A small spherical shell evident in the centre of some specimens, otherwise interior dense, due to secondary infilling. Rare forms with marginal spines or a hyaline girdle are provisionally included.

\section{Family SPONGODISCIDAE Haeckel 1862, emend. Riedel 1967a}

\section{Genus FLUSTRELLA Ehrenberg 1838}

Flustrella charlestonensis (Clark and Campbell) [Plate 2, fig. 6]

Porodiscus charlestonensis Clark and Campbell 1945, p. 23, pl. 3, fig. 11-16; Suzuki et al. 2009, p. 252, pl. 13, fig. 9-12.

Stylotrochus charlestonensis (Clark and Campbell), Sanfilippo and Riedel 1973, p. 525, pl. 13, fig. 9-14; pl. 30, fig. 7-10.

Flustrella sp. B, Suzuki et al., 2009, p. 252, pl. 15, fig. 1a-6b.

This species name was applied to all discoidal forms composed of well-defined, closely spaced concentric rings, with or without short marginal spines.

Flustrella sp. H sensu Suzuki [Plate 2, fig. 7]

Flustrella sp. H, Suzuki et al., 2009, p. 253, pl. 15, fig. 7a-8b.

This morphotype closely resembles Flustrella charlestonensis, except that it bears a pylom. It might be a variant of $F$. charlestonensis as they co-occur in assemblages of Site 207.

\section{Genus LITHOCYCLIA Ehrenberg 1847}

Lithocyclia spp. [Plate 2, fig. 8]

The specimens found at Site 1123 and 206 are incomplete, the distal part of the spongy disc is missing, so it cannot be determined whether they belong to L. ocellus or $L$. aristotelis.

BIOGEOGRAPHIC AFFINITY: Low latitude.

Lithocyclia aristotelis [Plate 2, fig. 9]

Astromma aristotelis Ehrenberg, 1847, p. 55, fig. 10; 1873, p. 217; 1875, pl. 30, fig. 3, 4

Astractinium aristotelis (Ehrenberg) group, Petrushevskaya and Kozlova 1972, p. 524, pl. 17, fig. 1

Lithocyclia aristotelis (Ehrenberg), Riedel and Sanfilippo 1970, p. 522, pl. 13, fig. 1,2 
Lithocyclis aristotelis (Ehrenberg) group, Riedel and Sanfilippo 1971, p. 1588, pl. 3A, figs. 4, 5; 1973, p. 739; 1978, p. 70, pl. 6, fig. 6; 1986, pl. 2, figs. 23, 24; Moore 1971, p. 737, pl. 4, figs. 4, 5; Sanfilippo and Riedel 1973, p. 523; 1974, p. 1022; Dinkelman 1973, p. 768; Johnson 1974, p. 545, pl. 5, figs. 13, 14; 1976, p. 435; 1978, p. 781; Nigrini 1974, p. 1065, pl. 2A, fig. 7; Holdsworth 1975, p. 528; Ling 1975, p. 725, pl. 3, figs. 7, 8; Renz 1984, p. 459; Sanfilippo et al. 1985, p. 653, fig. 7.2a-2c (partim); Nigrini and Sanfilippo 2000, p. 73; Funakawa et al. 2006b, p. 41, pl. 14, fig. 3-4; Moore and Kamikuri 2012, p. 8, pl. 5, fig. 6, 9.

BIOGEOGRAPHIC AFFINITY: Low latitude.

Lithocyclia ocellus Ehrenberg group [Plate 2, fig. 10]

Lithocyclia ocellus Ehrenberg 1854b, pl. 36, fig. 30; 1873, p. 240; Petrushevskaya and Kozlova, 1972, p. 523, pl. 15, figs. 1, 2.

Lithocyclia ocellus Ehrenberg group, Riedel and Sanfilippo 1970, p. 522, pl. 5, fig. 1-2; Sanfilippo and Riedel 1973, p. 523, pl. 10, fig. 1-2; Funakawa et al. 2006b, p. 42, pl. 15, fig. 1; Nigrini et al. 2006, p. 42; Moore and Kamikuri 2012, p. 8, pl. 6, fig. 2.

BIOGEOGRAPHIC AFFINITY: Low latitude.

\section{Genus PERICHLAMYDIUM Ehrenberg 1847}

Perichlamydium limbatum Ehrenberg [Plate 2, fig. 11]

Perichlamydium limbatum Ehrenberg 1847, p.43; 1854b, pl 22, fig 20; Haeckel, 1887, p. 514; Petrushevskaya, 1975, p. 575, pl. 6, fig. 11; pl. 39, figs. 1-4; Kruglikova 1977, pl 110, fig. 15.

\section{Genus PLECTODISCUS Kozlova 1972}

Plectodiscus circularis (Clark and Campbell) [Plate 2, fig. 12]

Porodiscus circularis Clark and Campbell 1945, p. 42, pl. 11, fig. 2, 6, 10.

Plectodiscus circularis (Clark and Campbell), Petrushevskaya and Kozlova 1972, p. 526, pl. 19, fig. 9-12; Hollis 2002, p. 288, pl. 2, fig. 20-22.

Xiphospira circularis (Clark and Campbell), Sanfilippo and Riedel 1973, p. 526, pl. 14, fig. 5-12; pl. 31, fig. 4-7; Nishimura 1992, p. 329, pl. 12, fig. 9.

Circodiscus circularis (Clark and Campbell), Suzuki et al. 2009, p. 254, pl. 16, fig. 12$13 b$.

Circodiscus sp. A and C, Suzuki et al. 2009, p. 254, pl. 17, fig. 1a-9.

The broad definition of this species follows Sanfilippo and Riedel (1973). Circodiscus sp. A and C of Suzuki et al. (2009) conform to this concept of P. circularis.

BIOGEOGRAPHIC AFFINITY: Cosmopolitan.

\section{Genus RHOPALODICTYUM Clark and Campbell 1942}

Rhopalodictyum californicum [Plate 2, fig. 13] 
Rhopalodictyum californicum Clark and Campbell 1942, p. 49, pl. 1, fig. 13; Funakawa et al. 2006b, p. 45, pl. 17, fig. 10.

BIOGEOGRAPHIC AFFINITY: Cosmopolitan.

\section{Genus SPONGODISCUS Ehrenberg 1854a}

\section{Spongodiscus communis Clark and Campbell}

Spongodiscus communis Clark and Campbell 1942, p. 47, pl. 2, fig. 1, 11, 13 ,14; Suzuki et al. 2009, p. 252, pl. 13, fig. 9-12.

Spongodiscus americanus Kozlova \& Gorbovets 1966, p. 88, pl. 14, fig. 1-2; Sanfilippo and Riedel 1973, p. 524, pl. 11, fig. 9-13; pl. 27, fig. 1; pl. 28, fig. 9; Caulet 1991, p. 539; Nishimura 1992, p. 329.

Large discoidal test with weak concentric layers; may bear a marginal notch.

BIOGEOGRAPHIC AFFINITY: Cosmopolitan.

Spongodiscus craticulatus (Stöhr) [Plate 2, fig. 14]

Spongodiscus craticulatus (Stöhr), Petrushevskaya 1975, pl. 5, fig. 9-10.

Ommatodiscus sp. A Suzuki et al 2009, pl. 14, fig. 6-11.

Spongodiscus cruciferus (Clark and Campbell) [Plate 2, fig. 15]

Spongasteriscus (Spongasteriscinus) cruciferus Clark and Campbell 1942, p. 50, pl. 1, fig. 1-6, 8, 10, 11, 16-18; Sanfilippo and Riedel 1973, p. 524, pl. 11, fig. 14-17; pl 28, fig. 10, 11; Riedel and Sanfilippo 1973, p. 740; Sanfilippo and Riedel 1974, p. 1024; Caulet 1991, p. 539; Crouch and Hollis 1996, p. 26; Hollis et al., 1997, O'Connor 1999a, p. 36, pl. 10, fig. 20; p. 50; Suzuki et al. 2009, p. 252, pl. 14, fig. 1a-5b.

BIOGEOGRAPHIC AFFINITY: Cosmopolitan.

Spongodiscus festivus (Clark and Campbell) [Plate 2, fig. 16]

Stylotrochus festivus Clark and Campbell 1942, p. 48, pl. 2, fig. 5-8; Suzuki et al. 2009, p. 251, pl. 13, fig. 4-7.

Stylotrochus nitidus Sanfilippo and Riedel 1973, p. 525, pl. 13, fig. 9-14, pl. 30, fig. 7-10; Caulet 1991, p. 539; Nishimura 1992, p. 329.

This species is distinguished by having numerous cylindrical spines radiating from the margin. Forms with an internal meshwork that ranges from densely spongy ( $S$. festivus s.s.) to being arranged in closely-spaced concentric rings (S. nitidus s.s) are included here. BIOGEOGRAPHIC AFFINITY: Cosmopolitan.

Spongodiscus rhabdostylus (Ehrenberg) [Plate 2, fig. 17] Spongosphaera rhabdostyla Ehrenberg 1873, p. 256; 1875, pl. 26, fig. 1-2. Stylotrochus rhabdostylus (Ehrenberg), Haeckel 1887, p. 584.

Spongodiscus rhabdostylus (Ehrenberg), Sanfilippo and Riedel 1973, p. 525, pl. 13, fig.

1-3, pl. 30, fig. 1-2; Caulet 1991, p. 539; Hollis 1997, p. 51, pl. 10, fig. 6-8.

Spongodiscus rhabdostyla (Ehrenberg), Suzuki et al. 2009, p. 251, pl. 13, fig. 1-3. 
Lenticular test with irregular spongy meshwork and usually four robust conical radial spines. In contrast to Sanfilippo and Riedel (1973) but in line with Suzuki et al. (2009), forms with up to 10 radial spines are included here.

BIOGEOGRAPHIC AFFINITY: Cosmopolitan.

\section{Genus SPONGOPYLE Dreyer 1889}

Spongopyle osculosa Dreyer [Plate 2, fig. 18]

Spongopyle osculosa Dreyer, 1889, p. 42, pl. 6, fig. 99, 100; Riedel 1958, p. 226, pl. 1, fig. 12; Ling 1975, p. 725, pl. 4, fig. 6; Abelmann 1990, p. 693, pl. 3, fig. 11; Apel et al. 2002, p. 21; Expedition IODP 306, 2006.

Spongodiscus osculosus (Dreyer), Chen 1975, p. 455, pl. 24, fig. 4; Caulet 1991, p. 539; Hollis et al. 1997, p. 50; Suzuki et al. 2009, p. 251, pl. 12, fig. 12-14.

Spongodiscus resurgens Ehrenberg osculosa (Dreyer), Petrushevskaya 1975, p. 574, pl. 5, fig. 11; pl. 36, fig. 1-4.

Spongodiscus sp. D Suzuki et al. 2009, p. 252, pl. 12, fig. 10-11.

Spongodiscus osculosa (Dreyer), Suzuki et al. 2009, p. 251, pl. 12, fig. 12-14.

All forms with a circular to oval outline, covered with a spongy meshwork, no internal structure visible and a pylome or notch on the rim are included here. Spongodiscus sp. D of Suzuki et al. (2009) also conforms to this concept of S. osculosa.

BIOGEOGRAPHIC AFFINITY: High latitude.

\section{Genus SPONGOSTAURUS Haeckel 1881}

Spongostaurus sp. [Plate 2, fig. 19]

? Flustrella sp. G Suzuki et al. 2009, p. 253, pl. 14, fig. 12, 13.

Discoidal form with 4 strong, bladed radial spines on the margin. The encountered specimen is covered with spongy meshwork, unlike Suzuki's specimen, that is clearly showing rings.

\section{Genus STYLODICTYA Ehrenberg 1847, emend. Petrushevskaya and Kozlova 1972}

Stylodictya spp. [Plate 2, fig. 20]

Due to time constraints and often incomplete specimens, this genus has not been differentiated to the level of species. All specimens included in the genus here are clearly identified based on the rosette shape of the first ring and the presense of four main radial beams that extend out from the test margin as short spines.

\section{Genus TRIPODICTYA Haeckel 1881}

Tripodictya sp. [Plate 2, fig. 21]

The morphotype encountered in this study has concentric rings and three radial spines, emerging from the margin of the disc at equal angles. 


\section{Family SPONGURIDAE Haeckel 1862, sensu Petrushevskaya}

\section{5}

Genus AMPHICRASPEDUM Haeckel 1881, sensu Sanfilippo and Riedel 1973

Amphicraspedum murrayanum Haeckel [Plate 3, fig. 1]

Amphicraspedum murrayanum Haeckel 1887, p. 523, pl. 44, fig. 10; Sanfilippo and Riedel 1973, p. 524, pl. 10, fig. 3-6, pl. 28, fig. 1; Riedel and Sanfilippo 1973, p. 737; Sanfilippo and Riedel 1974, p. 1000; Nigrini 1974, p. 1065, pl. 3, fig. 2; WestbergSmith \& Riedel 1984, p. 488; Nishimura 1987, p. 719, pl. 1, fig. 14, 18; O’Connor 1999a, pl. 10, fig. 7; Sanfilippo and Nigrini 1998b, pl. 13.1, fig. 1; Nigrini and Sanfilippo 2000, pl. 3, fig. 11-13; Kamikuri et al. 2012b, p. 3.

BIOGEOGRAPHIC AFFINITY: Low latitude.

Amphicraspedum prolixum Sanfilippo and Riedel group [Plate 3, fig. 2, 3, 4, 5]

Amphicraspedum prolixum Sanfilippo and Riedel gr. 1973, p. 524, pl. 11, fig. 4-5, pl. 28, fig.5; Nishimura 1987, p. 719; Westberg-Smith and Riedel 1984, p. 488; Strong et al. 1995, p. 208; Caulet 1991, p. 537; O’Connor 1999a, pl. 8, fig. 3.

Amphicarydiscus gracilis (Lipman), Kozlova 1999 (in part), p. 98, pl. 15, fig. 5.

This species group includes spongurids with elongated cylindrical arms, usually with longitudinally aligned meshwork, and thickened at the ends; the test may or may not be inflated medially.

BIOGEOGRAPHIC AFFINITY: Low latitude.

Amphicraspedum prolixum Sanfilippo and Riedel sensu strictu [Plate 3, fig. 6, 7]

? Amphibrachium gracilis Lipman 1972, p. 55, pl. 9, fig. 11-13.

Amphicraspedum prolixum Sanfilippo and Riedel gr. 1973, p. 524, pl. 10, fig. 7-11, pl. 28, fig. 3-4.

Amphicarydiscus gracilis (Lipman), Kozlova 1999 (in part), p. 98, pl. 20, fig. 5 (mislabelled in the caption), pl. 22, fig. 15, pl. 42, fig. 1-2.

Amphicraspedium? prolixum Sanfilippo and Riedel, Kozlova 1999, p. 100, pl. 20, fig. 6, pl. 22, fig. 16, pl. 42, fig. 2 (also fig. 5).

This species is distinguished from A. prolixum gr. by having long cylindrical arms (sometimes $500 \mu \mathrm{m}$ in total length) with distinctly linear alignment of the meshwork, with bulbous or spathulate terminations. In his description of Amphibrachium gracilis, which is almost certainly the senior synonym of this species, Lipman (1972, p. 655) notes "the form of the ends of the apophyses varies: spathulate, rounded, tapered or blunt, thereby one end is almost always tapered, whereas the other one is more rounded." When spathulate, two short spines often diverge from the distalmost margin' when blunt a single spine or cluster of spines extend linearly from the centre of the knob-like termination. BIOGEOGRAPHIC AFFINITY: Low latitude.

\section{Genus AMPHYMENIUM Haeckel 1881}


Amphymenium splendiarmatum Clark and Campbell [Plate 3, fig. 8, 9]

Amphymenium splendiarmatum Clark and Campbell 1942, p. 46, pl. 1, fig. 12, 14; Sanfilippo and Riedel 1973, p. 524, pl. 11, fig. 6-8; pl. 28, fig. 6-8; Petrushevskaya 1975, p. 577, pl. 7, fig. 1; pl. 37, fig. 1-3; Caulet 1991, p. 537; O'Connor 1993, p. 40, pl. 2, fig. 16, 17; Apel et al. 2002, p. 16, pl. 4, fig. 8; Suzuki et al. 2009, p. 253, pl. 6, fig. 9-12; Kamikuri et al. 2012b, p. 3.

Amphymenium cf. splendiarmatum Clark and Campbell, Hollis 1997, p. 46, pl. 7, fig. 810; Hollis et al. 1997, p. 49, pl. 3, fig. 9.

? Tessarastrum sp. Caulet 1986, pl. 2, fig. 5.

BIOGEOGRAPHIC AFFINITY: Cosmopolitan.

\section{Genus HISTIASTRUM Ehrenberg 1847}

\section{Histiastrum quadribrachiatus quadribrachiatus (Sanfilippo and Riedel)}

[Plate 3, fig. 10, 11]

Stylotrochus quadribrachiatus quadribrachiatus (Sanfilippo and Riedel) 1973, p. 526, pl. 14, fig. 1-2, pl. 31, fig. 1; Weaver and Dinkelman 1978, p. 873; Johnson 1978, p. 784, pl. 1, fig. 10.

Spongaster? ignorabilis (Krasheninnikov), Kozlova 1999, p. 93, pl. 18, fig. 4, pl. 21, fig. 7, pl. 42, fig. 6 .

This species resembles $A$. murrayanum except there are four arms that form a cross, which may or may not be equally long, and covered in meshwork along the outline. At the ends spines can emerge.

BIOGEOGRAPHIC AFFINITY: Low latitude.

\section{Genus MIDDOURIUM Kozlova 1999}

Middourium regulare (Borissenko) [Plate 3, fig. 12]

Cromyodruppa regulare Borissenko 1958, p. 89, pl. 5, fig. 13, 14.

Spongurus? regularis (Borissenko), Nishimura 1992, p. 328, pl. 2, fig. 11, 12; pl. 12, fig. 4-6.

Prunopyle? sp. Hollis et al. 1997, pl. 2, fig. 11.

Middourium regulare (Borissenko), Kozlova 1999, p. 101, pl. 8, fig. 13; Hollis et al., 2005; Hollis 2006, p. S84, pl. 1, fig. 11, pl. 3, fig. 9.

Regular ellipsoidal test with well-developed narrow pylome. Outer surface smooth, with irregular, small, rounded pores, no spines. Internal meshwork may be dense or arranged in 5-10 concentric layers. Length $=200-250 \mu \mathrm{m}$.

Superficially similar to $P$. titan which is distiguished by a consistently dense internal meshwork. A similar species from the Eocene of California, Larcopyle occidentalis (Clark and Campbell), is distinguished by larger size (length $>300 \mu \mathrm{m}$ ), an egg-shaped test, dense internal meshwork, and a ragged pylome at the narrow pole. Distinguished from Monobracchium irregulare by a smooth outline without change in contour.

BIOGEOGRAPHIC AFFINITY: Low latitude, but so far only recorded in the boreal Paleogene, the North Atlantic and the Southwest Pacific during periods of warmer climatic condtions. 


\section{Genus MONOBRACHIUM Kozlova 1999}

Monobrachium irregulare (Nishimura) [Plate 3, fig. 13]

Prunopyle ovata Kozlova and Gorbovetz, p. 67, pl. 10, fig. 5-8; Hollis et al. 1997, p. 48, pl. 2, fig. 6-10.

Spongodiscid gen et sp. indet., Sanfilippo and Riedel 1973, pl. 27, fig. 10.

Spongurus? irregularis Nishimura 1992, p. 327, pl. 2, fig. 7-9; pl. 12, fig. 3, 7.

Monobrachium irregulare (Nishimura), Kozlova 1999, p. 102, pl. 7, fig. 3; pl. 43, fig. 89; Hollis et al., 2005; Hollis 2006, p. S84, pl. 1, fig. 12-13.

BIOGEOGRAPHIC AFFINITY: Low latitude, but so far only recorded in the boreal Paleogene, the North Atlantic and the Southwest Pacific during periods of warmer climatic condtions.

\section{Genus SPONGURUS Haeckel 1860}

Spongurus bilobatus Clark and Campbell [Plate 3, fig. 14, 15]

Spongurus bilobatus Clark and Campbell 1942, p. 36, fig. 7-9. Blueford 1988, p. 252, pl. 6, fig. 9; pl. 7, fig. 1; Shilov 1995, p. 124; Hollis et al. 1997, p. 50, pl. 3, fig. 5-6.; Suzuki et al. 2009, p. 247, pl. 6, fig. 13-19.

Spongurus illepidus Krasheninnikov, Suzuki et al. 2009, p. 248, pl. 5, fig. 11-16.

S. illepidus of Suzuki et al. (2009) is included in the concept of S. bilobatus.

BIOGEOGRAPHIC AFFINITY: Cosmopolitan.

\section{Family LITHELIIDAE Haeckel 1862}

All spumellarians with spherical to ellipsoidal cortical shells, an inner shell structure of closely spaced spiral or concentric layers, and with or without a pylome are included in this family.

\section{Genus LARCOPYLE Dreyer 1889, emend. Lazarus et al. 2005}

\section{Larcopyle spp.}

Spumellarians with an ellipsoidal or flattened ellipsoidal cortical shell (prune-shaped), usually bearing a pylome at one pole. A spongy, spiral, tightly concentric or pylonid inner shell structure is connected to the outer shell either directly (last whorl in spiral) or by randomly distributed radial beams that may form radial spines.

Larcopyle frakesi (Chen) [Plate 4, fig. 1, 2, 3]

Prunopyle frakesi Chen 1975, p. 454, pl. 10, fig. 1-3; Caulet 1991, p. 539; Takemura 1992, p. 742.

Lithocarpium monikae Petrushevskaya 1975, p. 572, pl. 4, fig. 6-10, pl. 30, fig. 1-7.

Cortical shell prune-shaped with small pylome, internal shell spongy. 
BIOGEOGRAPHIC AFFINITY: High latitude.

Larcopyle hayesi (Chen) [Plate 4, fig. 4]

Prunopyle hayesi Chen 1975, p. 454, pl. 9, fig. 3-5; Caulet 1986, p. 853; 1991, p. 539; Abelmann 1990, p. 693, pl. 3, fig. 14; Takemura 1992, p. 742, pl. 1, fig. 13, 14; Hollis et al. 1997, p. 48, pl. 2, fig. 12-14; Takemura and Ling, 1997, p. 114.

Ommatodiscus haeckeli Stöhr. Petrushevskaya 1975 (in part), p. 572, pl. 3, fig. 9, 12, 13; pl. 32, fig. 1-8.

Prunopyle cf. decipiens (Stöhr), Hollis et al. 1997, p. 47, pl. 2, fig. 18-24.

Larcopyle hayesi (Chen), Lazarus et al. 2005, p. 119, pl. 11, fig. 1-21.

Inflated ellipsoidal outer shell, with a densely spiral or concentric inner shell structure. Broad pylome is surrounded by short spines. All subspecies of L. hayesi are assigned to the high-latitude group (Larcopyle hayesi irregularis of Suzuki et al. (2009)).

BIOGEOGRAPHIC AFFINITY: High latitude.

Larcopyle labyrinthusa Lazarus [Plate 4, fig. 5]

Larcopyle labyrinthusa Lazarus et al. 2005, p.111, pl.5, figs. 14-24.

Subspherical whorl-shaped shell, beams connecting the spirals, pylome present with rather long teeth. Described from middle Miocene of Weddell Sea (Lazarus et al., 2005).

BIOGEOGRAPHIC AFFINITY: High-latitude

Larcopyle occidentalis (Clark and Campbell) [Plate 4, fig. 6a, b]

Prunopyle occidentalis Clark and Campbell 1942, p. 35, pl. 5, fig. 27.

Larcopyle occidentalis (Clark and Campbell), Suzuki et al. 2009, p. 249, pl. 8, fig. 1-3, pl. 9, fig. 1-13.

BIOGEOGRAPHIC AFFINITY: Cosmopolitan.

Larcopyle polyacantha (Campbell and Clark) group [Plate 4, fig. 7, 8]

Ommatodiscus fragilis Stöhr, 1880, p. 116, pl. 6, fig. 10.

Larnacantha polyacantha Campbell and Clark 1944a (in part), p. 30, pl. 5, fig. 4-6 (not fig. 7).

Prunopyle polyacantha (Campbell and Clark) Caulet 1991, p. 539; Crouch and Hollis 1996, p. 26; Hollis et al. 1997, p. 48, pl. 2, fig. 25-27 (also fig. 11).

Prunopyle titan Campbell and Clark 1944a, p. 20, pl. 3, fig. 1-3; Hays 1965, p. 173, pl. 2, fig. 4; Caulet 1986, p. 853. Abelmann 1990, p. 693, pl. 3, fig. 16.

Lithocarpium polyacantha (Campbell and Clark). Petrushevskaya 1975, p. 572, pl. 3, fig. 6-8 (also fig. 9), pl 29, fig. 6; Abelmann 1990, p. 694, pl. 4, fig. 2; O'Connor 1993, p. 37, pl. 2, fig. 12, 13.

Lithocarpium fragilis (Stöhr). Petrushevskaya 1975, p. 572, pl. 4, fig. 2-4.

Prunopyle sp. B gr. Abelmann 1990, p. 693, pl. 4, fig. 3a, b.

Prunopyle fragilis (Stöhr), Crouch and Hollis 1996, p. 26; Hollis et al. 1997, p. 47, pl. 2, fig. 28-29.

Prunopyle cf. titan Campbell and Clark, Crouch and Hollis 1996, p. 26; Hollis et al. 1997, p. 49, pl. 2, fig. 31-32.

Larcopyle polyacantha (Campbell and Clark) group, Lazarus et al. 2005, p. 106, pl. 2, fig. $1-17$; pl. 3, fig. 1; pl. 4, fig. 1-10. 
Subcylindrical to ellipsoidal cortical shell, usually with clusters of spines at one or both poles. Inner shell structure composed of weakly increasing single or double spirals; spongy meshwork may obscure spiral structure. Caps may develop at poles. A pylome is usually present. All subspecies of Larcopyle polyacantha are included in this group (including L. polyacantha amplissa of Suzuki et al. 2009).

BIOGEOGRAPHIC AFFINITY: High latitude.

Larcopyle cf. pylomaticus (Riedel) [Plate 4, fig. 9a, b]

Larcopyle pylomaticus (Riedel), Lazarus et al. 2005, p.115, pl.9, fig.1-12.

This species differs from L. pylomaticus by lacking a double spiral with constantly spaced whorls. The specimens have a thick shell with small pores, a diffuse, spongy inner structure and, occasionally, a strong pylome with teeth. It differs from the specimens illustrated by Lazarus et al. (2005) by having a more elliptical shape.

BIGEOGRAPHIC AFFINITY: High latitude.

\section{Genus LITHELIUS Haeckel 1862}

Lithelius minor Jörgensen group [Plate 4, fig. 10, 11, 12]

Litheliid gen. gr. A. Petrushevskaya and Kozlova 1972, p. 529, pl. 5, fig. 14, 15.

Lithelius minor Jörgensen, Nigrini and Moore 1979, p. S135, pl. 17, fig. 3, 4a, b. O'Connor 1993, p. 37, pl. 10, fig. 3, 4; Westberg-Smith et al. 1986, p. 772.

Lithelius minor Jörgensen gr. Hollis, 1997, p. 45. pl. 6, fig. 6-16; Hollis et al., 1997, p. 47. Ommatodiscus aff. haeckeli Stöhr, Hollis et al. 1997, p. 47, pl. 2, fig. 16, 17.

Larcopyle compositus (Mamedov), Suzuki et al. 2009, p. 250, pl. 5, fig. 17, pl. 10, fig. 17.

Larcopyle hayesi hayesi (Chen), Suzuki et al. 2009, p. 250, pl. 10, fig. 8-18.

This group includes all litheliids with densely concentric or spiral internal structures of varying width and size and that lack a pylome. Larcopyle compositus and Larcopyle hayesi hayesi of Suzuki et al. (2009), which don't have the characteristic pylome of Larcopyle, are included in this group.

BIOGEOGRAPHIC AFFINITY: Cosmopolitan.

\section{Genus SPHAEROPYLE Dreyer, 1889}

Spheroidal test with concentric inner shells and distinct pylome.

Sphaeropyle tetrapila (Hays) $=$ Larcopyle tetrapila / Prunopyle tetrapila $[$ Plate 4, fig. 13]

Prunopyle tetrapila Hays 1965, p. 172, pl. 2, fig. 5; Chen 1975, p. 454, pl. 23, fig. 3-4; Abelmann 1990, p. 693, pl. 3, fig. 16; Caulet 1991, p. 539; Takemura 1992, p. 742, pl. 2, fig. 1-2; Hollis et al. 1997, p. 48, pl. 2, fig. 30; Takemura and Ling 1997, p. 114.

Transferred to Sphaeropyle based on the spherical outline of the test.

BIOGEOGRAPHIC AFFINITY: High latitude. 


\section{Order NASSELLARIA Ehrenberg 1875}

\section{Family TRISSOCYCLIDAE Haeckel 1881, emend. Goll 1968}

Members of this family have not been differentiated, except for the taxa below.

Genus DORCADOSPYRIS Haeckel 1881, emend. Goll 1969

Dorcadospyris argisca (Ehrenberg) [Plate 5, fig. 1]

Petalospyris argiscus Ehrenberg 1873, p. 246; 1875, pl. 22, fig. 1-2; Ogane et al., 2009, pl. 2, fig. 11, pl. 18, fig. 7a-7e, pl. 39, fig. 8a-8c.

Dorcadospyris argisca (Ehrenberg), Chen 1975, p. 456, pl. 3, fig. 9; de Wever 1981, p. 511, pl. 2, fig. 11; Kamikuri et al. 2012b, p. 3.

BIOGEOGRAPHIC AFFINITY: Low latitude.

Genus GIRAFFOSPYRIS Haeckel 1881, emend. Goll 1969

Giraffospyris didiceros (Ehrenberg) [Plate 5, fig. 2]

Ceratospyris didiceros Ehrenberg 1873, p. 228; 1875, pl. 21, fig. 6.

Giraffospyris didiceros (Ehrenberg), Goll 1969, p. 332, pl. 60, fig. 5-7; Riedel and

Sanfilippo 1970, pl. 5, fig. 5; Chen 1975, p. 456, pl. 3, fig. 4; de Wever 1981, p. 511, pl. 2, fig. 13.

Dendrospyris didiceros (Ehrenberg), Kamikuri et al. 2012b, p. 3; 2013, fig. 6.7.

BIOGEOGRAPHIC AFFINITY: Low latitude.

\section{Genus TRISTYLOSPYRIS Haeckel 1881}

Tristylospyris triceros (Ehrenberg) [Plate 5, fig. 3]

Petalospyris triceros (Ehrenberg), de Wever 1981, p. 511.

Tristylospyris triceros (Ehrenberg). Sanfilippo et al. 1985, p. 665, fig. 10.3a, b. O'Connor 1993, p. 47, pl. 3, fig. 27, 28; Kamikuri et al. 2012b, p. 5; Moore and Kamikuri 2012, p. 12 , pl. 10 , fig. $2-4$.

BIOGEOGRAPHIC AFFINITY: Low latitude.

The occurrence of this taxon ranges from the middle Eocene to early Oligocene from low to middle latitudes, for which reason it is assigned to the low-latitude group.

\section{Genus ZYGOCIRCUS Bütschli 1882}

Zygocircus bütschli Haeckel [Plate 5, fig. 4] 
Zygocircus bütschli Haeckel, Petrushevskaya and Kozlova 1972, p. 534, pl. 41, fig. 8-11; Takemura 1992, p. 743, pl. 5, fig. 4; Hollis et al., 1997, pl. 3, fig. 11; Takemura and Ling, 1997, pl. 1, fig. 4.

BIOGEOGRAPHIC AFFINITY: Cosmopolitan.

Family PLAGIACANTHIDAE Hertwig 1879, emend.

Petrushevskaya, 1971a

\section{Genus AMPHICENTRIA Ehrenberg 1861}

Amphicentria sp. 1 sensu Suzuki [Plate 5, fig. 5]

Amphicentria sp. 1, Suzuki et al. 2009, p. 257, pl. 22, fig. 4.

This species is characterized by a large cephalis with a large apical pore.

BIOGEOGRAPHIC AFFINITY: High latitude.

\section{Genus ANTARCTISSA Petrushevskaya 1967}

Antarctissa cylindrica Petrushevskaya [Plate 5, fig. 6]

Antarctissa cylindrica Petrushevskaya 1975, p. 591, pl. 11, fig. 19-20; Caulet 1991, p. 537; Lazarus 1992, p. 797; Takemura 1992, p. 739.

BIOGEOGRAPHIC AFFINITY: High latitude.

Antarctissa robusta Petrushevskaya [Plate 5, fig. 7)

Antarctissa robusta Petrushevskaya 1975, p. 591, pl. 11, fig. 21-22; Abelmann 1990, p. 694; Caulet 1991, p. 537; Lazarus 1992, p. 797; Apel et al. 2002, p. 16, pl. 5, fig. 8.

BIOGEOGRAPHIC AFFINITY: High latitude.

\section{Genus ARCHIPILIUM Haeckel 1881}

Archipilium macropus (Haeckel) [Plate 5, fig. 8]

Sethopilium macropus Haeckel 1887 p.1203; pl.97, fig.9.

Archipilium spp. aff. A. macropus (Haeckel), Petrushevskaya and Kozlova 1972, pl. 29, fig. 14.

Archipilium macropus (Haeckel), Petrushevskaya 1981, p. 249.

\section{Genus CALLIMITRA Haeckel 1881, emend. Goll 1979}

Callimitra aff. atavia Goll [Plate 5, fig. 9]

? Callimitra atavia Goll 1979, p. 338, pl. 5, fig. 1, 5-9, 11. O'Connor 1993, p. 60, pl. 5, fig. 26, 27; Hollis et al. 1997, pl. 3, fig. 30. 
Differs from $C$. atavia by having a latticed cephalic structure connecting four branched spines, rather than a solid perforated cephalis.

\section{Genus CERATOCYRTIS Bütschli 1882, sensu Petrushevskaya 1971b}

Ceratocyrtis spp. [Plate 5, fig. 10, 11, 12]

This highly variable genus has not been differentiated. The genus is characterised by a small spherical cephalis with multiple short spines, a thorax that is often spinose in the upper part and has pores of irregular size and shape. Ceratocyrtis rhabdophora of Suzuki et al. (2009) is included.

BIOGEOGRAPHIC AFFINITY: High latitude.

\section{Genus CLADOSCENIUM Haeckel 1881}

Cladoscenium ancoratum Haeckel [Plate 5, fig. 13]

Cladoscenium ancoratum Haeckel 1887, pl. 53, fig.13.

Cladoscenium ancoratum Haeckel, Abelmann 1992, pl.4, fig. 9.

\section{Genus CORYTHOMELISSA Campbell 1951, sensu Petrushevskaya 1975}

Corythomelissa spp. [Plate 5, fig. 14, 15]

Species assigned to this genus have a broadly triangular outline, with a flattened cephalis bearing an apical horn; short feet extend from the lower thorax, which may or may not be closed. In the original description of Corythomelissa by Campbell 1951 (also Campbell 1953), based on Lithomelissa corythium Ehrenberg 1975, the genus is described by having multiple horns, which is is clearly not the case for the species listed below. The group of species is very diverse in the Eocene but has been little studied. For this reason, the genus name is conservatively applied in the sense of Petrushevskaya (1975) and Funakawa (1994, 1995), who described several species from the upper Oligocene to Miocene.

Corythomelissa adunca (Sanfilippo and Riedel) [Plate 5, fig. 16]

Spongomelissa adunca Sanfilippo and Riedel 1973, pl. 34, fig. 1-3 (partim).

Corythomelissa horrida Petrushevskaya, Takemura 1992, p. 744, pl. 3, fig. 14, Takemura and Ling 1997, p. 111.

Corythomelissa adunca (Sanfilippo and Riedel), Strong et al. 1995, p. 208, fig. 9b; Hollis et al., 1997, p. 51.

This species is distinguished from $C$. cucumella Sanfilippo and Riedel and $C$. horrida Petrushevskaya by the thorax being open at the base, although it may terminate in a thickened peristome with an internal rim. In these other two species, the thorax contracts distally and terminates in a constricted peristome, which may be closed with a latticed plate. In the specimen illustrated by Takemura (1992), the thorax is not constricted distally and instead terminates with a ragged margin. The same species is assumed to have been recorded by Takemura and Ling (1997). C. adunca bears some resemblance to Pseudodictyophimus gracilipes but is distinguished by its large hemispherical cephalis, 
comprising 2-3 lobes, and the absence of a well-developed vertical spine, extending outside the cephalis. If a vertical spine does protrude from the cephalis in $C$. adunca, it is surrounded by a short latticed tube. The specimens found in this study do not have latticed feet and, as such, differ slightly from the specimens illustrated by Sanfilippo and Riedel (1973).

\section{Genus LITHOMELISSA Ehrenberg 1847}

\section{Lithomelissa spp.}

Dicyrtid shell, large cephalis, sometimes with one or more horns, thorax bears three lateral wings, no terminal feet. This grouping includes all members of the genus that cannot be confidently ascribed to any of the species listed below due to poor or incomplete preservation. As all of these species have a high-latitude affinity, this undifferentiated genus is also assigned to the high-latitude group. However, the species recorded as Lithomelissa sp. 4, 5, F, G, H, I from ODP Site 1172 were not included as their illustrations were inadequate for comparison with the species listed below.

Lithomelissa challengerae Chen [Plate 6, fig. 1, 2, 3]

Lithomelissa challengerae Chen 1975, p. 457, pl. 8, fig. 3; Caulet 1991, p. 521,523; Takemura 1992, p. 744, pl. 4, fig. 11-12; Takemura and Ling 1997, p. 113.

BIOGEOGRAPHIC AFFINITY: High latitude.

Lithomelissa ehrenbergi Bütschli [Plate 6, fig. 4, 5]

Lithomelissa macroptera Ehrenberg 1875 (in part), pl. 3, fig. 8 (not fig. 9-10).

Lithomelissa ehrenbergi Bütschli 1882, p. 519, pl. 33, fig. 21; Haeckel 1887, p. 1204;

Caulet 1991, p. 538, pl. 2, fig. 3; Crouch and Hollis 1996, p. 26; Hollis et al. 1997, p.

51, pl. 3, fig. 17-20; Suzuki et al., 2009, p. 256, pl. 20, fig. 1a-b.

Lithomelissa sp. B aff. L. mitra Bütschli, Chen 1975, p. 458, pl. 8, fig. 4-5.

Lithomelissa haeckeli Bütschli, Suzuki et al. 2009, p. 256, pl. 20, fig. 2.

Characterised by a bulbous, perforated cephalis with well-developed apical, dorsal and lateral spines (see comments in Caulet 1991, p. 533, and figure in Ehrenberg 1875, pl. 3, fig. 8). Distinguished from L. haeckeli by having straight or slightly curved dorsal and lateral spines; spines in $L$. haeckeli are strongly convex. For this reason, the species referred to L. haeckeli by Suzuki et al. (2009) is included in L. ehrenbergi here.

BIOGEOGRAPHIC AFFINITY: High latitude.

Lithomelissa gelasinus O'Connor [Plate 6, fig. 6, 7]

Lithomelissa gelasinus O'Connor, 1997, pl. 2, fig. 3-6, pl. 6, fig. 6-9; Hollis et al. 1997, p. 52, pl. 3, fig. 15-16; Kamikuri et al. 2006, p. 8.

Poreless, but dimpled cephalis, irregular pore size on abdomen. Very similar to $L$. sphaerocephalis from which it is distinguished by a thorax which is cylindrical rather than conical and about as wide as the cephalis.

BIOGEOGRAPHIC AFFINITY: High latitude.

Lithomelissa cf. haeckeli Bütschli [Plate 6, fig. 8]

cf. Lithomelissa haeckeli Bütschli, 1882, p. 519, pl. 33, fig. 23. 
Lithomelissa cf. haeckeli Bütschli, Hollis et al. 1997, p. 52, pl. 3, fig. 22.

Uncertainly ascribed to $L$. haeckeli based on the strongly curved lateral spines.

Lithomelissa macroptera Ehrenberg [Plate 6, fig. 9a, b]

Lithomelissa macroptera Ehrenberg 1873, p. 241; 1875, pl. 3, fig. 9-10 (not fig. 8). non Dictyophimus macropterus (Ehrenberg), Takahashi 1991, p.116; pl.39, fig.8-11.

Haeckel 1887 does not illustrate this species and modern specimens (e.g. Takahashi) do not appear to conform to Ehrenberg's description.

Lithomelissa robusta Chen [Plate 6, fig. 10]

Lithomelissa robusta Chen 1975, p. 457, pl. 9, fig. 1, 2; Caulet 1991, p. 538; Funakawa and Nishi 2005, p. 233.

non Lithomelissa robusta Chen 1975, Hollis et al. 1997, p. 52, pl. 3, fig. 23; Abelmann 1990, p. 695, pl. 5, fig. 2.

Cephalis is markedly smaller than thorax. The specimen of Hollis et al. 1997 is Lithomelissa ehrenbergi. As pointed out by Funakawa and Nishi (2005), Abelmann's specimen differ from the original described specimen by lacking three thoracic wings.

BIOGEOGRAPHIC AFFINITY: High latitude.

Lithomelissa sphaerocephalis Chen [Plate 6, fig. 11]

Lithomelissa sphaerocephalis Chen 1975, p. 457, pl. 8, fig. 1, 2; Caulet 1991, p. 538; Takemura 1992, p. 744, pl. 4, fig. 8, 9; Crouch and Hollis 1996, p. 26; Hollis et al. 1997, p. 52, pl. 3. Fig. 12-13; Takemura and Ling 1997, p. 113.

Spheroidal cephalis, dimpled, poreless, and bears a short apical spine. Short downward directed dorsal and lateral spines. Thorax conical, with subcircular to irregular pores, often covered with spongy meshwork.

BIOGEOGRAPHIC AFFINITY: High latitude.

Lithomelissa tricornis Chen [Plate 6, fig. 12]

Lithomelissa tricornis Chen 1975, p. 458, pl. 8, fig. 6-7; Abelmann 1990, p. 695, pl. 5, fig. 3; Takemura 1992, p. 744, pl. 2, fig. 11-12; Hollis et al. 1997, p. 53; Takemura and Ling, 1997, p. 113.

Distinguished from other members of the genus by possessing three apical spines.

BIOGEOGRAPHIC AFFINITY: High latitude.

Lithomelissa? sakaii O'Connor [Plate 6, fig. 13, 14]

Lithomelissa sakaii O'Connor 2000, p. 200, pl.2, fig. 9-15.

Lithomelissa challengerae Chen, Hollis et al. 1997, p. 51, pl. 3, fig. 21.

Robust shell, latticed feet and apical horn, irregular pore size.

BIOGEOGRAPHIC AFFINITY: High latitude.

Genus LOPHOPHAENA Ehrenberg 1847, emend. Petrushevskaya 1971b 


\section{Lophophaena spp.}

Morphotypes assigned to this genus are nondescript, incomplete two-segmented plagiacanthids, that have a rather small cephalis with horn and lack the thoracic wings of Lithomelissa. Typically, very rare.

Lophophaena capito Ehrenberg [Plate 6, fig. 15]

Lophophaena capito Ehrenberg 1873, p. 242; 1875, pl. 8, fig. 6; Petrushevskaya and Kozlova 1972, p. 535, pl. 33, fig. 20-23; Petrushevskaya 1975, pl. 9, fig. 21 (not from Leg 29); Crouch and Hollis 1996, p. 26; Apel et al. 2002, p. 18, pl. 6, fig. 6; Funakawa et al. 2006b, p. 20, pl. 3, fig. 3-4.

This taxon has a large spheroidal cephalis with short horn and a small neck. It is distinguished from Lithomelissa by the absence of thoracic wings.

BIOGEOGRAPHIC AFFINITY: Cosmopolitan.

Lophophaena radians Ehrenberg [Plate 6, fig. 16]

Lophophaena radians Ehrenberg 1873, p. 243; 1875, pl. 8, fig. 7-9; Funakawa et al. 2006b, p. 20, pl. 3, fig. 5-6.

Lophophaenoma radians (Ehrenberg), Haeckel 1887, p. 1304; Caulet 1991, p. 538.

Lophophaena simplex Funakawa [Plate 6, fig. 17]

Lophophaena simplex Funakawa 1994, p.465-466, pl.8, fig.1a-2c

\section{Genus PSEUDODICTYOPHIMUS Petrushevskaya 1971b}

Pseudodictyophimus spp. [Plate 6, fig. 18, 19, 20, 21].

Undifferentiated members of this genus include incomplete or poorly preserved specimens and morphotypes wih a small cephalis with apical spine, long thoracic wings and a strong vertical secondary spine.

Pseudodictyophimus galeatus Caulet [Plate 6, fig. 22]

Pseudodictyophimus galeatus Caulet 1991, p. 534, pl. 2, fig. 9-10.

This species differs from Pseudodictyophimus gracilipes gr. by having a thick-walled, spongy shell.

BIOGEOGRAPHIC AFFINITY: High latitude.

Pseudodictyophimus gracilipes (Bailey) group [Plate 6, fig. 23, 24, 25]

Dictyophimus gracilipes Bailey 1856, p. 4, pl. 1, fig. 8; Abelmann 1990, p. 696, pl. 7, fig. 10.

Pseudodictyophimus gracilipes (Bailey), Petrushevskaya 1971b, p. 93, fig. 47-49; 1975, p. 592, pl. 11, fig. 17; Caulet 1986, p. 853; Apel et al. 2002, p. 20, pl. 7, fig. 12.

Lithomelissa dupliphysa Caulet, Crouch and Hollis 1996, p. 26.

Petrushevskaya (1971b) described two subspecies of $P$. gracilipes: $P$. gracilipes gracilipes and $P$. gracilipes tetracanthus. The latter is said to be confined to the tropics whereas the former is restricted to high latitudes (bipolar). However, the type specimen appears to bear closest resemblance to $P . g$. tetracantha despite being described from the boreal Kamchatka Sea (Bailey 1856). Nevertheless, the specimens encountered in our 
study are consistent with Petrushevskaya's inference as they most closely resemble the high latitude morphotype: $P$. g. gracilipes. This subspecies is distinguised by a lobate outline, a cephalis that is subcircular in outline, and large irregularly distributed pores. $P$. g. tetracantha is distinguished by a subtriangular outline, thin tapering feet, and smaller regularly distributed pores.

BIOGEOGRAPHIC AFFINITY: High latitude.

\section{Genus TRIPILIDIUM Haeckel 1881}

Tripilidium sp. A [Plate 6, fig. 26]

This morphotype is characterised by a relatively large, regular, almost spongy shell which has many small irregular pores. A small horn, less then half the length of the shell, is also present. Three strongly bladed divergent feet, which are approximately as long as the cephalis, arise from the base of the shell. This type can be distinguished from $T$. longipes Clark and Campbell in having much smaller irregular pores and an almost spongy shell. The shell is also larger and has a regular outline. It was found in the early Eocene of Site 207 (Dm-Dh) only. It can be distinguished from the genus Tripodiscinus by having simple, unbranched feet.

\section{Genus TRIPODISCINUS Haeckel 1887, sensu Petrushevskaya and Kozlova 1979}

Tripodiscinus clavipes (Clark and Campbell) [Plate 6, fig. 27]

Tripilidium clavipes Clark and Campbell 1942, p. 64, pl. 9, fig. 29; Abelmann 1990, p. 695, pl. 5, fig. 1; Caulet 1991, p. 539.

Tripodiscinus clavipes (Campbell). Petrushevskaya and Kozlova 1979, p. 115, fig. 302; Caulet 1986, p. 854; Apel et al. 2002, p. 21, pl. 6, fig. 9.

? Clathrocanium sp. O'Connor 1993, p. 60, pl. 10, fig. 16.

BIOGEOGRAPHIC AFFINITY: Cosmopolitan.

\section{Family CANNOBOTRYIDAE Haeckel 1881, emend. Riedel $1967 \mathbf{a}$}

Genus ARTOBOTRYS Petrushevskaya 1971b

Placed in the Cannobotryidae by Petrushevskaya (1971b).

Artobotrys auriculaleporis (Clark and Campbell) [Plate 7, fig. 1a, b, 2, 3a, b]

Lophophaena auriculaleporis Clark and Campbell 1942, p. 76, pl. 8, fig. 20, 27-29; Blueford 1988, p. 246, pl. 3, fig. 1-3.

Lophocyrtis biaurita (Ehrenberg), Foreman 1973b (in part), p. 442, pl. 8, fig. 23.

Artobotrys auriculaleporis (Clark and Campbell), Caulet 1991, p. 537; Shilov 1995, p. 127, pl. 4, fig. 4.

Lophocyrtis? auriculaleporis (Clark and Campbell), Strong et al. 1995, p. 208, fig. 10s, t. Cycladophora auriculaleporis (Clark and Campbell), Hollis et al., 1997, p. 59 pl. 3, fig. 31. 
Artobotrys norvegiensis (Bjørklund and Kellogg), Suzuki et al. 2009, p. 258, pl. 21, fig. 3.

Distinguished from Artobotrys biaurita by a stout thorax with regularly arranged pores, at least in the central area, and a short peristome that is not flared. The morphotype that Suzuki et al. (2009) ascribed to A. norvegiensis is included here.

BIOGEOGRAPHIC AFFINITY: Cosmopolitan.

Artobotrys biaurita (Ehrenberg) [Plate 7, fig. 4, 5]

Eucyrtidium biaurita Ehrenberg, 1873, p. 226, 1875, p. 70, pl. 10, fig. 7-8

Lophocyrtis biaurita (Ehrenberg), Foreman 1973b, p. 442, pl. 8, fig. 23-26

Artobotrys biaurita (Ehrenberg), Petrushevskaya and Kozlova 1979, p. 136; Caulet 1991, p. 537.

Much smaller size and more slender compared to A. auriculaleporis.

BIOGEOGRAPHIC AFFINITY: Cosmopolitan.

Artobotrys titanothericeraos (Clark and Campbell) [Plate 7, fig. 6, 7a, b]

Lophoconus titanothericeraos Clark and Campbell 1942, p. 89, pl. 8, fig. 24-26, 28, 30-

37.

Artobotrys titanothericeraos (Clark and Campbell), Suzuki et al. (2009), p. 259, pl. 21, fig. $4 \mathrm{a}-5 \mathrm{~b}$.

Artobotrys kryschotofovichi (Lipman 1953), Suzuki et al. 2009, p. 259, pl. 21, fig. 6.

Distinguished from Artobotrys auriculaleporis by having three segments and a welldefined lumbar stricture. A. kryschotofovichi of Suzuki at al. (2009) is included in the concept of A. titanothericeraos.

\section{Genus BOTRYOCELLA Haeckel 1881}

Botryocella? sp. A, sensu Apel 2002 [Plate 7, fig. 8, 9, 10, 11]

Botryocella? sp. A, Apel et al. 2002, p. 44, pl. 6, fig. 12.

\section{Genus GLYCOBOTRYS Campbell 1951}

This genus includes several species that have previously been placed in Botryocella. Campbell (1951) notes that the type species of Botryocella has a closed thorax and lacks cephalic tubes. He described Glycobotrys as having cephalic tubules and a fenestrated (open) thorax. The name was applied to all cannobotryiids with simple tubes extending from the antecephalic or postcephalic lobe. This definition encompasses the range of variation exhibited by the type species, Lithobotrys geminata Ehrenberg (1875, pl. 3, fig. 19), and the related species, Lithobotrys nasuta Ehrenberg (1875, pl. 3, fig. 21).

Glycobotrys nasuta (Ehrenberg) group, New Group [Plate 7, fig. 12, 13, 14]

Lithobotrys nasuta Ehrenberg, 1873, p. 237; 1875, pl. 3, fig. 21.

Lithobotrys geminata Ehrenberg, 1875, pl. 3, fig. 19.

Botryopyle dictyocephalus (Haeckel) gr., Riedel and Sanfilippo 1971 (in part), p. 1602, pl. 2J, fig. 18; pl. 3F, fig. 12; Takemura 1992, p. 743, pl. 3, fig. 7; O'Connor 1993, p. 56, pl. 10, fig. 15; Takemura and Ling, 1997, p. 111. 
Botryocella aff. cribrosa (Ehrenberg) gr., Petrushevskaya and Kozlova 1972, p. 554, pl. 39, fig. 4-6.

Botryocella? appenninica Vinassa de Regny gr. Petrushevskaya 1975, p. 589, pl. 13, fig. 16.

Botryocella cribrosa (Ehrenberg) gr., Caulet 1986, p. 852.

Botryopyle sp. Crouch and Hollis 1996, p. 26.

Botryocella pauciperforata O'Connor 1999a, p. 10, pl. 1, fig. 21a-24; pl. 5, fig. 20a-24.

Glycobotrys geminata (Ehrenberg), Suzuki et al. 2009, p. 258, pl. 18, fig. 1a-b.

non Lithobotrys cribrosa Ehrenberg 1873, p. 237; 1875, pl. 3, fig. 20 (no cephalic tubes).

All morphotypes with a large antecephalic lobe and a postcephalic tube are included in this group. Thorax may be open or closed. Distinguished from Botryopyle dictyocephalus by a postcephalic tube at base of cephalis.

BIOGEOGRAPHIC AFFINITY: Cosmopolitan.

\section{Family ARTOSTROBIIDAE Riedel 1967a, emend. Foreman}

\section{$1973 b$}

\section{Genus BURYELLA Foreman 1973b}

Buryella foremanae Petrushevskaya, emend. O'Connor 2001 [Plate 8, fig. 1]

Buryella sp. A Dumitrica 1973, p. 789, pl. 1, fig. 1, pl. 4, fig. 1-4.

Buryella? foremanae Petrushevskaya 1977, p. 16, pl. 3, fig. d,e.

Buryella foremanae Petrushevskaya, Hollis 1993, p. 322, pl. 1, fig. 12; 1997, p. 80, pl. 21, fig. 6-9; Strong et al., 1995, p. 208, fig. 8K; O’Connor 2001, p. 6, pl. 1, fig. 6-11; pl. 3, fig. 5-15; Hollis 2002, p. 299.

BIOGEOGRAPHIC AFFINITY: Possibly high latitude; so far only known from the Southwest Pacific Paleocene to early Eocene.

Buryella granulata (Petrushevskaya) [Plate 8, fig. 2]

Lithocampe sp. A Dumitrica 1973, p. 789, pl. 10, fig. 3; pl. 11, fig. 3.

Lithocampe? granulata Petrushevskaya 1977, p. 18, pl. 3, fig. a, b, v.

Stichomitra granulata (Petrushevskaya), Hollis 1991, p. 134, pl. 20, fig. 7-12; 1993, p. 321, pl. 1, fig. 10, 11. Strong et al. 1995, p. 209, fig. 8j.

Buryella granulata (Petrushevskaya), Hollis 1997, p. 80, pl. 21, fig. 1-5; Hollis et al. 1997, p. 57, pl. 5, fig. 6.

BIOGEOGRAPHIC AFFINITY: Possibly high latitude; so far only known from the Southwest Pacific Paleocene to early Eocene. Reworked specimen at Site 277 and ODP1123.

Buryella tetradica Foreman [Plate 8, fig. 3]

Buryella tetradica Foreman 1973b, p. 433, pl. 8, fig. 4, 5; pl. 9, fig. 13, 14; Sanfilippo et al. 1985 , p. 668 , fig. $14.3 \mathrm{a}$,b; Nishimura 1987, p. 721, pl. 2, fig. 8; 1992, p. 329, pl. 10, fig. 18; Hollis 1993, p. 323; 1997, p. 81, pl. 21, fig. 16-19; 2002, p. 300, pl. 4, fig. 
12-14; Strong et al. 1995, p. 208, fig. 8n, 9q; Hollis et al. 1997, p. 58; O'Connor 2001, p. 11, pl. fig. 14-18, pl. 3, fig. 16-21.

Buryella cf. tetradica Foreman, Dumitrica 1973, p. 790.

BIOGEOGRAPHIC AFFINITY: Cosmopolitan; Note: specimens found in the middle Eocene (Bortonian stage) at Site 206 and in the late Eocene-early Oligocene at Site 1123 are reworked.

\section{Genus SIPHOCAMPE Haeckel 1881, emend. Nigrini 1977}

= Lithomitra Bütschli, 1882; Lithomitrella Haeckel, 1887.

Siphocampe nodosaria (Haeckel) [Plate 8, fig. 4]

Lithomitra nodosaria Haeckel 1887, p. 1484, pl. 79. fig. 1; Petrushevskaya1967, pl. 83, figs. 8-9; Kruglikova 1969, pl. 4, fig. 3; Petrushevskaya and Kozlova 1972, pl. 24, figs. 29-30.

? Lithomitra embrionalis Vinassa de Regny 1900, pl. 3, fig. 21.

Lithomitra eruca Haeckel. 1887, p. 1485, pl. 79, fig. 3; Petrushevskaya 1971b, pl. 122, fig. 6; Petrushevskaya and Kozlova 1972, p. 539, pl. 24, figs. 32. 33.

? Siphocampe annulosa Haeckel 1887, p. 1500, pl. 79, fig. 10; cf. Nakaseko, 1963, p. 195, pl. 4, fig. 8.

Lithomitra lineata (Ehrenberg), Riedel and Sanfillippo 1971 (in part), p. 1600, pl. 11, fig. 1, 3-7, 9-10 (not 2, 8, 11); pl. 2l, fig. 14, 16 (not fig. 15); Foreman 1973b, p. 431, pl. 8, fig. 18-19.

Siphocampe nodosaria (Haeckel), Nigrini 1977, p. 256, pl. 3, fig. 11; Takemura 1992, p. 743, pl. 3, fig. 15; O'Connor 1993, p. 52, pl. 4, fig. 23-24; Takemura and Ling, 1997, p. 114; Apel et al. 2002, p. 21, pl. 9, fig. 11.

Siphocampe arachnea (Ehrenberg), Abelmann 1990, p. 698, pl. 8, fig. 4a, b; Strong et al. 1995, p. 209.

Siphocampe imbricata (Ehrenberg), Caulet 1991, p. 539, pl. 3, fig. 13; Suzuki et al. 2009, p. 264, pl. 18, fig. 12a-b.

Siphocampe elegans (Ehrenberg), Suzuki et al. 2009, p. 263, pl. 18, fig. 10.

This species name is applied broadly to all members of the genus with regular crenulations on the abdomen and longitudinal ridges between pores.

BIOGEOGRAPHIC AFFINITY: Cosmopolitan.

Siphocampe quadrata (Petrushevskaya and Kozlova) [Plate 8, fig. 5]

Lithamphora sacculifera quadrata Petrushevskaya and Kozlova 1972, p. 539, pl. 30, fig. 4-6 (also fig. 1, 2 and Pl. 24, fig. 7).

Lithomitra docilis Foreman 1973b, p. 431, pl. 8, fig. 20-22; pl. 9, fig. 3-5; Johnson 1974, p. 552, pl. 3, fig. 16; Johnson 1978, p. 781; Nishimura 1992, p. 329.

Siphocampe? quadrata (Petrushevskaya and Kozlova), Nigrini 1977, p. 257, pl. 3, fig. 12; Caulet 1991, p. 539; Takemura 1992, p. 743, pl. 7, fig. 7; Takemura and Ling, 1997, p. 114; Funakawa et al. 2006b, p. 19, pl. 2, fig. 14-15; Suzuki et al., 2009, p. 264, pl. 18, fig. 9.

Siphocampe? sp. Caulet 1986, pl. 2, fig. 11.

Siphocampe sacculifera (Clark and Campbell), Suzuki et al., 2009, p. 264, pl. 18, fig. $11 \mathrm{a}-\mathrm{b}$. 
This species name is assigned to all members of the genus with a smooth outline and abdominal pores arranged in closely spaced transverse rows, with no longitudinal ridges. Abdomen is widest medially.

BIOGEOGRAPHIC AFFINITY: Cosmopolitan.

Siphocampe? acephala (Ehrenberg) group [Plate 8, fig. 6, 7, 8]

? Eucyrtidium elegans Ehrenberg, 1854b, pl. 36, fig. 17; 1875, pl. 11, fig. 12.

? Eucyrtidium acephalum Ehrenberg, 1875, p. 70, pl. 11, fig. 5.

Lithomitra laevigata Principi 1909, p. 17, pl. 1, fig. 55.

Lithomitra urnula Clark and Campbell 1942, p. 91, pl. 9. fig. 19.

Lithomitra elizabethae Clark and Campbell 1942, p. 92, pl. 9, fig. 18.

Lithocampe minuta Clark and Campbell 1942, p. 93, pl. 9, fig. 17.

Theocampe spp. Johnson 1974, pl. 3, fig. 13-15 (also fig. 11).

Theocampe amphora Haeckel. Chen 1975 (in part), p. 456, pl. 2, fig. 2.

Theocampe minuta (Clark and Campbell), Petrushevskaya 1975, p. 578, pl. 26, figs. 5, 6.

Siphocampe acephala (Ehrenberg). Nigrini 1977, p. 254, pl. 3, fig. 5; Takemura 1992, p. 743, pl. 6, fig. 9; Takemura and Ling, p. 114.

Lithomitrella minuta (Clark and Campbell) Petrushevskaya and Kozlova 1979, p. 154, fig. 412, 413, 478; Shilov 1995, p. 127, pl. 2, fig. 5; Caulet 1986, p. 853.

Lithomitrella elizabethae (Clark and Campbell), Petrushevskaya and Kozlova 1979, p. 153, fig. 418, 419, 483-486, 540-544; Shilov 1995, p. 127.

Artostrobus elegans (Ehrenberg). Caulet 1986, p. 851.

Lithomitrella acephala (Ehrenberg). Caulet 1986, p. 853.

Siphocampe pachyderma (Ehrenberg). Caulet 1991, p. 539, pl. 3, fig. 12.

Siphocampe missilis O'Connor 1994, p. 340, pl. 1, fig. 7, 9-12. pl. 3, fig. 8-12.

Siphocampe acephala (Ehrenberg) group, Hollis et al. 1997, p. 54, pl. 4, fig. 8-20.

Siphocampe minuta (Clark and Campbell), Suzuki et al. 2009, p. 264, pl. 18, fig. 5a-6b.

non Siphocampe elizabethae (Clark and Campbell), Nigrini 1977, p. 256, pl. 3, fig. 6 (= S.? amygdala).

Bullet-shaped test of 3 segments. Cephalis partially submerged in thorax, becoming more prominent in later part of range, lacks vertical tube, rarely bears a small apical horn. Thorax hemispherical, with 3-5 rows of circular pores. Lumbar stricture absent to distinct. Abdomen cylindrical, may narrow distally, with 4-8 rows of small subcircular pores, becoming large and subquadrangular in later part of range.

Specimens referred to this species by Nigrini (1977) and subsequent workers appear closer to Principi's species than E. acephalum s.s. Under Nigrini's usage the species ranges from early to late Eocene. Takemura reported the species in the middle Eocene, with an isolated occurrence in early Oligocene. For practical considerations co-occurring variants have not been differentiated, i.e. S. elegans (Ehrenberg), which has a welldeveloped apical horn, S. missilis O'Connor, which has a perforate, centred, rather than asymmetrically-placed, cephalis and a longer abdomen with 8-17 rows of pores.

This species group is only tentatively placed in Siphocampe because its artostrobiid cephalic structure has not been confirmed. It appears to be closely related to the multisegmented S.? amygdala.

Siphocampe? amygdala (Shilov) [Plate 8, fig. 9, 10]

Theoperid gen. et sp. indet. Johnson, 1974, pl. 3, fig. 12. 
Siphocampe elizabethae (Clark and Campbell). Nigrini 1977, p. 256, pl. 3, fig. 6.

Lithomitrella elizabethae (Clark and Campbell). Caulet 1986, p. 853.

Archaeodictyomitra? sp. Takemura 1992, p. 744, pl. 3, fig. 1-2.

Mita sp. Strong et al. 1995, p. 209, fig. 10x.

Dictyomitra amygdala Shilov 1995, p. 126, pl. 1, fig. 4-6b.

Siphocampe? "elizabethae" sensu Nigrini, Hollis et al. 1997, p. 55, pl. 4, fig. 21-26.

Dictyoprora? amygdala (Shilov), Suzuki 2009, p. 263, pl. 18, fig. 3.

non Lithomitra elizabethae Clark and Campbell 1942, p. 92, pl. 9, fig. 18.

Fusiform test of 5-6 segments with indistinct strictures. Thorax hemi-spherical with pores evenly distributed and smaller than in subsequent segments. Pores of post-thoracic segments longitudinally aligned and arranged in 3 rows on each segment. Outline smooth to slightly lobate, narrows distally, basal margin ragged. Differs from $S$. acephala gr. in that the post-thoracic part is not a single abdomen but 2-5 segments, each having 2-3 rows of subcircular pores.

BIOGEOGRAPHIC AFFINITY: Cosmopolitan.

\section{Genus SPIROCYRTIS Haeckel 1881, emend. Nigrini 1977}

Spirocyrtis greeni O'Connor [Plate 8, fig. 11a, b]

Spirocyrtis greeni O'Connor 1999a, p. 8, pl. 1, fig. 15-20b, pl. 5, fig. 16a-19.

Spirocyrtis joides (Petrushevskaya) [Plate 8, fig. 12a, b]

Botryostrobus sp. P, Petrushevskaya and Kozlova 1972, p. 539, pl. 24, fig. 8-11.

Botryostrobus joides Petrushevskaya 1975, p. 585, pl. 10, fig. 37; Hull 1996, p. 137, pl. 4,

fig. 5, 6, 20; Sanfilippo and Fourtanier 2003, p. 11, pl. P1, fig. 3, 12.

Spirocyrtis sp. A. Hollis et al. 1997, p. 56, pl. 4, fig. 33-35.

Narrowly conical test of 6-10 segments. Thorax truncate-conical with 3 rows of pores. Cephalis hemispherical, internal features obscured by a "cockscomb" of webbed spines linking apical horn and vertical tube. Post-thoracic segments are rounded with 4 rows of closely-spaced subcircular pores. Final segment narrows, may terminate with a narrow peristome.

BIOGEOGRAPHIC AFFINITY: Cosmopolitan.

\section{Genus THEOCAMPE Haeckel 1887 (= DICTYOPRORA Haeckel 1881)}

Theocampe spp. [Plate 8, fig. 13, 14, 15]

Specimens that cannot be assigned to one of the taxa below, including morphotypes with irregularly distributed abdominal pores.

Theocampe amphora (Haeckel) [Plate 8, fig. 16a, b]

Dictyocephalus amphora Haeckel 1887, p. 1305, pl. 62, fig. 4.

Theocampe amphora (Haeckel), Foreman 1973b, p. 431, pl. 8, fig. 7, 9-13; pl. 9, fig. 8, 9; Chen 1975 (in part), p. 456, pl. 2, fig. 2; Johnson 1978, p. 782; Hollis et al. 1997, p. 56, pl. 4, fig. 38-39. 
Dictyoprora amphora (Haeckel), Nigrini 1977, p. 250, pl. 4, fig. 1, 2; Palmer 1987, p. 355; Caulet 1991, p. 538; O'Connor 1993, p. 48, pl. 4, fig. 14, pl. 10, fig. 10; Shilov 1995, p. 126, pl. 2, fig. 7-8; Funakawa et al. 2006b, p. 16, pl. 2, fig. 1-2.

non Dictyoprora amphora (Haeckel), Lazarus and Pallant 1989, p. 363, pl. 6, fig. 8, 9.

BIOGEOGRAPHIC AFFINITY: Cosmopolitan.

Theocampe mongolfieri (Ehrenberg) [Plate 8, fig. 17a, b]

Eucyrtidium mongolfieri Ehrenberg 1854, pl.36, fig.18; 1873, p.230

Dictyoprora mongolfieri (Ehrenberg), Nigrini 1977, p.250, pl.4, fig.7; De Wever 1981, p. 511, pl. 4, fig. 8, 9; Suzuki et al. 2009, pl. 18, fig. 2; Sanfilippo et al 1985, p. 702, fig. 33.1a-d.

Theocampe mongolfieri (Ehrenberg), Burma 1959, p. 239; Riedel and Sanfilippo 1970, p. 536, pl. 12, fig. 9; Foreman 1973b, p. 432, pl. 8, fig. 1, pl. 9, fig. 17; Johnson 1974, p. 552, pl. 5, fig. 1; Johnson 1978, p. 782.

BIOGEOGRAPHIC AFFINITY: Low-latitude affinity, as noted by Sanfilippo et al. (1985).

Theocampe cf. mongolfieri (Ehrenberg) [Plate 8, fig. 18a, b]

This morphotype has a 3-segmented shell similar to T. mongolfieri. The abdomen is medially inflated and has tranverse pore rows. Although longitudinal ridges are present, pores are not perfectly aligned longitudinally. This morphotype is only present at DSDP Site 207, in the same sample as one specimen of T. mongolfieri.

Theocampe pirum (Ehrenberg) [Plate 8, fig. 19a, b]

Eucyrtidium pirum Ehrenberg, 1873, p. 232

Dictyoprora pirum (Ehrenberg), Nigrini 1977, p. 250, pl. 4, fig. 7; De Wever, p. 511, pl. 4 , fig. 7

Theocampe pirum (Ehrenberg), Riedel and Sanfilippo, 1978, p. 76, pl. 9, fig. 14; Johnson 1978, p. 782

BIOGEOGRAPHIC AFFINITY: Low latitude, as noted by Sanfilippo et al. (1985).

Theocampe urceolus (Haeckel) [Plate 8, fig. 20]

Dictyocephalus urceolus Haeckel, 1887, p. 1305.

Theocampe urceolus (Haeckel), Foreman 1973b, p. 432, pl. 8, fig. 14-17; pl. 9, fig. 6, 7; Chen 1975, p. 456, pl. 3, fig. 7; Hollis et al. 1997, p. 56, pl. 4, fig. 36-37.

Dictyoprora urceolus (Haeckel), Nigrini 1977, p. 251, pl. 4, fig. 9, 10; Palmer 1978, p. 356; O'Connor 1993, p. 50, pl. 10, fig. 11.

? Dictyoprora physothorax Caulet 1991, p. 535, pl. 3, fig. 11.

Dictyoprora pirum (Ehrenberg), Takemura 1992, p. 743, pl. 5, fig. 11; Takemura and Ling, 1997, p. 111.

Specimens with a thorax as wide as the abdomen $(=T$. physothorax $)$ are included in $T$. urceolus here. Takemura's figured specimen lacks the flattened abdomen characteristic of T. pirum.

BIOGEOGRAPHIC AFFINITY: Cosmopolitan. 


\section{Family ACROPYRAMIDIDAE Haeckel 1881}

\section{Genus ARTOSTROBUS Haeckel 1887}

Artostrobus spp. [Plate 8, fig. 21, 22]

Specimens consisting of two segments, a small cephalis with usually a horn, and a long thorax with horizontal pore rows, are assigned to this genus. Termination indistinct.

Artostrobus annulatus (Bailey) [Plate 8, fig. 23]

Cornutella annulatus Bailey 1856, p. 3, fig. 5.

Artostrobus annulatus (Bailey), Ling 1973, p. 781, pl. 2, fig. 14; Petrushevskaya 1975, p. 579, pl. 10, fig. 4, 5; Hollis et al. 1997, p. 57, pl. 5, fig. 1-2; Reynolds 1980; Abelmann 1990, p. 683, 685, 687.

BIOGEOGRAPHIC AFFINITY: High latitude.

Artostrobus cf. pretabulatus Petrushevskaya [Plate 8, fig. 24]

cf. Artostrobus? pretabulatus Petrushevskaya 1975, p. 580, pl. 10, fig. 2-3.

Artostrobus cf. pretabulatus Petrushevskaya, Takemura 1992, p. 745, pl. 5, fig. 12; Crouch and Hollis 1996, p. 26; Hollis et al., 1997, p. 57, pl. 5, fig. 3; Takemura and Ling, 1997, p. 111.

Distinguished from A. pretabulatus by a broader and more conical thorax.

BIOGEOGRAPHIC AFFINITY: High latitude.

\section{Genus CINCLOPYRAMIS Haeckel 1879}

Cinclopyramis Haeckel 1879; Bathropyramis Haeckel 1882; Peripyramis Haeckel 1882; Sethopyramis Haeckel 1882; Enneapleuris Haeckel 1887

As noted by Suzuki et al. (2009), the synonymised generic names have been inconsistently applied in the past and serve only to confuse species level discrimination within what is here considered to be a single long-ranging genus. Cinclopyramis is the senior synonym.

Cinclopyramis circumtexta (Haeckel) [Plate 8, fig. 25]

Peripyramis circumtexta Haeckel 1887. p. 1162, pl. 54, fig. 5; Riedel 1958, p. 231, pl. 2,

fig. 8-9; Kling 1973, p. 637, pl. 2, fig. 15-19, pl. 9, fig. 1-3; Chen 1975, p. 462; Petrushevskaya 1975, pl. 13, fig. 29, pl. 44, fig. 5-6; Weaver 1983, p. 678; Abelmann 1990, p. 683; Expedition 306 Scientists 2006.

Sethopyramis magnifica Clark and Campbell 1942, p. 72, pl. 8, fig. 1, 5, 9.

Bathropyramis magnifica (Clark and Campbell), Hollis et al. 1997, p. 57, pl. 6, fig. 22.

Cinclopyramis quadrata (Haeckel), Suzuki et al., 2009, p. 262, pl. 22, fig. 13.

non Bathropyramis quadrata Haeckel 1887, p. 1159, pl. 54, fig. 1.

The specimens of $C$. circumtexta illustrated by Riedel (1958) indicate that the species is the senior synonym for $S$. magnifica Clark and Campbell. Both species are distinguished from $C$. quadrata by having a small subcircular cephalis with a distinct collar stricture, transverse pore frames being slightly offset between longitudinal beams, and a change in 
contour in the proximal thorax where pores change from being circular to rectangular. In C. quadrata, transverse beams are closely aligned along the length of the shell. According to Petrushevskaya, the distinctive outer layer of coarsely spongy meshwork is only seen from the middle Miocene onwards. However, Clark and Campbell (1942) mention this secondary mesh also occurring in some Eocene specimens.

BIOGEOGRAPHIC AFFINITY: Cosmopolitan.

Cinclopyramis scalaris (Ehrenberg) [Plate 8, fig. 26, 27]

Cornutella scalaris Ehrenberg 1873, p. 221; 1875, pl. 2, fig. 1.

Bathropyramis scalaris (Ehrenberg), Petrushevskaya and Kozlova 1972, p. 551, pl. 31, fig. 6.

\section{Genus CORNUTELLA Ehrenberg 1838}

Cornutella profunda [Plate 8, fig. 28]

Cornutella clathrata profunda Ehrenberg 1854a, p. 241; Ehrenberg 1854b, pl. 35B, fig. 21

Cornutella profunda Ehrenberg, Riedel 1958, p. 232, pl. 3, figs. 1-2; Kling 1973, p. 635, pl. 3, fig. 1-4, pl. 9, fig. 8-17; Chen 1975, p. 459; Petrushevskaya 1975, p. 587, pl. 13, fig. 29, pl. 44, fig. 5-6; Pisias \& Moore 1978, p. 847, pl. 1, fig. 5; Kamikuri et al. 2006, p. 7; Suzuki et al. 2009, p. 263, pl. 22, fig. 12a-b.

BIOGEOGRAPHIC AFFINITY: Cosmopolitan.

\section{Family EUCYRTIDIIDAE Ehrenberg 1847}

\section{Genus ARTOPHORMIS Haeckel 1881}

Artophormis aff. dominasinensis sensu Chen [Plate 9, fig. 1]

Artophormis sp. aff. dominasinensis (Ehrenberg), Chen 1975, pl. 4, fig. 3-4

The two specimens encountered here are similar to the specimens illustrated by Chen (1975). Unfortunately, Chen's taxon is not included in his taxonomic list or range charts, and so its stratigraphic range in DSDP Leg 28 cores is unknown. The specimens have 3 segments: a cephalis with a long conical horn and several small spines, a short thorax with one spine close to the abdominal stricture and a long abdomen with very small pores, irregularly distributed. A short peristome is present.

\section{Genus ASPIS Nishimura 1992}

Aspis sp. A, sensu Hollis 2002 [Plate 9, fig. 2, 3, 4]

Ceratocyrtis? sp., Dumitrica 1973, p. 788, pl. 3, fig. 2-4.

Aspis sp. A, Hollis 2002, p. 303, pl. 6, fig. 1-2. 
BIOGEOGRAPHIC AFFINITY: High latitude. So far only encountered in the SW Pacific Paleocene (Dumitrica 1973; Hollis 2002; this study) and the middle Eocene to early Oligocene of Leg 29 and ODP Site 1123 (this study).

\section{Genus CALOCYCLAS Ehrenberg 1847}

Calocyclas hispida (Ehrenberg) [Plate 9, fig. 5a, b]

Anthocyrtis hispida Ehrenberg 1873, p. 216; 1875, pl. 8, fig. 2.

Calocyclas hispida (Ehrenberg), Foreman 1973b, p. 434, pl. 1, fig. 12-15; pl. 9, fig. 18; Chen p. 459, pl. 3, fig. 10.

\section{Genus CALOCYCLOMA Haeckel 1887}

Calocycloma spp. [Plate 9, fig. 6]

Two segmented nassellarian; cephalis with few pores and apical horn, collar stricture distinct, thorax hemispherical, small pores more or less equally sized, however, no particular arrangement. These forms vary in size and differ from Calocycloma by the absence of thoracic spines.

Calocycloma ampulla (Ehrenberg) [Plate 9, fig. 7a, b]

Eucyrtidium ampulla Ehrenberg 1854, pl. 36, fig. 15a-c; 1873, p. 22.

Calocycloma ampulla (Ehrenberg), Foreman 1973b, p. 434, pl. 1, fig. 1-5; Hollis et al. 1997, p. 58, Nishimura (1987), p. 721, pl. 3, fig. 2.

? Calocycloma ampulla (Ehrenberg), Strong et al. 1995, p. 208, fig. 9v-x; Foreman (1973), pl. 9, fig. 20; Riedel and Sanfilippo (1970), p. 524, pl. 6, fig. 1; Sanfilippo et al. (1985), p. 668, fig. 14-5.

The specimens here agree in general with the description of Foreman (1973). They possess a cephalis with a small apical horn and a hemispherical thorax, which is more inflated distally. However, the thorax does not have a conical proximal part. In this respect, morphotypes that were included in C. ampulla by Foreman (1973, in part), Sanfilippo et al. (1985), Riedel and Sanfilippo (1970) and Strong et al. (1995) resemble C. castum, which has a distinct constriction in the upper part of the thorax. The specimens in this study closely resemble the specimen illustrated by Nishimura (1987), which has spines restricted to the distal thorax around the mouth.

Calocycloma cf. Lamptonium pennatum Foreman [Plate 9, fig. 8a, b] Lamptonium pennatum Foreman 1973b, p. 436, pl. 6, fig. 3-5; pl. 11, fig. 13.

Hemispherical cephalis, with dimples rather than pores, bearing a short, bladed horn. Collar stricture is expressed in a change in contour. Thorax is hemispherical, and inflated more distally. Three long bladed spines arise from the distal part of the thorax, just below the widest part, protruding downwards. Thoraxic pores have hexagonal pore frames and are evenly distributed. This form differs from Lamptonium pennatum by the absence of an abdomen and a larger cephalis.

\section{Genus CASSIDEUS Pessagno 1969}




\section{Cassideus mariae Nishimura}

Microsciadiocapsa? sp. Dumitrica 1973, p. 789, pl. 13, fig. 6-8; Hollis 1993, p. 320;

Strong et al. 1995, p. 209, fig. 9c; Hollis et al. 1997a, p. 64.

Clathrocycloma sp. A, Blome 1992, p. 644, pl. 2, fig. 18.

Cassideus mariae Nishimura 1992, p. 333, pl. 4, fig. 1-3.

Cassideus aff. mariae Nishimura, Hollis 2002, p. 305, pl. 6, fig. 9-11.

The specimen encountered in this study are from a picked sample at DSDP Site 277.

\section{Genus CLATHROCYCLAS Haeckel 1881}

\section{Clathrocyclas spp.}

Taxa assigned to the genus are only found in picked samples and could not be identified to species level.

\section{Clathrocyclas australis Hollis}

Clathrocycloma sp. A. Hollis 1993, p. 322; Strong et al. 1995, p. 208, fig. 8p.

Clathrocyclas n.sp. A, Hollis et al. 1997, p. 59.

Clathrocyclas australis Hollis 1997, p. 74, pl. 22, fig. 1-4.

BIOGEOGRAPHIC AFFINITY: Possible high latitude. So far, this species has only been encountered in the Paleocene Southwest Pacific. (Note: One specimen was found in a picked sample at DSDP Site 277).

Clathrocyclas universa Clark and Campbell [Plate 9, fig. 9, 10, 11]

Clathrocyclas universa Clark and Campbell 1942, p. 86, pl. 7, fig. 8-12, 14-21, 25; Chen 1975, p. 459, pl. 1, fig. 2, 3; Petrushevskaya 1975, pl. 15, fig. 15-16; Blueford 1988, p. 244, pl. 2, fig. 1-3; Takemura 1992, p. 745, pl. 7, fig. 8; Strong et al. 1995 (in part), p. 208; Shilov 1995, p. 125; Hollis et al. 1997, p. 59, pl. 5, fig. 17-20; Takemura and Ling 1997, p. 111; Kamikuri et al. 2012b, p. 3.

Clathrocyclas ex. gr. extensa Clark and Campbell, Suzuki et al. 2009, p. 265, pl. 21, fig. 8-9.

Clathrocyclas ex. gr. extensa from Suzuki et al. (2009) is included in the concept of $C$. universa here.

BIOGEOGRAPHIC AFFINITY: Cosmopolitan.

\section{Genus CYCLADOPHORA Ehrenberg 1847, emend. Lombari and Lazarus 1988}

Cycladophora spp. [Plate 9, fig. 12, 13]

Distinguished from Clathrocyclas by a smaller, subspherical, cephalis with pores smaller and/or less numerous than those of the thorax, and flared thorax divided into upper and lower parts.

BIOGEOGRAPHIC AFFINITY: High latitude.

Cycladophora cosma cosma Lombari and Lazarus [Plate 9, fig. 14]

Cycladophora cosma cosma Lombari and Lazarus 1988, p.104, pl. 1, figs. 1-6. 
BIOGEOGRAPHIC AFFINITY: High latitude. Lombardi and Lazarus (1988) considered this species to be high-latitude, as it was found in Miocene sediments of high-latitude sites.

Cycladophora humerus (Petrushevskaya) [Plate 9, fig. 15]

Clathrocyclas humerus Petrushevskaya 1975, p. 586, pl. 15, fig. 17, 12, 22, 23; pl. 43, fig. 1- 2.

Cycladophora humerus (Petrushevskaya), Lombari and Lazarus 1988, p. 123, pl. 9, fig. 16; Abelmann 1990, p. 698, pl. 8, fig. 3; Caulet 1991, p. 538.

Cycladophora cf. humerus (Petrushevskaya), Hollis et al. 1997, p. 59, pl. 5, fig. 21.

BIOGEOGRAPHIC AFFINITY: High latitude.

\section{Genus CYMAETRON Caulet 1991}

Cymaetron sinolampas Caulet [Plate 9, fig. 16a, b]

Cymaetron sinolampas Caulet 1991, p. 536, pl. 4, fig. 10-12.

\section{Genus CYRTOCAPSA emend. O'Connor 1997}

Cyrtocapsa osculum O'Connor [Plate 9, fig. 17a, b]

Theocorys sp. aff. Theocorys (?) spongoconus Kling, Foreman 1973b, p. 440, pl. 11, fig. 14.

? Theocorys sp. Caulet 1986, pl. 6, fig. 3

Theocorys? sp. A O'Connor 1993, p. 79, pl. 9, figs. 16-20.

Cyrtocapsa osculum O’Connor 1997, p. 75, pl. 1, fig. 15-17, pl. 2, fig. 1-2, pl. 8, fig. 310.

\section{Genus CYRTOPERA Haeckel 1887}

Cyrtopera laguncula Haeckel [Plate 9, fig. 18]

Cyrtopera laguncula Haeckel 1887, p. 1451; pl. 75, fig. 10.

Cyrtopera laguncula Haeckel 1887, Benson 1966, p. 510-513, pl. 35, fig. 3-4; Chen 1975, p. 460, pl. 18, fig. 9; Lazarus and Pallant 1989, p. 361, pl. 4, fig. 9-10; Abelmann 1990, p. 696; Caulet 1991, p. 538; Takahashi 1991, p. 119, pl. 73, fig. 15.

BIOGEOGRAPHIC AFFINITY: Cosmopolitan.

\section{Genus DICTYOPODIUM Ehrenberg 1847}

This genus is put under the Eucyrtidiidae due to similarities in general features with the genus Thyrsocyrtis.

Dictyopodium aff. oxylophus sensu Chen [Plate 9, fig. 19, 20, 21a, b] 
Dictyopodium sp. aff. oxylophus Ehrenberg, Chen 1975, p. 460, pl. 4, fig. 1, 2.

? Dictyopodium oxylophus Ehrenberg 1873, p. 223; 1875, pl. 19, fig. 4; Haeckel 1887, p. 1353; Funakawa et al. 2006b, p. 27, pl. 7, fig. 1-3.

The specimens in this study have rather short spongy feet and a row of large pores below the collar and lumbar stricture. The cephalis and thorax often bear spines and seem rough (as in Chen 1975).

BIOGEOGRAPHIC AFFINITIES: Funakawa et al. (2006b) found this species in the late Eocene of the low-latitude ODP Leg 199; however, their specimens have in general a wider thorax and abdomen. Chen (1975) and this study found the species in the middle Eocene. It is tentatively included in the low-latitude group here, due to the fossil occurrence in Barbados and the middle Eocene on Lord Howe Rise and at Site 264. It is surprising that this taxon has only been found in the late Eocene of the low-latitude Pacific.

Dictyopodium sp. A [Plate 9, fig. 22a, b, 23]

This morphotype consists of three segments and three feet. The test is thickened and the cephalis bears multiple spines. Few pores are scattered irregularly on thorax and abdomen. The feet are spongy or perforate and are similar to $D$. aff. oxylophus. It can be distinguished from the latter species by a much smaller test.

\section{Genus EUCYRTIDIUM Ehrenberg 1847}

Eucyrtidium antiquum Caulet [Plate 10, fig. 1]

Eucyrtidium sp., Chen 1975, p. 461, pl. 7, fig. 6-8; O'Connor 1993 (in part), p. 73, pl. 8, fig. 6, 7.

Eucyrtidium antiquum Caulet 1991, pl. 4, fig. 1, 2 (also fig. 5); Hollis et al. 1997, p. 60, pl. 5, fig. 30-31; Takemura and Ling 1997, p. 113, pl. 1, fig. 9; Suzuki et al. (2009), p.259, pl. 21, fig. 14.

Eucyrtidium cheni Takemura 1992, p. 746, pl. 4, fig. 1-4.

E. cheni was synonymised with E. antiquum by Takemura and Ling (1997).

BIOGEOGRAPHIC AFFINITY: High latitude.

Eucyrtidium mariae Caulet [Plate 10, fig. 2]

Eucyrtidium mariae Caulet 1991, p. 536, pl. 4, fig. 3, 4; Crouch and Hollis 1996, p. 26; Hollis et al. 1997, p. 61 (as E.? mariae).

Distinguished from E. spinosum by a more slender and thin-walled test, with small circular pores lacking well-developed frames. Internal segmentation of post-thoracic chambers frequently asymmetric.

BIOGEOGRAPHIC AFFINITY: High latitude.

Eucyrtidium microporum Ehrenberg [Plate 10, fig. 3]

Eucyrtidium microporum Ehrenberg, 1873, p. 230; 1875, pl. 11, fig. 20.

Stichopodium? microporum Ehrenberg, Funakawa et al., 2006b, pl. 13, fig. 3-4.

Eucyrtidium montiparum Ehrenberg [Plate 10, fig. 4] 
Eucyrtidium montiparum Ehrenberg, Hollis et al. 1997, p. 61, pl. 5, fig. 25-27; Nishimura 1992 , p. 329.

Eucyrtidium cf. cheni Takemura, Strong et al. 1995, p. 208, fig. 11x, y.

? Eucyrtidium aff. montiparum Ehrenberg, Petrushevskaya and Kozlova 1972, p. 548, pl. 26, fig. 2-4.

Eucyrtidium ventriosum O'Connor 1999a, p. 21, pl. 3, fig. 17-21b, pl. 6, fig. 28a-31. non Eucyrtidium montiparum Ehrenberg, Funakawa et al. 2006b, p. 23, pl. 5, fig. 10. Eucyrtidium sp. F Funakawa et al. 2006b, pl. 6, fig. 1-3.

Differs from E. nishimurae by lacking an elongate, subcylindrical, spongy fourth segment.

BIOGEOGRAPHIC AFFINITY: Cosmopolitan.

Eucyrtidium nishimurae Takemura and Ling [Plate 10, fig. 5a, b]

Eucyrtidium nishimurae Takemura and Ling 1997, p. 113, pl. 2, fig. 1-6; Suzuki et al. (2009), p. 259, pl. 21, fig. 15.

Spongy fourth segment.

BIOGEOGRAPHIC AFFINITY: This species has only been encountered at high-latitude sites of middle to late Eocene age, however, it was consistently found, but with few specimens, at Site 206 in this study.

Eucyrtidium spinosum Takemura [Plate 10, fig. 6]

Eucyrtidium sp. A, Petrushevskaya 1975, p. 581, pl. 14, fig. 21-22.

Eucyrtidium? aff. montiparum Ehrenberg, Caulet 1991, p. 538, pl. 4, fig. 5- 7.

Eucyrtidium spinosum Takemura 1992, p. 746, pl. 5, fig. 5-8; Crouch and Hollis 1996, p. 26; Hollis et al. 1997, p. 61, pl. 5, fig. 38-31; Takemura and Ling 1997, p. 113, pl. 1, fig. 10.

BIOGEOGRAPHIC AFFINITY: High latitude.

\section{Genus EURYSTOMOSKEVOS Caulet 1991}

Eurystomoskevos cauleti O'Connor [Plate 10, fig. 7a, b]

Eurystomoskevos “cauleti” O'Connor, Hollis et al. 1997, p. 61, pl. 5, fig. 4-5 (nom. Nud.). Eurystomoskevos cauleti O'Connor 1999a, pl. 3, fig. 22-26; pl. 7, fig. 1a-3.

Distinguished from E. petrushevskaae by a smaller apical horn, a more distinct cephalis and a thorax that usually is not flared.

BIOGEOGRAPHIC AFFINITY: High latitude.

Eurystomoskevos petrushevskaae Caulet [Plate 10, fig. 8]

Diplocyclas sp. A Petrushevskaya and Kozlova 1972, p. 541, pl. 33, fig. 14-16; Petrushevskaya 1975 , p. 587, pl. 24, fig. 4; Chen 1975 , p. 460, pl. 7, fig. 4, 5; Takemura 1992, p. 746, pl. 3, fig. 16.

Eurystomoskevos petrushevskaae Caulet 1991, p. 536, pl. 3, fig. 14, 15; O'Connor 1993, p. 74, pl. 8, fig. 12-14; Crouch and Hollis 1996, p. 26; Hollis et al.1997, p. 62, pl. 5, fig. 22-23; Suzuki et al. 2009, p. 265, pl. 22, fig. 5a-6; Funakawa et al. 2006b, p. 38, pl. 13, fig. 9; Kamikuri et al. 2012b. 
BIOGEOGRAPHIC AFFINITY: High latitude.

Eurystomoskevos sp.? [Plate 10, fig. 9, 10]

Assigned doubtfully to this genus because of similarities to Eurystomoskevos petrushevskaae.

\section{Genus EUSYRINGIUM Haeckel 1881}

Eusyringium fistuligerum (Ehrenberg) [Plate 10, fig. 11, 12, 13]

Eucyrtidium fistuligerum Ehrenberg 1873, p. 229; 1875, pl. 9, fig. 3

Eusyringium fistuligerum (Ehrenberg), Foreman 1973b, p. 435, pl. 11, fig. 6; Chen 1975, p. 461, pl. 3, fig. 3; Johnson 1978, p. 781; Sanfilippo et al. 1985, p. 672, fig. 17.2a-c; Strong et al. 1995, p. 208, fig. 11C; Sanfilippo and Blome 2001, p. 212; Funakawa et al. 2006b, p. 35, pl. 12, fig. 1-3; Suzuki et al. 2009, pl. 22, fig. 14; Kamikuri et al. 2012 b, p. 3, pl. 1, fig. 4 .

BIOGEOGRAPHIC AFFINITY: Cosmopolitan.

Eusyringium lagena (Ehrenberg) [Plate 10, fig. 14]

Eusyringium lagena (Ehrenberg), Foreman 1973b, p. 435, pl. 11, fig. 4-5; Chen 1975, p. 461; Johnson 1978, p. 781; Sanfilippo et al. 1985, p. 672, fig. 17.2a-c; Palmer 1987, p. 356; Strong et al. 1995, p. 208, fig. 11c; Hollis et al. 1997, p. 62, pl. 5, fig. 15-16; Sanfilippo and Blome 2001, p. 212; Kamikuri et al. 2012b, p. 3, pl. 1, fig. 5.

Can be distinguished from Eusyringium fistuligerum by a smaller pear-shaped thorax and usually the absence of a tube extending from the base of the thorax. A very thin tube may be present in later speciments (Sanfilippo et al. 1985, p. 672) near the evolutionary transition to E. fistuligerum.

BIOGEOGRAPHIC AFFINITY: Cosmopolitan.

\section{Genus EWINGELLA O'Connor 1999a}

Ewingella? sp. O’Connor 1999a [Plate 10, fig. 15]

Ewingella? sp. O’Connor 1999a, p. 32, pl. 9, fig. 18.

\section{Genus LAMPTONIUM Haeckel 1887}

Lamptonium cf. pennatum Foreman [Plate 10, fig. 16a, b] Lamptonium pennatum Foreman 1973b, p. 436, pl. 6, fig. 3-5, pl. 11, fig. 13.

? Lamptonium? aff. pennatum Foreman, O’Connor 1999a, p. 32, pl. 9, fig. 19.

This species differs from Lamptonium pennatum by having a hemispherical cephalis with pores and a wider abdomen. It is also stratigraphically younger than the range of $L$. pennatum. It differs from Lamptonium fabaeforme fabaeforme by possessing three long 
thin spines protruding from the thorax. The morphotype referred to $L$. aff. pennatum by O'Connor (1999a) differs in having a poreless cephalis.

\section{Genus PHORMOCYRTIS Haeckel 1887}

Phormocyrtis ligulata Clark and Campbell [Plate 10, fig. 17a, b]

Phormocyrtis ligulata Clark and Campbell 1942, p. 81, pl. 7, fig. 22, 23, 27, 28; Blueford 1988, p. 246, pl. 2, fig. 7-9; Strong et al. 1995, p. 209, fig. 11, U, V.

Longitudinal ribs are present on the thorax, however disappear on the upper abdomen. It can be distinguished from Phormocyrtis proxima, whose abdomen does not narrow distally. $P$. proxima might have evolved from $P$. ligulata, as the latter species seems to disappear in the Bortonian (Site 206 and 207), when P. proxima appears at Site 206.

BIOGEOGRAPHIC AFFINITY: Cosmopolitan, distinct component of mid-latitude assemblages of the middle Eocene.

Phormocyrtis proxima Clark and Campbell [Plate 10, fig. 18]

Phormocyrtis proxima Clark and Campbell 1942, p. 82, pl. 7, fig. 24, 26; Chen 1975, p. 456, pl. 2, fig. 6

BIOGEOGRAPHIC AFFINITY: Cosmopolitan, distinct component of mid-latitude assemblages of the middle Eocene, with occurrences in the southern Indian Ocean during warmer climates; was only encountered at the northernmost Site 206 in this study.

Phormocyrtis striata striata Brandt [Plate 10, fig. 19a, b]

Phormocyrtis striata striata Brandt, Foreman 1973b, p. 438, pl. 7, fig. 5, 6, 9; Chen 1975, p. 456, pl. 3, fig. 8; Sanfilippo et al. 1985, p. 679, fig. 20.1a, b; Palmer 1987, p. 356; Johnson 1990, p. 407; O'Connor 1993, p. 78, pl. 9, fig. 8; Strong et al. 1995, p. 209, fig. 9o, p; Hollis et al. 1997, p. 65.

The single specimen at Site 277 in the upper Eocene might be reworked as this taxon has an earlier range elsewhere.

BIOGEOGRAPHIC AFFINITY: Low latitude.

\section{Genus SETHOCYRTIS Haeckel 1887}

Sethocyrtis chrysallis Sanfilippo and Blome [Plate 10, fig. 20a, b]

Sethocyrtis sp. Chen 1975, p. 459, pl. 1, fig. 4, 5; Takemura 1992, p. 747, pl. 7, fig. 14, 15; Strong et al. 1995 (in part), p. 209, fig. 11w; Takemura and Ling 1997, p. 114, pl. 1, fig. 11.

Sethocyrtis sp. A Hollis et al. 1997, p. 65, pl. 6, fig. 7.

Calocyclas? nakasekoi Takemura and Ling 1998, p. 160, fig. 3.1-7, fig. 5.1-2.

Sethocyrtis chrysallis Sanfilippo and Blome 2001, p. 206, fig. 6j-n.

Calocyclas? nakasekoi Takemura and Ling 1998 is the senior synonym.

BIOGEOGRAPHIC AFFINITY: Cosmopolitan, although most records are from mid and high latitudes, the occurrence is primarily in warm climate intervals at the studied sites. 


\section{Genus THEOCORYS Haeckel 1881, sensu Foreman 1973b}

The species that Sanfilippo and Riedel (1970) and Foreman (1973) ascribed to this genus are unlikely to be related to the type species but are included "for convenience until their relationships are understood" (Foreman, 1973, p. 439.).

Theocorys spp. [Plate 11, fig. 1, 2]

This category includes specimens which cannot be assigned to a species-level taxon due to their abdomen being incomplete. Morphotypes have a three-segmented test, a relatively large spherical, poreless cephalis and thoracic and abdominal pores of similar size.

BIOGEOGRAPHIC AFFINITY: Low latitude, as the genus is only known from lowlatitude localities.

Theocorys acroria Foreman [Plate 11, fig. 3a, b]

Theocorys acroria Foreman 1973b, p.439, pl. 5. Fig. 11-13, pl. 12, fig. 2; Weaver and Dinkelmann 1978, p. 873, pl. 7, fig. 6, 7; Kamikuri et al. 2012b, p. 5; 2012b, p. 104, pl. 6, fig. 1; Sanfilippo and Nigrini 1998b, p. 273, pl. 13.2, fig. 14, 15.

This species is the oldest member of a well-defined lineage that terminates with $T$. anaclasta. T. acroria is distinguished from its descendent species, T. anapographa, by having larger pores on the abdomen, typically resulting in a ragged margin, and a less conical thorax. The thorax of $T$. acroria typically has a shoulder that bears tiny thorns or wings. However, these two species intergrade where their ranges overlap (e.g. Foreman 1973b, pl. 5, fig. 10).

BIOGEOGRAPHIC AFFINITY: Low latitude.

Theocorys anapographa Riedel and Sanfilippo [Plate 11, fig. 4, 5]

Theocorys anapographa Riedel and Sanfilippo, 1970, p. 530, pl. 10, fig. 2-3; Foreman, 1973, p.440, pl. 5, fig. 9-10; Popova et al. 2002, p. 50, pl. 17G; Kamikuri et al. 2012b, p. 5; 2012b, p. 104, pl. 1, fig. 5.

This species is distinguished from $T$. acroria by having a relatively small thorax and smaller, more regularly distributed pores on the abdomen.

Specimens encountered in this study (DSDP Site 206) are similar to Theocorys anapographa Var. A (see below), which has been observed in the upper range of $T$. anapographa and might have evolved from it.

BIOGEOGRAPHIC AFFINITY: Low latitude.

Theocorys anapographa Riedel and Sanfilippo Var. A [Plate 11, fig. 6a, b]

Theocorys anapographa Riedel and Sanfilippo Var. A, Sanfilippo and Blome 2001, p. 219 , fig. $11 \mathrm{~m}$, $\mathrm{n}$.

Theocorys anapographa Riedel and Sanfilippo Var. A, Kamikuri et al. 2012b, p. 5.

Theocorys sp. A Kamikuri 2015, pl. 10, fig. 17.

Three segmented form, with large cephalis and long conical horn in relation to the rest of the test. Surface is overall hyaline with a few small scattered pores.

BIOGEOGRAPHIC AFFINITY: Low latitude. 


\section{Genus THEOCOTYLE Riedel and Sanfilippo 1970}

Theocotyle? spp. [Plate 11, fig. 7a, b, 8]

Specimens tentatively assigned to this genus consist of three segments. The cephalis has small pores and is encased in the thorax, with no collar stricture. It bears a bladed apical horn that can be up to twice the length of the cephalis. A secondary spine arises from the base of the cephalis. The thorax is conical with irregularly distributed rounded pores. The abdomen is cylindrical to inverse conical and the pores are only slighly larger than on the thorax. The margin is ragged and indistinct.

Theocotyle nigriniae Riedel and Sanfilippo [Plate 11, fig. 9]

Theocorys sp. Nigrini, in Cita et al. 1970, p. 404, pl. 2L.

Theocotyle cryptocephala (?) nigriniae Riedel and Sanfilippo 1970, p. 525, pl. 6, fig. 5, 6. Theocotyle nigriniae Riedel and Sanfilippo 1982, p. 178, pl. 2, fig. 1-3; Sanfilippo et al. 1985 , p. 685, fig. 25.1a, b.

BIOGEOGRAPHIC AFFINITY: Low latitude according to Sanfilippo et al. (1985).

\section{Genus THEOCOTYLISSA Foreman 1973b}

Theocotylissa ficus (Ehrenberg) [Plate 11, fig. 10]

Eucyrtidium ficus Ehrenberg 1873, p. 228; 1875, pl. 11, fig. 19.

Theocotyle (Theocotylissa) ficus (Ehrenberg), Foreman 1973b, p. 441, pl. 4, fig. 16-20; Johnson 1974, p. 549, pl. 4, fig. 10/

Theocotyle ficus (Ehrenberg), Riedel and Sanfilippo 1973, p. 740; Johnson 1978, p. 782; Weaver and Dinkelmann 1978, p. 873.

Theocotylissa ficus (Eherenberg), Sanfilippo and Riedel 1982, p. 180, pl. 2, fig. 19-20; Sanfilippo et al. 1985, p. 686, fig. 25.7a, b; Palmer 1987, p. 357; Nigrini et al. 2006, p. 49, pl. P5, fig. 1; Kamikuri et al. 2012b, p. 5; Moore and Kamikuri et al. 2012b, p. 10, pl. 7, fig. 16 .

BIOGEOGRAPHIC AFFINITY: Low latitude; this species is usually restricted to low latitudes, but it is also found at mid-latitudes in the North Atlantic (Sanfilippo et al. 1985).

\section{Genus THYRSOCYRTIS Ehrenberg 1847 \\ Subgenus Thyrsocyrtis Ehrenberg 1847}

Thyrsocyrtis $\boldsymbol{c f}$. (T.) norrisi Sanfilippo and Blome [Plate 11, fig. 11, 12a, b, 13a, b] cf. Thyrsocyrtis (T.) norrisi Sanfilippo and Blome 2001, p. 207, fig. 7f-j, l, m Thyrsocyrtis cf. norrisi Moore and Kamikuri 2012, p. 35, pl. 9, fig. 11-12.

The species encountered in this study has a broad bladed apical horn with the distal part being thorny in some specimens. The thorax is conical and the collar stricture is indistinct. The abdomen is shorter than in T. norrisi, has pores that tend to be irregularly distributed and a hyaline peristome, which is not as broad as in T. norrisi. The feet are also not divergent in contrast to T. norrisi. This species differs from $T$. bromia in having 
much smaller abdominal pores and a distinct peristome with feet. It differs from $T$. pinguisicoides in having feet.

BIOGEOGRAPHIC AFFINITY: As discussed by Sanfilippo and Blome (2001), $T$. norrisi, $T$. pinguisicoides and the form described here are very similar to T. bromia and may be regional variants of this species. All species are assigned to the low-latitude group.

Thyrsocyrtis (Thyrsocyrtis?) pinguisicoides O'Connor [Plate 11, fig. 14a, b]

Thyrsocyrtis sp. Dinkelman 1973, p. 788, pl. 3, fig. 7, 8.

Theocotyle "pinguisicoides" O'Connor, Hollis et al. 1997, p. 65, pl. 6, fig. 10-12 (nom. nud.).

Thyrsocyrtis pinguisicoides O'Connor 1999a, p. 29, pl. 4, fig. 28-32; pl. 7, fig. 28a-31; Kamikuri et al. 2012a, p. 104; Funakawa et al. 2006b, p. 34, pl. 4, fig. 7-12; Moore and Kamikuri 2012, p. 12, pl. 9, fig. 13-16.

Distinguished from other members of the genus by the absence of terminal feet.

BIOGEOGRAPHIC AFFINITY: Low latitude. Although this species was described from Oamaru (New Zealand), it has subsequently been found at low-latitude sites and is occurring at Oamaru and Southwest Pacific sites during warmer intervals.

Thyrsocyrtis (T.) rhizodon Ehrenberg [Plate 11, fig. 15a, b, 16, 17a, b]

Thyrsocyrtis rhizodon Ehrenberg 1873, p. 262; 1875, pl. 12, fig. 1; Petrushevskaya and Kozlova 1972, p. 542; Foreman 1973b, p. 442, pl. 3, fig. 1, 2; Ling 1975, p. 730; Johnson 1978, p. 782.

Thyrsocyrtis (Thyrsocyrtis) rhizodon Ehrenberg, Sanfilippo and Riedel 1982, p. 173, pl. 1, fig. 14-16, pl. 3, fig. 12-17; Sanfilippo et al. 1985, p. 687, fig. 26.3a, 3b; Palmer 1987, p. 357; p. 407; Kamikuri et al. 2012b, p. 5.; Kamikuri 2015, pl. 11, fig. 1, 2, 7.

The two specimens encountered in this study are slightly atypical, however, this taxon exhibits a great variation in the shape of the abdomen throughout its range (http://www.riedel-william-and-elizabeth.net/samples-investigated-from-site-149.html last accessed 22/04/2016). The specimens here have a quite long abdomen with 3 feet that are not tapered or branched.

BIOGEOGRAPHIC AFFINITY: Low latitude.

\section{Subgenus Pentalocorys Haeckel 1881}

Thyrsocyrtis (P.) cf. triacantha (Ehrenberg) [Plate 11, fig. 18a, b]

Podocyrtis triacantha Ehrenberg 1873, p. 254; 1875, pl. 13, fig. 4

Thyrsocyrtis triacantha (Ehrenberg), Riedel and Sanfilippo 1970, p. 526, pl. 8, fig. 2, 3; Petrushevskaya and Kozlova 1972, p. 542, pl. 32, fig. 9, pl. 34, fig. 6; Foreman 1973b, p. 442, pl. 12, fig. 9-11; Johnson 1978, p. 782.

Thyrsocyrtis (Pentalocorys) triacantha (Ehrenberg), Sanfilippo and Riedel 1982, p. 176, pl. 1, fig. 8-10, pl. 3, fig. 3-4; Nigrini et al. 2006, p. 55; Moore and Kamikuri 2012, p. 11, pl. 9, fig. 1,2 .

The specimens encountered in this study differ from $T$. triacantha by having larger pores on the thorax and smaller pores on the abdomen. The three feet do not taper distally. The species differs from $T$. tensa by having more slender feet and a larger abdomen. 
Sanfilippo and Riedel (1982) have ascribed similar forms to T. rhizodon and postulated that they might be a result of hybridisation with $T$. triacantha. Further study might reveal if this is a distinct mid-latitude species of Thyrsocyrtis.

BIOGEOGRAPHIC AFFINITY: Based on the distribution of the genus, this species is assigned to the low-latitude group.

Thyrsocyrtis sp. A [Plate 11, fig. 19a, b, 20]

This species has three segments. The cephalis has large pores and long conical apical horn with a pore at its base; the thorax is hemispherical; the abdomen is $1 \frac{1 / 2-2}{2}$ times wider than the thorax, and barrel-shaped with large pores in hexagonal pore frames. In some specimens tiny beams are visible inside the pores. Three to five feet, tapered and broad distally, arise from the peristome. This specimen differs from T. tensa by the shape and size of the feet, from $T$. triacantha by the larger thoracic pores, the shorter feet and smaller abdominal pores, from $T$. rhizodon by larger abdominal pores, from $T$. bromia and $T$. pinguisicoides by the presence of feet and from $T$. norrisi by larger abdominal pores and a less developed peristome.

This morphotype has only been found at mid-latitude Site 206.

Thyrsocyrtis sp. D sensu Kamikuri [Plate 11, fig. 21a, b, c]

Thyrsocyrtis sp. D Kamikuri 2015, pl. 5, fig. 1, 2

This species has three segments, a cephalis with pores and a short bladed apical horn up to twice the length of the cephalis, a hemispherical thorax and an abdomen which is inflated and has larger pores than the thorax. Three porous feet arise from the margin. This form can be distinguished from T. tensa, which has porous feet (Sanfilippo and Riedel 1982, pl. 3, fig. 2), by a hemispherical thorax and an abdomen that is not barrelshaped. The porous feet are also much shorter.

BIOGEOGRAPHIC AFFINITY: Low latitude; it has only been encountered in the tropical Pacific and at Site 206 (this study) during the late middle Eocene.

\section{Genus VERUTOTHOLUS O'Connor 1999a}

Verutotholus edwardsi O'Connor [Plate 11, 22a, b]

Verutotholus edwardsi O’Connor 1999a, p. 15, pl. 2, fig. 17-20, pl. 6, fig. 5-8; O’Connor 2000, p. 210.

\section{Family LYCHNOCANIIDAE Haeckel 1881}

\section{Genus DICTYOPHIMUS Ehrenberg 1847, emend. Nigrini 1967}

Dictyophimus spp. [Plate 12, fig. 1, 2, 3]

Included here are two-segmented morphotypes, with 3 thoracic ribs that form divergent feet. Distinguished from Pterocyrtidum by indistinct separation between thorax and abdomen, triangular outline and large pores. Pterocyrtidium has a bullet-shaped outline. Rhopalocanium is similar to Pterocyrtidium but the feet extend from the abdomen and are often connected to it by transverse bars. 
Dictyophimus craticula Ehrenberg [Plate 12, fig. 4a, b]

Dictyophimus craticula Ehrenberg 1873, p. 223; 1875, pl. 5, fig. 4, 5; Sanfilippo and Riedel 1973, p. 529, pl. 19, fig. 1, pl. 33, fig. 11; Palmer 1987, p. 355; Nigrini et al. 2006, p. 31; Kamikuri et al. 2012b, p. 3, pl. 2, fig. 7

BIOGEOGRAPHIC AFFINITY: Cosmopolitan.

Dictyophimus pocillum Ehrenberg [Plate 12, fig. 5, 6]

Dictyophimus pocillum Ehrenberg 1873, p. 223; 1875, pl. 5, fig. 6; Petrushevskaya and Kozlova 1972, p. 553, pl. 29, fig. 5; Caulet 1991, p. 538; O’Connor 1999b, p. 500, pl. 4, fig. Q, R.

BIOGEOGRAPHIC AFFINITY: Cosmopolitan.

Dictyophimus? archipilium Petrushevskaya [Plate 12, fig. 7a, b, 8]

Dictyophimus? archipilium Petrushevskaya 1975, p. 583, pl. 25, fig. 1, 2; Caulet 1991, p. 538.

Dictyophimus cf. archipilium Petrushevskaya, Crouch and Hollis 1996, p. 26 (in part); Hollis et al. 1997, p. 60 (in part).

Dictyophimus archipilium Petrushevskaya, Apel et al. 2002, p. 18, pl. 7, fig. 10.

This species is distinguished by its small size, weak apical horn and terminal feet that extend out from the lower thorax, and typically are short protuberances. Hollis et al (1997) failed to identify the distinguishing features of this species and erroneously included some specimens in which the feet are attached to the abdomen. Such specimens are referred to D.? aff. archipilium here (sensu Hollis 1997).

BIOGEOGRAPHIC AFFINITY: High latitude.

Dictyophimus? aff. archipilium Petrushevskaya [Plate 12, fig. 9a, b, 10, 11, 12, 13, 14]

Dictyophimus? spp. Dumitrica 1973, p. 788, pl. 7, fig. 3-9; pl. 8, fig. 4; pl. 9, fig. 8; pl. 12, fig. 6, 7; pl 13, fig. 14; Hollis 1993, p. 322.

Dictyophimus sp. A, Strong et al. 1995, p. 208, fig. 8o; Hollis et al. 1997, p. 60.

Dictyophimus cf. archipilium Petrushevskaya, Crouch and Hollis 1996, p. 26 (in part);

Hollis et al. 1997, p. 60 (in part), pl. 5, fig. 38-19.

Dictyophimus aff. archipilium Petrushevskaya, Hollis 1997, p. 82, pl. 22, fig. 5-7.

This Paleocene-Eocene species is distinguished from D.? archipilium by its distinctive feet, which extend from the base of the thorax and are connected to the abdomen by transverse bars. These bars are evident in the specimens referred to $D$. cf. archipilium by Hollis et al. (1997), indicating that the species persists into the Early Oligocene.

BIOGEOGRAPHIC AFFINITY: High latitude.

Dictyophimus? aff. constrictus Nishimura [Plate 12, fig. 15, 16]

aff. Dictyophimus? constrictus Nishimura 1992, O’Connor 1999a, pl. 9, fig. 13.

\section{Genus LITHOCHYTRIS Ehrenberg 1847}

Lithochytris archaea Riedel and Sanfilippo [Plate 12, fig. 17] 
Lithochytris archaea Riedel and Sanfilippo, 1970, p. 528, pl. 9, fig. 7; 1971, pl. 7, fig. 3; Foreman, 1973, p. 436, pl. 2, fig. 4, 5.

Lithochytris vespertilio Ehrenberg [Plate 12, fig. 18]

Lithochytris vespertilio Ehrenberg, 1873, p. 239; 1875, pl. 4, fig. 10; Foreman, 1973, p. 436, p. 2, fig. 2, 3; pl. 11, fig. 3; Johnson 1978, p. 781; 1990, p. 407; Nigrini et al. 2006, p. 42; Kamikuri et al. 2012b, p. 4.

Lithochytris cheopsis Clark and Campbell, 1942, p. 81, pl. 9, fig. 37.

There is no discernible difference between this species and that described by Clark and Campbell (1942). L. vespertilio is distinguished from $L$. archaea by latticed meshwork covering most of the terminal feet.

BIOGEOGRAPHIC AFFINITY: Low latitude.

\section{Genus LYCHNOCANIUM Ehrenberg 1847, sensu O'Connor 1997}

Lychnocanium spp. [Plate 12, fig. 19, 20, 21, 22, 23]

Included here is a highly variable range of two-segmented morphotypes with three feet arising from the lower thorax or the basal margin, bladed or unbladed and of varying length. The cephalis always has an apical horn, which is of variable length. Sometimes the remnants of an abdomen are present. This genus seems to be most abundant in mid latitudes during the middle Eocene.

Lychnocanium alma O'Connor [Plate 12, fig. 24a, b]

Lychnocanium alma O'Connor 1999a, p. 24, pl. 4, fig. 1-5, pl. 7, fig. 8-11; Kamikuri 2015, p. 144, pl. 3, fig. 7.

Lychnocanium amphitrite (Foreman) [Plate 12, fig. 25, 26, 27, 28]

Lychnocanoma amphitrite Foreman 1973b, p. 437, pl. 11, fig. 10; Chen 1975, p. 462, pl. 2. fig. 7; Caulet 1986, p. 853; Palmer 1987, p. 356; Takemura 1992, p. 747, pl. 7, fig. 9-10; O'Connor 1993, p. 76, pl. 8, fig. 29; Strong et al. 1995, p. 208, fig. 11k-1; Takemura and Ling 1997, p. 114, pl. 1, fig. 21; Funakawa et al. 2006b, p. 35, pl. 12, fig. 8; Suzuki et al. 2009, p. 261, pl. 19, fig. 5a-6b; Moore and Kamikuri 2012, p. 9, pl. 7, fig. 1-2; Kamikuri et al. 2012a, p. 102.

Lychnocanoma bellum (Clark and Campbell), Foreman 1973b (in part), pl. 1, fig. 17.

Lychnocanium amphitrite (Foreman), Hollis et al. 1997, p. 63, pl. 6, fig. 1-4.

Specimens with any vestige of a third segment, such as that figured as L. bellum by Foreman (1973, pl. 1, fig. 17), are here included in L. amphitrite.

BIOGEOGRAPHIC AFFINITY: Cosmopolitan.

Lychnocanium auxillum (Foreman) [Plate 13, fig. 1]

Lychnocanoma auxilla Foreman 1973b, p. 437, pl. 2, fig. 6; pl. 11, fig. 1, 2; Strong et al. 1995, p. 208, fig. 91.

Lychnocanium auxillum (Foreman), Hollis et al. 1997, p. 63.

Distinguished from its descendant Lithochyrtis archaea by the absence of a fully formed abdomen. 
Lychnocanium babylonis (Clark and Campbell) [Plate 13, fig. 2a, b, 3]

Dictyophimus babylonis Clark and Campbell 1942, p. 67, pl. 9, fig. 32, 36.

Lychnocanoma babylonis (Clark and Campbell), Foreman 1973b, p. 437, pl. 2, fig. 1;

Chen 1975, p. 462, pl. 2. fig. 8; Caulet 1986, p. 853; Strong et al. 1995, p. 208, fig. 11a, b; Funakawa et al. 2006b, p. 35, pl. 13, fig. 1; Kamikuri et al. 2012b, p. 4; Kamikuri et al. 2012a, p. 102.

Lychnocanoma cf. babylonis Clark and Campbell, Takemura 1992, p. 747, pl. 7, fig. 13; Takemura and Ling, 1997, p. 114.

Sethochytris babylonis (Clark and Campbell), Hollis et al., 1997, p. 65, pl. 5, fig. 32; Hollis, 2002; Johnson 1990, p. 407.

Cephalis may be partially encased in thoracic wall. Distinguished from Lychnocanium auxillum and Rhopalocanium ornatum by the absence of an abdomen.

BIOGEOGRAPHIC AFFINITY: Cosmopolitan.

Lychnocanium bellum Clark and Campbell [Plate 13, fig. 4]

Lychnocanium bellum Clark and Campbell 1942, p. 72, pl. 9, fig. 35, 39; Hollis et al. 1997, p. 63, pl. 6, fig. 5-6.

Lychnocanoma bellum (Clark and Campbell); Foreman 1973b (in part), p. 437, pl. 11, fig. 9; Johnson 1978, 481; Caulet 1986, p. 853; Johnson 1990, p. 407; Caulet 1991, p. 538; Strong et al. 1995, p. 208, fig. 11i, j; Sanfilippo and Blome 2001, p. 214; Suzuki et al. 2009, p. 261, pl. 19, fig. 1a-b.

BIOGEOGRAPHIC AFFINITY: Cosmopolitan.

Lychnocanium aff. carinatum Ehrenberg [Plate 13, fig. 5]

? Lychnocanium carinatum Ehrenberg 1875, p. 78, pl. 8, fig. 5; Haeckel 1887, p. 1226.

Theopodium sp. aff. Lychnocanium carinatum Ehrenberg, Nishimura, 1992, p. 7, fig. 11.

This species was ascribed to Theopodium by Nishimura (1992) because it consists of three segments and has three solid feet. As the third segment is not fully developed and in other respects this species closely resembles $L$. auxilla, the species was transferred to Lychnocanium. This species is distinguished from L. sphinx by the presence of a third segment. It is distinguished from $L$. auxilla by having longitudinal costae on the thorax. It also differs from both species by having feet that curve inwards.

Lychnocanium conicum Clark and Campbell [Plate 13, fig. 6, 7]

Lychnocanium conicum Clark and Campbell 1942, p. 71, pl. 9, fig. 38.

Lychnocanoma? conica (Clark and Campbell), Suzuki et al. 2009, p. 261, pl. 19, fig. 1a-b. non Lychnocanoma conica (Clark and Campbell). Abelmann 1990, p. 697, pl. 6, fig. 8; pl. 7, fig. 1a, b; Takemura 1992, p. 747, pl. 2, fig. 13-14; Takemura and Ling 1997, p. 114, pl. 1, fig. 20.

L. conicum s.s. differs from the morphotypes ascribed to the species by Abelmann (1990) and subsequent researchers, by having a pear-shaped thorax with a small aperture. It differs from $L$. babylonis by having a more inflated thorax and more slender feet.

Lychnocanium cf. conicum [Plate 13, fig. 8, 9]

? Theoperid gen et sp. indet. Sanfilippo et al. 1985, p. 673, fig. 17.5, 6. 
This morphotype is much smaller than Lychnocanium conicum, the cephalis is partly encased in the thorax, with a horn that can be up to 1.5 times the size of the cephalis. The thorax is barrel-shaped; the feet are relatively short and straight, arising from the base of the thorax or slightly above. Pores on the thorax can be in longitudinal rows or indistincly scattered.

Lychnocanium continuum Ehrenberg [Plate 13, fig. 10a, b]

Lychnocanium continuum Ehrenberg, 1873, p. 243; 1875, pl. 7, fig. 11; Funakawa et al. 2006b, pl. 12, fig. 7.

Lychnocanium aff. grande sensu Chen [Plate 13, fig. 11, 12a, b, 13a, b, 14a, b]

Lychnocanium sp. aff. L. grande Clark and Campbell, Chen 1975 p. 462, pl. 1, fig. 6, 7;

Strong et al. 1995, p. fig. 11f-h (as Lychnocanoma).

Specimens included in this taxon exhibit considerable variation in the length of the thorax. All have a 'bottleneck'-like contour between cephalis and thorax; collar stricture indistinct. The upper thorax sometimes has only few pores just below the collar stricture. Bladed feet are of variable length. This morphotype differs from $L$. grande Clark and Campell by having smaller thoracic pores and the distinctive contour between cephalis and thorax. No other species of Lychnocanium have this distinctive feature. Early forms tend to have a longer thorax and straighter feet and the 'bottleneck' is reduced.

Lychnocanium satelles (Kozlova) [Plate 13, fig. 15a, b, 16a, b, 17a, b] Theopodium satelles Kozlova, in Kozlova and Gorbovetz 1966, p. 105, pl. 16, fig. 8. Rhopalocanium satelles (Kozlova), Kozlova 1999, p. 132, pl. 24, fig. 10; pl. 45, fig. 17. Lychnocanium satelles (Kozlova), Hollis, 1992, p. 313, pl. 9, fig. 10-13.

Transferred to Lychnocanium because the abdomen is not fully developed. Distinguished from L. auxilla by its slender bladed feet and a cephalis that is not encased in the thoracic wall. It differs from $L$. aff. carinata by lacking costae on the thorax. Some of the specimens here are very large, with long, thick feet and a pear-shaped thorax. Feet arise around the abdominal structure and are connected to the abdomen. A large variation of forms with 3 segments and feet connected in various ways to the region between thorax and abdomen have been found in this study. Rhopalocanium cf. ornatum (see below) is distinguished from L. satelles by its more hemispherical thorax and short, very thick feet.

Lychnocanium tetrapodium Ehrenberg [Plate 13, fig. 18a, b]

Lychnocanium tetrapodium Ehrenberg 1873, p. 244; Ogane et al. 2009, pl. 7, fig. 9.

? Lychnocanoma tetrapodium (Ehrenberg), Kamikuri et al. 2012a, p. 103, pl. 2, fig. 9, 10.

Distinguished by having four feet. The specimens illustrated by Kamikuri et al. (2012a) appear to have only three feet.

Lychnocanium trichopus Ehrenberg [Plate 14, 1, 2a, b, c, 3a, b]

Lychnocanium trichopus Ehrenberg 1873, p. 244; 1875, pl. 7, fig. 5; Ogane et al. 2009, pl. 42, fig. 1, 2(?). 
Distinguished from other members of the genus by its very long and slender conical feet. As mentioned in Ogane et al. (2009), Ehrenberg included a form with thick bladed feet (Pl. 42, fig. 1), which he, however, did not illustrate in 1875.

Lychnocanium cf. tridentatum Ehrenberg [Plate 14, fig. 4]

Lychnocanium tridentatum Ehrenberg 1873, p. 244; 1875, pl. 7, fig. 4; Funakawa et al. 2006b, p. 37, pl. 12, fig. 6; Ogane et al. 2009, pl. 97, fig. 5, 6, pl. 98, fig, 1;

The two specimens found in this study differ from L. tridentatum by the absence of the little thorn on each feet. This form might be the ancestor of the late Eocene $L$. tridentatum.

Lychnocanium turgidum Ehrenberg [Plate 14, fig. 5a, b] Lychnocanium turgidum Ehrenberg 1873, p. 246; 1875, pl. 7, fig. 6.

? Lychnocanium pyriforme Haeckel, 1887, p. 1225, pl. 61, fig. 11.

Gen. et sp. indet.; Riedel and Sanfilippo, 1970, pl. 8, fig. 10.

Lithochytris (Lithochytroides) turgidulum [sic] (Ehrenberg), Petrushevskaya and Kozlova, 1972, p. 552, pl. 27, fig. 8, 9.

Lithochytris sp. T, Petrushevskaya and Kozlova, 1972, p. 552, pl. 27, fig. 6.

Sethochytris cavipodis O’Connor, 1999, p. 28, pl. 4, figs. 22- 27; pl. 7, figs. 24a-27.

Lychnocanoma turgidum (Ehrenberg), Nigrini et al., 2006, p. 44, pl. 4, fig. 6; Moore and Kamikuri 2012, p. 9, pl. 7, fig. 4.

Lychnocanium waiareka O'Connor [Plate 14, fig. 6a, b]

Lychnocanium waiareka O'Connor 1999a, p. 25, pl. 4, fig. 6-11, pl. 7, fig. 12a-15.

Lychnocanium tripodium Ehrenberg, Hollis et al. 1997, p. 64, pl. 5, fig. 34-37.

? Lychnocanium hamosum Ehrenberg 1875, pl. 7, fig. 9; Ogane et al. 2009, pl. 7, fig. 8a-b.

? Lychnocanium tripodium Ehrenberg 1875, pl. 7, fig. 2.

? Lychnocanium neptunei O’Connor 1997, pl. 3, fig. 7-10, pl. 9, fig. 7-12.

This species is distinguished by a campanulate thorax, which is almost as wide as it is long, and terminal feet that are only slightly flared. A delicate abdomen is preserved on well-preserved specimens. In less well-preserved specimens, all that remains of the abdomen are short thorns on the inner sides of the feet (e.g. Hollis et al. 1997, pl. 5, fig. 35-37). Such forms closely resemble L. hamosum Ehrenberg. Specimens with smooth feet (e.g. Hollis et al. 1997, pl. 5, fig. 34), which may be L. tripodium Ehrenberg or $L$. neptunei $\mathrm{O}$ 'Connor, are provisionally included here.

Lychnocanium waitaki O'Connor [Plate 14, fig. 7a, b]

Lychnocanium waitaki O’Connor 1999a, p. 26, pl. 4, fig. 12-15, pl. 7, fig. 16-19.

Lychnocanium sp. A [Plate 14, fig. 8, 9a, b, 10a, b]

Lychnocanoma sp. Chen 1975, p. 462, pl. 1, fig. 8, 9.

This species has a small thorax and relatively large cephalis with a conical horn of varying size. Pores are more or less regularly distributed and tend to get slightly larger towards the distal part of the thorax. Three very stout conical feet arise from the base of the thorax and diverge slightly outward. Sometimes a remnant of an abdomen is present. It might be related to Rhopalocanium ornatum. This morphotype has also been observed 
at the DSDP Leg 4 Site 29 (Caribbean) (http://www.riedel-william-andelizabeth.net/extras.html accessed 21/04/2016).

\section{Genus PTEROCANIUM Ehrenberg 1847}

Pterocanium sp. [Plate 14, fig. 11a, b]

This morphotype is ascribed to Pterocanium because it has pores on the proximal part of the feet. The horn is strong and bladed, cephalis with pores, and thorax with rounded pores. Sometimes a remnant of a third segment is present which is connected to the feet. Tiny spines on the inner side of the proximal feet are visible.

Pterocanium cf. sphinx [Plate 14, fig. 12, 13a, b]

Pterocanium sphinx Ehrenberg 1873, p. 255; 1875, pl. 17, fig. 5; Ogane et al. 2009, pl. 1, fig. 4, pl. 46, fig. 2, 3, pl.97, fig. 4 .

This morphotype differs from Pterocanium sphinx by having a differently shaped thorax and abdomen. The thorax is much larger and conical, rather than hemispherical, the abdomen is only slightly wider than the thorax. A secondary horn is present on the side of the cephalis. Most specimens are incomplete. The feet emerge from the abdomen.

\section{Genus PTEROCODON Ehrenberg 1847}

Pterocodon apis Ehrenberg [Plate 14, fig. 14, 15a, b]

Pterocodon apis Ehrenberg 1873, p. 255, Ehrenberg 1875, pl. 19, fig. 3; Ogane et al. 2009, pl. 5, fig. 8a-d.

? Pteropilium sp. B, O’Connor 1999b, p. 507, pl. 6, fig. C.

Three segmented, strong apical horn, two lateral wings emerging from its thorax. The species described by O'Connor (1999b) is similar, but appears to have fewer pores on thorax and abdomen. Our specimens have larger, hexagonal pores on the abdomen and smaller, rounded pores on the thorax.

\section{Genus PTEROPILIUM Haeckel 1881}

Pteropilium aff. contiguum (Ehrenberg) [Plate 14, fig. 16, 17, 18a, b]

Pteropilium aff. Pterocanium contiguum Caulet 1991, p. 539, pl. 2, fig. 11; Nigrini et al. 2006, p. 47, pl. 5, fig. 5.

aff. Pterocanium contiguum Ehrenberg 1873, p. 255, 1875, pl. 17, fig. 7.

Three-segmented form, cephalis with a few pores and a bladed horn of about the length of the cephalis or even longer (see Caulet 1991). The thorax is conical with transverse pore rows; however, some areas are poreless. The abdomen is cylindrical and may be constricted distally. Rows of pores with imperforate zones. There is an imperforate band in the distal part of the abdomen. Three prominent wings on the thorax. In Caulet (1991), one specimen from Site 277 and two specimens from Site 1123, the wings and horn are much larger. This type has been observed in the Caribbean, DSDP Leg 4 Site 29, (http://www.riedel-william-and-elizabeth.net/extras.html accessed on 21/04/2016). 


\section{Genus RHOPALOCANIUM Ehrenberg 1847}

Rhopalocanium ornatum Ehrenberg [Plate 14, fig. 19, 20]

Rhopalocanium ornatum Ehrenberg, 1847, fig. 3; 1854b, pl. 36, fig. 9; 1873, p. 256; 1875 , p. 82, pl. 17, fig. 8; Foreman 1973b, p. 439, pl. 2, fig. 8-10, pl. 12, fig. 3.

Distinguished from the Lychnocanium auxillum - Lithochytris vespertilio lineage by its hemispherical thorax and a cephalis that is not enclosed within the thoracic wall. Three sturdy feet with rough, pitted surface extend from the lower thorax/upper abdomen.

Rhopalocanium cf. ornatum [Plate 14, fig. 21, 22, 23, 24, 25, 26]

This morphotype is a distinct variant of several morphotypes made up of three segments, in which the abdomen is only partly preserved, and have three feet that arise from the base of the thorax but are connected to the abdomen. This form can be distinguished from Rhopalocanium ornatum by a much smaller cephalic horn and shorter feet. This form is more common than the very rare $R$. ornatum. The thickness of the feet appears to be reduced in later forms of $R$. cf. ornatum, which are present at DSDP Site 206.

\section{Genus SETHOCHYTRIS Haeckel 1881}

Sethochytris triconiscus Haeckel [Plate 14, fig. 27a, b]

Sethochytris triconiscus Haeckel 1887, p. 1239, pl. 57, fig. 13; Riedel and Sanfilippo 1970, p. 528, pl. 9, fig. 5-6; Sanfilippo et al. 1985, p. 680, fig. 22.1a-d; Johnson 1990, p. 407 ; Nigrini et al. 2006, p. 47

BIOGEOGRAPHIC AFFINITY: Low latitude, as noted by Sanfilippo et al. (1985).

\section{Family LOPHOCYRTIIDAE sensu Sanfilippo and Caulet 1998}

\section{Genus APHETOCYRTIS Sanfilippo and Caulet 1998}

This genus comprises the lineage Aphetocyrtis gnomabax - A. rossi - A. catalexis. All three species have a porous subspherical cephalis with a small apical horn; a hemispherical to campanulate (bell-shaped) thorax with a rough thorny surface; and a subcylindrical to inverted truncate conical abdomen that may be closed and lacks a peristome or terminal feet.

Sanfilippo and Caulet (1998) differentiate species in this genus by skeletal features within the cephalis. This criterion is difficult to apply consistently to variably preserved material and the skeletal features are difficult to see in published illustrations. I focused on the more general features of the species that facilitate discrimination in our census studies.

The genus appears to arise in low latitudes in the middle Eocene (A. gnomabax) and migrates to high latitudes in the late middle to late Eocene, with A. rossi (late Eocene-late Oligocene) largely and $A$. catalexis (late Oligocene-Miocene) completely restricted to high latitudes. 
Aphetocyrtis bianulus (O'Connor) [Plate 15, fig. 1]

Theocorys bianulus O'Connor 1997, p. 84, pl. 4, fig. 1-4; pl. 10, fig. 1-4; pl. 11, fig. 5; Sanfilippo and Fourtanier 2003, p. 12, pl. P1, fig. 8, 9, 13; Funakawa et al. 2006b, p. 24, pl. 6, fig. 7.

Aphetocyrtis bianulus (O’Connor), Suzuki et al. 2009, pl. 18, fig. 16a-b.

This species closely resembles $A$. rossi, differing by having two distinctive bulges on the abdomen. It is uncertain how this species is related to the lineage; it might be a regional variant of $A$. rossi.

Aphetocyrtis gnomabax Sanfilippo and Caulet [Plate 15, fig. 2, 3, 4, 5, 6, 7]

Calocyclas semipolita Clark and Campbell, Caulet 1991, p. 537, pl. 4, fig. 9.

Aphetocyrtis gnomabax Sanfilippo and Caulet 1998, p. 16, pl. 2, fig. 6, 7, 10, 11, 14-17; pl. 7, fig. 10-13.

? Cyrtocapsella aff. japonica (Nakaseko), Takemura 1992, p. 746, pl. 1, fig.11-12.

non Calocyclas semipolita Clark and Campbell, Strong et al. 1995, p. p. 208, fig. 10V [ $L$. semipolita?].

non Calocyclas cf. semipolita Clark and Campbell, Abelmann 1990, p. 697, pl. 7, fig. 4 [A. catalexis].

Thorax is bell-shaped to narrowly hemispherical. Pores on thorax and abdomen are of similar size. Abdomen is subcylindrical to inverted conical with a ragged basal margin.

BIOGEOGRAPHIC AFFINITY: High latitude.

Aphetocyrtis rossi Sanfilippo and Caulet [Plate 15, fig. 8, 9, 10, 11]

Calocyclas semipolita? Clark and Campbell, Chen 1975, p. 459, pl. 6, fig. 3-6.

Calocyclas asperum (Ehrenberg), Caulet 1992, p. 537, pl. 4, fig. 8, fig. 4, no. 4 (not no. $3)$.

Calocyclas cf. semipolita Clark and Campbell, Takemura 1992, p. 745, pl. 4, fig. 5-6; Takemura and Ling 1997, p. 111, pl. 1, fig. 16.

Calocyclas semipolita Clark and Campbell group, Crouch and Hollis 1996, p. 26; Hollis et al. 1997, p. 58, pl. 5, fig. 11-12.

Cyrtocapsella robusta Abelmann, Hollis et al., 1997, p. 60, pl. 5, fig. 13-14.

Aphetocyrtis rossi Sanfilippo and Caulet 1998, p. 18, pl. 2, fig. 8-9, 12-13; pl. 7, fig. 1-9. Aphetocyrtis cf. rossi Sanfilippo and Caulet, Suzuki et al. (2009), p. 260, pl. 18, fig. 17.

Hemispherical thorax. The subcylindrical abdomen narrows distally, may be closed with a lattice plate, and its pores are slightly larger than on the thorax. Distinguished from $A$. gnomabax and $C$. robusta by its hemispherical thorax. Distinguished from Lophocyrtis (Apoplanius) aspera by thorax and abdomen being of similar thickness. The two morphotypes illustrated by Hollis et al. (1997) appear to represent end-member variation within the species from slender forms with the cephalis free of the thoracic wall and a long cylindrical abdomen, open distally (" $C$. semipolita"), to more squat forms with the cephalis partly enclosed in the thoracic wall and a short abdomen, which is closed or has a basal lattice plate ("C. robusta").

BIOGEOGRAPHIC AFFINITY: High latitude.

\section{Genus CLINORHABDUS Sanfilippo and Caulet 1998}


Comprises the lineage Clinorhabdus anantomus $-C$. ocymora $-C$. robusta $-C$. longithorax. Distinguished from other lophocyrtids by a short apical horn (when present), a bell-shaped or truncate conical thorax, and an abdomen that is subcylindrical and commonly closed. This genus is endemic to the Southern Ocean and ranges from the Middle Eocene to the Early Miocene.

Clinorhabdus anantomus Sanfilippo and Caulet [Plate 15, fig. 12, 13]

Clinorhabdus anantomus Sanfilippo and Caulet 1998, p. 20, pl. 1, fig. 14-25; pl. 8, fig. 1a-b, 3a-b.

Apical spine, vertical spine and apophyses from mitral arches protrude from cephalis as, respectively, a moderately robust apical horn, a short spine and several short thorns. Thorax has a distinct neck and primary dorsal and lateral spines may protrude as short spines. Abdomen thin-walled with a ragged distal margin.

BIOGEOGRAPHIC AFFINITY: High latitude.

\section{Clinorhabdus robusta (Abelmann) emend. Sanfilippo and Caulet}

Cyrtocapsella robusta Abelmann 1990, p. 696, pl. 5, fig. 10, 11; Caulet 1991, p. 538, fig.

4; Takemura 1992, p. 746, pl. 1, fig. 5, 6; Takemura and Ling, 1996, p. 111, pl. 1, fig. 18.

Clinorhabdus robusta (Abelmann), Sanfilippo and Caulet 1998, p. 22, pl. 1, fig. 7-10; pl. 8, fig. 9-14.

non Cyrtocapsella robusta Abelmann, Hollis et al. 1997, p. 60, pl. 5, fig. 13-14 [= A. rossi]

Abdomen is subcyclindrical or inverted truncate conical and usually closed. Pores on the abdomen only slightly larger than those on the thorax.

BIOGEOGRAPHIC AFFINITY: High latitude.

\section{Genus LOPHOCYRTIS Haeckel 1887, sensu Sanfilippo 1990}

The genus includes Lophocyrtis jacchia and all of its descendants. Most species have three segments, pores of thorax quincuncially arranged; many have an apical horn, three feet and a closed abdomen.

\section{Subgenus APOPLANIUS Sanfilippo and Caulet 1998}

The subgenus comprises the lineage $L$. (A.) klydus - L. (A.) keraspera - L. (A.) aspera $L$. (A.) nomas. The transition from $L$. (A.) klydus to $L$. (A.) aspera includes a shortening and reduction in number of spines protruding from the cephalis; an expansion of the proximal thorax, with its overall shape changing from narrowly campanulate to hemispherical, and reductions in abdominal length, width and test thickness.

The first three members of the lineage span the early Eocene to Oligocene in low latitudes and co-occur in the middle to late Eocene in high latitudes.

Lophocyrtis (Apoplanius) aspera Form A (Ehrenberg), emend. Sanfilippo and Caulet [Plate 15, fig. 14a, b, 15, 16a, b]

Eucyrtidium asperum Ehrenberg 1873, p. 226; 1875, pl. 8, fig. 15. 
Calocyclas asperum (Ehrenberg), Petrushevskaya and Kozlova 1972, p. 548, pl. 28, fig. 16-18.

Theocyrtis diabloensis (Clark and Campbell), Chen 1975, p. 459, pl. 5, figs. 4-6 (not fig. 7).

Theocorys minuta Takemura and Ling 1998, p. 162, fig. 3-16 to 3-21, 5-5,6.

Calocyclas sp. B, Takemura 1992, p. 745, pl. 5, fig. 13; Takemura and Ling 1997, fig. 11, pl. 1, fig. 15; Hollis et al. 1997, p. 58, pl. 5, fig. 7-10.

Lophocyrtis (Apoplanius) aspera (Ehrenberg), Sanfilippo and Caulet 1998, p. 14, pl. 3A, fig. 8-10.

The morphotype referred to as $L$. aspera Form A represents the Antarctic form described by Sanfilippo and Caulet (1998) and morphotypes that were referred to Theocorys minuta and Calocyclas sp. B Takemura (1992) and Takemura and Ling (1997) are also included under this taxon. L. aspera Form A seems to have a shorter stratigraphic range (middle to late Eocene) than the low-latitude form (early middle Eocene to early late Oligocene). It has a very short apical horn, generally no longer than the cephalis and a subsphaerical thorax. Antarctic forms have a thicker walled abdomen than low-latitude forms (referred to as L. aspera Form B below), however the abdomen is often incomplete. The lumbar stricture in high-latitude forms is wider than in the low-latitude forms. The low-latitude form described by Sanfilippo and Caulet (1998) seems to have a slightly longer, more slender horn and a thinner walled abdomen and thorax. The morphotype described by Ehrenberg (1873) from Barbados seems to be the low-latitude form of L. aspera. However, no other study could be found where these forms were distinguished.

BIOGEOGRAPHIC AFFINITY: High latitude.

Lophocyrtis (Apoplanius) aspera Form B (Ehrenberg), emend. Sanfilippo and Caulet [Plate 15, fig. 17a, b, 18a, b, 19a, b]

Lophocyrtis (Apoplanius) aspera (Ehrenberg), Sanfilippo and Caulet 1998, p. 14, pl. 3A, fig. 5-7, pl. 3B, fig. 1, 2, 5-9; pl. 6, fig. 6-8; O’Connor 1999a, p. 32, pl. 9, fig. 5; Funakawa et al. 2006b, p. 25, pl. 7, fig. 5-7 (not 4=L. keraspera).

? Eucyrtidium asperum Ehrenberg 1873, p. 226; 1875, pl. 8, fig. 15; Ogane et al. 2009, pl. 89, fig. 3a-f.

? Calocyclas asperum (Ehrenberg), Strong et al. 1995, p. 208, fig. 9E.

The above synonymy list is based on illustrated specimens only, so the range of morphotypes the authors included in L. aspera is unknown. It can be difficult to distinguish the low-latitude form of L. aspera from Lophocyrtis keraspera. Internal structures of the cephalis are used to separate between these two species, but they are difficult to examine in routine census studies, so the criterion for separating these two taxa was the size of the horn, which is more robust in L. keraspera.

BIOGEOGRAPHIC AFFINITY: Possibly low latitude; some specimens at Sites 1123, 206, 207 agree with the low-latitude morphotype, however, more study is needed and therefore this form is not included in the biogeographic affinity counts.

\section{Lophocyrtis (Apoplanius) keraspera Sanfilippo and Caulet}

[Plate 15, fig. 20, 21, 22, 23a, b, 24]

Lophocyrtis (Apoplanius) keraspera Sanfilippo and Caulet 1998, p. 14, pl. 3a, fig. 13-15, pl. 3b, fig. 12-14, pl. 6, fig. 9-12. 
This species is distinguished by a robust apical horn, short vertical horn, hemispherical thorax with short spines projecting from the lower part in some specimens, and subcylindrical to truncate conical abdomen. Abdomen is thin-walled and often incomplete. As mentioned under L. aspera Form B, the criterion for distinguishing between these two taxa is the size of the horn. The late Eocene specimens found in this study almost never had their abdomen preserved, and the pores on the thorax are closed (dimples). The middle Eocene forms commonly have the abdomen preserved and bear a cephalic horn that is slightly smaller than in late Eocene forms. This species is common in the late Eocene at Sites 277 and 1123 and rare in the middle Eocene at Site 277. This is contrary to the observations of Sanfilippo and Caulet (1998), who found the species to be restricted to the middle Eocene in the low-latitude Atlantic and Southern Ocean. Although these authors distinguished between high- and low-latitude morphology in the illustrated specimens, the distinguishing characteristics were not explained. High-latitude forms seem to have larger, less regularly distributed pores in polygonal frames. Lowlatitude species bear small circular pores arranged in longitudinal rows and a more slender and curved apical horn. With the exception of Suzuki et al. (2009), no other studies have reported this species, perhaps because it is not distinguished from L. aspera. In Pascher et al. (2015) this species was assigned to the high-latitude group. But considering the problems in identifying the correct morphotype and the issue with the occurrence of this species in time, it is suggested to restudy this species and its occurrence and reassess its biogeographic significance by examining more locations in the low and mid latitudes.

Lophocyrtis (Apoplanius) nomas Sanfilippo and Caulet [Plate 15, fig. 25a, b, 26a, b, 27]

Lophocyrtis nomas Sanfilippo and Caulet 1998, p. 15, pl. 3A, fig. 1-4, pl. 3B, fig. 3, 4, pl. 6, fig. 1-5.

This form consists of three segments: a small spherical cephalis, poreless, with a very short horn; a very large hemispherical thorax with pores arranged more or less in longitudinal rows, and an inverted conical abdomen with irregularly distributed pores. It can be distinguished from Lophocyrtis aspera by its much larger test. Sanfilippo and Caulet (1998) proposed that L. nomas evolved from L. aspera in the early Oligocene in the low-latitudes and migrated into the higher latitudes during the late Oligocene. However, in this study this species was encountered in the middle Eocene at Site 207.

\section{Subgenus CYCLAMPTERIUM Haeckel 1887}

Lophocyrtis (Cyclampterium) hadra Riedel and Sanfilippo [Plate 16, fig. 1a, b] Lophocyrtis hadra Riedel and Sanfilippo 1986, p. 168, pl. 7, fig. 12-15.

Lophocyrtis (Cyclampterium) hadra (Riedel and Sanfilippo), Sanfilippo 1990, p. 304, pl. 1, fig. 11, (not 12=L. jacchia hapsis); Moore and Kamikuri 2012, p. 8, pl. 6, fig. 3, 4.

Lophocyrtis (Cyclampterium) milowi (Riedel and Sanfilippo) [Plate 16, fig. 2]

Cyclampterium? milowi Riedel and Sanfilippo 1971, p. 1593, pl. 3B, fig. 3, pl. 7, fig. 8, 9; 1978, p. 67, pl. 4, fig. 14; Ling 1975, p. 731, pl. 12, fig.15.

Lophocyrtis (Cyclampterium) milowi (Riedel and Sanfilippo), Sanfilippo 1990, p. 306, pl. 1, fig. 13-16, pl. 2, fig. 1, 2; Moore and Kamikuri 2012, p. 8, pl. P6, fig. 6, 7. 


\section{Subgenus LOPHOCYRTIS Haeckel, emend. Sanfilippo and Caulet 1998}

The subspherical cephalis is perforate and bears a well-developed apical horn, which may bear thorns distally. The inflated hemispherical thorax has a rough, sometimes thorny, surface. The subcylindrical to inverted truncate conical abdomen has a proximal row of larger pores, and no distinct peristome. Some species have three terminal or subterminal feet.

Primarily a tropical subgenus with incursions in high latitudes in the Middle Eocene.

\section{Lophocyrtis (Lophocyrtis) jacchia hapsis Sanfilippo and Caulet}

[Plate 16, fig. 3, 4, 5a, b, 6a, b]

Lophocyrtis (Cyclampterium) hadra (Riedel and Sanfilippo), Sanfilippo 1990, p. 304 (partim), pl. 1, fig. 12.

Calocyclas sp. C, Takemura 1992, p. 745, pl. 7, figs. 3-4.

Lophocyrtis jacchia (Ehrenberg), Chen 1975, p. 461, pl. 3, fig. 5, 6.

Lophocyrtis (Lophocyrtis) jacchia hapsis Sanfilippo and Caulet, 1998, p. 10, pl. 5, fig 6, $7 \mathrm{a}-\mathrm{b}, 9$.

Lophocyrtis haywardi O’Connor 1999a, pl. 3, fig. 27-31.

The so-called cold-water form of Lophocyrtis hadra illustrated by Sanfilippo (1990) is included in L. jacchia hapsis here. Although Sanfilippo and Caulet (1998) suggest that the latter can be distinguished from the former by having smaller abdominal pores, I have found it impossible to apply this criterion and find that the two morphotypes are indistiguishable. In contrast, Lophocyrtis hadra s.s. is easily distinguished by its slender test, much larger pores on the abdomen and a very thorny thorax.

Sanfilippo and Caulet (1998) reported that Lophocyrtis jacchia hapsis was found in the middle and late Eocene in the Southern Atlantic and Indian Oceans. This occurrence agrees with the present study where the species is found in high- and mid-latitudes of the SW Pacific from the late middle Eocene to late Eocene. The mid-latitude forms of the middle Eocene of Site 206 seem however more slender than the middle and late Eocene forms at Sites 277, 592, 283 and 1123. The late Eocene forms also possess a shorter abdomen.

BIOGEOGRAPHIC AFFINITY: High latitude; endemic to the Antarctic according to Sanfilippo and Caulet (1998). However, this species only occurred in warm intervals (MECO and late Eocene warming event) at high-latitude Site 277.

Lophocyrtis (Lophocyrtis) jacchia jacchia (Ehrenberg) [Plate 16, fig. 7, 8, 9]

Thyrsocyrtis jacchia Ehrenberg 1873, p. 261; 1875, pl. 12, fig. 7.

Lophocyrtis (?) jacchia (Ehrenberg), Riedel and Sanfilippo 1970, p. 530; non Dinkelmann 1973, p. 780, pl. 2, fig. 7 (=L. hadra).

Lophocyrtis (Lophocyrtis) jacchia (Ehrenberg), Sanfilippo 1990, p. 302, pl. 1, fig. 5-10, pl. 3, fig. 6; Johnson 1990, p. 407; Funakawa et al. 2006b, p. 26, pl. 8, fig. 6, 7; Nigrini et al. 2006, p. 43; Moore and Kamikuri 2012, p. 9, pl. 6, fig. 5; Kamikuri et al. 2012a, p. 102.

Lophocyrtis jacchia jacchia (Ehrenberg), Sanfilippo and Caulet 1998, p. 10, pl. 4, fig. 1. 
The species observed in this study doe s not possess a bladed horn, which is instead simple, rather thin and conical. The pores beneath the lumbar stricture are very large, the feet very long.

BIOGEOGRAPHIC AFFINITY: Low latitude.

Lophocyrtis sp. A [Plate 16, fig. 10, 11]

This morphotype has a small hemispherical cephalis, poreless, with dimples and a short horn like L. aspera; the thorax is hemispherical to conical, sometimes with very irregular sides. The pores are rounded to hexagonal, sometimes in longitudinal rows, or irregularly distributed. The abdomen is cylindrical, the pores very large, up to 2-3 times as large as the thoracic ones. The pores just below the abdominal stricture are even larger. This taxon can be distinguished from $L$. aspera by the larger pores on the abdomen and from $L$. keraspera by a smaller horn. It differs from L. jacchia jacchia, with which it co-occurs, by the absence of feet and the presence of dimples, instead of pores, on the cephalis.

Lophocyrtis (Lophocyrtis?) semipolita (Clark and Campbell) emend. Sanflippo and Caulet 1998 [Plate 16, fig. 12a, b, 13a, b]

Calocyclas semipolita Clark and Campbell 1942, p. 83, pl. 8, fig. 12, 14, 17-19, 21-23; Blueford 1988, p. 246, pl. 2, fig. 4-5 (non 6).

? Calocyclas semipolita Clark and Campbell, Caulet 1991, p. 437, fig. 4; Strong et al. 1995, p. 208, fig. 10v.

Lophocyrtis (Lophocyrtis?) semipolita (Clark and Campbell), Sanfilippo and Caulet 1998, p. 9, pl. 4, fig. 2-6, 8 .

non Calocyclas cf. semipolita Clark and Campbell, Chen 1975, p. 259, pl. 6, fig. 3-6; Abelmann 1990, p. 697, pl. 7, fig. 4; Takemura 1992, p. 745, pl. 4, fig. 5-6; Takemura and Ling 1997, p. 111, pl. 1, fig. 16. [=A. rossi].

non Calocyclas semipolita Clark and Campbell group, Crouch and Hollis 1996, p. 26; Hollis et al. 1997, p. 58, pl. 5, fig. 11-12. [= A. rossi $]$.

A long, narrow, curved apical horn; the thorax is hemispherical to conical and can bear little spines. The abdomen lacks a row of larger pores below the lumbar stricture, ranges from narrowly cylindrical to inflated medially, and terminates indistinct. Pores on the abdomen are slightly larger than on the thorax. Most high-latitude records of this species or C. cf. semipolita are more likely to be Aphetocyrtis rossi or A. catalexis (see above).

\section{Subgenus PARALAMPTERIUM Sanfilippo 1990}

Lophocyrtis (Paralampterium) dumitricai Sanfilippo [Plate 16, fig. 14, 15]

Lophocyrtis (Paralampterium) dumitricai Sanfilippo 1990, p. 308, pl. 3, fig. 7-13; O'Connor 1993, p. 74, pl. 8, fig. 18 19; Strong et al. 1995, p. 208, fig. 11n; Crouch and Hollis 1996, p. 26; Hollis et al. 1997, p. 62, pl. 6, fig. 19; Suzuki et al. 2009, p. 260, pl. 19, fig. 8a-b.

BIOGEOGRAPHIC AFFINITY: Cosmopolitan (cool-water preference). Sanfilippo (1990) reported this species as occurring in mid- to high-latitudes from late early Eocene to early Oligocene.

Lophocyrtis (Paralampterium) cf. dumitricai [Plate 16, fig. 16a, b, 17, 18] cf. Lophocyrtis (Paralampterium) dumitricai Sanfilippo 1990, p. 308, pl. 3, fig. 7. 
Lophocyrtis (Lophocyrtis) aff. jacchia (Ehrenberg), Strong et al. 1995, p. 208, fig. 11r. Lophocyrtis (Paralampterium) cf. dumitricai Sanfilippo, Hollis et al. 1997, p. 63, pl. 6, fig. 20.

Sanfilippo (1990) identified this morphotype as a possible transitional form from the ancestor L. jacchia jacchia. L. cf. dumitricai is slightly constricted in the distal abdomen, the pores on the abdomen are smaller than in L. dumitricai and its feet are much stronger and thicker (almost spongy).

Lophocyrtis (Paralampterium) longiventer (Chen) [Plate 16, fig. 19, 20] Cyclampterium? longiventer Chen 1975, p. 459, pl. 10, fig. 7; Palmer 1987, p. 355.

Lophocyrtis (Paralampterium) longiventer (Chen), Sanfilippo 1990, p. 309, pl. 3, fig. 1-5; Strong et al. 1995, p. 208, fig. 11m; Crouch and Hollis 1996, p. 26; Hollis et al. 1997, p. 63, pl. 6, fig. 13-17; Takemura and Ling, 1997, pl. 1, fig. 12 (and fig. 13); Suzuki et al. 2009, p. 260, pl. 19, fig. 7a-b.

Cyclampterium milowi Riedel and Sanfilippo, Takemura 1992, p. 745, pl. 5, fig. 1-3.

BIOGEOGRAPHIC AFFINITY: High latitude.

Lophocyrtis? sp. B [Plate 16, fig. 21a, b, 22, 23a, b]

Thyrsocyrtis? sp. Caulet 1986, p. 859, pl. 4, fig. 14-15.

Lophocyrtis? sp. Caulet 1986, p. 859, pl. 4, fig. 12-13.

This form is uncertainly placed in Lophocyrtis based on its similarities with L. jacchia hapsis. The shell has a spongy overgrowth, in some specimens only partly starting on the abdomen. The horn is broad and thick and sometimes distally thorny. In less spongy specimens, a row of larger pores below the abdominal stricture is visible, which is similar to L. jacchia hapsis, but feet were never observed.

Both forms of Lophocyrtis? sp. and Thyrsocyrtis? sp. of Caulet (1986) are included in Lophocyrtis? sp. B herein, as both forms are commonly observed together, just with a difference in the degree of sponginess. As this form was only observed in a short interval in the late Eocene, it might be a short-range variant of L. jacchia hapsis. It might be also related to Thyrsocyrtis (T.?) pinguisicoides, which also has a short range in the late Eocene. It differs from $T$. (T.?) pinguisicoides by having a conical rather than strongly bladed apical horn and an abdomen of highly variable length (thorax and abdomen are of equal length in $T$. (T?) pinguisicoides).

BIOGEOGRAPHIC AFFINITY: This species is only found within the late Eocene warming event at Sites 277 and 592 and in the late Eocene at Site 1123. Caulet (1986) also found this species at Site 592.

\section{Genus PTEROSYRINGIUM Haeckel 1887}

Pterosyringium hamata O'Connor [Plate 16, fig. 24a, b, 25a, b, 26a, b]

Pterosyringium hamata O'Connor 1999a, p. 27, pl. 4. fig. 16-21, pl. 7, fig. 20-23.

Pterocyrtidium barbadense (Ehrenberg), Suzuki et al. 2009, p. 262, pl. 18, fig. 14a-b.

? Pterocanium barbadense Ehrenberg 1873, p. 82; 1875, pl. 17, fig. 6.

? Pterocyrtidium barbadense (Ehrenberg), Bütschli 1882, pl. 33, fig. 29.

? Pterocyrtidium sp. Petrushevskaya and Kozlova 1972, pl. 27, fig. 15. 
? Pterocyrtidium barbadense (Ehrenberg) group, Petrushevskaya and Kozlova 1972, pl. 27, fig. 18, 19.

? Lophocyrtis (Lophocyrtis?) barbadense (Ehrenberg), Sanfilippo and Caulet 1998, p. 8, pl. 4, fig. 9, 10a, b; Funakawa et al. 2006b, p. 26, pl. P8, fig. 4, 5.

Small test, very short horn, tiny thoracic wings, which are often absent or only one is visible. This morphotype is similar to Lophocyrtis (L.?) barbadense but does not possess strong thoracic wings and has much more irregularly distributed pores on thorax and abdomen. Both species might be related to each other, with $P$. hamata being a variant of L. (L.?) barbadense.

Pterosyringium cf. hamata O'Connor [Plate 16, fig. 27a, b]

These specimens differ from $P$. hamata by the wings protruding from the sides of the abdomen, rather than the thorax.

\section{Family PTEROCORYTHIDAE Haeckel 1881, emend. Moore}

\section{2}

Pterocorythidae? indet. sp. A [Plate 17, fig. 1a, b]

This morphotype is tentatively placed in the family Pterocorythidae because of its similarities to both Theocyrtis and Cryptocarpium. The morphotype has three segments: a cephalis that is partly encased in the thoracic wall and has a long bladed horn; a conical to bell-shaped thorax with small, irregularly distributed pores, and an abdomen with a spongy overgrowth layer, which sometimes extends upwards onto the thorax.

\section{Genus CRYPTOCARPIUM Sanfilippo and Riedel 1992}

Cryptocarpium spp. [Plate 17, fig. 2a, b, 3a, b, 4a, b, 5a, b]

Cryptocarpium sp. Sanfilippo and Riedel 1992, p. 6, pl. 2, fig. 8, 17.

Undifferentiated specimens of this genus are distinguished from Cryptocarpium ornatum by the presence of an apical horn and a cephalis that is not encased in the thoracic wall. Pores are aligned longitudinally on the abdomen, less so on the thorax. Cephalis and upper thorax can sometimes bear many spines, and pores are slightly larger on the thorax than the abdomen. The early Eocene specimens at Site 207 greatly resemble the late Paleocene species illustrated as Cryptocarpium sp. by Sanfilippo and Riedel (1992, pl. 2, fig. 8). The specimens found in the middle Eocene of Site 206 and late Eocene of Site 1123 more closely resemble the middle Eocene form of Sanfilippo and Riedel (1992, pl.

2 , fig. 17), with a stronger horn.

Cryptocarpium azyx Sanfilippo and Riedel [Plate 17, fig. 6a, b]

Cryptocarpium azyx Sanfilippo and Riedel 1992, pl. 2, fig. 21; Nigrini et al. 2006, p. 30; Funakawa et al. 2006b, p. 28, pl. 9, fig. 5; Moore and Kamikuri 2012, p. 5, pl. 2, fig. 1.

BIOGEOGRAPHIC AFFINITY: Low latitude. 
Cryptocarpium bussonii (Carnevale) group, New Group [Plate 17, fig. 7a, b, 8a, b] Sethocorys bussonii Carnevale 1908, p. 31, pl. 4, fig. 17.

Sethocorys cristata Carnevale 1908, p. 31, pl. 4, fig. 18, 19.

Dictyocephalus bergontianus Carnevale 1908, p. 32, pl. 4, fig. 20.

Dictyocephalus crassus Carnevale 1908, p. 32, pl. 4, fig. 21.

Carpocanistrum spp. Riedel and Sanfilippo 1971 (in part), p. 1596, pl. 3D, fig. 4, 8, 9; Abelmann 1990, p. 695, pl. 5, fig. 13; Takemura 1992, p. 744, pl. 3, fig. 5, 6; O'Connor 1993 (in part), p. 57, pl. 5, fig. 14; Crouch and Hollis 1996, p. 26; Hollis et al., 1997, p. 66, pl. 6, fig. 26-27; Takemura and Ling 1997, p. 111.

Tricolocapsa bergontiana (Carnevale), Caulet 1986, p. 854.

Subconical to ovate test made up of 2 segments. Cephalis weakly lobed, ovate, imperforate, no apical spine. Thorax egg-shaped to subconical, basal aperture surrounded by a thick peristome.

BIOGEOGRAPHIC AFFINITY: Cosmopolitan.

Cryptocarpium ornatum (Ehrenberg) [Plate 17, fig. 9a, b]

Cryptoprora ornata Ehrenberg, Sanfilippo et al. 1985, p. 693, fig. 27.2a, b.

Phormocyrtis proxima (?) Clark and Campbell, Chen 1975, p. 456, pl. 2, fig. 6.

Cryptocarpium ornatum (Ehrenberg), Hollis et al., 1997, p. 66, pl. 6, fig. 23-25; Kamikuri et al. 2012b, p. 3; Funakawa et al. 2006b, p. 28, pl. 9, fig. 6-8.

BIOGEOGRAPHIC AFFINITY: Cosmopolitan.

\section{Genus GONDWANARIA Petrushevskaya 1975}

Gondwanaria spp. [Plate 17, fig. 10a, b, 11a, b]

Three-segmented test, cephalis is relatively large with pores and a short horn, similar to Lithomelissa and Lophophaena. However, it can be distinguished from these genera by the presence of an abdomen. Neck-like connection between cephalis and thorax. Occasionally short wings extend from the thorax.

\section{Genus LAMPROCYCLAS Haeckel 1881}

Lamprocyclas sp. [Plate 17, fig. 12a, b]

This middle Eocene form contains the characteristic goose-neck typical for Lamprocyclas particollis, but has a much shorter abdomen.

Lamprocyclas particollis O'Connor [Plate 17, fig. 13]

Lamprocyclas "particollis" O’Connor, Hollis et al. 1997, p. 66, pl. 7, fig. 1-7 (nom. nud.). Lamprocyclas particollis O'Connor, 1999a, pl. 3, fig. 5-11; pl. 6, fig. 19a-23.

Distinguished from L. matakohe by pores on the thorax and abdomen being of equivalent size, and a weakly differentiated peristome. It differs from Calocycletta parva Moore (1972) by its elongate, rather than ovate, cephalis with a eucephalic lobe that extends into a markedly bladed apical horn; from Anthocyrtidium odontatum O'Connor (1994, p. 342, 
pl. 2, fig. 5-8; pl. 4, fig. 1-5) by a distinct lumbar stricture and a thorax which tends to be campanulate rather than hemispherical.

BIOGEOGRAPHIC AFFINITY: High-latitude.

\section{Genus PODOCYRTIS Ehrenberg 1847b}

The Podocyrtis lineage has only been observed in the low or mid latitudes of the North Atlantic and Southwest Pacific during the early Eocene (Sanfilippo and Riedel 1992, p. 3). Therefore, all taxa encountered here are assigned to the low-latitude group.

Podocyrtis spp. [Plate 17, fig. 14a, b, 15a, b]

This category includes specimens that have the characteristic spindle shape, longitudinally aligned pore rows and a complex three-lobed cephalis structure, but cannot be confidently ascribed to any of the species listed below.

BIOGEOGRAPHIC AFFINITY: Low latitude; members of this genus have only been encountered in low-latitude sites.

Podocyrtis? pupa (Clark and Campbell) [Plate 17, fig. 16a, b, 17a, b, 18a, b] Anthocyrtidium pupa Clark and Campbell 1942, p. 74, pl. 7, fig. 30-32.

This species does not conform to the definition of Anthocyrtidium introduced by Nigrini and Caulet (1988). Clark and Campbell's description of the species mentioned inward curved teeth at the base of the thorax, similar to Haeckel's drawing of Anthocyrtidium cineraria (1887, pl. 62, fig. 16). However, as the authors themselves admit, none of the illustrated specimens have well-developed teeth. The "teeth" in this species are simply remnants of an abdomen. Moreover, the cephalis structure is different to the typical one for Anthocyrtidium, as it is not elongated enough and is thus more similar to Podocyrtis. It can be distinguished from Podocyrtis papalis by the absence of longitudinal ridges between the vertical pore rows, more pores per half circumference, and a larger test. Furthermore, no complete abdomen was observed. The apical horn is also larger.

\section{Subgenus LAMPTERIUM Haeckel 1881}

Podocyrtis (Lampterium) acalles Sanfilippo and Riedel [Plate 17, fig. 19a, b]

Podocyrtis (L.) acalles Riedel and Sanfilippo 1992, p. 12, pl. 3, fig. 2-5; Sanfilippo and Nigrini 1998b, p. 273, pl. 13.2, fig. 4.

It can be distinguished from Podocyrtis papalis by reaching maximum width below the lumbar stricture, while $P$. papalis does so above the lumbar stricture.

BIOGEOGRAPHIC AFFINITY: Low latitude.

\section{Subgenus PODOCYRTIS Riedel and Sanfilippo 1992}

Podocyrtis (Podocyrtis) papalis Ehrenberg [Plate 17, fig. 20a, b]

Podocyrtis (Podocyrtis) papalis Ehrenberg. Sanfilippo and Riedel 1973, p. 531, pl. 20, fig. 11-14; pl. 36, fig. 2, 3; Strong et al. 1995, p. 209, fig. 9s; Hollis et al. 1997, p. 67. 
BIOGEOGRAPHIC AFFINITY: Low latitude.

\section{Subgenus PODOCYRTOGES Sanfilippo and Riedel 1992}

Podocyrtis (Podocyrtoges) aphorma (Riedel and Sanfilippo) [Plate 17, fig. 21a, b]

Podocyrtis (Lampterium) aphorma Riedel and Sanfilippo 1970, p. 534, pl. 11, fig. 2, Sanfilippo and Riedel 1992, p. 36.

This species is widest above the lumbar stricture, like $P$. papalis. It can be distinguished from the latter species by possessing a thorax which is longer than its abdomen and an externally expressed lumbar stricture.

BIOGEOGRAPHIC AFFINITY: Low latitude.

\section{Genus STICHOPILIUM Haeckel 1881}

Stichopilium cf. bicorne Haeckel [Plate 18, fig. 1a, b, 2a, b]

Stichopilium bicorne Haeckel 1887, p. 1437, pl. 77, fig. 9; Takahashi, 1981, p. 254, pl. 39, figs. 13-19.

Stichopilium bicorne? Lazarus 1992, pl. 9, fig. 9-10, 12-17.

Unlike the original description by Haeckel (1887), the species encountered in this study has a thorax and abdomen that are fairly narrow and short and resemble the morphotype found by Lazarus (1992).

\section{Genus THEOCYRTIS Haeckel 1887}

Theocyrtis tuberosa Riedel [Plate 18, fig. 3, 4, 5]

Theocyrtis tuberosa Riedel 1959, p.298, pl.2, figs.10-11; Johnson 1978, p. 782;

Sanfilippo et al. 1985 (in part), p. 701, fig. 32.1a-b; Nigrini 1985, p. 523; Palmer 1987, p. 357; Johnson 1990, p. 407; Takemura 1992, p. 744, pl. 6, fig. 1, 2; O'Connor 1993 (in part), p. 70, pl. 7, fig. 22; Aitchison and Flood 1995, p. 573; Takemura and Ling 1997, p. 114; Funakawa et al. 2006b, p. 30.

Theocyrtis aff. tuberosa Riedel, Strong et al. 1995, p. 209, fig. 10y; Hollis et al. 1997, p. 67.

The early form of T. tuberosa described by Strong et al. (1995) has well-developed plicae but lacks the tubercles on the thorax that are diagnostic of the species.

BIOGEOGRAPHIC AFFINITY: Low latitude.

\section{Family SETHOPHORMIDIDAE Haeckel 1881}

\section{Genus VELICUCULLUS Riedel and Campbell 1952}

Velicucullus spp. [Plate 18, fig. 6] 
All morphotypes assigned to this genus have a wide conical to flat dicyrtid shape with a large cephalis, which is however not always preserved.

Velicucullus magnificum (Clark and Campbell) [Plate 18, fig. 7, 8, 9]

Soreuma magnificum Clark and Campbell, 1942, p. 51, pl. 4, fig. 15.

\section{Family AMPHIPYNDACIDAE Riedel 1967b}

This family includes multi-segmented nassellarians whose cephalis is divided into two superposed chambers by a transverse internal ledge.

\section{Genus AMPHIPTERNIS Foreman 1973b}

Amphipternis alamedaensis (Clark and Campbell) [Plate 18, fig. 10]

Phormocampe alamedaensis Campbell and Clark 1944b, p. 37, pl. 7, fig. 41.

Amphipternis alamedaensis (Campbell and Clark), Hollis 1997, p. 67, pl. 15, fig. 15-16.

Amphipternis clava (Ehrenberg) [Plate 18, fig. 11a, b]

Lithocampe? clava Ehrenberg 1873, p. 238; 1875, p. 76, pl. 4, fig. 2.

Eucyrtidium clava (Ehrenberg), Buetschli 1882, pl. 30, fig. 22.

Lithocampe clava (Ehrenberg), Haeckel 1887, p. 1507.

Amphipternis clava (Ehrenberg), Foreman 1973b, p. 430, pl. 7, fig. 16, 17, pl. 9, fig. $2,7$.

\section{Genus AMPHIPYNDAX Foreman 1966}

Amphipyndax stocki (Campbell and Clark) [Plate 18, fig. 12]

Amphipyndax stocki (Campbell and Clark), Takemura 1992, p. 743, pl. 6, fig. 10-11; Hollis 1993, p. 323.

\section{Reworked specimens}

The following specimens are considered to be reworked, but are included here for the sake of completeness.

Dictyomitra multicostata Zittel [Plate 18, fig. 13]

Dictyomitra multicostata Zittel 1876 (part.), p. 81, pl. 2, fig. 2, 4 (not fig. 3).

Cretaceous species, found at ODP 181 Site 1123 in the late Eocene.

Mita regina (Campbell and Clark) [Plate 18, fig. 14]

Lithomitra (Lithomitrissa) regina Campbell and Clark 1944b, p. 41, pl. 8, fig. 30, 38, 40.

Cretaceous to late Paleocene species, found at ODP 181 Site 1123 in the late Eocene.

Phormocyrtis striata exquisita (Kozlova) [Plate 18, fig. 15] 
Podocyrtis exquisita Kozlova in Kozlova and Gorbovets 1966, p. 106, pl. 17, fig. 2.

Phormocyrtis striata exquisita (Kozlova), Foreman 1973b, p. 438, pl. 7, fig. 1-4, 7-8, pl. 12, fig. 5.

The single specimen was found in the middle Eocene of Site 206 is most likely reworked as $P$. striata exquisita has an earlier range.

Stichocorys delmontensis (Clark and Campbell) [Plate 18, fig. 16a, b]

Eucyrtidium (Eucyrtis) delmontense Clark and Campbell 1944a, p. 56, pl. 7, fig. 19, 20.

Miocene species, found at ODP 181 Site 1123 in the early Oligocene. 
Table A.1: List of encounteres species at high-latitude sites 280, 281, 283, 1172 and 277 and mid-latitude sites 1123, 592, 207 and 206. For Site 1172, a full species list of all encountered taxa can be found in Appendix B Table 6. Biogeographic affinity (BA) assignments to taxa: $\mathrm{H}=$ high latitude, $\mathrm{C}=$ cosmopolitan, $\mathrm{L}=$ low latitude. Location of images on plates for selected species.

\begin{tabular}{|c|c|c|c|c|c|c|c|c|c|c|c|}
\hline TAXA & $\mathrm{BA}$ & ఖ્న & 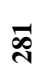 & $\stackrel{*}{\stackrel{*}{\Xi}}$ & ळి & $\stackrel{\overbrace{}}{\sim}$ & 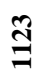 & $\hat{)}$ & ชิ & ปั่ & PLATE \\
\hline SPUMELLARIA undet. & & $\mathrm{x}$ & $\mathrm{x}$ & & $\mathrm{x}$ & $\mathrm{x}$ & $\mathrm{x}$ & $\mathrm{x}$ & $\mathrm{x}$ & $\mathrm{x}$ & \\
\hline Actinommidae undet. & & $\mathrm{x}$ & $\mathrm{x}$ & & $\mathrm{x}$ & $\mathrm{x}$ & & & & & \\
\hline Actinommidae n.sp. A sensu Hollis & & & & & & $\mathrm{x}$ & & & & & Pl. 1, fig. 1 \\
\hline Amphisphaera coronata gr. & $\mathrm{C}$ & & & $\mathrm{x}$ & $\mathrm{x}$ & $\mathrm{x}$ & $\mathrm{x}$ & $\mathrm{x}$ & $\mathrm{x}$ & $\mathrm{x}$ & Pl. 1, fig. 2 \\
\hline Amphisphaera macrosphaera & & & & & & $\mathrm{x}$ & & $\mathrm{x}$ & & & \\
\hline Amphisphaera radiosa & & & & & & $\mathrm{x}$ & $\mathrm{x}$ & & $\mathrm{x}$ & & Pl. 1, fig. 3a, b \\
\hline Amphisphaera aff. radiosa & & & & & & $\mathrm{x}$ & $\mathrm{x}$ & & $\mathrm{x}$ & & Pl. 1, fig. $4 a, b$ \\
\hline Amphisphaera spinulosa & $\mathrm{C}$ & & & & $\mathrm{x}$ & $\mathrm{x}$ & $\mathrm{x}$ & $\mathrm{x}$ & & $\mathrm{x}$ & Pl. 1, fig. 5 \\
\hline Amphisphaera? megapora & & $\mathrm{x}$ & $\mathrm{x}$ & & $\mathrm{x}$ & $\mathrm{x}$ & $\mathrm{x}$ & & $\mathrm{x}$ & & Pl. 1, fig. 6 \\
\hline Anomalacantha dentata & & $\mathrm{x}$ & $\mathrm{x}$ & & $\mathrm{x}$ & $\mathrm{x}$ & & & & & Pl. 1, fig. 7 \\
\hline Stylosphaera minor gr. & $\mathrm{C}$ & $\mathrm{x}$ & & $\mathrm{x}$ & $\mathrm{x}$ & $\mathrm{x}$ & $\mathrm{x}$ & $\mathrm{x}$ & $\mathrm{x}$ & $\mathrm{x}$ & Pl. 1, fig. 8 \\
\hline Zealithapium anoectum & $\mathrm{C}$ & & & & & & & $\mathrm{x}$ & & & Pl. 1, fig. 9 \\
\hline Zealithapium mitra & $\mathrm{C}$ & & & & $\mathrm{x}$ & $\mathrm{x}$ & $\mathrm{x}$ & $\mathrm{x}$ & $\mathrm{x}$ & $\mathrm{x}$ & Pl. 1, fig. 10 \\
\hline Zealithapium oamaru & & & & & & & $\mathrm{x}$ & & & & Pl. 1, fig. 11 \\
\hline Axoprunum bispiculum & $\mathrm{H}$ & & & & $\mathrm{x}$ & $\mathrm{x}$ & $\mathrm{x}$ & & & & Pl. 1, fig. 12 \\
\hline Axoprunum pierinae gr. & $\mathrm{C}$ & $\mathrm{x}$ & $\mathrm{x}$ & $\mathrm{x}$ & $\mathrm{x}$ & $\mathrm{x}$ & $\mathrm{x}$ & $\mathrm{x}$ & $\mathrm{x}$ & $\mathrm{x}$ & Pl. 1, fig. 13, 14 \\
\hline Axoprunum? irregularis & $\mathrm{H}$ & & & $\mathrm{x}$ & & $\mathrm{x}$ & $\mathrm{x}$ & & & & Pl. 1, fig. 15 \\
\hline Saturnalis circularis & & & & & $\mathrm{x}$ & & $\mathrm{x}$ & & & & Pl. 1, fig. 16 \\
\hline Spongatractus pachystylus & $\mathrm{L}$ & & & & & $\mathrm{x}$ & & & & $\mathrm{x}$ & Pl. 1, fig. 17 \\
\hline Phacodiscidae undet. & & & & & & $\mathrm{x}$ & $\mathrm{x}$ & $\mathrm{x}$ & $\mathrm{x}$ & $\mathrm{x}$ & \\
\hline Heliodiscus inca & & & & & $\mathrm{x}$ & $\mathrm{x}$ & $\mathrm{x}$ & $\mathrm{x}$ & $\mathrm{x}$ & $\mathrm{x}$ & Pl. 2, fig. 1 \\
\hline Heliostylus spp. & & & & & & $\mathrm{x}$ & & $\mathrm{x}$ & & & Pl. 2, fig. 2 \\
\hline Periphaena decora & $\mathrm{C}$ & $\mathrm{x}$ & $\mathrm{x}$ & $\mathrm{x}$ & $\mathrm{x}$ & $\mathrm{x}$ & $\mathrm{x}$ & $\mathrm{x}$ & $\mathrm{x}$ & $\mathrm{x}$ & Pl. 2, fig. 3 \\
\hline Periphaena heliastericus & $\mathrm{C}$ & $\mathrm{x}$ & $\mathrm{x}$ & $\mathrm{x}$ & $\mathrm{x}$ & $\mathrm{x}$ & $\mathrm{x}$ & $\mathrm{x}$ & $\mathrm{x}$ & $\mathrm{x}$ & Pl. 2, fig. 4 \\
\hline Periphaena? duplus & & & & & & $\mathrm{x}$ & & & & & Pl. 2, fig. 5 \\
\hline Spongodiscidae undet. & & $\mathrm{x}$ & $\mathrm{x}$ & & & $\mathrm{x}$ & $\mathrm{x}$ & $\mathrm{x}$ & $\mathrm{x}$ & $\mathrm{x}$ & \\
\hline Flustrella charlestonensis & & & & & & & $\mathrm{x}$ & $\mathrm{x}$ & $\mathrm{x}$ & $\mathrm{x}$ & Pl. 2, fig. 6 \\
\hline Flustrella sp. H sensu Suzuki & & & & & & & $\mathrm{x}$ & $\mathrm{x}$ & & $\mathrm{x}$ & Pl. 2, fig. 7 \\
\hline Lithocyclia spp. & $\mathrm{L}$ & & & & & & $\mathrm{x}$ & & & $\mathrm{x}$ & Pl. 2, fig. 8 \\
\hline Lithocyclia aristotelis & $\mathrm{L}$ & & & & & & & & & $\mathrm{x}$ & Pl. 2, fig. 9 \\
\hline Lithocyclia ocellus & $\mathrm{L}$ & & & & & & & $\mathrm{x}$ & & $\mathrm{x}$ & Pl. 2, fig. 10 \\
\hline Perichlamydium limbatum & & $\mathrm{x}$ & & & & & & & & & Pl. 2, fig. 11 \\
\hline Plectodiscus circularis & $\mathrm{C}$ & $\mathrm{x}$ & $\mathrm{x}$ & $\mathrm{x}$ & $\mathrm{x}$ & $\mathrm{x}$ & $\mathrm{x}$ & $\mathrm{x}$ & $\mathrm{x}$ & $\mathrm{x}$ & Pl. 2, fig. 12 \\
\hline Rhopalodictyum californicum & $\mathrm{C}$ & & & & & & $\mathrm{x}$ & & & & Pl. 2, fig. 13 \\
\hline Spongodiscus communis & $\mathrm{C}$ & & & $\mathrm{x}$ & & & & $\mathrm{x}$ & & $\mathrm{x}$ & \\
\hline Spongodiscus craticulatus & & & $\mathrm{x}$ & & & & & & & $\mathrm{x}$ & Pl. 2, fig. 14 \\
\hline Spongodiscus cruciferus & $\mathrm{C}$ & & $\mathrm{x}$ & $\mathrm{x}$ & & $\mathrm{x}$ & $\mathrm{x}$ & $\mathrm{x}$ & $\mathrm{x}$ & $\mathrm{x}$ & Pl. 2, fig. 15 \\
\hline Spongodiscus festivus & $\mathrm{C}$ & & & $\mathrm{x}$ & & $\mathrm{x}$ & $\mathrm{x}$ & $\mathrm{x}$ & $\mathrm{x}$ & $\mathrm{x}$ & Pl. 2, fig. 16 \\
\hline Spongodiscus rhabdostylus & $\mathrm{C}$ & & & $\mathrm{x}$ & & & & $\mathrm{x}$ & & $\mathrm{x}$ & Pl. 2, fig. 17 \\
\hline Spongopyle osculosa & $\mathrm{H}$ & $\mathrm{x}$ & $\mathrm{x}$ & $\mathrm{x}$ & $\mathrm{x}$ & $\mathrm{x}$ & $\mathrm{x}$ & & & $\mathrm{x}$ & Pl. 2, fig. 18 \\
\hline Spongostaurus spp. & & & & & & $\mathrm{x}$ & & & & & Pl. 2, fig. 19 \\
\hline Stylodictya spp. & & $\mathrm{x}$ & $\mathrm{x}$ & & $\mathrm{x}$ & $\mathrm{x}$ & $\mathrm{x}$ & $\mathrm{x}$ & $\mathrm{x}$ & $\mathrm{x}$ & Pl. 2, fig. 20 \\
\hline Tripodictya sp. & & & & & & & & $\mathrm{x}$ & & $\mathrm{x}$ & Pl. 2, fig. 21 \\
\hline Sponguridae undet. & & & & & & $\mathrm{x}$ & & $\mathrm{x}$ & $\mathrm{x}$ & & \\
\hline Amphicraspedum murrayanum & $\mathrm{L}$ & & & & & $\mathrm{x}$ & & $\mathrm{x}$ & & $\mathrm{x}$ & Pl. 3, fig. 1 \\
\hline Amphicraspedum prolixum gr. & $\mathrm{L}$ & $\mathrm{x}$ & & & & $\mathrm{x}$ & $\mathrm{x}$ & $\mathrm{x}$ & $\mathrm{x}$ & $\mathrm{x}$ & Pl. 3, fig. 2, 3, 4, 5 \\
\hline Amphicraspedum prolixum s.s. & $\mathrm{L}$ & & & & & $\mathrm{x}$ & & $\mathrm{x}$ & & $\mathrm{x}$ & Pl. 3, fig. 6, 7 \\
\hline Amphymenium splendiarmatum & $\mathrm{C}$ & $\mathrm{x}$ & $\mathrm{x}$ & $\mathrm{x}$ & $\mathrm{x}$ & $\mathrm{x}$ & $\mathrm{x}$ & $\mathrm{x}$ & & $\mathrm{x}$ & Pl. 3, fig. 8,9 \\
\hline Histiastrum q. quadribrachiatus & $\mathrm{L}$ & & & & & & & $\mathrm{x}$ & & & Pl. 3, fig. 10, 11 \\
\hline Middourium regulare & $\mathrm{L}$ & & & & & $\mathrm{x}$ & & $\mathrm{x}$ & & $\mathrm{x}$ & Pl. 3, fig. 12 \\
\hline Monobrachium irregulare & $\mathrm{L}$ & & & & & $\mathrm{x}$ & & $\mathrm{x}$ & & & Pl. 3, fig. 13 \\
\hline Spongurus bilobatus & $\mathrm{C}$ & & $\mathrm{x}$ & $\mathrm{x}$ & $\mathrm{x}$ & $\mathrm{x}$ & $\mathrm{x}$ & $\mathrm{x}$ & & $\mathrm{x}$ & Pl. 3, fig. 14,15 \\
\hline
\end{tabular}




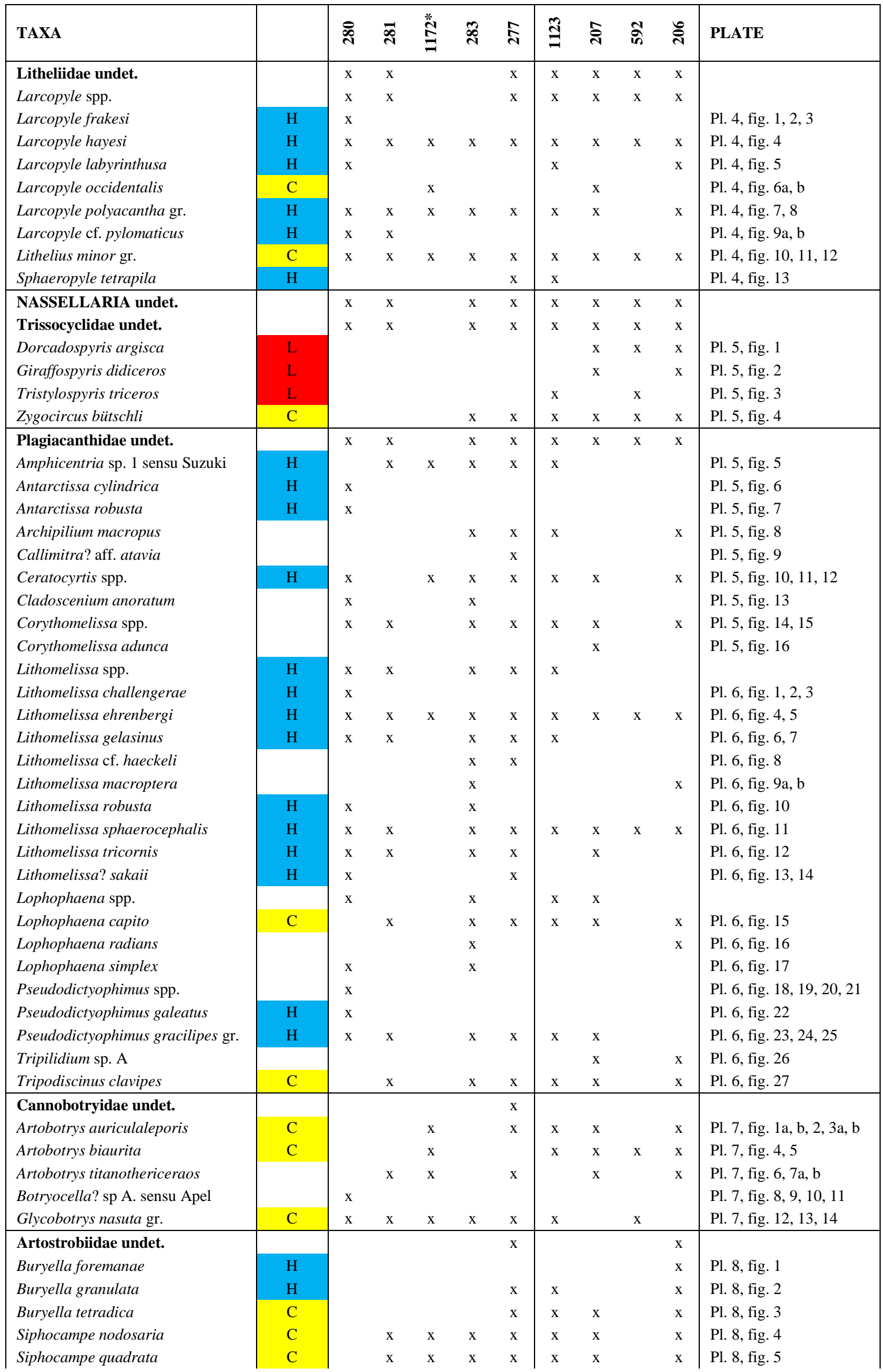




\begin{tabular}{|c|c|c|c|c|c|c|c|c|c|c|c|}
\hline TAXA & & \&્స & 丞 & $\stackrel{*}{\stackrel{*}{\Xi}}$ & $\ddot{\sim}$ & ㅊ & $\stackrel{\overparen{Z}}{\Xi}$ & సิ & ชิ & ๕్సి & PLATE \\
\hline Siphocampe? acephala gr. & & \multirow{7}{*}{$\mathrm{x}$} & \multirow[b]{3}{*}{$\mathrm{x}$} & \multirow[t]{3}{*}{$\mathrm{x}$} & $\mathrm{x}$ & $\mathrm{x}$ & $\mathrm{x}$ & $\mathrm{x}$ & $\mathrm{x}$ & $\mathrm{x}$ & Pl. 8 , fig. $6,7,8$ \\
\hline Siphocampe? amygdala & $\mathrm{C}$ & & & & $\mathrm{x}$ & $\mathrm{x}$ & $\mathrm{x}$ & $\mathrm{x}$ & & $\mathrm{x}$ & Pl. 8, fig. 9, 10 \\
\hline Spirocyrtis greeni & & & & & $\mathrm{x}$ & $\mathrm{x}$ & & $\mathrm{x}$ & & & Pl. 8 , fig. $11 \mathrm{a}, \mathrm{b}$ \\
\hline Spirocyrtis joides & $\mathrm{C}$ & & $\mathrm{x}$ & & $\mathrm{x}$ & $\mathrm{x}$ & $\mathrm{x}$ & & & $\mathrm{x}$ & Pl. 8, fig. 12a, b \\
\hline Theocampe spp. & & & & & & & $\mathrm{x}$ & $\mathrm{x}$ & & $\mathrm{x}$ & Pl. 8 , fig. $13,14,15$ \\
\hline Theocampe amphora & $\mathrm{C}$ & & & & & $\mathrm{x}$ & & $\mathrm{x}$ & & & Pl. 8, fig. 16a, b \\
\hline Theocampe mongolfieri & $\mathrm{L}$ & & & $\mathrm{x}$ & & & $\mathrm{x}$ & $\mathrm{x}$ & & $\mathrm{x}$ & Pl. 8, fig. 17a, b \\
\hline Theocampe cf. mongolfieri & & & & & & & & $\mathrm{x}$ & & & Pl. 8 , fig. $18 \mathrm{a}, \mathrm{b}$ \\
\hline Theocampe pirum & $\mathrm{L}$ & & & & & & $\mathrm{x}$ & & $\mathrm{x}$ & $\mathrm{x}$ & Pl. 8, fig. 19a, b \\
\hline Theocampe urceolus & $\mathrm{C}$ & $\mathrm{x}$ & $\mathrm{x}$ & & $\mathrm{x}$ & $\mathrm{x}$ & $\mathrm{x}$ & $\mathrm{x}$ & $\mathrm{x}$ & $\mathrm{x}$ & Pl. 8, fig. 20 \\
\hline Acropyramididae undet. & & & & & $\mathrm{x}$ & $\mathrm{x}$ & & $\mathrm{x}$ & & & \\
\hline Artostrobus spp. & & & $\mathrm{x}$ & & $\mathrm{x}$ & $\mathrm{x}$ & & & $\mathrm{x}$ & $\mathrm{x}$ & Pl. 8, fig. 21, 22 \\
\hline Artostrobus annulatus & $\mathrm{H}$ & & & & $\mathrm{x}$ & $\mathrm{x}$ & & & & & Pl. 8, fig. 23 \\
\hline Artostrobus cf. pretabulatus & $\mathrm{H}$ & & & & & $\mathrm{x}$ & $\mathrm{x}$ & & & & Pl. 8, fig. 24 \\
\hline Cinclopyramis circumtexta & $\mathrm{C}$ & $\mathrm{x}$ & $\mathrm{x}$ & $\mathrm{x}$ & $\mathrm{x}$ & $\mathrm{x}$ & $\mathrm{x}$ & $\mathrm{x}$ & $\mathrm{x}$ & $\mathrm{x}$ & Pl. 8, fig. 25 \\
\hline Cinclopyramis scalaris & & & & & & & & $\mathrm{x}$ & & & Pl. 8 , fig. 26,27 \\
\hline Cornutella profunda & $\mathrm{C}$ & $\mathrm{x}$ & $\mathrm{x}$ & $\mathrm{x}$ & $\mathrm{x}$ & $\mathrm{x}$ & $\mathrm{x}$ & $\mathrm{x}$ & $\mathrm{x}$ & $\mathrm{x}$ & Pl. 8, fig. 28 \\
\hline Eucyrtidiidae undet. & & $\mathrm{x}$ & & & $\mathrm{x}$ & $\mathrm{x}$ & $\mathrm{x}$ & $\mathrm{x}$ & & $\mathrm{x}$ & \\
\hline Artophormis aff. dominasinensis & & & & & & & & & & $\mathrm{x}$ & Pl. 9, fig. 1 \\
\hline Aspis sp. A sensu Hollis & $\mathrm{H}$ & $\mathrm{x}$ & & & $\mathrm{x}$ & $\mathrm{x}$ & $\mathrm{x}$ & & & $\mathrm{x}$ & Pl. 9 , fig. $2,3,4$ \\
\hline Calocyclas hispida & & & & & & & & $\mathrm{x}$ & & $\mathrm{x}$ & Pl. 9, fig. 5a, b \\
\hline Calocycloma spp. & & & & & & $\mathrm{x}$ & & $\mathrm{x}$ & & & Pl. 9, fig. 6 \\
\hline Calocycloma ampulla & & & & & & & & $\mathrm{x}$ & & $\mathrm{x}$ & Pl. 9, fig. 7a, b \\
\hline Calocycloma cf. L. pennatum & & & & & & & & $\mathrm{x}$ & & & Pl. 9, fig. 8a, b \\
\hline Cassideus mariae & & & & & & $\mathrm{x}$ & & & & & \\
\hline Clathrocyclas spp. & & & & & & $\mathrm{x}$ & & & & & \\
\hline Clathrocyclas australis & $\mathrm{H}$ & & & & & $\mathrm{x}$ & & & & & \\
\hline Clathrocyclas universa & $\mathrm{C}$ & & $\mathrm{x}$ & $\mathrm{x}$ & $\mathrm{x}$ & $\mathrm{x}$ & $\mathrm{x}$ & $\mathrm{x}$ & $\mathrm{x}$ & $\mathrm{x}$ & Pl. 9, fig. 9, 10, 11 \\
\hline Cycladophora spp. & $\mathrm{H}$ & & $\mathrm{x}$ & & $\mathrm{x}$ & $\mathrm{x}$ & & & & & Pl. 9, fig. 12,13 \\
\hline Cycladophora cosma cosma & $\mathrm{H}$ & $\mathrm{x}$ & & & & & & & & & Pl. 9, fig. 14 \\
\hline Cycladophora humerus & $\mathrm{H}$ & $\mathrm{x}$ & $\mathrm{x}$ & & $\mathrm{x}$ & & & & & & Pl. 9, fig. 15 \\
\hline Cymaetron sinolampas & & $\mathrm{x}$ & & & $\mathrm{x}$ & & & & & & Pl. 9, fig. 16a, b \\
\hline Cyrtocapsa osculum & & & & & & $\mathrm{x}$ & $\mathrm{x}$ & $\mathrm{x}$ & $\mathrm{x}$ & $\mathrm{x}$ & Pl. 9, fig. 17a, b \\
\hline Cyrtopera laguncula & $\mathrm{C}$ & & & & $\mathrm{x}$ & $\mathrm{x}$ & & $\mathrm{x}$ & & & Pl. 9, fig. 18 \\
\hline Dictyopodium aff. oxylophus & $\mathrm{L}$ & & & & & & & $\mathrm{x}$ & & $\mathrm{x}$ & Pl. 9, fig. 19, 20, 21a, b \\
\hline Dictyopodium sp. A & & & & & & & & $\mathrm{x}$ & & & Pl. 9, fig. 22a, b, 23 \\
\hline Eucyrtidium antiquum & $\mathrm{H}$ & $\mathrm{x}$ & & $\mathrm{x}$ & & $\mathrm{x}$ & $\mathrm{x}$ & & & & Pl. 10, fig. 1 \\
\hline Eucyrtidium mariae & $\mathrm{H}$ & & & & & $\mathrm{x}$ & $\mathrm{x}$ & & & & Pl. 10, fig. 2 \\
\hline Eucyrtidium microporum & & & & & $\mathrm{x}$ & & $\mathrm{x}$ & & & $\mathrm{x}$ & Pl. 10, fig. 3 \\
\hline Eucyrtidium montiparum & $\mathrm{C}$ & & & & $\mathrm{x}$ & $\mathrm{x}$ & $\mathrm{x}$ & $\mathrm{x}$ & $\mathrm{x}$ & $\mathrm{x}$ & Pl. 10, fig. 4 \\
\hline Eucyrtidium nishimurae & $\mathrm{H}$ & & $\mathrm{x}$ & $\mathrm{x}$ & $\mathrm{x}$ & & & & & $\mathrm{x}$ & Pl. 10, fig. 5a, b \\
\hline Eucyrtidium spinosum & $\mathrm{H}$ & & $\mathrm{x}$ & $\mathrm{x}$ & $\mathrm{x}$ & $\mathrm{x}$ & $\mathrm{x}$ & & $\mathrm{x}$ & & Pl. 10, fig. 6 \\
\hline Eurystomoskevos cauleti & $\mathrm{H}$ & $\mathrm{x}$ & $\mathrm{x}$ & & $\mathrm{x}$ & $\mathrm{x}$ & & $\mathrm{x}$ & & & Pl. 10, fig. 7a, b \\
\hline Eurystomoskevos petrushevskaae & $\mathrm{H}$ & $\mathrm{x}$ & $\mathrm{x}$ & $\mathrm{x}$ & $\mathrm{x}$ & $\mathrm{x}$ & $\mathrm{x}$ & & & $\mathrm{x}$ & Pl. 10 , fig. 8 \\
\hline Eurystomoskevos? sp. & & & & & & & & $\mathrm{x}$ & & & Pl. 10, fig. 9,10 \\
\hline Eusyringium fistuligerum & $\mathrm{C}$ & & & $\mathrm{x}$ & & $\mathrm{x}$ & $\mathrm{x}$ & $\mathrm{x}$ & & $\mathrm{x}$ & Pl. 10, fig. 11, 12, 13 \\
\hline Eusyringium lagena & $\mathrm{C}$ & & & & $\mathrm{x}$ & & & $\mathrm{x}$ & & $\mathrm{x}$ & Pl. 10, fig. 14 \\
\hline Ewingella sp.? & & & & & & & & $\mathrm{x}$ & & $\mathrm{x}$ & Pl. 10, fig. 15 \\
\hline Lamptonium cf. pennatum & & & & & & & & $\mathrm{x}$ & & & Pl. 10, fig. 16a, b \\
\hline Phormocyrtis ligulata & $\mathrm{C}$ & & & & & & $\mathrm{x}$ & $\mathrm{x}$ & & $\mathrm{x}$ & Pl. 10, fig. 17a, b \\
\hline Phormocyrtis proxima & $\mathrm{C}$ & & & $\mathrm{x}$ & & & & & & $\mathrm{x}$ & Pl. 10 , fig. 18 \\
\hline Phormocyrtis striata striata & $\mathrm{L}$ & & & & & $\mathrm{x}$ & & $\mathrm{x}$ & & $\mathrm{x}$ & Pl. 10, fig. 19a, b \\
\hline Sethocyrtis chrysallis & $\mathrm{C}$ & & & & & $\mathrm{x}$ & & $\mathrm{x}$ & & $\mathrm{x}$ & Pl. 10, fig. 20a, b \\
\hline Theocorys spp. & $\mathrm{L}$ & & & & & & & $\mathrm{x}$ & & $\mathrm{x}$ & Pl. 11, fig. 1, 2 \\
\hline Theocorys acroria & $\mathrm{L}$ & & & & & & & $\mathrm{x}$ & & & Pl. 11, fig. 3a, b \\
\hline Theocorys anapographa & $\mathrm{L}$ & & & & & & & & & $\mathrm{x}$ & Pl. 11, fig. 4,5 \\
\hline Theocorys anapographa Var.A & $\mathrm{L}$ & & & & & & & & & $\mathrm{x}$ & Pl. 11, fig. 6a, b \\
\hline
\end{tabular}




\begin{tabular}{|c|c|c|c|c|c|c|c|c|c|c|c|}
\hline TAXA & & ఖ্ণ & 穴 & $\stackrel{*}{\cong}$ & $\ddot{\sim}$ & $\stackrel{N}{N}$ & 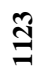 & ริ & ชั & 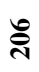 & PLATE \\
\hline Theocotyle? spp. & & & & & & & & $\mathrm{x}$ & & & Pl. $11,7 a, b, 8$ \\
\hline Theocotyle nigriniae & $\mathrm{L}$ & & & & & & & $\mathrm{x}$ & & & Pl. 11, fig. 9 \\
\hline Theocotylissa ficus & $\mathrm{L}$ & & & & & & & & & $\mathrm{x}$ & Pl. 11, fig. 10 \\
\hline Thyrsocyrtis cf. norrisi & $\mathrm{L}$ & & & & & & $\mathrm{x}$ & & $\mathrm{x}$ & $\mathrm{x}$ & $\begin{array}{l}\text { Pl. 11, fig. 11, 12a, b, } \\
13 \mathrm{a}, \mathrm{b}\end{array}$ \\
\hline Thyrsocyrtis pinguisicoides & $\mathrm{L}$ & & & & $\mathrm{x}$ & $\mathrm{x}$ & $\mathrm{x}$ & & $\mathrm{x}$ & & Pl. 11, fig. 14a, b \\
\hline Thyrsocyrtis rhizodon & $\mathrm{L}$ & & & & & & & $\mathrm{x}$ & & & $\begin{array}{l}\text { Pl. 11, fig. 15a, b, 16, } \\
\text { 17a, b }\end{array}$ \\
\hline Thyrsocyrtis cf. triacantha & $\mathrm{L}$ & & & & & & & & & $\mathrm{x}$ & Pl. 11, fig. 18a, b \\
\hline Thyrsocyrtis sp. A & & & & & & & & & & $\mathrm{x}$ & Pl. 11, fig. 19a, b, 20 \\
\hline Thyrsocyrtis sp. D sensu Kamikuri & $\mathrm{L}$ & & & & & & & & & $\mathrm{x}$ & Pl. 11, fig. 21a, b, c \\
\hline Verutotholus edwardsi & & & & & & & $\mathrm{x}$ & & & & Pl. 11, fig. 22a, b \\
\hline Lychnocaniidae undet & & & & & $\mathrm{x}$ & $\mathrm{x}$ & & $\mathrm{x}$ & & & \\
\hline Dictyophimus spp. & & $\mathrm{x}$ & & & $\mathrm{x}$ & $\mathrm{x}$ & & $\mathrm{x}$ & & & Pl. 12, fig. 1, 2, 3 \\
\hline Dictyophimus craticula & $\mathrm{C}$ & & & & & & & $\mathrm{x}$ & & $\mathrm{x}$ & Pl. 12 , fig. $4 a, b$ \\
\hline Dictyophimus pocillum & $\mathrm{C}$ & & & & & $\mathrm{x}$ & $\mathrm{x}$ & $\mathrm{x}$ & & $\mathrm{x}$ & Pl. 12 , fig. 5,6 \\
\hline Dictyophimus? archipilium & $\mathrm{H}$ & $\mathrm{x}$ & & & $\mathrm{x}$ & $\mathrm{x}$ & $\mathrm{x}$ & & & & Pl. 12, fig. 7a, b, 8 \\
\hline Dictyophimus? aff. archipilium & $\mathrm{H}$ & & $\mathrm{x}$ & & $\mathrm{x}$ & $\mathrm{x}$ & & $\mathrm{x}$ & & & $\begin{array}{l}\text { Pl. 12, fig. 9a, b, 10, 11, } \\
12,13,14\end{array}$ \\
\hline Dictyophimus? aff. constrictus & & $\mathrm{x}$ & & & & & & & & & Pl. 12 , fig. 15,16 \\
\hline Lithochytris archaea & & & & & & & & $\mathrm{x}$ & & & Pl. 12, fig. 17 \\
\hline Lithochytris vespertilio & $\mathrm{L}$ & & & & & & & $\mathrm{x}$ & & $\mathrm{x}$ & Pl. 12, fig. 18 \\
\hline Lychnocanium spp. & & $\mathrm{x}$ & & & $\mathrm{x}$ & & $\mathrm{x}$ & $\mathrm{x}$ & $\mathrm{x}$ & $\mathrm{x}$ & $\begin{array}{l}\text { Pl. 12, fig. 19, 20, 21, } \\
22,23\end{array}$ \\
\hline Lychnocanium alma & & & & & & & $\mathrm{x}$ & & & $\mathrm{x}$ & Pl. 12, fig. 24a, b \\
\hline Lychnocanium amphitrite & $\mathrm{C}$ & & & $\mathrm{x}$ & $\mathrm{x}$ & $\mathrm{x}$ & $\mathrm{x}$ & $\mathrm{x}$ & $\mathrm{x}$ & $\mathrm{x}$ & $\begin{array}{l}\text { Pl. } 12 \text {, fig. } 25,26,27, \\
28\end{array}$ \\
\hline Lychnocanium auxillum & & & & & & $\mathrm{x}$ & & & & & Pl. 13, fig. 1 \\
\hline Lychnocanium babylonis & $\mathrm{C}$ & & & & $\mathrm{x}$ & $\mathrm{x}$ & $\mathrm{x}$ & $\mathrm{x}$ & $\mathrm{x}$ & $\mathrm{x}$ & Pl. 13, fig. 2a, b, 3 \\
\hline Lychnocanium bellum & $\mathrm{C}$ & & & $\mathrm{x}$ & $\mathrm{x}$ & $\mathrm{x}$ & $\mathrm{x}$ & $\mathrm{x}$ & $\mathrm{x}$ & $\mathrm{x}$ & Pl. 13, fig. 4 \\
\hline Lychnocanium aff. carinatum & & & & & & $\mathrm{x}$ & & $\mathrm{x}$ & & $\mathrm{x}$ & Pl. 13, fig. 5 \\
\hline Lychnocanium conicum & & & & & & $\mathrm{x}$ & & $\mathrm{x}$ & $\mathrm{x}$ & $\mathrm{x}$ & Pl. 13 , fig. 6,7 \\
\hline Lychnocanium cf. conicum & & & & & & & & $\mathrm{x}$ & & $\mathrm{x}$ & Pl. 13, fig. 8,9 \\
\hline Lychnocanium continuum & & & & & $\mathrm{x}$ & & & & & & Pl. 13 , fig. 10a, b \\
\hline Lychnocanium aff. grande & & & & & & & & $\mathrm{x}$ & & $\mathrm{x}$ & $\begin{array}{l}\text { Pl. 13, fig. } 11,12 a, b \text {, } \\
13 a, b, 14 a, b\end{array}$ \\
\hline Lychnocanium satelles & & & & & & & & $\mathrm{x}$ & & $\mathrm{x}$ & $\begin{array}{l}\text { Pl. } 13 \text {, fig. } 15 a, b, 16 a \\
\text { b, } 17 a, b\end{array}$ \\
\hline Lychnocanium tetrapodium & & & & & & $\mathrm{x}$ & & & & & Pl. 13, fig. 18a, b \\
\hline Lychnocanium trichopus & & & & & & & & $\mathrm{x}$ & & & Pl. 14, 1, 2a, b, c, 3a, b \\
\hline Lychnocanium cf. tridentatum & & & & & & & & $\mathrm{x}$ & & & Pl. 14, fig. 4 \\
\hline Lychnocanium turgidum & & & & & & & $\mathrm{x}$ & $\mathrm{x}$ & $\mathrm{x}$ & $\mathrm{x}$ & Pl. 14, fig. 5a, b \\
\hline Lychnocanium waiareka & & & & & $\mathrm{x}$ & $\mathrm{x}$ & $\mathrm{x}$ & & $\mathrm{x}$ & $\mathrm{x}$ & Pl. 14, fig. 6a, b \\
\hline Lychnocanium waitaki & & & & & & & $\mathrm{x}$ & & & $\mathrm{x}$ & Pl. 14, fig. 7a, b \\
\hline Lychnocanium sp. A & & & & & & & & $\mathrm{x}$ & & $\mathrm{x}$ & $\begin{array}{l}\text { Pl. } 14 \text {, fig. } 8,9 a, b, 10 a \text {, } \\
\text { b }\end{array}$ \\
\hline Pterocanium sp. & & & & & & & & $\mathrm{x}$ & & & Pl. 14, fig. 11a, b \\
\hline Pterocanium cf. sphinx & & & & & & & & $\mathrm{x}$ & & & Pl. 14, fig. 12, 13a, b \\
\hline Pterocodon apis & & & & & $\mathrm{x}$ & & & & & & Pl. 14 , fig. $14,15 a, b$ \\
\hline Pteropilium aff. contiguum & & & & & & $\mathrm{x}$ & $\mathrm{x}$ & $\mathrm{x}$ & & $\mathrm{x}$ & $\begin{array}{l}\text { Pl. } 14 \text {, fig. } 16,17,18 \mathrm{a}, \\
\text { b }\end{array}$ \\
\hline Rhopalocanium ornatum & & & & & & & & $\mathrm{x}$ & & $\mathrm{x}$ & Pl. 14, fig. 19, 20 \\
\hline Rhopalocanium cf. ornatum & & & & & & & & $\mathrm{x}$ & & $\mathrm{x}$ & $\begin{array}{l}\text { Pl. 14, fig. 21, 22, 23, } \\
24,25,26\end{array}$ \\
\hline Sethochytris triconiscus & $\mathrm{L}$ & & & & & & & & & $\mathrm{x}$ & Pl. 14, fig. 27a, b \\
\hline Lophocyrtiidae undet. & & $\mathrm{x}$ & & & $\mathrm{x}$ & $\mathrm{x}$ & $\mathrm{x}$ & $\mathrm{x}$ & $\mathrm{x}$ & $\mathrm{x}$ & \\
\hline Aphetocyrtis bianulus & & & & $\mathrm{x}$ & $\mathrm{x}$ & $\mathrm{x}$ & & & & $\mathrm{x}$ & Pl. 15 , fig. 1 \\
\hline Aphetocyrtis gnombax & $\mathrm{H}$ & $\mathrm{x}$ & $\mathrm{x}$ & & $\mathrm{x}$ & $\mathrm{x}$ & $\mathrm{x}$ & $\mathrm{x}$ & & $\mathrm{x}$ & $\begin{array}{l}\text { Pl. } 15 \text {, fig. } 2,3,4,5,6 \text {, } \\
7\end{array}$ \\
\hline Aphetocyrtis rossi & $\mathrm{H}$ & $\mathrm{x}$ & & $\mathrm{x}$ & $\mathrm{x}$ & $\mathrm{x}$ & $\mathrm{x}$ & & & & Pl. 15 , fig. $8,9,10,11$ \\
\hline Clinorhabtus anatomus & $\mathrm{H}$ & & $\mathrm{x}$ & & & $\mathrm{x}$ & & & & & Pl. 15 , fig. 12,13 \\
\hline Clinorhabdus robusta & $\mathrm{H}$ & & & $\mathrm{x}$ & & & & & & & \\
\hline
\end{tabular}




\begin{tabular}{|c|c|c|c|c|c|c|c|c|c|c|c|}
\hline TAXA & & ๙ึ & $\overline{\text { ని }}$ & $\stackrel{*}{\Xi}$ & ஷิ & 究 & $\cong$ & 今ิ & ถิ่ & ปั & PLATE \\
\hline Lophocyrtis (A.) aspera Form A & $\mathrm{H}$ & & $\mathrm{x}$ & & $\mathrm{x}$ & $\mathrm{x}$ & $\mathrm{x}$ & $\mathrm{x}$ & $\mathrm{x}$ & $\mathrm{x}$ & $\begin{array}{l}\text { Pl. 15, fig. 14a, b, 15, } \\
\text { 16a, b }\end{array}$ \\
\hline Lophocyrtis (A.) aspera Form B & & & & & & & $\mathrm{x}$ & $\mathrm{x}$ & & $\mathrm{x}$ & $\begin{array}{l}\text { Pl. } 15 \text {, fig. } 17 \mathrm{a}, \mathrm{b}, 18 \mathrm{a} \\
\text { b, 19a, b }\end{array}$ \\
\hline Lophocyrtis (A.) keraspera & & & & $\mathrm{x}$ & $\mathrm{x}$ & $\mathrm{x}$ & $\mathrm{x}$ & $\mathrm{x}$ & $\mathrm{x}$ & $\mathrm{x}$ & $\begin{array}{l}\text { Pl. } 15 \text {, fig. } 20,21,22 \text {, } \\
\text { 23a, b. } 24\end{array}$ \\
\hline Lophocyrtis (A.) nomas & & & & & & & & $\mathrm{x}$ & & & $\begin{array}{l}\text { Pl. } 15 \text {, fig. 25a, b, 26a, } \\
\text { b, } 27\end{array}$ \\
\hline Lophocyrtis (C.) hadra & & & & & & & $\mathrm{x}$ & & & & Pl. 16, fig. 1a, b \\
\hline Lophocyrtis (C.) milowi & & & & & & & $\mathrm{x}$ & & & & Pl. 16, fig. 2 \\
\hline Lophocyrtis (L.) jacchia hapsis & $\mathrm{H}$ & & & & $\mathrm{x}$ & $\mathrm{x}$ & $\mathrm{x}$ & $\mathrm{x}$ & $\mathrm{x}$ & $\mathrm{x}$ & $\begin{array}{l}\text { Pl. 16, fig. } 3,4,5 a, b \text {, } \\
6 \text { a, b }\end{array}$ \\
\hline Lophocyrtis (L.) jacchia jacchia & $\mathrm{L}$ & & & & & & & $\mathrm{x}$ & & & Pl. 16, fig. $7,8,9$ \\
\hline Lophocyrtis sp. A & & & & & & & & $\mathrm{x}$ & & & Pl. 16, fig. 10, 11 \\
\hline Lophocyrtis (L.?) semipolita & & & & & & & & $\mathrm{x}$ & & & Pl. 16, fig. 12a, b, 13a, b \\
\hline Lophocyrtis (P.) dumitricai & $\mathrm{C}$ & & & $\mathrm{x}$ & & $\mathrm{x}$ & $\mathrm{x}$ & $\mathrm{x}$ & $\mathrm{x}$ & $\mathrm{x}$ & Pl. 16, fig. 14, 15 \\
\hline Lophocyrtis (P.) cf. dumitricai & & & & & & & & $\mathrm{x}$ & & & $\begin{array}{l}\text { Pl. 16, fig. 16a, b, 17, } \\
18\end{array}$ \\
\hline Lophocyrtis $(P$.$) longiventer$ & $\mathrm{H}$ & $\mathrm{x}$ & $\mathrm{x}$ & $\mathrm{x}$ & $\mathrm{x}$ & $\mathrm{x}$ & $\mathrm{x}$ & $\mathrm{x}$ & $\mathrm{x}$ & $\mathrm{x}$ & Pl. 16, fig. 19, 20 \\
\hline Lophocyrtis? sp. B & & & & & $\mathrm{x}$ & $\mathrm{x}$ & $\mathrm{x}$ & & $\mathrm{x}$ & $\mathrm{x}$ & $\begin{array}{l}\text { Pl. 16, fig. 21a, b, 22, } \\
\text { 23a, b }\end{array}$ \\
\hline Pterosyringium hamata & & & & $\mathrm{x}$ & & & $\mathrm{x}$ & $\mathrm{x}$ & $\mathrm{x}$ & $\mathrm{x}$ & $\begin{array}{l}\text { Pl. 16, fig. 24a, b, 25a, } \\
\text { b, 26a, b }\end{array}$ \\
\hline Pterosyringium cf. hamata & & & & & & & $\mathrm{x}$ & & & & Pl. 16, fig. 27a, b \\
\hline Pterocorythidae undet. & & & & & & $\mathrm{x}$ & & & & & \\
\hline Pterocorythidae? indet. sp. A & & & & & & & & & & $\mathrm{x}$ & Pl. 17, fig. 1a, b \\
\hline Cryptocarpium spp. & & & & & & & $\mathrm{x}$ & $\mathrm{x}$ & & $\mathrm{x}$ & $\begin{array}{l}\text { Pl. 17, 2a, b, 3a, b, 4a, } \\
\text { b, 5a, b }\end{array}$ \\
\hline Cryptocarpium azyx & $\mathrm{L}$ & & & & & & $\mathrm{x}$ & & & & Pl. 17, fig. 6a, b \\
\hline Cryptocarpium bussonii gr. & $\mathrm{C}$ & $\mathrm{x}$ & $\mathrm{x}$ & & $\mathrm{x}$ & $\mathrm{x}$ & $\mathrm{x}$ & & $\mathrm{x}$ & $\mathrm{x}$ & Pl. 17, fig. 7a, b, 8a, b \\
\hline Cryptocarpium ornatum & $\mathrm{C}$ & & & & $\mathrm{x}$ & $\mathrm{x}$ & $\mathrm{x}$ & & $\mathrm{x}$ & $\mathrm{x}$ & Pl. 17, fig. 9a, b \\
\hline Gondwanaria spp. & & $\mathrm{x}$ & & & & $\mathrm{x}$ & & & & & Pl. 17, fig. 10a, b, 11a, b \\
\hline Lamprocyclas sp. & & & & & & & & & $\mathrm{x}$ & $\mathrm{x}$ & Pl. 17, fig. 12a, b \\
\hline Lamprocyclas particollis & $\mathrm{H}$ & $\mathrm{x}$ & $\mathrm{x}$ & & $\mathrm{x}$ & $\mathrm{x}$ & $\mathrm{x}$ & & & & Pl. 17, fig. 13 \\
\hline Podocyrtis spp. & $\mathrm{L}$ & & & & & & $\mathrm{x}$ & $\mathrm{x}$ & & & Pl. 17, fig. 14a, b, 15a, b \\
\hline Podocyrtis? pupa & & & & & & & & $\mathrm{x}$ & & $\mathrm{x}$ & $\begin{array}{l}\text { Pl. 17, fig. 16a, b, 17a, } \\
\text { b, 18a, b }\end{array}$ \\
\hline Podocyrtis (L.) acalles & $\mathrm{L}$ & & & & & & & $\mathrm{x}$ & & & Pl. 17, 19a, b \\
\hline Podocyrtis (P.) papalis & $\mathrm{L}$ & & & & & $\mathrm{x}$ & & $\mathrm{x}$ & & $\mathrm{x}$ & Pl. 17, fig. 20a, b \\
\hline Podocyrtis (P.) aphorma & $\mathrm{L}$ & & & & & & & $\mathrm{x}$ & & & Pl. 17, fig. 21a, b \\
\hline Stichopilium cf. bicorne & . & $\mathrm{x}$ & $\mathrm{x}$ & & $\mathrm{x}$ & $\mathrm{x}$ & $\mathrm{x}$ & $\mathrm{x}$ & & & Pl. 18, fig. 1a, b, 2a, b \\
\hline Theocyrtis tuberosa & $\mathrm{L}$ & & & & $\mathrm{x}$ & $\mathrm{x}$ & $\mathrm{x}$ & & & & Pl. 18 , fig. $3,4,5$ \\
\hline Sethophormididae & & & & & & & & & & & \\
\hline Velicucullus spp. & & $\mathrm{x}$ & & & $\mathrm{x}$ & $\mathrm{x}$ & $\mathrm{x}$ & $\mathrm{x}$ & & $\mathrm{x}$ & Pl. 18, fig. 6 \\
\hline Velicucullus magnificum & & & & & & & & $\mathrm{x}$ & & $\mathrm{x}$ & Pl. 18, fig. $7,8,9$ \\
\hline Amphipyndacidae undet. & & & & & $\mathrm{x}$ & $\mathrm{x}$ & & $\mathrm{x}$ & & & \\
\hline Amphipternis alamedaensis & & & & & & & & $\mathrm{x}$ & & & Pl. 18 , fig. 10 \\
\hline Amphipternis clava & & & & & & & $\mathrm{x}$ & $\mathrm{x}$ & & $\mathrm{x}$ & Pl. 18, fig. 11a, b \\
\hline Amphipyndax stocki & & & & & & $\mathrm{x}$ & & $\mathrm{x}$ & & & Pl. 18, fig. 12 \\
\hline Reworked specimens & & & & & & & & & & & \\
\hline Dictyomitra multicostata & & & & & & & $\mathrm{x}$ & & & & Pl. 18, fig. 13 \\
\hline Mita regina & & & & & & & $\mathrm{x}$ & & & & Pl. 18, fig. 14 \\
\hline Phormocyrtis striata exquisita & & & & & & & & & & $\mathrm{x}$ & Pl. 18 , fig. 15 \\
\hline Stichocorys delmontensis & & & & & & & $\mathrm{x}$ & & & & Pl. 18, fig. 16a, b \\
\hline
\end{tabular}




\section{Plates 1-18}




\section{PLATE 1: Actinommidae}

Scale bars equal $100 \mu \mathrm{m}$. Images of selected radiolarian species:

1) Actinommidae n.sp. A (Sample 277-23R-1, 33 cm, slide A),

2) Amphisphaera coronata gr. (Sample 277-25R-1, $60 \mathrm{~cm}$, slide A),

3a, b) Amphisphaera radiosa (Sample 1123C-33X-1, $31 \mathrm{~cm}$ ),

4a, b) Amphisphaera aff. radiosa (Sample 277-17R-3, $33 \mathrm{~cm}$ ),

5) Amphisphaera spinulosa (Sample 283-8R-2, $25 \mathrm{~cm}$, slide A),

6) Amphisphaera? megapora (Sample 277-25R-1, $60 \mathrm{~cm}$, slide C),

7) Anomalocantha dentata (Sample 280A-5R-1, $104 \mathrm{~cm}$, slide C),

8) Stylosphaera minor (Sample 277-32R-3, $100 \mathrm{~cm}$ ),

9) Zealithapium anoectum (Sample 207A-18R-2, $102 \mathrm{~cm}$, slide A)

10) Zealithapium mitra (Sample 277-23R-1, 33cm, slide B),

11) Zealithapium oamaru (Sample 1123C-32X-1, $86 \mathrm{~cm}$ ),

12) Axoprunum bispiculum (Sample 277-17R-3, 33cm),

13) Axoprunum pierinei gr. (Sample 277-25R-1, 60cm, slide A),

14) Axoprunum pierinei gr. (Sample 281-14R-1, 100cm, slide A),

15) Axoprunum? irregularis (Sample 277-15R-3, 100cm),

16) Saturnalis circularis (Sample 283-8R-2, $25 \mathrm{~cm}$, slide A),

17) Spongatractus pachystylus (Sample 206C-17R-4, 100cm, slide B). 

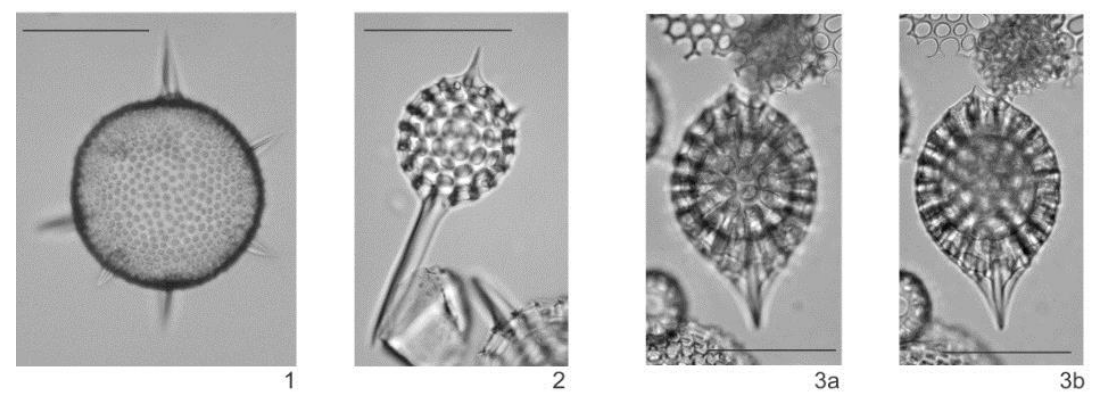

Plate 1
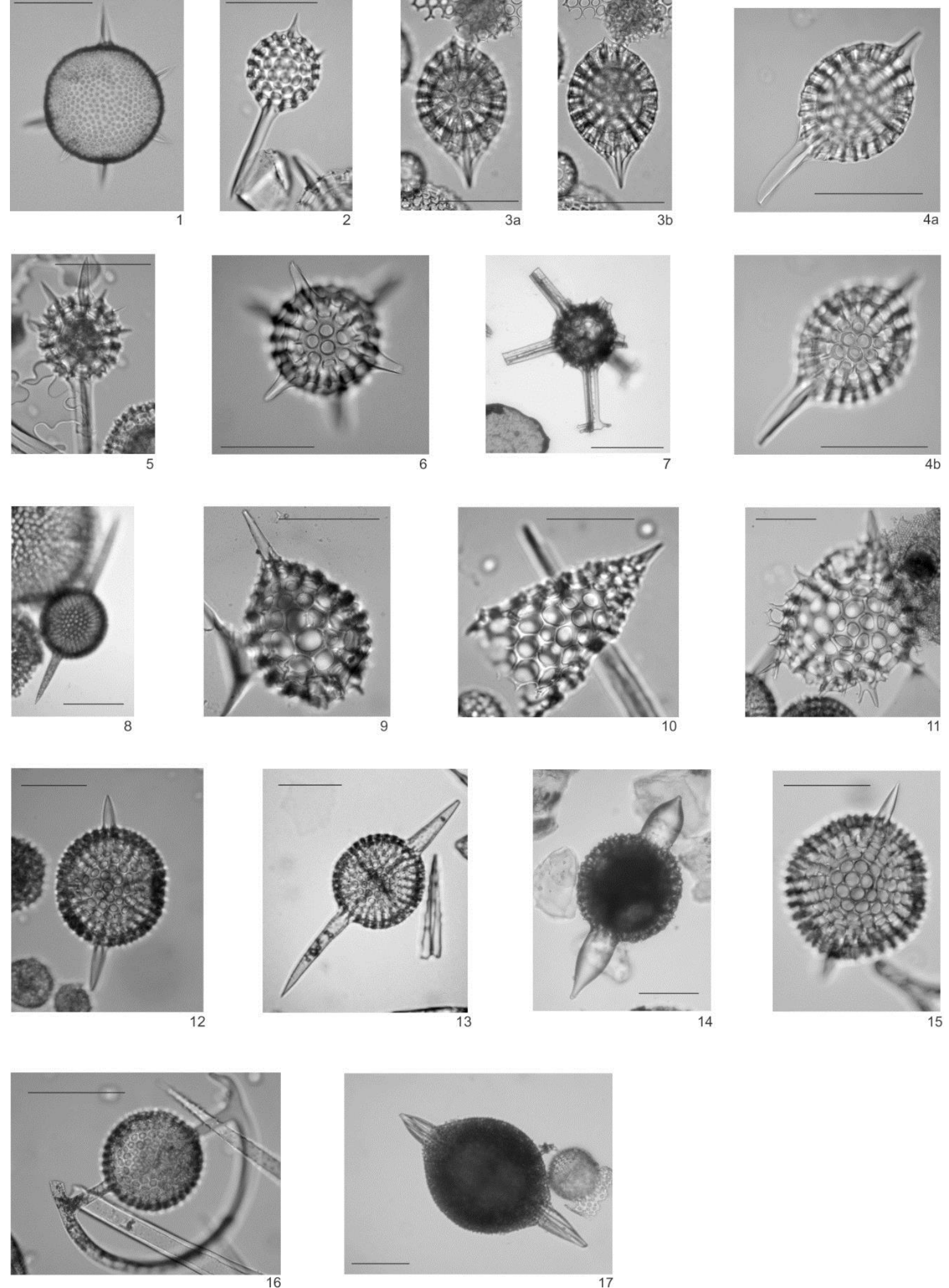


\section{PLATE 2: Phacodiscidae}

Scale bars equal $100 \mu \mathrm{m}$. Images of selected radiolarian species:

1) Heliodiscus inca (Sample 283-8R-2, $25 \mathrm{~cm}$, slide A),

2) Heliostylus sp. (Sample 207A-16R-2, $90 \mathrm{~cm}$, slide B),

3) Periphaena decora (Sample 277-18R-3, $20 \mathrm{~cm}$ ),

4) Periphaena heliastericus (Sample 277-24R-2, $20 \mathrm{~cm}$, slide B),

5) Periphaena? duplus (Sample 277-44R-3, 1cm, slide D).

\section{PLATE 2: Spongodiscidae}

6) Flustrella charlestonensis (Sample 207A-14R-2, $101 \mathrm{~cm}$, slide B),

7) Flustrella sp. H (Sample 207A-12R-1, $100 \mathrm{~cm}$, slide C),

8) Lithocyclia sp. (Sample 1123C-32X-1, $86 \mathrm{~cm}$ ),

9) Lithocyclis aristotelis (Sample 206C-15R-2, $35 \mathrm{~cm}$, slide B),

10) Lithocyclia ocellus (Sample 207A-13R-4, $100 \mathrm{~cm}$, slide C),

11) Perichlamydium limbatum (Sample 280A-5R-1, $104 \mathrm{~cm}$, slide C),

12) Plectodiscus circularis (Sample 207A-19R-4, $97 \mathrm{~cm}$, slide A),

13) Rhopalodictyum californicum (Sample 1123C-32X-1, $86 \mathrm{~cm}$ ),

14) Spongodiscus craticulatus (Sample 281-14R-5, $105 \mathrm{~cm}$ ),

15) Spongodiscus cruciferus (Sample 207A-16R-3, $66 \mathrm{~cm}$, MRC slide),

16) Spongodiscus festivus (Sample 277-43R-2, $78 \mathrm{~cm}$ ),

17) Spongodiscus rhabdostylus (Sample 207A-12R-1, $100 \mathrm{~cm}$, slide C),

18) Spongopyle osculosa (Sample 277-24R-2, 20cm, slide B),

19) Spongostaurus sp. (Sample 277-33R-2, $20 \mathrm{~cm}$, slide A),

20) Stylodictya sp. (Sample 207A-19R-4, $97 \mathrm{~cm}$, slide A),

21) Tripodictya sp. (Sample 207A-20R-5, $101 \mathrm{~cm}$, slide A). 

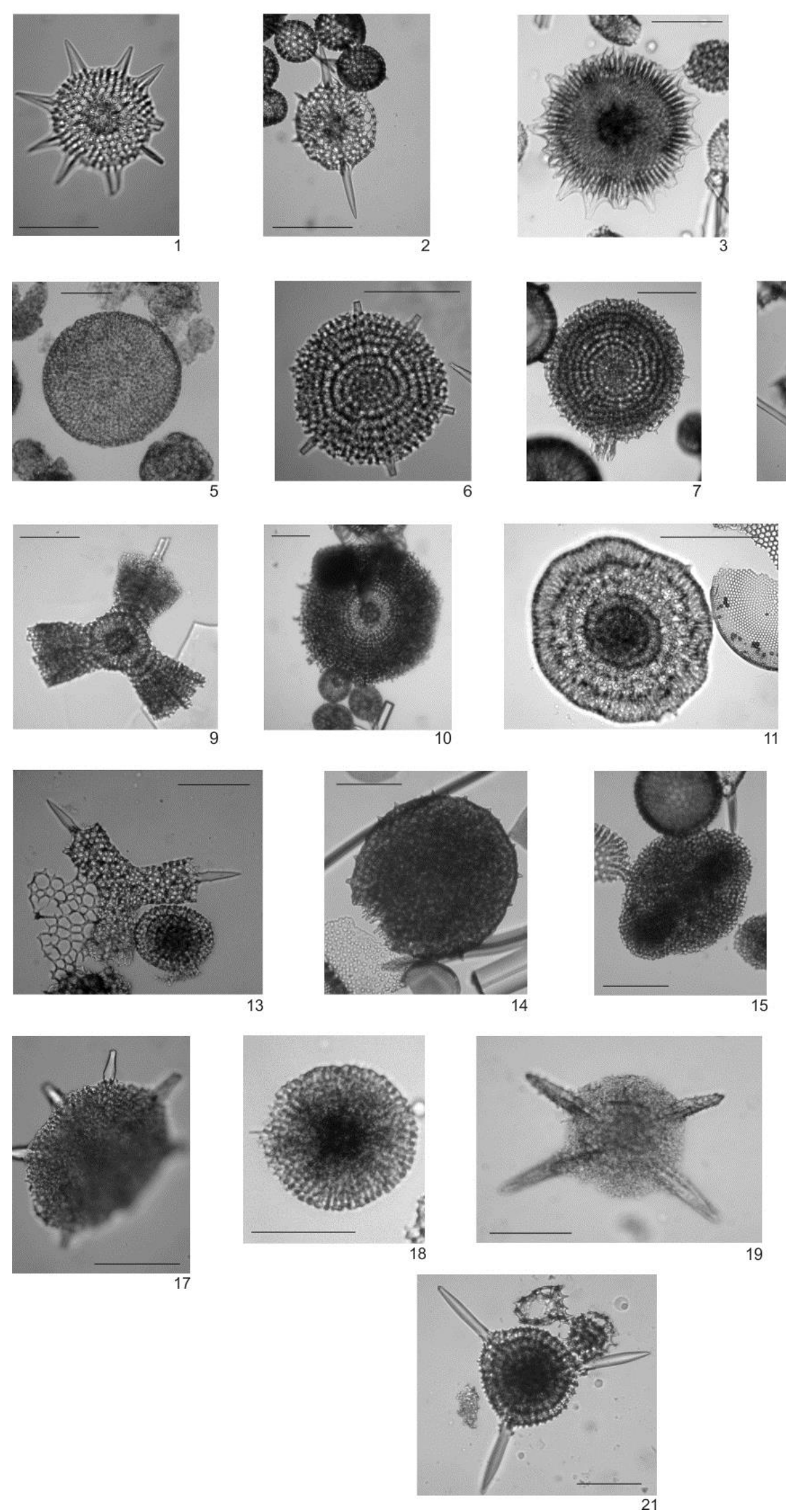

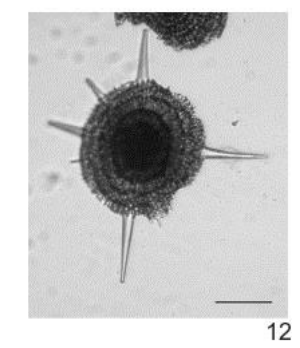

PLATE 2
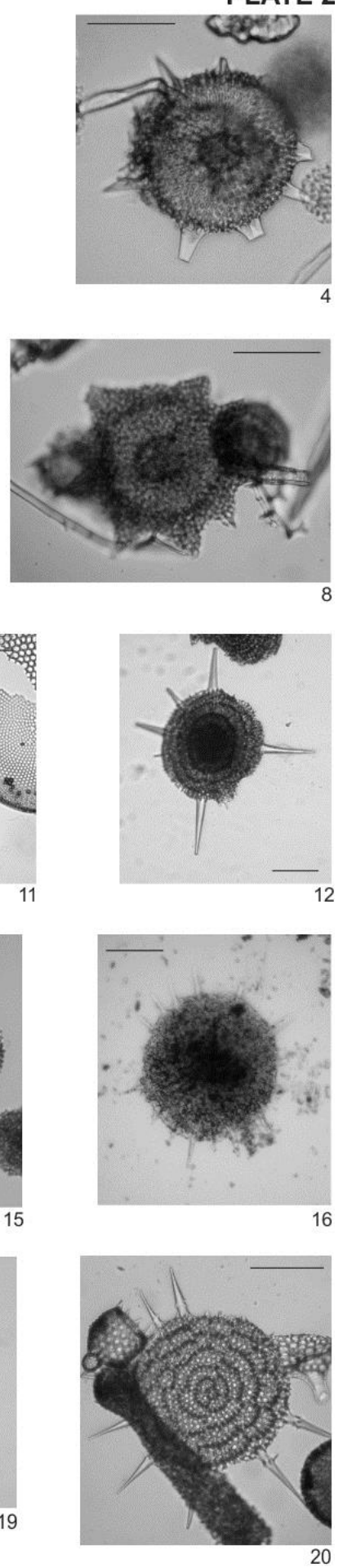


\section{PLATE 3: Sponguridae}

Scale bars equal $100 \mu \mathrm{m}$. Images of selected radiolarian species:

1) Amphicraspedum murrayanum (Sample 277-32R-3, $100 \mathrm{~cm}$ ),

2) Amphicraspedum prolixum gr. (Sample 277-22R-1, $82 \mathrm{~cm}$, slide A),

3) Amphicraspedum prolixum gr. (Sample 280A-6R-2, $60 \mathrm{~cm}$, slide A),

4) Amphicraspedum prolixum gr. (Sample 277-33R-2, $100 \mathrm{~cm}$ ),

5) Amphicraspedum prolixum gr. (Sample 207A-19R-4, $97 \mathrm{~cm}$, slide A),

6) Amphicraspedum prolixum s.s. (Sample 207A-18R-2, $102 \mathrm{~cm}$, slide A),

7) Amphicraspedum prolixum s.s. (Sample 207A-17R-2, $101 \mathrm{~cm}$, slide A),

8) Amphymenium splendiarmatum (Sample 277-32R-3, $100 \mathrm{~cm}$ ),

9) Amphymenium splendiarmatum (Sample 277-32R-3, $100 \mathrm{~cm}$ ),

10) Histiastrum quadribrachiatus quadribrachiatus (Sample 207A-20R-5, $101 \mathrm{~cm}$, slide A),

11) Histiastrum quadribrachiatus quadribrachiatus (Sample 207A-19R-2, $90 \mathrm{~cm}$, slide A),

12) Middourium regulare (Sample 207A-19R-2, $90 \mathrm{~cm}$, slide A),

13) Monobrachium irregulare (Sample 207A-15R-3, $100 \mathrm{~cm}$, slide A),

14) Spongurus bilobatus (Sample 207A-14R-1, $119 \mathrm{~cm}$, slide A),

15) Spongurus bilobatus (Sample 207A-14R-2, $101 \mathrm{~cm}$, slide B). 

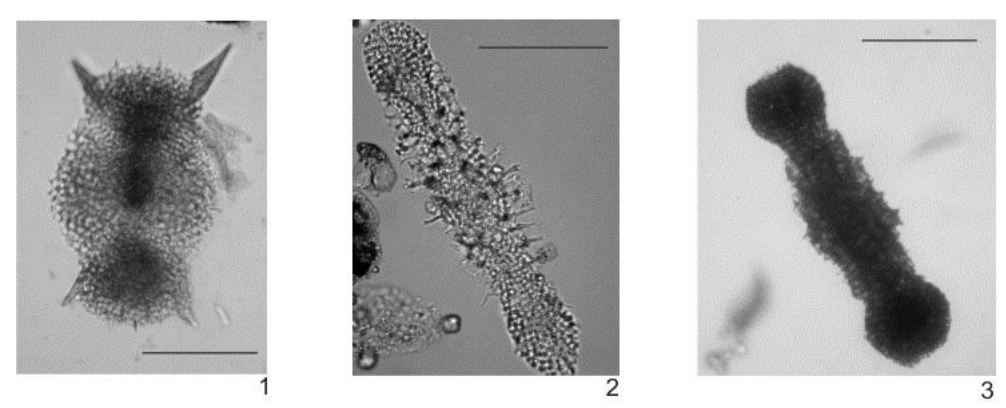

PLATE 3
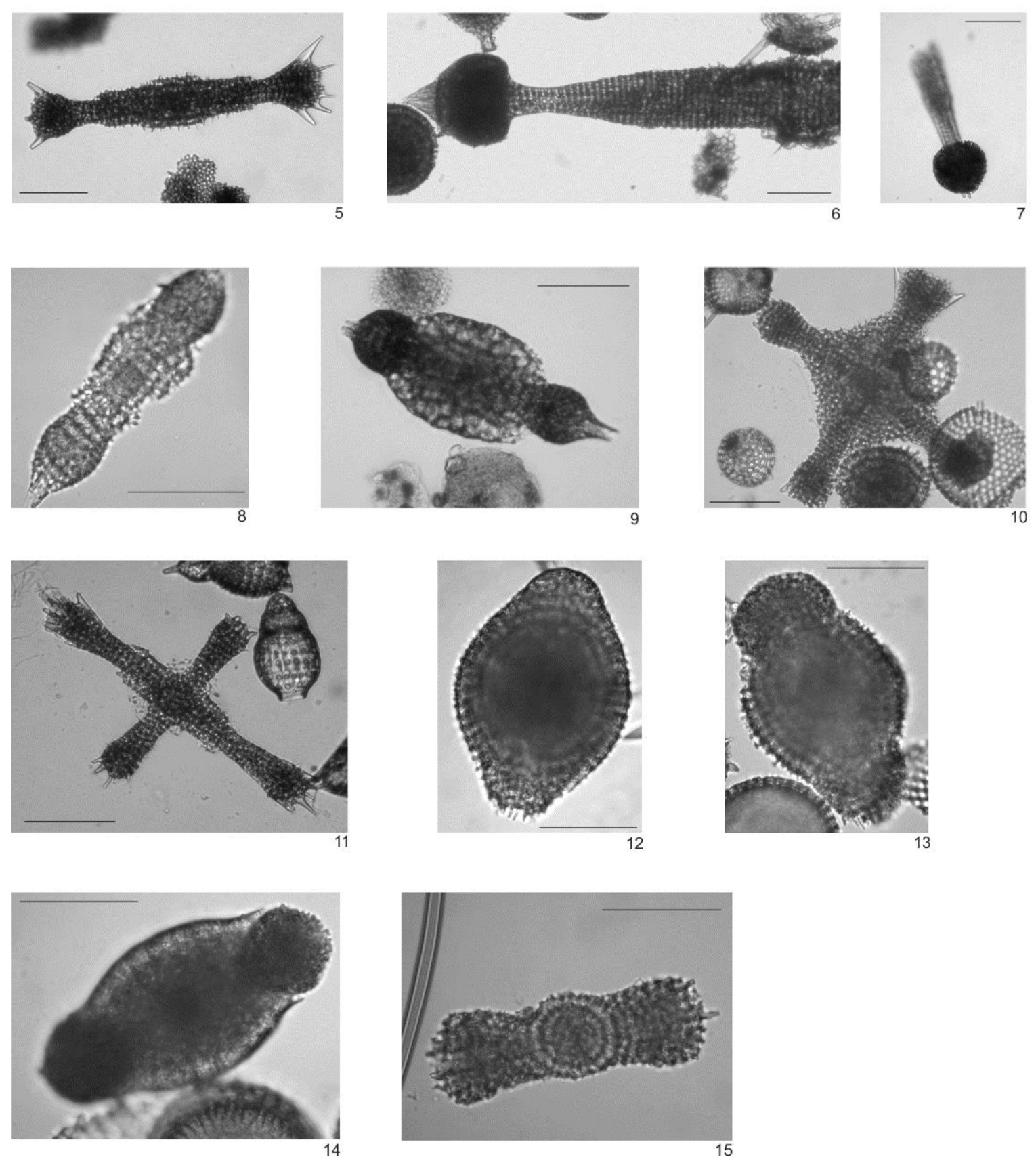


\section{PLATE 4: Litheliidae}

Scale bars equal $100 \mu \mathrm{m}$. Images of selected radiolarian species:

1) Larcopyle frakesi (Sample 280A-5R-1, 104cm, slide C),

2) Larcopyle frakesi (Sample 280A-5R-1, 104cm, slide C),

3) Larcopyle frakesi (Sample 280A-5R-1, 104cm, slide C),

4) Larcopyle hayesi (Sample 277-24R-2, 20cm, slide B),

5) Larcopyle labyrinthusa (Sample 280A-5R-1, 104cm, slide C),

6a, b) Larcopyle occidentalis (Sample 207A-14R-2, $101 \mathrm{~cm}$, slide B),

7) Larcopyle polyacantha gr. (Sample 280A-5R-1, 104cm, slide C),

8) Larcopyle polyacantha gr. (Sample 277-24R-2, 20cm, slide B),

9a, b) Larcopyle cf. pylomaticus (Sample 280A-5R-1, 104cm, slide C),

10) Lithelius minor gr. (Sample 277-32R-3, 100cm),

11) Lithelius minor gr. (Sample 277-24R-2, 20cm, slide B),

12) Lithelius minor gr. (Sample 277-24R-2, 20cm, slide B),

13) Sphaeropyle tetrapila (Sample 277-18R-3, 20cm). 

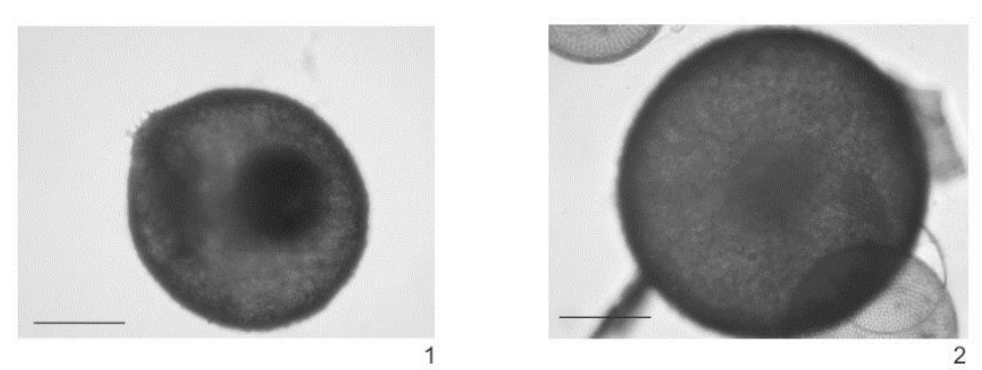

PLATE 4
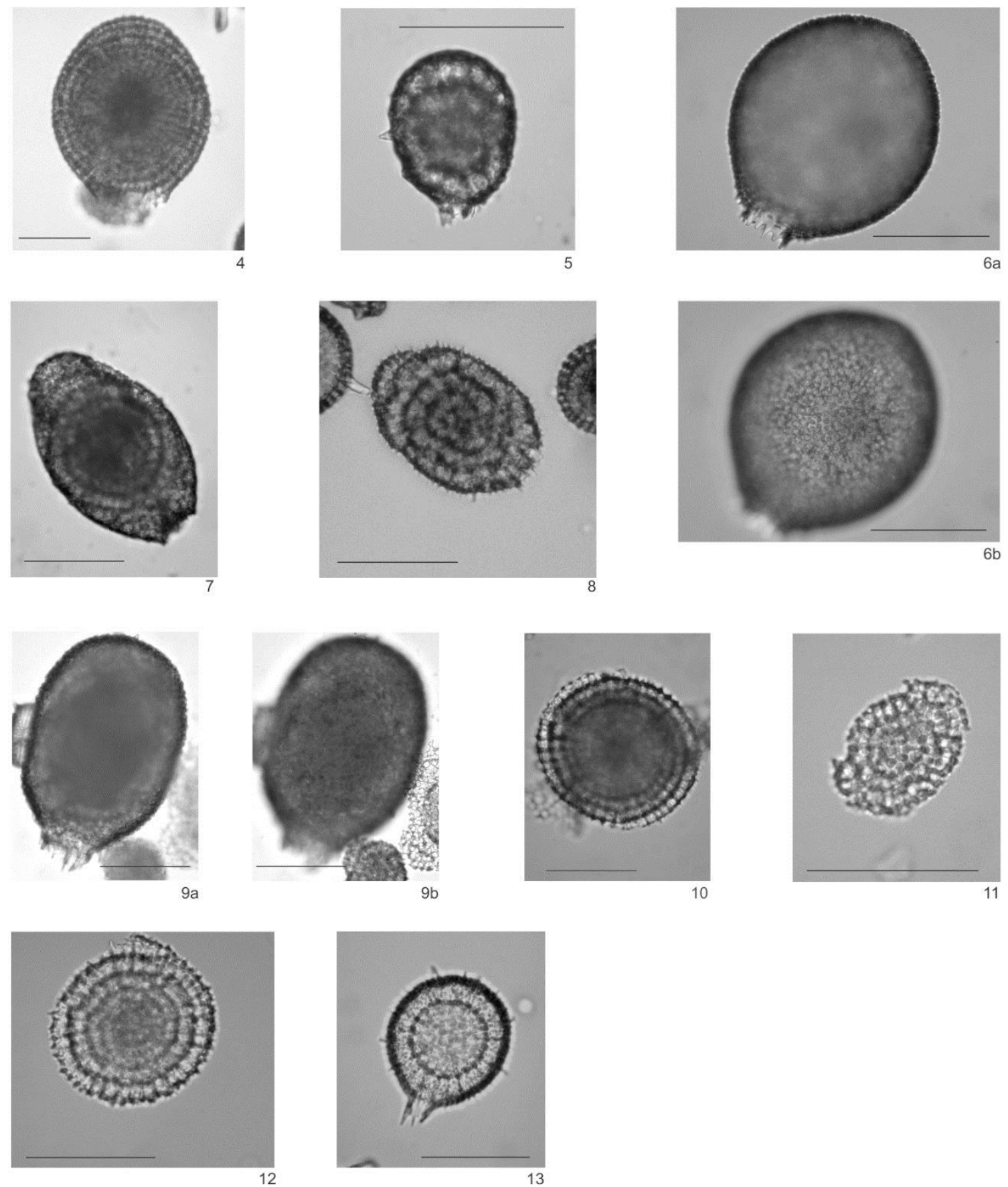


\section{PLATE 5: Trissocyclidae}

Scale bars equal $100 \mu \mathrm{m}$. Images of selected radiolarian species:

1) Dorcadospyris argisca (Sample 207A-12R-1, $100 \mathrm{~cm}$, slide C),

2) Giraffospyris didiceros (Sample 207A-16R-2, $90 \mathrm{~cm}$, slide B),

3) Tristylospyris triceros (Sample 1123C-32X-4, $5 \mathrm{~cm}$ ),

4) Zygocircus bütschli (Sample 207A-12R-1, $100 \mathrm{~cm}$, slide B).

\section{PLATE 5: Plagiacanthidae}

5) Amphicentria sp. 1 (Sample 277-22R-1, 82cm, slide B),

6) Antarctissa cylindrica (Sample 280A-7R-3, $40 \mathrm{~cm}$, slide A),

7) Antarctissa robusta (Sample 280A-7R-1, $90 \mathrm{~cm}$, slide A),

8) Archipilium macropus (Sample 277-23R-1, $33 \mathrm{~cm}$, slide A),

9) Callimitra aff. atavia (Sample 277-22R-1, 82cm),

10) Ceratocyrtis sp. (Sample 280A-5R-1, 104cm, slide C),

11) Ceratocyrtis sp. (Sample 280A-5R-1, 104cm, slide B),

12) Ceratocyrtis sp. (Sample 283-7R-1, 20cm, slide A),

13) Cladoscenium ancoratum (Sample 280A-7R-1, $90 \mathrm{~cm}$, slide A),

14) Corythomelissa sp. (Sample 207A-16R-2, 90 cm, slide B),

15) Corythomelissa sp. (Sample 207A-13R-4, $100 \mathrm{~cm}$, slide C),

16) Corythomelissa adunca (Sample 207A-16R-2, $90 \mathrm{~cm}$, slide B). 

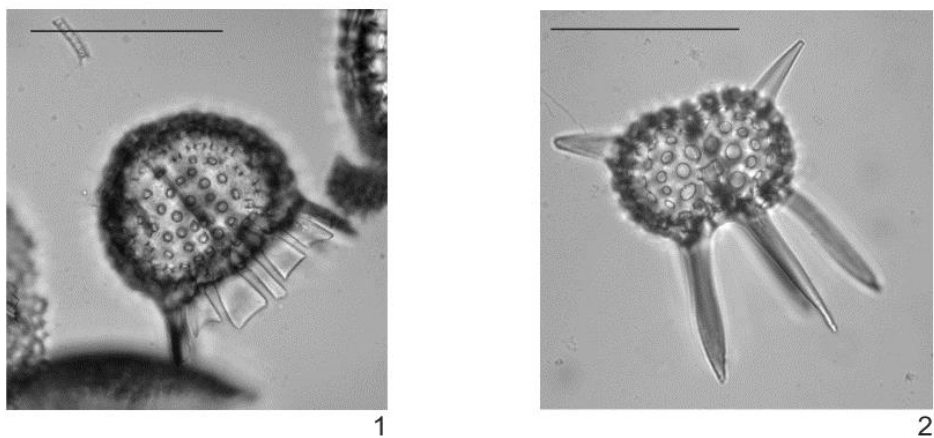

PLATE 5
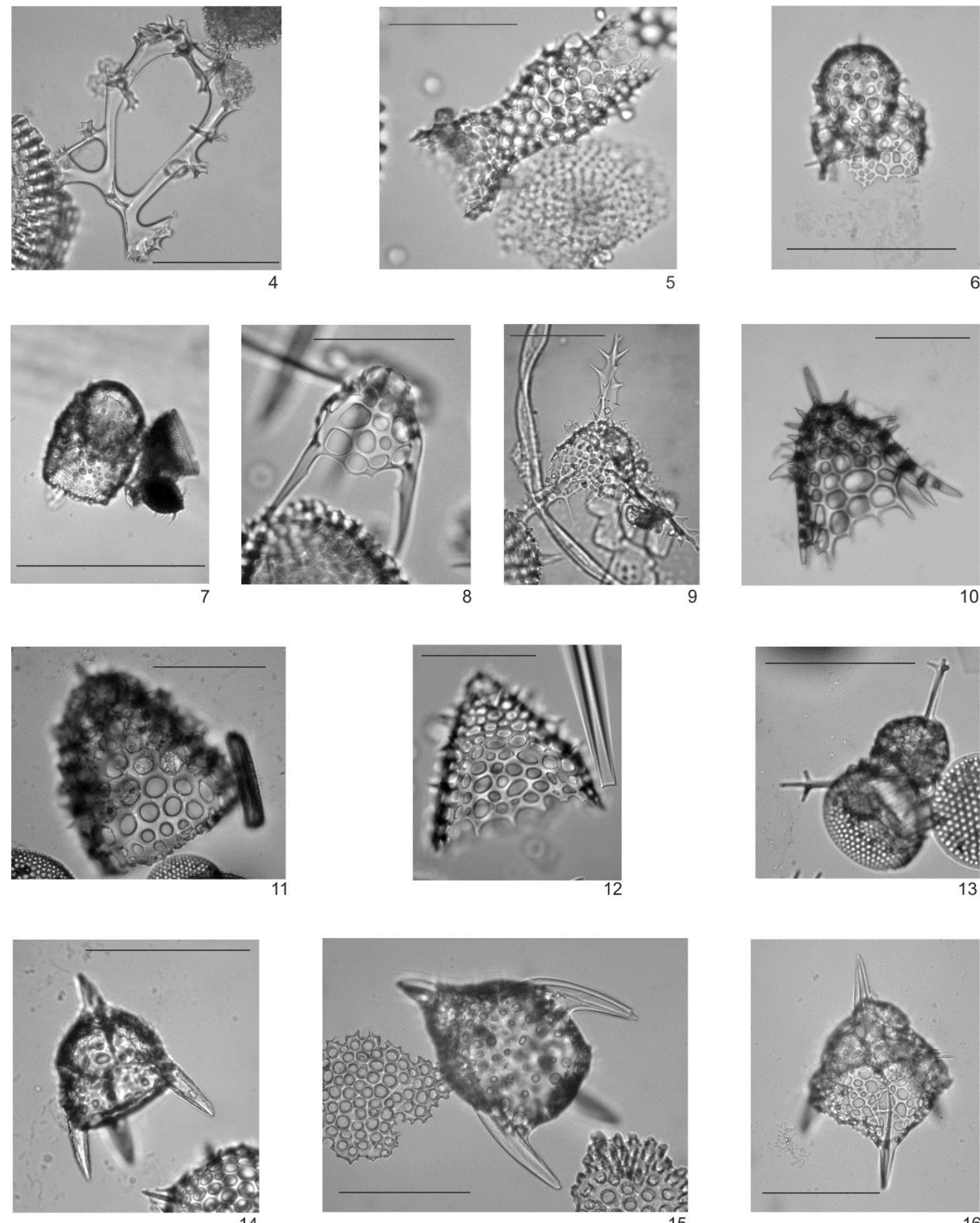


\section{PLATE 6: Plagiacanthidae}

Scale bars equal $100 \mu \mathrm{m}$. Images of selected radiolarian species:

1) Lithomelissa challengerae (Sample $280 \mathrm{~A}-6 \mathrm{R}-2,60 \mathrm{~cm}$, slide A),

2) Lithomelissa challengerae (Sample $280 \mathrm{~A}-6 \mathrm{R}-2,60 \mathrm{~cm}$, slide A),

3) Lithomelissa challengerae (Sample $280 \mathrm{~A}-6 \mathrm{R}-2,60 \mathrm{~cm}$, slide A),

4) Lithomelissa ehrenbergi (Sample 280A-5R-1, 104cm, slide B),

5) Lithomelissa ehrenbergi (Sample 283-6R-2, 40cm, slide A),

6) Lithomelissa gelasinus (Sample 280A-5R-1, 104cm, slide A),

7) Lithomelissa gelasinus (Sample 280A-5R-1, 104cm, slide A),

8) Lithomelissa cf. haeckeli (Sample 277-22R-1, 82cm, slide B),

9a, b) Lithomelissa macroptera (Sample 283-5R-2, 25cm, slide A),

10) Lithomelissa robusta (Sample 280A-7R-1, 90cm, slide A),

11) Lithomelissa sphaerocephalis (Sample 280A-7R-3, $40 \mathrm{~cm}$, slide A),

12) Lithomelissa tricornis (Sample 280A-7R-1, 90cm, slide A),

13) Lithomelissa? sakai (Sample 280A-5R-1, 104cm, slide B),

14) Lithomelissa? sakai (Sample 277-23R-1, $33 \mathrm{~cm}$, slide C),

15) Lophophaena capito (Sample 277-23R-2, $22 \mathrm{~cm}$ ),

16) Lophophaena radians (Sample 283-6R-2, $40 \mathrm{~cm}$, slide A)

17) Lophophaena simplex (Sample 283-6R-2, $40 \mathrm{~cm}$, slide A),

18) Pseudodictyophimus sp. (Sample 280A-7R-3, 40cm, slide A),

19) Pseudodictyophimus sp. (Sample 280A-7R-1, 90cm, slide A),

20) Pseudodictyophimus sp. (Sample 280A-7R-1, 90cm, slide A),

21) Pseudodictyophimus sp. (Sample 280A-5R-1, 104, slide A),

22) Pseudodictyophimus galeatus (Sample 280A-7R-3, 40cm, slide A),

23) Pseudodictyophimus gracilipes gr. (Sample 280A-7R-1, 90cm, slide A),

24) Pseudodictyophimus gracilipes gr. (Sample 280A-7R-1, 90cm, slide A),

25) Pseudodictyophimus gracilipes gr. (Sample 283-5R-2, 25cm, slide B),

26) Tripilidium sp. A (Sample 207A-19R-2, $90 \mathrm{~cm}$, slide A),

27) Tripodiscinus clavipes (Sample 207A-14R-1, $119 \mathrm{~cm}$, slide A). 

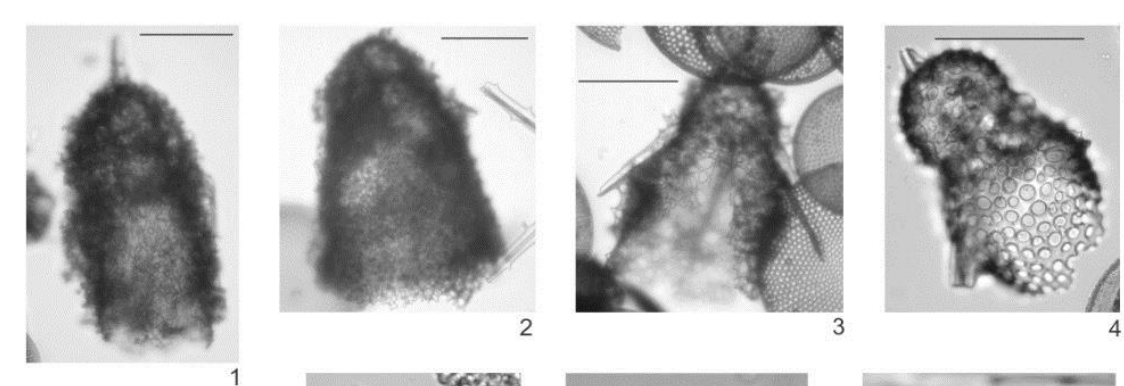

PLATE 6
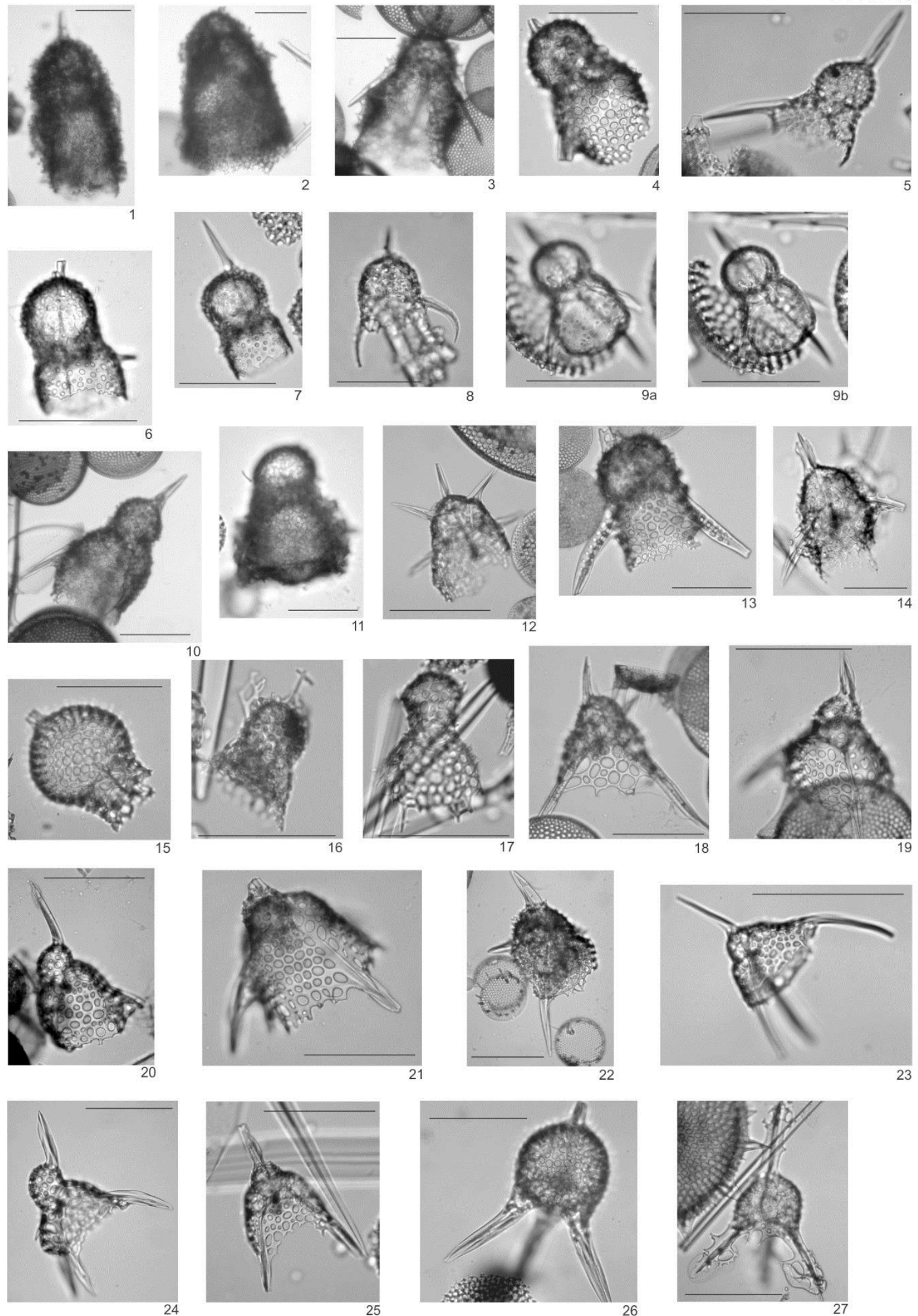


\section{PLATE 7: Cannobotryidae}

Scale bars equal $100 \mu \mathrm{m}$. Images of selected radiolarian species:

1a, b) Artobotrys auriculaleporis (Sample 207A-16R-2, $90 \mathrm{~cm}$, slide B),

2) Artobotrys auriculaleporis (Sample 207A-12R-1, $100 \mathrm{~cm}$, slide C),

3a, b) Artobotrys auriculaleporis (Sample 207A-12R-1, $100 \mathrm{~cm}$, slide C),

4) Artobotrys biaurita (Sample 207A-12R-1, $100 \mathrm{~cm}$, slide C),

5) Artobotrys biaurita (Sample 206C-17R-4, $100 \mathrm{~cm}$, slide B),

6) Artobotrys titanothericeraos (Sample 207A-13R-4, $100 \mathrm{~cm}$, slide A),

7a, b) Artobotrys titanothericeraos (Sample 207A-13R-4, $100 \mathrm{~cm}$, slide A),

8) Botryocella sp. A (Sample 280A-5R-1, $104 \mathrm{~cm}$, slide A),

9) Botryocella sp. A (Sample 280A-5R-1, $104 \mathrm{~cm}$, slide A),

10) Botryocella sp. A (Sample 280A-5R-1, $104 \mathrm{~cm}$, slide A),

11) Botryocella sp. A (Sample 280A-5R-1, $104 \mathrm{~cm}$, slide A),

12) Glycobotrys nasuta gr. (Sample 280A-5R-1, $104 \mathrm{~cm}$, slide A),

13) Glycobotrys nasuta gr. (Sample 277-25R-1, $60 \mathrm{~cm}$, slide A),

14) Glycobotrys nasuta gr. (Sample 277-24R-2, 20 cm, slide A). 

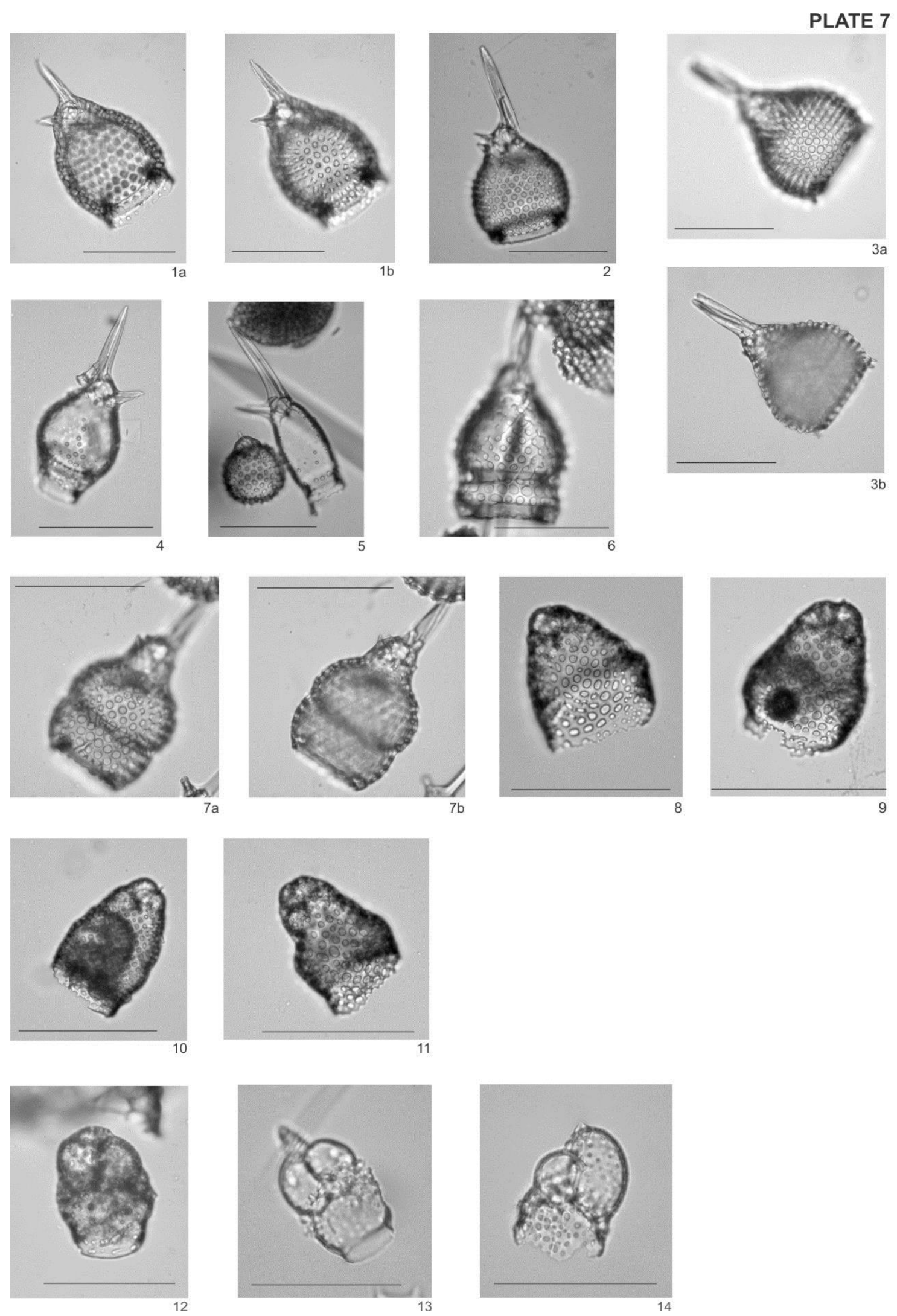


\section{PLATE 8: Artostrobiidae}

Scale bars equal $100 \mu \mathrm{m}$. Images of selected radiolarian species:

1) Buryella foremanae (Sample 206C-18R-2, $100 \mathrm{~cm}$, slide B),

2) Buryella granulata (Sample 277-29R-2, $100 \mathrm{~cm}$, slide A),

3) Buryella tetradica (Sample 207A-25R-CC, slide A),

4) Siphocampe nodosaria (Sample 277-24R-2, $20 \mathrm{~cm}$, slide B),

5) Siphocampe quadrata (Sample 207A-14R-2, $132 \mathrm{~cm}$, MRC slide),

6) Siphocampe (?) acephala gr. (Sample 277-25R-1, 60cm, slide A),

7) Siphocampe (?) acephala gr. (Sample 277-25R-1, 60cm, slide A),

8) Siphocampe (?) acephala gr. (Sample 277-25R-1, 60cm, slide A),

9) Siphocampe? amygdala (Sample 277-24R-2, 20cm, slide B),

10) Siphocampe? amygdala (Sample 277-23R-1, 33cm, slide A),

11a, b) Spirocyrtis greeni (Sample 283-6R-2, $40 \mathrm{~cm}$, slide A),

12a, b) Spirocyrtis joides (Sample 283-7R-1, $20 \mathrm{~cm}$, slide B),

13) Theocampe sp. (Sample 207A-15R-3, $100 \mathrm{~cm}$, slide A),

14) Theocampe sp. (Sample 207A-14R-2, $101 \mathrm{~cm}$, slide B),

15) Theocampe sp. (Sample 207A-14R-2, $101 \mathrm{~cm}$, slide B),

16a, b) Theocampe amphora (Sample 207A-13R-6, $100 \mathrm{~cm}$, slide B),

17a, b) Theocampe mongolfieri (Sample 206C-17R-4, $100 \mathrm{~cm}$, slide B),

18a, b) Theocampe cf. mongolfieri (Sample 207A-15R-3, $100 \mathrm{~cm}$, slide A),

19a, b) Theocampe pirum (Sample 1123C-32X-1, $86 \mathrm{~cm}$ ),

20) Theocampe urceolus (Sample 207A-14R-2, $101 \mathrm{~cm}$, slide B).

\section{PLATE 8: Acropyramididae}

21) Artostrobus sp. (Sample 277-23R-1, $33 \mathrm{~cm}$, slide A),

22) Artostrobus sp. (Sample 277-23R-1, $33 \mathrm{~cm}$, slide A),

23) Artostrobus annulatus (Sample 283-5R-2, $25 \mathrm{~cm}$, slide B),

24) Artostrobus cf. pretabulatus (Sample 277-23-1, 33cm, slide A),

25) Cinclopyramis circumtexta (Sample 207A-14R-1, $119 \mathrm{~cm}$, slide A),

26) Cinclopyramis scalaris (Sample 207A-14R-2, $101 \mathrm{~cm}$, slide B),

27) Cinclopyramis scalaris (Sample 207A-19R-4, $97 \mathrm{~cm}$, slide A),

28) Cornutella profunda (Sample 280A-7R-3, $40 \mathrm{~cm}$, slide A). 

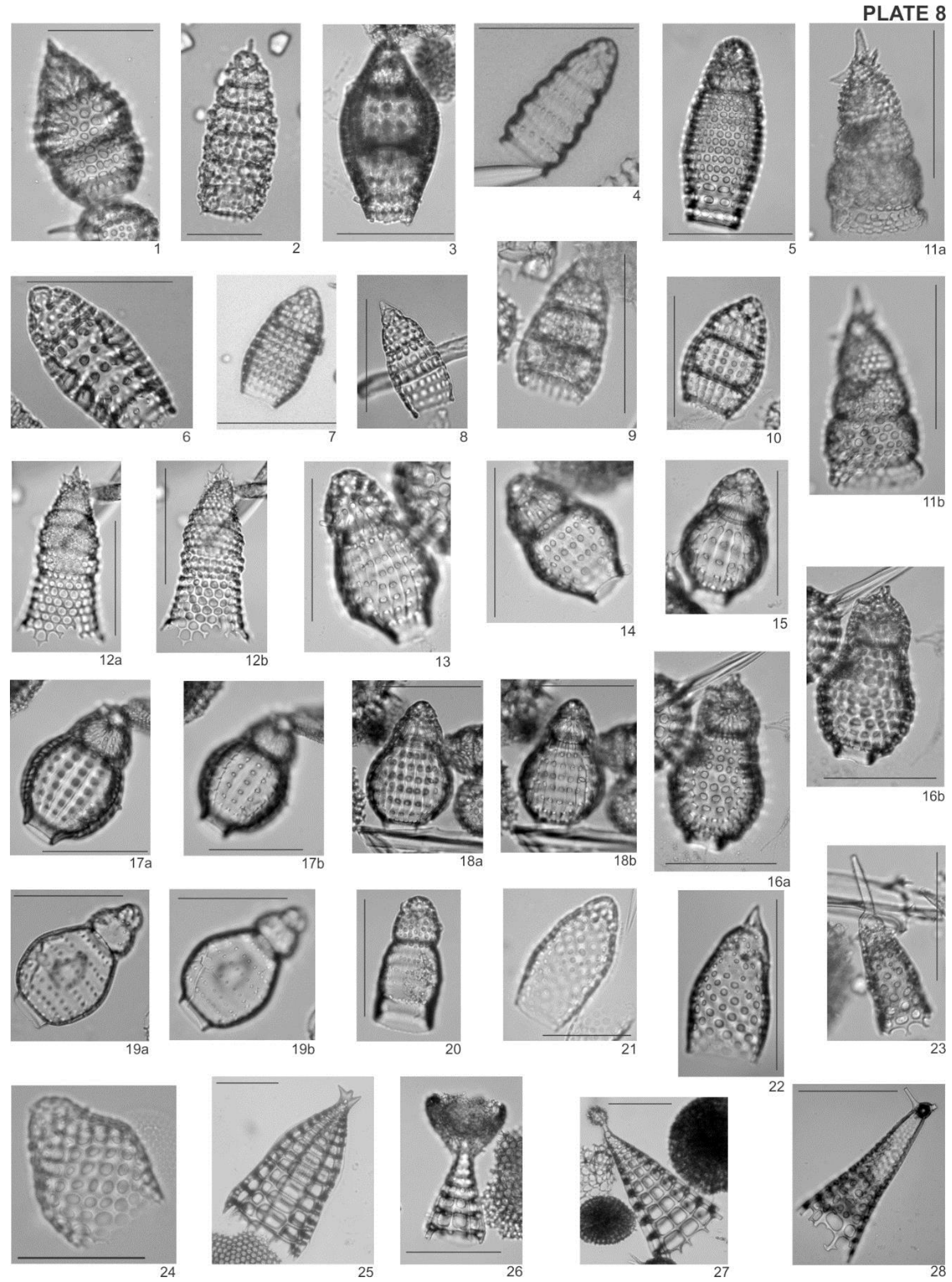


\section{PLATE 9: Eucyrtidiidae}

Scale bars equal $100 \mu \mathrm{m}$. Images of selected radiolarian species:

1) Artophormis aff. dominasinensis (Sample 206C-17R-6, $100 \mathrm{~cm}$, slide C),

2) Aspis sp. A (Sample 277-22R-1, $82 \mathrm{~cm}$ ),

3) Aspis sp. A (Sample 283-7R-5, $94 \mathrm{~cm}$, slide A),

4) Aspis sp. A (Sample 280A-6R-2, 60 cm, slide A),

5a, b) Calocyclas hispida (Sample 207A-12R-1, $100 \mathrm{~cm}$, slide C),

6) Calocycloma sp. (Sample 207A-16R-2, $90 \mathrm{~cm}$, slide B),

7a, b) Calocycloma ampulla (Sample 207A-18R-2, $102 \mathrm{~cm}$, slide A),

8a, b) Calocycloma cf. Lamptonium pennatum (Sample 207A-19R-2, $90 \mathrm{~cm}$, slide A),

9) Clathrocyclas universa (Sample 207A-14R-2, $101 \mathrm{~cm}$, slide B),

10) Clathrocyclas universa (Sample 207A-14R-1, $119 \mathrm{~cm}$, slide A),

11) Clathrocyclas universa (Sample 277-23R-1, $33 \mathrm{~cm}$, slide A),

12) Cycladophora sp. (Sample 283-8R-1, $40 \mathrm{~cm}$, slide A),

13) Cycladophora sp. (Sample 283-5R-2, $25 \mathrm{~cm}$, slide B),

14) Cycladophora cosma cosma (Sample 280A-7R-3, $40 \mathrm{~cm}$, slide A),

15) Cycladophora humerus (Sample 280A-5R-1, $104 \mathrm{~cm}$, slide A), 16a, b) Cymaetron sinolampas (Sample 280A-7R-1, $90 \mathrm{~cm}$, slide A), 17 a, b) Cyrtocapsa osculum (Sample 207A-13R-4, $100 \mathrm{~cm}$, slide C),

18) Cyrtopera laguncula (Sample 283-5R-2, $25 \mathrm{~cm}$, slide B),

19) Dictyopodium aff. oxylophus (Sample 207A-16R-2, $90 \mathrm{~cm}$, slide B),

20) Dictyopodium aff. oxylophus (Sample 207A-16R-2, $90 \mathrm{~cm}$, slide B),

21a, b) Dictyopodium aff. oxylophus (Sample 207A-16R-3, 66 cm, MRC slide),

22a, b) Dictyopodium sp. A (Sample 207A-13R-4, $100 \mathrm{~cm}$, slide A),

23) Dictyopodium sp. A (Sample 207A-13R-4, 100 cm, slide C). 

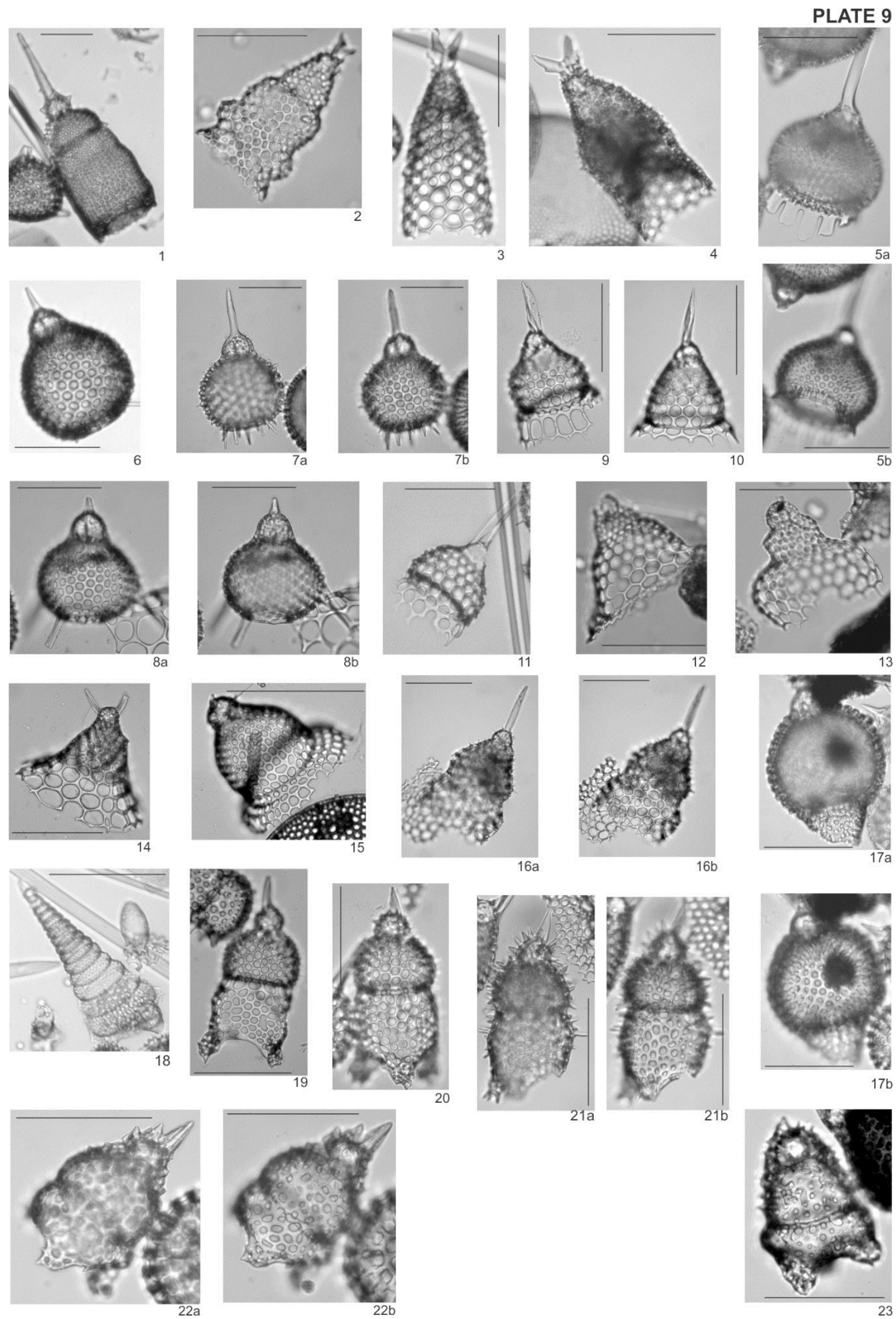


\section{PLATE 10: Eucyrtidiidae}

Scale bars equal $100 \mu \mathrm{m}$. Images of selected radiolarian species:

1) Eucyrtidium antiquum (Sample $280 \mathrm{~A}-7-1,90 \mathrm{~cm}$, slide A),

2) Eucyrtidium mariae (Sample 1123C-31X-5, $20 \mathrm{~cm}$ ),

3) Eucyrtidium microporum (Sample 283-7R-5, 94 cm, slide A),

4) Eucyrtidium montiparum (Sample 277-23R-1, $33 \mathrm{~cm}$, slide A),

5a, b) Eucyrtidium nishimurae (Sample 283-8R-2, $25 \mathrm{~cm}$, slide A),

6) Eucyrtidium spinosum (Sample 283-7R-5, $94 \mathrm{~cm}$, slide A),

7a, b) Eurystomoskevos cauleti (Sample 280A-7R-3, 40 cm, slide A),

8) Eurystomoskevos petrushevskaae (Sample 277-23R-1, $33 \mathrm{~cm}$, slide A),

9) Eurystomoskevos sp.? (Sample 207A-19R-2, 90 cm, slide A),

10) Eurystomoskevos sp.? (Sample 207A-19R-4, $97 \mathrm{~cm}$, slide A),

11) Eusyringium fistuligerum (Sample 277-33R-2, $20 \mathrm{~cm}$, slide A),

12) Eusyringium fistuligerum (Sample 207A-12R-1, $100 \mathrm{~cm}$, slide C),

13) Eusyringium fistuligerum (Sample 206C-17R-1, $15 \mathrm{~cm}$ ),

14) Eusyringium lagena (Sample 207A-14R-2, $132 \mathrm{~cm}$, MRC slide),

15) Ewingella? sp. (Sample 207A-20R-5, $101 \mathrm{~cm}$, slide A),

16a, b) Lamptonium cf. pennatum (Sample 207A-20R-5, $101 \mathrm{~cm}$, slide A),

17a, b) Phormocyrtis ligulata (Sample 207A-14R-1, 119 cm, slide A),

18) Phormocyrtis proxima (Sample 206C-17R-1, $15 \mathrm{~cm}$ ),

19a, b) Phormocyrtis striata striata (Sample 207A-14R-1, $119 \mathrm{~cm}$, slide A),

20a, b) Sethocyrtis chrysallis (Sample 277-32R-3. 100 cm). 

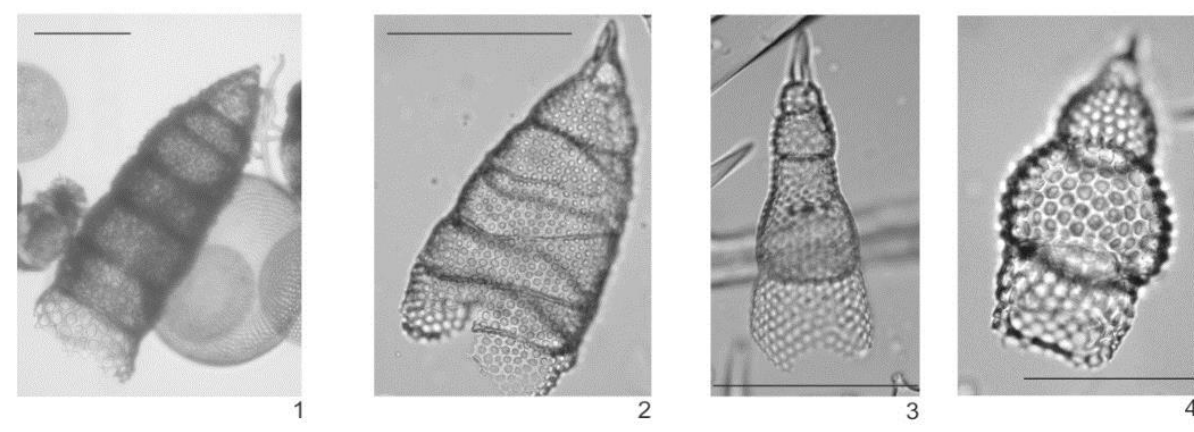

PLATE 10
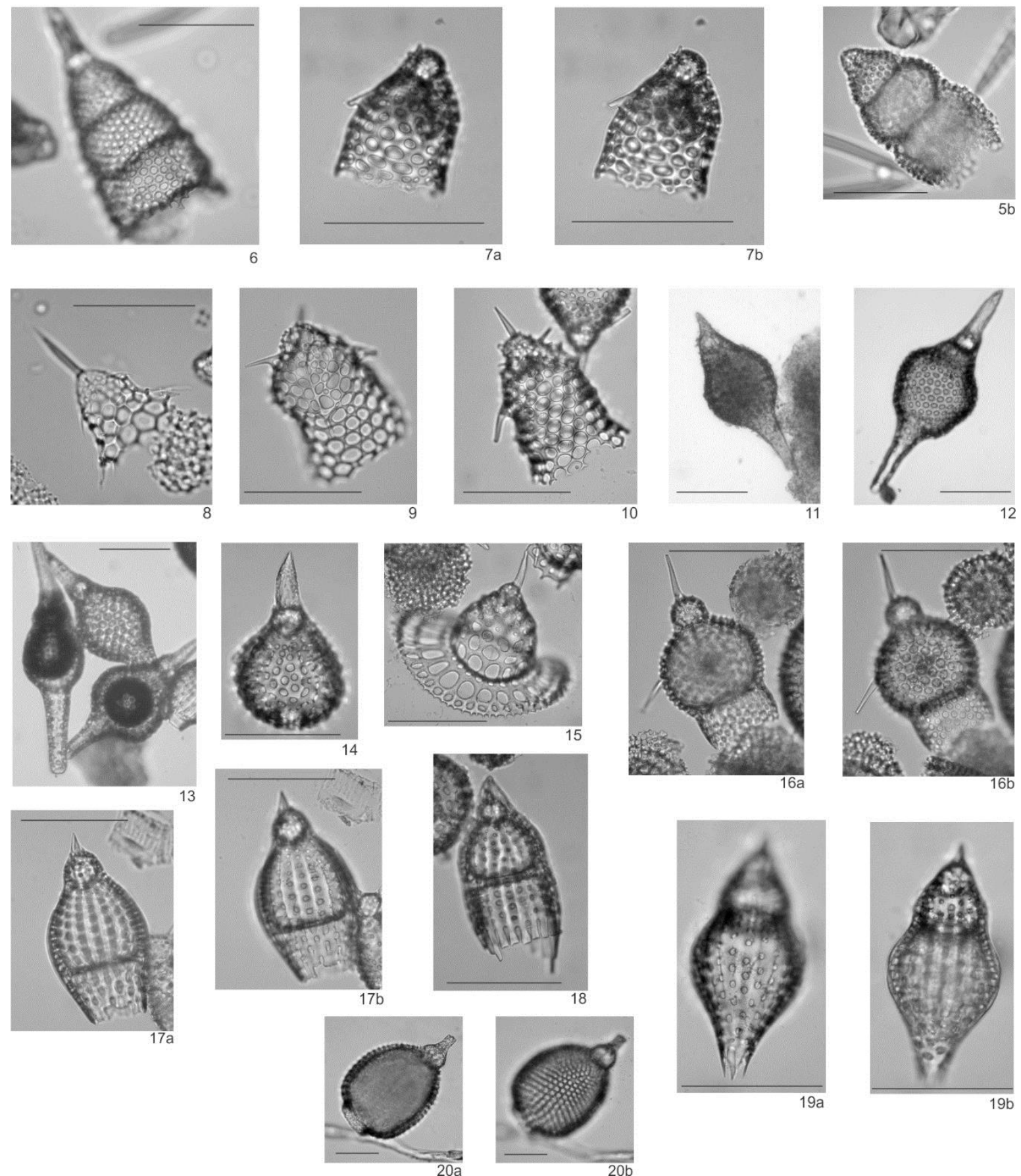


\section{PLATE 11: Eucyrtidiidae}

Scale bars equal $100 \mu \mathrm{m}$. Images of selected radiolarian species:

1) Theocorys sp. (Sample 207A-18R-5, $100 \mathrm{~cm}$, slide B),

2) Theocorys sp. (Sample 207A-14R-2, $132 \mathrm{~cm}$, MRC slide), 3a, b) Theocorys acroria (Sample 207A-19R-4, $97 \mathrm{~cm}$, slide A),

4) Theocorys anapographa (Sample 206C-17R-4, $100 \mathrm{~cm}$, slide B),

5) Theocorys anapographa (Sample 206C-17R-6, $100 \mathrm{~cm}$, slide C),

6a, b) Theocorys anapographa Var. A (Sample 206C-15R-2, $78 \mathrm{~cm}$, slide B),

7a, b) Theocotyle? sp. (Sample 207A-14R-2, $101 \mathrm{~cm}$, slide B),

8a, b) Theocotyle? sp. (Sample 207A-13R-4, $100 \mathrm{~cm}$, slide C),

9) Theocotyle nigriniae (Sample 207A-18R-2, $102 \mathrm{~cm}$, slide A),

10) Theocotylissa ficus (Sample 206C-17R-4, $100 \mathrm{~cm}$, slide B),

11) Thyrsocyrtis $\boldsymbol{c f}$. (Thyrsocyrtis) norrisi (Sample 592-40X-1, $80 \mathrm{~cm}$ ),

12a, b) Thyrsocyrtis $\boldsymbol{c f}$. (Thyrsocyrtis) norrisi (Sample 1123C-32X-2, $31 \mathrm{~cm}$ ),

13a, b) Thyrsocyrtis $\boldsymbol{c f}$. (Thyrsocyrtis) norrisi (Sample 1123C-32X-2, $31 \mathrm{~cm}$ ),

14a, b) Thyrsocyrtis (Thyrsocyrtis?) pinguisicoides (Sample 277-23R-1, $33 \mathrm{~cm}$, slide A),

15a, b) Thyrsocyrtis (Thyrsocyrtis) rhizodon (Sample 207A-20R-5, $101 \mathrm{~cm}$, slide A),

16) Thyrsocyrtis (Thyrsocyrtis) rhizodon (Sample 207A-18R-2, $102 \mathrm{~cm}$, slide A),

17a, b) Thyrsocyrtis (Thyrsocyrtis) rhizodon (Sample 207A-18R-5, $100 \mathrm{~cm}$, slide B),

18a, b) Thyrsocyrtis (Pentalocorys) cf. triacantha (Sample 206C-16R-3, $100 \mathrm{~cm}$, slide A),

19a, b) Thyrsocyrtis sp. A (Sample 206C-17R-1, $15 \mathrm{~cm}$ ),

20) Thyrsocyrtis sp. A (Sample 206C-17R-1, $15 \mathrm{~cm}$ ),

21 a, b, c) Thyrsocyrtis sp. D (Sample 206C-15R-2, 78 cm, slide B),

22a, b) Verutotholus edwardsi (Sample 1123C-32X-3, $39 \mathrm{~cm}$ ). 

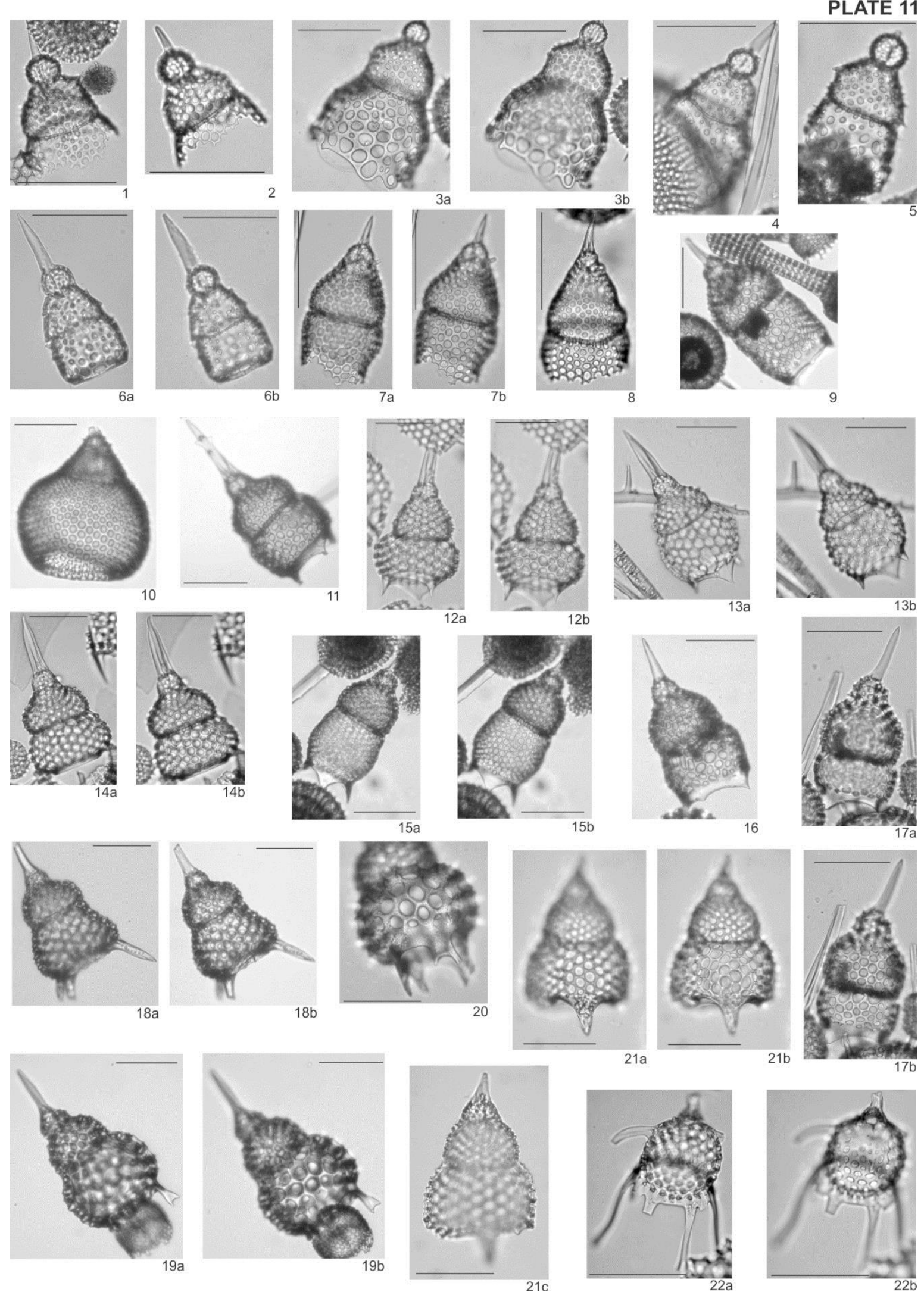


\section{PLATE 12: Lychnocaniidae}

Scale bars equal $100 \mu \mathrm{m}$. Images of selected radiolarian species:

1) Dictyophimus sp. (Sample 283-6R-2. 40 cm, slide A),

2) Dictyophimus sp. (Sample 207A-20R-5, $101 \mathrm{~cm}$, slide A),

3) Dictyophimus sp. (Sample 207A-19R-2, 90 cm, slide A),

4a, b) Dictyophimus craticula (Sample 207A-14R-2, $132 \mathrm{~cm}$, MRC slide),

5) Dictyophimus pocillum (Sample 207A-14R-1, $119 \mathrm{~cm}$, slide A),

6) Dictyophimus pocillum (Sample 277-20R-6, $100 \mathrm{~cm}$, slide A),

7a, b) Dictyophimus? archipilium (Sample 283-7R-1, 20cm, slide A),

8) Dictyophimus? archipilium (Sample 283-7R-1, 20cm, slide A),

9a, b) Dictyophimus? aff archipilium (Sample 277-17R-3, $33 \mathrm{~cm}$ ),

10) Dictyophimus? aff archipilium (Sample 283-8R-1, $40 \mathrm{~cm}$, slide B),

11) Dictyophimus? aff archipilium (Sample 283-8R-1, $40 \mathrm{~cm}$, slide B),

12) Dictyophimus? aff archipilium (Sample 283-8R-1, $40 \mathrm{~cm}$, slide B),

13) Dictyophimus? aff archipilium (Sample 277-23R-1, $22 \mathrm{~cm}$, slide A),

14) Dictyophimus? aff archipilium (Sample 277-23R-1, $22 \mathrm{~cm}$, slide A),

15) Dictyophimus aff. constrictus (Sample 280A-7R-1, $90 \mathrm{~cm}$, slide A

16) Dictyophimus aff. constrictus (Sample 280A-6R-2, $60 \mathrm{~cm}$, slide A),

17) Lithochytris archaea (Sample 207A-21R-4, $96 \mathrm{~cm}$, slide A),

18) Lithochytris vespertilio (Sample 207A-13R-6, $100 \mathrm{~cm}$, slide B),

19) Lychnocanium sp. (Sample 207A-12R-1, $100 \mathrm{~cm}$, slide C),

20) Lychnocanium sp. (Sample 207A-12R-1, $100 \mathrm{~cm}$, slide C),

21) Lychnocanium sp. (Sample 207A-12R-1, $100 \mathrm{~cm}$, slide C),

22) Lychnocanium sp. (Sample 207A-18R-5, $100 \mathrm{~cm}$, slide B),

23) Lychnocanium sp. (Sample 207A-19R-2, 90 cm, slide A),

24a, b) Lychnocanium alma (Sample 1123C-32X-4, $5 \mathrm{~cm}$ ),

25) Lychnocanium amphitrite (Sample 277-33R-2, $20 \mathrm{~cm}$, slide A),

26) Lychnocanium amphitrite (Sample 277-24R-2, $20 \mathrm{~cm}$, slide B),

27) Lychnocanium amphitrite (Sample 277-25R-1, $60 \mathrm{~cm}$, slide A),

28) Lychnocanium amphitrite (Sample 277-25R-1, $60 \mathrm{~cm}$, slide A). 

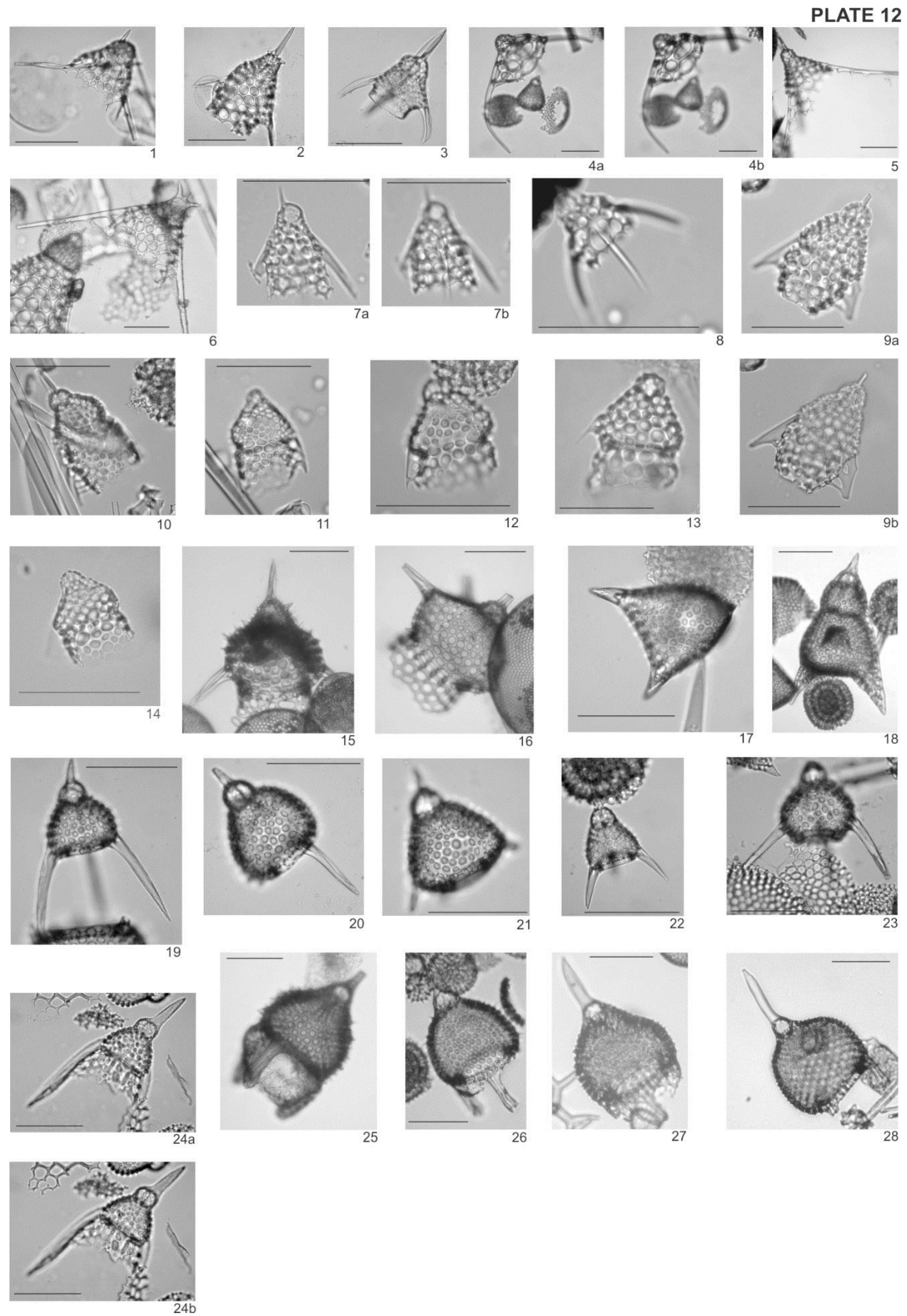


\section{PLATE 13: Lychnocaniidae}

Scale bars equal $100 \mu \mathrm{m}$. Images of selected radiolarian species:

1) Lychnocanium auxillum (Sample 277-43R-3, $121 \mathrm{~cm}$, slide B), 2a, b) Lychnocanium babylonis (Sample 283-8R-2, 25 cm, slide A),

3) Lychnocanium babylonis (Sample 277-23R-1, 33 cm, slide A),

4) Lychnocanium bellum (Sample 206C-17R-6, $100 \mathrm{~cm}$, slide C),

5) Lychnocanium aff. carinatum (Sample 207A-21R-4, $96 \mathrm{~cm}$, slide A),

6) Lychnocanium conicum (Sample 207A-16R-2, $90 \mathrm{~cm}$, slide B),

7) Lychnocanium conicum (Sample 207A-12R-1, $100 \mathrm{~cm}$, slide C),

8) Lychnocanium cf. conicum (Sample 207A-12R-1, $100 \mathrm{~cm}$, slide C),

9) Lychnocanium cf. conicum (Sample 207A-14R-2, $101 \mathrm{~cm}$, slide B), 10a, b) Lychnocanium continuum (Sample 283-6R-2, $40 \mathrm{~cm}$, slide A),

11) Lychnocanium aff. grande, early form (Sample 207A-18R-5, $100 \mathrm{~cm}$, slide B),

12a, b) Lychnocanium aff. grande, early form (Sample 207A-18R-5, $100 \mathrm{~cm}$, slide B),

13a, b) Lychnocanium aff. grande (Sample 207A-14R-2, $132 \mathrm{~cm}$, MRC slide),

14a, b) Lychnocanium aff. grande (Sample 207A-12R-1, $100 \mathrm{~cm}$, slide C),

15a, b) Lychnocanium satelles (Sample 207A-14R-1, $119 \mathrm{~cm}$, slide A),

16a, b) Lychnocanium satelles (Sample 207A-18R-6, 90 cm, slide B),

17a, b) Lychnocanium satelles (Sample 207A-18R-6, 90 cm, slide B),

18a, b) Lychnocanium tetrapodium (Sample 277-23R-1, $33 \mathrm{~cm}$, slide A). 

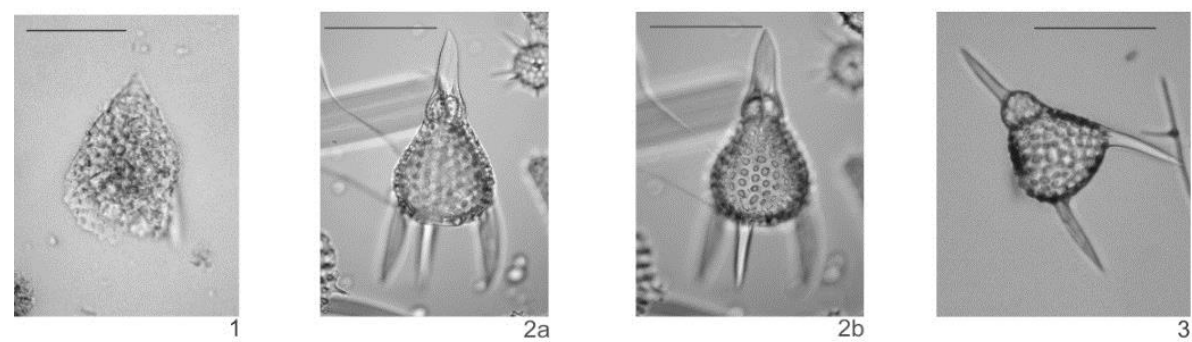

PLATE 13
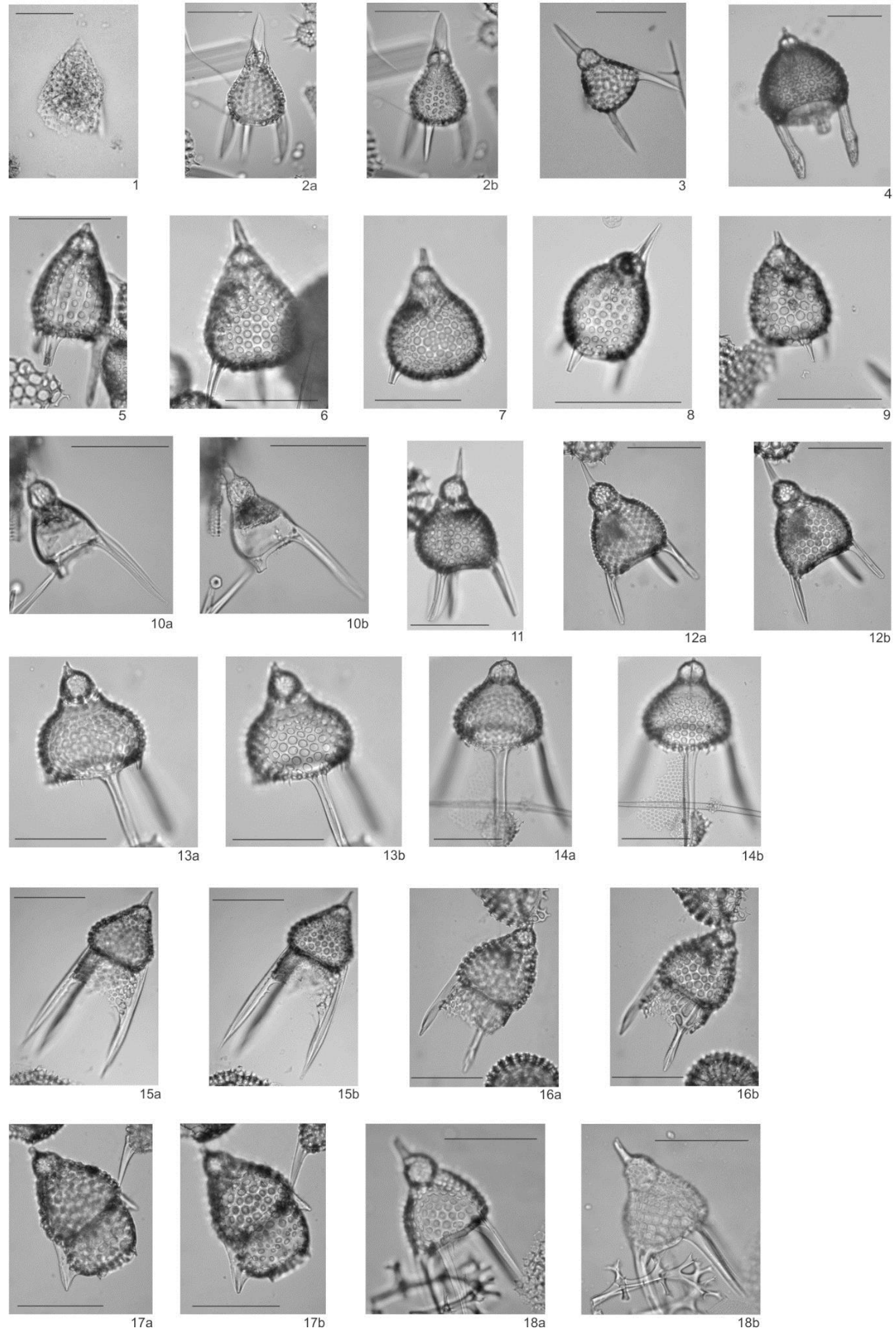


\section{PLATE 14: Lychnocaniidae}

Scale bars equal $100 \mu \mathrm{m}$. Images of selected radiolarian species:

1) Lychnocanium trichopus (Sample 207A-14R-2, $132 \mathrm{~cm}$, MRC slide), 2a, b, c) Lychnocanium trichopus (Sample 207A-14R-1, $119 \mathrm{~cm}$, slide A), 3a, b) Lychnocanium trichopus (Sample 207A-14R-1, 119 cm, slide A),

4) Lychnocanium cf. tridentatum (Sample 207A-19R-4, $97 \mathrm{~cm}$, slide A), 5a, b) Lychnocanium turgidum (Sample 1123C-31X-5, $20 \mathrm{~cm}$ ), 6a, b) Lychnocanium waiareka (Sample 1123C-32X-4, $5 \mathrm{~cm}$ ), 7a, b) Lychnocanium waitaki (Sample 1123C-32X-4, $5 \mathrm{~cm}$ ), 8) Lychnocanium sp. A (Sample 207A-18R-5, $100 \mathrm{~cm}$, slide B), 9a, b) Lychnocanium sp. A (Sample 207A-13R-6, $100 \mathrm{~cm}$, slide C), 10a, b) Lychnocanium sp. A (Sample 207A-14R-1, $119 \mathrm{~cm}$, slide A), 11a, b) Pterocanium sp. (Sample 207A-18R-2, $102 \mathrm{~cm}$, slide A),

12) Pterocanium cf. sphinx (Sample 207A-18R-5, $100 \mathrm{~cm}$, slide B), 13a, b) Pterocanium cf. sphinx (Sample 207A-19R-4, $97 \mathrm{~cm}$, slide A),

14) Pterocodon apis (Sample 283-7R-1, $20 \mathrm{~cm}$, slide $B$ ), 15a, b) Pterocodon apis (Sample 283-6R-2, $40 \mathrm{~cm}$, slide A), 16) Pteropilium aff. contiguum (Sample 1123C-31X-CC), 17) Pteropilium aff. contiguum (Sample 277-23-1, $33 \mathrm{~cm}$, slide A), 18a, b) Pteropilium aff. contiguum (Sample 207A-21R-4, $96 \mathrm{~cm}$, slide A), 19) Rhopalocanium ornatum (Sample 207A-19R-4, $97 \mathrm{~cm}$, slide A), 20) Rhopalocanium ornatum (Sample 206C-15R-2, 78 cm, slide B), 21) Rhopalocanium cf. ornatum (Sample 207A-15R-3, $100 \mathrm{~cm}$, slide A), 22) Rhopalocanium cf. ornatum (Sample 207A-15R-3, $100 \mathrm{~cm}$, slide A), 23) Rhopalocanium cf. ornatum (Sample 207A-16R-2, $90 \mathrm{~cm}$, slide B), 24) Rhopalocanium cf. ornatum (Sample 206C-15R-2, $35 \mathrm{~cm}$, slide B), 25) Rhopalocanium cf. ornatum (Sample 206C-15R-2, $78 \mathrm{~cm}$, slide B), 26) Rhopalocanium cf. ornatum (Sample 206C-15R-2, $78 \mathrm{~cm}$, slide B), 27a, b) Sethochytris triconiscus (Sample 206C-17R-4, 100cm, slide B). 

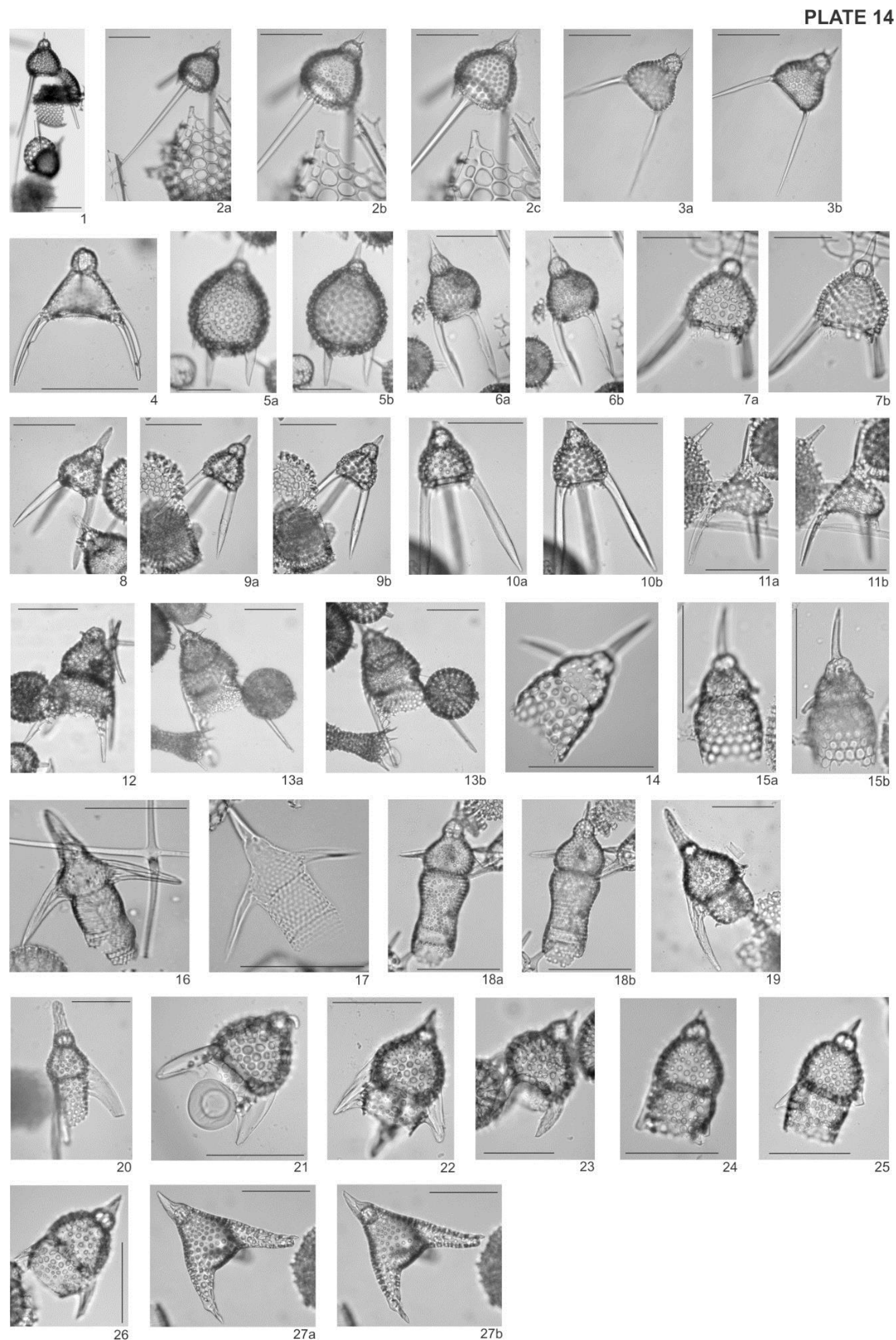


\section{PLATE 15: Lophocyrtiidae}

Scale bars equal $100 \mu \mathrm{m}$. Images of selected radiolarian species:

1) Aphetocyrtis bianulus (Sample 277-22R-1, $82 \mathrm{~cm}$, slide A),

2) Aphetocyrtis gnomabax (Sample 280A-6R-2, $60 \mathrm{~cm}$, slide A),

3) Aphetocyrtis gnomabax (Sample 280A-5R-1, $104 \mathrm{~cm}$, slide A),

4) Aphetocyrtis gnomabax (Sample 280A-5R-1, $104 \mathrm{~cm}$, slide A),

5) Aphetocyrtis gnomabax (Sample 280A-5R-1, $104 \mathrm{~cm}$, slide A),

6) Aphetocyrtis gnomabax (Sample 280A-5R-1, $104 \mathrm{~cm}$, slide A),

7) Aphetocyrtis gnomabax (Sample 277-24R-2, $20 \mathrm{~cm}$, slide A),

8) Aphetocyrtis rossi (Sample 283-6R-2, $40 \mathrm{~cm}$, slide A),

9) Aphetocyrtis rossi (Sample 280A-5R-1, $104 \mathrm{~cm}$, slide A),

10) Aphetocyrtis rossi (Sample 280A-7R-1, $90 \mathrm{~cm}$, slide A),

11) Aphetocyrtis rossi (Sample 277-23R-1, $33 \mathrm{~cm}$, slide A),

12) Clinorhabdus anantomus (Sample 283-7R-1, $20 \mathrm{~cm}$, slide A),

13) Clinorhabdus anantomus (Sample 283-7R-1, $20 \mathrm{~cm}$, slide A),

14a, b) Lophocyrtis (Apoplanius) aspera Form A (Sample 283-7R-1, 20 cm, slide A),

15) Lophocyrtis (Apoplanius) aspera Form A (Sample 283-7R-1, $20 \mathrm{~cm}$, slide A), 16a, b) Lophocyrtis (Apoplanius) aspera Form A (Sample 1123C-33X-CC, slide B),

17a, b) Lophocyrtis (Apoplanius) aspera Form B (Sample 207A-12R-1, $100 \mathrm{~cm}$, slide C),

18a, b) Lophocyrtis (Apoplanius) aspera Form B (Sample 1123C-32X-4, $5 \mathrm{~cm}$ ),

19a, b) Lophocyrtis (Apoplanius) aspera Form B (Sample 1123C-32X-4, $5 \mathrm{~cm}$ ),

20) Lophocyrtis (Apoplanius) keraspera (Sample 277-23R-1, $33 \mathrm{~cm}$, slide A),

21) Lophocyrtis (Apoplanius) keraspera (Sample 277-23R-1, $33 \mathrm{~cm}$, slide A),

22) Lophocyrtis (Apoplanius) keraspera (Sample 277-23R-1, $33 \mathrm{~cm}$, slide A),

23a, b) Lophocyrtis (Apoplanius) keraspera (Sample 1123C-32X-3, $39 \mathrm{~cm}$ ),

24) Lophocyrtis (Apoplanius) keraspera (Sample 1123C-33X-CC, slide B),

25a, b) Lophocyrtis (Apoplanius) nomas (Sample 207A-14R-1, $119 \mathrm{~cm}$, slide A),

26a, b) Lophocyrtis (Apoplanius) nomas (Sample 207A-14R-1, $119 \mathrm{~cm}$, slide A),

27) Lophocyrtis (Apoplanius) nomas (Sample 207A-14R-1, $119 \mathrm{~cm}$, slide A). 

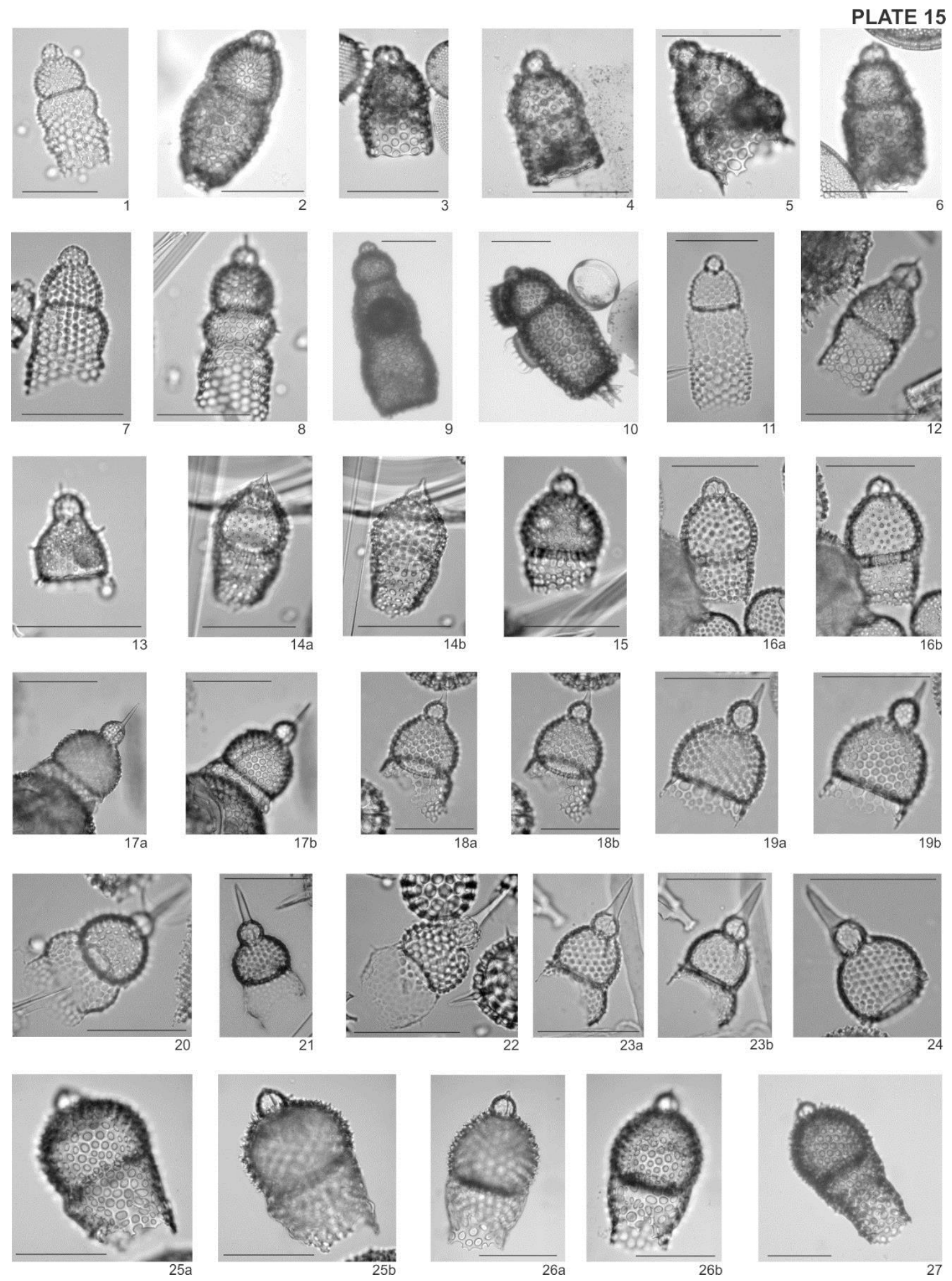


\section{PLATE 16: Lophocyrtiidae}

Scale bars equal $100 \mu \mathrm{m}$. Images of selected radiolarian species:

1a, b) Lophocyrtis (Cyclampterium) hadra (Sample 1123C-31X-5, $20 \mathrm{~cm}$ ),

2) Lophocyrtis (Cyclampterium) milowi (Sample 1123C-29X-CC),

3) Lophocyrtis (Lophocyrtis) jacchia hapsis (Sample 283-8R-1, $40 \mathrm{~cm}$, slide A),

4) Lophocyrtis (Lophocyrtis) jacchia hapsis (Sample 277-32R-3, $100 \mathrm{~cm}$ ),

5a, b) Lophocyrtis (Lophocyrtis) jacchia hapsis (Sample 1123C-32X-4, $5 \mathrm{~cm}$ ),

6a, b) Lophocyrtis (Lophocyrtis) jacchia hapsis (Sample 206C-15R-2, $25 \mathrm{~cm}$, slide B),

7) Lophocyrtis (Lophocyrtis) jacchia jacchia (Sample 207A-19R-4, $97 \mathrm{~cm}$, slide A),

8) Lophocyrtis (Lophocyrtis) jacchia jacchia (Sample 207A-20R-4, 70 cm, MRC slide),

9) Lophocyrtis (Lophocyrtis) jacchia jacchia (Sample 207A-20R-5, $101 \mathrm{~cm}$, slide A),

10) Lophocyrtis sp. A (Sample 207A-19R-4, 97 cm, slide A),

11) Lophocyrtis sp. A (Sample 207A-19R-4, $97 \mathrm{~cm}$, slide A),

12a, b) Lophocyrtis (Lophocyrtis?) semipolita (Sample 207A-18R-2, $102 \mathrm{~cm}$, slide A),

13a, b) Lophocyrtis (Lophocyrtis?) semipolita (Sample 207A-19R-2, 90 cm, slide A),

14) Lophocyrtis (Paralampterium) dumitricai (Sample 207A-14R-2, $101 \mathrm{~cm}$, slide B),

15) Lophocyrtis (Paralampterium) dumitricai (Sample 207A-18R-2, $102 \mathrm{~cm}$, slide A),

16a, b) Lophocyrtis (Paralampterium) cf. dumitricai (Sample 207A-21R-4, $96 \mathrm{~cm}$, slide A),

17) Lophocyrtis (Paralampterium) cf. dumitricai (Sample 207A-21R-4, $96 \mathrm{~cm}$, slide A),

18) Lophocyrtis (Paralampterium) cf. dumitricai (Sample 207A-21R-4, $96 \mathrm{~cm}$, slide A),

19) Lophocyrtis (Paralampterium) longiventer (Sample 277-25R-1, $60 \mathrm{~cm}$, slide A),

20) Lophocyrtis (Paralampterium) longiventer (Sample 277-25R-1, $60 \mathrm{~cm}$, slide A),

21a, b) Lophocyrtis? sp. B (Sample 1123C-33X-2, $31 \mathrm{~cm}$ ),

22) Lophocyrtis? sp. B (Sample 592-40X-1, $80 \mathrm{~cm}$ ),

23a, b) Lophocyrtis? sp. B (Sample 592-40X-1, $80 \mathrm{~cm}$ ),

24a, b) Pterosyringium hamata (Sample 1123C-31X-5, $20 \mathrm{~cm}$ ),

25a, b) Pterosyringium hamata (Sample 1123C-32X-1, $86 \mathrm{~cm}$ ),

26a, b) Pterosyringium hamata (Sample 1123C-32X-4, $5 \mathrm{~cm}$ ),

27a, b) Pterosyringium cf. hamata (Sample 1123C-29X-5, $20 \mathrm{~cm}$ ). 

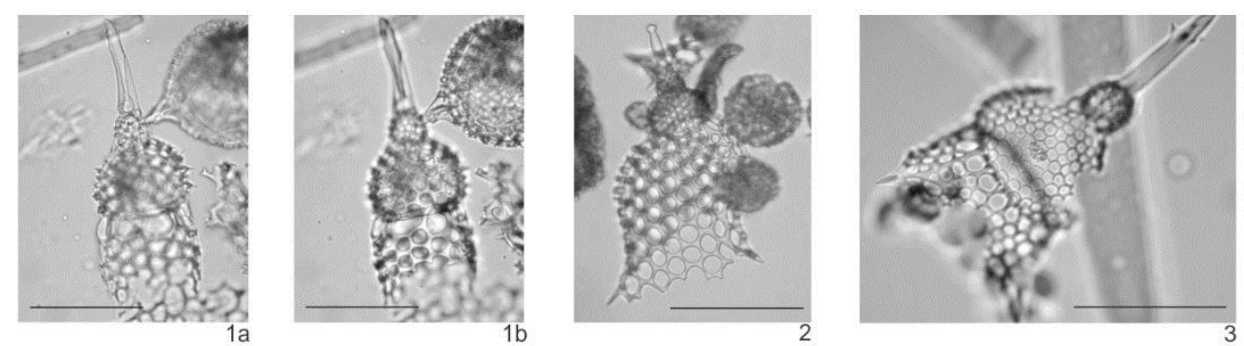

PLATE 16
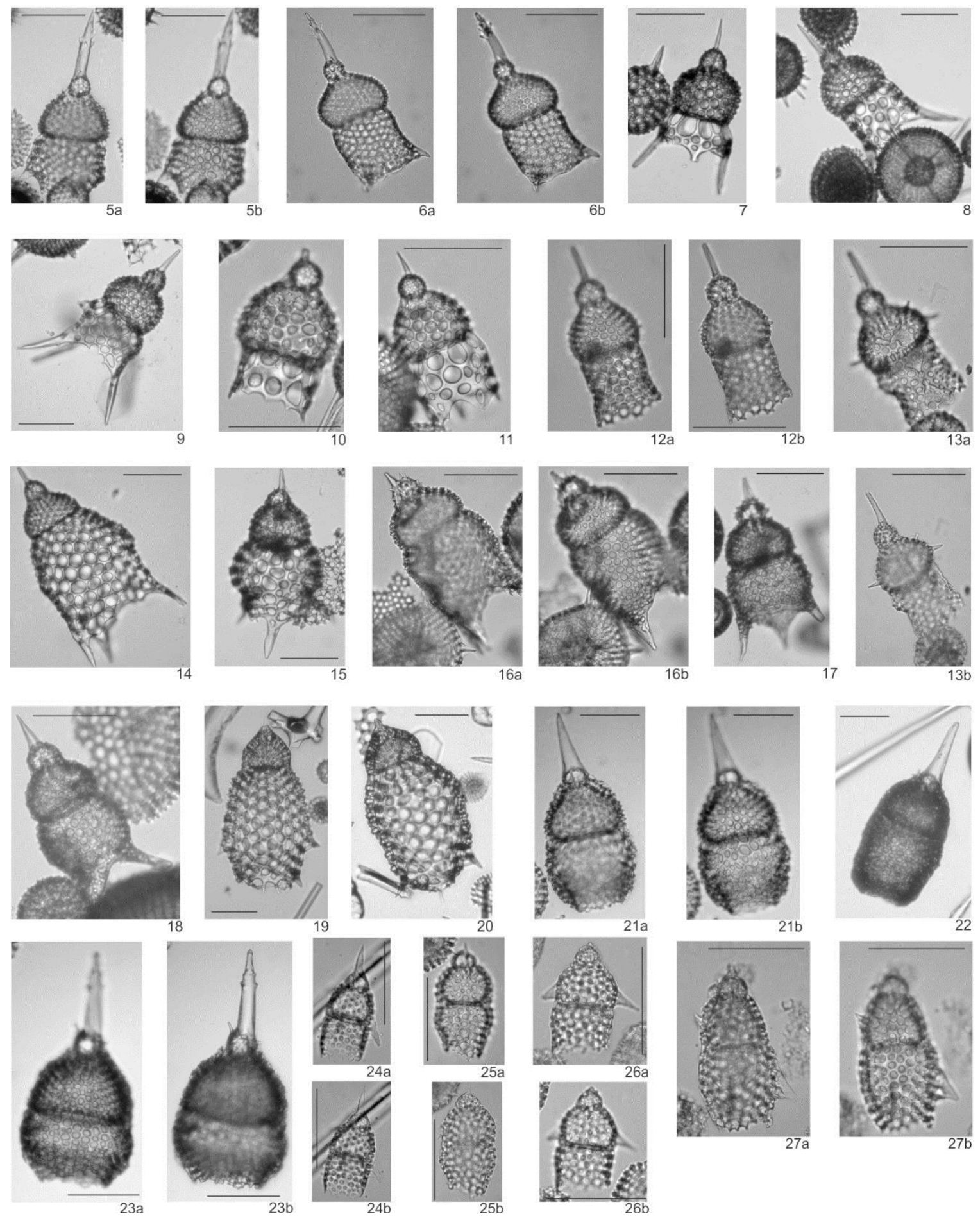


\section{PLATE 17: Pterocorythidae}

Scale bars equal $100 \mu \mathrm{m}$. Images of selected radiolarian species:

1a, b) Pterocorythidae? indet. sp. A (Sample 206C-17R-4, $100 \mathrm{~cm}$, slide B),

2a, b) Cryptocarpium sp., late Eocene form (Sample 1123C-33X-1, $31 \mathrm{~cm}$ ),

3a, b) Cryptocarpium sp., spiny form (Sample 1123C-33X-1, $31 \mathrm{~cm}$ ),

4a, b) Cryptocarpium sp., early Eocene form (Sample 207A-20R-5, $101 \mathrm{~cm}$, slide A),

5a, b) Cryptocarpium sp., middle Eocene form (Sample 206C-15R-2, $25 \mathrm{~cm}$, slide A),

6a, b) Cryptocarpium azyx (Sample 1123C-32X-CC),

7a, b) Cryptocarpium bussonii gr. (Sample 277-18R-3, $20 \mathrm{~cm}$ ),

8a, b) Cryptocarpium bussonii gr. (Sample 277-18R-3, $20 \mathrm{~cm}$ ),

9a, b) Cryptocarpium ornatum (Sample 1123C-32X-4, 5cm),

10a, b) Gondwanaria sp. (Sample 280A-7R-1, 90 cm, slide A),

11a, b) Gondwanaria sp. (Sample 280A-6R-2, $60 \mathrm{~cm}$, slide A),

12a, b) Lamprocyclas sp. (Sample 206C-17R-2, 100 cm, slide C),

13) Lamprocyclas particollis (Sample 277-25R-1, $60 \mathrm{~cm}$, slide A),

14a, b) Podocyrtis sp. (Sample 207A-18R-2, $102 \mathrm{~cm}$, slide A),

15a, b) Podocyrtis sp. (Sample 207A-15R-3, 100 cm, slide A),

16a, b) Podocyrtis? pupa (Sample 207A-13R-6, $100 \mathrm{~cm}$, slide B),

17a, b) Podocyrtis? pupa (Sample 207A-13R-6, $100 \mathrm{~cm}$, slide B),

18a, b) Podocyrtis? pupa (Sample 207A-13R-6, $100 \mathrm{~cm}$, slide B),

19a, b) Podocyrtis (Lampterium) acalles (Sample 207A-20R-5, $101 \mathrm{~cm}$, slide A),

20a, b) Podocyrtis (Podocyrtis) papalis (Sample 207A-19R-2, $90 \mathrm{~cm}$, slide A),

21a, b) Podocyrtis (Podocyrtoges) aphorma (Sample 207A-20R-4, $70 \mathrm{~cm}$, MRC slide), 

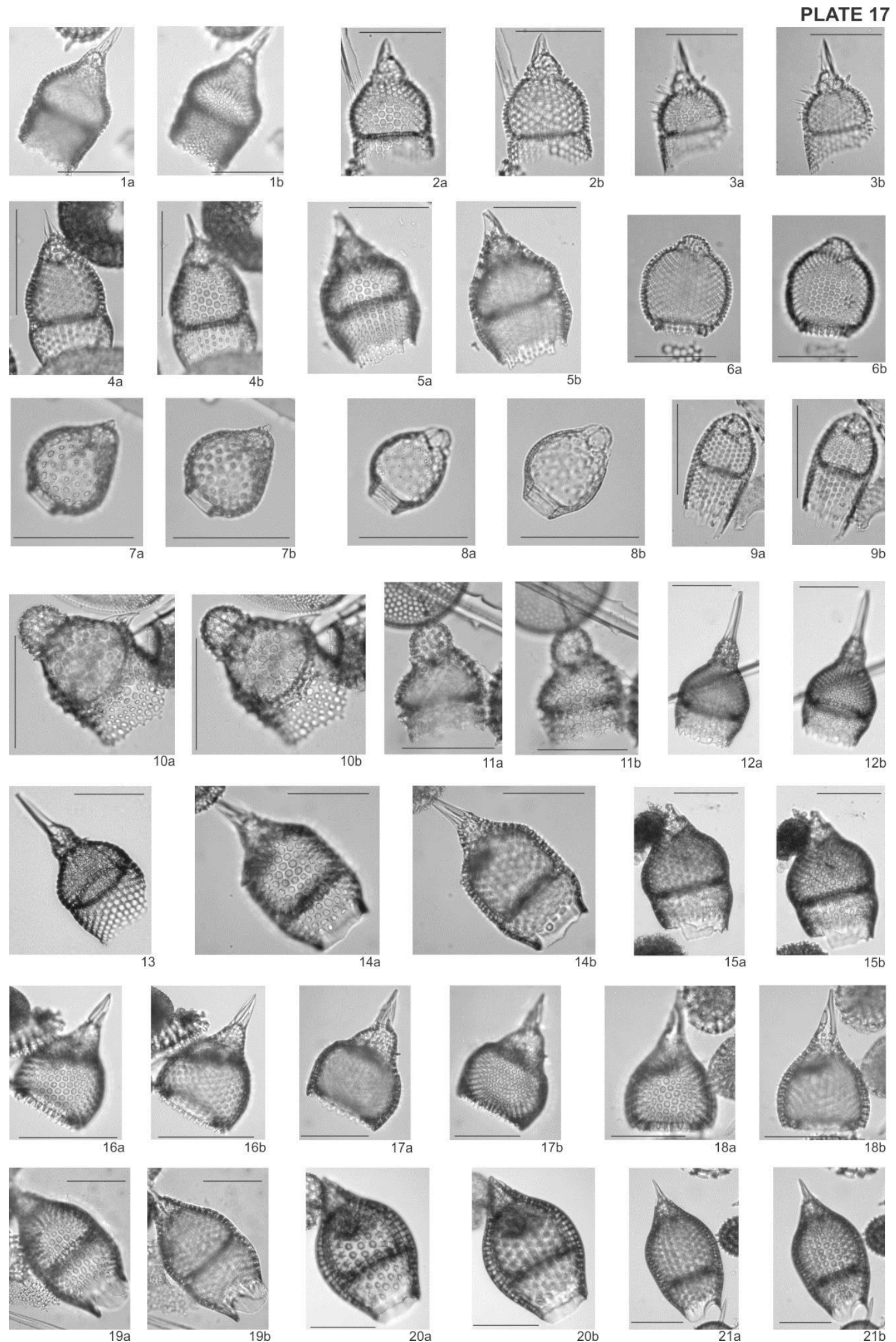


\section{PLATE 18: Pterocorythidae}

Scale bars equal $100 \mu \mathrm{m}$. Images of selected radiolarian species:

1a, b) Stichopilium cf. bicorne (Sample 207A-16R-2, $90 \mathrm{~cm}$, slide B),

2a, b) Stichopilium cf. bicorne (Sample 283-7R-1, $20 \mathrm{~cm}$, slide A),

3) Theocyrtis tuberosa (Sample 283-5R-2, $25 \mathrm{~cm}$, slide B),

4) Theocyrtis tuberosa (Sample 1123C-29X-5, $20 \mathrm{~cm}$ ),

5) Theocyrtis tuberosa (Sample 1123C-29X-5, $20 \mathrm{~cm}$ ).

PLATE 18: Sethophormididae

6) Velicucullus sp. (Sample 277-25R-1, $60 \mathrm{~cm}$, slide A),

7) Velicucullus magnificum (Sample 207A-16R-2, $90 \mathrm{~cm}$, slide B),

8) Velicucullus magnificum (Sample 207A-19R-4, $97 \mathrm{~cm}$, slide A),

9) Velicucullus magnificum (Sample 207A-16R-2, $90 \mathrm{~cm}$, slide B).

PLATE 18: Amphipyndacidae

10) Amphipternis alamedaensis (Sample 207A-18R-6, $90 \mathrm{~cm}$, slide B),

11a, b) Amphipternis clava (Sample 207A-20R-5, $101 \mathrm{~cm}$, slide A),

12) Amphipyndax stocki (Sample 207A-28R-1, $100 \mathrm{~cm}$, slide A).

\section{PLATE 18: reworked specimens}

13) Dictyomitra multicostata (Sample 1123C-32X-CC),

14) Mita regina (Sample 1123C-32X-CC),

15) Phormocyrtis striata exquisita (Sample 206C-17R-4, $100 \mathrm{~cm}$, slide B)

16a, b) Stichocorys delmontensis (Sample 1123C-30X-1, $60 \mathrm{~cm}$ ). 

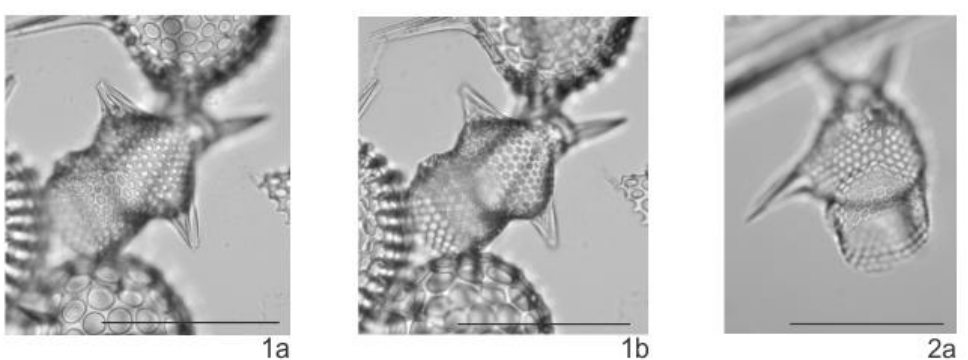

PLATE 18
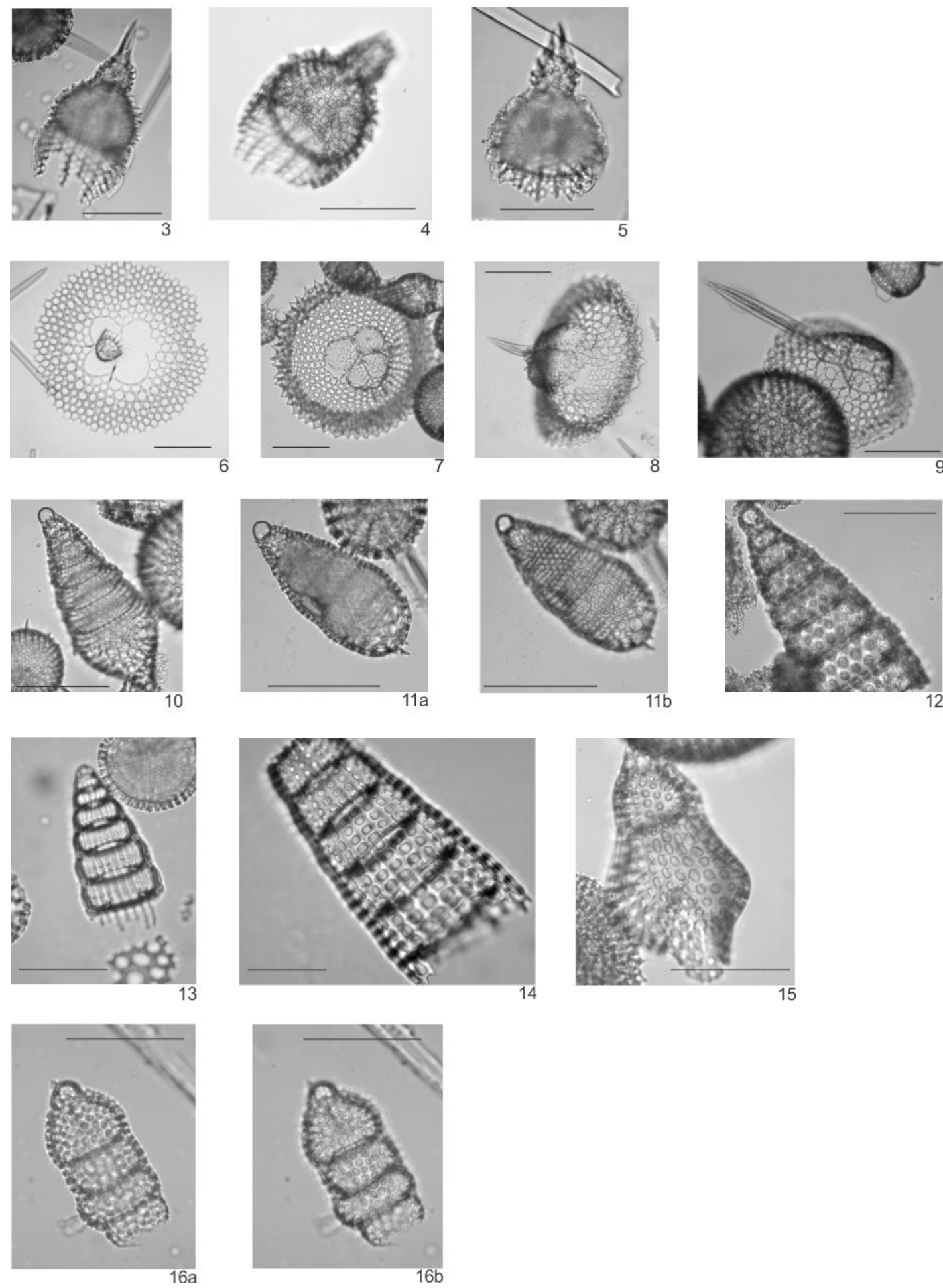


\section{References}

Abelmann, A. (1990). Oligocene to Middle Miocene radiolarian stratigraphy of southern high latitudes from Leg 113, sites 689, and 690, Maud Rise. In: Baker, P.F., Kennett, J.P. et al. (Eds.), Proceedings of the Ocean Drilling Program, Scientific Results, Vol. 113, College Station, TX (Ocean Drilling Program), 675-708.

Aitchison, J.C. and Flood, P.G. (1995). Data report: Cenozoic radiolarians from Leg 143, Hole 869A, Equatorial Pacific Ocean. In: Winterer, E.L., Sager, W.W., Firth, J.V. and Sinton, J.M. (Eds.), Proceedings of the Ocean Drilling Program, Scientific Results, Vol. 143, College Station, TX (Ocean Drilling Program), 571-574.

Anderson, O.R. (1976). A cytoplasmic fine-structure study of two spumellarian Radiolaria and their symbionts. Marine Micropaleontology, 1, 81-99.

Apel, M., Kiessling, W., Böhm, F. and Lazarus, D. (2002). Radiolarian faunal characteristics in Oligocene sediments of the Kerguelen Plateau, Leg 183, Site 1138. In: Frey, F.A., Coffin, M.F., Wallace, P.J. and Quilty, P.G. (Eds.), Proceedings of the Ocean Drilling Program, Scientific Results, Vol. 183, College Station, TX (Ocean Drilling Program), 1-48.

Bailey, J.W. (1856). Notice of microscopic forms found in the soundings of the Sea of Kamtschatka - with a plate. American Journal of Science and Arts, Series 2, 22, 16.

Barker, P.F. (2001). Scotia Sea regional tectonic evolution: implications for mantle flow and palaeocirculation. Earth-Science Reviews, 55(1), 1-39.

Beerling, D.J. and Royer, D.L. (2011). Convergent cenozoic $\mathrm{CO}_{2}$ history. Nature Geoscience, 4(7), 418-420, doi: 10.1038/ngeo1186.

Belkin, I.M. and Gordon, A.L. (1996). Southern Ocean fronts from the Greenwich meridian to Tasmania. Journal of Geophysical Research: Oceans (1978-2012), 101(C2), 3675-3696.

Benson, R.N. (1966). Recent Radiolaria from the Gulf of California. Ph.D. Thesis, Minnesota University, 1-577.

Berggren, W.A., Kent, D.V., Swisher, C.C., III and Aubry, M.-P. (1995). A revised Cenozoic geochronology and chronostratigraphy. In: Berggren, W.A., Kent, D.V., Aubry, M.-P. and Hardenbol, J. (Eds.), Geochronology, time scales and global stratigraphic correlation, SEPM Special Publication 54, 129-212.

Berggren, W.A. and Person, P.N. (2005). A revised tropical to subtropical Paleogene planktonic foraminiferal zonation. Journal of Foraminiferal Research, 35(4), 279298, doi:10.2113/35.4.279.

Besse, J. and Courtillot, V. (2002). Apparent and true polar wander and the geometry of the geomagnetic field over the last 200 Myr. Journal of Geophysical Research: Solid Earth, 107(B11), doi: 10.1029-2000JB000050.

Beu, A.G., Maxwell, P.A. and Brazier, R. (1990). Cenozoic Mollusca of New Zealand: New Zealand Geological Survey.

Bijl, P.K., Schouten, S., Sluijs, A., Reichart, G.-J., Zachos, J.C., and Brinkhuis, H. (2009). Early Palaeogene temperature evolution of the southwest Pacific Ocean. Nature, 461(7265), 776-779.

Bijl, P.K., Houben, A.J., Schouten, S., Bohaty, S.M., Sluijs, A., Reichart, G.-J., Damsté, J.S.S. and Brinkhuis, H. (2010). Transient Middle Eocene atmospheric $\mathrm{CO}_{2}$ and temperature variations. Science, 330(6005), 819-821. 
Bijl, P.K., Pross, J., Warnaar, J., Stickley, C.E., Huber, M., Guerstein, R., Houben, A.J., Sluijs, A., Visscher, H. and Brinkhuis, H. (2011). Environmental forcings of Paleogene Southern Ocean dinoflagellate biogeography. Paleoceanography, 26(1), PA1202, doi:10.1029/2009PA001905.

Bijl, P.K., Bendle, J.A., Bohaty, S.M., Pross, J., Schouten, S., Tauxe, L., Stickley, C.E., McKay, R.M., Röhl, U., \& Olney, M. (2013). Eocene cooling linked to early flow across the Tasmanian Gateway. Proceeding of the National Academy of Sciences U.S.A., 110(24), 9645-9650, doi: 10.1073/pnas.1220872110.

Bjørklund, K.R. (1976). Radiolaria from the Norwegian Sea, Leg 38 of the Deep Sea Drilling Project. In: Talwani, M. et al. (Eds.), Initial Reports of the Deep Sea Drilling Project, Vol. 38, U.S. Government Printing Office, Washington D.C., 1101-1168.

Blueford, J. (1988). Radiolarian biostratigraphy of siliceous Eocene deposits in central California, Micropaleontology, 34, 236-258.

Bohaty, S.M. and Zachos, J.C. (2003). Significant Southern Ocean warming event in the late middle Eocene. Geology, 31(11), 1017-1020.

Bohaty, S.M., Zachos, J.C., Florindo, F. and Delaney, M.L. (2009). Coupled greenhouse warming and deep-sea acidification in the middle Eocene. Paleoceanography, 24(2), PA2207, doi:10.1029/2008PA001676.

Bohaty, S.M., Zachos, J.C. and Delaney, M.L. (2012). Foraminiferal Mg/Ca evidence for Southern Ocean cooling across the Eocene-Oligocene transition. Earth and Planetary Science Letters, 317, 251-261.

Boyden, J.A., Müller, R.D., Gurnis, M., Torsvik, T.H., Clark, J.A., Turner, M., Ivey-Law, H., Watson, R.J. and Cannon, J.S. (2011). Next-generation plate-tectonic reconstructions using GPlates. In: Geoinformatics: cyberinfrastructure for the solid earth sciences, Cambridge University Press, 95-114.

Brassell, S., Eglinton, G., Marlowe, I., Pflaumann, U. and Sarnthein, M. (1986). Molecular stratigraphy: a new tool for climatic assessment. Nature, 320(6058), 129-133.

Burns, R.E., Andrews, J.E., van den Lingen, G.J., Churkin, J.M., Galehouse, J.S., Packham, G.H., Davies, T.A., Kennett, J.P., Dumitrica, P., Edwards, A.R., Von Herzen, R.P., Bangs, T.C. and Fields, M. (1973). Initial Reports of the Deep Sea Drilling Project, Vol. 21, U.S. Government Printing Office, Washington, D.C., doi: 10.2973/dsdp.proc.21.1973.

Burma, B.H. (1959). On the status of Theocampe Haeckel, and certain similar genera. Micropaleontology, 5(3), 325-330.

Bütschli, O. (1882). Beiträge zur Kenntnis der Radiolarienskelette, insbesondere der Cyrtida. Zeitschrift für Wissenschaftliche Zoologie, 36, 485-540.

Campbell, A.S. (1951). New genera and subgenera of Radiolaria. Journal of Paleontology, 25, 527-530.

Campbell, A.S. and Clark, B.L. (1944a). Miocene radiolarian faunas from southern California. Geological Society of America, Special Paper, no. 51, 1-76.

Campbell, A.S. and Clark, B.L. (1944b). Radiolaria from Upper Cretaceous of Middle California. Geological Society of America, Special Paper, no. 57, 1-61.

Cande, S.C. and Mutter, J.C. (1982). A revised identification of the oldest sea-floor spreading anomalies between Australia and Antarctica. Earth and Planetary Science Letters, 58(2), 151-160.

Cande, S.C. and Stock, J.M. (2004). Pacific-Antarctic-Australia motion and the formation of the Macquarie Plate. Geophysical Journal International, 157(1), 399-414. 
Carnevale, P. (1908). Radiolarie e silicoflagellati di Bergonzano (Reggio Emilia). Memorie del Reale Istituto Veneto di Scienze, Lettere ed Arti, 28, 1-46.

Carter, L., Garlick, R.D., Sutton, P., Chiswell, S., Oien, N.A. and Stanton, B.R. (1998). Ocean Circulation New Zealand. National Institute of Water and Atmospheric Research, Chart Miscellaneous Series, 76.

Carter, L., Carter, R.M. and McCave, I. (2004). Evolution of the sedimentary system beneath the deep Pacific inflow off eastern New Zealand. Marine Geology, 205(1), 9-27.

Carter, L., McCave, I. and Williams, M.J. (2008). Circulation and water masses of the Southern Ocean: a review. Developments in Earth and Environmental Sciences, 8, 85-114.

Carter, R.M. and Landis, C. (1972). Correlative Oligocene unconformities in southern Australasia. Nature, 237(70), 12-13.

Carter, R.M. (1985). The mid-Oligocene Marshall Paraconformity, New Zealand: coincidence with global eustatic sea-level fall or rise? Journal of Geology, 93(3), 359-371.

Carter, R.M., McCave, I.N., Richter, C., Carter, L., Aita, Y., Buret, C. and Di Stefano, A. (1999). Proceedings of the Ocean Drilling Program, Initial Reports, 181 [Online]. Available from World Wide Web: <http://wwwodp.tamu.edu/publications/181_IR/181ir.htm>. [Cited 2016-02-19].

Casey, R.E. (1993). Radiolaria. In: Lipps, J.H. (Ed.), Fossil Prokaryotes and Protists, Oxford/London, UK, Blackwell Scientific Publications, 249-284.

Caulet, J.P. (1986). Radiolarians from the Southwest Pacific. In: Kennett, J.P., Von der Borch et. al. (Eds.), Initial Reports of the Deep Sea Drilling Project, Vol. 90, U.S. Government Printing Office, Washington, D.C., 835-861.

Caulet, J.P. (1991). Radiolarians from the Kerguelen Plateau, Leg 119. In: Barron, J.A., Larsen, B. et al. (Eds.), Proceedings of the Ocean Drilling Program, Scientific Results, Vol. 119, College Station, TX (Ocean Drilling Program), 513-546.

Chen, P.H. (1975). Antarctic Radiolaria. In: Hayes, D.E., Frakes, L.A., et al. (Eds.), Initial Reports of the Deep Sea Drilling Project, Vol. 28, U.S. Government Printing Office, Washington, D.C., 437-513.

Chiswell, S.M., Bostock, H.C., Sutton, P.J. and Williams, M.J. (2015). Physical oceanography of the deep seas around New Zealand: a review. New Zealand Journal of Marine and Freshwater Research, 49(2), 286-317.

Cita, M.B., Nigrini, C.A. and Gartner, S. (1970). Biostratigraphy, Leg 2. In: Peterson, M.N.A., Edgar, N.T. et al. (Eds.), Initial Reports of the Deep Sea Drilling Project, Vol. 2, U.S. Government Printing Office, Washington, D.C., 391-411.

Clark, B.L. and Campbell, A.S. (1942). Eocene radiolarian faunas from the Monte Diablo area, California. Geological Society of America, Special Papers, 39, 1-112.

Clark, B.L. and Campbell, A.S. (1945). Radiolaria from the Kreyenhagen Formation near Los Baños, California. Geological Society of America, Memoir, 101, i-vii, 1-66.

Close, D.I., Watts, A. and Stagg, H. (2009). A marine geophysical study of the Wilkes Land rifted continental margin, Antarctica. Geophysical Journal International, 177(2), 430-450.

Cohen, K., Finney, S. and Gibbard, P. (2014). International Chronostratigraphic Chart v 2014/10. International Subcommission on Stratigraphy, available from World Wide Web: <http://www.stratigraphy.org/icschart/chronostratchart2014-02.pdf>

Contreras, L., Pross, J., Bijl, P.K., Koutsodendris, A., Raine, J.I., van de Schootbrugge, B. and Brinkhuis, H. (2013). Early to middle Eocene vegetation dynamics at the 
Wilkes Land Margin (Antarctica). Review of Palaeobotany and Palynology, 197, 119-142.

Cortese, G. and Prebble, J. (2015). A radiolarian-based modern analogue dataset for palaeoenvironmental reconstructions in the Southwest Pacific. Marine Micropaleontology, 118, 34-49.

Cox, A. and Hart, R. (1986). Plate Tectonics: How It Works, Blackwell Scientific Publications, $392 \mathrm{pp}$.

Coxall, H.K., Wilson, P.A., Pälike, H., Lear, C.H. and Backman, J. (2005). Rapid stepwise onset of Antarctic glaciation and deeper calcite compensation in the Pacific Ocean. Nature, 433(7021), 53-57.

Cramer, B., Toggweiler, J., Wright, J., Katz, M. and Miller, K. (2009). Ocean overturning since the Late Cretaceous: Inferences from a new benthic foraminiferal isotope compilation. Paleoceanography, 24(4), PA4216, doi:10.1029/2008PA001683.

Cramer, B., Miller, K., Barrett, P. and Wright, J. (2011). Late Cretaceous-Neogene trends in deep ocean temperature and continental ice volume: Reconciling records of benthic foraminiferal geochemistry $(\delta 18 \mathrm{O}$ and $\mathrm{Mg} / \mathrm{Ca})$ with sea level history. Journal of Geophysical Research: Oceans (1978-2012), 116(C12).

Croon, M.B., Cande, S.C. and Stock, J.M. (2008). Revised Pacific-Antarctic plate motions and geophysics of the Menard Fracture Zone. Geochemistry, Geophysics, Geosystems, 9(7), Q07001, doi: 10.1029/2008GC002019.

Crouch, E.M. and Hollis, C.J. (1996). Paleogene palynomorph and radiolarian biostratigraphy of DSDP Leg 29, sites 280 and 281 South Tasman Rise. Institute of Geological and Nuclear Sciences science report 96/19, 46pp.

Dallanave, E., Agnini, C., Bachtadse, V., Muttoni, G., Crampton, J.S., Strong, C.P., Hines, B.R., Hollis, C.J. and Slotnick, B.S. (2015). Early to middle Eocene magneto-biochronology of the southwest Pacific Ocean and climate influence on sedimentation: Insights from the Mead Stream section, New Zealand. Geological Society of America Bulletin, 127(5-6), 643-660.

Deflandre, G. (1953). Radiolaires fossiles. Traite de Zoologie, 1(2), 389-436.

De Wever, P. (1981). Spyrids, artostrobiids, and Cretaceous radiolarians from the western Pacific, Deep Sea Drilling Project Leg 61. In: Larson, R.L., Schlanger, S.O. et al. (Eds.), Initial Reports of the Deep Sea Drilling Project, Vol. 61, U.S. Government Printing Office, Washington, D.C., 507-520.

De Wever, P., Dumitrica, P., Caulet, J.P., and Caridroit, M. (2001). Radiolarians in the sedimentary record, Gordon and Breach Science Publishers, Amsterdam, 533 pp.

DeConto, R.M. and Pollard, D. (2003). Rapid Cenozoic glaciation of Antarctica induced by declining atmospheric $\mathrm{CO}_{2}$. Nature, 421(6920), 245-249.

DeConto, R.M., Pollard, D., Wilson, P.A., Pälike, H., Lear, C.H. and Pagani, M. (2008). Thresholds for Cenozoic bipolar glaciation. Nature, 455(7213), 652-656.

Diester-Haass, L., Robert, C. and Chamley, H. (1996). The Eocene-Oligocene preglacialglacial transition in the Atlantic sector of the Southern Ocean (ODP Site 690). Marine Geology, 131(3-4), 123-149.

Diester-Haass, L. and Zahn, R. (1996). Eocene-Oligocene transition in the Southern Ocean: History of water mass circulation and biological productivity. Geology, 24(2), 163-166.

Dinkelman, M.G. (1973). Radiolarian stratigraphy: Leg 16, Deep Sea Drilling Project. In: Van Andel, T.H., Heath, G.R. et al. (Eds.), Initial Reports of the Deep Sea Drilling Project, Vol. 16, U.S. Government Printing Office, Washington, D.C., 747-813.

Doubrovine, P.V., Steinberger, B. and Torsvik, T.H. (2012). Absolute plate motions in a reference frame defined by moving hot spots in the Pacific, Atlantic, and Indian 
oceans. Journal of Geophysical Research: Solid Earth, 117(B9), doi: 10.10292011JB009072.

Dreyer, F. (1889). Die Pylombildungen in vergleichend-anatomischer und entwicklungsgeschichtlicher Beziehung bei Radiolarien und bei Protisten überhaupt. Jenaische Zeitschrift für Naturwissenschaft, 23, 1-138.

Dumitrica, P. (1973). Paleocene Radiolaria, DSDP Leg 21. In: Burns, R.E., Andrews, J.E., et al. (Eds.), Initial Reports of the Deep Sea Drilling Project, Vol. 21, U.S. Government Printing Office, Washington, D.C., 787-817.

Dutkiewicz, A., Müller, R.D., O'Callaghan, S. and Jónasson, H. (2015). Census of seafloor sediments in the world's ocean. Geology, 43(9), 795-798.

Eberle, J.J. and Greenwood, D.R. (2012). Life at the top of the greenhouse Eocene worldA review of the Eocene flora and vertebrate fauna from Canada's High Arctic. Geological Society of America Bulletin, 124(1-2), 3-23.

Edwards, A.R. (1973). Southwest Pacific regional unconformities encountered during Leg 21. In: Burns, R.E., Andrews, J.E. et al. (Eds.), Initial Reports of the Deep Sea Drilling Project, Vol. 21, U.S. Government Printing Office, Washington D.C., 701-720.

Edwards, A.R. and Perch-Nielsen, K. (1975). Calcareous nannofossils from the southern southwest Pacific, Deep Sea Drilling Project, Leg 29. In: Kennett, J. P., Houtz, R. E. et al. (Eds.), Initial Reports of the Deep Sea Drilling Project, Vol. 29, U.S. Government Printing Office, Washington, D.C., 469-539.

Ehrenberg, C.G. (1838). Über die Bildung der Kreidefelsen und des Kreidemergels durch unsichtbare Organismen. Abhandlungen der Königlichen Preussischen Akademie der Wissenschaften zu Berlin, 59-147.

Ehrenberg, C.G. (1847a). Über die mikroskopischen kieselschaligen Polycystinen als mächtige Gebirgsmasse von Barbados und über das Verhältniss der aus mehr als 300 neuen Arten bestehenden ganz eigenthümlichen Formengruppe jener Felsmasse $\mathrm{zu}$ den jetzt lebenden Thieren und zur Kreidebildung. Eine neue Anregung zur Erforschung des Erdlebens. Berichte der Königlichen Preussischen Akademie der Wissenschaften zu Berlin, 40-60.

Ehrenberg, C.G. (1847b). Über eine halibiolithische, von Herrn R. Schomburgk entdeckte, vorherrschend aus mikroskopischen Polycystinen gebildete, Gebirgsmasse von Barbados. Bericht der Königlichen Preussischen Akademie der Wissenschaften zu Berlin, 382-385.

Ehrenberg, C.G. (1854a). Die systematische Charakteristik der neuen mikroskopischen Organismen des tiefen atlantischen Oceans. Bericht über die zur Bekanntmachung geeigneten Verhandlungen der Königlichen Preussischen Akademie der Wissenschaften zu Berlin, 236-250.

Ehrenberg, C.G. (1854b). Mikrogeologie. Das Erden und Felsen schaffende Wirken des unsichtbar kleinen selbststandigen Lebens auf der Erde. Leopold Voss, Leipzig, Germany, xxviii + 374pp.

Ehrenberg, C.G. (1861). Über die Tiefgrund-Verhaltnisse des Oceans am Eingange der Davisstrasse und bei Island. Monatsberichte der Königlichen Preussischen Akademie der Wissenschaften zu Berlin, 275-315.

Ehrenberg, C.G. (1873). Grossere Felsproben des Polycystinen-Mergels von Barbados mit weiteren Erlauterungen. Monatsberichte der Königlichen Preussischen Akademie der Wissenschaften zu Berlin, 213-263.

Ehrenberg, C.G. (1875). Fortsetzung der mikrogeologischen Studien als GesammtUebersicht der mikroskopischen Paläontologie gleichartig analysirter Gebirgsarten der Erde, mit specieller Rücksicht auf den Polycystinen-Mergel von Barbados. 
Abhandlungen der Königlichen Preussischen Akademie der Wissenschaften zu Berlin, 1-225.

Elderfield, H. and Ganssen, G. (2000). Past temperature and $\delta 180$ of surface ocean waters inferred from foraminiferal Mg/Ca ratios. Nature, 405(6785), 442-445.

Emiliani, C. (1955). Pleistocene temperatures. The Journal of Geology, 63(6), 538-578.

Exon, N.F., Kennett, J.P., Malone, M.J., Bringhuis, H., Chaproniere, G.C.H., Ennyu, A., Fothergill, P., Fuller, M.D., Grauert, M. and Hill, P.J. (2001). Proceedings of the Ocean Drilling Program, Initial Reptorts, Vol. 189 [Online]. Available from: World Wide Web: <http://www-odp.tamu.edu/publications/189_IR/189ir.htm>. [Cited 2016-02-20].

Exon, N.F., Kennett, J.P. and Malone, M.J. (2004). Leg 189 synthesis: CretaceousHolocene history of the Tasmanian gateway. Proceedings of the Ocean Drilling Program, Scientific Results, Vol. 189, 1-37.

Expedition 306 Scientists (2006). Site U1313. In: Channell, J.E.T., Kanamatsu, T., Sato, T., Stein, R., Alvarez Zarikian, C.A., Malone, M.J., and the Expedition 303/306 Scientists (Eds.), Proceedings of the Integrated Ocean Drilling Program, Vol. 306, College Station TX (Integrated Ocean Drilling Program Management International, Inc.), doi:10.2204/iodp.proc.303306.112.2006.

Expedition 320/321 Scientists (2010). Site U1331. In: Paelicke, H., Lyle, M., Nishi, H., Raffi, I., Gamage, K., Klaus, A. and the Expedition 320/321 Scientists (Eds.), Proceedings of the Integrated Ocean Drilling Program, Vol. 320/321, Tokyo (Integrated Ocean Drilling Program Management International, Inc.).

Florindo, F. and Roberts, A.P. (2005). Eocene-Oligocene magnetobiochronology of ODP Sites 689 and 690, Maud Rise, Weddell Sea, Antarctica. Geological Society of America Bulletin, 117(1-2), 46-66.

Foreman, H.P (1966). Two Cretaceous radiolarian genera. Micropaleontology, 12(3), 355-359.

Foreman, H.P. (1973a). Radiolaria from DSDP Leg 20. In: Heezen, B.C., MacGregor, J.D. et al. (Eds.), Initial Reports of the Deep Sea Drilling Project, Vol. 20, U.S. Government Printing Office, Washington, D.C., 249-305.

Foreman, H.P. (1973b). Radiolaria of Leg 10 with systematics and ranges for the families Amphipyndacidae, Artostrobiidae and Theoperidae. In: Worzel, J.L., Bryant, W. et al. (Eds.), Initial Reports of the Deep Sea Drilling Project, Vol. 10, U.S. Government Printing Office, Washington, D.C., 407-474.

Fulthorpe, C.S., Carter, R.M., Miller, K.G. and Wilson, J. (1996). Marshall Paraconformity: a mid-Oligocene record of inception of the Antarctic Circumpolar Current and coeval glacio-eustatic lowstand? Marine and Petroleum Geology, 13(1), 61-77.

Funakawa, S. (1994). Plagiacanthidae (Radiolaria) from the Upper Miocene of eastern Hokkaido, Japan. Transactions and Proceedings of the Palaeontological Society of Japan, New Series, 174, 458-483.

Funakawa, S. (1995). Intrageneric variation and temporal change in the internal skeletal structures of plagiacanthids (Radiolaria) from Hokkaido, Japan. Transactions and Proceedings of the Palaeontological Society of Japan, New Series, 180, 208-225.

Funakawa, S. and Nishi, H. (2005). Late middle Eocene to late Oligocene radiolarian biostratigraphy in the Southern Ocean (Maud Rise, ODP Leg 113, Site 689). Marine Micropaleontology, 54(3-4), 213-247.

Funakawa, S., Nishi, H., Moore, T.C. and Nigrini, C.A. (2006a). Radiolarian faunal turnover and paleoceanographic change around Eocene/Oligocene boundary in the 
central equatorial Pacific, ODP Leg 199, Holes 1218A, 1219A, and 1220A. Palaeogeography, Palaeoclimatology, Palaeoecology, 230(3-4), 183-203.

Funakawa, S., Nishi, H., Moore, T.C. and Nigrini, C.A. (2006b). Data report: Late Eocene-early Oligocene radiolarians, ODP Leg 199 Holes 1218A, 1219A, and 1220A, central Pacific. In: Wilson, P.A., Lyle, M. and Firth, J.V. (Eds.), Proceedings of the Ocean Drilling Program, Scientific Results, Vol. 199, 1-74.

Funakawa, S. and Nishi, H. (2008). Radiolarian faunal changes during the EoceneOligocene transition in the Southern Ocean (Maud Rise, ODP Leg 113, Site 689) and its significance in paleoceanographic change. Micropaleontology, 54(1), 1526.

Goll, R.M. (1968). Classification and phylogeny of Cenozoic Trissocyclidae (Radiolaria) in the Pacific and Caribbean Basins, Part I. Journal of Paleontology, 42(6), 14091432.

Goll, R.M. (1969). Classification and phylogeny of Cenozoic Trissocyclidae (Radiolaria) in the Pacific and Caribbean basins, Part II. Journal of Paleontology, 43, 322-339.

Goll, R.M. (1979). The Neogene evolution of Zygocircus, Neosemantis and Callimitra: their bearing on nassellarian classification. A revision of the Plagiacanthoidea, Micropaleontology, 25, 365-396.

Gordon, A. (1988). Spatial and temporal variability within the Southern Ocean. Antarctic Ocean and resources variability, Springer, 41-56.

Gradstein, F., Ogg, J., Schmitz, M. and Ogg, G. (2012). The geologic time scale 2012, Vol. 2, Elsevier New York.

Granot, R., Cande, S., Stock, J. and Damaske, D. (2013). Revised Eocene-Oligocene kinematics for the West Antarctic rift system. Geophysical Research Letters, 40(2), 279-284.

Greenwood, D.R., Moss, P.T., Rowett, A.I., Vadala, A.J. and Keefe, R.L. (2003). Plant communities and climate change in southeastern Australia during the early Paleogene. Geological Society of America, Special Papers, 369, 365-380.

Greenwood, D.R., Wilf, P., Wing, S.L. and Christophel, D.C. (2004). Paleotemperature estimation using leaf-margin analysis: is Australia different? Palaios, 19(2), 129142.

Haeckel, E. (1860). Uber neue, lebende Radiolarien des Mittelmeeres. Königlich Preussische Akademie der Wissenschaften, Berlin, Monatsbericht, 794-817.

Haeckel, E. (1862). Die Radiolarien (Rhizopoda Radiolaria). Eine Monographie, Tafel 1, Reimer, Berlin, 572pp.

Haeckel, E. (1879). Naturliche Schopfungsgeschichte, 7th ed., Reimer, Berlin, Germany, 718 pp.

Haeckel, E. (1881). Entwurf eines Radiolarien-Systems auf Grund von Studien der Challenger-Radiolarien. Jenaische Zeitschrift für Naturwissenschaft, 15, 418-472.

Haeckel, E. (1887). Report on the Radiolaria collected by H.M.S. Challenger during the years 1873-1876. Report on the Scientific Results of the Voyage of the H.M.S. Challenger, Zoology 18, 1803pp.

Hammer, Ø., Harper, D. and Ryan, P. (2001). Past: Paleontological Statistics Software Package for education and data analysis. Paleontología Electrónica 4, 1-9. URL:< http://palaeo-electronica. org/2001_1/past/issue1_01. html.

Harper, D.A.T. (1999). Numerical Palaeobiology: Computer-Based Modelling and Analysis of Fossils and their Distributions. John Wiley \& Sons, Chichester, England. 
Hay, W., DeConto, R., Wold, C., Wilson, K. and Voigt, S. (1999). Alternative global Cretaceous paleogeography. Geological Society of America, Special Papers, 332, 1-47. doi: 10.1130: 0-8137-2332-9.1.

Hays, J.D. (1965). Radiolaria and late Tertiary and Quaternary history of AntarcticSeas. In: Biology of Antarctic Seas II, American Geophysical Union, Antarctic Research Series 5, Llano, G.A., 125-184.

Heath, R. (1985). A review of the physical oceanography of the seas around New Zealand-1982. New Zealand Journal of Marine and Freshwater Research, 19(1), 79-124.

Hertwig, R. (1879). Der Organismus der Radiolarien (Vol. 2). Fischer.

Hill, D.J., Haywood, A.M., Valdes, P.J., Francis, J.E., Lunt, D.J., Wade, B.S. and Bowman, V.C. (2013). Paleogeographic controls on the onset of the Antarctic circumpolar current. Geophysical Research Letters, 40(19), 5199-5204.

Hill, P.J. and Exon, N.F. (2004). Tectonics and basin development of the offshore Tasmanian area incorporating results from deep ocean drilling. In: Exon, N.F., Kennett, J.P. and M. J. Malone, M.J. (Eds.), The Cenozoic Southern Ocean: Tectonics, Sedimentation, and Climate Change Between Australia and Antarctica, American Geophysical Union, Washington, D.C., Geophysical Monograph Series 151, doi: 10.1029/151GM0319-42.

Holdsworth, B.K. (1975). Cenozoic Radiolaria biostratigraphy: Leg 30: tropical and equatorial Pacific. In: Andrews, J.E., Packham, G., and et al. (Eds.), Initial Reports of the Deep Sea Drilling Project, Vol. 30, U.S. Government Printing Office, Washington, D.C., 499-537.

Hollis, C.J. (1991). Latest Cretaceous to Late Paleocene Radiolaria from Marlborough (New Zealand) and DSDP Site 208. The University of Auckland, ResearchSpace@Auckland.

Hollis, C.J. (1993). Latest Cretaceous to Late Paleocene radiolarian biostratigraphy: A new zonation from the New Zealand region. Marine Micropaleontology, 21, 295327.

Hollis, C.J. (1997). Cretaceous-Paleocene Radiolaria from eastern Marlborough, New Zealand. Institute of Geological and Nuclear Sciences, Monograph, 17, 1-152.

Hollis, C.J., Waghorn, D.B., Strong, C.P., and Crouch, E.M. (1997). Integrated Paleogene Biostratigraphy of DSDP Site 277 (Leg 29): Foraminifera, Calcareous Nannofossils, Radiolaria, and Palynomorphs. Institute of Geological and Nuclear Sciences, 73pp.

Hollis, C.J. (2002). Biostratigraphy and paleoceanographic significance of Paleocene radiolarians from offshore eastern New Zealand. Marine Micropaleontology, 46(3), 265-316.

Hollis, C.J. and Neil, H. (2005). Sedimentary record of radiolarian biogeography, offshore eastern New Zealand. New Zealand Journal of Marine and Freshwater Research, 39(1), 165-192.

Hollis, C.J., Dickens, G.R., Field, B.D., Jones, C.M., and Strong, C.P. (2005). The Paleocene-Eocene transition at Mead Stream, New Zealand: a southern Pacific record of early Cenozoic global change. Palaeogeography, Palaeoclimatology, Palaeoecology, 215(3), 313-343.

Hollis, C.J. (2006). Radiolarian faunal turnover through the Paleocene-eocene transition, Mead Stream, New Zealand. Eclogae Geologicae Helvetiae, 99, S79-S99.

Hollis, C.J., Handley, L., Crouch, E.M., Morgans, H.E., Baker, J.A., Creech, J., Collins, K.S., Gibbs, S.J., Huber, M. and Schouten, S. (2009). Tropical sea temperatures in the high-latitude South Pacific during the Eocene. Geology, 37(2), 99-102. 
Hollis, C.J., Taylor, K.W.R., Handley, L., Pancost, R.D., Huber, M., Creech, J.B., Hines, B.R., Crouch, E.M., Morgans, H.E.G., Crampton, J.S., Gibbs, S., Pearson, P.N. and Zachos, J.C. (2012). Early Paleogene temperature history of the Southwest Pacific Ocean: Reconciling proxies and models. Earth and Planetary Science Letters, 349, 53-66, doi: DOI 10.1016/j.eps1.2012.06.024.

Hollis, C.J., Tayler, M.J., Andrew, B., Taylor, K.W., Lurcock, P., Bijl, P.K., Kulhanek, D.K., Crouch, E.M., Nelson, C.S. and Pancost, R.D. (2014). Organic-rich sedimentation in the South Pacific Ocean associated with Late Paleocene climatic cooling. Earth-Science Reviews, 134, 81-97.

Hollis, C.J., Hines, B.R., Littler, K., Villasante-Marcos, V., Kulhanek, D.K., Strong, C.P., Zachos, J.C., Eggins, S.M., Northcote, L. and Phillips, A. (2015). The PaleoceneEocene Thermal Maximum at DSDP Site 277, Campbell Plateau, southern Pacific Ocean. Climate of the Past, 11(7), 1009-1025, doi: 10.5194/cp-11-1009-2015.

Hollis, C.J., Pascher, K.M., Shepherd, C.L., Hines, B., Morgans, H.E.G., Strong, C.P., Naafs, D. and Pancost, R.D. (2016). The tolerable warmness of the Eocene hyperthermal ocean. 12th International Conference on Paleoceanography (ICP12), Utrecht, The Netherlands.

Hornibrook, N.d.B. (1992). New Zealand Cenozoic marine paleoclimates: a review based on the distribution of some shallow water and terrestrial biota. Pacific Neogene: environment, evolution, and events. University of Tokyo Press, Tokyo, 83-106.

Houben, A.J., Bijl, P.K., Pross, J., Bohaty, S.M., Passchier, S., Stickley, C.E., Röhl, U., Sugisaki, S., Tauxe, L. and van de Flierdt, T. (2013). Reorganization of Southern Ocean Plankton Ecosystem at the Onset of Antarctic Glaciation. Science, 340(6130), 341-344.

Huber, M. and Sloan, L.C. (2001). Heat transport, deep waters, and thermal gradients: Coupled simulation of an Eocene greenhouse climate. Geophysical Research Letters, 28(18), 3481-3484.

Huber, M., Brinkhuis, H., Stickley, C.E., Döös, K., Sluijs, A., Warnaar, J., Schellenberg, S.A., and Williams, G.L. (2004). Eocene circulation of the Southern Ocean: Was Antarctica kept warm by subtropical waters? Paleoceanography, 19, PA4026. doi: doi:10.1029/2004PA001014.

Huber, M. and Caballero, R. (2011). The early Eocene equable climate problem revisited. Climate of the Past, 7(2), 603-633.

Hull, D.M. (1996). Paleoceanography and biostratigraphy of Paleogene radiolarians from the Norwegian-Greenland Sea. In: Thiede, J., Myhre, A.M., Finh, J.V., Johnson, G.L. and Ruddiman, W.F. (Eds.), Proceedings of the Ocean Drilling Program, Scientific Results, Vol. 151, College Station, TX (Ocean Drilling Program), 125152.

Intergovernmental Panel on Climate Change (2014). Climate Change 2014: Synthesis Report. Contribution of Working Groups I, II and III to the Fifth Assessment Report of the Intergovernmental Panel on Climate Change [Core Writing Team, Pachauri, R.K. and Meyer, L.A. (Eds.)]. IPCC, Geneva, Switzerland, pp. 151.

Ivany, L.C., Lohmann, K.C., Hasiuk, F., Blake, D.B., Glass, A., Aronson, R.B. and Moody, R.M. (2008). Eocene climate record of a high southern latitude continental shelf: Seymour Island, Antarctica. Geological Society of America Bulletin, 120(5-6), 659-678.

Jenkins, D.G. (1971). New Zealand Cenozoic Planktonic Foraminifera. New Zealand Gelological Survey, Paleontological Bulletin 42.

Jenkins, D.G. (1975). Cenozoic planktic foraminiferal biostratigraphy of the southwestern Pacific and Tasman Sea - DSDP Leg 29. In: Kennett, J.P., Houtz, R.E. et al. 
(Eds.), Initial Reports of the Deep Sea Drilling Project, Vol. 29, U.S. Government Printing Office, Washington, D.C., 449-467.

Jenkins, D.G. (1993). The evolution of the Cenozoic southern high-and mid-latitude planktonic foraminiferal faunas. In: Kennett, J.P. and Warkne, D.A. (Eds.), The Antarctic Paleoenvironment: A Perspective on Global Change: Part Two, American Geophysical Union, Washington, D.C., 175-194, doi: 10.1002/9781118668061.ch9.

Johnson, D.A. (1974). Radiolaria from the eastern Indian Ocean, DSDP Leg 22. In: Von der Borch, C.C., Sclater, J.G., et al. (Eds.), Initial Reports of the Deep Sea Drilling Project, Vol. 22, U.S. Government Printing Office, Washington, D.C., 521-575.

Johnson, D.A. (1978). Cenozoic Radiolaria from the eastern tropical Atlantic, DSDP Leg 41. In: Lancelot, Y., Seibold, E., et al. (Eds.), Initial Reports of the Deep Sea Drilling Project, Vol. 41, U.S. Government Printing Office, Washington, D.C., 763-789.

Johnson, D.A. (1990). Radiolarian biostratigraphy in the central Indian Ocean, Leg 115. In: Duncan, R.A., Backman, J., Peterson, L.C., et al. (Eds.), Proceedings of the Ocean Drilling Program, Scientific Results, Vol. 115, College Station, TX (Ocean Drilling Program), 395-409.

Kamikuri, S.-i., Nishi, H., Moore, T.C., Nigrini, C.A. and Motoyama, I. (2005). Radiolarian faunal turnover across the Oligocene/Miocene boundary in the equatorial Pacific Ocean. Marine Micropaleontology, 57(3-4), 74-96.

Kamikuri, S.-i., Nishi, H., Moore, T.C., Nigrini, C.A., and Motoyama, I. (2006). Data report: Late Oligocene and early Miocene radiolarians, Sites 1218 and 1219, Central Pacific. In: Wilson, P.A., Lyle, M., and Firth, J.V. (Eds.), Proceedings of the Ocean Drilling Program, Scientific Results, Vol. 199, College Station, TX (Ocean Drilling Program), 1-13.

Kamikuri, S.-i., Moore, T.C., Ogane, K., Suzuki, N., Pälike, H. and Nishi, H. (2012a). Early Eocene to early Miocene radiolarian biostratigraphy for the low-latitude Pacific Ocean. Stratigraphy, 9(1), 77-108.

Kamikuri, S.-i., Moore, T.C., Ogane, K., Suzuki, N., Pälike, H., and Nishi, H. (2012b). Data report: early to middle Eocene radiolarian biostratigraphy, IODP Expedition 320 Site U1331, eastern equatorial Pacific. Proceedings of the Integrated Ocean Drilling Program, Scientific Results, Vol. 320, 1-11, doi:10.2204/ iodp.proc.320321.320202.322012.

Kamikuri, S.-i., Moore, T.C., Lyle, M., Ogane, K. and Suzuki, N. (2013). Early and Middle Eocene radiolarian assemblages in the eastern equatorial Pacific Ocean (IODP Leg 320 Site U1331): Faunal changes and implications for paleoceanography. Marine Micropaleontology, 98, 1-13. doi: doi:10.1016/ j.marmicro.2012.09.004.

Kamikuri, S.-i. (2015). Radiolarian assemblages during the middle-late Eocene transition at Site 1052, ODP Leg 171B, Blake Nose, western North Atlantic Ocean. News of Osaka Micropaleontologists (NOM), Special Volume, No. 15, 139-167.

Keating-Bitonti, C.R., Ivany, L.C., Affek, H.P., Douglas, P. and Samson, S.D. (2011). Warm, not super-hot, temperatures in the early Eocene subtropics. Geology, 39(8), 771-774.

Keigwin, L. (1980). Palaeoceanographic change in the Pacific at the Eocene-Oligocene boundary. Nature, 287(5784), 722-725.

Kennett, J., Burns, R., Andrews, J., Churkin, M., Davies, T., Dumitrica, P., Edwards, A., Galehouse, J., Packham, G. and Van der Lingen, G. (1972). Australian-Antarctic 
continental drift, palaeocirculation changes and Oligocene deep-sea erosion. Nature Physical Science, 239, 51-55.

Kennett, J.P., Houtz, R.E., Andrews, P.B., Edwards, A.R., Gostin, V.A., Hajós, M., Hampton, M., Jenkins, D.G., Margolis, S., Ovenshine, T. and Perch-Nielsen, K. (1975). Initial Reports of the Deep Sea Drilling Project, Vol. 29, U.S. Government Printing Office, Washington, D.C.

Kennett, J.P. (1977). Cenozoic evolution of Antarctic glaciation, the circum-Antarctic Ocean, and their impact on global paleoceanography. Journal of Geophysical Research, 82(27), 3843-3860.

Kennett, J.P. (1978). The development of planktonic biogeography in the Southern Ocean during the Cenozoic. Marine Micropaleontology, 3(4), 301-345.

Kennett, J.P. (1980). Paleoceanographic and biogeographic evolution of the Southern Ocean during the Cenozoic, and Cenozoic microfossil datums. Palaeogeography, Palaeoclimatology, Palaeoecology, 31, 123-152.

Kennett, J.P. and Von der Borch, C. (1985). Southwest Pacific Cenozoic paleoceanography. Initial Reports of the Deep Sea Drilling Project, Vol. 90, 14931517.

Kennett, J.P., Von der Borch, C.C., Baker, P.A., Barton, C.E., Boersma, A., Caulet, J.P., Dudley, J.W., Gardner, J., Jenkins, D.G., Lohmann, W.H., Martini, E., Merrill, R., Morin, R., Nelson, C.S., Robert, C., Srinivasan, M., Stein, R. and Takeuchi, A. (1985). Initial Reports of the Deep Sea Drilling Project, Vol. 90, U.S. Government Printing Office, Washington D.C.

Kennett, J.P. and Exon, N.F. (2004). Paleoceanographic evolution of the Tasmanian Seaway and its climatic implications. In: Exon, N.F., Kennett, J.P. and M. J. Malone, M.J. (Eds.), The Cenozoic Southern Ocean: Tectonics, Sedimentation, and Climate Change Between Australia and Antarctica, American Geophysical Union, Washington, D.C., Geophysical Monograph Series 151, 345-367.

Kent, D.V. and Irving, E. (2010). Influence of inclination error in sedimentary rocks on the Triassic and Jurassic apparent pole wander path for North America and implications for Cordilleran tectonics. Journal of Geophysical Research: Solid Earth, 115(B10), doi: 10.1029-2009JB007205.

Kim, J.-H., Van der Meer, J., Schouten, S., Helmke, P., Willmott, V., Sangiorgi, F., Koç, N., Hopmans, E.C. and Damsté, J.S.S. (2010). New indices and calibrations derived from the distribution of crenarchaeal isoprenoid tetraether lipids: Implications for past sea surface temperature reconstructions. Geochimica et Cosmochimica Acta, 74(16), 4639-4654.

Kling, S. A. (1973). Radiolaria from the eastern North Pacific, Deep Sea Drilling Project Leg 18. In: Kulm, L.D., Von Huene, R. et al. (Eds.), Initial Reports of the Deep Sea Drilling Project, Vol. 18, U.S. Government Printing Office, Washington, D.C., 617-671.

Kozdon, R., Kelly, D.C., Kita, N.T., Fournelle, J.H. and Valley, J.W. (2011). Planktonic foraminiferal oxygen isotope analysis by ion microprobe technique suggests warm tropical sea surface temperatures during the Early Paleogene. Paleoceanography, 26(3), PA3206, doi: 10.1029/2010PA002056.

Kozlova, G.E. and Gorbovetz, A.N. (1966). Radiolarians of the Upper Cretaceous and Upper Eocene deposits of the West Siberian Lowland. Proceedings of the All Union Petroleum Scientific Research Institute for Geological Survey (VNIGRI) 248, 1-159. 
Kozlova, G.E. (1999). Paleogene Boreal Radiolarians from the Russia. Ministry of Natural resources of Russian Federation, All-Russian Petroleum Research Exploration Institute (VNIGRI), 324pp.

Kruglikova, S.B. (1969). Radiolarians in the core of station 4066 (northern part of the Pacific Ocean). In: Jouse, A.P., Izdatelstvo (Eds.), Basic problems of Micropaleontology and the accumulation of organogenic sediments in oceans and seas, Akademiya Nauk SSSR, Okeanografitcheskaya Komissiya, Moscow, USSR, 115-126.

Kruglikova, S.B. (1977). Radiolaria. In: A.P. Jouse (Ed.), Atlas of Microorganisms in Bottom Sediments of the Oceans: diatoms, radiolaria, silicoflagellates and coccoliths. Academy of Sciences USSR, Moscow, Publishing house "Nauka", p. 7, 13-17 (pl. 86-145).

Kulhanek, D., Morgans, H., Bache, F., Collot, J., Rouillard, P. and Sutherland, R. (2013). Uplift of Lord Howe Rise during the Late Paleogene: Constraints from Micropaleontological Proxies. Paper presented at the AGU Fall Meeting Abstracts.

Kulhanek, D.K. and Morgans, H.E.G. (2013). Micropaleontological constraints on age and paleodepth across Paleogene unconformities on Lord Howe Rise and in New Caledonia Basin. GNS Science Consultancy Report 2013/201, 67 pp.

Lawver, L.A., Gahagan, L.M. and Coffin, M.F. (1992). The development of paleoseaways around Antarctica. In: Kennett, J.P. and Warkne, D.A. (Eds.), The Antarctic Paleoenvironment: A Perspective on Global Change: Part One, American Geophysical Union, Washington, D.C., 7-30, doi: 10.1029/AR056p0007.

Lawver, L.A. and Gahagan, L.M. (2003). Evolution of Cenozoic seaways in the circumAntarctic region. Palaeogeography, Palaeoclimatology, Palaeoecology, 198(1-2), 11-37, doi: http://dx.doi.org/10.1016/S0031-0182(03)00392-4.

Lazarus, D. and Pallant, A. (1989). Oligocene and Neogene radiolarians from the Labrador Sea, ODP Leg 105. In: Srivastava, S.P., Arthur, M., Clement, B. et al. (Eds.), Proceedings of the Ocean Drilling Program, Scientific Results, Vol. 105, College Station, TX (Ocean Drilling Program, 349-380.

Lazarus, D. (1992). Antarctic Neogene radiolarians from the Kerguelen Plateau, Legs 119 and 120. In: Wise, S.W., Jr., Schlich, R., et al. (Eds.), Proceedings of the Ocean Drilling Program, Scientific Results, Vol. 120, College Station, TX (Ocean Drilling Program), 785-809.

Lazarus, D. and Caulet, J.P. (1993). Cenozoic Southern Ocean reconstructions from sedimentologic, radiolarian, and other microfossil data. Antarctic Research Series, 60, 145-174.

Lazarus, D. (1994). Neptune: A marine micropaleontology database. Mathematical Geology, 26(7), 817-832, doi: 10.1007/BF02083119.

Lazarus, D., Faust, K. and Popova-Goll, I. (2005). New species of prunoid radiolarians from the Antarctic Neogene. Journal of Micropaleontology, 24(2), 97-121.

Lazarus, D., Hollis, C.J. and Apel, M. (2008). Patterns of opal and radiolarian change in the Antarctic mid-Paleogene: Clues to the origin of the Southern Ocean. Micropaleontology, 54(1), 41-48.

Lazarus, D., Suzuki, N., Caulet, J.P., Nigrini, C., Goll, I., Goll, R., Dolven, J.K., Diver, P. and Sanfilippo, A. (2015). An evaluated list of Cenozic-Recent radiolarian species names (Polycystinea), based on those used in the DSDP, ODP and IODP deep-sea drilling programs. Zootaxa, 3999(3), 301-333. 
Lea, D.W., Mashiotta, T.A. and Spero, H.J. (1999). Controls on magnesium and strontium uptake in planktonic foraminifera determined by live culturing. Geochimica et Cosmochimica Acta, 63(16), 2369-2379.

Lea, D.W. (2014). Elemental and Isotopic Proxies of Past Ocean Temperatures. In: Hollande, H.D. and Tureklan, K.K. (Eds.), Treatise on Geochemistry, Second Edition, Elsevier, Oxford, U.K., 373-397.

Lear, C.H., Elderfield, H. and Wilson, P. (2000). Cenozoic deep-sea temperatures and global ice volumes from $\mathrm{Mg} / \mathrm{Ca}$ in benthic foraminiferal calcite. Science, 287(5451), 269-272.

Lear, C.H., Rosenthal, Y. and Slowey, N. (2002). Benthic foraminiferal Mg/Capaleothermometry: A revised core-top calibration. Geochimica et Cosmochimica Acta, 66(19), 3375-3387.

Lear, C.H., Bailey, T.R., Pearson, P.N., Coxall, H.K. and Rosenthal, Y. (2008). Cooling and ice growth across the Eocene-Oligocene transition. Geology, 36(3), 251-254.

Lear, C.H., Mawbey, E.M. and Rosenthal, Y. (2010). Cenozoic benthic foraminiferal $\mathrm{Mg} / \mathrm{Ca}$ and $\mathrm{Li} / \mathrm{Ca}$ records: Toward unlocking temperatures and saturation states. Paleoceanography, 25(4), PA4215, doi:10.1029/2009PA001880.

Ling, H.Y. (1973). Radiolaria: Leg 19 of the Deep Sea Drilling Project. In: Creager, J.S., Scholl, D.W. et al. (Eds.), Initial Reports of the Deep Sea Drilling Project, Vol. 19, U.S. Government Printing Office, Washington, D.C., 777-797.

Ling, H.Y. (1975). Radiolaria: Leg 31 of the Deep Sea Drilling Project. In: Karig, D.E., Ingle, J.C.J. et al. (Eds.), Initial Reports of the Deep Sea Drilling Project, Vol. 31, U.S. Government Printing Office, Washington, D.C., 703-761.

Lipman, R.K. (1972). New Eocene Radiolaria from the Turgai trough and northern Aral region. In: New species of ancient plants and invertebrates in the USSR, Nauka, Moscow, USSR, 42-56.

Littler, K., Hollis, C.J. and Morgans, H.E.G. (2016). Pilot study of geochemical climate proxies from DSDP sites 206 and 208. GNS Science Internal Report 2016/02, 112.

Liu, Z., Pagani, M., Zinniker, D., DeConto, R., Huber, M., Brinkhuis, H., Shah, S.R., Leckie, R.M. and Pearson, A. (2009). Global cooling during the EoceneOligocene climate transition. Science, 323(5918), 1187-1190.

Loeblich, A.R., and Tappan, H. (1961). Remarks on the systematics of the Sarkodina (Protozoa), renamed homonyms and new validated genera. Proceedings of the Biological Society of Washington, 74, 213-234.

Lombari, G. and Lazarus, D. (1988). Neogene cycladophorid radiolarians from the North Atlantic, Antarctic, and North Pacific deep-sea sediments. Micropaleontology, 34, 97-135.

Mamedov, N.A. (1969). New representatives of Eocene radiolarians in Azerbaidzhan. In: Vyalov, O.S. (Ed.), Fossil and Recent Radiolarians: Materials of the Second All Union Seminar on Radiolaria, Izdatelstvo Lvovskogo Universiteta (Lvov University), Lvov, USSR, 94-101.

Martini, E. (1970). Standard Palaeogene calcareous nannoplankton zonation. Nature, 226, $560-561$.

Martini, E. (1971). Standard Tertiary and Quaternary calcareous nannoplankton zonation. In: Farinacci, A. (Ed.), Proceedings of the Second Planktonic Conference Roma 1970, Rome (Ed. Tecnosci.), 2, 739-785.

Mast, H. (1910). Die Astrosphaeriden. Wissenschaftliche Ergebnisse der Deutschen Tiefsee-Expedition auf dem Dampfer "Valdivia" 1898-1899, vol. 19 (4), 123-190. 
McKay, R., Barrett, P., Levy, R., Naish, T., Golledge, N. and Pyne, A. (2016). Antarctic Cenozoic climate history from sedimentary records: ANDRILL and beyond. Philosophical Transactions of the Royal Society A, 374(2059), 20140301.

Meehl, G.A., Stocker, T.F., Collins, W.D., Friedlingstein, P., Gaye, A.T., Gregory, J.M., Kitoh, A., Knutti, R., Murphy, J.M. and Noda, A. (2007). Global climate projections. Climate change, 3495, 747-845.

Meyen, F.J.F. (1834). Über das Leuchten des Meeres und Beschreibung einiger Polypen und anderer niederer Tiere. Beiträge zur Zoologie, gesammelt auf einer Reise um die Erde. Nova acta Academiae Caesareae Leopoldino Carolinae germanicae naturae curiosorum, 125-216.

Miller, K.G. and Katz, M.E. (1987). Oligocene to Miocene benthic foraminiferal and abyssal circulation changes in the North Atlantic. Micropaleontology, 33(2), 97149.

Miller, K.G., Wright, J.D. and Browning, J.V. (2005). Visions of ice sheets in a greenhouse world. Marine Geology, 217(3), 215-231.

Miller, K.G., Browning, J.V., Aubry, M.-P., Wade, B.S., Katz, M.E., Kulpecz, A.A. and Wright, J.D. (2008). Eocene-Oligocene global climate and sea-level changes: St. Stephens Quarry, Alabama. Geological Society of America Bulletin, 120(1-2), 3453.

Moore, T.C. (1972). Mid-Tertiary evolution of the radiolarian genus Calocycletta, Micropaleontology, 18, 144-152.

Moore, T.C., \& Kamikuri, S.-i. (2012). Data report: radiolarian stratigraphy across the Eocene/Oligocene boundary in the equatorial Pacific, Sites 1218, U1333, and U1334. In: Pälike, H., Lyle, M., Nishi, H., Raffi, I., Gamage, K., Klaus, A., and the Expedition 320/321 Scientists (Eds.), Proceedings of the Integrated Ocean Drilling Program, Scientific Results, Vol. 320/321, doi:10.2204/iodp.proc. 320321.204.2012.

Morgans, H. (2009). Late Paleocene to Middle Eocene foraminiferal biostratigraphy of the Hampden Beach section, eastern South Island, New Zealand. New Zealand Journal of Geology and Geophysics, 52(4), 273-320.

Müller, J. (1858). Über die Thalassicollen, Polycystinen und Acanthometren des Mittelmeeres. Abhandlungen der Königlich Preussischen Akademie der Wissenschaften zu Berlin, 1-62.

Müller, R.D., Royer, J.-Y. and Lawver, L.A. (1993). Revised plate motions relative to the hotspots from combined Atlantic and Indian Ocean hotspot tracks. Geology, 21(3), 275-278.

Murphy, M. and Kennett, J. (1986). Development of latitudinal thermal-gradients during the Oligocene - oxygen isotope evidence from the Southwest Pacific. Initial Reports of the Deep Sea Drilling Project, Vol. 90, 1347-1360, doi: doi:10.2973/dsdp.proc.90.140.1986.

Nakaseko, K. (1963). Neogene Cyrtoidea (Radiolaria) from the Isozaki Formation in Ibaraki Prefecture, Japan. Science Reports, College of General Education Osaka University, 12, 165-198.

Nelson, C.S. and Cooke, P.J. (2001). History of oceanic front development in the New Zealand sector of the Southern Ocean during the Cenozoic-a synthesis. New. Zealand Journal of Geology and Geophysics, 44(4), 535-553.

Nigrini, C. (1967). Radiolaria in pelagic sediments from the Indian and Atlantic Oceans. Bulletin of the Scripps Institution of Oceanography, University of California, San Diego, La Jolla, California, 11, 1-125. 
Nigrini, C. (1968). Radiolaria from eastern tropical Pacific sediments. Micropaleontology, 14, 51-63.

Nigrini, C. (1971). Radiolarian zones in the Quaternary of the equatorial Pacific Ocean. In: Funnell, B.M. and Riedel, W.R. (Eds.), The Micropalaeontology of Oceans, Cambridge University Press, Cambridge, UK, 443-461.

Nigrini, C. (1974). Cenozoic Radiolaria from the Arabian Sea, DSDP Leg 23. In: Davies, T.A., Luyendyk, B.P. et al. (Eds.), Initial Reports of the Deep Sea Drilling Project, Vol. 23, U.S. Government Printing Office, Washington, D.C., 1051-1121.

Nigrini, C. (1977). Tropical Cenozoic Artostrobiidae (Radiolaria). Micropaleontology, 23(3), 241-269.

Nigrini, C. and Moore, T.C. (1979). A guide to modern Radiolaria. Cushman Foundation for foraminiferal Research, Special Publication, $257 \mathrm{pp}$.

Nigrini, C. A. (1985). Radiolarian biostratigraphy in the central Equatorial Pacific, Deep Sea Drilling Project Leg 85. In: Mayer, L.A., Theyer, F., Thomas, E. et al. (Eds.), Initial Reports of the Deep Sea Drilling Project, Vol. 85, U.S. Government Printing Office, Washington, D.C., 511-551.

Nigrini, C. and Caulet, J.P. (1988). The genus Anthocyrtidium (Radiolaria) from the tropical late Neogene of the Indian and Pacific Oceans. Micropaleontology, 34(4), 341-360.

Nigrini, C. and Sanfilippo, A. (2000). Paleogene radiolarians from Sites 998, 999, and 1001 in the Caribbean. In: Leckie, R.M., Sigurdsson, H., Acton, G.D., and Draper, G. (Eds.), Proceedings of the Ocean Drilling Program, Scientific Results, Vol. 165, College Station, TX (Ocean Drilling Program), 57-81.

Nigrini, C., Sanfilippo, A., and Moore Jr., T.J. (2006). Cenozoic radiolarian biostratigraphy: a magnetobiostratigraphic chronology of Cenozoic sequences from ODP Sites 1218, 1219, and 1220, equatorial Pacific. In: Wilson, P.A., Lyle, M. and Firth, J.V. (Eds.), Proceedings of the Ocean Drilling Program, Scientific Results, Vol. 199, 1-76.

Nishimura, A. (1987). Cenozoic Radiolaria in the western North Atlantic, Site 603, Leg 93 of the Deep Sea Drilling Project. In: Van Hinte, J.E., Wise, S.W.J. et al. (Eds.), Initial Reports of the Deep Sea Drilling Project, Vol. 93, U.S. Government Printing Office, Washington, D.C., 713-737.

Nishimura, A. (1992). Paleocene radiolarian biostratigraphy in the northwest Atlantic at Site 384, Leg 43, of the Deep Sea Drilling Project. Micropaleontology, 38(4), 317-362.

Norris, R., Wilson, P., Liebrand, D. and Whiteside, J. (2012). Integrated Ocean Drilling Program Expedition 342 Preliminary Report. Paleogene Newfoundland Sediment Drifts, 1 June-30 July 2012, College Station, TX, USA, International Ocean Drilling Program Management International, Inc, 263pp, doi:10.2204/ iodp.pr.342.2012

Nürnberg, D. (1995). Magnesium in tests of Neogloboquadrina pachyderma sinistral from high northern and southern latitudes. Journal of Foraminiferal Research, 25, 350368.

Nürnberg, D., Bijma, J. and Hemleben, C. (1996). Assessing the reliability of magnesium in foraminiferal calcite as a proxy for water mass temperatures. Geochimica et Cosmochimica Acta, 60(5), 803-814.

O'Connor, B.M. (1993). Radiolarian from the Mahurangi Limestone, Northland, New Zealand. University of Auckland, Auckland, $136 \mathrm{pp}$.

O'Connor, B.M. (1994). Seven new radiolarian species from the Oligocene of NewZealand. Micropaleontology, 40(4), 337-350. 
O'Connor, B.M. (1997). New Radiolaria from the Oligocene and Early Miocene of Northland, New Zealand. Micropaleontology, 43(1), 63-100.

O'Connor, B.M. (1999a). Radiolaria from the Late Eocene Oamaru Diatomite, South Island, New Zealand. Micropaleontology, 45(1), 1-55.

O'Connor, B.M. (1999b). Distribution and biostratigraphy of latest Eocene to latest Oligocene Radiolaria from the Mahurangi Limestone, Northland, New Zealand. New Zealand Journal of Geology and Geophysics, 42(4), 489-511.

O'Connor, B.M. (2000). Stratigraphic and geographic distribution of Eocene Miocene Radiolaria from the southwest Pacific. Micropaleontology, 46(3), 189-228.

Ogane, K., Suzuki, N., Aita, Y., Sakai, T. and Lazarus, D. (2009). Ehrenberg's Radiolarian Collections from Barbados. In: Tanimura, Y. and Aita, Y. (Eds.), Joint Haeckel and Ehrenberg Project: Reexamination of the Haeckel and Ehrenberg Microfossil Collections as a Historical and Scientific Legacy, National Museum of Nature and Science Monographs, 97-106.

Okada, H. and Bukry, D. (1980). Supplementary modification and introduction of code numbers to the low-latitude coccolith biostratigraphic zonation (Bukry, 1973; 1975). Marine Micropaleontology, 5, 321-325.

O'Neill, C., Müller, D. and Steinberger, B. (2005). On the uncertainties in hot spot reconstructions and the significance of moving hot spot reference frames. Geochemistry, Geophysics, Geosystems, 6(4). doi: 10.1029-2004GC000784.

Orsi, A.H., Whitworth, T. and Nowlin, W.D. (1995). On the meridional extent and fronts of the Antarctic Circumpolar Current. Deep Sea Research Part I: Oceanographic Research Papers, 42(5), 641-673.

Orsi, A.H. and Harris, U. (2001). Locations of the various fronts in the Southern Ocean, Australian Antarctic Data Centre-CAASM Metadata.

Orsi, A.H. and Whitworth, T. (2005). Hydrographic Atlas of the World Ocean Circulation Experiment (WOCE): Volume 1: Southern Ocean, WOCE International Project Office.

Palmer, A.A. (1987). Cenozoic radiolarians from Deep Sea Drilling Project sites 612 and 613 (Leg 95, New Jersey Transect) and Atlantic Slope Project Site ASP 15. In: Poag, C.W., Watts, A.B., Cousin, M. et al. (Eds.), Initial Reports of the Deep Sea Drilling Project, Vol. 95, U.S. Government Printing Office, Washington, D.C., 339-357.

Pancost, R.D., Taylor, K.W., Inglis, G.N., Kennedy, E.M., Handley, L., Hollis, C.J., Crouch, E.M., Pross, J., Huber, M. and Schouten, S. (2013). Early Paleogene evolution of terrestrial climate in the SW Pacific, Southern New Zealand. Geochemistry, Geophysics, Geosystems, 14(12), 5413-5429.

Shipboard Scientific Party (2001). Site 1172. Proceedings of the Ocean Drilling Program, Initial Reports, Vol. 189, 1-149, doi:10.2973/odp.proc.ir.189.107.2001

Pascher, K.M., Hollis, C.J., Bohaty, S.M., Cortese, G., McKay, R.M., Seebeck, H., Suzuki, N. and Chiba, K. (2015). Expansion and diversification of high-latitude radiolarian assemblages in the late Eocene linked to a cooling event in the southwest Pacific. Climate of the Past, 11(12), 1599-1620.

Pearson, P.N., Ditchfield, P.W., Singano, J., Harcourt-Brown, K.G., Nicholas, C.J., Olsson, R.K., Shackleton, N.J. and Hall, M.A. (2001). Warm tropical sea surface temperatures in the Late Cretaceous and Eocene epochs. Nature, 413(6855), 481487.

Pearson, P.N., van Dongen, B.E., Nicholas, C.J., Pancost, R.D., Schouten, S., Singano, J.M. and Wade, B.S. (2007). Stable warm tropical climate through the Eocene Epoch. Geology, 35(3), 211-214, doi: 10.1130/G23175A.1. 
Pearson, P.N., Foster, G.L. and Wade, B.S. (2009). Atmospheric carbon dioxide through the Eocene-Oligocene climate transition. Nature, 461(7267), 1110-1113.

Petrushevskaya, M.G. (1967). Radiolarians of orders Spumellaria and Nassellaria of the Antarctic region (from material of the Soviet Antarctic Expedition). In: Andriyashev, A.P. and Ushakov, P.V. (Eds.), Biological Reports of the Antarctic Expeditions (1955-1958), Academy of Science of the USSR, Zoological Institute, 5-186.

Petrushevskaya, M.G. (1971a). On the natural system of polycystine Radiolaria (Class Sarcodina). In: Farinacci, A (Ed.), Proceedings of the II Planktonic Conference, Roma 1970, Edizioni Tecnoscienza, Roma, Italy, 981-992.

Petrushevskaya, M.G. (1971b). Nassellarian radiolarians in the plankton of the World Ocean. In: Bykhovskij, B.E. (Ed.), Explorations of the Fauna of the Seas IX: Radiolarians of the World Ocean, Academy of Sciences of the USSR, Institute of Zoology, 294pp.

Petrushevskaya, M.G. and Kozlova, G.E. (1972). Radiolaria: Leg 14, Deep Sea Drilling Project. In: Hayes, D.E., Pimm, A.C. et al. (Eds.), Initial Reports of the Deep Sea Drilling Project, Vol. 14, U.S. Government Printing Office, Washington, D.C., 495-648.

Petrushevskaya, M.G. (1975). Cenozoic radiolarians of the Antarctic, Leg 29, DSDP. In: Kennett, J.P., Houtz, R.E. et al. (Eds.), Initial Reports of the Deep Sea Drilling Project, Vol. 29, U.S. Government Printing Office, Washington, D.C., 541-675.

Petrushevskaya, M.G. (1977). New species of the radiolarians of the order Nassellaria. In: Exploration of the Fauna of the Seas XXI: New Species and Genera of Marine Invertebrates, Academy of Sciences of the USSR, Institute of Zoology, 10-19.

Petrushevskaya, M.G. and Kozlova, G.E. (1979). Description of the radiolarian genera and species. In: Sterlkov, A.A., and Petrushevskaya, M.G. (Eds.), The history of the microplankton of the Norwegian Sea (on the Deep Sea Drilling materials), Academy of Sciences of the USSR, Institute of Zoology, 86-157.

Petrushevskaya, M.G. (1981). Nassellarian radiolarians from the World Oceans. In: Publications of the Zoological Institute, Academy of Sciences of the USSR, Description of the Fauna of the USSR, Nauka, Leningradskoe Otdelenie, Leningrad, USSR, 405pp.

Pisias, N.G., and Moore, T.C. (1978). Cenozoic Radiolaria from Deep Sea Drilling Project, Leg 40. In: Bolli, H.M., Ryan, W.B.F. et al. (Eds.), Initial Reports of the Deep Sea Drilling Project, Vol. 40, U.S. Government Printing Office, Washington, D.C., 845-856.

Popofsky, A. (1912). Die Sphaerellarien des Warmwassergebietes. In: Von Drygalski, E. (Ed.), Deutsche Südpolar-Expedition, 1901-1903, Band XIII, Berlin, Germany, 75-159.

Popova, I.M., Baumgartner, P.O., Guex, J., Tochilina, S.V. and Glezer, Z.I. (2002). Radiolarian biostratigraphy of Paleogene deposits of the Russian Platform (Voronesh Anticline), Geodiversitas, 24(1), 7-59.

Principi, P. (1909). Contributo allo studio dei Radiolari Miocenici Italiani, Bollettino della Società Geologica Italiana, 28, 1-22.

Pross, J., Contreras, L., Bijl, P.K., Greenwood, D.R., Bohaty, S.M., Schouten, S., Bendle, J.A., Röhl, U., Tauxe, L. and Raine, J.I. (2012). Persistent near-tropical warmth on the Antarctic continent during the early Eocene epoch. Nature, 488(7409), 73-77.

Raine, J.I., Beu, A.G., Boyes, A.F., Campbell, H.J., Cooper, R.A., Crampton, J.S., Crundwell, M.P., Hollis, C.J. and Morgans, H.E.G. (2015). Revised calibration of 
the New Zealand Geological Timescale: NZGT2015/1. GNS Science, Lower Hutt, N.Z., GNS Science report 2012/39, 53 p.

Renaudie, J. (2016). Quantifying the Cenozoic marine diatom deposition history: links to the C and Si cycles. Biogeosciences, 13, 6003-6014, doi:10.5194/bg-13-60032016.

Reynolds, R. (1980). Radiolarians from the western north Pacific, Leg 57, Deep Sea Drilling Project. In: Lee, M., Stout, L.-N., Langseth, M., Okada, H. et al. (Eds.), Initial Reports of the Deep Sea Drilling Project, Vol. 57, U.S. Government Printing Office, Washington, D.C., 735-769.

Riedel, W.R. and Campbell, A.S. (1952). A new Eocene radiolarian genus. Journal of Paleontology, 26(4), 667-669.

Riedel, W.R. (1958). Radiolaria in Antarctic sediments. Reports of the B.A.N.Z. Antarctic Research Expedition, Series B, 6, 217-255.

Riedel, W.R. (1959). Oligocene and Lower Miocene Radiolaria in tropical Pacific sediments. Micropaleontology, 5, 285-302.

Riedel, W.R. (1967a). Protozoa (Subclass Radiolaria). In: Harland, W.B., Holland, C.H., House, M.R. et al. (Eds.), The Fossil Record, A symposium with documentation, Geological Society of London, London, 291-298.

Riedel, W.R. (1967b). Some new families of Radiolaria, Proceedings of the Geological Society of London, 1640, 148-149.

Riedel, W.R. and Sanfilippo, A. (1970). Radiolaria, Leg 4, Deep Sea Drilling Project. In: Bader, R.G. et al. (Eds.), Initial Reports of the Deep Sea Drilling Project, Vol. 4, U.S. Government Printing Office, Washington, D.C., 503-575.

Riedel, W.R. and Sanfilippo, A. (1971). Cenozoic Radiolaria from the western tropical Pacific, Leg 7. In: Winterer, E.L., Riedel, W.R. et al. (Eds.), Initial Reports of the Deep Sea Drilling Project, Vol. 7, U.S. Government Printing Office, Washington, D.C., 1529-1672.

Riedel, W.R. and Sanfilippo, A. (1973). Cenozoic Radiolaria from the Caribbean, Deep Sea Drilling Project, Leg 15. In: Edgar, N.T., Saunders, J.B. et al. (Eds.), Initial Reports of the Deep Sea Drilling Project, Vol. 15, U.S. Government Printing Office, Washington, D.C., 705-751.

Riedel, W.R. and Sanfilippo, A. (1977). Cainozoic Radiolaria. In: Ramsay, A.T.S. (Ed.), Oceanic Micropalaeontology, Academic Press, London/New York/San Francisco, 847-912.

Riedel, W.R. and Sanfilippo, A. (1978). Stratigraphy and evolution of tropical Cenozoic radiolarians. Micropaleontology, 24(1), 61-96.

Riedel, W.R. and Sanfilippo, A. (1986). Morphological characters for a natural classification of Cenozoic Radiolaria, reflecting phylogenies. Marine Micropaleontology, 11, 151-170.

Röhl, U., Brinkhuis, H., Stickley, C.E., Fuller, M., Schellenberg, S.A., Wefer, G. and Williams, G.L. (2004). Sea level and astronomically induced environmental changes in middle and late Eocene sediments from the East Tasman Plateau. In: Exon, N.F., Kennett, J.P. and Malone, M.J. (Eds.), The Cenozoic Southern Ocean: tectonics, sedimentation, and climate change between Australia and Antarctica, American Geophysical Union, Geophysical Monograph, 151, 127-151.

Rosenthal, Y., Boyle, E.A. and Slowey, N. (1997). Temperature control on the incorporation of magnesium, strontium, fluorine, and cadmium into benthic foraminiferal shells from Little Bahama Bank: Prospects for thermocline paleoceanography. Geochimica et Cosmochimica Acta, 61(17), 3633-3643. 
Rosenthal, Y., Lear, C.H., Oppo, D.W. and Linsley, B.K. (2006). Temperature and carbonate ion effects on $\mathrm{Mg} / \mathrm{Ca}$ and $\mathrm{Sr} / \mathrm{Ca}$ ratios in benthic foraminifera: Aragonitic species Hoeglundina elegans. Paleoceanography, 21(1), PA1007, doi:10.1029/2005PA001158.

Sanfilippo, A. and Riedel, W.R. (1973). Cenozoic Radiolaria (exclusive of theoperids, artostrobiids and amphipyndacids) from the Gulf of Mexico, DSDP Leg 10. In: Worzel, J.L., Bryant, W. et al. (Eds.), Initial Reports of the Deep Sea Drilling Project, Vol. 10, U.S. Government Printing Office, Washington, D.C., 475-611.

Sanfilippo, A. and Riedel, W.R. (1974). Radiolaria from the west-central Indian Ocean and Gulf of Aden, DSDP Leg 24. In: Fisher, R.L., Bunce, E.T. et al. (Eds.), Initial Reports of the Deep Sea Drilling Project, Vol. 24, U.S. Government Printing Office, Washington, D.C., 997-1035.

Sanfilippo, A., Westberg-Smith, M.J. and Riedel, W.R. (1985). Cenozoic radiolaria. In: Bolli, H.M., Saunders, J.B. and Perch-Nielsen, K. (Eds.), Plankton stratigraphy: Volume 2, Radiolaria, Diatoms, Silicoflagellates, Dinoflagellates and Ichthyoliths, Cambridge University Press, 631-712.

Sanfilippo, A. (1990). Origin of the subgenra Cyclampterium, Paralampterium and Sciadiopeplus from Lophocyrtis (Lophocyrtis) (Radiolaria, Theoperidae). Marine Micropaleontology, 15(3-4), 287-312.

Sanfilippo, A. and Riedel, W.R. (1992). The origin and evolution of Pterocorythidae (Radiolaria): A Cenozoic phylogenetic study. Micropaleontology, 38(1), 1-36.

Sanfilippo, A. and Caulet, J.P. (1998). Taxonomy and evolution of Paleogene Antartic and Tropical Lophocyrtid radiolarians. Micropaleontology, 44(1), 1-43.

Sanfilippo, A. and Nigrini, C. (1998a). Code numbers for Cenozoic low latitude radiolarian biostratigraphic zones and GPTS conversion tables. Marine Micropaleontology, 33(1), 109-156.

Sanfilippo, A. and Nigrini, C. (1998b). Upper Paleocene-lower Eocene deep-sea radiolarian stratigraphy and the Paleocene/Eocene series boundary. In: Aubry, M.P., Lucas, S.G. and Berggren, W.A. (Eds.), Late Paleocene-early Eocene, Climatic and biotic events in the marine and terrestrial records, Columbia University Press, New York, 244-276.

Sanfilippo, A. and Blome, C.D. (2001). Biostratigraphic implications of mid-latitude Palaeocene-Eocene radiolarian faunas from Hole 1051A, Ocean Drilling Program Leg 171B, Blake Nose, western North Atlantic. In: Kroon, D., Norris, R.D. and Klaus, A. (Eds.), Western North Atlantic Palaeogene and Cretaceous Palaeoceanography, Special Publications of the Geological Society of London, 185-224.

Sanfilippo, A. and Fourtanier, E. (2003). Oligocene radiolarians, diatoms, and ebridians from the Great Australian Bight (ODP Leg 182, Site 1128). In: Hine, A.C., Feary, D.A. and Malone, M.J. (Eds.), Proceedings of the Ocean Drilling Program, Scientific Results, Vol. 182, College Station, TX (Ocean Drilling Program), 1-24.

Scher, H.D., Bohaty, S.M., Smith, B.W. and Munn, G.H. (2014). Isotopic interrogation of a suspected late Eocene glaciation. Paleoceanography, 29(6), 2014PA002648, doi: 10.1002/2014PA002648.

Scher, H.D., Whittaker, J.M., Williams, S.E., Latimer, J.C., Kordesch, W.E. and Delaney, M.L. (2015). Onset of Antarctic Circumpolar Current 30 million years ago as Tasmanian Gateway aligned with westerlies. Nature, 523(7562), 580-583.

Schmitz, W.J. (1995). On the interbasin-scale thermohaline circulation. Reviews of Geophysics, 33(2), 151-173. 
Schouten, S., Hopmans, E.C., Schefuß, E. and Damste, J.S.S. (2002). Distributional variations in marine crenarchaeotal membrane lipids: a new tool for reconstructing ancient sea water temperatures? Earth and Planetary Science Letters, 204(1), 265274.

Schrag, D.P. (1999). Effects of diagenesis on the isotopic record of late paleogene tropical sea surface temperatures. Chemical Geology, 161(1-3), 215-224, doi: http://dx.doi.org/10.1016/S0009-2541(99)00088-1.

Scotese, C.R. (2001). Atlas of earth history. University of Texas at Arlington, Department of Geology, PALEOMAP Project.

Segev, E. and Erez, J. (2006). Effect of $\mathrm{Mg} / \mathrm{Ca}$ ratio in seawater on shell composition in shallow benthic foraminifera. Geochemistry, Geophysics, Geosystems, 7(2), doi:10.1029/2005GC000969.

Seton, M., Müller, R., Zahirovic, S., Gaina, C., Torsvik, T., Shephard, G., Talsma, A., Gurnis, M., Turner, M. and Maus, S. (2012). Global continental and ocean basin reconstructions since 200Ma. Earth-Science Reviews, 113(3), 212-270.

Sexton, P.F., Wilson, P.A. and Norris, R.D. (2006). Testing the Cenozoic multisite composite delta(18)O and delta(13)C curves: New monospecific Eocene records from a single locality, Demerara Rise (Ocean Drilling Program Leg 207). Paleoceanography, 21(2), PA2019, doi: 10.1029/2005pa001253.

Shackleton, N. and Kennett, J. (1975). Paleotemperature history of the Cenozoic and the initiation of Antarctic glaciation: oxygen and carbon isotope analyses in DSDP Sites 277, 279, and 281. In: Kennett, J.P., Houtz, R. E. et al. (Eds.), Initial reports of the Deep Sea Drilling Project, Vol. 29, Government Printing Office, Washington, D.C., 743-755.

Shea, D.J., Trenberth, K.E. and Reynolds, R.W. (1992). A global monthly sea surface temperature climatology. Journal of Climate, 5(9), 987-1001.

Shilov, V.V. (1995). Eocene-Oligocene Radiolarians from Leg 145, North Pacific. In: Rea, D.K., Basov, I.A., Scholl, D.W., and Allan, J.F. (Eds.), Proceedings of the Ocean Drilling Program, Scientific Results, Vol. 145, College Station, TX (Ocean Drilling Program), 117-132.

Shipboard Scientific Party (1998). Site 1052. In: Norris, R.D., Kroon, D., Klaus, A. et al. (Eds.), Proceedings of the Ocean Drilling Program, Initial Reports, Vol. 171B, College Station, TX (Ocean Drilling Program), 241-319. doi:10.2973/ odp.proc.ir.171b.106.1998.

Shipboard Scientific Party (1999). Site 1123: North Chatham Drift-a 20-Ma Record of the Pacific Deep Western Boundary Current. In: Carter, R.M., McCave, I.N., Richter, C., Carter, L. et al. (Eds.), Proceedings of the Ocean Drilling Program, Initial Reports, Vol. 181, College Station, TX (Ocean Drilling Program), 1-184.

Shipboard Scientific Party (2001). Site 1172. In: Exon, N.F., Kennett, J.P., Malone, M.J., et al. (Eds.), Proceedings of the Ocean Drilling Program, Initial Reports, Vol. 189, available from: World Wide Web: <http://www-odp.tamu.edu/publications/ 189_IR/chap_03/chap_03.htm>. [Cited 2016-02-20].

Sluijs, A., Schouten, S., Pagani, M., Woltering, M., Brinkhuis, H., Damsté, J.S.S., Dickens, G.R., Huber, M., Reichart, G.-J. and Stein, R. (2006). Subtropical Arctic Ocean temperatures during the Palaeocene/Eocene thermal maximum. Nature, 441(7093), 610-613.

Sluijs, A., Schouten, S., Donders, T.H., Schoon, P.L., Röhl, U., Reichart, G.-J., Sangiorgi, F., Kim, J.-H., Damsté, J.S.S. and Brinkhuis, H. (2009). Warm and wet conditions in the Arctic region during Eocene Thermal Maximum 2. Nature Geoscience, 2(11), 777-780. 
Spencer-Cervato, C. (1999). The Cenozoic deep sea microfossil record: explorations of the DSDP/ODP sample set using the Neptune database. Palaeontologia Electronica, 2(2), 270.

Spiess, V. (1990). Cenozoic magnetostratigraphy of Leg 113 drill sites, Maud Rise, Weddell Sea, Antarctica. In: Barker, P.F., Kennett, J.P. et al. (Eds.), Proceedings of the Ocean Drilling Program, Scientific Results, Vol. 113, College Station, TX (Ocean Drilling Program), 261-315.

Stepanjants, S., Cortese, G., Kruglikova, S. and Bjørklund, K. (2006). A review of bipolarity concepts: history and examples from Radiolaria and Medusozoa (Cnidaria). Marine Biology Research, 2(3), 200-241.

Stickley, C.E., Brinkhuis, H., Schellenberg, S.A., Sluijs, A., Röhl, U., Fuller, M., Grauert, M., Huber, M., Warnaar, J., \& Williams, G.L. (2004a). Timing and nature of the deepening of the Tasmanian Gateway. Paleoceanography, 19(4), PA4027, doi: 10.1029/2004PA001022.

Stickley, C.E., Brinkhuis, H., McGonigal, K., Chaproniere, G., Fuller, M., Kelly, D., Nürnberg, D., Pfuhl, H., Schellenberg, S. and Schoenfeld, J. (2004b). Late Cretaceous-Quaternary Biomagnetostratigraphy of ODP Sites 1168, 1170, 1171, and 1172, Tasmanian Gateway. In: Exon, N.F., Kennett, J.P. and Malone, M.J. (Eds.), Proceedings of the Ocean Drilling Program, Scientific Results, Vol. 189, $1-57$.

Stocker, T.F., D. Qin, G.-K. Plattner, L.V. Alexander, S.K. Allen, N.L. Bindoff, F.-M. Bréon, J.A. Church, U. Cubasch, S. Emori, P.F., P. Friedlingstein, N. Gillett, J.M. Gregory, D.L. Hartmann, E. Jansen, B. Kirtman, R. Knutti, K. , Krishna Kumar, P.L., J. Marotzke, V. Masson-Delmotte, G.A. Meehl, I.I. Mokhov, S. Piao, V. Ramaswamy, D., \& Randall, M.R., M. Rojas, C. Sabine, D. Shindell, L.D. Talley, D.G. Vaughan and S.-P. Xie (2013). Technical Summary. In: Stocker, T.F., D. Qin, G.-K. Plattner, M. Tignor, S.K. Allen, J. Boschung, A. Nauels, Y. Xia, V. Bex and P.M. Midgley (Eds.), Climate Change 2013: The Physical Science Basis. Contribution of Working Group I to the Fifth Assessment Report of the Intergovernmental Panel on Climate Change. Cambridge University Press, Cambridge, United Kingdom and New York, NY, USA.

Stöhr, E. (1880). Die Radiolarienfauna der Tripoli von Grotte, Provinz Girgenti in Sicilien. Palaeontographica, 26, 71-124.

Strong, C.P., Hollis, C.J. and Wilson, G. (1995). Foraminiferal, radiolarian, and dinoflagellate biostratigraphy of Late Cretaceous to Middle Eocene pelagic sediments (Muzzle Group), Mead Stream, Marlborough, New Zealand. New Zealand Journal of Geology and Geophysics, 38(2), 171-209.

Sutherland, R., Collot, J., Lafoy, Y., Logan, G.A., Hackney, R., Stagpoole, V., Uruski, C., Hashimoto, T., Higgins, K. and Herzer, R.H. (2010). Lithosphere delamination with foundering of lower crust and mantle caused permanent subsidence of New Caledonia Trough and transient uplift of Lord Howe Rise during Eocene and Oligocene initiation of Tonga-Kermadec subduction, western Pacific. Tectonics, 29(2), TC2004, doi:10.1029/2009TC002476.

Suzuki, N., Ogane, K. and Chiba, K. (2009). Middle to Late Eocene polycystine radiolarians from the Site 1172, Leg 189, Southwest Pacific. News of Osaka Micropaleontologists, Special Volume, 14, 239-296.

Suzuki, N. and Aita, Y. (2011). Radiolaria: achievements and unresolved issues: taxonomy and cytology. Plankton Benthos Researchs, 6(2), 69-91. 
Takahashi, K. (1991). Radiolaria: Flux, Ecology, and Taxonomy in the Pacific and Atlantic. In: Honjo, S. (Ed.), Ocean Biocoenosis Series, Woods Hole Oceanographic Institution, Woods Hole, Massachusetts, 1-303.

Takahashi, K. and Ling, H.Y. (1980). Distribution of Sticholonche (Radiolaria) in the upper $800 \mathrm{~m}$ of the waters in the equatorial Pacific. Marine Micropaleontology, 5(3), 311-319.

Takahashi, K. and Honjo, S. (1981). Vertical flux of Radiolaria: a taxon-quantitative sediment trap study from the western tropical Atlantic. Micropaleontology, 27(2), 140-190.

Takemura, A. (1992). Radiolarian Paleogene biostratigraphy in the southern Indian Ocean, Leg 120. In: Wise, S.W.J., Schlich, R. et al. (Eds.), Proceedings of the Ocean Drilling Program, Scientific Results, Vol. 120, College Station, TX (Ocean Drilling Program), 735-756.

Takemura, A. and Ling, H.Y. (1997). Eocene and Oligocene radiolarian biostratigraphy from the Southern Ocean-correlation of ODP Legs 114 (Atlantic Ocean) and 120 (Indian Ocean). Marine Micropaleontology, 30, 97-116.

Torsvik, T.H., Van der Voo, R., Preeden, U., Mac Niocaill, C., Steinberger, B., Doubrovine, P.V., van Hinsbergen, D.J., Domeier, M., Gaina, C. and Tohver, E. (2012). Phanerozoic polar wander, palaeogeography and dynamics. Earth-Science Reviews, 114(3), 325-368.

Tripati, A.K., Delaney, M.L., Zachos, J.C., Anderson, L.D., Kelly, D.C. and Elderfield, H. (2003). Tropical sea-surface temperature reconstruction for the early Paleogene using $\mathrm{Mg} / \mathrm{Ca}$ ratios of planktonic foraminifera. Paleoceanography, 18(4), 1101, doi: 10.1029/2003PA000937.

van Hinsbergen, D.J., de Groot, L.V., van Schaik, S.J., Spakman, W., Bijl, P.K., Sluijs, A., Langereis, C.G. and Brinkhuis, H. (2015). A Paleolatitude Calculator for Paleoclimate Studies. PloS one, 10(6), e0126946.

Vanhove, D., Stassen, P., Speijer, R. and Steurbaut, E. (2011). Assessing paleotemperature and seasonality during the early Eocene climatic optimum (EECO) in the Belgian Basin by means of fish otolith stable $\mathrm{O}$ and $\mathrm{C}$ isotopes. Geologica Belgica, 14(3-4), 143-157.

Villa, G., Fioroni, C., Pea, L., Bohaty, S. and Persico, D. (2008). Middle Eocene-late Oligocene climate variability: calcareous nannofossil response at Kerguelen Plateau, Site 748. Marine Micropaleontology, 69(2), 173-192.

Villa, G., Fioroni, C., Persico, D., Roberts, A.P. and Florindo, F. (2014). Middle Eocene to Late Oligocene Antarctic glaciation/deglaciation and Southern Ocean productivity. Paleoceanography, 29(3), 2013PA002518. doi: 10.1002/ 2013PA002518

Vinassa de Regny, P. E. (1900). Radiolari Miocenici Italiani, Memorie della Reale Accademia delle Scienze dell'Istituto di Bologna, 8, 227-257 (565-595).

Vonhof, H.B., Smit, J., Brinkhuis, H., Montanari, A., \& Nederbragt, A.J. (2000). Global cooling accelerated by early late Eocene impacts? Geology, 28(8), 687-690.

Wade, B.S., Pearson, P.N., Berggren, W.A. and Pälike, H., (2011). Review and revision of Cenozoic tropical planktonic foraminiferal biostratigraphy and calibration to the geomagnetic polarity and astronomical time scale. Earth-Science Reviews, 104(1-3), 111-142. doi:10.1016/j.earscirev.2010.09.003

Weaver, F.M. and Dinkelman, M.G. (1978). Cenozoic radiolarians from the Blake Plateau and the Blake Bahama Basin, DSDP Leg 44. In: Benson, W.E., Sheridan, R.E. et al. (Eds.), Initial Reports of the Deep Sea Drilling Project, Vol. 44, U.S. Government Printing Office, Washington, D.C., 865-885. 
Westberg-Smith, M. J., and Riedel, W. R. (1984). Radiolarians from the western margin of the Rockall Plateau: Deep Sea Drilling Project Leg 81. In: Roberts, D.G., Schnitker, D. et al. (Eds.), Initial Reports of the Deep Sea Drilling Project, Vol. 81, U.S. Government Printing Office, Washington, D.C., 479-501.

Westberg-Smith, M.J., Tway, L.E., and Riedel, W.R. (1986). Radiolarians from the North Atlantic Ocean, Deep Sea Drilling Project Leg 94. In: Ruddiman, W.F., Kidd, R.B., Thomas, E. et al. (Eds.), Initial Reports of the Deep Sea Drilling Project, Vol. 94, U.S. Government Printing Office, Washington, D.C., 763-777.

Whittaker, J.M., Williams, S.E. and Müller, R.D. (2013). Revised tectonic evolution of the Eastern Indian Ocean. Geochemistry, Geophysics, Geosystems, 14(6), 18911909.

Wilson, D.S., Pollard, D., DeConto, R.M., Jamieson, S.S. and Luyendyk, B.P. (2013). Initiation of the West Antarctic Ice Sheet and estimates of total Antarctic ice volume in the earliest Oligocene. Geophysical Research Letters, 40(16), 43054309.

Wise Jr, S.W., Breza, J., Harwood, D., Wei, W. and Zachos, J. (1991). Paleogene glacial history of Antarctica. Controversies in modern geology, 133-171.

Wobbe, F., Gohl, K., Chambord, A. and Sutherland, R. (2012). Structure and breakup history of the rifted margin of West Antarctica in relation to Cretaceous separation from Zealandia and Bellingshausen plate motion. Geochemistry, Geophysics, Geosystems, 13(4), Q04W12, doi:10.1029/2011GC003742.

Won, M.-Z. and Below, R. (1999). Cambrian Radiolaria from the Georgina Basin, Queensland, Australia. Micropaleontology, 45(4), 325-363.

Woodburne, M.O. and Case, J.A. (1996). Dispersal, vicariance, and the Late Cretaceous to early Tertiary land mammal biogeography from South America to Australia. Journal of Mammalian Evolution, 3(2), 121-161.

Zachos, J.C., Breza, J.R. and Wise, S.W. (1992). Early Oligocene ice-sheet expansion on Antarctica: Stable isotope and sedimentological evidence from Kerguelen Plateau, southern Indian Ocean. Geology, 20(6), 569-573.

Zachos, J.C., Quinn, T.M., \& Salamy, K.A. (1996). High-resolution (104 years) deep-sea foraminiferal stable isotope records of the Eocene-Oligocene climate transition. Paleoceanography, 11(3), 251-266.

Zachos, J., Pagani, M., Sloan, L., Thomas, E. and Billups, K. (2001). Trends, rhythms, and aberrations in global climate 65 Ma to present. Science, 292(5517), 686-693.

Zachos, J.C. and Kump, L.R. (2005). Carbon cycle feedbacks and the initiation of Antarctic glaciation in the earliest Oligocene. Global and Planetary Change, 47(1), 51-66.

Zachos, J.C., Röhl, U., Schellenberg, S.A., Sluijs, A., Hodell, D.A., Kelly, D.C., Thomas, E., Nicolo, M., Raffi, I. and Lourens, L.J. (2005). Rapid acidification of the ocean during the Paleocene-Eocene thermal maximum. Science, 308(5728), 1611-1615.

Zachos, J.C., Dickens, G.R. and Zeebe, R.E. (2008). An early Cenozoic perspective on greenhouse warming and carbon-cycle dynamics. Nature, 451(7176), 279-283. 